\title{
A grammar of Tawala \\ an Austronesian language of the Milne Bay area, Papua New Guinea
}




\section{PACIFIC LINGUISTICS}

FOUNDING EDITOR: Stephen A. Wurm

EDITORIAL BOARD: Malcolm D. Ross and Darrell T. Tryon (Managing Editors), Thomas E. Dutton, Nikolaus P. Himmelmann, Andrew K. Pawley

Pacific Linguistics is a publisher specialising in linguistic descriptions, dictionaries, atlases and other material on languages of the Pacific, the Philippines, Indonesia and Southeast Asia. The authors and editors of Pacific Linguistics publications are drawn from a wide range of institutions around the world.

Pacific Linguistics is associated with the Research School of Pacific and Asian Studies at the Australian National University. Pacific Linguistics was established in 1963 through an initial grant from the Hunter Douglas Fund. It is a non-profit-making body financed largely from the sales of its books to libraries and individuals throughout the world, with some assistance from the School.

The Editorial Board of Pacific Linguistics is made up of the academic staff of the School's Department of Linguistics. The Board also appoints a body of editorial advisors drawn from the international community of linguists. Publications in Series A, $\mathrm{B}$ and $\mathrm{C}$ and textbooks in Series D are refereed by scholars with relevant expertise who are normally not members of the editorial board.

To date Pacific Linguistics has published over 400 volumes in four series:

- Series A: Occasional Papers; collections of shorter papers, usually on a single topic or area.

- Series B: Monographs of intermediate length.

- Series C: Books; publications of greater length, especially reference books such as dictionaries and grammars, and conference proceedings.

- Series D: Special Publications; including archival materials, pedagogical works, maps, audiovisual productions, and materials that do not fit into the other series. 


\title{
A GRAMMAR OF TAWALA \\ AN AUSTRONESIAN LANGUAGE OF THE MILNE BAY AREA, PAPUA NEW GUINEA
}

\author{
Bryan Ezard
}

Pacific Linguistics

Research School of Pacific and Asian Studies The Australian National University Canberra 
Published by Pacific Linguistics

Research School of Pacific and Asian Studies

The Australian National University

PO Box 1428

Canberra ACT 2601

Australia

Copyright $(\subseteq$ The author

First published 1997

ISSN 0078-7558

ISBN 0858834588

Copyedited by Janet Ezard, typeset by Sue Tys, proofread by Janet Ezard, maps drawn by Neville Minch 


\section{TABLE OF CONTENTS}

PREFACE

Map 1: Villages of Tawala Area

Map 2: Tawala Dialects

Map 3: The Four Clusters of Western Melanesian

xiv

Map 4: Austronesian Language Groupings

Map 5: Intrusive Use of Church Languages

$\mathrm{xvi}$

CHAPTER 1: INTRODUCTION ................................................................ 1

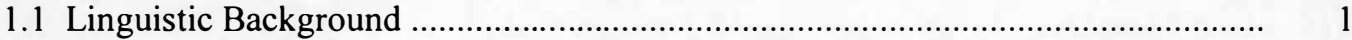

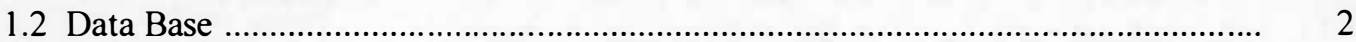

1.3 On Tawala Lifestyle ................................................................................ 4

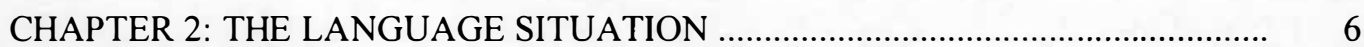

2.1 The Tawala Language ..................................................................................... 6

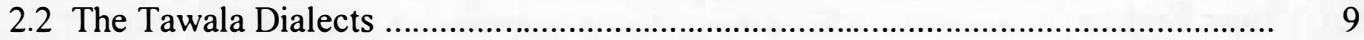

2.3 Languages of Western Melanesia .................................................................... 10

2.4 Language Relationships in Milne Bay ................................................................ 12

2.5 Previous Studies of Tawala ......................................................................... 14

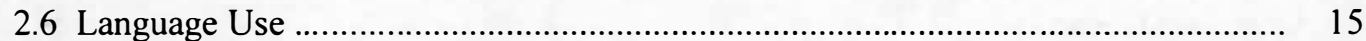

2.7 Language Change - Borrowings .................................................................... 17

CHAPTER 3: DISTINCTIVE ASPECTS OF TAWALA GRAMMAR ...................... 20

3.1 Reduplication .......................................................................................... 20

3.2 Derivational Processes ............................................................................. 20

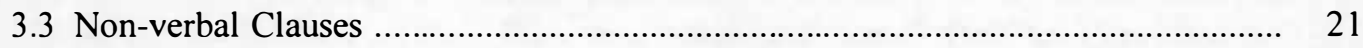

3.4 Head-marking Grammar ........................................................................... 21

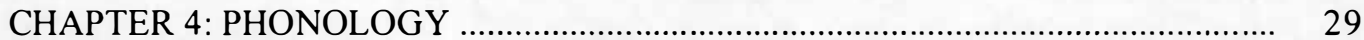

4.1 Segmental Phonemes ..................................................................................... 29

4.2 Syllable Structure …...................................................................................... 33

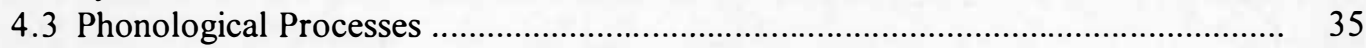

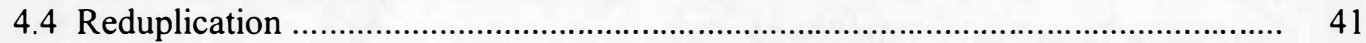

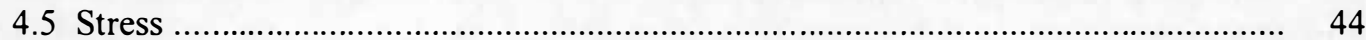

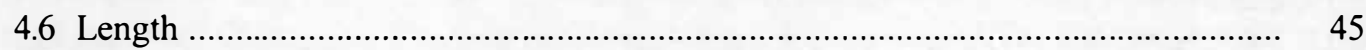

4.7 Phonological versus Grammatical Word ....................................................... 45

CHAPTER 5: MAJOR WORD CLASSES …........................................................ 46

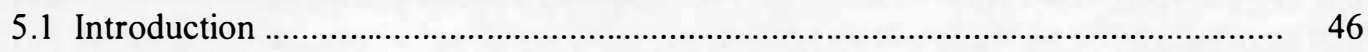

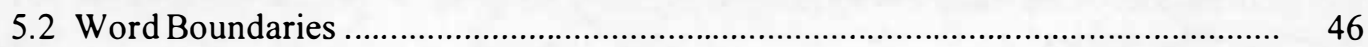


5.3 Distinguishing Open Word Classes ...................................................................... 49

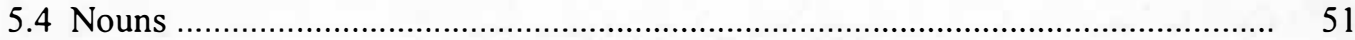

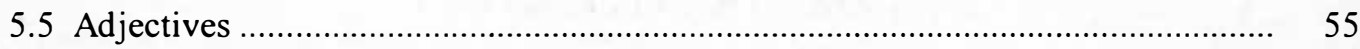

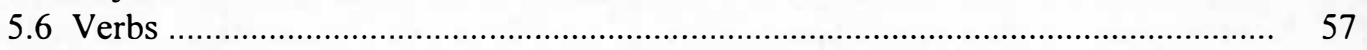

CHAPTER 6: CLOSED WORD CLASSES AND RELATED ISSUES …………........ 72

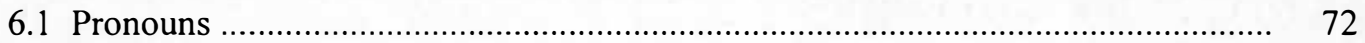

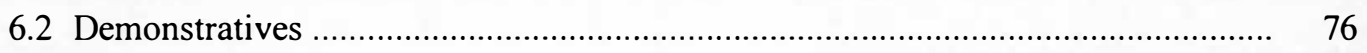

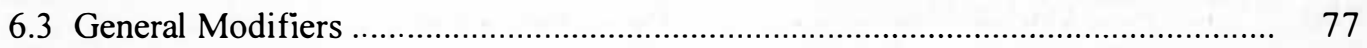

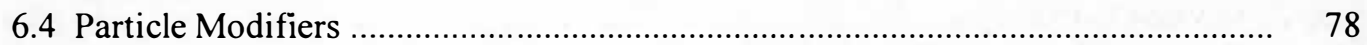

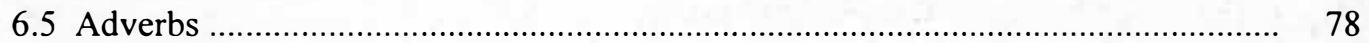

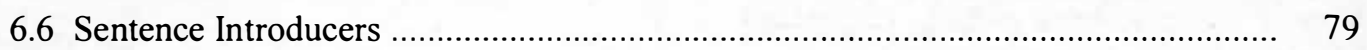

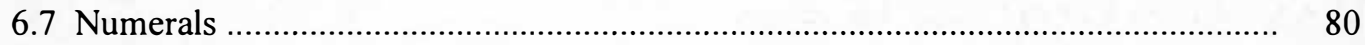

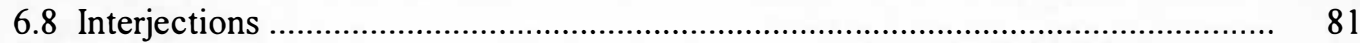

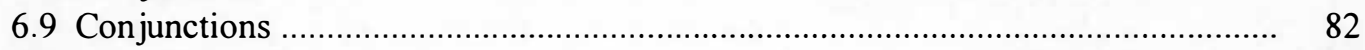

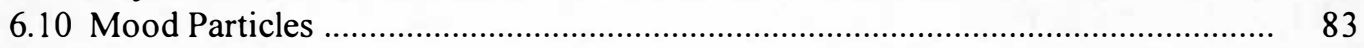

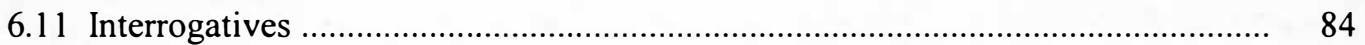

CHAPTER 7: VERBAL CLAUSES …………………......................................... 86

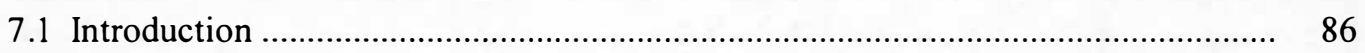

7.2 Layered Structure of the Verbal Clause ................................................................... 86

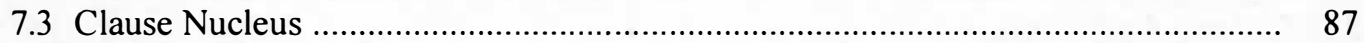

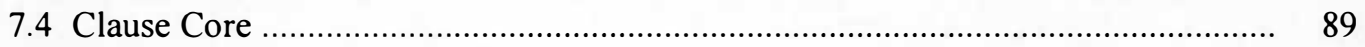

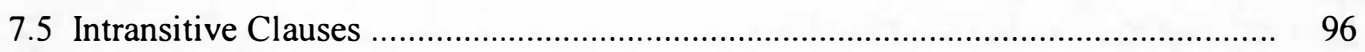

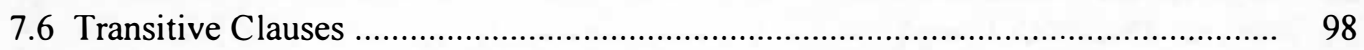

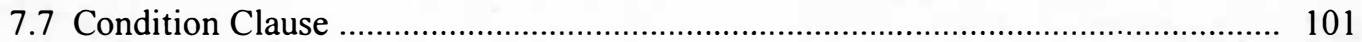

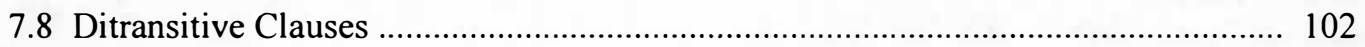

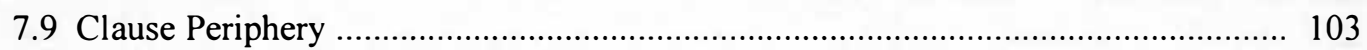

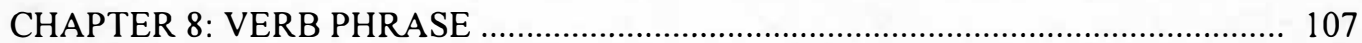

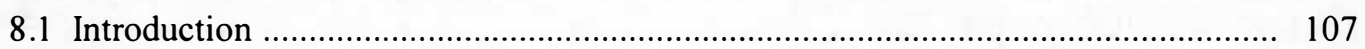

8.2 Constituents of the Verb Phrase ...................................................................... 107

8.3 Word Breaks within the Verb Phrase ................................................................ 108

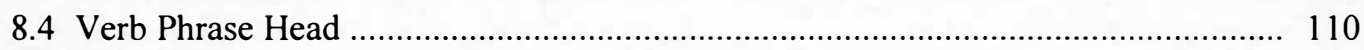

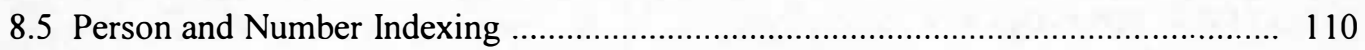

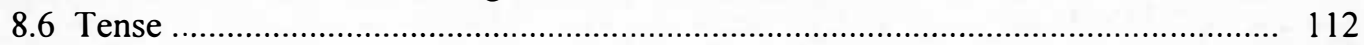

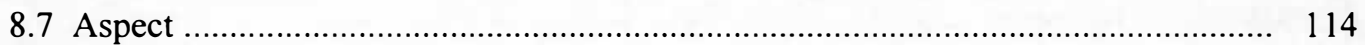

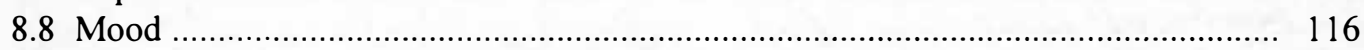

8.9. Combining Tense, Aspect and Mood ................................................................ 118

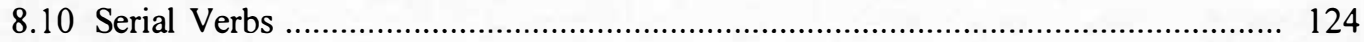

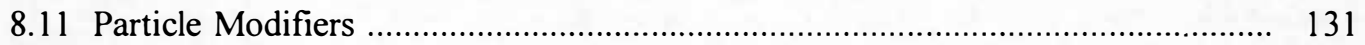

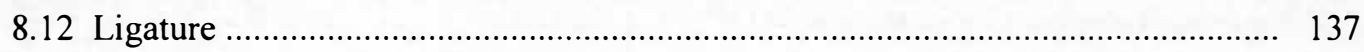

CHAPTER 9: NOUN PHRASES ………………............................................... 139

9.1 Constituents of the Simple Noun Phrase ............................................................ 139

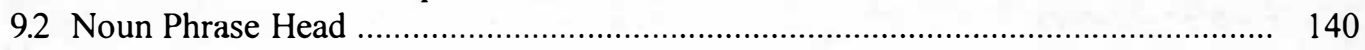

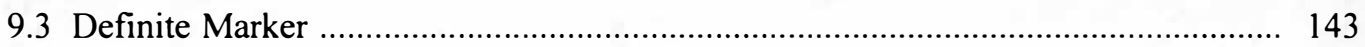


9.4 Demonstratives ..................................................................................... 144

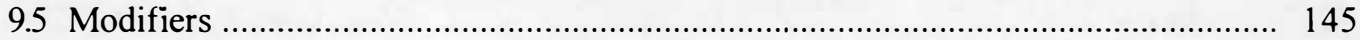

9.6 Number Phrases .......................................................................................... 146

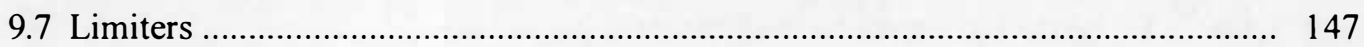

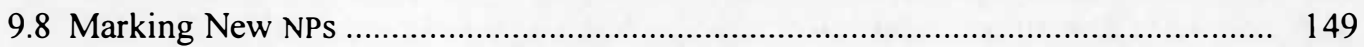

9.9 The Modifier gasi .................................................................................... 149

9.10 Possessive Phrases .................................................................................. 149

9.11 Ablative Enclitic .............................................................................................. 154

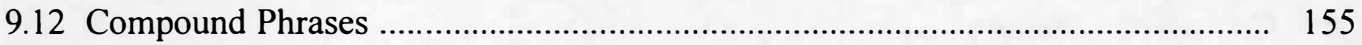

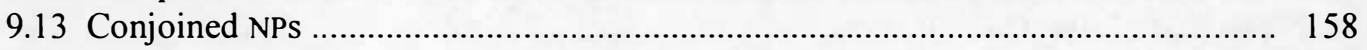

9.14 Phrases in Apposition .............................................................................. 160

CHAPTER 10: ADPOSITIONAL PHRASES ....................................................... 161

10.1 Prepositional Phrases ............................................................................ 161

10.2 Postpositional Phrases ................................................................................. 167

CHAPTER 11: NON-VERBAL CLAUSES ................................................................ 174

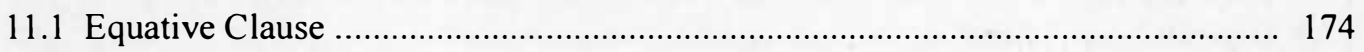

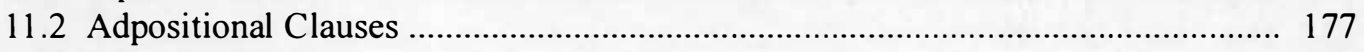

11.3 Existential Clause .................................................................................. 180

11.4 Head-marked Non-verbal Clauses ............................................................. 183

11.5 Complement Clauses ................................................................................. 190

CHAPTER 12: A UNIFIED CLAUSE MODEL ........................................................ 193

12.1 Verbal versus Non-verbal Clauses ................................................................ 193

12.2 A Theoretical Approach To Non-verbal Clauses ........................................... 194

12.3 Isolating Non-verbal Clauses ...................................................................... 197

12.4 Uniting Verbal and Non-verbal Clauses ...................................................... 200

12.5 Clause Operators with Non-verbal Clauses ................................................. 203

CHAPTER 13: RELATIVE CLAUSES ............................................................ 206

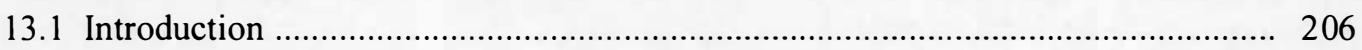

13.2 Definite Relative Clause ................................................................................. 206

13.3 Indefinite Relative Clause ................................................................... 211

13.4 Non-verbal Relative Clauses ..................................................................... 211

CHAPTER 14: NOMINALISED CLAUSES ….................................................. 213

14.1 Introduction ............................................................................................. 213

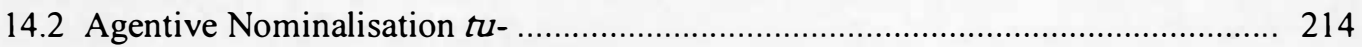

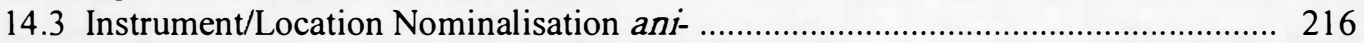

14.4 Action Nominalisation ................................................................................... 217

14.5 Further Functions of Nominalised Clauses .................................................. 219

CHAPTER 15: COMPLEMENT CLAUSES ....................................................... 220

15.1 Notions of Complementation ................................................................ 220

15.2 Classes of Complementation ............................................................................ 228

15.3 Quotation Sentence ............................................................................. 233 
CHAPTER 16: COMBINATION OF CLAUSES ........................................................ 234

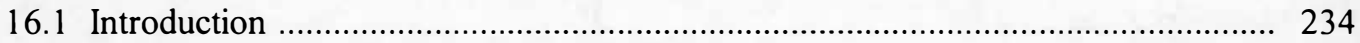

16.2 Clauses Embedded in Postpositional Phrases.................................................... 236

16.3 Clauses Embedded In Prepositional Phrases ………………………………...... 238

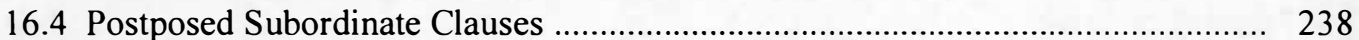

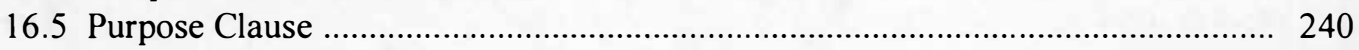

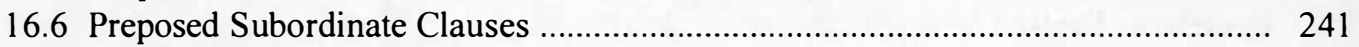

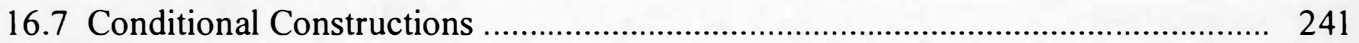

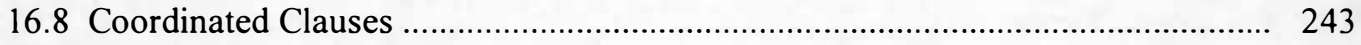

16.9 Types of Clause Coordination .................................................................. 244

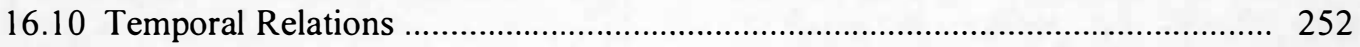

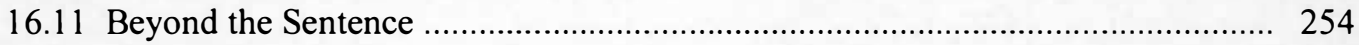

CHAPTER 17: DERIVATIONAL PROCESSES ....................................................... 255

17.1 Derivational versus Inflectional Morphology .................................................. 255

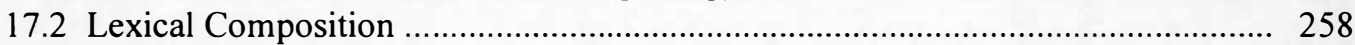

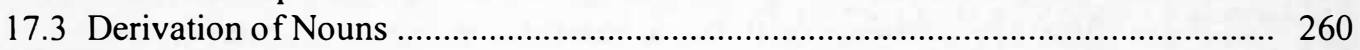

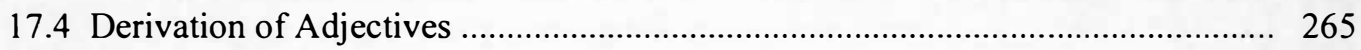

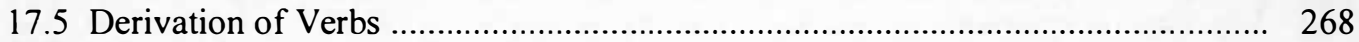

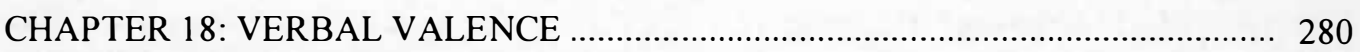

18.1 Grammatical Relations and Valence Change ................................................ 280

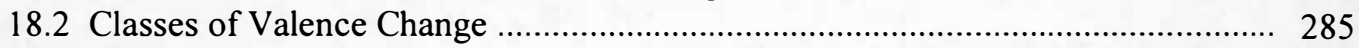

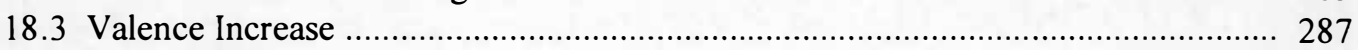

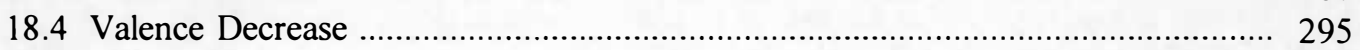

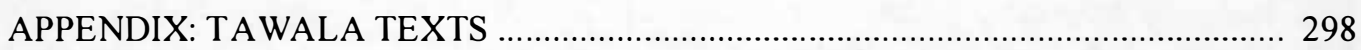

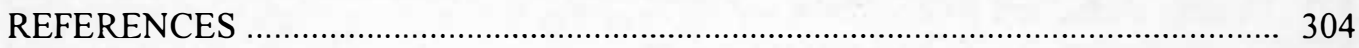

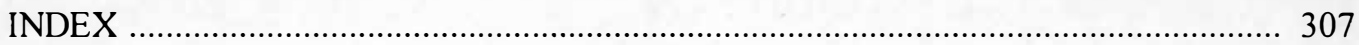




\section{PREFACE}

The content of this grammar was presented as a doctoral dissertation, to the Australian National University, Canberra in 1991. In this published version, some of the chapters have been moved around, at the suggestion of the publishers, but the basic content has not been altered.

I benefitted at many points in my analysis from comments offered by Professor R.M.W. Dixon, Dr Harold Koch, Dr Ulrike Mosel and Dr Malcolm Ross, and later by my examiners, Dr Ross Clark, Professors Andrew Pawley and Johanna Nichols. I owe the deepest gratitude to Harold Koch, my main supervisor in the final year of my doctoral program. He was untiring in his ef forts to assist my progress; weekly and sometimes twiceweekly meetings (which at crucial times extended well beyond the appointed hour, as I grappled with some point of Tawala grammar) were a highlight of my university days. Constantly I was encouraged to find facts to support my intuitions and to take full cognisance of structure, as each draft was returned with ever finer points of criticism.

I am immeasurably indebted to the Tawala people for their hospitality and constant encouragement as I lived among them and learned their language. In particular I would like to thank Yailo Robert, my untiring co-translator and advisor on Tawala issues over many years.

Finally, I express my appreciation to my wife, Janet, who has not only been my fellow 'pilgrim' throughout my ventures, but has also given her professional services in editing the final manuscripts. 


\section{ABBREVIATIONS AND SYMBOLS}

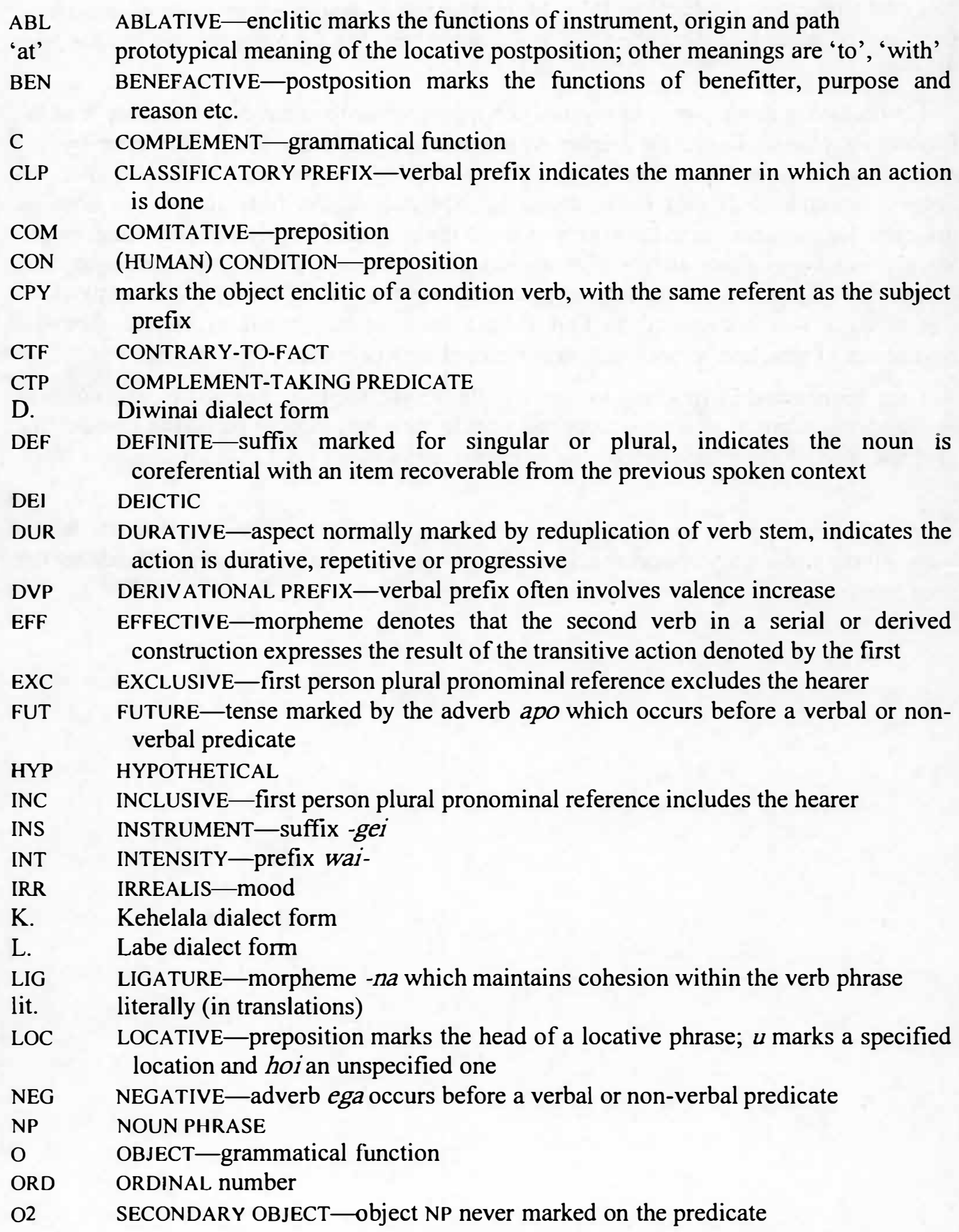




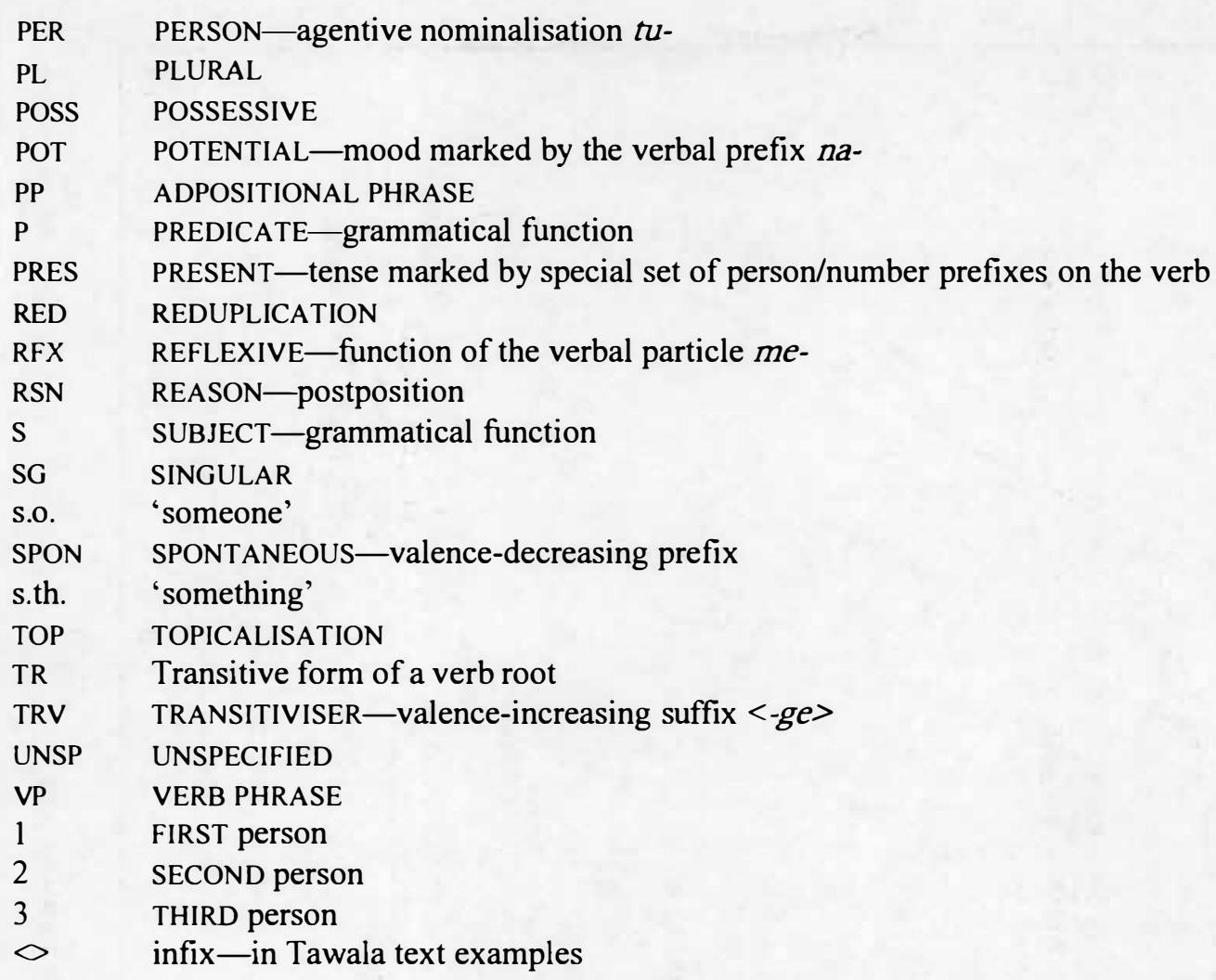




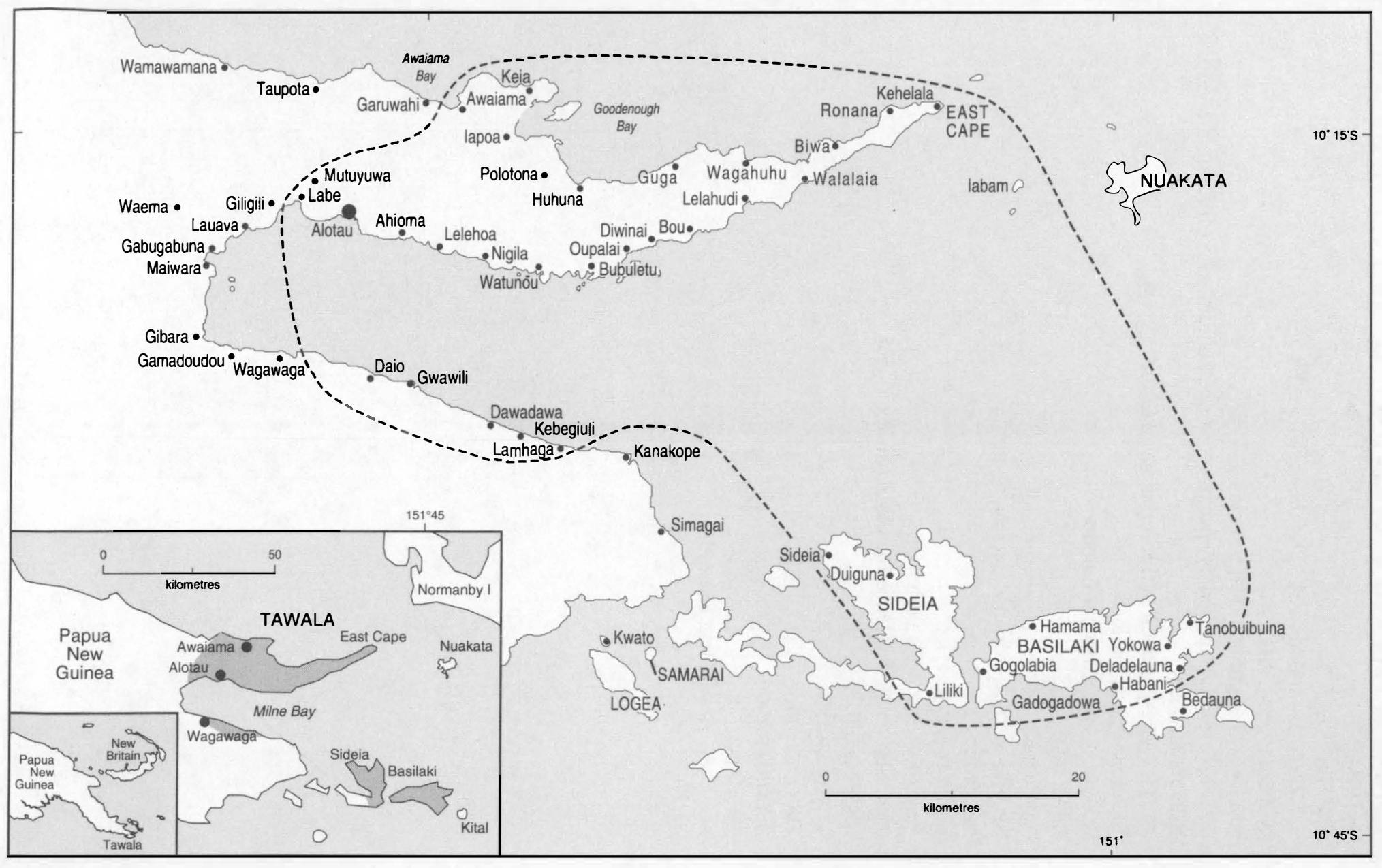




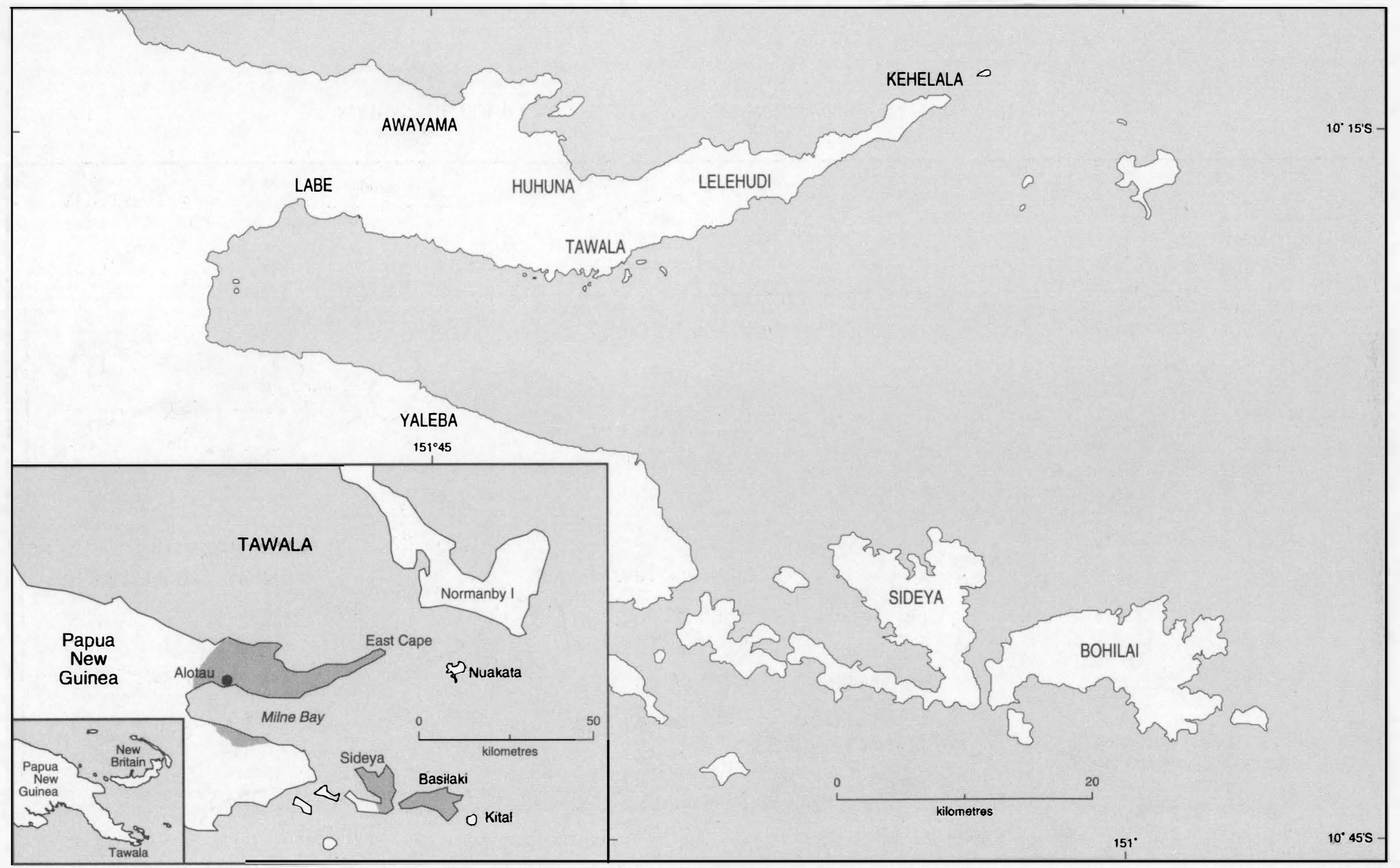




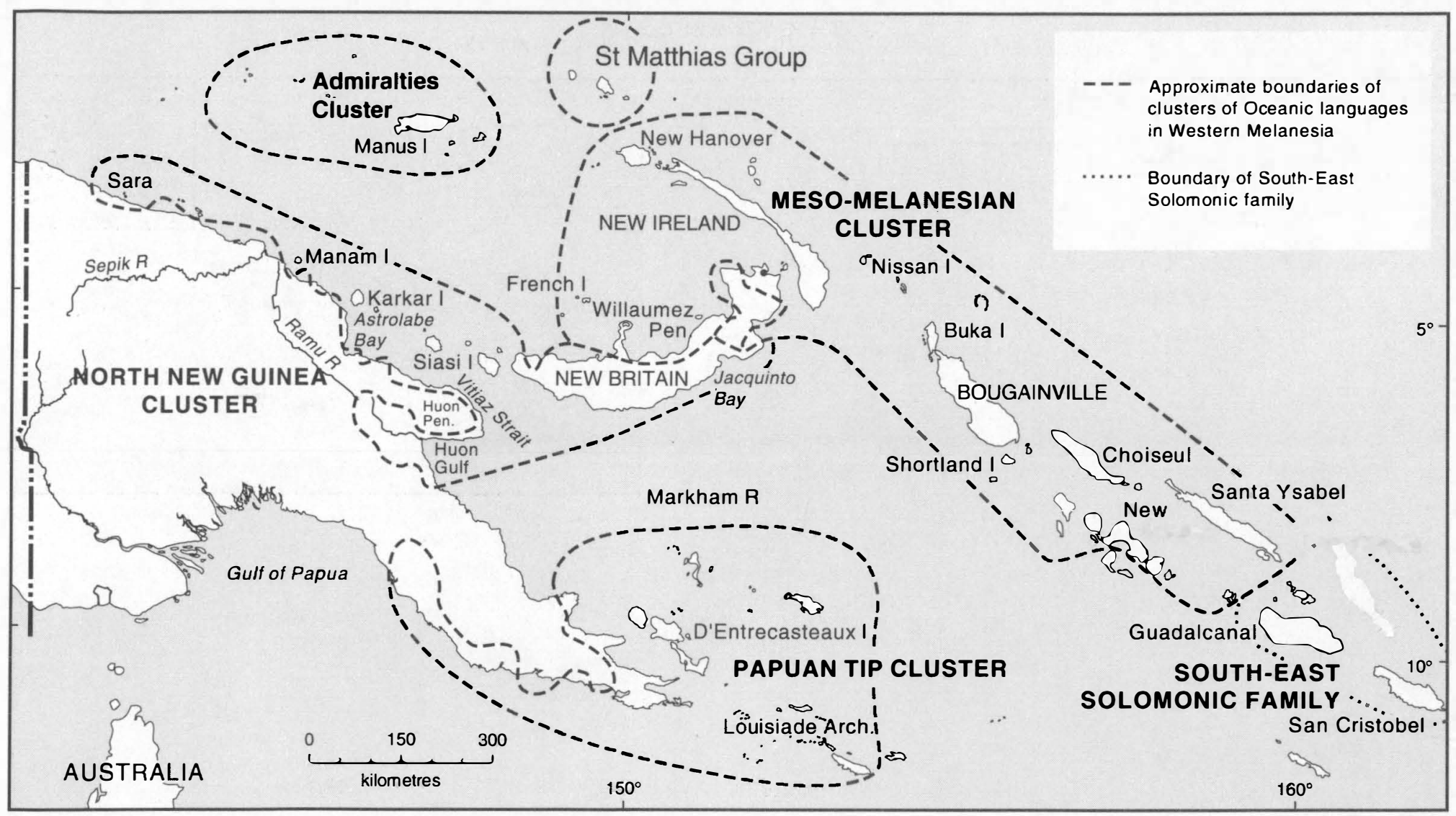

MAP 3: THE FOUR CLUSTERS OF WESTERN MELANESIAN (RosS 1986) 


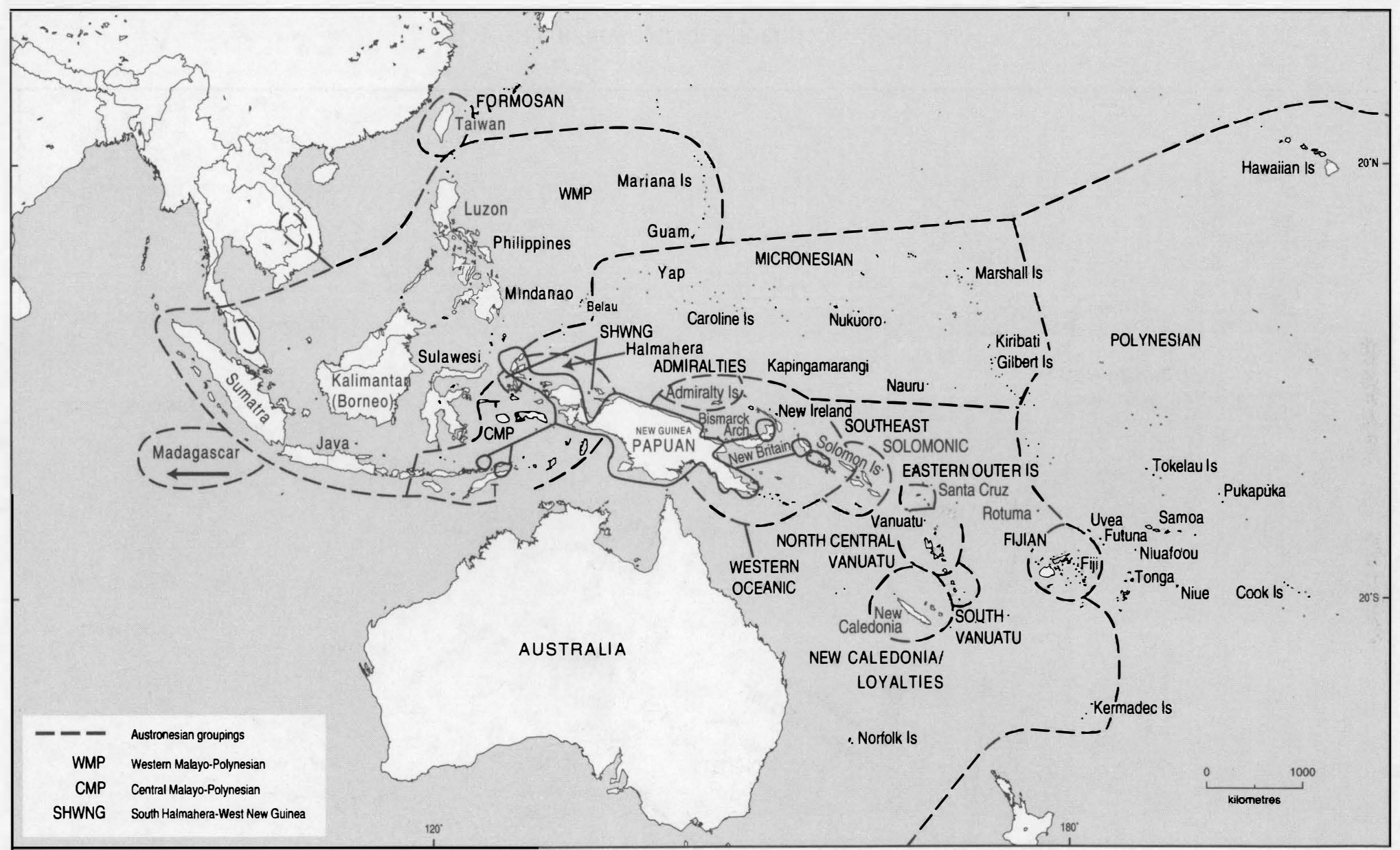

MAP 4: AUSTRONESIAN LANGUAGE GROUPINGS 


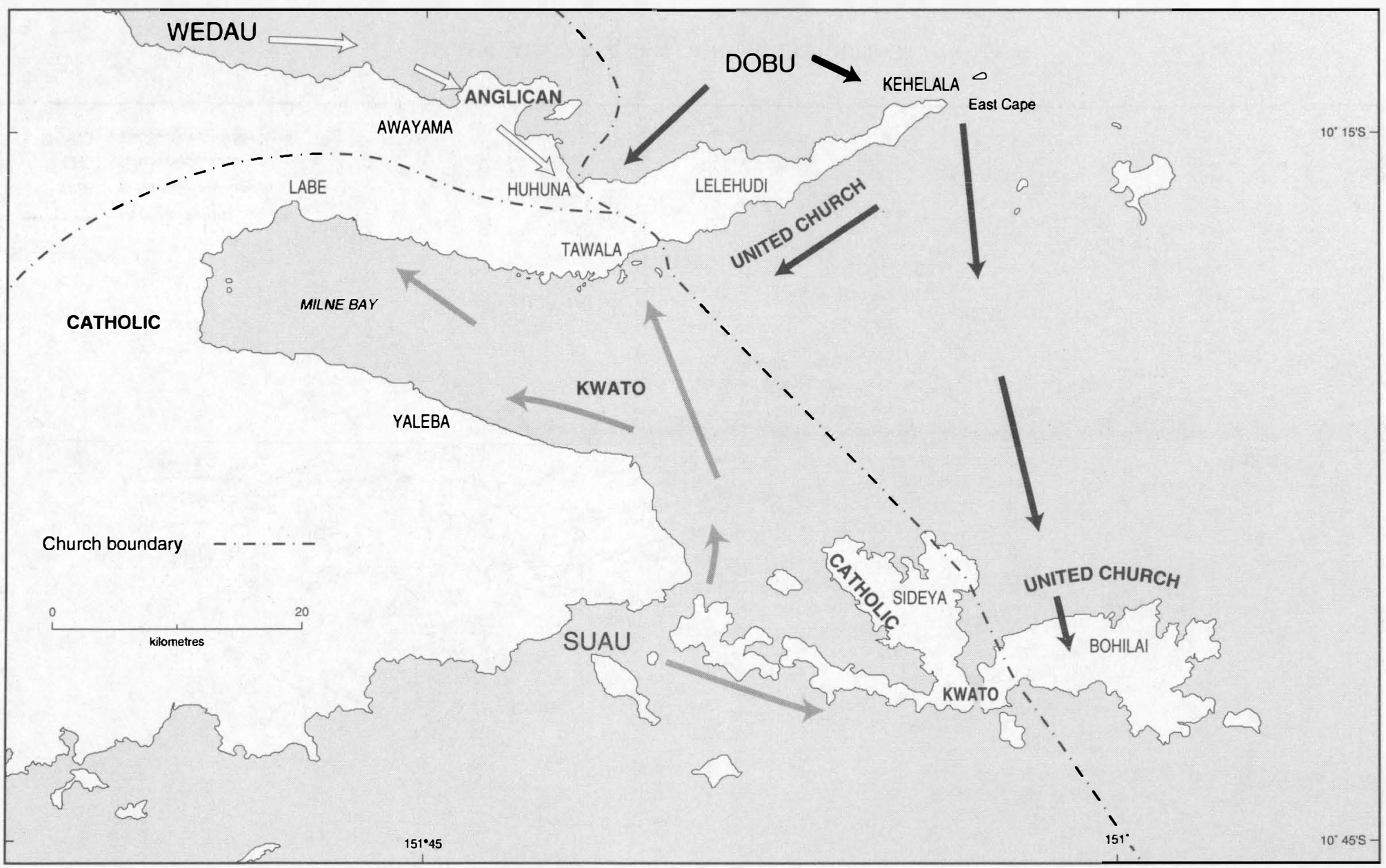




\title{
INTRODUCTION
}

\begin{abstract}
Human languages are extraordinarily similar in terms of the meanings they encode, and the ways these are combined. They vary a good deal in the grammatical apparatus that is evolved to handle this matter of combination. It is from this that most apparent differences between languages stem. The linguist's task is to expose and analyse these differences, using whatever theoretical ideas are of most value in this task, and remembering that it is basically MEANING that a language (and the linguist) is concerned with.

Dixon (1987:30)
\end{abstract}

\subsection{LINGUISTIC BACKGROUND}

The linguistic approach taken in this grammar is eclectic. A word about my personal brand of eclecticism will help orient the reader to my view of language.

From my initial linguistic training in tagmemics I retain a strong sense of grammatical hierarchy: phonemes combine to form morphemes and morphemes combine to form words, which in turn combine to form phrases which are the building blocks of clauses (or sentences as some linguists refer to them). Clauses in turn combine to form sentences, the upper limit of this description. Sentences of course combine to form paragraphs and discourses.

While the hierarchical model gives a clear view of language structure it is not the whole picture. The model cannot be pushed rigorously. For example, the distinction between words, phrases and clauses is not always clear. Both words and phrases can function as clauses in Tawala. As with other languages, clauses can be embedded within phrases.

I have adopted a functional approach: every grammatical form has a function, just as a lexical form (word) has meaning. Thus "the noun phrase can 'function' in clause structure as subject, object, complement, etc." (Crystal 1980:155). This approach comes originally from tagmemics, where items are viewed as units functioning within larger units, with utterances themselves having a communicational function. As Pike (1967:29) expresses it, "Analysis of the linguistic phase of events...is also seen to be heavily and essentially dependent upon its relation to nonlanguage behavior". The functional approach has been reinforced by other approaches, and in particular by Givón's (1984 and 1990).

It needs to be stressed that while units typically have a function on the next level of the hierarchy, this is frequently not their only function. Thus, while a pronoun may function as a constituent of an NP, it may simultaneously signal discourse topic and maintain discourse cohesion. The actual communicational function lies outside the scope of this grammar and ties in rather with "the sociolinguistic and social anthropological study of language in social interaction" (Van Valin and Foley 1980).

In Chapter 3 I acknowledge Nichols (1986) for her invaluable contribution to my understanding of Tawala - a prototypical head-marking language. I am heavily indebted to Givón (1984 and 1990) at many points in my analysis, as is evident from the number of 
quotes throughout the grammar. I have also been influenced by certain aspects of the Foley and Van Valin (1984) model of the clause. The priority accorded to semantics by Dixon $(1982,1984)$ is seminal to my approach. Finally, the three Shopen (1985) volumes have been a source of insight at many points in the grammar. In addition to these major influences, other authors are acknowledged within the text for their contribution to my understanding of specific points.

While I attempt to give an accurate account of Tawala grammatical forms, I have tried to avoid the extreme formalisms of tagmemics or any other linguistic theory. While formalism has a useful function within linguistic theory, this usefulness does not extend to language description intended as a reference grammar for the educated public. Today there is common ground shared by most modern linguists; as far as possible I keep to this common ground.

It has been my aim to describe the structure of the Tawala language itself and not to impose structure upon it or to describe it in terms of the latest universal theory. As far as possible I have limited my terminology to the terms most widely used by functionalist grammarians today. Many of these terms turn out to be traditional ones, e.g. nouns and verbs, subject and object. Thus my aim is similar to that of role and reference grammar in providing a description

\begin{abstract}
that falls somewhere between the extremes of describing each language in its own terms, thereby making cross-linguistic comparison problematic, and describing each language in purely universal terms, which often results in the glossing over of the important grammatical distinctions in the language in favour of those imposed by theory.
\end{abstract}

Foley and Van Valin (1984:33)

\title{
1.2 DATA BASE
}

My wife, Janet, and I commenced learning the Tawala language in 1974 under the auspices of the Summer Institute of Linguistics. I worked more or less non-stop on the language until 1991, with perhaps six years total spent in residence within the Tawala language area. An initial six-month period of fieldwork was carried out in the village of Diwinai. Subsequently we lived on the Koeabule plantation (known as KB in the area) on the outskirts of Alotau while we built a house at nearby Diwala. Residence at Diwala brought me into daily contact with the Labe dialect, though I continued to also work with the Diwinai dialect through work with my co-translator, Yailo, and regular visits to his village.

It has been my aim to collect natural language. From the first day of fieldwork I have only worked monolingually even though this severely restricted my understanding for several months. By being an observer of village life and collecting data as the occasion arose, rather than having any artificial eliciting procedures, I learned what was important to the people themselves. In the early days I often found Tawala people assumed the role of language teachers, drilling me on material that they thought was crucial. As fluency increased and I began to communicate creatively, my investigation was mostly in terms of enquiring into activities and culturally relevant subjects, rarely in terms of substitution frames.

The transcription and annotation of text provided the next stage in cultural understanding and grammatical analysis. Transcribed texts continue to be a grammatical-analysis 
challenge, even as I add final touches to this grammar; it seems that every time I look at it I discover something new. It is said by artists that a great painting is never finished - it is simply laid aside. That is certainly how I feel about this grammar - it is far from complete but the time has come to publish what I know of it.

I found the challenge of Bible translation a great stimulus to language leaming. At times, hours and even days were spent in thrashing out some point of biblical or Melanesian culture, with the by-product of growing fluency and an appreciation of some fine distinctions that I may well have overlooked without this particular challenge. Thus, for example, I came to learn that the non-verbal construction tewela dewadewana could mean either 'it is a good child' or 'the child is good'.

The primary data base for this grammar is spoken and written texts. Perhaps $90 \%$ of examples come from the spoken texts. I have included very few elicited sentences - almost exclusively embedded structures - as my aim has been to give priority to the structures in common use. I have been aware that it would be all too easy to impose structure on the language by the bias I bring to the process of elicitation.

A number of different types of text have been used and are listed according to reliability, commencing with the most reliable texts.

1) Recorded texts - 32 texts totalling almost 20,000 words were transcribed and lightly edited from spoken texts, representing some ten speakers and both Diwinai and Labe dialects. A wide range of text types is included in this group: traditional stories, narratives of recent and long-past experiences, descriptions of traditional customs and of new places and experiences, instruction on culture, procedural texts, prayers, sermons etc. A printed concordance of this material proved invaluable in the selection of suitable examples for this grammar as well as for checking hypotheses formed in its writing.

2) Letters - five short letters sent from educated Tawala people, living outside the area, to their parents were included within the above concordance but have been treated with caution because of a slight bias towards English structure.

3) Newspaper - a 22-page newspaper GEKA TUWEGA 'This is News', published in 1981 by Tawala youth, has proved a useful addition to my data at one or two points in the grammar.

4) Notebooks - during my early language-leaming days I filled five notebooks with snippets of conversation which impressed me at the time. These represent a particularly rich source of idioms and non-verbal clauses as well as other normal 'everyday' constructions.

5) New Testament - I have used a concordance of the complete Tawala New Testament as a secondary source of examples, only when examples from other sources were not suitable or were non-existent. I have treated these data with caution because they are translated. However, in defence of this material I would offer the following justification. Firstly, the drafts were all produced by native speakers. Secondly, while I had an input at the level of meaning, my co-translator Yailo was always responsible for the final form of the Tawala. Finally, Tawala speakers consistently testify to the naturalness of the text. Doubtless errors remain in the translation, but these are more 
likely to be at a discourse level, rather than the actual grammatical structure of the individual clauses and sentences which I have occasionally used in the grammar. The 'religious' sentences contained in the grammar come from spoken sentences, never from the New Testament translation. After all, the people are deeply religious and religion is a common topic of conversation.

\subsection{ON TAWALA LIFESTYLE}

Each language draws a magic circle round the people to which it belongs, a circle from which there is no escape save by stepping out of it into another.

(Humboldt)

It has been my privilege to live with the Tawala people and learn their language and culture. This personal involvement in the people's lives has been the most enriching experience of my life and far outweighs the academic achievements I have gained in the process.

One feature that stands out above all others is that Melanesians have time - especially time to talk. Many hours are spent each day sitting in groups, talking. Even a work party includes several hours sitting around, chewing betel nut and talking. The evenings, uncluttered by TV and meetings, are usually devoted to talk - talk which will go on well beyond midnight if there is a visitor or a crisis situation. This aspect of their culture elevates the spoken word above anything I have experienced in the West and immeasurably enriches their lives.

A second aspect of their culture that has impressed me is the centrality of the clan, with its totem bird. During my early days in the Tawala area people kept asking me what my "bird" was. I soon learned that the answer "I don't have one" was too incredible to be believed, and mercifully an old man adopted me into his clan, giving me bunebune 'pigeon' as my bird. Any Tawala person can go to any village of any language in the southern Milne Bay area and announce his clan and someone of that clan will call him up to his verandah and provide for him for the duration of his stay. Of course the Tawala visitor will reciprocate when someone who is of his clan visits his village. That I can travel for thousands of kilometres in Australia, through town after town and not be offered bed and lodging at any one of these places is a total enigma to the Tawala people.

My turn for 'unbelief' came when I came to understand that 'matrilineal descent' means that the clan grouping is stronger than the nuclear family and that children belong to their mother's clan and regard their mother's brother as closer than their biological father. Their father is, in fact, clearly a stranger in his children's village and he often visits his sister and provides for her children.

Attitudes to work are radically different from those in the West. As with most cultures around the world, there are clear roles for males and females; for example, while both men and women can fish, only the men go out in canoes for this purpose. Another difference is that fishing and hunting are not considered recreational as they are in the West, but are just as much work as collecting firewood or gardening.

As an outsider I have been fascinated by people's views of themselves. Many changes have come to Milne Bay in the last 100 years. None is more important than the cessation of inter-tribal fighting and cannibalism. I have not heard any Tawala person decry these changes. However, I have heard them talk about "the days of great darkness when people 
ate each other". On the other hand the loss of dancing and other aspects of pageantry is considered unfortunate: "We know Samoan" dances but not our own!".

The Second World War had a powerful impact on the lives of the people. Those living in Milne Bay had to move residence across the mountains for several years, to make way for 120,000 Allied troops. Stories abound of horrors seen and of experiences of friendships made with troops (by the men who acted as carriers and helpers). I have found it difficult to penetrate beyond the war years in talking with people. Stories from the 'old' days are inevitably war stories rather than myths or exploits of the ancestors.

Missions have also played a major role in moulding today's culture - at least in the externals. In the Kwato area bells wake the villagers at dawn and indicate meeting times throughout the day. Washing is essential before a church service and clean clothes and even white shirts and ties are common. As most people are church-goers, rules for Sunday - no canoeing, fishing or gardening - are universally observed (at least in the Kwato and United Church areas). At a deeper level the old practices are still alive. Sorcery (by males) and witch activity (by females) are prevalent even in the highest church circles. Many people desire to escape these, their 'big fears'. Christianity and their old beliefs form a two-tier system, with Christianity dictating the externals, and traditional beliefs having an inner control on values and actions. An example of this two-tier system was expressed to me by one man: "Christianity taught us that it was wrong to kill people with a knife, but not that it was wrong to kill by sorcery".

Finally, I think the difference in attitude between the people of Milne Bay and the West can best be summed up in the words, reportedly of an Indonesian, "You Europeans are not human beings but human 'doings"'. Above all else my years in Milne Bay have taught me that the important thing in being human is to be a human 'being'.

The area saw an influx of Samoan missionaries in the early mission days; they introduced not only dancing but also weaving and some superior varieties of breadfruit, bananas and pineapple, etc. 


\section{THE LANGUAGE SITUATION}

\subsection{THE TAWALA LANGUAGE}

According to details provided by the 1981 Provincial Data System Rural Community Registrar for the Milne Bay Province, the Tawala language is spoken by some 10,000 people. They live in hamlets and small villages on the East Cape peninsula, along the shores of Milne Bay and on parts of the islands of Sideia and Basilaki (Map 1). In all, there are about 40 major centres of population, each with its own dialect, but in the accidental course of colonisation a number of these centres have played a larger role than others. The dialects (Map 2) listed in Table 1 have been recognised in the literature. Each dialect is presented, with the major alternate spellings and names that have been encountered in the literature, along with the authority who first proposed the dialect in print, though not necessarily with the present name. The Tawala people recognise all these names as important centres.

I justify using the word 'Tawala' for the whole language on the following grounds:

1) It is the name used by the people of Milne Bay to refer to their language.'

2) Diwinai is the central dialect of the language and these people refer to their language as Tawala.

3) Considerable literature has appeared in Tawala, certainly more than in any other dialect.

4) The people generally recognise the unity of their language but have no other name for it.

TABLE I: MAJOR TAWALA DIALECTS

\begin{tabular}{|lll|}
\hline DIALECT & \multicolumn{1}{c|}{ ALTERNATE NAMES } & \multicolumn{1}{c|}{ AUTHORITY } \\
\hline $\begin{array}{l}\text { Awayama } \\
\text { Huhuna }\end{array}$ & Awaiama, Awalama & MacGregor 1890 \\
Kehelala & Keherara, East Cape & Ezard 1977 \\
Lelehudi & Armstrong 1923 \\
Tawala & Tavara, Diwinai, Divinai & Ezard 1977 \\
Labe & Ray 1907 \\
Yaleba & Wagawaga, Gwawili, & Lithgow 1976b \\
& Gwavili, Ealeba & Ray 1907 \\
Bohilai & Bohira'i, Basilaki & Armstrong 1923 \\
Sideya & Sideia & Ezard 1977 \\
\hline
\end{tabular}

The first intimation of the Tawala language received by the western world was in a list of some 650 items of the "aboriginal vocabulary of Awaiama", given in the ANNUAL REPORT of British New Guinea in 1890 , by W. MacGregor. It would be almost a century before the

In Tawala folk etymology Tawala is considered to have derived from ata lawa 'our friends'. 
relationship of the Awayama dialect to the Tawala language came to be understood (but that is to get ahead of the story).

The linguistic procedure followed in the assembling of the Awayama Vocabulary contained a most unfortunate presupposition that resulted in considerable confusion. The presupposition was that three small coastal villages separated by only a few miles of almost straight beach would all speak the same language, or at least be close dialects of the same language. The presupposition is evident in the sub-title: "Table showing certain Principal Words, etc., used by Aboriginals of Awaiama, Taupota, and Garua, ${ }^{2}$ British New Guinea".

There could be few worse places in the world in which to make such an assumption. The three villages, in fact, speak three separate languages, so that the people of that time may not have been able to actually communicate with each other, depending of course on their social contacts. Awayama has its relations with the Tawala language to the east; Taupota has its relationships to the west and south, and 'Garua' is an isolate sandwiched between the two. From the point of view of comparative linguistics, these distinctions are not important; the three languages all derive from a single ancestor and are genetically 'closely' related. However, the view of this grammar is not comparative but descriptive (a synchronic description of the Tawala language) and Tawala is quite distinct from Taupota and Gweda (as Garua is now known). Though its name differs from place to place there is unanimity among Tawala speakers as to the borders of the Tawala language, which for them ends at Awayama.

The Awayama Vocabulary suffers from a number of deficiencies which need not detain us here, but one insurmountable problem lies in not knowing from which village each item was collected. Thus it is not possible to assess whether the numerous differences with the current Awayama dialect represent language change or were, even in 1890, forms used in the other languages.

In 1907 Sidney Ray published his Melanesian Languages of British New Guinea, modelled on the monumental Melanesian Languages of Robert Codrington (1885). Ray demonstrated the relationship that exists between the languages of coastal Papua and island Melanesia. Vocabulary together with grammatical and phonological detail are presented for 39 languages of Papua, including two Tawala dialects: 'Tavara' spoken on the "east end of Milne Bay"; and 'Awalama,3 ("Chad Bay"), the Awayama we have already mentioned.

In referring to "Tavara" Ray simply mentions the "east end of Milne Bay". Was he aware that the dialects on the north and south shores of the bay are almost identical? (Armstrong (1923) was the first to explicitly make this observation.) No comment is offered by Ray as to the relationship between "Tavara" and "Awalama", but a count based on his vocabulary lists shows them to have only $70 \%$ of shared vocabulary items - a figure deflated by errors in both vocabulary lists and exacerbated by similar inaccuracies within the phonology and grammar. Both languages are listed within his "group 8", which corresponds to the modern Are-Taupota chain (Ross 1988). While many questions remained unanswered, the picture

2 I am assuming that 'Garua' is in fact 'Gweda', the language spoken at Garuwahi (the last syllable of Garuwahi is sometimes devoiced).

3 With regards to the spelling discrepancies, Ray (1907:4 18) notes that / $/ /$ "does not appear in Tavara"! (Ray 1938 has the spelling "Tawala" with Tavara in brackets). He comments on the Awayama dialect: "Ihas a tendency to the sound of $y$ " (p.419). I would reverse this (see §4.1.1). 
was emerging of Tawala as a language with its closest relatives on the north coast of Papua, and more distantly related to those of coastal and island Melanesia. Unnecessary division might have been spared had the internal relations of the Tawala dialects been similarly known. As we see below, government, mission and educational policies were being enacted that would permanently splinter the Tawala people.

Meanwhile, the next landmark in the recognition of the Tawala language was a comparative word list of some 250 items in 14 languages published posthumously by the government anthropologist W.E. Armstrong in the ANNUAL REPORT of Papua 1923. On this occasion three Tawala dialects were presented - Bohilai, Tawala and Kehelala - though Armstrong recognised that they were "really better regarded as a single dialect, 'Tawala', in spite of its strange distribution". It was now understood that the language was spoken over a wide geographical area, but half a century was to pass before the exact borders became known. Unfortunately, Armstrong followed his own advice of regarding Tawala as a "single dialect" and for the second half of his lists he omitted the Tawala and Kehelala forms, making comparison with present-day data less meaningful.

Ray (1938) adds nothing to clarify the picture. In his work, the Tawala language as we know it is represented by five separate dialects, all of which are accorded the status of full languages: Awalama, Kehelala, Tawala, Bohilai and Wagawaga. Considerable confusion is introduced with the mention for the first time of Wagawaga. Ray presents two word lists for Wagawaga - one that is similar to the other Tawala dialects, and another which is clearly a separate language. The source of confusion seems to be due to exogamous marriage practices. As Wagawaga is only a small language, most of the males come from the dominant language of the area - Tawala. However, Wagawaga is the mother tongue of the children, and strictly speaking the language of the Wagawaga village belongs to the Suau network of languages (Lithgow 1976b, Ross 1988).

Capell (1943) represents a departure from the previous studies in that he was the first to systematically apply the comparative method to the Austronesian languages of Papua, which he divides into eleven groups. Group 6 is devoted to four "languages" which are "really a matter of dialect, not language" (p.67). His four dialects are Tavara, Keherara, Bohira' $i$ and Wagawaga. (Capell commented on the "flapped" nature of the $/ I /$ in these names and wrote them with a superscripted dot.) Capell confirms the modern Are-Taupota chain when he notes the "relationships of Group 6 are essentially with those of Groups 7 and 8". However, he considers Awayama (based on Ray 1907) to be transitional between groups 6 and 7: "The difference [of Group 7] from the languages south of East Cape is radical. A transition can be seen in Awalama, which resembles Keherara" (p.73).

In the 1950s, Swadesh developed a procedure for measuring the relationships between related languages by the method of lexicostatistics - the counting of shared cognates in basic vocabulary items. Problems were quickly encountered in the method, and scholars came to distinguish glottochronology from lexicostatistics in the hope of salvaging the latter.

McElhanon (1971) reviews the application of lexicostatistics in New Guinea, noting some of the reasons why the method had failed as a classificatory tool. What McElhanon failed to notice was the purpose and perspective of the linguist in the application of lexicostatistics, as pointed out by Simons (1977). While few linguists would regard 
lexicostatistics as a suitable tool for unravelling genetic relationship between languages, it has another purpose:

The linguist who wishes to use lexical similarity as an indication of how well groups could be expected to communicate with one another approaches lexicostatistics with a synchronic perspective.

Simons (1977:14)

Within the Milne Bay Province, the synchronic perspective of the lexicostatistical approach is important because it correlates with the view of the people themselves. When the grammar between two dialects or languages is similar, as is usually the case in Milne Bay, then lexicostatistics correlates to a high degree with mutual intelligibility. For the first time Lithgow (1976), using a lexicostatistical approach, placed the boundaries of Tawala and surrounding languages with a high degree of accuracy. However, as his work was largely based on lexicostatistics, it must be treated with extreme caution or even ignored in tracing the genetic relationships between languages. ${ }^{4}$

Armed with Lithgow (1976) the linguist can walk into many areas of the Milne Bay Province knowing what language the people speak, and able to discuss dialects, language names and relationships with the people in an intelligent manner. Here at last the full extent of the Tawala language was recognised by the outside world. The border as drawn in Map 1 differs from Lithgow (1976:444) only at the eastern end of Basilaki Island. Lithgow comments that Tawala is not spoken at Pitt Bay; however it is on the peninsula to the south of Pitt Bay that Tawala is not spoken. ${ }^{5}$

One would have expected Lithgow's work to have been the last word on the matter; unfortunately, this was not so. In 1981 the brilliantly conceived and produced maps of the Language atlas of the Pacific area came of $\mathrm{f}$ the press. It was with great disappointment that I viewed the Tawala area. Almost everything is wrong, even the name. 'Kehelala' (a village name at East Cape) is the name given to the language, with the wrongly spelled 'Tavara' in brackets. The Labe dialect is included with the Taupota family. The southern shore of Milne Bay (Yaleba coast) is not included in the Tawala area but has been subsumed under the Wagawaga language. The south-western peninsula of Sideia Island (Suau dialect) is included in Tawala, as is the peninsula south of Pitt Bay and the Kitai Islands (Tubetube language). The bibliography for the map includes Lithgow (1976), but sadly it was not used for the Tawala area. Unfortunately, Ross (1988) - which promises to be the definitive work on the area for years to come - follows the Language atlas boundaries, though the language names are thankfully correct.

\subsection{THE TAWALA DIALECTS}

In Figure 1, I present lexicostatistical relationships for the nine dialects found in Table 1. Diwinai, of course, represents the central Tawala dialect. Lamhaga has been chosen to

Lithgow (1976) takes some cognisance of grammatical features, and his practice of visiting every village and discussing language relationships involves a degree of sociolinguistics in his methodology. Ross (1983:8) acknowledges 'considerable correspondence' between Lithgow's and his groupings. However, there are discrepancies (Ross 1988:191-192).

This confusion possibly arose from Lithgow's habit of placing a number of wordlists side by side on the same page; his comment re Tawala and Pitt Bay may have become associated with the wrong column. 
represent the Yaleba dialects. Because of the wide divergence of the dialects on Basilaki Island, both Deladelauna and Hamama have been chosen to represent the Bohilai dialect. Liliki represents the Sideya dialect.

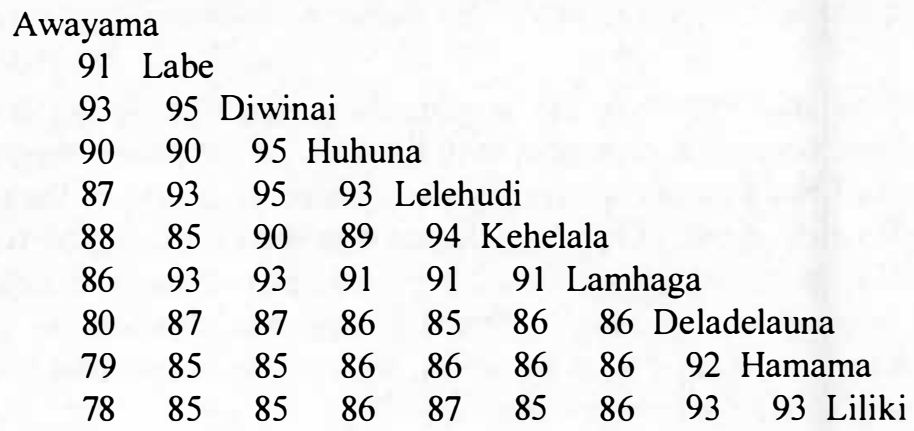

FIGURE 1: MAJOR TAWALA DIALECTS - LEXICOSTATISTICAL RELATIONSHIPS

Ezard (1981) presents an examination of the data relating to these statistics. In addition to the lexicostatistical data, phonological, grammatical and sociolinguistic aspects of the situation are discussed. The figures are based on a new 100-word list I developed to avoid distortion due to the presence of couplets, cultural items etc. in the standard lists (Ezard 1977).

I have found lexicostatistics a useful guide to intelligibility, within Milne Bay. Swadesh $(1954)^{6}$ proposed $81 \%$ shared cognates as the cut-off point for language boundaries and this seems to reflect the situation as viewed by the people of Milne Bay fairly well. The Tawala dialects are mostly well above the $81 \%$ cut-off and Tawala people claim they have no difficulty in communicating with any of the other dialects. On the other hand, they classify nearby speech communities that are below this threshold (e.g. Gweda ${ }^{7}$ at $75 \%$ ) as being separate languages. As a speaker of the Diwinai dialect, I have had some initial problems in moving from dialect to dialect, but not to the point where I doubted that the people were speaking Tawala (doubtless speakers aided me by moving towards the dialect I was using).

\subsection{LANGUAGES OF WESTERN MELANESIA}

Within Melanesia all languages belong to one of two major divisions - Austronesian or Papuan. $^{8}$ The Austronesian languages belong to one of the world's largest family of languages, both in extent and in number. They extend all the way from Hawai'i and Easter Island in the east, to Taiwan, Malaysia and Madagascar in the west (Map 4). The Intercontinental dictionary series (Tryon ed. 1995) lists 1185 languages as belonging to this

6 Data from Gudschinsky (1964).

7 I found listening to Gweda, which shares $75 \%$ common vocabulary with Tawala, a strange experience. The language sounded like a distorted form of Tawala and 1 constantly felt I ought to be able to understand, but could not.

8

Many linguists prefer the term non-Austronesian, as the term 'Papuan' might be taken to imply that the languages have a genetic unity, which is not the case: "Papuan languages are not genetically related... On the basis of present knowledge, they belong to at least sixty different language families" (Foley 1986:3). 
huge AN family. Tawala belongs to a grouping of 482 languages commonly referred to as the Oceanic subgroup, which includes most of the Micronesian languages, all the Polynesian languages and all the AN languages of Melanesia. "There are few if any scholars now active in Austronesian comparative linguistics who doubt the essential correctness of the Oceanic hypothesis". (Pawley and Green 1985)

On the evidence available, prehistorians have concluded that the original language (Proto Oceanic) "broke up sometime around $2000 \mathrm{BC}$, and the Austronesian settlement of the wider Pacific began" (Ross 1989:4). At that time the island of New Guinea was already occupied by non-Austronesian speakers, so that Austronesian languages are mainly "intrusive" coastal languages, with the original Papuan languages spoken in the interior and on the occasional "last stand" island (Map 3 - areas not included within Papuan Tip Cluster). This situation is reflected in the Milne Bay Province, where a single Papuan language is spoken in the east on Rossel Island and a further six Papuan languages (constituting the Daga family - SIL 1973) are spoken in the rugged mountains of the mainland. The remaining 40 languages of Milne Bay Province (including Tawala) are all Austronesian.

Ross (1988) proposes that the area of Melanesia which includes Papua New Guinea should be called Western Melanesia (Map 3). The Milne Bay Austronesian languages are included in a subgrouping of Western Melanesian called the Papuan Tip Cluster, which also includes the Austronesian languages of Central and Oro Provinces. However, languages of the Papuan Tip Cluster have been so influenced by the original Papuan languages of the area that it is now difficult to know just when the movement of Western Oceanic (WO) speakers occurred; as Ross (1990:145) observes, "the WO dialect which became the Proto Papuan Tip underwent radical changes induced by contact with one or more (nonAustronesian) languages...such that features specifically diagnostic of the origins of the Proto Papuan Tip would have been obliterated".

Recent consensus among students of Austronesian culture history is that Austronesian roots can be traced back more than 5,000 years to ancestors who probably lived in Taiwan and spoke Proto Austronesian (PAN). These early Austronesians developed not only considerable seamanship but also other cultural traits which admirably fitted their expansion into the island world of the Indo-Pacific.

The Papuan Tip languages are thus descendants of this original PAN language and still bear many traces of this relationship, in spite of convergence with Papuan languages. It is difficult to date the arrival and dispersion of the speakers of Proto Papuan Tip, but pottery evidence suggests that it took place some 2000 years ago. 


\subsection{LANGUAGE RELATIONSHIPS IN MILNE BAY}

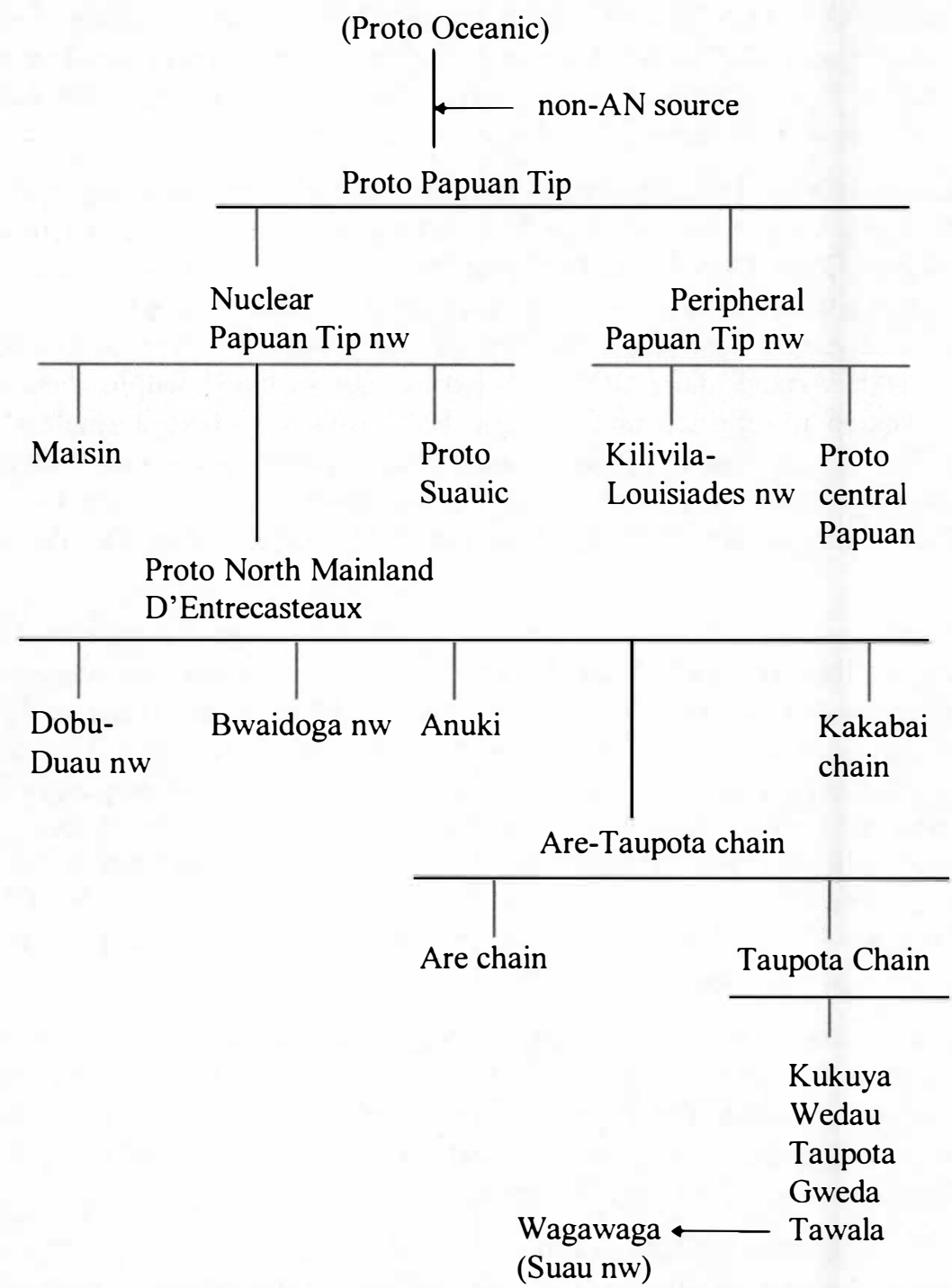

FIGURE 2: GENETIC RELATIONSHIPS OF TAWALA TO PAPUAN TIP LANGUAGES (ADAPTED FROM ROSS 1988)

Ross (1988) presents a modified family tree of the languages around Milne Bay (Figure 2). Ross has adapted the family tree diagram to incorporate dialect and language chaining and networks (nw) by the use of horizontal lines ${ }^{10}$ which extend beyond the vertical lines: 


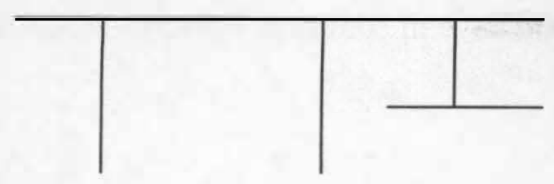

A

B

External influence is indicated by an arrow entering the system:

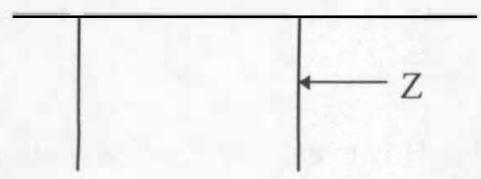

A

B

Both features are incorporated by Ross into his Papuan Tip 'tree'.

Two relationships are of special importance to the Tawala language: the Taupota Chain and the Are-Taupota Chain.

\subsubsection{The TaUPOTa Chain}

To one familiar with the Tawala language, the similarities between it and the other members of the Taupota Chain are unmistakable. This is also reflected in the large number of shared cognates in common lexical items, as indicated in Figure 3 (data from Ezard 1977). These numbers are clearly well below Swadesh's $81 \%$ cut-off point for separate languages, but they are in the $59-75 \%$ range as opposed to many Papuan Tip languages which would be in the $10-30 \%$ range.

\section{Wedau}

63 Tawala

$59 \quad 75 \quad$ Gweda (Garuwahi)

$60 \quad 71 \quad 66 \quad$ Maiwara

FIGURE 3: LANGUAGES OF THE TAUPOTA CHAIN

These statistics reflect the degree of similarity in basic vocabulary between the languages. They correlate with the genetic relationships proposed by the comparative method (Capell 1943; Ross 1979, 1988). The situation is further confirmed by reference to extant grammars - Tawala parallels to Wedau grammar constantly come to mind as King's (1901) Wedau grammar is read. Parallels are much less frequent with grammars of other subgroups of the Papuan Tip Cluster.

\subsubsection{The ARe-Taupota Chain}

Ray (1907) proposed an Are-Taupota chain, which has been confirmed by the subsequent comparative studies of Capell (1943) and Ross (1988). ${ }^{11}$ Ross (1983:37ff.)

11 Lithgow (1976) does not combine Are and Taupota as a sub-group, though his figure of $40 \%$ shared cognates would suggest a fruitful line of enquiry. 
shows the innovations which the languages of the chain have in common. Features in which they differ from the proposed Proto Papuan Tip (PPT) are:

(a) devoicing of the stops ${ }^{*} b,{ }^{*} d,{ }^{*} g$ in certain words

(b) PPT $\mathrm{p}^{*} t>$ PROTO ARE-TAUPOTA ${ }^{*} s / \ldots$

(c) the formation of Agent nouns by suffixing the third person marker to the reduplicated verb:

$$
\begin{array}{lll}
\text { ARE } & \text { vera run }> & \text { vera-vera-na } \text { runner } \\
\text { WEDAU } & \text { vere give }> & \text { vere-vere-na giver }
\end{array}
$$

This grammatical feature does not extend to Tawala. However, the Tawala agentive nominalising particle is the same as the one used in Wedau.

TAWALA bagibagi work > tu-bagibagi worker

WEDAU nola work $>$ tau-nola worker

Unless the Are form is confirmed in other languages of the Taupota chain, the Wedau evidence may reflect borrowing rather than a genetic relationship:

(d) The POC causative *va[ga]- has undergone an unusual vowel shift > PROTO ARETAUPOTA *vi:

$$
\begin{array}{llll}
\text { ARE } & \text { bonua full }>\text { bi-bonua fill (TR) } \\
\text { WEDAU } & \text { peu } & \text { fall }>\text { vi-peu-ni fall-it }
\end{array}
$$

(e) The use of an allative preposition:

$\begin{array}{ll}\text { ARE } & k a u \\ \text { WEDAU/UBIR/ARIFAMA } & a u \\ \text { TAWALA } & u\end{array}$

I propose a further innovation:

(f) PROTO ARE-TAUPOTA * vo- verbal prefix (Ezard 1988):

$\begin{array}{ll}\text { ARE } & \text { bo- } \\ \text { WEDAU } & \text { Vo- } \\ \text { TAWALA } & \text { WO- }\end{array}$

This feature is limited to the Are-Taupota family.

\subsection{PREVIOUS STUDIES OF TAWALA}

Most of the published data on the Tawala language are of an anecdotal nature, presented by the authors to illustrate their sundry comparative claims. "Tavara" data are occasionally encountered in Ray (1907), culled from translations of Charles Abel and T. Matthew. No new Tawala data are found in Ray (1938).

Capell (1943) is the first to present some solid Tawala data, though these are not always accurate. Lithgow (1976) and Ross (1988) and others have added to the overall understanding of the Papuan Tip languages, but added little to our knowledge of the Tawala language itself. 


\subsubsection{BALDWIN's GRAMMAR (c.1950)}

A manuscript grammar of the Bohilai dialect was prepared by Fr Baldwin, consisting of brief notes but containing some valuable insights on the morphology of Tawala. I have only viewed 23 pages of this work, but the index indicates that the original manuscript was well over 60 pages. ${ }^{12}$

\subsubsection{WiLliaM's DictionaRY (c.1962)}

This work is a manuscript dictionary of several thousand items for the Kehelala dialect of East Cape, by the Rev. H.T. Williams. The 19-page grammatical introduction lists many of the functional morphemes of Tawala. Much of the grammar consists of lists, for example 24 adjectives of quality. I found the material useful in my early days of language learming, but would now disagree with many of the categories and conclusions of this work. His dictionary, however, formed the basis of my Tawala dictionary and I have no doubt that Williams was a good language observer and probably a fluent Tawala speaker.

\subsubsection{Published Papers}

In my work on the Tawala language under the auspices of the Summer Institute of Linguistics I have endeavoured to make a number of data-based papers available on the language (1978a, 1978b, 1980, 1992 and 1995).

In addition a number of publications have been made available in the Tawala language: a learn-to-read primer; 40 pre-school story books; several editions of a Tawala hymnbook; and the complete New Testament, as well as earlier editions of separate books of the New Testament.

\subsection{LANGUAGE USE}

It has been the fate of the Tawala people to suffer fragmentation by the successive policies involved in the colonisation process. We have seen above that linguistic maps have also often divided the language, placing bits with other languages; to a large extent, however, that sort of problem does not directly affect the people. Far more serious is the division engendered by mission and educational policies and the boundaries introduced by the colonial political process.

The first consistent contact with the outside world began in the last decade of the 19th century with the three Christian missions converging on the Tawala language area. According to an agreement reached under the leadership of Sir William MacGregor in 1890 , the missions were allocated separate areas to help keep law and order so that efforts would not be duplicated (as he had few resources) and to avoid the confusion of having different missions preaching different dogma in the same area. The Anglicans were assigned the north coast of the mainland; the Methodists (subsequently the United Church)

12 The copy of the grammar I have inherited is in the last stages of disintegration, as is common with books kept in the tropics. The 'Syntax' page numbers are all missing, but consisted of at least four sections. 
were assigned the islands and part of the East Cape peninsula; the London Missionary Society (subsequently the Kwato Extension) was assigned the south coast and the shores of Milne Bay. Undoubtedly this was a sensible working relationship, but, like many of the maps drawn by colonists, inadequate thought was given to the people involved. In this case boundaries dissected the Tawala language in several places, driving a wedge between kith and kin (Map 5). The effects of the divisions thrust upon the people are still very much in evidence today, with Anglicans working in the Wedau language, the United Church in Dobu and Kwato in Suau. Though some efforts were made at producing Tawala literature, for generations work proceeded predominantly in the three church languages, which also began to be used as lingue franche, especially as education was also conducted in these same languages.

In the early 1930s Catholic work began in the area, centred at Sideia. Over the years some of their work was done in the Tawala language, but only in a token way in comparison with the literature available in the other church languages of the area.

Since the introduction of universal education in English, in the 1960s, the divisive barriers have been less extreme. However, while this latter policy has helped to unite the youth from different areas, it has created a deep gulf between the generations. What is more, children have continued to be sent away to high schools in different areas, where the culture, language and church traditions are vastly different.

In recent years the situation has been exacerbated by the introduction of local government councils and election areas which reinforce the arbitrary boundary lines of map makers. Over the years the Tawala people increasingly looked on their own language as unimportant. This conclusion was reinforced by government operations being centred nearby at Samarai in the Suau language area, with Suau or Hiri (formerly Police) Motu (the lingua franca of Papua - the section of the island of New Guinea then governed by the British) commonly used by government officers in their contact with Tawala people. However, moves were afoot in government circles which were to change the scene.

The forces that militated against the language were so strong that the people themselves say their "language was dying", and today there are people of Tawala descent living in the area who do not speak their own language; this is particularly true of the area under Suau influence, as children were forbidden to speak Tawala at school. Other languages - Wedau, Dobu, Suau, Motu and English - were important; Tawala was not. This attitude is seen in the constant misspelling by outsiders of place names (e.g. Tawala is still commonly referred to as "Tavara" even though the language has neither $/ \mathrm{v} /$ nor $/ \mathrm{r} /$ ). I have even heard educated Tawala people referring to their language as 'Tavara', using the non-Tawala phonemes.

In recent years, however, the language is undergoing a revival, and may well become a lingua franca of the province in the years ahead. In 1968 the hopelessly overcrowded island of Samarai was abandoned as the administrative headquarters of the Milne Bay Province in favour of the mainland centre of Alotau on the north coast of Milne Bay. This changeover was completed in 1976 with the opening of the international wharf at Alotau. With the change of leadership at independence, in 1975, Samarai was relegated to the colonial past. Alotau, the new capital, is situated within the Tawala area. While there have been many results of the change of administrative location, none is more important than the effect it has had on the Tawala people, who have a new-found sense of the importance of their language, which is increasingly heard in the market place, hospital, government 
departments and even on Radio Milne Bay. The Rev. Gray, a United Church minister active in the Alotau area during the early changeover period, reported a dramatic swing to the use of the vernacular in church services. Today the swing is almost complete, with Tawala hymns and New Testament available and popular, and church services throughout much of the language area conducted in the Tawala language. In 1981 some Tawala young people published the first Tawala newspaper-GEKA TUWEGA 'This is News'. What is more, people from other language areas are increasingly using Tawala in their contacts with the local people.

The Tawala people are now proud of their language and welcome efforts on the part of outsiders to speak it. This makes an ideal language-learning situation. Unlike some places in the world, the outsider only has to go to the nearest house, beach hut or garden shelter to find people ready to help with language learning.

\subsection{LANGUAGE CHANGE - BORROWINGS}

Borrowings are a fruitful source of new lexical items; modem borrowings are mainly from European languages. In listing some typical borrowings we can distinguish those roots which appear to have had no influence on Tawala phonetics from those which do.

\subsubsection{Influence on Tawala Phonology}

\subsubsection{NO INFLUENCE}

Austronesian languages:

$\begin{array}{lll}\text { tapalolo } & \text { worship } & \text { (Tubetube: 'let us bow') } \\ \text { tautau } & \text { photograph } & \text { (Suau) } \\ \text { sagena } & \text { fast } & \text { (Suau) } \\ \text { dimdim } & \text { European } & \text { (Suau: 'from the ocean') } \\ \text { pilipou } & \text { trousers } & \text { (Samoa) }\end{array}$

European languages:

$\begin{array}{lll}\text { masisi } & \text { matches } & \text { (English) } \\ \text { oniyani } & \text { onion } & \text { (English) } \\ \text { siluba } & \text { silver } & \text { (English) } \\ \text { motaka } & \text { car } & \text { (English) } \\ \text { basileiya } & \text { country } & \text { (Greek: }{ }^{13} \text { basileia } \text { kingdom) } \\ \text { ekelesiya } & \text { Christian } & \text { (Greek: ekklesia } \text { gathered) }\end{array}$

\subsubsection{INTRODUCING CHANGES}

(a) Final Vowel Omitted

All Tawala words end in vowels or a syllabic $/ \mathrm{m} /$. Many borrowed items, including those in the following list, do not follow this norm.

13 Greek words were sometimes used by missionaries, when they could find no equivalent lexical item in the language. 


$\begin{array}{lll}\text { amnos } & \text { sheep } & \text { (Greek: amnos lamb) } \\ \text { epot } & \text { airport } & \text { (English) } \\ \text { botol(o)* } & \text { bottle } & \text { (English) } \\ \text { buk }(a)^{*} & \text { book } & \text { (English) } \\ \text { sikis(i)* } & \text { six } & \text { (English) } \\ \text { nain(i)* } & \text { nine } & \text { (English) }\end{array}$

*Vowels in brackets are added by speakers who have had less contact with English.

(b) Transitional Vowel Omitted

Tawala has no consonant clusters except where syllabic $/ \mathrm{m} /$ is followed by a syllable beginning with a consonant. Only the first word in the following list is used according to Tawala conventions.

$\begin{array}{lll}\text { sensi } & \text { change } & \text { (English) } \\ \text { bensin } & \text { petrol } & \text { (German: Benzin) } \\ \text { klak } & \text { clerk } & \text { (English) } \\ \text { diploma } & \text { diploma } & \text { (English) } \\ \text { Mosbi } & \text { Moresby }{ }^{14} & \end{array}$

\subsubsection{NolNS}

Nouns are thoroughly incorporated into the grammatical system, as the following NPs demonstrate.

$$
\begin{aligned}
& \text { a. gawiya kapena-na } \\
& \text { war captain-3SG } \\
& \text { the fighting captain }
\end{aligned}
$$
b. ita kampani-na our company-3SG our business

c. fael-gei file-INS with a file

\subsubsection{VERBS}

While not as numerous as borrowed nouns, a considerable number of borrowed verbs are found in everyday use - normally where there is no Tawala word to express a particular notion.

$\begin{array}{ll}\text { wi-sikulu } & \text { attend school } \\ \text { wi-nesi } & \text { practise nursing } \\ \text { laki } & \text { be lucky } \\ \text { dalaew-e-ya } & \text { drive it (a car) } \\ \text { om-bulum } & \text { sweep (with broom) } \\ \text { om-printing } & \text { work a printing press }\end{array}$

As verbs are always embedded within grammatical structures, the following examples are given within complete sentences. 
2(2) Klak apo hi-na-sain-e-ya.

clerk FUT 3PL-POT-sign-TRV-3SG

The clerks will sign it.

2(3) I-wi-pensil-ge-ya.

3SG-DVP-pencil-TRV-3SG

He made it into a writing implement.

2(4) Diploma bi-nei e-i-treining.

diploma BEN-3SG 3SG-DUR-training

She is doing the course to get a diploma.

2(5) U luhogala ipa motaka a-dalaew-e-ya.

my desire IRR car ISG-drive-TRV-3SG

I want to drive the motor car. 


\section{DISTINCTIVE ASPECTS OF TAWALA GRAMMAR}

\subsection{REDUPLICATION}

A very common pattern of word formation in Tawala is reduplication of all or part of a root, for example many nouns are reduplicated in their basic forms. Thus the dictionary contains many items like these:

$$
\begin{array}{ll}
\text { bagibagi } & \text { work } \\
\text { kewokewou } & \text { canoe }
\end{array}
$$

Reduplication marks a grammatical category of some nouns; for example most nouns referring to humans are reduplicated for plural.

$$
\begin{array}{lll}
\text { hewali } & >\text { hewahewali } & \text { young man }>\text { young men } \\
\text { keduluma } & >\text { kedukeduluma } & \text { woman }>\text { women }
\end{array}
$$

A large proportion of Tawala adjectives are derived by the process of reduplication.

$$
\begin{array}{ll}
\text { dewadewa-na } & \text { good-3SG } \\
\text { witewitei-na } & \text { heavy/difficult-3SG }
\end{array}
$$

Many Tawala verbs can be reduplicated if the action is durative, repeated or progressive.

\section{hi-woe-woe-ya they kept on paddling it}

hi-dewa-dewa-ya they were doing it

We can combine reduplicated words to form perfectly natural-sounding sentences. I made up the next two sentences for the purpose of illustrating this point; it is not often that all the forms in the sentence would be reduplicated.

\section{3(1) Kedu-keduluma bagibagi dewadewa-na hi-dewa-dewa-ya. PL-woman work good-3SG 3PL-DUR-do-3SG}

The women were doing good work.

3(2) Hewa-hewali kewokewou witewitei-na hi-woe-woe-ya. PL-young.man canoe heavy-3SG 3PL-DUR-paddle-3SG The young men are paddling the heavy (difficult) canoe.

\subsection{DERIVATIONAL PROCESSES}

Verb derivation is extremely important in the Tawala language (Ezard 1978a, 1992). Linguists have tended to treat derivation as a lexical rather than grammatical concern (Harlow and Vincent 1988:5) and hence of only minor grammatical importance. In my study of Tawala I have found that nothing could be further from the truth; an understanding of the highly complex field of derivational prefixes is central to an understanding of Tawala grammar. 
Fundamental to the meaning of Tawala derivational prefixes is the word class and subclass of the roots to which they are attached (Ezard 1992); hence I have come to deeply appreciate the 'semantics prior' approach of Dixon (1982).

The complexity of the subject precludes any adequate treatment within the scope of an overview (see Chapter 18 for details) and I merely present some examples of their use with the stative verbs $i$-dao 'it is long' and $i$-gobu 'it is dirty'.

a. Hai baha hi-wi-dao- ya. their talk 3PL-DVP-long-3SG OBJECT--.-- S-

O-

They talked on and on.
a. Lawa hi-lu-gobu. people 3PL-DVP-dirty SUBJECT S-
They're an unkempt people. ${ }^{1}$
b. Hai numa hi-li-dao- ya. their house 3PL-DVP-long- 3SG OBJECT-.--.--. S- They extended their house.

b. Nima-hi-yei hi-wo-i-gobu- ya. hand-3PL-ABL 3PL-DVP-EFF-dirty-3SG INSTRUMENT SThey dirtied it with their hands.

\subsection{NON-VERBAL CLAUSES}

Although often overlooked in grammars and typological studies of the area, Tawala, along with many Austronesian languages, is typologically interesting in the extensive use made of non-verbal constructions - what Capell (1969:38-39) refers to as "structurally verbless sentencesThe following data are a few simple examples of non-verbal clauses; in each case there is no copula or verb of any kind (Chapter 11 gives detailed treatment of these and other clause constructions; Chapter 12 demonstrates the functional unity of nonverbal and verbal clauses).

a. Polo hai am. pig their food The pigs have food. b. Tau geka.

I here

I am here.

3(6) Tauyai uyahi-yai ega geno-na, ma tam tunawa-m om geno. weEXC 'at'-IPL.EXC NEG worry-DEF but youSG alone-2SG yoursG worry For us it is not a worry, but it is your worry only.

\subsection{HEAD-MARKING GRAMMAR}

...the literature generally recognizes the complementarity between certain morphological categories. What has not been recognized is that such complementarities neatly reduce to two polar possibilities - marking of heads vs. marking of dependents - and that a language is likely to make a consistent choice as to marking type throughout its morphosyntax.

Nichols (1986:66)

In Head-marking and dependent-marking grammar, Nichols (1986) proposes a typology which is applicable across several levels of grammar. She points out (p.57) that linguists from:

This is a reference to the state of a person who is in mourning. 
...divergent theoretical persuasions are in almost complete agreement as to what is the head and what is the non-head in a given construction...the head is the word which governs, or is subcategorized for - or otherwise determines the possibility of occurrence of - the other word.

Table 1 shows the dependency relations discussed by Nichols.

TABLE I: UNIVERSAL DEPENDENCY RELATIONS

\begin{tabular}{|l|l|l|}
\hline LEVEL & \multicolumn{1}{|c|}{ HEAD } & \multicolumn{1}{c|}{ DEPENDENT } \\
\hline Phrase & $\begin{array}{l}\text { possessed noun } \\
\text { noun } \\
\text { adposition }\end{array}$ & $\begin{array}{l}\text { possessor } \\
\text { modifying adjective } \\
\text { complement of adposition }\end{array}$ \\
\hline Clause & $\begin{array}{l}\text { predicate } \\
\text { auxiliary verb }\end{array}$ & $\begin{array}{l}\text { arguments and adjuncts } \\
\text { lexical ('main') verb }\end{array}$ \\
\hline Sentence & main-clause predicate & relative or subordinate clause \\
\hline
\end{tabular}

Languages differ as to whether they mark syntactic relations on the head or the dependent constituent. With possessive constructions English marks the dependent and Tawala the head. In the following examples the head is marked by capitals and the morphological marking is underlined.

ENGLISH: the man-'s CHILD

TAWALA:

3(7) bada NATU-na

man child-3SG

the man's child

In the English example above, the possessive construction is marked by the genitive case on the dependent noun 'man'; in 3(7) it is the head noun which is marked by a pronominal enclitic.

It is remarkable that this head-dependent typological distinction has remained unnoticed for so long. Nichols (1986:56) suggests that one reason for this is that:

...mainstream theory, despite considerable efforts to test ideas on exotic languages, happens to have looked almost exclusively at those languages which differ little from Indo-European with regard to the phenomenon at issue.

This approach offered considerable insight into Tawala grammar, Tawala being a headmarking language and hence an enigma for me as I grappled with modern linguistic approaches. Having worked on the Tawala language for a number of years before reading Nichols' (1986) paper, I was excited by the fresh insight gained from the new approach. Viewing Tawala in the light of head-marking typology explains what were for me a number of idiosyncratic facts. In addition it gave a theoretical framework for my intuition that grammatical relations are morphologically marked.

\subsubsection{Head Markingin Ta wala}

Nichols (1986:58) demonstrates that head/dependent marking can signal dependency in three ways:

1) The morphological marker may simply register the presence of syntactic dependency; as we have noted this can be either on the head or the dependent. The English genitive 
$\underline{s}$ is of this kind; it simply marks the dependent possessor as dependent on the head. Tawala ligature is also this kind of marking, simply marking on the head that a modifier is following.

$\begin{array}{llll}\text { Ma a-BAH'-e-ya. } & >\quad M a \text { a-BAH'-e-na } & \text { me-ya. } \\ \text { but 1SG-Say-TRV-3SG } & & \text { but ISG-say-TRV-LIG } & \text { again-3SG } \\ \text { But I said it. } & & \text { But I said it again. }\end{array}$

That ligature attaches to the head rather than the following dependent is indicated by penultimate stress - aba'hena 'meya.

2) The morphological affix can mark not only the presence but the type of dependency: its role or grammatical relation. For example, the person marker on a Tawala verb identifies an NP not just as a dependent but as the subject (or object) NP.

3(9) Hewali ma kedewa hi-HILAGE LUWAGA.

youth and dog 3PL-die two

The youth and the dog died together.

3) "...the morphological affix may, in addition, index particular inflectional or lexical categories of either the head or the dependent, marking them on the other constituent." Thus in Tawala clauses, person marking on the head gives the person and number of the dependent; compare 3(9) with the sentences in 3(10).
a. Kedewa-na gasi i-HILAGE.
b. ...ta-HILAGE PAHI-ta.
dog-DEF also 3SG-die
The dog also died.
IPL.INC-die completely-IPL.INC ...we might be destroyed.

Table 2 summarises head- and dependent-marking strategies for Tawala.

TABLE 2: HEAD/DEPENDENT-MARKING IN TAWALA

\begin{tabular}{|l|l|l|l|}
\hline $\begin{array}{l}\text { GRAMMATICAL } \\
\text { LEVEL }\end{array}$ & $\begin{array}{l}\text { Place of } \\
\text { marking }\end{array}$ & $\begin{array}{l}\text { Type of } \\
\text { dependency }\end{array}$ & $\begin{array}{l}\text { Categories } \\
\text { indexed }\end{array}$ \\
\hline $\begin{array}{l}\text { phrase: } \\
\text { POSSESSIVE } \\
\text { ADPOSITIONAL } \\
\text { MODIFIED NP } \\
\text { MODIFIED VP }\end{array}$ & $\begin{array}{l}\text { head } \\
\text { head } \\
\text { dependent } \\
\text { head }\end{array}$ & $\begin{array}{l}\text { possessor } \\
\text { complement } \\
\text { modifier } \\
\text { modified }\end{array}$ & $\begin{array}{l}\text { person/number } \\
\text { person/number } \\
\text { person/number }\end{array}$ \\
\hline $\begin{array}{l}\text { clause: } \\
\text { VERBAL }\end{array}$ & $\begin{array}{l}\text { head } \\
\text { head } \\
\text { head } \\
\text { zero }\end{array}$ & $\begin{array}{l}\text { subject } \\
\text { object } \\
\text { subject } \\
\text { none }\end{array}$ & $\begin{array}{l}\text { person/number } \\
\text { person/number } \\
\text { person/number }\end{array}$ \\
\hline NON-VERBAL i. & ii. & \multicolumn{2}{|l}{} \\
\hline
\end{tabular}

The theoretical insight of head marking is central to an understanding of Tawala discourse pragmatics: the person markers found on most heads are the main cohesive element of Tawala discourse - "keeping track of old information" (Grimes 1975:113); the optionality of dependents makes them the prototypical markers of 'prominence', a term which "covers the entire area for which investigators have used such terms as theme, attention, focus, foreground, figure, topic, and emphasis" (Callow 1974:50).

Tawala pronominal enclitics function with adjectives, quantifiers, inalienably possessed nouns, postpositions (with or without the ablative suffix) and object indexing on the verb. 
Table 3 illustrates these structures (apart from quantifiers) with first person singular examples.

TABLE 3: RANGE OF PRONOMINAL ENCLITIC FUNCTIONS

\begin{tabular}{|c|c|c|c|c|}
\hline POSSESSIVE & ADJECTIVE & POSTPOSITION & $\begin{array}{l}\text { POSTPOSITION } \\
+ \text { ABLATIVE }\end{array}$ & OBJECT \\
\hline $\begin{array}{l}\text { ama-u } \\
\text { father-1SG } \\
\text { my father }\end{array}$ & $\begin{array}{l}\text { dewadewa-u } \\
\text { good-1SG } \\
\text { my goodness }\end{array}$ & $\begin{array}{l}\text { uyahi-u } \\
\text { 'at'-1SG } \\
\text { to/on me }\end{array}$ & $\begin{array}{l}\text { uyahi-u-gei } \\
\text { 'at'-1SG-ABL } \\
\text { from me }\end{array}$ & $\begin{array}{l}\text { i-gale-u } \\
\text { 3SG-see-1SG } \\
\text { he saw me }\end{array}$ \\
\hline
\end{tabular}

The cover term 'enclitic' is problematical because postpositions take suffixes rather than enclitics. With possessives and adjectives the pronominal enclitic attaches to the phrase not to the noun stem.

$\begin{array}{llll}3(11) \text { a. } \begin{array}{l}\text { ama duma-u } \\ \text { father true-1SG } \\ \text { my true father }\end{array} & \text { b. } & \begin{array}{l}\text { dewadewa } \\ \text { good } \\ \text { truly good }\end{array} & \begin{array}{l}\text { duma-na } \\ \text { true-3SG }\end{array}\end{array}$

Similarly the object enclitic attaches to the end of the verb phrase.
3(12) I-na-gale-na imahi-ye-u.
3SG-POT-see-LIG properly-TRV-1SG
She will look after me properly.

\subsubsection{PosSessive Noun PHRASE}

The head noun of a possessive phrase is marked for agreement with the possessor noun. Because the person and number of the dependent is marked on the head (possessed noun), the dependent (possessor noun) is always optional in Tawala; the head is a phrase in its own right, capable of standing by itself as an NP.

3(13) (tewela) HINA-na po AMA-na
child mother-3SG and father-3SG
the (child)'s mother and father

Even within NPs, dependents are used to mark pragmatic functions and not grammatical relations. In this, a head-marking system differs from a dependent-marking system. Replacing the head noun with a pronoun in a dependent-marking system does not remove the dependent - it simply replaces it with a pronoun, an option available to Tawala also (though the pronoun is emphatic in Tawala as it operates in combination with the person marker).

$\begin{array}{lll}3(14) & \text { (tauyai) } \text { GOG' }^{\prime} \text { iyai } \\ \text { weEXC } & \text { ancestor- } & \text { PPL.EXC } \\ \text { PRONOUN HEAD } & \text { PERSON MARKER } \\ \text { our ancestor } & \end{array}$

The pronoun in the English gloss is not optional, whereas it is in Tawala. 


\subsubsection{Postpositional Phrase}

The head of a postpositional phrase is a postposition which is head marked with a pronominal enclitic that agrees with the dependent noun or pronoun (often referred to as the 'object of the postposition').

\section{3(15) meyagai UYAHI-hi \\ village 'at'-3PL \\ at/in the villages}

Again it should be noted that only the head needs to be present in the Tawala postpositional phrase; the dependent has pragmatic function. However, although it can be omitted it seldom is, except in first and second persons, where it is normally absent.

3(16) U-nei UYAHI-u.

2SG-come 'at'-1SG

You came to me.

\subsubsection{MOdifiER NOUN PHRASE}

Tawala noun phrases with modifying adjectives mark the dependent adjective rather than the head noun. The dependent adjective is marked for person and number agreement with the head noun by a pronominal enclitic. ${ }^{2}$

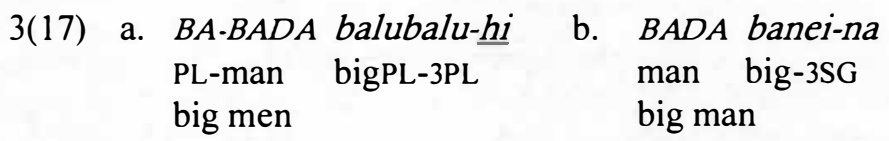

This situation seems contrary to initial expectations; a head-marking language, one would think, ought to mark the noun and not the adjective. Four observations need to be made in this regard.

1) Head marking within the modifier NP is typologically rare. In Nichols' core sample of 60 languages, only two have such marking. She comments (p.76):

Within phrases, NPs with modifying adjectives are least prone to be head-marked...Headmarked treatment of these phrases seems to occur only in languages that are generally headmarking at the phrase level...but it is extremely rare even in such languages.

2) Head marking of a modifier NP in Tawala would be largely vacuous: the noun would simply be marked to show a dependent adjective is present. Some languages mark the noun for class or gender, but this is not head marking in the same sense, as it says nothing about the dependent. The marking of the dependent adjective is, on the other hand, a meaningful process (indicating the person and number of the head), disregarding only the sensibilities of analysts, who recognise inconsistencies in headmarking patterns.

There is an alternative analysis. It is possible the adjective should be treated as a nominalised modifier and thus the head of the phrase. In support of this is the fact that an adjective in Tawala can occur without its head noun. Such a view would regard all modifier verb phrases as embedded nominalised clauses. 
3) In Tawala, dependent marking of adjectives results in surface strings similar to the head marking of other nominal phrases - in each case a pronominal enclitic is used.

3(18) keduluma NATU-na POSTPOSITIONAL MODIFIER woman child-3SG keduluma UYAHI-na KEDULUMA banei-na the woman's child woman 'at'-3SG to the woman big-3SG woman a big woman
b. muhomuho-hi
smallPL-3PL
the small ones

4) There is a sharp distinction in Tawala between the attributive use of the adjective and its predicative use. Although the surface string is identical in each case, the noun is the head of the modifier noun phrase, and the adjective is the head of the non-verbal clause.

ATTRIBUTIVE ADJECTIVE

3(20) WAM dewadewa-na a-gale-ya. boat good-3SG ISG-see-3SG I saw a good boat.
PREDICATIVE ADJECTIVE

Wam DEWADEWA-na.

boat good-3SG

The boat is good.

\subsubsection{Modifier Verb Phrase}

It was noted above that the head of some verb phrases is head-marked with ligature, indicating that a dependent modifier follows. This construction is a further example of head marking, included at this point only for ease of reference (for discussion see $§ 8.11$ ).

\begin{tabular}{|c|c|c|c|c|c|}
\hline $3(21)$ & $\begin{array}{l}\text { Ma a-BAH'-e-ya. } \\
\text { but ISG-Say-TRV-3SG } \\
\text { But I said it. }\end{array}$ & $>$ & $\begin{array}{l}\text { Ma } \\
\text { but } \\
\text { But I }\end{array}$ & $\begin{array}{l}a-B A H^{\prime}-e-n a \\
\text { ISG-say-TRV-LIG } \\
\text { said it again. }\end{array}$ & $\begin{array}{l}\text { me-ya } \\
\text { again-3SG }\end{array}$ \\
\hline
\end{tabular}

The ligature is always -na; it never varies.

\subsubsection{Verbal Clause}

I argue that grammatical relations in Tawala operate within the clause nucleus rather than the clause core. I also argue that, in line with head-marking strategy, Tawala nouns are not dependent-marked for grammatical relations, but instead the grammatical relations are head-marked on the verb by person markers indexing subject and object.

(a) Subject - unstressed pronoun with an anaphoric function; the first prefix of the verb phrase is marked for person and number of the subject argument.

(b) Object - unstressed pronominal enclitic with a non-emphatic, referential function; the final clitic of the VP is marked for the person and number of the object argument. 
3(22) Polo a- MATUT'-e- ya.

pig ISG- fear-TRV- 3SG

TOPIC:S S PREDICATE O-

I feared (was afraid of) the pig.

3(23) Ba-bada polo hi- GALE- ni.

PL-man pig 3PL-see- 3SG

TOPIC I:S TOPIC II:O S- PREDICATE O-

The men saw the pig.

Tawala has no auxiliary verbs, so that parameter discussed by Nichols is not relevant. However, more needs to be said about the nature of the Tawala clause, in particular with respect to grammatical relations.

\subsubsection{NoN-verbal Clauses}

Tawala has non-verbal clauses; some of these are head-marked and others have no morphological marking at all. We look only briefly at the unmarked variety.

\subsubsection{UnMarked Non-verbal Clauses}

Equative clauses consist of two juxtaposed noun phrases functioning as dependent subject and head predicate (underlined).

NPSUBJECT NPPREDICATE

3(24) a. Geka tau.

this me

This is me.

b. Tau geka.

I here

I am here.

With these clauses there is no marking of either head or dependent; as shown in 3(24) grammatical relations are indicated by word order.

\subsubsection{Marked Non-Verbal Clauses}

The descriptive clause consists of a dependent 'subject' NP and a head adjective functioning as the predicate and marked for subject with a pronominal enclitic.

\section{NPSUBJECT ADJECTIVE<-na>PREDICATE}

The surface string of the descriptive clause is identical to the noun phrase but the underlying structures are different.

NOUN PHRASE

3(25) HOUGA gehou-na i-nei. time other-3SG 3SG-come Another time he came.
INDEPENDENT CLAUSE

Houga GEHOU-na.

time other-3SG

It was another time.

The NP consists of a single clause-level constituent and the clause has two clause-level constituents. 
The two structures in 3(25) are thus clearly distinct, as are their distribution and intonation, the clause having sentence-final intonation not found on the phrase. However, this is not just a case of simple constructional homonymity, since it seems likely that the clause is related to the NP.

The main evidence for two structures is the contrastive use of the negative, which is placed immediately prior to the non-verbal predicate - houga ega dewadewana 'the time was not good'. Further evidence is the substitution of the non-verbal predicate by a verbal predicate.
NON-VERBAL PREDICATE
A dewa dewadewa-na. his custom good-3SG His custom is good.

VERBAL PREDICATE

$A$ dewa i-dewadewa. his custom 3SG-good

His custom is good. 


\section{CHAPTER 4}

\section{PHONOLOGY}

\subsection{SEGMENTAL PHONEMES}

...the AN languages [of Western Melanesia] present no particular difficulties on the phonetic level.

Capell (1969:36)

The orthography of Tawala presents no great difficulties, but it does differ from some writing conventions of some publications. As noted in the introduction, several different traditions have been perpetuated by the different churches of the area. I have made the following changes in line with data I have recorded and the interpretations set out below:

(a) the retroflex approximant written alternatively as $l$ and $r \rightarrow / 1 /$

(b) the high front approximant written as both $e$ and $i \rightarrow \mid y /$

(c) the high back approximant often written as $u$ or $v \rightarrow / W /$

(d) labialisation $g^{u}$ etc. $\rightarrow / g w /$ etc.

The Tawala phonemes were established in Ezard and Ezard (1974); the details and evidence provided in that paper are not repeated here.

\subsubsection{CONSONANTS}

Table 1 presents a composite consonant chart for Tawala. No dialect uses all the consonants represented (the details of dialect differences are given in Table 2).

TABLE 1: TAWALA CONSONANTS

\begin{tabular}{|l|l|c|c|c|c|c|}
\hline \multicolumn{2}{|c|}{ CONSONANTS } & labial & alveo-dental & retroflex & velar & glottal \\
\hline \multirow{2}{*}{ plosives } & voiceless & $p$ & $t$ & & $k$ & $q$ \\
& voiced & $b$ & $d$ & & $g$ & \\
\hline labialised & voiceless & $p w$ & & & $k W$ & \\
plosives & voiced & $b w$ & & & $g W$ & \\
\hline nasals & & $m$ & $n$ & & & \\
\hline $\begin{array}{l}\text { labialised } \\
\text { nasal }\end{array}$ & & $m w$ & & & & \\
\hline fricatives & & & $s$ & & & $h$ \\
\hline approximants & & & $y$ & $l$ & $w$ & \\
\hline
\end{tabular}

The placement of the approximant $/ y /$ within the alveo-dental column indicates the unusual nature of this sound which even has a fricative quality between low vowels, following a stressed syllable. The tongue is brought forward so the blade is below the upper teeth.

i-waya he/she/it takes it 
This is the sound found in the place name Awaiama that led to some confusion in the literature (see Chapter 2 fn. 3).

In all there are nineteen consonants, though historically there were only eighteen, as $/ s /$ was an allophone of $/ t /: / s /$ preceding $/ i /$ and $/ t /$ elsewhere.

$$
s /{ }^{i}{ }^{i} \text { elsewhere }
$$

The dialect variation of some forms reflect this rule:

$$
\begin{array}{ll}
\text { emota/emosi } & \text { one } \\
\text { hota/hosi } & \text { only }
\end{array}
$$

Today, some Tawala words have been universally changed, hence the common greeting tinani, formerly sinani - a form rarely heard these days. The word magisubu 'eagle' (clan name) on the other hand, never occurs with the form * magitubu, to my knowledge - it may well be a borrowed form, as clans are not restricted to language boundaries. A few other words show fluctuation, e.g. tu-wiatatiyana/tu-wiatasiyana 'teacher'.

Borrowings have often been in line with historical usage: masisi 'matches', pusi 'pussy', sipuni 'spoon', sipi 'sheep', pasi 'putty'. Other borrowings have helped to reinforce the change or, more probably, helped initiate it: samane 'tinned fish (salmon)', sospani 'saucepan', lesa 'razor', batin 'batten', goti 'goat', siyeti 'shirt'. An anomaly lies in the fact that at least one word has been borrowed using the 'wrong' consonant: sawelo 'towel'.

\subsubsection{Consonant Sequences}

There are no true consonant clusters in Tawala. Two consonants can only occur together across syllable boundaries, but this is limited to syllable final $/ m /$ (historically $m u$ ) as the first consonant in the cluster.

The derivational prefix om-, ending in a syllabic nasal, creates contiguous consonants in numerous derived words. The morphology of these forms is often rather opaque, so that true consonant clusters may be in the process of developing.

$\begin{array}{llll}\text { om-hoe } & \text { leave } & \text { (hoe } & \text { untie) } \\ \text { om-boho } & \text { selfish } & \text { (boho } & \text { extinguish) } \\ \text { om-teina } & \text { persuade } & \text { (teina } & \text { pull) }\end{array}$

Two contiguous $/ \mathrm{m} /$ consonants can occur in this situation:

om-momota hold tightly (momota tighten)

Reduplication often results in clusters:

kamkam chicken

dimdim European

Similar clusters are commonly found across word boundaries.

4(1) Tam bada, naka om ginouli. yousG man that yoursG thing You sir, that is your possession. 
Borrowing has resulted in the introduction of other consonant clusters. However, attempts to interpret labialisation as $\mathrm{CV}$ or $\mathrm{CC}$ sequences result in uncharacteristic phonological sequences, downglides and consonant clusters respectively (Ezard and Ezard 1974).

\subsubsection{Dialectal Distinctions}

Table 2 lists a three-way distinction between the ten dialects. (The Tawala dialects are listed in $\S 2.2$, along with an indication of their lexicostatistical relationships.) There appears to be no explicable relationship between the phonological distinctions and the lexicostatistical data.

TABLE 2: CONSONANT INVENTORY OF TAWALA DIALECTS

\begin{tabular}{|c|c|c|c|c|c|c|c|c|c|c|c|c|c|c|c|c|}
\hline DIALECT & \multicolumn{16}{|c|}{ CONSONANTS } \\
\hline Island & $p \quad b$ & $t$ & $d$ & $k$ & & $p w$ & $b_{w}$ & $k w$ & $g_{W}$ & $m$ & $n$ & $m w$ & $s$ & $h w$ & & $y 1$ \\
\hline Central & $p \quad b$ & $t$ & $d$ & $k$ & $g$ & & & $k w$ & $g_{W}$ & $m$ & $n$ & & $s$ & $h w$ & & $\begin{array}{ll}y & 1 \\
\end{array}$ \\
\hline Inland & $p \quad b$ & $t$ & $d$ & $k$ & $g$ & & & $k w$ & $g_{W}$ & $m$ & $n$ & & $s$ & $h$ & $w$ & $\begin{array}{ll}y & 1\end{array}$ \\
\hline
\end{tabular}

The Island dialects of East Cape (Kehelala and Lelehudi) and the islands (Bohilai, Liliki and Deladelauna) have eighteen consonants with only the glottal plosive missing from their inventory. The designation 'Island' is appropriate for these dialects, even though some are on the mainland, as the island languages of the Milne Bay Province generally have the extra labialised consonants, and they are presumably the result of language contact, though generally absent from the Are-Taupota chain (Ross 1988:198ff.).

Of the nineteen consonants in Table 2, only fifteen are used in the present-day Central dialects of Diwinai, Yaleba, Huhuna and Awayama; the three bilabial labialised consonants and the glottal plosive are not used. Synchronically these dialects, along with Labe, simply omit the labialisation.

$\begin{array}{lll}\text { gimwala } & \text { gimala } & \text { trade } \\ \text { umwa } & \text { uma } & \text { drink } \\ \text { mwateta } & \text { mateta } & \text { doorway } \\ \text { bwadebwade } & \text { badebade } & \text { insane } \\ \text { bwayobwayo } & \text { wayawaya } & \text { crow } \\ \text { pwaoli } & \text { paodi } & \text { make compensation }\end{array}$

The presence of a labialised consonant in any dialect does not guarantee that the labialised form of a lexical item is employed. Thus the form for 'doorway' at East Cape is mateta and not $m$ wateta.

The Inland dialect of Labe has a glottal plosive not found in other dialects. This occurs not only at certain morpheme boundaries but also between a few vowel sequences found within Diwinai vocabulary items. There are also vocabulary differences where $/ n /$ is replaced by the glottal plosive.' 


$\begin{array}{lll}\text { LABE } & \text { DIWINAI } & \\ \text { hi-qeno } & \text { hi-eno } & \text { they slept } \\ \text { wiqaloni } & \text { wialoni } & \text { face a storm } \\ \text { buquwa } & \text { buuwa } & \text { crazy } \\ \text { tuqawa-na } & \text { tunawa-na } & \text { by him/her/itself }\end{array}$

\subsubsection{VOWELS}

Capell (1969:27) notes that most Austronesian languages of Western Melanesia "fit into a five vowel system", and Tawala is no exception.

TABLE 3: TAWALA VOWELS

\begin{tabular}{|c|c|c|c|}
\hline & Front & Central & Back \\
\hline High & $i$ & & $u$ \\
\hline Mid & $e$ & & $o$ \\
\hline Low & & a & \\
\hline
\end{tabular}

The only vowel to display significant environmental variation is / $a /$.

(a) It is fronted before $/ u /$ in a stressed syllable:

/tulau/ [tulæu] my friend

(b) The tongue is raised slightly at the end of words:

liyetal [iyet] day

\subsubsection{Vowel SEQUENCES}

\subsubsection{NON-IDENTICAL VOWELS}

All possible two-vowel sequences occur. The two vowels involved in any sequence normally retain their individual character including their length, so that they must be regarded as a sequence of two vowels and not a glide. However the two vowels run together so that the boundary between them is indeterminate and has a glide-like character. When the sequence is descending, an approximant is often clearly discernible between the two vowels (eya-na 'his/her aunt', meyagai 'village', gowa-na 'his/her/its name'); it is always written, even when the sequence is indeterminate (iyana 'fish', labiya 'sago', iyeta 'day', buuwa 'crazy') helping, to maintain the dominant $\mathrm{CV}$ syllable pattern of the language. These transitional approximants are not phonemic, rather they are a writing convention. Thus there is no contrast between / e.ya/ and /e.a/; within morphemes the latter sequence does not exist because we have chosen to write the sequence with an intervening transitional approximant. On the other hand, across morpheme boundaries the transitional approximant is not added (i-am 'he/she ate', hi-eno 'they slept').

Vowel sequences are, in any case, not very common in Tawala. In a random count of lexical items in the dictionary, well under $10 \%$ contained vowel sequences. The preferred $\mathrm{CVCV}$ sequence is normally maintained within the word, though VV sequences are much more plentiful across morpheme and word boundaries, because a high percentage of morphemes in use are single vowels (e.g. the singular subject agreement markers on verbs are all single vowels). 
Sequences of more than two vowels only occur across morpheme and word boundaries.

4(2) Hidomo, ae-u e-i-yuwa.

friend leg-1SG 3SG.PRES-DUR-pain

Mate, my leg is paining.

\subsubsection{IDENTICAL VOWELS}

Sequences involving identical vowels are very rare in lexical items - well below $1 \%$ of words. (The occurrence of two identical vowels is to be distinguished from length induced by stress.) These involve only a very small number of common vocabulary items.

$\begin{array}{ll}\text { buuwa } & \text { crazy } \\ \text { deewa } & \text { custom } \\ \text { diidiga-na } & \text { beautiful } \\ \text { huuhula } & \text { spring } \\ \text { umaald }^{2} & \text { goanna type }\end{array}$

Identical sequences are a little more common within texts, as two morphological features are marked by such sequences, though within a highly prescribed context.

$\begin{array}{llll}\text { goga-ta } & >\text { go-o-ga-ta } & \text { (PLURAL) } & \text { our grandparents } \\ \text { totogo }>\text { to-o-togo } & \text { (DURATIVE) } & \text { be sick }\end{array}$

\subsection{SYLLABLE STRUCTURE}

Although not all linguists accept the syllable as an essential phonological unit, syllables are a useful construct, enabling us to describe certain phenomena in an economical way (Hyman 1975:192-193). In Tawala the syllable is basic to a number of phonological processes, such as reduplication and stress placement.

The basic syllable structure of Tawala consists of an onset (C) and a nucleus (V). A second, less common type consists of a nucleus without an onset. Both types are incorporated within the formula (C)V. The use of brackets should not be taken to imply that syllable types occurs with the same frequency. By far the majority of syllables have a CV structure, with the result that $\mathrm{V}$ syllables are quite marked.

Both syllable types occur in initial, medial and final positions.

$$
\begin{array}{ll}
\text { aeu } & \text { my leg } \\
\text { gowana } & \text { his/her/its name }
\end{array}
$$

Underived roots carrying the basic meaning of words typically have two syllables, in a CV.CV pattern. Grammatical morphemes on the other hand are normally a single syllable with a much higher proportion of $\mathrm{V}$ syllables. 
Tawala has no word- or morpheme-final $m u$ syllable; instead there are words ending with a syllabic $m \rightarrow$ (C)V.m. The syllabic $/ m /$ is given normal syllable length, which contrasts with a nasal used as a syllable onset. ${ }^{3}$

Many of these words ending in syllabic $/ \mathrm{m} /$ are inflectional or derivational prefixes.

$\begin{array}{ll}\text { tam } & \text { you(SG) } \\ \text { om } & \text { your(SG) } \\ \text { nam } & \text { what's-his-name }\end{array}$

The syllabic $/ \mathrm{m} /$ follows the normal (C)VCV process in reduplication.

bembem bean

dimdim white person

There is ample evidence that the syllabic $/ \mathrm{m} /$ is diachronically (i.e. historically) derived from $m u$. For example, during fieldwork on Fergusson Island my wife and I noticed that different dialects of Yamalele are synchronically involved in this same sound change (Janet Ezard 1970), contrasted with Tawala in the following. ${ }^{4}$

$\begin{array}{llll}\text { SAIBUTU DIALECT } & \text { NAYE DIALECT } & \text { TAWALA } & \\ \text { tamu } & \operatorname{tam}(u) & \operatorname{tam} & \text { you(SG) } \\ \text { dimudimu } & \operatorname{dim}(u) \operatorname{dim}(u) & \operatorname{dim} \operatorname{dim} & \text { white person } \\ \text { kamukamu } & \operatorname{kam}(u) \operatorname{kam}(u) & \text { kamkam } & \text { chicken }\end{array}$

While the approximants $/ w /$ and $/ y /$ share phonological features with the corresponding vowels, they are distinguished by their syllabic distribution, as onsets to syllables rather than nuclei. Failure to distinguish between the two has resulted in some researchers recording uncharacteristic vowel clusters, e.g. Williams (c.1962) has waiawaiyau instead of wayawayau 'fan'.

The Kwato Extension uses both $/ e /$ and $/ i /$ for $/ y /$, hence the plantation name is Koeabule instead of Koyabule. Compare the spelling of a 1930 gospel of Mark in "Tawara" with the orthography I have promoted through literacy and translated materials.

$\begin{array}{lll}\text { KWATO } & \text { CURRENT SPELLING } & \\ \text { Ioane } & \text { Yowane (better Yoni) } & \text { John } \\ \text { guiau } & \text { guyau } & \text { chief (lord) } \\ \text { eabaeababa } & \text { yabayababa } & \text { uninhabited } \\ \text { tahaea } & \text { tahaya } & \text { path }\end{array}$

Official government spelling shows similar confusion: Ealeba for Yaleba, Awaiama for Awayama, and Sideia for Sideya.

One further factor of considerable importance is that stress patterns become very complex if the regular CVCV pattern is lost. Penultimate stress is clear with the spelling $g u^{\prime} y a u$, but rather opaque with the spelling gu'iau 'chief', where one would have expected gui'au as in a'eu 'my leg'.

The distinction is very clear when Tawala is sung, creating an exotic sound of a greatly lengthened nasal continuant. The effect is especially pleasant when a whole choir is singing. 


\subsection{PHONOLOGICAL PROCESSES}

In Tawala, phonological processes are mostly applied to a subset of the data; rarely does a rule apply consistently.

\subsubsection{Vowel Elision at MORPHEME BOUNDARIES}

Elision can occur when two vowels are contiguous, but not consistently; it applies rather to a limited set of common phrases, most of which are represented below. Sometimes the first vowel is elided, sometimes the second.

\subsubsection{Elision of FiRst Vowel IN SEQuenCE}

$$
\mathrm{v} \rightarrow \varnothing \mathrm{I} \mathrm{v}
$$

\begin{tabular}{|c|c|c|c|}
\hline /meka e-nenae?/ & $>$ & mek'e-nenae? & where are you going? \\
\hline / amaka u-(w)am?/ & $>$ & amak'u-wam? & have you eaten? \\
\hline / geka u numal & $>$ & gek'u numa & this is my house \\
\hline / nima i-tutu/ & $>$ & nim'i-tutu & five (a hand is joined) \\
\hline / iyai ma iyail & $>$ & iyai m'iyai & whoever (who and who) \\
\hline / apo eegal & $>$ & ap'eega & it will not be so \\
\hline / apo una-peu/ & $>$ & ap'una-peu & you'll fall! \\
\hline
\end{tabular}

The limited extent of this process is seen in the fact that it is not extended to constructions involving other person/number prefixes, hence *ap'inapeu 'he/she/it will fall', *mek'onenae 'where are you all going?' are unacceptable.

Some data which seem to fit this pattern may have historically had vowels elided, but the synchronic explanation is to be found in the presence of a transitional consonant, as the potential aspect (-na) is not now found in first person constructions. ${ }^{5}$

$\begin{array}{llll}\text { /ta-na-eno/ } & > & \text { ta-(n)eno } & \text { let's sleep } \\ \text { /a-na-am/ } & > & a-(n) a m & \text { I am going to eat } \\ \text { /ta-na-omhoe/ } & > & \text { ta-n'omhoe } & \text { let's go }\end{array}$

\section{NOTES:}

(1) The slash lines $/ x x X /$ in this section indicate that $x X X$ is a reconstructed underlying form and is never actually pronounced this way.

(2) The bracketed letter $(n)$ indicates that it does not occur in all dialects.

One regular application of this rule applies to the class of transitive verbs which add $-i$ clitics plus person markers to mark specific object. These verbs all have a final low central vowel $a$ which is omitted when the object clitic is used.

$\begin{array}{llll}\text { /-himila-il } & > & \text {-himil'-i } & \text {-send-3SG } \\ \text { /-himila-i-hil } & > & \text {-himil'-ihi } & \text {-send-3PL } \\ \text { /-Iupena-i/ } & > & \text {-lupen'-i } & \text {-open-3SG }\end{array}$

Thus we can say apo i-na-nae 'he/she will go', but not *apo a-na-nae 'I will go'; this latter meaning is expressed without the morpheme marking potential aspect: apo a-nae. 


\subsubsection{Elision of SeCond Vowel in SEQuence}

$$
v \rightarrow \varnothing / \mathrm{v}
$$

Deletion of the second vowel in a sequence is limited to the derivational prefix om-, which results in irregular verb paradigms, presumably because of its syllable structure, with a $v$ syllable followed by a syllabic nasal. This form of deletion is regular and applies irrespective of which vowel precedes the prefix and irrespective of the grammatical function of the preceding morpheme.

\begin{tabular}{|c|c|c|c|}
\hline / ani-omgiluma/ & $>$ & ani'mgiluma & pen (writing thing) \\
\hline / tu-omginoula/ & $>$ & tu'mginoula & builder \\
\hline / hi-omhoel & & hi'mhoe & they left \\
\hline /a-ompoyal & & a-'mpoya & I apply heat (magic) \\
\hline
\end{tabular}

\subsubsection{WORD-INITIAL VOWEL ELISION}

This form of vowel deletion is very specific and limited to a single grammatical context: second person singular imperatives. This is the only case of the omission of subject agreement, which is otherwise diagnostic of the verbal clause. In actual fact the absence of the vowel is compensated for by initial stress.

$\begin{array}{llll}\text { /U-na-duhuna!/ } & > & \text { Na-duhuna! } & \text { Sit down! } \\ \text { /U-na-nei!/ } & > & \text { Na-nei! } & \text { Come here! } \\ / \text { U-na-lowo!/ } & > & \text { Na-lowo! } & \text { Run away! }\end{array}$

\subsubsection{Elision of IDENTICAL Vowel in SEQuenCE}

In such situations it is not clear which vowel has been deleted. I have interpreted the situation in line with the most common deletion: the first of the two vowels. These deletions are automatic and apply in all cases. However, the Labe dialect often separates the vowels with a glottal plosive. ${ }^{6}$

\begin{tabular}{|c|c|c|c|}
\hline & $>$ & $E g^{\prime}$ & no $\mathrm{v}$ \\
\hline$/ U$ & 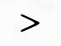 & $U n^{\prime}$ & $\mathrm{Ea}$ \\
\hline & & uma. & \\
\hline & & & om) \\
\hline 1 & & $A n$ & I have eaten enough \\
\hline
\end{tabular}

\subsubsection{VOWEL ELISION WITHIN WORDS}

A small number of basic vocabulary items have a two-vowel sequence which is reduced to a single vowel when followed by a morpheme that belongs to the same word or phrase. In the case of the motion verbs, this usage conforms with the reduplication rule in which the first $\mathrm{V}$ of the root is deleted.

6 Thus the second phrase in the following list becomes una-qam, even though the first and third phrases delete the vowel. As my main sphere of study has been the Diwinai dialect, I am not aware of the parameters under which the Labe dialect inserts the glottal plosive. 


$$
\begin{array}{llll}
\text { nae } & > & \text { ne- } & \text { go } \\
\text { gae } & > & \text { ge- } & \text { go up } \\
\text { mae }> & \text { me- } & \text { stay } \\
\text { beiha }> & \text { bihe- } & \text { search } \\
\text { meiha }>\text { mihe- } & \text { price }
\end{array}
$$

$\begin{array}{lll}\text { 4(3) } \begin{array}{l}\text { I-mae. } \\ \text { 3SG-stay }\end{array} & \text { I-me duma. } \\ \text { 3SG-stay very }\end{array}$

He stayed. He stayed a long time.

\subsubsection{Vowel DisSimilation}

An exception to the above identical-vowel assimilation rule is a rule which avoids the loss of the first person pronominal enclitic $-u$ by the application of a dissimilation rule following a high back vowel:

$$
\begin{array}{llll}
-u \rightarrow-w e / u- & \\
\text { /natu-u/ } & > & \text { natu-we } & \text { my child } \\
\text { /-hagu-u/ }> & \text {-hagu-we } & \text { help me } \\
\text { /habulu-u/ }> & \text { habulu-we } & \text { my smallness (childhood) }
\end{array}
$$

\subsubsection{Vowel Alternation}

In some dialects a low-high sequence shows an alternation to mid-high when a suffix is added; the rule applies to both front and back vowels:

$$
\begin{aligned}
& a u \rightarrow O u \\
& \begin{array}{llll}
\text { mayau } & > & \text { mayou-na } & \text { that tree } \\
\text {-wayau } & > & \text { wayowayou-na } & \text { cold-3SG }
\end{array} \\
& a i \rightarrow e i \\
& \text { meyagai > meyagei-na that village } \\
& \text { gaima }>\text { gi-geima-na stoney-3SG }
\end{aligned}
$$

The change could be related to stress, as the raised vowel is usually stressed. However, the final example in the above list is an exception. A further example which does not fit the rule, but is similar, involves the change:

$$
\begin{array}{r}
a \rightarrow \text { ou } \\
\text {-maga }>\text { magomagou-na many-3SG }
\end{array}
$$

The rule applies across morpheme boundaries.

$$
\text { lama-u-nal > amo-u-na that father of mine }
$$


A very similar rule applies to a sequence involving the syllabic bilabial nasal $/ m /:^{7}$ when a morpheme is added to a word ending in am the sequence becomes $o m$.

/-wiwam-ge-ya/> -wiwom-ge-ya make it into a boat

/-witenam-yal > -witenom-ya float it

The above rules help explain the adjectival forms of some roots, though there are clearly other factors involved as well in the following data.

$\begin{array}{llll}\text {-witai } & > & \text { witewitei-<na }> & \text { heavy } \\ \text {-maga } & > & \text { magomagou-<na }> & \text { many } \\ \text {-tenam } & > & \text { tenotenom-<na } & \text { floating } \\ \text { gaima } & > & \text { gigeima-<na }> & \text { stony }\end{array}$

\subsubsection{REDUPLICATION SYMMETRY}

The examples which follow demonstrate the process of vowel elision plus reduplication of the elided form which spreads to both parts of a reduplicated form, from right to left.

$\begin{array}{llll}\text { dewa-dewa-ya } & > & \text { dewadewaya } & \text { DUR-make-3SG } \\ \text { /dewa-dewa-e-yal } & > & \text { dewedeweya } & \text { DUR-make-TRV-3SG } \\ \text { /dewa-dewa-iyail } & > & \text { dewidewiyai } & \text { DUR-make-1PL.EXC } \\ \text { tona-tona-ya } & > & \text { tonatonaya } & \text { DUR-pierce-3SG } \\ \text { /tona-tona-e-yal } & > & \text { tonetoneya } & \text { DUR-pierce-TRV-3SG } \\ \text { /baha-baha-e-yal } & > & \text { bahebaheya } & \text { DUR-Say-TRV-3SG } \\ \text { /wiwasawasa-e-yal } & >\text { wiwasewaseya } & \text { enrich-TRV-3SG } \\ \text { /pitapita-eil } & >\text { pitepitei } & \text { bush-ABL }\end{array}$

\subsubsection{FURTHER SUFFIX-DERIVED CHANGES}

Suffixes with the underlying form $-g e(i)$ have three surface forms (-ge(i), $-e(i)$ and -ye(i)), depending on the environment in which they occur. Two common suffixes are involved in this process:

1) the transitive marker $-g e$

$\begin{array}{llll}\text { /-pali-ge-yal } & > & \text { paliyeya } & \text { scold-TRV-3SG } \\ \text { /-widakule-ge-yal } & > & \text { widakuleya } & \text { spread.gravel-TRV-3SG } \\ \text { /-wiwom-ge-yal } & > & \text { wiwomgeya } & \text { make.boat-TRV-3SG }\end{array}$

2) the ablative enclitic $-g e i$

\begin{tabular}{|c|c|c|c|}
\hline / kadidili-geil & $>$ & kadidiliyei & by strength \\
\hline /nih & & nihei & from the beach \\
\hline /uyahi-m-geil & & uyahimgei & from you(SG) \\
\hline /dewa-gei & $>$ & dewei & following the custom \\
\hline
\end{tabular}

While $/ \mathrm{u} /$ and $/ \mathrm{m} /$ share the distinctive feature of [+grave], this is not sufficient reason to collapse the two rules, as $/ o /$ shares the same feature but does not follow the rule. 
Rules applying to the ablative suffix -gei and transitiviser -ge can be collapsed into a single set. However, the synchronic similarity in the operation of these two morphemes blurs the diachronic situation, namely, that their origins are distinct.

$$
\begin{array}{ll}
-g e i<{ }^{*} \text { iai } & \text { locative proform (Ross 1988:208) } \\
- \text {-ge }<{ }^{*} \text {-aki } & \text { remote transitive (Ross 1988:101) }
\end{array}
$$

Rules:

(1) -ge(i) becomes -ye(i) following $/ i \%$

(2) -ge(i) becomes $-e(i)$ following $/ e /$ or $/ a /$.

These rules are really only a rough guide, as dialects differ in their rules of application and one speaker can even use more than one form within a single text. The above rules generally apply to the Diwinai dialect. Labe dialect speakers tend to use the -ge(i) forms in all situations.

The postpositional relatoruyahi, with a full range of pronominal enclitics and the ablative suffixes, illustrates these processes and also introduces one or two exceptions.

TABLE 4: POSTPOSITIONAL RELATOR WITH ABLATIVE SUFFIX

\begin{tabular}{|lll|}
\hline /uyahi-u-geil & $>$ uyahiugei & from me \\
/uyahi-m-geil & $>$ uyahimgei & from you(SG) \\
/uyahi-na-geil & $>$ uyahinei & from him/her/it \\
/uyahi-ta-geil & $>$ uyahitiyes & from us(INC) \\
/uyahi-iyai-geil & $>$ uyahiyel & from us(EXC) \\
/uyahi-mi-geil & $>$ uyahimiyei & from you(PL) \\
/uyahi-hi-geil & $>$ uyahihiyei & from them \\
\hline
\end{tabular}

Even at Diwinai exceptions to the above general rules are heard, so that the following forms are common, possibly as a result of constant contact with other dialects.

$\begin{array}{ll}\text { odubona-gei } & \text { from olden times } \\ \text { koyama-gei } & \text { by his/her lies } \\ \text { moni-gei } & \text { with money } \\ \text { woe-gei } & \text { by paddle }\end{array}$

Note that all these changes are in the direction of the -gei form and hence in line with the Labe dialect.

The following examples demonstrate the variety of phonetic processes involved with the transitivising suffix $-g e$, the loss of a stem-final vowel is indicated by an apostrophe. As already indicated, the altemate third person singular object forms are largely a dialectal distinction.

I have no explanation for this exception to the above rules, unless it is by analogy with the exclusive form. 


$\begin{array}{ll}\text { otu-ge-ni/ya } & \text { call to s.o. } \\ \text { geno-ge-ni/ya } & \text { worry about s.th. } \\ \text { wibaabani-ye-ni/ya } & \text { discuss s.th. } \\ \text { bagibagi-ye-ni/ya } & \text { work at s.th. } \\ \text { pali-ye-ni/ya } & \text { scold s.o. } \\ \text { bah'-e-ni/ya } & \text { speak to/about s.o. } \\ \text { gigim'-e-ni/ya } & \text { invite s.o. } \\ \text { nehal'-e-ni/ya } & \text { leave s.o. } \\ \text { widakul'-e-ni/ya } & \text { spread gravel over area }\end{array}$

\subsubsection{Transitional Consonant}

The Diwinai dialect has a transitional consonant between certain morphemes where Labe speakers use a glottal plosive. Many of these situations involve approximants.
u-(w)am
you(SG) dined
hi-(y)ani
they ate s.th.
omi-(y)u numa
to your(PL) houses

That these transitional consonants are psychologically 'real' is seen by the fact that they are usually written, and they can affect the reduplicated form where no transitional consonant is needed, for example yaniyani 'vegetables', which is commonly aniani in the languages of Milne Bay. The final proof comes from their presence in forms where they are in no way transitional glides, but separate consonants. Contrast the final example in the above data with the following.
ata $(y) u$ tano
to our(INC) garden
u (y)u numa
to my house

One would be tempted to think that the locative $u$ becomes $y u$ following a possessive pronoun, but this is not always the case. There is no transitional consonant following the second person singular possessive pronoun: om $u$. Also another transitional consonant $/ \mathrm{n} /$, which does not seem to have any phonetic explanation, follows the third person singular possessive pronoun: $a \mathrm{nu}$ (though some speakers use $a \mathrm{yu}$ ). The normal paradigm of forms for the Diwinai dialect is as follows, though speakers differ as to the form used.

$\begin{array}{ll}\text { u yu ala } & \text { in my g-string } \\ \text { om u numa } & \text { to your(SG) house } \\ \text { a nu tupo } & \text { to his/her/its region } \\ \text { ata yu tano } & \text { to our(INC) garden } \\ \text { i yu meyagai } & \text { to our(EXC) village } \\ \text { omi yu tapalolo } & \text { in your(PL) church service } \\ \text { hai yu oya } & \text { at their garden (mountain) }\end{array}$

The third person form is possibly derived by analogy from a further set of situations in which the transitional consonant $/ n /$ is found.

A morpheme (C)a when followed by a vowel takes the transitional consonant $/ n /$. The most frequent examples of this are when the third person possessive pronoun is followed by the nominaliser $a n i$, and the first person subject prefix is followed by a verb root commencing in a vowel. 


$\begin{array}{ll}\text { kabudala a (n)ani geleta } & \text { east (lit. sun its place arrive) } \\ \text { a (n)uma } & \text { his/her/its drink } \\ \text { a-(n)am } & \text { I have eaten } \\ \text { ta-(n)eno } & \text { let's sleep } \\ \text { ta-(n)am } & \text { let's eat }\end{array}$

\subsection{REDUPLICATION}

Reduplication is used in Tawala in a productive way. The reduplicated morpheme often carries a specific meaning which can be contrasted with the non-reduplicated form. Reduplication is a process that operates in several areas of the morphology. Adjectives usually have reduplicated forms, being derived from unreduplicated verb stems. Reduplication also is used to mark plural on nouns and durative aspect on verbs. In addition, some lexical items have reduplicated forms clearly dependent on the semantic domains to which they belong, some still having a clear relationship to an unreduplicated form. The pattern of reduplication operates to a large degree independently of syntax or semantics.

Reduplication consists of the repetition of the initial part of the stem, and can be complete (repetition of the first two syllables) or partial (repetition of the first syllable or lengthening of the first vowel). In addition, one form of partial reduplication disregards syllable boundaries. The following rules are needed to account for reduplication patterns in Tawala.

\subsubsection{COMPLETE Reduplication}

By far the most common pattern of reduplication is the repetition of the first two syllables, termed 'complete' reduplication. In this, Tawala differs from languages where 'complete' reduplication means the repetition of the whole stem, sometimes termed 'compounding'. Tawala reduplication rules are generally sensitive to the syllabic shape of the root, and there are five syllable types which show complete (or close to complete) reduplication.

\subsubsection{CVCV}

\begin{tabular}{|c|c|c|c|}
\hline $\begin{array}{l}\text { hopu } \\
\text { geleta } \\
\text { huneya } \\
\text { keduluma } \\
\text { hewali } \\
\text { kaya } \\
\text { dewa }\end{array}$ & $\begin{array}{l}\text { woman } \\
\text { unmarried man } \\
\text { red (verb) } \\
\text { custom }\end{array}$ & $\begin{array}{l}\text { hopu-hopu } \\
\text { gele-geleta } \\
\text { hune-huneya } \\
\text { kedu-keduluma } \\
\text { hewa-hewali } \\
\text { kaya-kayana } \\
\text { dewa-dewa }\end{array}$ & $\begin{array}{l}\text { to go down } \\
\text { to arrive } \\
\text { to praise } \\
\text { women } \\
\text { unmarried men } \\
\text { red (adjective) } \\
\text { good }\end{array}$ \\
\hline
\end{tabular}




\subsubsection{2 (C)VC}

\begin{tabular}{|c|c|c|c|}
\hline $\begin{array}{l}\text { am } \\
\text { lum }\end{array}$ & slow (verb) & $\begin{array}{l}\text { bam-bamna } \\
\text { dum-dum } \\
\text { am-am }\end{array}$ & $\begin{array}{l}\text { slow (adjective) } \\
\text { deep ocean } \\
\text { to dine }\end{array}$ \\
\hline
\end{tabular}

\subsubsection{CVV}

Words with CVV structure show a good deal of irregularity, as is seen by comparing these regular constructions with their irregular counterparts below. There does not appear to be any phonological explanation for class membership, which must simply be learnt. Fortunately, there are only a small number of these words.

$\begin{array}{llll}\text { dao } & \text { long (verb) } & \text { dao-daona } & \text { long (adjective) } \\ \text { gao } & \text { gap } & \begin{array}{l}\text { gao-gao } \\ \text { woe-woe }\end{array} & \text { week } \\ \text { woe } & & \text { to paddle } \\ \text { bui } & & \text { to tur over }\end{array}$

\subsubsection{VV}

oi-u myaunt oi-oi-u my aunts

\subsubsection{VCV}

Vowel-initial forms are completely regular across all word classes in repeating the initial VC. In so doing, this form of reduplication cuts across the syllable pattern of the language.

$\begin{array}{lll}\text { apu } & \text { ap-apu } & \text { to bake } \\ \text { eno } & \text { en-eno } & \text { to sleep } \\ \text { uma } & \text { um-uma } & \text { to drink } \\ \text { ama-u my father } & \text { am-ama-u } & \text { my fathers } \\ \text { iwa-u my brother-in-law } & \text { iw-iwa- } u & \text { my brothers-in-law } \\ \text { odubo } & \text { od-odubo-na } & \text { old }\end{array}$

One adjective follows this pattern even though the underlying verb no longer exists.

ap-apoe be bad

\subsubsection{Reduplication OF First 'Syllable'}

This pattern is mainly limited to words where the first syllable has no consonant onset, and demonstratives (though a few other items are also involved).

\subsubsection{DEMONSTRATIVES}

The closed class of demonstratives reduplicate the first syllable even though they have a CVCV structure. 


$\begin{array}{llll}\text { geka } & \text { this } & \text { ge-geka } & \text { exactly-this } \\ \text { naka } & \text { that } & \text { na-naka } & \text { exactly-that } \\ \text { noka } & \text { that (distal) } & \text { no-noka } & \text { exactly-that (distal) }\end{array}$

\subsubsection{2(CV) $)^{2}$}

When a root that is not a verb consists of two identical syllables the one-syllable reduplication rule applies.
dede root
de-dede story
kuku skin
ku-kuku pheasant coucal

\subsubsection{IRREGULAR ITEMS}

Some CVV verbs reduplicate the first syllable rather than the whole root.

$\begin{array}{lll}\text { nei } & \text { ne-nei } & \text { to come } \\ \text { gei } & \text { ge-gei } & \text { to come up } \\ & \text { ko-koe } & \text { to finish } \\ \text { mae (noun) } & \text { ma-mae (L. verb) } & \text { stay }\end{array}$

One CVCV noun also uses reduplication of the first syllable only, instead of both syllables. bada man ba-bada men (titles of respect)

\subsubsection{Consonant and SeCond-Vowel Reduplication}

Although we have seen two patterns for reduplication of CVV words above, their most common form is in fact to repeat the second vowel with the consonant, as in the following:

$\begin{array}{lll}\text { gae } & \text { ge-gae } & \text { go up } \\ \text { houni } & \text { hu-houni } & \text { put it } \\ \text { beiha } & \text { bi-beiha } & \text { search } \\ \text { tou } & \text { tu-tou } & \text { weep } \\ \text { teina } & \text { ti-teina } & \text { pull } \\ \text { mae (noun) } & \text { me-mae (verb, D.) } & \text { stay }\end{array}$

One example also introduces a new vowel:

peu pi-peu to fall

\subsubsection{LENGTHENED VOWELS}

Verbs that begin with two identical syllables $-(\mathrm{CV})^{2}-$ lengthen the first syllable in their reduplicated form to mark durative aspect. 


$\begin{array}{lll}\text { SIMPLE } & \text { DURATIVE } & \\ \text { totogo } & \text { tootogo } & \text { be sick } \\ \text { guguya } & \text { guuguya } & \text { preach } \\ \text { tatawa } & \text { taatawa } & \text { tremble } \\ \text { tete } & \text { teete } & \text { cross (bridge) } \\ \text { kiki } & \text { kiiki } & \text { strangle }\end{array}$

One noun that has the potential to follow this pattern is guguhini 'maiden', but the form * guuguhini does not occur; there is in fact no plural form of the word, making it an irregular human referent term. The reason may lie in the fact that the first syllable of a foursyllable word receives secondary stress, making length difficult to hear. Oddly enough, the noun goga-na 'grandparent/grandchild-3SG' has the plural form googa-na even though its vowels are dissimilar.

\subsection{STRESS}

Stress in Tawala is predictable, occurring on the penultimate (second to last) syllable. Stress includes not only increased volume but also increased length and a rise in pitch. Thus mili is pronounced more like the English 'mealy' than 'Millie'. There is a distinction between primary stress (penultimate) and secondary stress (word or root initial etc.), the latter showing little increase in length. Stress is not normally marked, but in this section I mark primary stress with a single stroke (' $\mathrm{CV}$ ) and secondary stress with a double stroke ("CV). For convenience it is marked at the beginning of the syllable, whereas its influence is chiefly on the syllable nucleus - the vowel.

Stress rules are applied after all the preceding rules have been applied.

The phonological word in Tawala is a group of syllables attached to a primary stress. The word nucleus is marked by a primary-stressed syllable and it has optional prenuclear margins and a single postnuclear margin. Hence stress is placed on the penultimate syllable: $\left[\mathrm{CV}^{\mathrm{n}}\right]^{\prime} \mathrm{CVCV}$.

$\begin{array}{ll}\text { 'bada } & \text { man } \\ \text { kedu'luma } & \text { woman } \\ \text { te'wela } & \text { child }\end{array}$

Secondary stress is applied (counting leftward) to the first of every two syllables prior to the primary-stressed syllable, subject to the rule: (“CVCV) n' $\mathrm{CVCV}$.
i-"dewa'dewa
it is good
i-"hopu"hopu'mai
he/she/it was coming down here

Secondary stress always applies to the beginning of a reduplicated form. This rule overrides the previous rule.
i-"dewade'waya
he/she/it is doing it
ina-"bulibu"lili'mai
he/she/it will be running here

When the syllable to be stressed (primary or secondary) is the second vowel in a VV sequence, if it is a higher vowel than the preceding one the stress moves to the preceding syllable and the double vowel becomes a glide. 


$\begin{array}{ll}\text { 'nou-na } & \text { his sister; her brother } \\ \text { 'kaoha } & \text { joy } \\ \text { ba'nei-na } & \text { big-3SG } \\ \text { 'ae-na } & \text { leg-3SG } \\ \text { 'bauli } & \text { north wind }\end{array}$

This rule also applies when the retroflex approximant $(/ 1 /)$ intervenes between the vowel sequences:
'bolima
year
halima
outrigger

This contrasts with numerous three-syllable words which have penultimate stress.

$\begin{array}{ll}\text { hi'puli } & \text { earth } \\ \text { ka'dau } & \text { journey } \\ \text { belana } & \text { blossom } \\ \text { ba'dila } & \text { native almond }\end{array}$

\subsection{LENGTH}

Mention is made above of two types of lengthening operational in Tawala: a slight lengthening of the vowel is involved in stressed syllables, and reduplication can result in a vowel becoming approximately double its normal length and hence being written as two vowels. In addition to marking durative aspect, length distinguishes the predicative negative from the negative particle.

Apart from the lengthening associated with stress, vowel length has been interpreted as the presence of homorganic vowels. A small number of vocabulary items have this feature as part of their lexical form, including: ee 'yes, and so'; oo 'or'; umaala (some speakers umaqala) 'small goanna type'; geegehana 'awake'; deewa 'custom'; diidiga 'beautiful'; huuhula 'spring'.

Stress confirms this analysis as secondary stress suggests the syllable pattern is, for example, $i$-"di.i'diga 'it is beautiful'.

\subsection{PHONOLOGICAL VERSUS GRAMMATICAL WORD}

The phonological word was established on the basis of primary stress placement and the reluctance of native speakers to break that unit, returning right to the beginning of the word if a mistake is made, rather than the beginning of the stem etc. A problem lies in the fact that the borders of the phonological word do not always coincide with the grammatical word consisting of its root plus affixes.
/i-nae 'pol
$>$ /i-na-pol
/-ga"le-na i'mahil > /-"gale"nai'mahil
he/she/it went and
/'ani "omgi'lumal > /"animgi'lumal
look properly
pen (thing carve) 


\section{MAJOR WORD CLASSES}

\subsection{INTRODUCTION}

Tawala nouns, adjectives and verbs are open word classes in that they cannot be exhaustively listed, and new members may readily be added.

\subsection{WORD BOUNDARIES}

\subsubsection{THE IDEAL}

The linguistic concept of 'word' is an abstraction difficult to apply consistently to the full range of Tawala data. Word boundaries are generally determined by a convergence of three main lines of analysis: ${ }^{1}$

1) Grammatical criteria - including cohesiveness and relative order of morphemes;

2) Phonological criteria - including stress and juncture features;

3) General criteria - including isolability and psychological reality for native speakers.

Considerable conflict exists between these three sets of criteria, so that the borders of words will differ depending on the relative importance placed on the respective features.

\subsubsection{ThE ACTUAL}

To outline the conflict between these principles, I present some systematic differences from the writing conventions of this grammar, evident in a 22-page newspaper, GEKA TUWEGA 'This is News' (published independently by Tawala people in 1981), where the following principles are at work.

1) Subject and other inflectional prefixesof verbs are generally (but not invariably) separated from the root or stem, e.g. hi nei 'they came'. In this feature English has probably had a strong influence on the writers, who have all had their main education in it. However, the phenomenon shows that there is a clear psychological appreciation of the distinction between stems and affixes. ${ }^{2}$

GEKA TUWEGA GRAMMAR FORM

hina haguhi hi-na-hagu-hi they'll help them

hinei hi-nei they came

idewaya i-dewa-ya he did it

I suggest another - a lexical criterion - in point (3) below.

In writings published for use by the Tawala people I follow this convention also. However, it requires the use of apostrophes where vowel deletion occurs (e.g. $\tan ^{\prime}$ omhoe 'let's go'). 
However, this rule is not applied consistently. If there is a single-phoneme prefix with a basic motion verb (-nae 'go', -nei 'come') the word is mostly written as a single word - evidently phonological criteria (initial / $n /$ or CVV?) over-ride the psychological criteria at this point. The first three words in the following data are single grammatical words, but the fourth example consists of two grammatical words but only a single phonological word.

$\begin{array}{lll}\text { GEKA TUWEGA } & \text { GRAMMAR FORM } & \\ \text { inei } & i \text {-nei } & \text { he came } \\ \text { inae } & i \text {-nae } & \text { he went } \\ \text { inapa } & i \text {-na-pa } & \text { he will say } \\ \text { hinepo } & \text { hi-ne'-po } & \text { they came and }\end{array}$

2) The root has a strong psychological reality, ${ }^{3}$ so that it is most often separated from its prefixes (both inflectional and derivational), destroying both the phonological and grammatical unity of the word.

$\begin{array}{lll}\text { GEKA TUWEGA } & \text { GRAMMAR FORM } & \\ \text { ata wi maamala } & \text { ata wi-maamala } & \text { our greetings } \\ \text { hi wi haguhagu } & \text { hi-wi-haguhagu } & \text { they were helping } \\ \text { tu wibaabani } & \text { tu-wi-baabani } & \text { speaker } \\ \text { lidumalu } & \text { li-dumalu } & \text { correctly }\end{array}$

This rule is also not applied consistently, and $25 \%$ of derivational prefixes are connected to their roots. The following forms occur in successive sentences within the same paragraph: tu wimulitago, tuwi mulitago, tuwimulitago 'follower'. The form *tu wi mulitago does not occur, however the parallel tu wi baabani 'speaker' does. Grammatically this construction consists of one or two words (depending on analysis), phonologically of one, but psycholinguistically of three.

3) Principle 2) gives rise to numerous isolated items that would be difficult to give meaning to in the lexicon, because derivational prefixes are attached to the person/number as aspect prefixes rather than to the root and would not always have a consistent meaning:

him... they always.../they are able to...

iwi... he/she/it cause/make/do...

hinai... they (IRR) cause/make/do...

This problem seems to demand an extra criterion, in addition to the general criteria for word-level analysis - a semantic criterion which would maintain the lexical unity of the word: Derivational prefixes must not be separated from their roots because the combined meaning is often not predictable and needs to be listed in the lexicon.

Lexical words are a further abstraction in which the part of the word carrying the distinctive meaning is stripped of grammatical morphemes.

4) GEKA TUWEGA writers mostly follow grammatical criteria in separating inflectional prefixes from the causative prefix $w i$, even when its durative form $(i-)$ is used. 


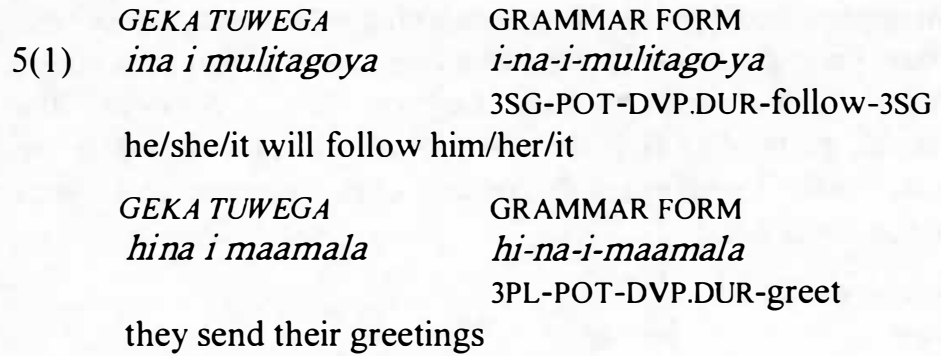

The phonological bond here is strong (not with the root but with the prefixes), with secondary stress (") moving back from the beginning of the stem to the inflectional prefixes when the durative is employed:

$$
\text { ina"wimu"lita'goya > i"naimu"lita'goya }
$$

With the stem wimulitagothe grammatical bond is strong between the prefix (wi-/ $i$-) and the remaining segment, which has no meaning by itself, though it is made up of meaningful roots (muli + tago 'behind' + 'over'). In this grammar I have attempted a degree of consistency by never separating derivational prefixes from roots or inflectional prefixes from stems. Because of the lexical nature of derivational prefixes, examples are frequently given with the stem not broken into morphemes.

5(2) i-na-wimulitago-ya

3SG-POT-follow-3SG

he/she/it will follow him/her/it

However, because the form of the derivational prefix changes for durative aspect, I often mark the durative form accordingly.

5(3) i-na-i-mulitago-ya

3SG-POT-DUR-follow-3SG

he/she/it will be following him/her/it

5) The forms geka-pite 'like this', noka-pite 'like that' etc. are consistently written as single words, reflecting the strong phonological unity of these two-grammatical-word forms: a head and modifier. While pite rarely occurs with anything other than demonstratives, hota 'only' not only occurs with demonstratives (noka-hota 'only that') but is also used to modify verbs, where the pressure of grammatical criteria is to separate the items. I have chosen to consistently separate modifiers from their heads, even though they are often phonologically single words. Other modifiers in GEKA TUWEGA are usually separated off from the head, as they are in this grammar, for example himaga duma 'they are very many', $i$ wi tulana imahi 'he was extremely friendly'. However, there is not complete consistency; for example, contrast banei dumana 'very big (SG)' and baneidumahi'very big (PL)'.

6) Apart from the above problems, GEKA TUWEGA generally confirms the writing conventions and word breaks adopted in this grammar. For example, the possessive pronouns are always free forms and never prefixes. The locative preposition $u$ - 'to/at' is mostly a separate word. However, in GEKA TUWEGA it is mostly joined in the specific form u-muli-na (LOC-behind-3SG) 'afterwards'. The nominalisers $t u$ - 'person who...' and ani- 'thing for...' are often joined to roots, though they also occur as free forms. 
Enough has been said to show the difficulty in drawing consistent word boundaries.

\title{
5.3 DISTINGUISHING OPEN WORD CLASSES
}

While it is assumed here that the assignment of words to parts-of-speech classes is based on properties that are grammatical rather than semantic, and are often language specific rather than universal, it is also assumed that the name that is chosen for a particular parts-of-speech class in a language may appropriately reflect universal semantic considerations.

Schachter (1985:4)

While noun and verb classes each have a prototypical core which is clearly distinguished from the other class, the two classes do overlap on their borders, with some roots taking both verbal and nominal affixes without any class-changing morphology being involved. Confusion results from failing to distinguish typical from atypical items and in the past led me to postulate 'fluid' word classes. Then in a detailed study of derivational prefixes (Ezard 1992) I discovered that a careful treatment of the underlying subclasses of the derived forms enabled me to predict both the semantics and syntax of the derived verbs. I was led by this to concur with Dixon's (1982:8) priority-of-semantics principle:

\begin{abstract}
We work from the assumption that the syntactic properties of a lexical item can largely be predicted from its semantic description. Semantics is thus held to be prior to syntax. The ways in which syntactic properties can be predicted on the basis of semantic representation are complex, and are not yet fully understood...
\end{abstract}

One aim in this grammar is to further investigate these syntactic properties for the Tawala language; hence this chapter is of fundamental importance as a starting place for Tawala grammar.

As the functions of the major word classes overlap it is important to gain a clear picture of the distinction between the open word classes on internal grammatical criteria. Word classes are distinguished on a multi-dimensional basis - morphological and syntactic - with a recognisable semantic scope, parallel to other languages. However, the major word classes do have semantic correlates:

.... in universal terms, we can predict that certain 'prototypical' percepts of thing-like entities will be coded in a grammatical form identifiable as nouns, while prototypical percepts of actions or events will be coded as grammatical verbs. Hopper and Thompson (1984:705)

TABLE 1: CRITERIA FOR OPEN WORD CLASSES

\begin{tabular}{|l|c|c|c|}
\hline DISTINCTION & NOUNS & VERBS & ADJECTIVES \\
\hline MORPHOLOGICAL & & & \\
(a) Reduplicated form & $15 \%$ & $1 \%$ & $98 \%$ \\
(b) Derived form & $25 \%$ & $50 \%$ & $90 \%$ \\
(c) Subject prefix & - & + & - \\
(d) Pronominal enclitic & $(+)$ & - & + \\
\hline SYNTACTIC & - & + & - \\
(e) Head of VP & - & + & - \\
(f) Head of NP & - & - & + \\
(g) Modifier of NP & - & - & \\
\hline
\end{tabular}

$\mathrm{KEY}+$ primary function

(+) function of subclass

- absence of the function 


\subsubsection{MoRPHOLOGICAL CRITERIA}

The morphological data presented here are based on about 1,000 items of Tawala vocabulary included in the International Dictionary Series (Ezard 1995). Approximately 500 nouns, 350 verbs and 50 adjectives are represented.

(a) Reduplicated Form

$98 \%$ of adjectives are reduplicated, many having the reduplicated form of the corresponding verb.

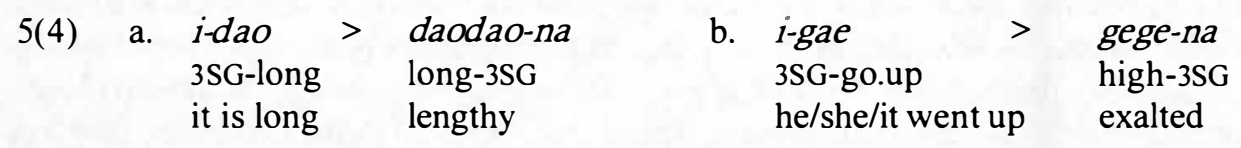

The inherent lexical form of some nouns is reduplicated, but only a handful of items functioning as verbs have an inherently reduplicated form (e.g. bagibagi 'work'). With most verb classes reduplication marks durative aspect.

5(5) Motaka a-ga-gale-hi ma hi-buli-bulili.

(From the air) I was seeing cars and they were running along.

With some noun subclasses reduplication marks plural.

$\begin{array}{ll}\text { 5(6) } \quad \text { bada }> & \text { ba-bada } \\ \text { man } & \text { PL-man } \\ \text { man } & \text { men }\end{array}$

Reduplication is important as one indicator in distinguishing adjectives from the noun subclass of quantifiers.

(b) Derived Form

Within basic vocabulary $25 \%$ of nouns, $50 \%$ of verbs and more than $90 \%$ of adjectives are derived. ${ }^{4}$ Most adjectives are derived by reduplication. Verbs are derived by classificatory prefixes, derivational prefixes and compounding. Nouns are derived by compounding and nominalising clitics. About $50 \%$ of underived roots of both verbs and nouns are disyllabic. This criterion will not distinguish word classes in isolation, but combined with other criteria it is useful.

(c) Subject person marker

Only verbs take a prefix indexing the person and number of the subject.

5(7) I-hopu mai.

3SG-come.down DEI

She came down (towards speaker).

Nouns require a verbalising prefix to be eligible for such a prefix.

5(8) Amaka i-wi-bada.

already 3SG-DVP-man

He has become a man. 
A subclass of adjectives can be used predicatively, in which case they function as stative verbs.

(d) Pronominal enclitic

Adjectives are always marked with a pronominal enclitic which marks the person and number of the head.

5(9) mawa daodao- na

distance long- 3SG

HEAD DEPENDENT PRONOMINAL ENCLITIC

a long way, a lengthy distance

Certain classes of noun also take the pronominal enclitic though with varying functions; however, the pronominal enclitic is always marked on the head and never on the dependent.

5(10) (kamkam) natu- na

fowl child- 3SG

DEPENDENT HEAD PRONOMINAL ENCLITIC

a/the chicken

That 5(10) consists of noun+noun and not noun+adjective is shown by the fact that natu-na can be made plural: natu-natu-na 'its children'.

\subsubsection{SYNTACTIC CRITERIA}

(e) Head of a VP

This item is the syntactic counterpart of (c) above. Only a verb can occur as the head of the verb phrase; other parts of speech require verbalising prefixes.

(f) Head of an NP

The head of a simple NP is normally a noun, pronoun, demonstrative, etc.

(g) Modifier of NP

The post-head modifier of a simple NP is an adjective. A similar surface string is found when a possessive noun phrase has a possessed NP following the possessor noun, however in this case the possessed noun is the head. If a noun modifies a noun then a different structure is used; the pronominal enclitic is absent.

\section{5(11) gaima Bou \\ stone Bou \\ the Bou stone}

\subsection{NOUNS}

Nouns fill the head slot of noun phrases and they require a derivational prefix in order to function as verbs. Semantically they belong to the class of words whose core members refer to concrete 'objects'. There are four major classes of nouns, corresponding to the appropriate response to four basic interrogatives. Each class contains a number of subclasses. 
CLASS A. PERSONAL NOUNS - response to question word: iyai 'who'

(a) personal names - Peuka, Keudi, Dalila

(b) human reference - bada 'man (respect)', tewela 'child'

(c) kinship terms - ama-na 'his father', natu-na 'his child'

CLASS B. PLACE NOUNS - response to question word: meka 'where'

(a) place names - Huhuna, Bubuleta, Diwala, Bou

(b) locational nouns - niha 'sea, beach', oya 'garden, mountain,5

CLASS C. TIME WORDS - response to question word: meyanai when

(a) relative time pom 'yesterday', amalai/ataima 'now'

(b) absolute time - malatomtom 'morning', uguwa 'night, dark'

CLASS D. COMMON NOUNS - response to question word: awai 'what'

(a) body parts - ae-na 'his leg', lugu-na its leaf'

(b) relationship - baba-na 'base-3SG,' gabouli-na 'underneath-3SG'

(c) quantifiers - tupo-na 'part-3SG', gehou-na 'other'

(d) cultural items - beda 'betelnut', polo 'pig'

(e) abstract nouns - emoemota-na 'ability-3SG', kamna-na 'health-3SG'

(f) other nouns - hipuli 'ground, earth', gatowa 'roof'

\section{FIGURE I: CLASSES AND SUBCLASSES OF NOUNS}

These classes and subclasses should not be regarded as rigid formal classes but rather as prototypical grammatical classes with fluid borders. Some nouns, for instance, belong in two separate subclasses, e.g. tepa-na 'its top (relationship term)' as opposed to tepa-na 'his face/forehead (body part)'.

Nouns can stand alone as the sole constituents of their NPs. Each noun class functions typically within the core and peripheral constituents of the clause. Personal nouns function as core constituents (including associative phrases) and also as constituents of benefactive phrases. Place nouns are constituents of locative phrases; other items require special marking when they fill this slot (uyahina instead of $u$ or hor). Time words typically fill the time margins. Common nouns typically fill the object NP slot of active verbs.

\subsubsection{MORPHOSYNTACTIC FUNCTIONS}

The derivation and the morphosyntax of nouns are sensitive to the above noun classes and subclasses; rules do not apply generally across all classes, but to semantic subclasses. Hence, the numerous semantic subclasses of noun are distinguished on the basis of the morphosyntactic functions they can fill. The classes (capital letters) and subclasses in Table 2 correspond to those listed in Figure 1. Table 2 summarises the morphology and normal functions of each subclass along a number of parameters: function as verbs with derivational prefixes, aspects of inflectional morphology and possession, and various syntactic frames. 
TABLE 2: SELECTED FUNCTIONS OF NOUN SUBCLASSES

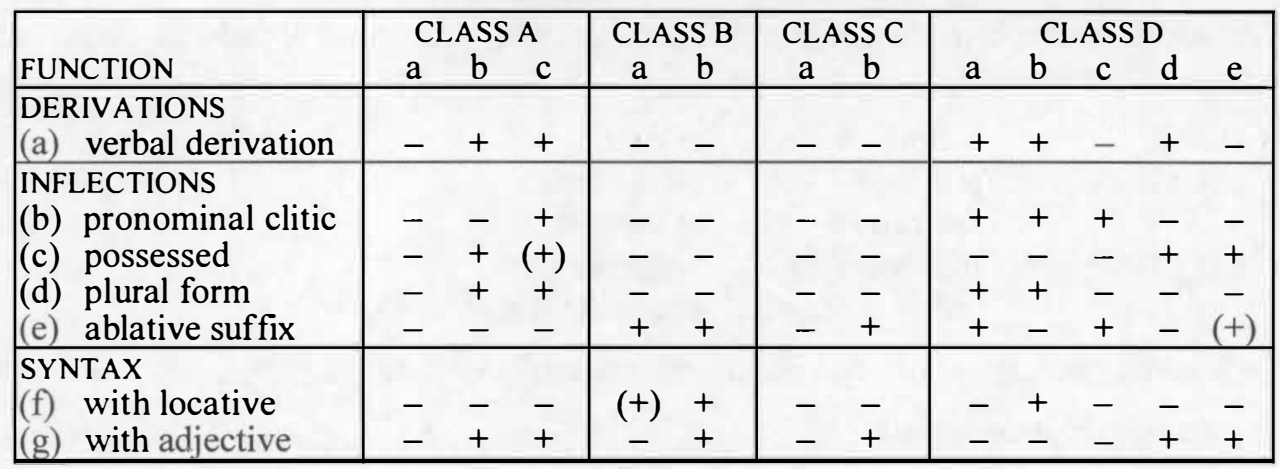

\subsubsection{Derivational Potential}

(a) The formation of verbs from various noun subclasses by means of derivational prefixes is outlined in $§ 17.5 .3$.

\subsubsection{INFLECTIONAL FUNCTIONS}

(b) The presence of a pronominal enclitic with nouns marks the person and number of the dependent possessor noun.

5(12) (kamkam) natu- na

fowl child- 3SG

DEPENDENT HEAD- PRONOMINAL ENCLITIC

a fowl's child (= chicken)

(c) Alienable possessive pronouns mark the person and number of the dependent possessor noun which semantically has a controlling relationship over the possessed noun.

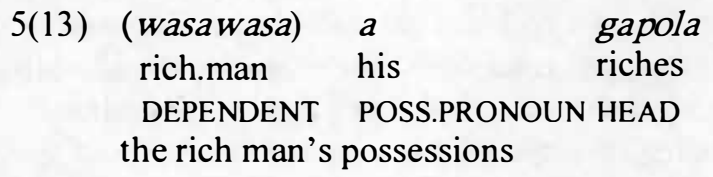

(d) Only human nouns, relationship terms and body-part terms are marked for plural.

$\begin{array}{lllll}5(14) \text { a. } & \text { hewali } & > & \text { hewa-hewali } & \text { b. natu-na } \\ & \text { youth } & \text { PL-youth } & \text { child-3SG } & \text { natu-natu-na } \\ & \text { h youth } & \text { youths } & \text { her child } & \text { hechild-3SG } \\ & \text { her children }\end{array}$

(e) The ablative suffix (-geI) has different functions with different subclasses of noun.

$\begin{array}{lll}\text { INSTRUMENTAL } & \text { wam-gei } & \text { by boat } \\ \text { LOCATIONAL } & \text { Bou-gei } & \text { from Bou } \\ \text { TEMPORAL } & \text { malatomtom-gei } & \text { in the morning }\end{array}$

Within the subclass of common nouns it marks instruments and hence does not apply to the whole subclass. 


\subsubsection{SynTACTIC FunCtIONS}

(f) The locative prepositions ( $u$, hor) only occur with place and locational nouns and relationship terms.

$\begin{array}{lll}\text { PLACE } & u \text { Bou } & \text { at Bou } \\ \text { LOCATION } & \begin{array}{l}u \text { niha } \\ \text { hoi tawali }\end{array} & \begin{array}{l}\text { on the beach } \\ \text { at the reef }\end{array} \\ \text { RELATIONSHIP } & \begin{array}{l}\text { ugabouli-na } \\ \text { numa u hine-na }\end{array} & \begin{array}{l}\text { underneath it } \\ \text { inside the house }\end{array}\end{array}$

(g) Only certain subclasses of noun occur with adjectives to form the simple NP.

5(15) numa dewadewa-na
house good-3SG
a good house

It is not my purpose to describe the noun subclasses per se; rather they are distinctions useful in the description of the inflectional and derivational morphology of nouns.

\subsubsection{PluRal Marking ON NOUNS}

With the noun subclass 'kinship terms' there is productive reduplication marking the nouns as plural. Some other subclasses of noun are reduplicated for plural marking. However the data are so irregular, and the functioning so distinct, that many forms are regarded as lexical reduplication rather than grammatical.

\subsubsection{BOUND AND FREE NOUNS}

Common nouns belong to one of two basic morphological types: 1) bound nouns, marked for person and number by pronominal enclitics; and 2) free nouns that have no such marking. Included among the bound nouns are kinship terms, relationship terms and body parts. If listing such items, a native speaker always includes an enclitic person marker, though it is possible to excise the pronoun under rare conditions; for example, the kinship term ama-na 'his father' can become the abstract ama 'a father, fathers, fatherhood'.

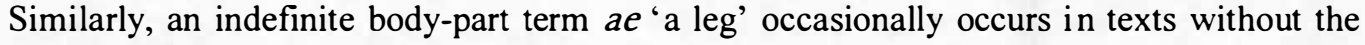
possessive enclitic. Quantifiers form a transition between the bound and free nouns, as some of them (e.g. guta 'part', tupo 'region') occur optionally with an enclitic person marker, though others are bound nouns (e.g. atapu-na'all-3SG').

\subsubsection{ABLATIVE ENCLITIC}

Note that the ablative enclitic, ${ }^{6}$ by a process of convergence (through analogy?), has come to share some of the formal characteristics of the transitive marker -ge. In each case the basic form is now $-\mathrm{ge}(i)$, and the rules for use of the other forms are identical for each morpheme (see $\$ 4.3 .6)$.

6 The Papuan Tip languages "reflect the POC locative proform *iai as a locative postposition" (Ross 1988:208). In Tawala the reflex is a nominal enclitic -gei(allomorphs -eil-yet) with a general 'ablative' meaning - 'from, by, via, with, during'; functioning with different noun subclasses it has different meanings. 
(a) Instrumental

With body-part nouns the ablative enclitic marks the noun as instrumental.
ae-u-gei with my feet/by foot
nima-hi-yei by their hands
giu-n'-ei with his tail (he stirred it)

The ablative enclitic is also used with a number of other nouns - possibly an instrumental subclass - to mark instruments or means of transport.

$\begin{array}{ll}\text { wam-gei } & \text { by boat } \\ \text { kwasikwasi-yei } & \text { with a machete } \\ \text { gaim-ei } & \text { with a stone }\end{array}$

(b) Temporal

With the absolute-time subclass of nouns the ablative enclitic indicates time during which the predication occurs.

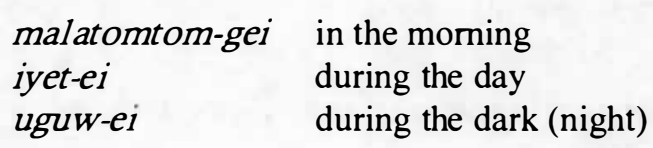

(c) Locational

With all subclasses of place nouns - place names, locational nouns, relationship terms - the ablative enclitic indicates the point of origin.

$\begin{array}{ll}\text { Bou-gei } & \text { from Bou } \\ \text { Dimdim-gei } & \text { from Europe } \\ \text { nih'-ei } & \text { from the beach } \\ \text { pitepit'-ei } & \text { from the bush } \\ \text { tepa-n'-ei } & \text { from its top } \\ \text { muli-hi-yei } & \text { from their backs }\end{array}$

With locational nouns and occasionally with relationship terms the ablative enclitic can indicate path of motion.

nih'ei via the beach

goil'ei via the river

If there is an adjective present in the NP then the ablative is attached to the pronominal enclitic.

\subsection{ADJECTIVES}

Adjectives are a derived class of words that modify nouns. They are marked for agreement in person and number with the head noun by pronominal enclitics.? 
TABLE 3: PERSON/NUMBER ENCLITICS USED WITH ADJECTIVES

\begin{tabular}{|c|c|ll|}
\hline PERSON & SINGULAR & \multicolumn{2}{|c|}{ PLURAL } \\
\hline 1 & $-u$ & $-t a$ & INC \\
& & $-i y a i$ & EXC \\
2 & $-m$ & $-m i$ & \\
3 & $-n a$ & $-h i$ & \\
\hline
\end{tabular}

As a class, adjectives are generally derived by reduplication of the verb root.

\subsubsection{Plural Marking}

As was mentioned above, all adjectives are marked for number agreement, which means they are marked for plural number if the head noun is plural and human. In addition, one antonym pair is unique in that human plural is marked by reduplicated forms; these are suppletive forms and not based on the singular forms. ${ }^{8}$

habulu- (singular) > muhomuho- (plural) small

banei- (singular) > balubalu- (plural) big

The distinction between human and non-human referents is indicated with this class.

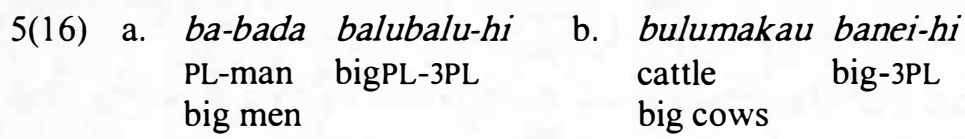

\subsubsection{CONDITION MARKER wai-}

A subclass of adjectives is derived by the condition proclitic wai-. The same form is used with some adjectives as an intensifier or marker of a more permanent or extreme condition.

$\begin{array}{lllll}\text { gigeima- } & \text { stony } & > & \text { wai-gigeima- } & \text { covered with stones } \\ \text { gomugomu- } & \text { broken } & > & \text { wai-gomugomu- } & \text { hinged, swinging } \\ \text { holiholi- } & \text { wound up } & > & \text { wai-holiholi- } & \text { springing } \\ \text { bigabiga- } & \text { muddy } & > & \text { wai-bigabiga- } & \text { swampy }\end{array}$

Three colour terms ${ }^{9}$ also employ this distinction, to draw the distinction between a general and exact colour, e.g. between a red cow (no proclitic) and a red car (with wai-). Other colour terms are derived using the prefix wai-.

$\begin{array}{llll}\text { wakewakeke- } & \text { whitish } & > & \text { wai-wakewakeke- intense white } \\ \text { dubaduba- } & \text { blackish } & >\text { wai-dubaduba- } & \text { pitch black } \\ \text { kayakaya- } & \text { reddish } & >\text { wai-kayakaya- } & \text { bright red }\end{array}$

\subsubsection{ADJECTIVES AND QUANTIFIERS}

It is important to distinguish the noun subclass of quantifiers (atapu-na 'entire/whole/all3SG', tapu-na 'different-3SG', gehou-na one/another-3SG', tupo-na 'part-/segment-3SG,

\footnotetext{
8 Interestingly, these are the first two items of the universal adjectival hierarchy proposed by Dixon (1982). and Kay (1969).
} 
tunawa-na 'alone-3SG') from adjectives. Within the NP the two classes function as separate constituents, overlapping in meaning and morphology and yet quite distinct, both formally and functionally. Example 5(17) demonstrates the overlap in meaning between the two classes. The meaning of the adjective magomagou- 'many, all' is very close to that of the noun atapu- 'all, the whole'.

$\begin{array}{lll}\text { 5(17) a. } \begin{array}{ll}\text { Lawa magomagou-hi hi-nae. } \\ \text { person many-3PL }\end{array} & \text { b. } & \text { Lawa atapu-hi hi-hopu. } \\ & \text { Many/all the people went. } & \text { person all-3PL 3PL-go.down }\end{array}$

Table 4 summarises the similarities $(a, b)$ and differences $(c, d)$ that exist between adjectives and quantifiers.

TABLE 4: QUANTIFIERS AND ADJECTIVES COMPARED

\begin{tabular}{|l|c|c|}
\hline FEATURES & QUANTIFIER & ADJECTIVE \\
\hline (a) Pronominal enclitics & + & + \\
(b) Modify a noun & + & + \\
\hline (c) Reduplicated form & - & + \\
(d) Modify an adjective & + & - \\
\hline
\end{tabular}

(a) Pronominal enclitics - Quantifiers and adjectives employ identical sets of pronominal enclitics, marked for person and number agreement, giving the superficial impression that the two word classes are functioning identically.

(b) Modify noun - Both items are postnominal modifiers

(c) Reduplicated form - Other features must be examined in order to correctly identify them. The most obvious feature indicating that quantifiers are nouns rather than adjectives is their unreduplicated form. As noted above, very few adjectives are not reduplicated. Of course, this criterion is only indicative and not definitive of word-class membership; corroborative evidence is required.

(d) Modify an adjective - An examination of the constituent structure shows that quantifiers fill a second order modifier slot within the NP.

5(18) Meyagai apapoe-hi gehou-hi to-gale-hi.

village bad-3PL other-3PL IPL.EXC-see-3PL

We saw other bad villages.

\subsection{VERBS}

Verbs are words that take a person/number prefix agreeing with the subject NP. Only a verb can function as the head of a VP; other word classes require derivational prefixes in order to function as verbs. In order to discuss the syntax of Tawala verbal clauses we need to distinguish five classes of verb. 


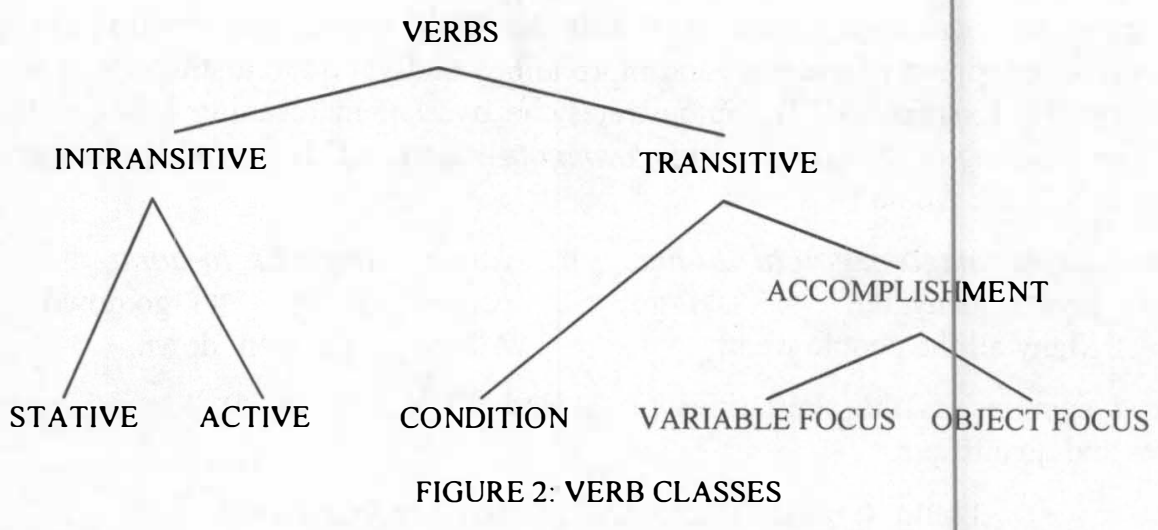

At the most fundamental level, Tawala verbs are either intransitive or ransitive. Intransitive verbs form a continuum, with two prototypical poles: stative and active. There are three basic types of transitive verbs: condition, variable focus and object focus. Accomplishment verbs form two classes: variable focus and object focus. These classes are discussed in detail here and are of vital significance in subsequent chapters. The following examples illustrate the four basic types (without the object-focus/variable-focus distinction).

\begin{tabular}{|c|c|c|c|c|}
\hline \multirow{4}{*}{$5(19)$} & STATIVE & ACTIVE & CONDITION & ACCOMPLISHMENT \\
\hline & I-kapala. & I-tou. & I-hogo-ya. & I-yaga-ya. \\
\hline & 3SG-hard & 3SG-cry.out & 3SG-full-3SG & 3SG-scrape-3SG \\
\hline & It is hard. & He cried out. & It is full. & He scraped it. \\
\hline
\end{tabular}

The distinguishing features of the five basic verb types are displayed in Table 5 .

TABLE 5: BASIC TYPES OF VERBS

\begin{tabular}{|l|c|c|c|c|c|}
\hline & \multicolumn{2}{|c|}{ INTRANSITIVE } & \multicolumn{3}{c|}{ TRANSITIVE } \\
\hline FUNCTION & STATIVE & ACTIVE & CONDITION & $\begin{array}{c}\text { VARIABLE } \\
\text { FOCUS }\end{array}$ & $\begin{array}{c}\text { OBJECT } \\
\text { FOCUS }\end{array}$ \\
\hline Valence & 1 & 1 & 1 & 2 & 2 \\
\hline S macrorole & $\mathrm{U}$ & $\mathrm{A}$ & $\mathrm{U}$ & $\mathrm{A}$ & $\mathrm{A}$ \\
\hline O macrorole & - & - & $\mathrm{U}$ & $\mathrm{U}$ & $\mathrm{U}$ \\
\hline Durative & - & + & - & + & + \\
\hline Optional O & & & - & + & - \\
\hline
\end{tabular}

(a) Valence

For purposes of the above classification verbal valence indicates the number of person markers on a verb and not the potential NPs within the clause. Intransitive verbs take a single subject marker. Transitive verbs take the same subject marker and also an object marker. Ditransitive verbs which take three core NPs, and condition verbs which only take one, are not distinguished at this point, since they each have subject and object markers on the verb. 
(b) Macroroles

Verbs differ in the semantic roles they assign to the core arguments. Foley and Van Valin (1984:30) propose two 'macroroles' - actor and undergoer - as universals. ${ }^{10}$ Actor (A) and undergoer (U) are the two prototypical roles of transitive verbs - subject and object respectively. However, in Tawala, condition verbs have an undergoer subject and object, co-referential to the same referent. Stative verbs have undergoer subjects, and active verbs have actor subjects, though Tawala inflectional morphology is not separately marked for these underlying macroroles.

(c) Durative aspect

Most verbs are reduplicated for durative aspect, an option not available to prototypical stative verbs; instead the corresponding adjective has a reduplicated form.

(d) Optional object marking

Optional marking of object on the verb is a feature of variable-focus verbs; object-focus verbs always have object marking on the verb.

\subsubsection{Stative VerbS}

The first subclass of intransitive verbs is stative verbs. Prototypical statives have no durative form, though like most verbs they have a related adjective stem that is normally a reduplicated form of the stem. The semantic distinction between the two forms is that the adjective indicates a greater degree of permanence than the verb.

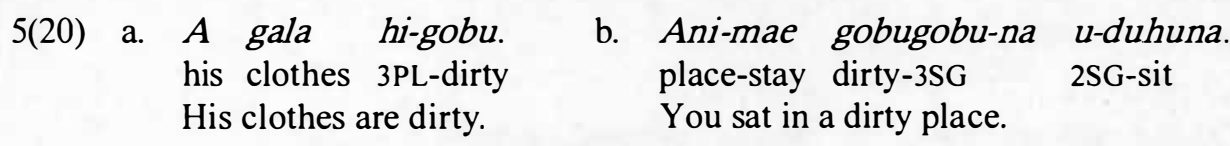

The examples below follow normal reduplication patterns except for the final four examples, which are slightly irregular in that the adjective has undergone vowel alternation.

They state: "macroroles which subsume particular groups of Fillmorean case roles or Gruberian thematic relations". In this scheme (p.32): "actor and undergoer, the two arguments of a transitive predication, have both semantic and syntactic significance. In an important sense they constitute an interface between syntactic relations such as subject and semantic relations such as case roles...". In the hierarchy proposed by Foley and Van Valin, accessibility to actor and to undergoer macroroles form the opposite poles of a cline. If more than one semantic role occurs with a verb, the actor/ undergoer hierarchy predicts which semantic role will be associated with actor and which with undergoer.

$\begin{array}{cc}\text { ACTOR } & \text { Agent } \\ & \vdots \\ & \text { Effector } \\ \vdots \\ \\ \text { Locative } \\ \vdots \\ \text { Theme } \\ \vdots \\ \text { UNDERGOER } & \text { Patient }\end{array}$

In my treatment of Tawala I consider the surface grammatical relations of subject (of both transitive and intransitive verbs) and object to be primitives (with surface marking on the VP), the macroroles of actor and undergoer being determined by the verb class. 


\begin{tabular}{|c|c|c|}
\hline $\begin{array}{l}\text { STATIVE VERB } \\
\text { (TEMPORARY) }\end{array}$ & $\begin{array}{l}\text { ADJECTIVE } \\
\text { (PERMANENT) }\end{array}$ & \\
\hline $\begin{array}{l}-g o t a \\
-g o b u\end{array}$ & $\begin{array}{l}\text { gotagota- } \\
\text { gobugobu- }\end{array}$ & $\begin{array}{l}\text { arrived } \\
\text { dirty }\end{array}$ \\
\hline -gupouma & gugupouma- & cold \\
\hline -haki & hakihaki- & good \\
\hline -hilage & hilahilage- & dead \\
\hline$-k a m$ & kamkam- & sharp \\
\hline -kapala & kapakapala- & hard \\
\hline -kokoe & kookoe- & finished \\
\hline -moyagahu & moyamoyagahu- & sweating \\
\hline$-m a e$ & meme- & stayed \\
\hline -maga & magomagou- & many \\
\hline -tenar & tenotenom- & floating \\
\hline -witai & witewitei- & heavy \\
\hline
\end{tabular}

Some stative verbs have an inherently reduplicated form and hence differ from the adjectival form only in affixation. In one case (dewadewa) the form has a diachronically related root that is not reduplicated (bracketed).

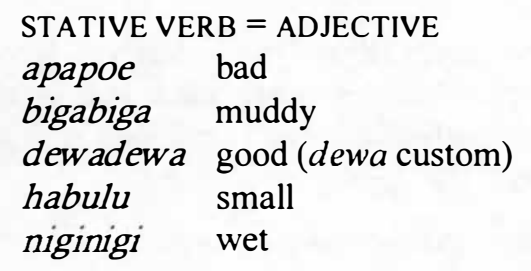

\section{STATIVE VERB}

5(21) Tahaya i-dewadewa. path The path is good.
ADJECTIVE

tahaya dewadewa-na

path good-3SG

(a/the) good path

The dimension adjectives are both irregular: habulu- 'small' has a non-reduplicated adjective; the adjective banei- 'big' is related to a stative verb with a suppletive form: -lata 'grow'. A further irregularity with the dimension statives is that the semantics of the two verbs are not symmetrical. Thus while -habulu means 'to be small', -lata means 'to become big, to grow'.

Along the continuum between active and stative verbs are a number of transitional subclasses; process verbs, for example, have undergoer subjects, bu are reduplicated for durative action.

I have not set up process verbs as a separate class because there are too few items and the characteristics of the individual members are too variable, hence the ned for a continuum.

$\begin{array}{lll}\text { SIMPLE } & \text { DURATIVE } & \\ \text {-gou } & \text {-gugou } & \text { ripen } \\ \text {-hahana } & \text {-haahana } & \text { (be) swollen } \\ \text {-totogo } & \text {-tootogo } & \text { be sick } \\ \text {-pou } & \text {-pupou } & \text { lay (eggs) }\end{array}$

Psychological verbs also have undergoer subjects but can be reduplicated for durative aspect. 


$\begin{array}{lll}\text {-matouta } & \text {-mato-matouta } & \text { be afraid } \\ \text {-lowo } & \text {-lowo-lowo } & \text { be fleeing (fearful) } \\ \text {-hanapu } & \text {-hana-hanapu } & \text { be wise } \\ \text {-kaoha } & \text {-kao-kaoha } & \text { be happy }\end{array}$

Other transitional verbs are the posture verbs. The subject is normally an undergoer, but if animate it may be an actor because of potential control.

$\begin{array}{lll}\text {-towolo } & \text {-towo-towolo } & \text { stand/be standing } \\ \text {-tugula } & \text {-tugu-tugula } & \text { sit/be sitting } \\ \text {-eno } & \text {-en-eno } & \text { lie/be lying } \\ \text {-tagela } & \text {-tage-tagela } & \text { swivel/be swivelling }\end{array}$

The derived class of 'automatic-action' verbs are unique in that they are motion verbs but seem to have undergoer subjects.

5(22) Polo i-'m-lupalupa.

pig 3SG-DVP-jumpDUR

The pig jerked (automatic response).

\subsubsection{ACTIVE VERBS}

The subclass of active verbs is the other pole on the intransitive continuum. The distinguishing features of active verbs is that they have actor-subjects and can be reduplicated for durative aspect.

$\begin{array}{lll}\text {-kadau } & \text {-kadakadau } & \text { travel } \\ \text {-kilolo } & \text {-kilokilolo } & \text { urinate } \\ \text {-togo } & \text {-togotogo } & \text { bathe } \\ \text {-tou } & \text {-tutou } & \text { cry out } \\ \text {-wao } & \text {-wowao } & \text { plant (by digging holes) } \\ \text {-woe } & \text {-woewoe } & \text { paddle (canoe) }\end{array}$

Included within active verbs are the subclass of verbs of motion, which have a distinctive morphology not shared by other active verbs.

$\begin{array}{lll}\text {-nae } & \text {-nenae } & \text { go } \\ \text {-gae } & \text {-gegae } & \text { go up } \\ \text {-nei } & \text {-nenei } & \text { come }\end{array}$

These motion verbs are marked for deictic direction of the action in relation to the speaker and addressee. Some verbs of speaking also share this feature but as yet no clearly defined classes have emerged.

TABLE 6: DEIXIS WITH MOTION VERBS

\begin{tabular}{|l|c|c|c|}
\hline DIRECTION & SPEAKER & ADDRESSEE & AWAY \\
\hline come/go & $n e-i^{*}$ & $n e-h i$ & $n a e$ \\
\hline come/go up & ge- $i^{*}$ & ge-hi & gae \\
\hline arrive & geleta- $i$ & geleta- $h i$ & geleta \\
\hline
\end{tabular}

* Normally written without the hyphen as these are the basic lexical items meaning 'to come'. 
5(23) Polo e-ge-ge-hi.

pig 3SG-DUR-come.up-DEI

The pig is coming towards you.

The 'speaker' forms are also used in the third person to mark the most salient participant (see Appendix Text B:6,7).

Verbs of transfer involve the bringing or taking of an item(s). The modifier is again an enclitic following the object enclitic, when one is present.

TABLE 7: VERBS OF TRANSFER

\begin{tabular}{|l|l|l|c|}
\hline DIRECTION & \multicolumn{1}{|c|}{ SPEAKER } & ADDRESSEE & AWAY \\
\hline send s.th. & himili yai & himili yahi & himili \\
\hline carry s.th. & nei yai & nei yahi & ni-ye-ya \\
\hline carry them & nei-hi ${ }^{\star}$ mai & nei-hi ${ }^{\star}$ mahi & ni-ye-hi \\
\hline
\end{tabular}

* Some speakers use ne-hi.

5(24) Ginouli anai tapu-hi e-ni-ni-ye-hi.

thing CON all-3SG 3SG.PRES-DUR-go-TRV-3PL

$\mathrm{He}$ is always carrying everything.

5(25) Natu-we a-himi-himili-yahi uyahi-mi.

child-ISG 1SG-DUR-send-DEI 'at'-2PL

I am sending my son to you.

5(26) O-na-nei-hi mai uyahi-u.

2PL-POT-come-3PL DEl 'at'-1SG

Bring them to me.

Another distinctive subclass - manner of motion - has been established on the basis of the distinctive part they play in verbal derivation.

$\begin{array}{lll}\text {-peu } & \text {-pipeu } & \text { fall } \\ \text {-dala } & \text {-daladala } & \text { crawl } \\ \text {-lupa } & \text {-lupalupa } & \text { jump/fly } \\ \text {-geleta } & \text {-gelegeleta } & \text { arrive }\end{array}$

Verbs of speaking are active verbs that require a transitivising suffix in order to take an object.

-lupali beg,make a request

-bowi make a denial

-baha speak

-gagayo make a vow

5(27) I-baha. > I-bah'-e-ya.

3SG-say 3SG-Say-TRV-3SG

He spoke. He said it.

\subsubsection{CONDITION VerbS}

Condition verbs are unique in that subject and object have the same referent - an undergoer. But while they are reflexive in form they are not in function. I can offer no explanation as to why these verbs are bivalent and not simply monovalent statives; clearly 
only one morpheme is required. In glossing the object CPY I do not wish to imply that the subject is the primary grammatical relation. As the argument is an undergoer it is possible that the object is the primary relation and the subject is copied.

5(28) Koiba-hi hi-hogo-hi.

stomach-3PL 3PL-full-CPY

They are pregnant.

The verb -hogo cannot mean 'to fill s.th.' and there is no form * $i$-hogo, these verbs require derivational prefixes to make them causative.

5(29) I wam a goila hi-wi-hogo-ya.

ourEXC boat its water 3PL-DVP-full-3SG

They filled our boat (tanks) with its fuel.

From a clausal point of view these verbs are monovalent in that they take only a single argument, but morphologically they are transitive, with both subject and object marked on the verb.

$\begin{array}{ll}\text { a-goholi-u } & \text { I jumped (with surprise) } \\ \text { i-hogo-ya } & \text { it is full } \\ \text { i-dumol-i } & \text { it is calm } \\ \text { i-ala-hi } & \text { it burns (itself) } \\ \text { i-luwotow-i } & \text { it is broken } \\ \text { i-libelibe-ya } & \text { it is floating (flotsam) } \\ \text { i-tein-i } i & \text { it is pulled }\end{array}$

A number of derivational processes actively produce condition verbs:

(a) The guna- prefix.

5(30) Hi-guna-lupeni-hi.

3PL-SPON-open-CPY

They (knots) opened themselves.

(b) The derivational prefix $1 u$-together with the transitivising suffix productively derive automatic-reflex condition verbs from intransitive stance verbs and one or two other roots.

5(31) A-lu-towologe-u.

ISG-DVP-stand-TRV-CPY

I jerked (myself) up (automatic response).

(c) The derivational prefix $1 i$ - used with cultural-item" nouns often results in condition verbs.

i-li-gaima-ya it is rock-covered

i-li-polo-ya it became a pig

11 These nouns are limited to common everyday items, e.g. 'rock-covered' refers to the area around the village which is kept free from weeds and covered with small rocks brought from the beach. 


\subsubsection{OBJECT-FOCUS VERBS}

Accomplishment verbs fall into two major classes: those with optional enclitics variable-focus verbs - and those with obligatory object enclitics - object-focus verbs.

Something like $20 \%$ of underived Tawala verbs are variable-focus verbs. I use the term 'focus' as that pragmatic function which characterises a constituent which presents relatively the most important information (following Dik 1978). Without the object marker these verbs are predicate focus - the speaker stresses the activity; with an object marker the verbs become object focus - the object is referential. Some typical Tawala examples follow.

PREDICATE FOCUS

a-awala I carried

$a$-buhu I drilled

a-buyo I squeezed

a-danene I stole

a-gelu I embarked

a-giluma I wrote

a-guluwa I buried

a-higu I drew (water)

a-hepa I beached (boat)

a-houna I put

a-kamota I caught

a-teina I pulled

a-woe I paddled
OBJECT FOCUS

$\begin{array}{ll}\text { a-awal-i } & \text { I carried s.th. } \\ \text { a-buhu-ya } & \text { I drilled s.th. } \\ \text { a-buyo-ya } & \text { I squeezed s.th. } \\ \text { a-danene-ya } & \text { I stole s.th. } \\ \text { a-gelu-ya } & \text { I embarked s.th. } \\ \text { a-gilum-i } & \text { I wrote s.th. } \\ \text { a-guluw-i } & \text { I buried s.th. } \\ \text { a-higu-ya } & \text { I drew s.th. } \\ \text { a-hepa-ya } & \text { I beached s.th. } \\ \text { a-houn-i } & \text { I put s.th. } \\ \text { a-kamo-hi } & \text { I caught s.th. } \\ \text { a-tein-i } & \text { I pulled s.th. } \\ \text { a-woe-ya } & \text { I paddled s.th. }\end{array}$

Verbs of consumption form a special subclass of variable-focus verbs on syntactic grounds.

$\begin{array}{llll}\text { a-kima } & \text { I chewed } & \text { a-kima-ya } & \text { I chewed s.th. } \\ \text { a-uma } & \text { I drank } & a-u m a-y a & \text { I drank s.th. } \\ \text { a-am } & \text { I ate } & a-a n-i & \text { I ate s.th. }\end{array}$

Variable-focus verbs occur with four pragmatic degrees of transitivity.

(a) With both an object enclitic and an object NP.

5(32) Hai pugole hi-awal'- $i$.

their pig.net 3PL-carry- 3SG

OBJECT NP.....

$\mathrm{O}$

They carried their pignet.

(b) With an object enclitic but no object NP.

\begin{tabular}{|c|c|c|}
\hline 33 & Ta-hopu & ta-awal'- \\
\hline
\end{tabular}

$\mathrm{O}$

Let us go down in order to carry him (a youth washed up on the shore).

(c) With an object NP but no enclitic on the verb. This construction is semantically akin to object incorporation, but there is no grammatical incorporation.

5(34) Bada a gapola u-na-awala po u-na-hopu u niha. man his possessions 2SG-POT-carry and 2SG-POT-go.down LOC salt OBJECT.NP----------

Carry (some of) the man's bags down to the beach. 
(d) Constructions with neither morphological marking nor an object NP. The surface form of these constructions is indistinguishable from intransitive verbs. The focus is on the predicate.

5(35) U-na-nei po u-na-awala po ta-hopu 2SG-POT-come and 2SG-POT-carry and IPL.INC-go.down Come and (help) carry (the pig) and we will go down.

Tawala motion-goal verbs are also variable-focus verbs:

$\begin{array}{llll}\text {-lui } & \text { enter (building) } & \text {-lui-ya } & \text { enter s.th. }{ }^{12} \\ \text {-damana } & \text { cross (bay/river) } & \text {-daman-i } & \text { cross s.th. } \\ \text {-tagona } & \text { cross (hill) } & \text {-tagon- } i & \text { cross over s.th. }\end{array}$

Tawala variable-focus verbs are semantically transitive, even when they formally lack a grammatical object enclitic or a syntactic object NP; an object is always implied. When an NP occurs with the predicate-focus form the 'object' is generic. Semantically the meaning is similar to object incorporation.

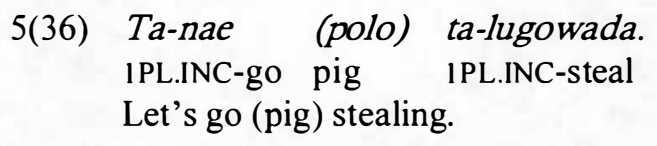

Verbs such as a-oga 'I washed (s.th.)' (a-oga-ya 'I washed it') cannot mean 'I bathed'; that is the meaning of a-togo, a separate lexical item. Similarly, a-gowada 'I hid (s.th.)' (agowad- $i$ 'I hid it') cannot mean 'I was hiding'; that meaning requires a derivational prefix: a-lu-gowadi-u 'I was hiding (-CPY)'.

Only one item included above has a clearly intransitive counterpart: gelu 'embark' which can occur with its 'object' as an oblique NP; in this case the object enclitic is obligatorily absent.

5(37) Bada hoi wam i-gelu ${ }^{*}$-ya.

man LOC boat 3SG-embark

The man boarded (onto) the boat.

While the verb gelu shows the same degrees of transitivity as awala, it seems to have a truly intransitive form.

There are two verbs for 'eat' in Tawala: $a m$ and $a n i$. These are predicate-focus and object-focus forms respectively ( $a m$ is also the noun 'food').
$5(38)$ a. Ta-nae ta-am.
IPL.INC-go IPL.INC-eat
Let's go and eat.
b. Amaka u-am? already 2SG-eat Have you eaten?
5(39) Ago-m a-un-i po a-an-i. spouse-2SG 1SG-kill-3SG and 1SG-eat-3SG I will kill and eat your wife.




\subsubsection{VARIABLE-FOCUS VERBS}

Some $20 \%$ of underived verbs are object-focus verbs and are thus unambiguously transitive, as they never occur without an object enclitic. In order to derive the predicatefocus counterpart of these verbs the valence-decreasing derivational prefix $o m$-is applied.

Object-focus verbs are verbs with highly affected objects; they are high on the transitivity scale (Hopper and Thompson 1980) - verbs of 'cutting, striking, tearing, wrapping, removing' etc. Condition verbs have bound object enclitics but they are semantically distinct from object-focus verbs in that with them the objects are not highly affected.

$\begin{array}{ll}\text { a-bol-i } & \text { I cut s.th. off } \\ \text { a-gugu-ya } & \text { I suck s.th. (breast) } \\ \text { a-hap-i } & \text { I chop s.th. } \\ \text { a-hapu-ya } & \text { I pull s.th. up } \\ \text { a-kik-i } & \text { I strangle s.th./s.o. } \\ \text { a-kila-ya } & \text { I scratch s.th. } \\ \text { a-lolo-ya } & \text { I tear s.th. } \\ \text { a-poha-ya } & \text { I put s.th. in a basket } \\ \text { a-un-i } & \text { I overcome/kill s.th./s.o. } \\ \text { a-laun-i } & \text { I hit/kill s.th./s.o. } \\ \text { a-wah-i } & \text { I remove s.th. }\end{array}$

The verb waya 'take s.th.' is irregular in that its form in all but the third person singular is the suppletive form: wini(-hi) 'take (-them)'.13

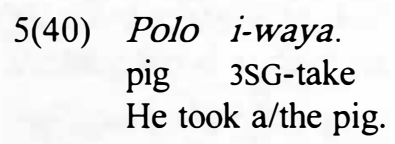

Presumably the final syllable / ya/ was originally a third person suffix which has become fused to the root and is no longer a productive object enclitic.

5(41) Iyana magou-hi wohepali i-wini-hi.

fish number-3PL four 3SG-take-3PL

She took four fish.

5(42) U-na-wini-u po mei am tu-bagibagi gehou-na.

2SG-POT-take-1SG and like yourSG PER-work other-3SG

Take me and (I will be) like one of your servants.

Derived object-focus verbs are very common.

A subgroup of object-focus verbs is a group of 'influence verbs' in which the object is not fully affected (as it is with object-focus verbs). With these verbs the object is potentially an experiencer and is typically marked for first or second person, which is not possible with most other object-focus verbs.

a-gale-ya I see s.th./s.o.

a-himil-i I send s.th./s.o.

13 The verb tami(-hi) 'take (them)' is used when a number of different types of items are selected to be taken. 
a-hune-ya I praise him/her

a-pego-ya I hold s.th./s.o. in my arms

Morphologically, ditransitive verbs belong to this class, as only two arguments are marked on the verb. However they form a unique subclass, as three NPs occur in the clause core. The object enclitic with a ditransitive verb always indexes the human (animate) recipient - the experiencer. The secondary object (marked in brackets in the glosses of the following examples) is not indexed on the verb.

$\begin{array}{ll}\text {-wi-atatiy-e-ya } & \text { show s.th./s.o. } \\ \text {-wele-ya } & \text { give s.th./s.o. } \\ \text {-pali-wele-ya } & \text { tell s.th./s.o. } \\ \text {-hagu-ya } & \text { help s.o. (with s.th.) }\end{array}$

The transitivising suffix with verbs of speaking (and a few others) derives object-focus verbs.

$\begin{array}{ll}\text {-gagayo-ge-ya } & \text { swear s.th./s.o. } \\ \text {-bowi-ye-ya } & \text { deny s.th./s.o. } \\ \text {-bah'-e-ya } & \text { say s.th. about s.o. } \\ \text {-taniwag'-e-ya } & \text { rule s.th./s.o. } \\ \text {-matout'-e-ya } & \text { fear s.th./s.o. }\end{array}$

\subsubsection{FORMS OF TRANSITIVE MARKING}

Marked transitive verbs belong to one of three subclasses, depending on the morphological marking of the object enclitic. There are four ways in which verbs mark the third person singular object enclitic: $-i,-y a,-y a / n i$ or $-h i$.

The following statistics are based mainly on the non-derived verb roots. Derived stems normally follow the pattern of the root. Which enclitic is used depends on 1) the phonological shape of the root - the number of syllables - and 2) the nature of the final syllable - usually just the final vowel. Table 8 summarises the possibilities, giving percentages of three types of transitive marking in specific phonological environments.

TABLE 8: PERCENTAGE DISTRIBUTION OF THIRD PERSON SINGULAR OBJECT ENCLITICS

\begin{tabular}{|c|c|c|c|}
\hline & \multicolumn{3}{|c|}{ TRANSITIVE ENCLITIC } \\
\hline SHAPE OF STEM & $-i$ & $-y a / n i$ & $-h i$ \\
\hline ending in ta & 0 & 0 & 100 \\
\hline polysyllabic ending in $a$ & 0 & 41 & 0 \\
\hline ending in $a$ & 48 & 0 & 0 \\
\hline ending in $i$ & 52 & 3 & 0 \\
\hline ending in $e$ & 0 & 22 & 0 \\
\hline ending in $O$ & 0 & 15 & 0 \\
\hline ending in $u$ & 0 & 19 & 0 \\
\hline
\end{tabular}




\subsubsection{STEMS TAKING $-h i$}

This is by far the smallest subclass of transitive verbs. In each case the stem is a trisyllabic intransitive verb with the final syllable / ta/ being replaced by / hil in the transitive form of the verb. ${ }^{14}$

\begin{tabular}{lll} 
PREDICATE FOCUS & \multicolumn{2}{l}{ OBJECT FOCUS } \\
-alata & -alahi & burn (s.th.) \\
-momota & -momohi & hold (s.th.) tightly \\
-ugota & -ugohi & plant (s.th.)
\end{tabular}

The remarkable thing about this class is that the singular enclitic has the same form as the plural pronominal enclitic. When marked with a plural enclitic this class repeats the suffix.

5(43) A-momohi-hi.

1SG-holdTR-3PL

I hold them (tightly).

\subsubsection{STEMS TAKING $-i$}

Two types of stems are involved in this subclass of transitive verbs. Firstly, there are polysyllabic stems ending in $/ a /$, where $/ i /$ is substituted for the final vowel of the stem. ${ }^{15}$

$\begin{array}{lll}\text { PREDICATE FOCUS } & \text { OBJECT FOCUS } & \\ \text {-himila } & \text {-himil'-i } & \text { send (s.o.) } \\ \text {-nonola } & \text {-nonol'-i } & \text { hear (s.th.) } \\ \text {-hiyawa } & \text {-hiyaw'-i } & \text { count/read (s.th.) } \\ \text {-ulona } & \text {-ulon'-i } & \text { cook (s.th.) } \\ \text {-lupena } & - \text { lupen'-i } & \text { release (s.th.) (lupa jump) } \\ \text {-geina } & \text {-gein'-i } & \text { climb (s.th.) (gei come up) }\end{array}$

In the second group are words in which the stem form is a transitive verb ending in $/ i$, with no evidence of any other underlying intransitive stem.

$\begin{array}{ll}\text {-bagibagi } & \text { work } \\ \text {-pani } & \text { bind s.th. } \\ \text {-boli } & \text { chop s.th. } \\ \text {-uni } & \text { strike/kill s.th. } \\ \text {-lupali } & \text { ask for s.th. }\end{array}$

When non-third person pronominal enclitics are added to these verbs it is clear that the transitive focus form actually ends in $/ i$. (Stressed syllable is underlined.)

\footnotetext{
14 Diachronically this group is a subclass of stems taking $-i$. Ross 1988:199 gives the rule that POC ${ }^{*} t$ became $h / \ldots i$ in Tawala. However, this rule is no longer productive and we must treat these $-h i$ enclitics as a separate class. 
i-himili-u he/she/it sends me

i-himili-m he/she/it sends you(SG)

i-himil'-1' ${ }^{16}$ he/she/it sends him/her/it

\subsubsection{STEMS TAKING $-y a$}

Included in this class are two-syllable words ending in / a/ as well as words ending in the other vowels, though rarely with /i/. The normal morpheme is $-y a$, though the Awayama dialect has the distinctive form -iya for this morpheme.

5(44) a-gale-ya/-iya

ISG-see-3SG

I saw it/her/him

This variant has spread along the north coast to East Cape, as Williams (c.1962) gives it as an alternative form for some words.

Many stems are variable-focus verbs. However, in other cases the stem does not occur without the object enclitic.

\begin{tabular}{llll}
\multicolumn{2}{l}{ PREDICATE FOCUS } & \multicolumn{2}{l}{ OBJECT FOCUS } \\
-yaga & chase & -yaga-ya & scrape (s.th.) \\
-uma & drink & -uma-ya & drink (s.th.) \\
-bui & turn over & -bui-ya & turn (s.th.) over \\
-(om)huna & praise & -hune-ya & praise (s.o.) \\
-walo & be trapped & -walo-ya & trap (s.th.) \\
-gelu & embark & -gelu-ya & board (s.th.)
\end{tabular}

\subsubsection{STEMS TAKING -ni/ya}

This 'remainder' class is also the largest class, especially as most derived verbs fit into this class. It would appear that the alternative pronominal enclitics $(-n i / y a)$ are both reflexes of the POC transitive marker ${ }^{*}-i$ (see comments in both previous sections). The two forms are dialectal:

\begin{tabular}{|c|c|c|}
\hline \multirow{3}{*}{$5(45)$} & LABE & KEHELALA \\
\hline & A-gale-ya. & A-gale-ni. \\
\hline & 1SG-see-3SG & ISG-see-3SG \\
\hline & I saw it. & I saw it. \\
\hline
\end{tabular}

This grammar is primarily based on the Diwinai dialect, which is midway between Kehelala and Labe. Diwinai speakers prefer the Kehelala form, though the Labe form is used and acceptable. During a period of years when Yailo lived at Labe I noted that he increasingly used the Labe form in this and other alternative morphemes (e.g. uyahi-/ugoli-), hence the object enclitics in this grammar are often the Labe forms.

A large proportion of these stems require the transitivising suffix -ge before the object enclitic is added. Stems or modifiers ending in $/ e /$ follow the same pattern.

16 The underlying form of the third person singular is -himili-i, with elision of the identical vowel in the surface form. 


$\begin{array}{lll}\text { LABE } & \text { KEHELALA } & \\ \text {-gale-ya } & \text {-gale-ni } & \text { see-s.th. } \\ \text {-tahae-ya } & \text {-tahae-ni } & \text { precede-s.th. } \\ \text {-wiqatati-ye-ya } & \text {-wiyatati-ye-ni } & \text { show-TRV-s.th. } \\ \text {-houna hopu-n-e-ya } & \text {-houna hopu-n-e-ni } & \text { put down-LIG-TRV-s.th. } \\ \text {-bah-e-ya } & \text {-bah-e-ni } & \text { say-TRV-s.th. } \\ \text {-hanapu-ge-ya } & \text {-hanapu-ge-ni } & \text { know-TRV-s.th. } \\ \text {-ROOT woloe-ya } & \text {-ROOT woloe-ni } & \text { VERB finish-s.th. } \\ \text {-ROOT imahi-ye-ya } & \text {-ROOT imahi-ye-ni } & \text { VERB properly-TRV-s.th. } \\ \text {-ROOT me-ya } & \text {-ROOT me-ni } & \text { VERB again-s.th. }\end{array}$

DIWINAI LABE

5(46) Om tano u-na-gale-ni. Am oya u-na-gale-ya. yourSG garden 2SG-POT-see-3SG yourSG mountain 2SG-POT-see-3SG Look at your garden. Look at your garden.

Other verbs offer this same pattern, though without this same phonological basis.

$\begin{array}{lll}\text { LABE } & \text { KEHELALA } & \\ \text {-dewa-ya } & \text {-dewa-ni } & \text { do/make s.th. }{ }^{18} \\ \text {-hanapu-ya } & \text {-hanapu-ni } & \text { know s.th. } \\ \text {-wigowa-ya } & \text {-wigowa-ni } & \text { name s.o. }\end{array}$

The most common stem involved in this class are polysyllabic ${ }^{19}$ stems, often ending in /al.

$\begin{array}{lll}\text { wigaigaima } & \text {-wigaigaim-e-ni/ya } & \text { stony (s.th.) } \\ \text { luodubona } & \text {-luodubo-ge-ni/ya } & \text { follow (tradition) } \\ \text { wimeiha } & \text {-wimih-e-ni/ya } & \text { pay back (s.th.) } \\ \text { winugokaoha } & \text {-winugokaoha-ni/ya } & \text { cheer (s.o.) }\end{array}$

\subsubsection{Semantic Scope of OBject Enclitics}

Verbs differ in the semantic scope of their object enclitics.

\subsubsection{HUMAN/ANIMATE}

$\begin{array}{ll}\text {-hagu-ya } & \text { help s.o. } \\ \text {-wele-ya } & \text { give to s.o. } \\ \text {-himil-i } & \text { send s.o. } \\ \text {-paliye-ya } & \text { scold s.o. } \\ \text {-nehale-ya } & \text { leave s.o. }\end{array}$




\subsubsection{INANIMATE}

-hiyaw-i count/read s.th.

-ugohi plants.th. (PL)

-yaga-ya scrape s.th.

-uma-ya drinks.th.

-gelu-ya board s.th. (vessel/vehicle)

\subsubsection{NON RESTRICTED}

These often involve verbs marked with the transitiviser -ge.

-hanapu-ge-ya know s.th./s.o.

-lupali-ye-ya beg for s.th., beg of s.o.

-bowi-ye-ya denys.th./s.o.

-bah-e-ya say s.th./speak to s.o.

-matout-e-ya fear s.th./s.o.

-gale-ya see s.th./s.o. 


\section{CLOSED WORD CLASSES AND RELATED ISSUES}

\subsection{PRONOUNS}

Pronouns are often a clear-cut category in languages, involving only free forms. In Tawala however, the functional domain of personal reference includes not only free forms but details of verb morphology, possessive clitics, marking on bound nouns and even postpositions.

Three persons are distinguished in Tawala: first (speaker), second (hearer) and third (other(s)), irrespective of gender or animacy. Only two grammatical numbers are distinguished: singular and plural. First person plural makes an inclusive (including hearer) versus exclusive (excluding hearer) distinction.

A possessive construction is used to express dual and trial (etc.) meaning: a numeral follows the appropriate (plural) possessive pronoun (hai luwaga 'the two of them', ata tonuga 'the three of us (inclusive)' etc.) and functions in addition to either an optional noun or an emphatic pronoun.

6(1) (tauta) ata luwaga

USINC ouriNC two

we two (OR us two)

Person and number marking is found on emphatic and possessive pronouns, on verbs (both subject and object), on bound nouns, and on adjectives, quantifiers and postpositions.

Third person plural forms are commonly used to encode impersonalisation, a function commonly associated with passive constructions in many languages.

6(2) Bod gehou-na hi-gilum-i uyahi-na to-geleta.

board other-3SG 3PL-write-3SG 'at'-3SG 1PL.INC-arrive

We arrived at a board on which something was written.

\subsubsection{PRONOUN FORMS}

Table 1 sets out the forms of all five classes of personal reference, demonstrating the considerable overlap that exists between the various classes. The third person singular forms show the highest degree of distinction. Only one set consists of pronouns proper: the independent pronouns (though possessive pronouns are also free forms). The remaining four classes of person markers can occur with independent pronouns within the phrase: possessive pronouns, object enclitics, subject prefixes and pronominal enclitics. 
TABLE 1: PRONOMINAL FORMS (SIMPLIFIED) COMPARED

\begin{tabular}{|l|c|c|c|c|c|c|c|}
\hline PRONOUN CLASS & ISG & 2SG & 3SG & 1PL.INC & 1PL.EXC & 2PL & 3PL \\
\hline INDEPEND. PRONOUN $^{1}$ & tau & tam & tauna & tauta & tauyai & taumi & tauhi \\
POSS. PRONOUN & $u$ & $o m$ & $a$ & ata & $i$ & $o m i$ & $h a i$ \\
OBJECT ENCLITIC & $-u / w e$ & $-m$ & $-n i /-y a$ & $-t a$ & $-y a i$ & $-m i$ & $-h i$ \\
SUBJECT PREFIX & $a-$ & $u-$ & $i-$ & ta- & to- & $o-$ & $h i-$ \\
PRONOM. ENCLITIC & $-u / w e$ & $-m$ & $-n a$ & $-t a$ & $-y a i$ & $-m i$ & $-h i$ \\
\hline
\end{tabular}

Example 6(3) illustrates four pronominal forms, three of which are coreferential.

6(3) Tauhi hai mae hi-nonogo-ge-ni.

they their stay 3PL-prepare-TRV-3SG

They prepared their residence.

\subsubsection{Pronominal EnClitics}

These are unstressed possessive clitics ${ }^{2}$ marking the person and number of the dependent or 'possessor' NP by a pronominal enclitic on the head or bound noun. They are classed as clitics in that they move to the end of the phrase, though only with general modifiers.

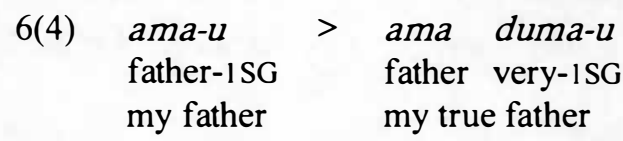

Pronominal enclitics are used to mark inalienable possession with kinship terms (6(4)), relationship terms (6(5)), body parts (6(6)) and postpositional relators $(6(7))$.

6(5) numa u gabouli-hi

house LOC under-3PL

under the houses

6(6) polo ae-na

pig leg-3SG

a/the pig's leg

6(7) lawa uyahi-hi

person 'at'-3PL

to/with/at the people

The set of pronominal enclitics is also employed in personal pronoun derivation and adjective phrasal agreement, including numerals and limiters. Thus pronominal enclitics form a highly cohesive reference system marked within noun phrases; nothing is more central to gaining an insight into the operation of Tawala noun phrases than an understanding of the operation of these pronominal clitics.

1 Ross (1988:279) observes that the emphatic pronouns are "based on a reflex of the noun POC *tau 'body, person'... with a pronominal possessive suffix". The original meaning of the noun is lost in present-day Tawala.

2 Some of the Tawala enclitics are clearly reflexes of POC, others are doubtful. One of the innovations of the Papuan Tip cluster is the use of a similar set of enclitics for object indexing on the verb. 


\subsubsection{PRONOUN FunCTIONS}

There are five distinctive functions assigned to pronouns in addition to those given in the previous section. The relevant pronouns are underlined in examples in this section.

\subsubsection{EMPHASIS}

The stressed independent pronoun has an emphatic function (cf. Appendix Text A.15).

6(8) Tau geka.

I here

I am here.

6(9) Tauna i-na-yabiyabi.

he 3SG-POT-steer

He (not the other) will steer.

With non-verbal clauses they also function as non-verbal predicates.

6(10) Geka tau.

this I

This is me.

As a set the emphatic pronouns are used for human referents; demonstratives are used for non-humans as well as humans.

\subsubsection{POSSESSION}

The independent stressed possessive pronoun indexes the following head (possessed) noun for the person and number of the possessor NP.

6(11) Lawa hai tano hi-dewa-hi.
person their garden 3PL-make-3PL
The people made their gardens.

\subsubsection{OBJECT MARKING}

The unstressed pronoun has a non-emphatic, referential function. It is the final clitic of the VP marked for person and number, and indexes the definite object.

$$
\begin{aligned}
& \text { 6(12) Palouma } \\
& \text { witch } \\
& \text { I feared the witch. }
\end{aligned}
$$

\subsubsection{SUBJECT MARKING}

The unstressed pronoun has an anaphoric or exophoric function. It is the first prefix of the verbal predicate, marked for person and number, and indexes the clausal subject. 
6(13) Apo a $\underline{\text { a-nae }}$ a-wisili.

FUT ISG-go ISG-fishing

I will go fishing.

\subsubsection{Adjectival AgREEMENT}

A further function of the adnominal enclitics is to mark adjectives and quantifiers for agreement with the head noun.

$\begin{array}{llll}\text { 6(14) bada dewadewa-na }> & \text { bada dewadewa duma-na } \\ \text { man good-3SG } & \text { man good } & \text { very-3SG } \\ \text { a good man } & & \text { a very good man }\end{array}$

In marking the dependent rather than the head, the adjectival enclitic is quite distinct from the pronominal enclitic functions listed in $\$ 6.1 .2$, though the surface string is identical. Example 6(15) contains both an adjective and a quantifier modifying the noun.

\section{6(15) logaloga muhomuho-hi atapu-hi \\ children smallPL-3PL all-3PL \\ all the small children}

\subsubsection{Problems in Classifying Pronouns}

There is historical evidence that the emphatic pronouns have developed from an inalienably possessed noun. A similar process has taken place with other nouns that have also lost their original nominal function. Thus nugo- $n$ '-ei 'by itself (automatically)' is derived from nugo-n(a)-ei 'mind-3SG-ABL' often carrying the connotation of 'without thought'. This set only occurs in the third person singular or plural.

6(16) Geka mateta-na nugo-n'-ei i-guna-hoe-ya.

this door-DEF mind-3SG-ABL 3SG-SPON-open-CPY

The door opened by itself.

The form tunawa-na (L. tuqawa-na) 'by itself' is probably derived from the nominalising proclitic tu- and the modifier awa 'only' - *tu-awa-na (person-only-3SG) - recalling that Labe dialect normally only uses glottal stops across word and morpheme boundaries, and that these often coincide with transitional consonants at Diwinai. This set is in common use and is inflected for all persons and numbers.

6(17) Tau tuqawa-u a-tagona.

I alone-1SG ISG-cross

I went across (the mountains) by myself.

The form of these two sets is that of inalienably possessed nouns; the function is 'automatic' and 'limiting' pronouns respectively.

A similar construction is found with the 'possessive pronoun' gali-n'-ei (fence-3SG-ABL) 'belonging to him', 'from him' (lit. 'from/via his fence'). 
6(18) K25 gali-m-gei... ma K10 walehi-ta gali-n'-ei. ${ }^{3}$

kina25 fence-3SG-ABL and kina10 brother-1PL.INC fence-3SG-ABL

25 kina (will be) from you... and 10 kina from our brother.

The non-verbal clause tam gali-m-gei 'it is your responsibility' parallels the use of the limiting pronoun tau tunawa-u 'it is only me'. Is this just an idiomatic use of an inalienably possessed noun? Or are we looking at another pronoun set in the process of development?

Another set of similar problems is involved with the analysis of postpositional relators. It seems that with a head-marking language the functional domain of personal reference becomes somewhat fuzzy.

\subsection{DEMONSTRATIVES}

Tawala demonstratives are stressed emphatic free forms that function as both spatial deictics ('here', 'there' and 'away there') and demonstrative pronouns ('this one', 'that one' and 'the absent one'). Their status as free forms is well established, as they frequently occur as the only word in non-verbal sentences, where the function is predicative and there is no subject.

\subsubsection{Demonstrative Forms}

Tawala demonstratives are reflexes of the "set of POC demonstratives/spatial deictics ${ }^{*} e{ }^{*} n e$ 'near speaker', *a/*na 'near addressee', and * $O{ }^{*} n o$ 'distant from both speaker and addressee" (Ross 1988:100). The Tawala reflexes have undergone both phonological and semantic changes, as is evident in the following:

PROXIMAL geka ${ }^{4}$ near speaker or hearer

NEUTRAL naka not near speaker

DISTAL noka out of sight of speaker or hearer

I have no suggestions as to the origin of the particle $-k a$, though it is also found with locational interrogative meka 'where' and the conjunction yaka.

The neutral form includes the Proto Oceanic (POC) meaning of 'near hearer', overlapping the meaning of the proximal forms. Speakers can thus use deictic forms appropriate to themselves or their hearers.

Demonstratives each have a partially reduplicated form which repeats the first syllable: ge-geka, na-naka, no-noka. The reduplicated form specifies exact location or time.

6(19) E-tugu-tugula no-noka.

3SG.PRES-DUR-sit RED-there

He has been sitting right there (in the exact position we put him).

The demonstrative may also be marked for directional deixis - near the hearer:

This non-verbal sentence is taken from a letter, hence the form here parallels the written original.

$g e$ - is not obviously a reflex of $\mathrm{POC}^{*} e / n e$, though the other reflexes are clearer.

However, the Maiwala (Taupota dialect) form is yana. 

6(20) Polo e-ge-ge-hi na-naka-hi.
pig 3SG.PRES-DUR-come.up-DEI RED-there-DEI
The pig is coming up right towards you.

\subsubsection{Demonstrative Functions}

Only an overview of demonstrative functions is presented here; a more detailed treatment is given in subsequent chapters. Demonstratives function within discourse to maintain topic and prominence; the neutral demonstrative naka 'that' is commonly used in complex sentences to indicate topicalisation.

Demonstratives may modify nouns.

6(21) geka dobu
this village
this village

They also function as heads of NPs.

6(22) Geka amaka a-howa-tepa-ni.

this already ISG-spit-top-3SG

I have already worked magic on it.

A demonstrative may function as a non-verbal predicate.

6(23) Tau geka.
I this
I am here.

The demonstrative naka is used as a complementiser.

6(24) Hi-i-wogatala naka apo iyowai hi-na-bagibagi.

3PL-DUR-plan that FUT how 3PL-POT-work

They were planning how they would (do their) work.

When speakers finish their discourse they will often conclude with the following nonverbal clause:

6(25) ...na-naka noka pite.

RED-that that like

...it is exactly like that.

\subsection{GENERAL MODIFIERS}

There is a set of five general modifiers functioning with the major parts of speech, though different word classes and even words have their own distinct preferences. The range of word classes with which each modifier is identified is listed in Table 2. 
TABLE 2: GENERAL MODIFIERS

\begin{tabular}{|ll|c|c|c|c|c|}
\hline MODIFIER & & NOUN & VERB & ADJ & DEM & QUEST \\
\hline duma & very & + & + & + & - & - \\
\hline hota/hosi & only, just & + & + & + & + & + \\
\hline awa/nawa & only & + & + & - & - & + \\
\hline gasi & also & + & + & - & - & - \\
\hline pite/pete & similarly & - & + & - & + & + \\
\hline
\end{tabular}

Note that alternative forms are dialectal in origin, but 'stylistic' in synchronic usage, with a single speaker often using different forms in close proximity.

These general modifiers are referred to throughout the grammar, but at this point their full range of functions is illustrated with the modifier hota/ hosi.

+ noun

+ verb

+ adjective

+ demonstrative

(most common usage)

+ question word ega lawa hota

I-dewadewa hota.

houga kuku hota-na

geka hota

meka hota not a real person (lit. not a person only)

It is really good. (lit. It is good only.)

soon (lit. a short time only)

right here (lit. here only)

whereabouts (lit. where only)

\subsection{PARTICLE MODIFIERS}

These include intensifiers, limiters and specifiers which modify the verb and operate within the verb phrase. For a listing of particle modifiers see $\S 8.10$.

\subsection{ADVERBS}

In contrast to particle modifiers (which are post-head clitics of the verb phrase) adverbs are free-form clausal items, occurring in any position before the predicate (either verbal or nominal) often favouring a clause-initial position following the conjunction, or (with nonverbal predicates) immediately prior to the predicate. They are clause operators, "concerned with grounding the reported event in the real world" (Foley and Van Valin 1984:209).

Only a few items are involved, belonging to a number of functional domains.

\subsubsection{TENSE}

The main item involved here is the future-tense operator apo (FUT), however amaka 'already' and ataima (L. amalai) 'today, now' are used as supplementary tense markers.
6(26) Apo ta-nae
po gulawa ta-boli.
FUT IPL.INC-go and twine IPL.INC-cut
Let's go and cut twine. 


\subsubsection{TIME}

Two relative time markers (yohola 'later, eventually' lolowa 'before, earlier') are used in combination with the tense adverbs.

6(27) Yohola apo i-na-nei.

later FUT 3SG-POT-come

She will come later.

6(28) A kadau tahaya-na amaka lolowa i-dewa-ya.

his journey first-3SG already earlier 3SG-make-3SG

He had already made his first journey earlier.

\subsubsection{Negative}

The main function of ega (NEG) is as the marker of negative polarity.

6(29) Ega a tano po puwaka.

NEG his garden and pig

He has no garden or pigs.

It often combines with the irrealis mood.

6(30) Ma lawa ega hi-ta-tu-tou duma.

but person NEG 3PL-IRR-DUR-cry very

But the people did not weep much.

The negative combines with the future adverb to form a single phonological and grammatical word apega (FUT.NEG) which combines with irrealis or potential mood.

6(31) Apega toleha-na a-ta-dewa-ya.

FUT.NEG feast-DEF 1SG-IRR-make-3SG

I will not provide the feast.

\subsubsection{Truth-Value Operators}

These are nugote 'perhaps' and moina 'truly'.

6(32) Ma moina a-kokoma duma.

and truly ISG-apprehensive very

And truly I was very apprehensive.

\subsection{SENTENCE INTRODUCERS}

\subsubsection{INTERACTION MARKERS}

These are heki 'on the contrary' and embateka 'try to, dare to'.

6(33) Heki, u-na-ludadan-i. contrary 2SG-POT-try-3SG

On the contrary, give it a try. 


\subsubsection{MODALITY MaRKERS}

These are hilaki 'if only' and kidahi 'surely'.

6(34) Hilaki pona Tawala uyahina buka hi-ta-dewa-ya. if.only voice Tawala 'at'-3SG book 3PL-IRR-make-3SG Oh that there were (3PL impersonal) books in the Tawala language.

\subsection{NUMERALS}

Tawala numerals differ from adjectives in that: 1) they are not marked for agreement with the head; 2) they do not have a reduplicated form; and 3) they can modify adjectives. They can function as the head of an NP, though their normal function is as a second-order nominal modifier. There are only four basic numerals:

$\begin{array}{ll}\text { emosi/emota } & \text { one } \\ \text { luwaga } & \text { two } \\ \text { tonuga } & \text { three } \\ \text { wohepali } & \text { four }\end{array}$

Other 'cardinal' numerals are constructed by forming sentences from basic numerals plus several nouns - nima 'five' (hand), ae 'five' (leg), oloto/lawa 'twenty' (male/person) - and two verbs - tutu 'hit', hilage 'finish'. They are included at this point for ease of reference and because they function as embedded clauses within the number constituent of the NP.

$\begin{array}{ll}\text { five } & \text { nima i-tutu (lit. 'hand 3SG-hit') } \rightarrow \text { nim'itutu' 'five' } \\ \text { six } & \text { nim'itutu po emosi (lit. 'five and one') } \\ \text { seven } & \text { nim'itutu po luwaga } \\ \text { eight } & \text { nim'itutu po tonuga } \\ \text { nine } & \text { nim'itutu po wohepali } \\ \text { ten } & \text { nima luwaga hi-tutu (lit. 'hand two 3PL-hit') } \\ \text { eleven } & \text { nima luwaga hi-tutu po emosi } \\ \text { twelve } & \text { nima luwaga hi-tutu po luwaga } \\ \text { thirteen } & \text { nima luwaga hi-tutu po tonuga } \\ \text { fourteen } & \text { nima luwaga hi-tutu po wohepali } \\ \text { fifteen } & \text { nima luwaga hi-tutu po ae emosi i-tutu (lit. 'hand two 3PL-hit and leg } \\ & \text { one 3SG-hit') } \\ \text { sixteen } & \text { nima luwaga hi-tutu po ae emosi i-tutu po emosi } \\ \text { seventeen } & \text { nima luwaga hi-tutu po ae emosi i-tutu po luwaga } \\ \text { eighteen } & \text { nima luwaga hi-tutu po ae emosi i-tutu po tonuga } \\ \text { nineteen } & \text { nima luwaga hi-tutu po ae emosi i-tutu po wohepali } \\ \text { twenty } & \text { oloto/lawa emosi } \text { i-hilage (lit. 'male/person one 3SG-finish') } \\ \text { twenty-one } & \text { oloto/lawa emosi } \text {-hilage po emosi } \\ \text { etc. } & \end{array}$

6 The latter form is a basic number, derived from the former constructed number. 
ninety-nine oloto/lawa wohepali hi-hilage po nima luwaga hi-tutu po ae emosi i-tutu po wohepali (lit. 'four men are finished, and two hands/arms are hit, and five and four')

Distributive numerals are formed by conjoining identical numerals with $p o$ 'and'.

emosi po emosi each one luwaga po luwaga two by two

Only basic numerals form ordinal numerals - derived forms using the derivational prefix wi-plus the third person singular pronominal enclitic $-n a{ }^{7}$

$\begin{array}{ll}\text { wiemosina } & \text { first }^{8} \\ \text { wiluwagana } & \text { second } \\ \text { witonugana } & \text { third } \\ \text { wiwohepalina } & \text { fourth } \\ \text { winimtutuna } & \text { fifth }\end{array}$

6(35) Ma gima-na wiluwagana Bilobilolo. and stone-DEF second Bilobilolo And the second stone is Bilobilolo.

\subsection{INTERJECTIONS}

\subsubsection{RESPONSES}

ee yes

eega no

Ee. It is.

ega'wai no way, definitely not apeega not (FUT)

Eega. It is not.

Apeega. It will not.

Iyaigalehi? Who knows? (lit. Who sees them?)

\subsubsection{ASSESSMENTS}

palapa! incredible, fantastic!

hawena! forget it!

amaka! enough!

ayuli! beautiful!

moina! true!

\subsubsection{GREETINGS AND FaREWELLS}

tinani thankyou, hello

kihoni farewell, goodbye 


\subsubsection{EMOTIONAL RESPONSES}

$\begin{array}{ll}\text { oo } & \text { oh (surprise) } \\ \text { aiyoi } & \text { ouch (pain) } \\ \text { aee } & \text { woe (danger) } \\ \text { uu } & \text { see you (sorrow at parting) }\end{array}$

\subsubsection{SEEKING Confirmation}

\section{(ee)mbo? right? (discourse-final particle)}

Some items that function as exclamations can also occur as interrogative or declarative utterances; they thus merge with existential clauses; for example, the exclamation Moina! 'True!' can also be the question Moina?'Is that so?' or the statement Moina. 'It is true.'

\subsection{CONJUNCTIONS}

All Tawala conjunctions occur between the elements they conjoin.

$\begin{array}{ll}\text { po } & \text { and - COUPLING } \\ \text { ma } & \text { and, then, but - CONTRAST } \\ \text { bo, oo } & \text { or - ALTERNATIVE } \\ \text { tamogi } & \text { but, on the other hand - ADVERSATIVE } \\ \text { apom(a) } & \text { then - SEQUENCE } \\ \text { (ega) yaka } & \text { so, consequently - CONSEQUENCE } \\ \text { baba-na/mata-baba-na } & \text { because - CAUSAL } \\ \text { meka po } & \text { lest - AVOIDANCE }\end{array}$

With the composite forms ega yaka (NEG so), meka po (where and) and mata-baba-na (eye-base-3SG), the meanings are not a combination of the parts involved in the sequence.

Sequences of conjunctions have meanings which are the combined meanings of the conjunctions involved.

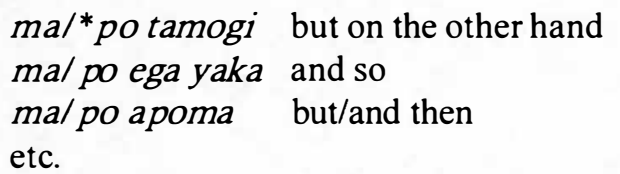

There is evidence that the conjunctions po and ma are often more closely associated with the previous conjunct than the following one, particularly when clauses are combined. ${ }^{9}$ The evidence is phonological: there is often (though not always) a greater potential for pausing after the conjunction than before. With motion verbs the conjunction actually becomes part of the same phonological word as the verb. Thus i-nae po 'he went and' becomes $i$-'na-po with stress (marked) remaining on the same syllable. This fused form can then end a sentence, having largely lost its connective function.

9 Postposed conjunctions is the expected norm with verb-final languages - Schachter 1985:47. 

6(36) Naka i-ne-po, i-ne-po, i-ne-po. Omhilage i-tapeun-i. that 3SG-come-and 3SG-come-and 3SG-come-and hunger 3SG-grab-3SG He came and came and came. Hunger consumed him.

The $p o$ versus $m a$ distinction is fundamental to Tawala discourse pragmatics; $p o$ signifies a 'close' connection and ma a 'loose' connection. The contrast operates at each level - word, phrase, clause and sentence - with the same force. In some situations only one option is available, thus with two identical items the connection is seen as close.

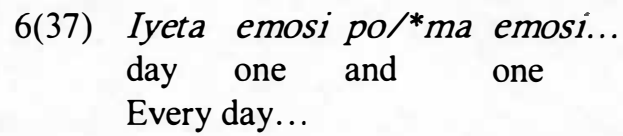

Most situations present a choice. When two items are to be coordinated the speaker must decide whether the conjuncts are to be seen as a unit ( $p o$ ) or as separate entities (ma). Thus amau po hinau means 'my father and mother' or simply 'my parents' (there is no general term). On the other hand amau ma hinau means '(both) my father and my mother'. The situation can be viewed from either point of view and speakers would differ as to the appropriate form to use in a given context. It might be thought that, because of its meaning, po would not be a suitable conjunction to join sentences, and generally this is so; however, I have a handful of what appear to be exceptions.

6(38) ...hi-me-mae. Po houga gehou-na ma lawa atapu-hi...
3PL-DUR-stay and time other-3SG and person all-3PL
...they lived (at that village). It was another time and all the people...

\subsection{MOOD PARTICLES}

The irrealis particle ipa marks uncertainty or unrealised action. It is usually used in combination with the potential mood.
6(39) Hewa-hewali ipa hi-na-gae u Naula, ma ega perol. PL-youth IRR 3PL-POT-go LOC Naura but NEG petrol
The youths wanted to go to Naura, but there was no petrol.

The particle ipa itself seems to be related to the direct quote particle pa 'say'.

6(40) I-otu i-pa, Bada, u-na-hagu-we.
3SG-call 3SG-say man 2SG-POT-help-ISG
He called out saying, 'Master, help me'.

As Schachter (1985:50) notes, "A good many languages have a complementizer that is rather transparently derived from the verb meaning 'say". This would appear true of the particle ipa, which has as one of its most common functions the irrealis complementiser.

The following mood markers are only used in conditional sentences and appear to be based on the singular and plural person markers ( $i$-3SG-, hi-3PL-) and mood markers (naPOT-, ta-IRR-). 
TABLE 3: TAWALA CONDITIONAL PARTICLES

\begin{tabular}{|l|c|c|}
\hline TRUTH CONDITIONS & HYPOTHETICAL & $\begin{array}{c}\text { CONTRARY-TO- } \\
\text { FACT }\end{array}$ \\
\hline ALWAYS TRUE & hinapa & hitapa \\
\hline UNCERTAIN & inapa & itapa \\
\hline
\end{tabular}

The conditional particles hinapa and inapa (HYP) mark hypothetical sentences, and particles hitapa and itapa (CTF), contrary-to-fact sentences.

\subsection{INTERROGATIVES}

\subsubsection{BASIC INTERROGATIVES}

$\begin{array}{ll}\text { awai } & \text { what } \\ \text { meyanai } & \text { when } \\ \text { meka } & \text { where } \\ \text { iyai } & \text { who(SG) } \\ \text { iyawoi } & \text { who(PL) } \\ \text { iyowai(L. iyowaka) } & \text { how, how's things } \\ \text { wabihaga(L. ibihaga) } & \text { how many } \\ \text { miyei } & \text { from where }\end{array}$

The basic forms can be used as indefinites within an NP.

6(41) Apo awai i-na-wiatatiye-ta?

FUT what 3SG-POT-teach-1PL.INC

What will he teach us?

\subsubsection{INDEFINITES}

Indefinites are also formed by repeating the respective basic interrogatives; most are optionally joined by $p o$. The implication of the complex form is that more than one item is involved.

$\begin{array}{ll}\text { awai (po) awai } & \text { whatever } \\ \text { meka (po) meka } & \text { wherever } \\ \text { iyai (po) iyai } & \text { whoever (SG) } \\ \text { iyawoi (po) iyawoi } & \text { whoever (PL) } \\ \text { wabihaga wabihaga } & \text { however many } \\ \text { bihaga bihaga } & \text { however many }\end{array}$

6(42) awai awai he-gele-geleta

what what 3PL.PRES-DUR-appear

whatever things happen

6(43) meka po meka he-gele-geleta

where and where 3PL.PRES-DUR-appear

wherever they go 


\subsubsection{SENTENTIAL INTERROGATIVES}

Namane? What is it again?

Nam? What's his/her name?

\subsubsection{COMPLEX INTERROGATIVES}

There is no basic form for 'why'; instead a number of constructions can be used.

6(44) baba-na awai > hai baba awai

base-3SG what their base what

what reason?, why? what are their reasons?

6(45) awai bi-nei > awai bi-hiyei

what BEN-3SG what BEN-3PL

for what reason? for what reasons?

The following construction is an alternative to the basic interrogative meyanai 'when'.

6(46) me-houga-na

stay-time-DEF(cataphoric)

whatever time 


\section{VERBAL CLAUSES}

\subsection{INTRODUCTION}

There are two fundamental clause types in Tawala: verbal (this chapter) and non-verbal (Chapter 11). Although these clause types differ radically in their morphology and syntax, they possess a degree of functional unity in terms of constituent structure (Chapter 12).

The diagnostic feature of all Tawala verbal clauses is the person-number prefix on the predicate, ${ }^{\prime}$ indexing subject.

\subsection{LAYERED STRUCTURE OF THE VERBAL CLAUSE}

Considerable insight is gained by viewing the clause as a layered structure. The three levels - nucleus, core and periphery - are clearly distinguished in Tawala. Figure 1 represents an idealised view of the layered structure of the Tawala verbal clause, showing the unmarked order of constituents, a model I have freely adapted from Foley and Van Valin (1984:77-80).

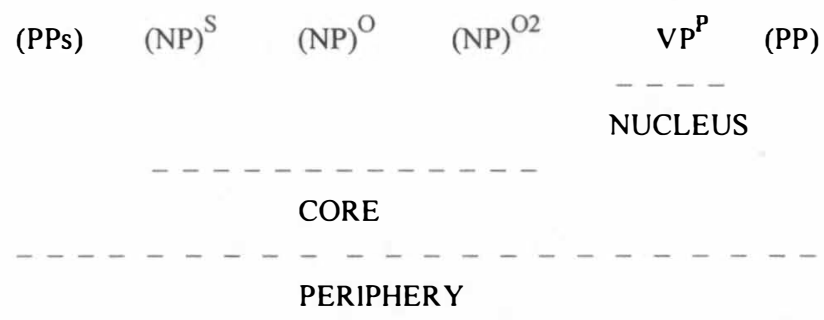

FIGURE 1: THE LAYERED STRUCTURE OF THE TAWALA VERBAL CLAUSE

The innermost layer is the NUCLEUS, consisting of the predicate, which in verbal clauses is a VP. The primary evidence for the nucleus as a distinct level is the fact that the nucleus can, and often does, stand as a clause in miniature. The grammatical relations of subject and object are marked on the predicate and operate independently of the core NPs. The sentences $7(1)$ and 7(2) have identical referents and are substitutable for each other; discourse pragmatics determine which sentence is used. (Square brackets enclose optional items which are indexed on the verb.)

7(1) Amalai $[\mathrm{kiu}]^{\mathrm{S}}[\text { hai pona }]^{\mathrm{O}}$ i-hanapu-ge-ya.

now bird their language S:3SG-know-TRV-O:3SG

The bird now knew their language.

I use the term 'predicate' to refer to the grammatical function played by the verb phrase within the clause. 
7(2) I-hanapu-ge-ya.

S:3SG-know-TRV-O:3SG

He knew it.

The next layer of the clause is the CORE, which contains the NPs directly involved with the predicate - the core arguments. In Tawala, one to three NPs can occur in the core, depending on the valence of the verb. Being optional, the subject and object NPs have a pragmatic (rather than a grammatical) function but can be identified as subject NP and object NP.

The outermost layer of the clause is the PERIPHERY, which contains peripheral constituents expressing the spatio-temporal setting of the event as well as secondary participants such as accompaniment, instrument and beneficiary. Non-spatio-temporal peripheral constituents are normally marked for their syntactic role by adpositions.

The main coding feature distinguishing core from peripheral constituents is that while core constituents are not morphologically marked for any syntactic role, peripheral constituents usually are, mainly with adpositions. In addition, though most core constituents are indexed by person and number marking on the predicate, peripheral constituents never are.

While more than one peripheral constituent can introduce a clause, in my data only a single constituent can follow the predicate.

\subsection{CLAUSE NUCLEUS}

In some fundamental way, every lexical verb is potentially in a class of its own, and could presumably display unique syntactic properties.

Givón (1984:86)

At the heart of the verbal clause is the nucleus - the predicate filled by a verb. The nature of each clause is determined by the valence of the particular verb involved. While it is true, as Givón suggests in the above quote, that every verb is ultimately in a class of its own, ${ }^{2}$ verbs may be grouped according to their valence - the number and type of arguments associated with the verb classes: stative, active, condition, variable focus and object focus. These classes are underived lexical items. (Chapter 18 demonstrates that the transitive classes are also at the heart of the valence-changing derivational processes.)

The intrinsic valence of each verb, whether derived or underived, determines the number of arguments indexed on the verb and the number of core NPs. Thus verbal valence determines whether a clause can have an object or not, whether it is transitive or intransitive. It also determines whether the object enclitic is optional or obligatory, whether the verb is variable focus or object focus.

Verbal valence also determines whether the arguments marked on the verb phrase (subject prefix and object enclitic) are the same as the potential NPs in the core (as with intransitive and transitive verbs generally) or if there is a mismatch between the nucleus and the core items (as with ditransitive and condition verbs). Because there is not a one-to-one correspondence between the nuclear and core arguments they are discussed together next under the aegis of the clause core. 
In addition, verbal valence determines the macrorole of the subject indexed on the predicate, whether it is an actor (7(3)) or an undergoer (7(4)).

7(3) Niha-gei to-bulili.

salt-ABL IPL.INC-run

We ran via the beach.

7(4) Koiba-na e-hogo-ya.

stomach-3SG 3SG.PRES-full-CPY

Her stomach is full. ${ }^{3}$

Subject prefixes and object enclitics mark the person and number of the arguments involved in the predication. This morphological marking is the primary indexing ${ }^{4}$ of person and number and cannot be regarded as agreement or cross-referencing to a primary syntactic referent for the following reasons.

Firstly, the subject/object NP is often not present in the clause. While the NP may be present in the context - an anaphoric reference - the referent may be present only in the extra-linguistic context - an exophoric reference.
a. Numa i-buda.
house 3SG-rot
b. Amaka i-buda.
already 3SG-rot
The house is rotten.
It has already rotted.

While it makes sense to speak of the subject prefix cross-referencing the subject NP in the first sentence of 7(5), it does not in the second sentence, where the referent is exophoric my informant and I were walking past the rotting remnants of a house. The subject prefix refers to a real-world entity and not to a grammatical NP.

Secondly, in some situations a subject NP is obligatorily absent. For example, the discourse marker $i$-kokoe 'it (is) finished' has a dummy subject prefix and no core NP is possible without changing the meaning.

Thirdly, person and number is often not marked on the NP but is always morphologically marked on the VP. As a head-marking language, Tawala marks pluralisation on the head clausal item (the verb phrase) rather than on the dependent NP.

$\begin{array}{lll}\text { 7(6) Numa i-buda. } & > & \text { Numa hi-buda. } \\ \text { house 3SG-rot } & \text { house 3PL-rot } \\ \text { The house is rotten. } & \text { The houses are rotten. }\end{array}$

In both sentences in 7(7) the person of the object is clearly marked on the verb and not the NP.

$\begin{array}{lll}\text { 7(7) Tula-u awai a-wele-ya? } & > & \text { Tula-u, awai a-wele-m? } \\ \text { friend-1SG what 1SG-give-3SG } & \text { friend-1SG what 1SG-give-2SG } \\ & \text { What will I give my friend? } & \text { What will I give you, my friend? }\end{array}$

Fourthly, a free-form emphatic pronoun is rare in the clause core. It is usually obligatorily absent as its presence would introduce a new participant.

This can mean 'she is pregnant'.

Lichtenberk (1983:108) proposes the term 'indexing' to capture this insight - a form is said "to 'index' the number or person of a participant, whether that participant is overtly expressed [in an NP] or not". 
7(8) Taumi i-paliwele-mi...

youPL 3SG-tell-2PL

It is you he tells...

With both first and second persons, person is marked on the verb and normally on the verb alone.

7(9) Geka ginouli-na apo to-wele-m.

this thing-DEF FUT IPL.EXC-give-2SG

We will give this thing to you.

Texts in my corpus carefully identify most third person referents, but rarely first and second person referents.

\subsection{CLAUSE CORE}

There are two major reasons for positing a distinction between the nucleus and the core. Firstly, core items are optional but the nucleus readily stands by itself as a clause in miniature. Secondly, there is a degree of mismatch between the arguments marked on the verb and the arguments which can occur as NPs.

These options result in four fundamental clause types.

1) Intransitive clauses have single morphological marking on the predicate with a single NP in the core.

2) Transitive clauses have double morphological marking on the predicate with two NPs in the core.

3) Ditransitive clauses have double morphological marking on the predicate with three NPs in the core.

4) Condition clauses have double morphological marking on the predicate with a single NP in the core.

These options are set out in Table 1.

TABLE I: BASIC TYPES OF VERBAL CLAUSES

\begin{tabular}{|l|ccccc|}
\hline & \multicolumn{3}{c}{ CORE } & \multicolumn{2}{c|}{ NUCLEUS } \\
& S-NP & O-NP & O2 & S & O \\
\hline Intransitive & + & - & - & + & - \\
Transitive & + & + & - & + & + \\
Ditransitive & + & + & + & + & + \\
Condition & + & - & - & + & + \\
\hline
\end{tabular}

Intransitive clauses include stative and active clause types with a number of variations between these poles. Transitive clauses include object-focus and variable-focus verbs.

Verbal valence determines the type and number of bonds which are inherent in the clause. In Tawala all core bonds can be broken; in other words the NPs are optional. Some nuclear bonds cannot be broken: subject indexing is obligatory with all verbs; object indexing is obligatory with ditransitive and object-focus verbs. However, with variablefocus verbs the nuclear bond can be broken; the object need not be indexed with these verbs. 


\subsubsection{GRAMMATICAL RELATIONS}

In Tawala all NPs are optional items of the verbal clause. The traditional approach has been to regard the NP as present in the underlying structure, with the verbal clitic marked for 'agreement' with the NP. Thus it has been usual to speak of verbal clitics 'crossreferencing' subject and object NPs, even when these are not present in the clause. In contrast, I regard the arguments of a proposition as primarily indexed by the verbal pronominal prefix and enclitic.

The definition of subject has been a thorny issue in recent years, as linguists have struggled to separate the semantic role and grammatical properties of rival NPs. One assumption that has only recently been questioned is that whatever the definition of subject may be, an NP will be central to that definition, a natural assumption for dependencemarked systems, where it is the dependents or core NPs themselves which are marked for grammatical relations (whether by order or morphological marking).

In approaching head-marking situations we face a different type of coding system. In Tawala, for example, where subject is obligatorily indexed by a prefix on the verb, and the subject NP is optional (or even obligatorily absent), there is surely no a priori reason why the subject prefix itself cannot mark the clausal grammatical relations. This then is the claim proposed for Tawala: that grammatical relations are primarily morphologically marked, within the clause nucleus, on the predicate and not on the dependent NP. The optional NP can be identified as the subject NP because it is co-referential with the subject prefix. In 7(10), subject (S) is marked primarily on the predicate, the subject NP is optional, and its presence or absence is determined by discourse pragmatics - topic and focus.

7(10) (Naka bada-na) i-woe-woe.

that man-DEF 3SG-DUR-paddle

SUBJECT.NP S-PREDICATE

That man was paddling away.

Thus it is still possible to identify an NP as the subject (or object) argument, but not to define subject (and object) in terms of the NP. The grammatical relations - subject and object - are marked on the verb itself, within the clause nucleus. Grammatical relations in Tawala are not syntactically marked. ${ }^{5}$

We need to stress that the Tawala pronominal prefix is not to be equated with a pronoun, which in a language such as English must replace the nominal subject if that is omitted. In Tawala an emphatic pronoun is a further pragmatic option of the clause core.

\section{7(11) (Taumi) o-boli me-ya. \\ youPL 2PL-cut again-3SG \\ SUBJECT S-PREDICATE \\ You (people), you've cut it again.}

Unlike many definitions, that of Givón (1984:138) seems to open the door to non-NP candidates for subject:

Most linguists seem to have been loath to take this step. Thus Lichtenberk claims (1983:110f.) that verbal prefixes "index the person and number of the subject, present or ellipted". For Lichtenberk person and number are indexed, but subject is not because the subject is an NP ("present or ellipted"). 
...there is no human language that does not use syntactic coding-devices, be these morphology, word-order or intonation, to code primary clausal topic. In this sense, then, all languages have the pragmatic case-role of "subject", though they may vary in the exact type of device - or combination of devices - for coding the subject/topic.

Of course, Givón may only be talking about the "coding-devices" marking NPs. If, however, it is recognised that in a head-marking grammar the "coding-device" is on the verb, then it seems logical to conclude that the associated NP is not crucial to defining subject.

In her description of Warlpiri and Spanish, Jelinek (1984:49) comes to a conclusion similar to that which I reached independently for Tawala: "There is no reason to assume that these languages should match English in requiring an independent lexical subject, which is then dropped, in the unmarked construction; grammatical relations may be marked in the morphology as well as in the syntax".

\subsubsection{SUBJeCt AND OBJeCt}

I regard subject and object as grammatical functions of equal status. Traditionally, clauses (sentences) were divided into a subject and predicate. This was an insight into pragmatics, and the constituents were more correctly labelled by the Prague School as topic and comment. The problem with the traditional approach was that the 'subject' coincided with a grammatical function and it was assumed that the other immediate constituent of the clause must also be a structural element of the clause. As Hockett (1958:201) puts it, "topics are usually subjects and comments are predicates". The confusion was perpetuated and given universal status in the formula:

$$
\Sigma(\text { sentence }) \rightarrow \text { NP VP }
$$

Lichtenberk (1983:89-92) advances solid arguments against the traditional distinction, because "it is necessary to separate the notion of the information expressed in a sentence from the sentence elements that encode that information" (p.89). He replaces the traditional bipartite analysis with a similar scheme to that proposed in this grammar. In his scheme, subject and object are equal 'peripheral' arguments, with a 'predicator' as the central nuclear element of the sentence.

\subsubsection{SUBJECT MARKING}

...many facets of subjecthood can be understood by regarding the prototype of subject as the intersection of agent and topic.

Comrie (1981:60)

Having the subject of the Tawala verbal clause indexed on the verb leaves the optional subject NP (whether name, noun, pronoun, etc.) to signal pragmatic roles of topic and focus. In terms of Comrie's "intersection", Tawala has divided the question, so to speak, with "agent" marked on the verb and "topic" marked by the presence or absence of the NP. While the systems differ radically, the general principle is similar to Philippine languages where "the properties are conveniently sorted out by the grammatical systems themselves" (Schachter 1976:514).

Example 7(12), a text portion, illustrates the situation nicely. There are three participants: the war leader, his followers and their captive. In this section of text the lastmentioned is never introduced with an NP - the referent is given throughout. The leader and 
his followers are introduced once each here (underlined), and thereafter both remain as given; however, the followers are introduced not by a subject NP but by an oblique adpositional phrase (line 3). Other subject NPs (also underlined) occur, but only as background material.

\section{7(12) Hai gawiya kapena-na i-baha i-pa, "O-na-awal'-i po their war captain-3SG 3SG-speak 3SG-say 2PL-POT-carry-3SG and} $\begin{array}{llll}\text { o-na-gi-gi-ye-ya } & \text { ega } & \text { o-na-ha-hale-ni. } & \text { Meka toke utaima } \\ \text { 2SG-POT-DUR-go.up-TRV-3SG } & \text { NEG } & \text { 2SG-POT-DUR-throw-3SG where like today }\end{array}$ i-tugu-tugula uyahi-n'-ei apo o-na-wi-tugula me-ya". Naka pete-nana 3SG-DUR-sit 'at'-3SG-ABL FUT 2SG-POT-DVP-sit again-3SG that like-DEF a hewa-hewali uyahi-hi i-baha po hi-awal'-i po hi-geleta his PL-youth 'at'-3PL 3SG-speak and 3PL-carry-3SG and 3PL-arrive po utaima nao-na i-gae $u$ pitepit'-ei ma naka toke ma and today face-3SG 3SG-go.up LOC bush-ABL and that like and hi-wi-tugul'-i. Hi-wi-tugul'-i po i-kokoe. Ma hi-hopu po 3PL-DVP-sit-3SG 3PL-DVP-sit-3SG and 3SG-finish and 3PL-go.down and hi-gelu i-ga-gale-hi. Ma hi-woe po hi-hopu po 3PL-embark 3SG-DUR-see-3PL and 3PL-paddle and 3PL-go.down and datu i-teina he-ne hale-ya po hi-nae boga shell.time 3SG-pull 3PL.PRES-go throw-3SG and 3PL-go ocean didibala-na hi-waya po hi-hopu po hi-nae u boga. dark-3SG 3PL-take.it and 3PL-go.down and 3PL-go LOC ocean Their war leader spoke saying, 'Carry him (the prisoner) and take him up (onto the land), don't drop him. Just where earlier today he was sitting, so [logical sequence] you sit him again'. Like that he commanded (to) his followers, and they carried him (the prisoner) and arrived (on shore) and where earlier he had been sitting with his face towards the bush; it is like that they sat him. They sat him and it was finished. Then he saw them go down and embark. Then they paddled and went down (towards the deep water) and they were leaving the tidal area that was pulling and went and took (= arrived at) the dark (= deep) water and went down and went to the sea.

The subject is indexed in every clause by the pronominal prefix. The optional NPs signal not the grammatical relations of the clause but discourse pragmatics.

\subsubsection{Clausal Topics}

What Philippine evidence suggests is that there are two basically quite different kinds of syntactic properties that are ordinarily associated with subjects. Since in most languages these two different kind of properties are associated with a single syntactic category, linguists have generally not been led to sort the properties out.

Schachter (1976:513-14)

Even though Tawala clause structure is flat, with subject and object occurring in either order before the verb, the verbal clause is in fact two-tiered: 1) grammatical relations (subject and object) are obligatorily marked by clitics on the verb within the clause nucleus; and 2) pragmatic roles (topic and focus) are marked by the optional NPs within the core. 
I borrow the terms 'primary topic' and 'secondary topic' from Givon (1984:138): " subject case tends to code the most important, recurrent, continuous topic...the primary clausal topic. The direct object case codes the topic next in importance, recurrence or continuity...the secondary clausal topic". In Tawala primary topic can be either subject or object depending on which NP occurs; if both are present then topic is the first NP.

The following tree diagram attempts to capture the relationship between grammatical relations and pragmatic functions of a transitive clause in Tawala: firstly, the grammatical structure is given in terms of the NPS and VP involved; secondly, the pragmatic functions are listed independently of the items which will fill them; thirdly, potential grammatical relations are listed for each slot; and finally, the surface string given $(7(13))$ is a clause with marked OSP order.

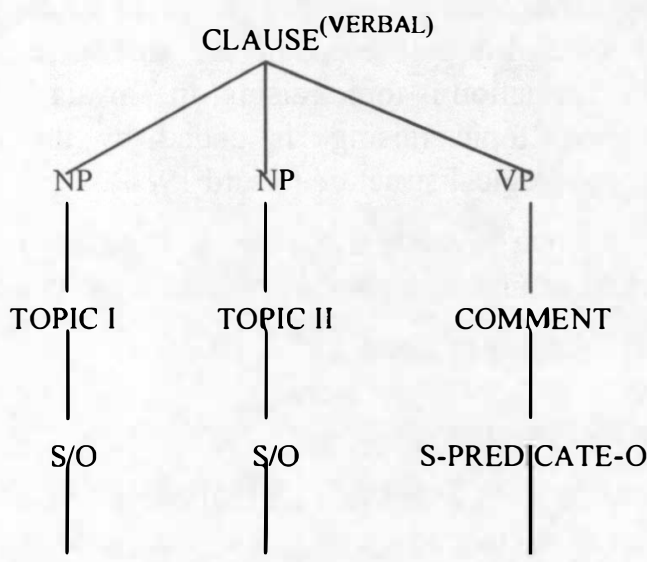

$7(13)$

$\begin{array}{lllll}\text { (Polo) (bada) i- uni } & -h i \\ \text { pig } & \text { man } & \text { 3SG- } & \text { catch } & -3 \mathrm{PL} \\ \text { It was (the) } & \text { pigs the man caught. }\end{array}$

FIGURE 2: GRAMMATICAL RELATIONS AND PRAGMATIC FUNCTIONS OF TRANSITIVE CLAUSES

The surface string could have the NPs reversed without a change of meaning, only a change in pragmatics: 'The man caught (the) pigs'. Sentences with two NPs are rare in Tawala, and when two are present subject is by far the most common choice for primary clausal topic.

There is nothing inherently improbable about topic being coded by the order of constituents. Linguists recognise that most grammatical functions can be coded by morphology, word order or intonation. It seems logical to expect that pragmatic functions should also be open to the same formal options.

\subsubsection{OBJECT MARKING}

All three core NPs precede the clause nucleus. A single NP is, of course, the only possibility with intransitive clauses, but it is also a feature of narrative discourse generally.

$6 \quad$ I intuitively feel that the slot immediately prior to the predicate is a position of strong focus in the Tawala clause - it can be filled by an adverb or an NP. I have not determined how focus interacts with secondary topic, which also often comes immediately prior to the predicate. 
When two core NPs are present the unmarked order is for the subject to be in the first position as primary clausal topic (I), with the object normally following the subject as secondary clausal topic (II).

7(14) $\quad$ I[ Wagaloke $]^{\mathrm{S}} \quad \mathrm{II}\left[\text { ginah }^{\mathrm{O}}\right]^{\mathrm{O}} \quad$ i-lunagil'-i. possum sago 3SG-break.open-3SG

Possum broke into the sago palm.

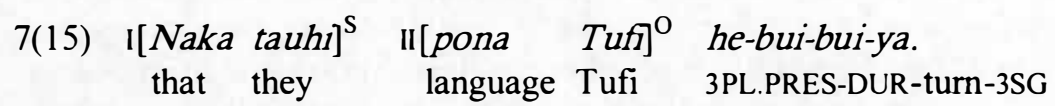

Those (people) are translating the Tufi language.

The object can be made primary clausal topic by a marked reversal of the order of the two core NPs. The context must make the grammatical relations of the two NPs clear. The factors determining primary clausal topic selection are discourse-based. One of the functions of the active-passive distinction is topic raising. In Tawala (a language without a productive passive construction) 'topic raising' is coded by the order of the core constituents and not by any morphological structure (Ezard 1984).

In 7(16) a pig is being frightened towards a net where Pheasant is hiding, waiting to capture the pig. The pig is clearly an undergoer and Pheasant one of two actors in the story.
7(16) $\left.\mathrm{I}_{[\mathrm{Polo}}\right]^{\mathrm{O}} \quad \mathrm{II}[\mathrm{Kukuku}]^{\mathrm{S}}$ ega i-ta-uni-i.
pig Pheasant NEG 3SG-IRR-catch-3SG
The pig wasn't caught by Pheasant.

Example $7(17)$ is a clause taken from a sentence $(7(18))$ consisting of two clauses. In the travel narrative from which it is taken, time and again the plane was hindered by bad weather. The sentence can be correctly interpreted on the 'dog bites man' principle: the plane's ascent is more likely to be blocked by rain than the ascending plane is to block the rain (though the latter reading might be possible in a rain-making discourse). The complete sentence demonstrates that $i$ anigae is a topicalisation of the previous predication to-gae.

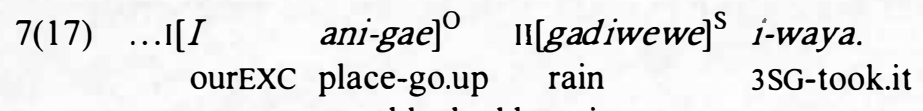
...our ascent was blocked by rain.

$\begin{array}{lllll}\text { 7(18) } & \text { Ma to-gae po } \quad \mathrm{I}\left[i \quad \text { ani-gae }^{\mathrm{O}}\right. & \mathrm{II}\left[\text { gadiwewe }^{\mathrm{S}}\right. & \text { i-waya. } \\ \text { and 1PL.EXC-go.up and ourEXC place-go.up } & \text { rain } & \text { 3SG-took.it } \\ \text { We went up, but the rain blocked our ascent. } & & \end{array}$

In 7(17) and 7(18) it would be most natural to render the English by a passive construction; certainly the Tawala construction is one of several functional equivalents of a syntactic passive. These two examples highlight another distinguishing feature of Tawala syntax: the object has become the primary clausal topic with identical intonation to a subject in the same position, a feature contrasting with many languages, where "topics occur external to the clause...normally set off from the rest of the sentence by a pause" (Foley and Van Valin 1984:124f). ${ }^{7}$

Grimes (1975:328) distinguishes two topics: "the sentence topic expressed by linkage and the internal clause topic may be independent". 


\subsubsection{REFERENTIAL AND NON-REFERENTIAL OBJECTS}

Myhill (1988:111-112) notes that, while passivisation has long been a cornerstone of linguistic theory:

More recently, linguists have studied the process of antipassivization, wherein the direct object of a transitive verb is made oblique or deleted altogether, leaving the verb intransitive. This shares with object incorporation the characteristic of demoting the direct object, and it shares with passivization the property of making a direct argument of the verb oblique or deleting it.

As stated above, Tawala has no actual passivisation strategy; however, it has both 'objects' that are expressed as oblique adpositional phrases and those that are not expressed.

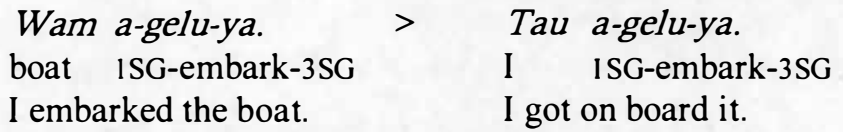

7(20) Wam uyahi-na a-gelu-*(ya).

boat 'at'-3SG ISG-embark-(3SG)

I got on the boat.

In the second sentence in $7(19)$ the object NP of the first sentence is not syntactically expressed, though it is morphologically expressed. In 7(20) the 'object' is expressed as an oblique argument, and in this case the predicate cannot be indexed for object; the verb is intransitive.

While the object NP is optional with all transitive verbs, the object enclitic is also optional with variable-focus verbs.

7(21) Wam amaka hi-gelu.

boat already 3PL-embark

They had already boarded a boat.

The presence of the object enclitic marks the object as referential $(7(22), 7(23), 7(26)){ }^{8}$ its absence marks the NP as generic $(7(21), 7(24), 7(25))$. The presence of an object NP marks the object as clause topic (underlined in $7(22), 7(25), 7(26)$ ). This makes four options, each of which is available.

1) An object marked by both a core NP and a verbal enclitic. All transitive clauses have this option.

7(22) $U$ houga tahatahaya-na apoma $\left[\text { plein }^{9}\right]^{\circ}$ a-gelu-ya. my time first-3SG then plane ISG-embark-3SG

It was my first time then I boarded the plane.

2) An object enclitic without a core NP. While the object NP may be absent from the clause it is often an anaphoric reference within the immediate context, though exophoric reference also occurs.

8 Tawala object NPs are either definite or indefinite. If the speaker wishes to mark the NP as clearly definite, the definite article is added - wam-na 'the boat (we are talking about)'; if he wishes to mark the NP as indefinite, the quantifier gehou<-na > 'other<-3SG>' is used. 
7(23) Hi-nae po hi-awal'-i.

3PL-go and 3PL-carry-3SG

They went and carried it.

3) A core NP without an object enclitic (contrast with a regular encliticised form $7(26))$.

7(24) [Pegapega ano-hi gou-h1 $]^{\mathrm{O}}$ i-'m-gomugomu. corn core-3PL ripe-3PL 3SG-DVP-break

She is breaking off ripe corn heads.

7(25) Ta-nae $[\text { polo }]^{\mathrm{O}}$ ta-lugowada.

IPL.INC-go pig 1PL.INC-steal

Let's go pig stealing.

In $7(24)$ and $7(25)$ the object is non-specific, in contrast to $7(26)$, which has a specific object (underlined).

7(26) Ta-nae $\quad\left[\begin{array}{lll}\text { Kama a } & \text { polo }\end{array}\right]^{0}$ ta-lugowad'-i.

1PL.INC-go Kama his pig IPL.INC-steal-3SG

Let's go and steal Kama's pig.

4) Variable-focus verbs can be used without either an object enclitic or a core NP. In this case the clause is marking predicate focus, with an undergoer understood. In $7(27)$ a pig and a pig net have to be carried; both items require several carriers. It is not stated what the addressee will carry, he is simply requested to come and help with the activity of carrying - the verb is functioning as an intransitive.

7(27) U-na-nei po u-n'-awala.

2SG-POT-come and 2SG-POT-carry

Come and carry.

\subsection{INTRANSITIVE CLAUSES}

Intransitive clauses have a nucleus filled with a single-valence verb and a clause core containing a single NP; the single argument of the intransitive clause is always the grammatical subject in Tawala. However clause types differ as to the macrorole of the subject: stative clauses have an undergoer as subject and active clauses have an actor as subject.

\subsubsection{Stative Clauses}

...propositions may pertain to states, i.e. existing conditions not involving change across time.

States may be either temporary at one extreme or permanent at the other.

Givón (1984:87)

Stative clauses have a stative verbs in their nucleus, and are limited to single core NPs in which the subject is the undergoer. They seldom occur with any periphery, as they are largely unaffected by space and time. In many languages a copula verb 'be' is needed as part of a predicate denoting states (hence the English translations in the examples below). 
7(28) Hini-na i-buda.

skin-3SG 3SG-rotten

Its body was rotten.

The main distinguishing characteristic of a Tawala stative clause is a parallel predicative non-verbal construction.

7(29) Mawa i-dao. > Mawa daodao-na.

distance 3SG-long distance long-3SG

The distance is long. The distance is long.

In 7(29) the two sentences each contain a single clause. Stative clauses indicate a state that is temporary or less permanent than the corresponding non-verbal construction. Hence it is possible to add tense marking to the first sentence of 7(30) but not the second.

7(30) Apo mawa i-na-dao. *Apo mawa daodao-na.

FUT distance 3SG-POT-long

The distance will be long.

Semantic distinctions differ according to the meaning of the root in each case. Thus, for example, tahaya i-bigabiga 'the path is muddy' indicates a slippery track resulting from recent rains. However, tahaya bigabiga-na 'the path is muddy' indicates a path that runs through a swamp and is always muddy. In some cases the distinction is between a process and a state, thus lawa i-hilage 'the person died (became dead)' versus lawa hilahilage-na 'the person is dead' (lit. 'a dead person').

A range of core NPs (in square brackets) is illustrated in the following data.

$7(31) \quad[\mathrm{Tau}]$ a-gobu wahaga ugoli-na.

I 1SG-dirty exceedingly 'at'-3SG

I am exceedingly defiled to him (= in his sight).

7(32) [Lawa] hi-maga duma.

person 3PL-many very

There were many people.

7(33) [Tahaya wai-bigabiga-na] i-witai.

path INT-muddy-3SG 3SG-heavy

The muddy path is difficult.

\subsubsection{Active Clauses}

In contrast to stative clauses are active clauses. These are not two discrete groups but rather represent the poles of a continuum (see $\$ 5.6 .1-2$ for intermediate options). Again Givón (1984:87) supplies a useful definition.

Propositions may also pertain to events, which are changes across time, either from an initial to a final state, if the event is bounded, or changes in the process of occurring, if the event is not construed as bounded.

Active clauses have an active intransitive verb in their nucleus. Such verbs never take an object enclitic. In order to transitivise an intransitive verb a derivational affix must be added to the root. Active intransitive clauses have a single core NP (in square brackets) which has an actor as subject. 
7(34) [ Tauna] i-woe-woe.

he 3SG-DUR-paddle

He kept paddling.

7(35) [ Togowa kaluwabu] i-togo mai.

wind east 3SG-wash DEI

The east wind blew on us.

Frequently no core NP is required, particularly with constructions involving the first and second persons.
Apo to-kadau
po to-nae
bala
daodao-hi...
FUT 1PL.EXC-travel and IPL.EXC-go distance long-3PL
If we go on long journeys...

Active clauses are distinguished from stative clauses in that many have no corresponding adjectival construction but can instead be marked for durative aspect, a distinction not found with prototypical stative clauses.
7(37) ...apo hi-na-tou ma ega hi-ta-tu-tou duma.
FUT 3PL-POT-cry but NEG 3PL-IRR-DUR-cry very
....if they cry they won't cry much.
7(38) Logaloga hi-na'-po u goila hi-togo-togo. children 3PL-go-and LOC river 3PL-DUR-wash
The children went and were bathing in the river.

Active clauses freely and frequently occur with peripheral items, as in 7(38). Motion verbs typically occur with a locational periphery (in square brackets in 7(39)).

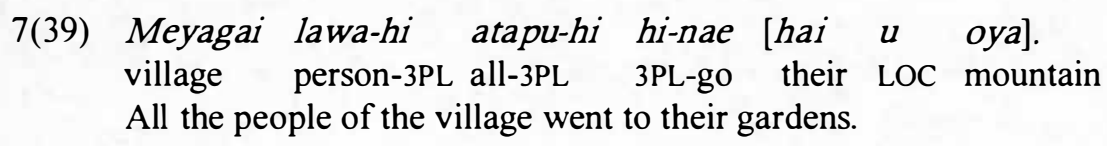

\subsection{TRANSITIVE CLAUSES}

...in many languages (and perhaps covertly in all languages) the transitivity relationship lies at the explanatory core of most grammatical processes.

Hopper and Thompson (1982:1)

Transitive clauses have a nucleus filled with a bivalent verb with two potential NPs in the clause core. As with intransitive verbs, a pronominal prefix indexes the person and number of the subject. In addition a pronominal enclitic indexes the person and number of the object. One of the NPs (normally the first) co-references the grammatical subject and the other the grammatical object. The presence or absence of a core NP is determined by pragmatic factors. In addition to the clear-cut classes of transitive verbs (both object-focus and variable-focus) there are a number of other parameters which distinguish modes of operation across the whole field.

There are two properties that single out the prototypical transitive verb. ${ }^{10}$

10 Following Givón (1984:96), but he uses the terms 'agent' and 'patient-of-change'. I express his two properties in terms of Foley and Van Valin (1984) macroroles. 
an ACTOR subject

an UNDERGOER object

\subsubsection{ACTOR AS SUBJECT}

Tawala transitive verbs are bivalent verbs with actor subjects. In this they are distinguished from condition verbs, which have undergoer subjects. The actor is "the argument of a predicate which expresses the participant which performs, effects, instigates, or controls the situation denoted by the predicate" (Foley and Van Valin 1984:29). The actor role is associated with the clausal subject irrespective of whether the nucleus is filled by an object-focus (7(40), 7(41)) or variable-focus (7(27), 7(42)) verb.

\section{7(40) Yoela a bagibagi ugoli-hi i-na-hagu-ya. \\ Yoela her work 'at'-3PL 3SG-POT-help-3SG \\ Yoela will help her with her jobs.}

7(41) Kedewa kamkam i-uni-hi.

dog chicken 3SG-kill-3PL

A dog killed the chickens.

7(42) Omi yakoyako ta-ulona.

yourPL shells IPL.INC-cook

Let us cook your shells.

\subsubsection{UNDERGOER AS OBJECT}

The prototypical object is an undergoer. The undergoer is "the argument which expresses the participant which does not perform, initiate, or control any situation but rather is affected by it in some way" (Foley and Van Valin 1984:29). This is true for all Tawala objects, though verbs differ as to the semantic scope of their objects in terms of animacy.

\subsubsection{INANIMATE OBJECT}

The prototype of a transitive verb...involves a physical, discernible change in the state of its patient object. One may measure the "degree of prototypicality" or "degree of deviation from prototype" of other verbs which belong syntactically to the group, partially in terms of the degree to which the change in the object is physical, obvious, concrete, accessible to observation etc.

Givón (1984:97)

Accomplishment verbs are the class of verbs involved with these transitive clauses; these verbs include both variable- and object-focus verbs. With an accomplishment verb filling the nucleus, the typical clausal object is an inanimate object, which is totally affected by the situation denoted by the predicate. The object enclitic is marked for number and for third person. Other persons are rarely distinguished since totally affected objects are ordinarily only third person referents.

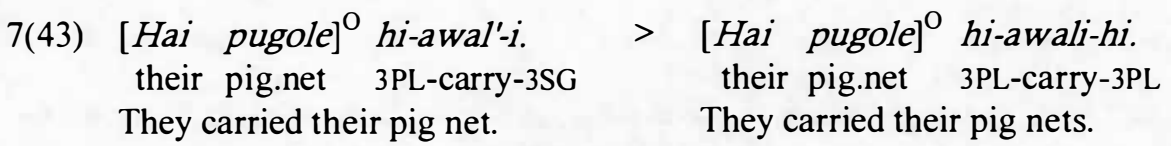


These transitive verbs are very common and belong to variable-focus $(7(43))$ and objectfocus verbs $(7(44))$.

7(44) $[\text { Tano }]^{\mathrm{O}}$ u-na-apu-ya.

garden 2SG-POT-burn-3SG

Burn off the garden.

\subsubsection{Human/ANIMATE OBJECT}

We have seen above that Givón (1984:97) suggests that one may measure the degree of prototypicality of a patient "partially in terms of the degree to which the change in the object is physical, obvious, concrete, accessible to observation etc.". In Tawala the prototypical inanimate object has no autonomous control. In contrast the human/animate object has a degree of control and is generally less affected by the situation denoted by the verb.

With these clauses the object enclitic may distinguish person as well as number, and emphatic pronouns may fill the object NP slot. Also of significance here is the fact that the third person singular animate object enclitic -ni/ya is normally only a dialectal distinction (with overlapping usage in the Diwinai dialect), whereas the inanimate object forms include the full range $(-i,-y a,-n i,-h i)$. The issue at stake here is that animate object verbs rarely have the requisite phonological shape to take these morphemes. The animate object enclitic is frequently preceded by the transitiviser -ge as part of the verb stem.

7(45) Ega tau o-na-bahe-bah'-e-u.

NEG me 2PL-POT-DUR-Say-TRV-1SG

Don't talk about me.

7(46) Meyagai lawa-hi i-pali-ye-hi.

village person-3PL 3SG-Scold-TRV-3PL

She rebuked the village people.

7(47) Tam u-himili-u po a-nae.

youSG 2SG-sent-1SG and 1SG-go

You sent me and I went.

7(48) A-hanapu-ge-m tam tu-baha.piko.

ISG-know-TRV-2SG youSG PER-prophecy

I know you are a prophet.

\subsubsection{Human-Propensity Clauses}

A highly productive area of Tawala grammar involves the use of human-propensity verbs, resulting in transitive and intransitive clauses based on body-part metaphors.

7(49) Nugo-na i-apapoe.

heart-3SG 3SG-bad

$\mathrm{He} / \mathrm{She}$ is angry.

Emotions, attitudes and psychological states can hardly be discussed in the Tawala language without the use of these constructions. They match closely the 'human propensity' 
adjectival class of Dixon (1982:19), but in Tawala they are clearly verbal, with a distinctive syntax.

Human-propensity clauses have standard clausal syntax. However, what is distinctive about them is 1) the limited nature of the core NP, and 2) the relationship between the human-propensity clause and the corresponding verb. These two issues are related.

The verb stem is a compound consisting of a body part and a following verb root. Most human-propensity verbs have a related clause in which the body part of the compound becomes the subject, and the verb root fills the verbal predicate. The difference between the two constructions is often the degree to which the human referent is in control.

$\begin{array}{lllcl}\text { 7(50) } & \begin{array}{l}\text { A-upu.dodola. } \\ \text { 1SG-back.stiff }\end{array} & > & \begin{array}{c}\text { Upu-we i-dodola. } \\ \text { back-1SG }\end{array} \\ & \text { [some control] } & \text { I am lazy. } & \text { [no control] }\end{array}$

Note that in 7(50)-7(52) the human referent is the subject in the first sentence, but only the possessor of an independently operating body part in the second.

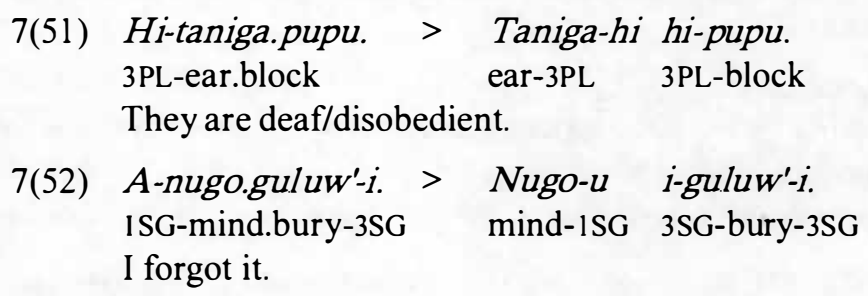

That the subject of the human-propensity verb has a degree of control is seen by the fact that the subject of the verb (but not the clause) can be used as a command.

7(53) Ipa o-na-nugo.kadidili. IRR 2PL-POT-mind.hard Be courageous.
* Ipa nugo-m i-na-kadidili. IRR mind-2SG 3SG-POT-hard Let your mind harden.

\subsection{CONDITION CLAUSE}

These clauses are unique in that the condition clause has a univalent nucleus with only a single NP in the core. However they are morphologically marked for identical subject and object. They are also unique in being the only doubly marked verbs to have undergoers and not actors as subjects. Thus while these verbs are morphologically transitive in form, the clause is intransitive. The construction is thus syntactically, though not semantically, reflexive (CPY).

7(54) Koiba-hi hi-hogo-hi.

stomach-3PL 3PL-full-CPY

Their stomachs were full.

As noted earlier, in glossing the object enclitic 'copy', I do not wish to imply that the subject is the primary grammatical relation. As the argument is an undergoer it is possible that the object is the primary relation, with the subject copied. I have no proof either way.
a. Togowa i-dumol'-i. wind 3SG-calm-CPY The wind has ceased.

b. Tau a-goholi-u. me ISG-jump-CPY I was surprised. 
7(56) Gaeba atapu-hi apo hi-na-hogo-hi.

bowl all-3PL FUT 3PL-POT-fill-CPY

All the bowls will be filled.

In 7(57) the first sentence contains a condition verb and has a single undergoer argument, and the second sentence has a single actor argument. The sentences are interchangeable in many contexts.
a. Apo ta-guna-wile-ta.
FUT IPL.INC-SPON-round-CPY
We will be back.
b. Apo ta-ne meme.
FUT 1PL.INC-come again
We will come again.

\subsection{DITRANSITIVE CLAUSES}

A ditransitive clause has a nucleus filled with a trivalent verb and a core containing three NPs: subject, object and secondary object. However, only two arguments are morphologically marked: subject and object. The order of the three core NPs is subject followed by either of the two objects.

$\begin{array}{ccc}\text { 7(58) } & \text { Bada }] \quad \text { logaloga }] \text { a ginouli } & \text { i-wiatatiye-hi. } \\ \text { man children his thing } & \text { 3SG-Show-3PL } \\ \text { SUBJECT OBJECT SECONDARY.OBJECT } & \text { PREDICATE } \\ \text { The man showed his things to the children. }\end{array}$

As with other verbs there is a prefix which indexes subject marked for person. Ditransitive verbs are a subclass of object-focus verbs, so that the object enclitic encodes the human/animate object and is the equivalent of what is referred to in English constructions as the indirect object. Some ditransitive verbs have a transitiviser (-ge), though with others it is possibly petrified (e.g. -wele) or absent altogether (e.g. -hagu). The object enclitic indexes the animate object and is marked for the full range of persons as well as number; a co-referential NP is optionally present in the core.

The secondary object is not cross-referenced on the verb, but is an NP in the core, usually in the pre-predicate (focus) position. The secondary object cannot be regarded as an oblique argument, as it has no adpositional marking. Among other things, the animacy hierarchy ensures referent disambiguation; the item lower on the hierarchy is the secondary object. With many ditransitive verbs the secondary object is obligatorily encoded as an NP in the clause core, presumably because it is not marked in the nucleus.

\begin{tabular}{|c|c|c|}
\hline $7(59)$ & $\begin{array}{l}{[A \text { ginoull }]^{02}} \\
\text { his thing } \\
\text { He showed his t }\end{array}$ & $\begin{array}{l}\text { i-wiatatiye-u. } \\
\text { 3SG-show-1SG } \\
\text { things to me. }\end{array}$ \\
\hline $7(60)$ & $\begin{array}{l}{\text { [Ginouli-na }]^{02}} \\
\text { thing-DEF } \\
\text { We will give yo }\end{array}$ & $\begin{array}{l}\text { apo to-wele-m. } \\
\text { FUT 1PL.EXC-give-2SG } \\
\text { u that thing. }\end{array}$ \\
\hline $7(61)$ & $\begin{array}{l}\text { Apo }[\text { om } \\
\text { FUT yoursG }\end{array}$ & $\begin{array}{ll}\text { bagibagl }^{\mathrm{O} 2} \text { hi-na-hagu-m. } \\
\text { work } & \text { 3PL-POT-help-2SG }\end{array}$ \\
\hline
\end{tabular}


The verb -hagu can also function as a transitive verb with the 'secondary object' is encoded as an oblique adpositional phrase.
Apo lawa $[i$
bagibagi uyahi-ht] $]^{\mathrm{O}}$ hi-na-hagu-yai.
FUT person ourEXC work 'at'-3PL 3PL-POT-help-IPL.EXC
People will help us at our work.

In my corpus of natural text, the verb -wele 'give' occurs with a subject NP in only $15 \%$ of examples (7(63), compare with 7(60)), as the referent is usually unambiguous.

$\begin{array}{lll}\text { 7(63) Yaubada } & \text { [ata tahaya }{ }^{02} & \text { i-wele-ta. } \\ \text { God } & \text { ourINC path } & \text { 3SG-give-IPL.INC }\end{array}$

God gives us our destiny.

In my corpus there is usually an object NP with ditransitive verbs if the referent is a third person, but never when it is first or second person; in the latter cases the marking on the verb is sufficient for identification. When there are both object and secondary object NPs my data is about half-and-half as to which NP is primary clausal topic and hence more topical than the other NP.

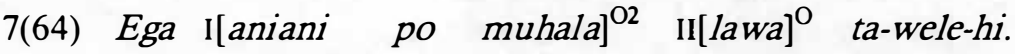

NEG vegetables and meat person IPL.INC-give-3PL

We did not give those people vegetables and meat.

$7(65) \quad{ }_{1}\left[\right.$ Tula-u $^{\mathrm{O}} \quad \mathrm{II}[\text { wawine mulamula-na }]^{\mathrm{O}}$ hi-wele-ya.

friend-ISG female medicine-3SG 3PL-give-3SG

They gave my friend the magic for (attracting) females.

\subsection{CLAUSE PERIPHERY}

Peripheral arguments are distinguished from core arguments by syntactic marking of adpositions, absence of indexing on the verb and the possibility of following the verb in the clause.

TABLE 2: FEATURES DISTINGUISHING CORE AND PERIPHERAL CONSTITUENTS

\begin{tabular}{|l|c|c|c|c|}
\hline & SUBJECT & OBJECT & SECOND. O & PER IPHERY \\
\hline SYNTATIC MARKING & - & - & - & + \\
FOLLOW VERB & - & - & - & + \\
INDEXED ON VERB & + & + & - & - \\
\hline
\end{tabular}

It will be seen from Table 2 that even though the secondary object is not indexed on the verb, it clearly shares more features with core NPs than with peripheral PPs. I have chosen to include the secondary object of a ditransitive verb with the core arguments because, like the other core arguments, it can only occur in the preverbal position. In addition, its unmarked position (ascertained by an overwhelming frequency of occurrence) is between the subject $\mathrm{NP}$ and the verb, whereas that position is highly marked for peripheral items. Finally, I find the fact that secondary object is not morphologically marked for its role to be more weighty than the fact that Tawala only cross-references two core NPS on the verb.

In addition many core NPs can be replaced by emphatic pronouns, but peripheral items never can, though postpositions are always marked for person and number and are usually employed without a dependent noun when marked for first or second person. Peripheral 
arguments of the clause are typically filled by adpositional phrases, whereas core arguments are always filled by NPs. Thus the presence of an adposition is a decisive factor in identifying clause periphery (7(57)).

\subsubsection{Clausal Adjuncts}

...external functions give the appearance of being essentially external to clause structure, and are each closely associated with a specific pragmatic function.

Andrews (1985:82)

The outermost layer of the clause contains peripheral constituents expressing the spatiotemporal setting of the event and other secondary participants and information not contained in the core arguments.

Syntactically, peripheral constituents are always optional. In addition, most items can operate in several positions within the sentence, determined by pragmatic factors. The following examples illustrate some of the options of locative relator phrases (in square brackets).

7(66) ...[hai bagibagi uyahi-na] utaima ta-ga-gale-hi.

their work 'at'-3SG today IPL.INC-DUR-see-3PL

...we now see them at their work.

$7(67)$...to-nae $[i \quad$ ani-bagibagi uyahi-na $]$.

IPL.EXC-go ourEXC place-work 'at'-3SG

...we went to our work place.

7(68) Tau amaka utaima [bagibagi gehou-na uyahi-na] a-me-mae.

I already today work other-3SG 'at'-3SG ISG-DUR-stay

I am today already staying at (= doing) other work.

In Tawala both prepositions (7.(69), 7(70)) and postpositions (7(71), 7(72)), as well as the ablative suf fix (7(73), 7(74)), are used to code adpositional phrases.

7(69) Pona-na i-nonol'-i [mei togowa $].$.

voice-3SG 3SG-hear-3SG like wind

She heard his voice (sounding) like wind ..

7(70) Hi-nae [a nima heuta-hi].

3PL-go COM hand torch-3PL

They went with their torches.

7(71) Lawa atapu-hi hi-hopu mai [tano uyahi-n'-el]. person all-3PL 3PL-go.down DEI garden 'at'-3SG-ABL All the people came down from the garden.

7(72) A-paliwele-hi [numa gatowa-na moni-na bi-ner]. ISG-tell-3PL house roof-3SG money-3SG BEN-3SG

I told them about the money for the house.

7(73) [Niha-get" $]$ to-bulili.

salt-ABL IPL.EXC-run

We ran via the beach. 
7(74) [Pona Suau-get] geka ketena hi-bah'-e-ya.

language Suau-ABL this ketena 3PL-say-TRV-3SG

In the Suau language they say 'ketena'.

\subsubsection{Alternative Case Frames}

Some verbs have alternative case frames for the object, with a second argument marked for an alternative case or a possessive construction. With some verbs, for example wogo 'make' and lihooholi 'shake clean', the alternative frames are ablative and benefactive. (Examples 7(75)-7(82) were elicited, not taken from natural texts.)

7(75) Keduluma [halewa] i-wogo-ya [outu bi-ne1]. woman pandanus 3SG-make-3SG bag BEN-3SG

The woman works pandanus for a bag.

7(76) Keduluma [liyapa] i-wogo-ya [halewa uyahi-n'-eI]. woman mat 3SG-make-3SG pandanus 'at'-3SG-ABL The woman makes a mat from pandanus.

7(77) Bada [keliko] i-lihoohol'-i [nudanuda bi-ne1]. man cloth 3SG-shake-3SG rubbish BEN-3SG The man shakes the cloth for rubbish.

7(78) Bada [nudanuda] i-lihoohol'-i [keliko uyahi-n'-eI]. man rubbish 3SG-shake-3SG cloth 'at'-3SG-ABL The man shakes the rubbish from the cloth.

Verbs can often substitute locative postposition phrases $(7(80))$ for locative preposition phrases (7(79)).

7(79) Guguhini [hoi hiyamont] [a outu] i-bih'-e-ni. maiden LOC grass her bag 3SG-search-TRV-3SG The teenage girl is looking in the grass for her bag.

7(80) Guguhini $\left[\begin{array}{ll}a & \text { outu }] \text { i-bih'-e-ni [hiyamoni uyahi-na]. }\end{array}\right.$ maiden her bag 3SG-search-TRV-3SG grass 'at'-3SG The teenage girl is looking for her bag in the grass.

The possessive construction is also a useful device for alternative case frames; in the following examples object alternates with the benefactive, but there are other possibilities.

7(81) Bada [mogaya lili-na] i-lawilawi. man crocodile song-3SG 3SG-sing The man sang the crocodile song.

7(82) Bada [lili] i-lawilawi [mogaya bi-neI]. man song 3SG-sing crocodile BEN-3SG The man sang the song about the crocodile. ${ }^{12}$ 


\subsubsection{Phrases Without Morphological Marking}

Some peripheral arguments have no morphological marking at all. These all belong to the spatio-temporal setting and contrast with adpositional phrases on contextual grounds.

In my corpus, spatial setting morphological marking is omitted only with English place names.

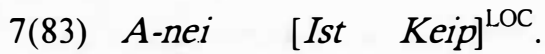

1SG-come East Cape

I came to East Cape.

7(84) Oktoba 1968 a-nae [Diwinai Comiuniti Sku] ${ }^{\mathrm{LOC}}$. October 1968 1SG-go Divinai Community School

In October 1968 I went to the Diwinai Community School.

Zero morphological marking is common with temporal phrases, including English dates (7(84)), but the construction is also common with truly indigenous temporal constructions.

7(85) [Geka houga-na] ${ }^{\mathrm{TOP}}$ PNG amaka yabiyabi hi-wele-ya.

this time-3SG PNG already rudder 3PL-give-3SG

At this time PNG has been given the rudder (= independence).

7(86) A-memae [bolima luwaga ${ }^{\mathrm{TOP}}$.

ISG-stay year two

I stayed (there) two years. 
CHAPTER 8

\section{VERB PHRASE}

\subsection{INTRODUCTION}

Following a common practice in Oceanic grammars, I use the term 'verb phrase' to include "the verb and all its associated verbal adjuncts and modifiers (but not the nominal arguments associated with it)" (Crowley 1982:118).

The defining characteristic of the verb phrase in Tawala is a head slot filled by a verb indexing the person and number of the subject by a pronominal prefix. Containing as it does both subject and predicate, the verb phrase may stand as a complete sentence in itself.

8(1) Hi-gelu.

3PL-embark

They embarked.

Excluded from this chapter is a systematic description of adverbs, which are clausal rather than phrasal in scope. The exceptions to this are the tense adverbs, which are included in this chapter because tense needs to be discussed along with mood and aspect.

\subsection{CONSTITUENTS OF THE VERB PHRASE}

The constituents of the verb phrase are always contiguous and function as a unit. While the order of items is fixed, there is a distinction between the tightly bonded prehead items with minimal stress which are written as prefixes (and are obligatorily present) and the more loosely bonded optional posthead modifiers which receive word-level stress and are written as separate words.

$$
\left[\left[S-\text { mood-aspect-HEAD }(\bmod )^{1}\right](\bmod )^{2}\right](-O)(\bmod )^{3}
$$

The constituents of the verb phrase are (in order):

1) $\mathrm{S}$ - subject prefix - a bound pronoun indexing the person and number of the subject; sometimes a portmanteau form marked also for present tense.

2) mood - three moods are distinguished: realis, irrealis and potential.

3) aspect - two aspects, simple and durative, are distinguished.

4) HEAD - a verbal stem or serial verb.

5) mod - modifier(s) - up to three modifiers occur. The second order of modifiers is a more restricted set than the first; the third order of modifiers is even more restricted and is further distinguished as the only phrasal item to occur after the object enclitic.

This is in contradistinction to the transformational usage which includes the object NP and other items within the VP (see $\$ 7.4 .2$ for justification of the rejection of this usage). 
6) $\mathrm{O}$ - object enclitic - a morpheme attached to the final item of the phrase (apart from the third order of modifiers, noted above), indexing the person and number of the clausal object.

There are a number of additional morphemes not included in the above formula, mainly of a deictic nature. These are only employed with a limited class of verbs, particularly motion verbs. In addition, ligature is used on heads ending in $/ e /$ and on a limited set of modifiers.

\subsection{WORD BREAKS WITHIN THE VERB PHRASE}

There is a distinction between the 'tightly bonded prehead' morphemes and the more 'loosely bonded posthead' modifiers.

The tightly bonded prehead morphemes are considered prefixes for the following reasons. Firstly, they do not receive word stress. Word stress (underlined) normally falls on the penultimate syllable. As Tawala verb stems typically have two or more syllables, stress falls naturally on the head.

Apo i-na-lata
FUT 3SG-POT-grow
It will be very big.

Single syllable heads cannot occur without a modifier following. ${ }^{2}$

$\begin{array}{lll}\text { 8(3) Apo i-na-me } & \text { imahi. } \\ \text { FUT 3SG-POT-stay } & \text { properly } \\ \text { He will live well. } & \end{array}$

In 8(3) normal stress patterns are broken, with stress on the ultimate syllable in order to maintain stress on the head. When the modifier contains only two syllables (i.e. with a stressed first syllable) the preceding one-syllable head is lengthened to fill a normal twosyllable rhythm pattern.

8(4) Apo i-na-me(e) duma.

FUT 3SG-POT-stay very

He will stay for a long time.

Secondly, in normal conversation it is not possible to pause between prehead items; any mistake will result in the speaker repeating the whole word from the subject prefix. Thirdly, under no circumstance can these morphemes be interrupted by any other morpheme. Finally, the order of these morphemes is absolutely fixed.

Some justification also needs to be given for the above claim that the posthead modifiers are 'more loosely bonded', receiving word-level stress. Hinging on the claim is whether these items should be written as separate words. As with other word-division problems there is a bracketing problem between the phonological, morphological, psychological and lexical evidence. 
(a) Every word receives separate stress, which normally falls on the penultimate syllable. Without word breaks secondary stress will tend to fall on every second syllable. This pattern is not followed with verbal modifiers, and hence they are written as separate words.

$$
\begin{array}{lll}
\text {-mae } & >\text { - } \text {-me duma } & \text { stay (long) } \\
\text {-mae } & >\text { - } m e \text { wahaga } & \text { stay (forever) } \\
\text {-hopu } & >\text { - } \text { hopu duma } & \text { go down (deep) } \\
\text {-tugula }> & \text {-tugula imahi } & \text { sit (properly) }
\end{array}
$$

In contrast, the object enclitic is part of the phonological word, so that word-final stress on the head changes position when a modifier is added (except when ligature replaces the enclitic), keeping stress on the penultimate syllable.

-hagu-ya > -hagu duma-ya (really) help s.o.

(b) The initial vowel of a modifier is not turned into a glide as it is within the word.

-galena imahi > -galena imahi watch properly

-galena+itete $>$-galenaitete ${\text { care } \text { for }^{3}}^{3}$

The contrast is quite marked within the phrase

igalenaitetena imahi he cared for him properly

where the double-underlined vowels receive normal vowel length in contrast to the sequence marked as a glide.

(c) With some transitive words the clitic boundary between the head and the object enclitic is not a natural word break. The object enclitic cannot be removed without violating the word.

-hagu-yal hi $>^{*}$-hagu help s.o.

However, this boundary can be interrupted by a modifier.

-hagu duma-hi really help s.o.

The interruption is marked by ligature when the verb stem ends in / $e /$, presumably with the function of allowing the incomplete form to stand alone, by indicating that there is more to follow.

-hanapuge-ya > -hanapuge-na imahiye-ya understand (properly) -luhogale-ya > -luhogale-na duma-ya love s.o. (truly)

Even with ligature present the head forms are incomplete (they cannot stand alone). However, it would be difficult to see any function for the ligature if it is not to mark a word break.

(d) The 'psychological reality' of a word break, as revealed in Tawala writings, is ambivalent at this point, as at other questionable borders. Although verb modifiers are rare, one writer (GEKA TUWEGA p.8) used both the following forms within a few sentences: 
to hanahanapugenameiyai we are understanding ourselves

$i$ wi tulana imahi duma he was really completely friendly

Presumably the object suffix -iyai resulted in the transitive modifier being attached to the stem.

(e) Verb heads with modifiers should not be regarded as lexical entries in that their combined meanings are always predictable (see discussion §5.1). The same applies to the two elements of serial verbs, which contrasts with compounds.

I conclude that the evidence is in favour of positing the posthead modifiers as belonging to a class of more loosely bonded items than one would expect to find within a lexical word; I have thus chosen to write modifiers and serial verbs as separate items. ${ }^{4}$

\subsection{VERB PHRASE HEAD}

At the head of a verb phrase stands a verb stem which may consist of a simple verb root, a derived verb or a human-propensity compound. There is a basic division between two different constructions, depending on the potential presence of the object enclitic within the verb phrase.

1) TRANSITIVE PREDICATE - marked by the potential presence of an object enclitic.

2) INTRANSITIVE PREDICATE - shown by the obligatory absence of an object enclitic.

Morphological devices are available that enable a verb stem to change membership between these two predicate types. Verbal valence determines not only the potential presence or absence of the object enclitic, but also the potential NPS in the clause.

\subsection{PERSON AND NUMBER INDEXING}

In this section the 'pronouns' found within the verb phrase are discussed; these are bound morphemes: a subject prefix and an object enclitic. (We noted in $\S 7.3$ that these bound morphemes mark the person and number of the arguments in a clause.) These pronominal affixes are distinct from emphatic pronouns.

8(5) a. Tauyai to-hanapu-ya.

weEXC 1PL.EXC-know-3SG

We know it. b. Tauna to-hanapu-ya.

she IPL.EXC-know-3SG

We know her.

In $8(5 a)$ the subject person marker to- is an obligatory morpheme within the VP; on the other hand, the emphatic pronoun tauyai is an optional morpheme used in addition to the (co-referential) person marker for pragmatic reasons. In $8(5 \mathrm{~b})$ the emphatic pronoun is coreferential with the object. 


\subsubsection{INDEXING OF SUBJECTS}

The subject prefix is the distinguishing feature of the verb phrase, and ultimately of the verbal clause. It is the only morpheme that must overtly occur with the head, and accordingly plays an extremely important role in Tawala syntax, though it is a third-order verbal prefix, preceding aspect and mood.

TABLE 1: SUBJECT PREFIXES

\begin{tabular}{|l|c|}
\hline ISG & $a-$ \\
2SG & $u-$ \\
3SG & $i-$ \\
IPL.INC & ta- \\
IPL.EXC & to- \\
2PL & $o-$ \\
3PL & hi- \\
\hline
\end{tabular}

The subject prefix must occur whether or not an NP is present in the clause (except in the imperative, where the second person singular prefix is normally omitted $-8(37))$.
a. Wam i-gota.
boat 3SG-arrive.
b. I-gota.
3SG-arrive
The boat arrived.
It arrived.

\subsubsection{INDEXING OF OBJECTS - TRANSITIVE VERBS}

One of the distinguishing features of the Papuan Tip cluster languages is the object pronominal suffixes on the verb. In Tawala the set of object enclitics is identical to the adnominal enclitics except in the third person singular forms.

TABLE 2: OBJECT AND ADNOMINAL ENCLITICS

\begin{tabular}{|l|l|c|}
\hline & OBJECT & ADNOMINAL \\
& ENCLITICS & ENCLITICS \\
\hline ISG & $-u /-w e$ & $-u /-w e$ \\
2SG & $-m$ & $-m$ \\
3SG & $-y a /-n i /-i /-h i$ & $-n a$ \\
IPL.INC & $-t a$ & $-t a$ \\
IPL.EXC & $-(i) y a i$ & $-(i) y a i$ \\
2PL & $-m i$ & $-m i$ \\
3PL & $-h i$ & $-h i$ \\
\hline
\end{tabular}

The first person singular form becomes - we following a stem ending in $/ u /$ :

$$
-u \rightarrow-w e / u_{-}
$$

Thus / natu-u/ becomes natu-we 'my child'.

The various third person singular object enclitics are largely a matter of verb class, but the $-y a / n i$ distinction is also dialectal. Owing to the frequency of occurrence of third person singular object enclitics in Tawala verb phrases, this is an important point of morphological divergence between the Labe and Kehelala dialects. 


\section{$\mathrm{LABE}$}

$8(7)$

a-gale-ya

ISG-see-3SG

I saw him
KEHELALA

a-gale-ni

ISG-see-3SG

I saw him

The transitive verb phrase differs from the intransitive verb phrase in a number of respects: the presence of an object enclitic (as above), a transitivising clitic and ligature.

The complex relationship between transitive and intransitive verbs is discussed in previous chapters. Enough to recall that the object enclitic is sometimes an optional morpheme. Its absence does not mark a verb as intransitive, as the following data demonstrate.
a. Niha i-higu-ya. salt 3SG-draw-3SG She drew the salt water.

b. Goila e-higu-higu. water 3SG.PRES-DUR-draw She is drawing water.

With ditransitive verbs, the object indexed on the verb is the undergoer highest on the animacy hierarchy:

$$
\text { HUMAN > ANIMATE > INANIMATE }
$$

Thus Tawala treats as a direct object what is often referred to in English as the 'indirect object'. For Tawala, I simply refer to object (the object indexed on the verb) and secondary object (the object occurring as an NP but never marked on the verb - in square brackets in the following example).

$\begin{array}{ccccc}\text { 8(9) Ega } & \text { [aniani po muhala] } & \text { hi-wele- } & \text { u. } \\ \text { NEG } & \text { vegetables and game } & \text { 3PL-give- ISG } \\ & \text { SECONDARY.OBJECT----- } & \text { S- } & \text { O }\end{array}$

They didn't give me vegetables and meat.

\subsection{TENSE}

In this section we draw together three separate systems for marking tense: the alternative set subject prefixes and a set of tense adverbs.

\subsubsection{TENSE PREFIXES}

Tawala has two sets of subject prefixes: the regular set and a set marked for present tense. Both sets function to index the person and number of the subject.

TABLE 3: SUBJECT/TENSE PREFIXES

\begin{tabular}{|l|c|c|}
\hline & REGULAR & PRESENT \\
\hline ISG & $a-$ & $a-$ \\
2SG & $u-$ & $e-$ \\
3SG & $i-$ & $e-$ \\
1PL.INC & ta- & $t a-$ \\
1PL.EXC & to- & to- \\
2PL & $o-$ & $o-$ \\
3PL & $h i-$ & $h e-$ \\
\hline
\end{tabular}


Neutralisation of tense in the first person is illustrated in $8(10)$.

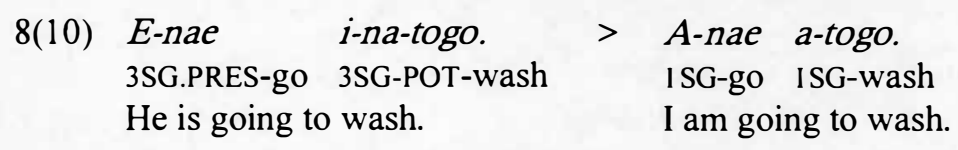

The present-tense set is only morphologically marked in the second and third person singular $(8(11))$ and third person plural. The regular set is used with past $(8(12))$ and future (8(13)).
8(11) Awai i yam e-an-an'-i?
what ourEXC food 3SG.PRES-DUR-eat-3SG
What keeps eating our food?

8(12) A yam madimadi ma tuwoya i-an-ani-hi.

his food grasshopper and honey 3SG-DUR-eat-3PL

He would eat grasshoppers and honey.

8(13) Ma pegapega-hi i-n'-an-ani-hi.

but corn-DEF.PL 3SG-POT-DUR-eat-3PL

But let it eat the corn.

The present-tense forms are only used with realis mood, never with irrealis or potential mood. The loss of distinction between second and third person singular in the present tense does not involve excessive ambiguities as contexts seldom overlap.

It is not possible to isolate tense from aspect and mood because the subject prefixes themselves combine with various other morphemes in a complex tense/aspect $/ \mathrm{mood}$ system that is given thorough treatment below.
$8(14)$
a. Mek' e-ne-nae?
b. Bada e-me-mae.
where 2SG.PRES-DUR-go
Where are you going?
man 3SG.PRES-DUR-stay
The man is staying.

In the first person, present tense is unmarked - the regular prefixes are used with durative aspect.

\section{8(15) To-i-gohagoha nae. \\ IPL.EXC-DUR-play DEI \\ We are just walking about.}

\subsubsection{TENSE ADVERBS}

Three adverbs are used to mark tense:
apo
amaka
FUTURE (FUT)
ataima (L. amalar)
PAST (already)
PRESENT (today, now)

Only the first of these is unambiguously a tense marker, as the other forms have clear lexical meanings.

Though these items have clausal rather than phrasal scope and are outside the verb phrase, they are included within this chapter for the expedient of viewing tense, aspect and 
mood concurrently. In $8(16)$ it is clear that the tense adverb is not part of the verb phrase (cf. 8(20)).

8(16) Amaka numa gatowa-na ta-wikokow'-i. already house roof-3SG 1PL.INC-finish-3SG We have finished the roof.

8(17) Ataima a-paliwele-m amaka gawiya i-geleta. now 1SG-tell-2SG already war 3SG-arrive I now tell you war has arrived.

8(18) Apo a-nae a-wisili.

FUT ISG-go ISG-fish

I will go fishing.

\subsubsection{Sentential AdVERBS}

Temporal nouns often place a clause or sentence within a temporal context, thus also marking it for tense; the past tense adverb amaka is often omitted in such situations, though less often the future apo.

8(19) Pom a-nae u pitapita.
yesterday I SG-go LOC bush
Yesterday I went into the bush.

8(20) Apo hoimalatom ta-nae u animae uyahi-na.
FUT tomorrow 1PL.INC-go LOC residence 'at'-3SG
Tomorrow we will go to my residence.

\subsection{ASPECT}

Aspect marking indicates whether the action of the verb is regarded as complete or incomplete, durative or momentaneous, etc.

Schachter (1985:10)

Every verb has its own inherent aspectual properties. However, in this section we are concerned with the morphological marking of aspect on verbs, rather than their inherent aspect. In Tawala, durative aspect is normally marked by the reduplication of the verb stem - a first order of verbal prefixes.

\begin{tabular}{llll}
\multicolumn{2}{l}{ SIMPLE ASPECT } & \multicolumn{2}{l}{ DURATIVE ASPECT } \\
-baha speak & -baha-baha be speaking \\
-uma drink & -um-uma & be drinking \\
-nae go & -ne-nae & be going \\
-geleta arrive & -gele-geleta be arriving
\end{tabular}

An unmarked stem (without reduplication) indicates simple or completed action - the situation is viewed as a single whole (Comrie 1976:16). Durative aspect indicates that the situation described by the verb was repeated, was in progress or remained constant; it endured through time. 
8(21) Motaka a-ga-gale-hi ma hi-buli-bulili.

car ISG-DUR-see-3PL and 3PL-DUR-run

I was seeing cars and they were running along.

Contrast the progressive use of the durative aspect in $8(21)$ with the repetitive use in $8(22)$.

8(22) Hi-ne'-po hi-dane-danene.

3PL-come-and 3PL-DUR-steal

They came and kept stealing (many times).

One unusual use of the durative aspect is its use in marking restrictive relative clauses. The distinguishing feature of Tawala relative clauses is the marking of the restrictive clause with durative aspect, regardless of the actual aspect required by the clause.

8(23) Kwasikwasi pom u-gima-gimal'-e-ya i-tutuma.

bush.knife yesterday 2SG-DUR-buy-TRV-3SG 3SG-blunt

The bush-knife that you bought yesterday is blunt.

Aspect is sensitive to the inherent aspectual properties of verbs. For example, stative verbs are not marked for durative aspect. The state of affairs described by the prototypical stative verb remains constant through time. In other words, the situation is inherently 'durative' and accordingly cannot be marked for durative aspect.
$U$ mae hi-witai duma.
*U mae hi-wita-witai.
my stay 3PL-heavy very
my stay 3PL-DUR-heavy
My life was very heavy (i.e. I faced many difficulties).

We note above that durative aspect is normally marked by reduplication of the first syllable(s) of the verb stem. When a verb stem is formed with a derivational prefix, reduplication rules are laid aside and durative aspect is marked by a separate set of morphemes as listed in Table 4 (cf. Table 6).

TABLE 4: DURATIVE FORMS OF DERIVATIONAL PREFIXES

\begin{tabular}{|cccc|}
\hline & SIMPLE ASPECT & & DURATIVE ASPECT \\
\hline (a) & $w i-$ & $>$ & $i-$ \\
(b) & $l u-$ & $>$ & $l a u-$ \\
(c) & $l i-$ & $>$ & $l a i-$ \\
(d) & $w o-$ & $>$ & $w o o-$ \\
(e) & $o m-$ & $>$ & yam- \\
\hline
\end{tabular}

An example of each type is contained in the following list:
(a) -wi-dagudagu struggle
(b) -lu-pali
ask, pray
-i-dagudagu
be struggling
(c) -li-bolu
talk together
-lau-pali
be asking/praying
(d) -wo-bagibagi
keep working
-lai-bolu
be talking together
(e) -om-boho
be greedy
-woo-bagibagi
be keeping working
-yam-boho
be being greedy

8(25) Mota ega kikina e-i-dagudagu.

snake NEG little 3SG.PRES-DUR-wriggle

The snake is not wriggling at all. 
8(26) Logaloga he-yam-datu.

children 3PL.PRES-DUR-low.tide

The children are collecting shell-food.

In this feature derivational prefixes are distinguished from classificatory prefixes, which are reduplicated in the normal manner.

8(27) Dimdim hai dewa a-pali-paliwele-mi.

European their custom 1SG-DUR-tell-2PL

I am telling you of the white man's custom.

\subsection{MOOD}

Mood characterizes the actuality of an event by comparing the event world(s) to a reference world, termed the actual world... Whereas there is basically one way for an event to be actual, there are numerous ways that an event can be less than completely actual.

Chung and Timberlake (1985:241)

Three moods are distinguished by Tawala verbal morphology - a second order of verbal prefixes.

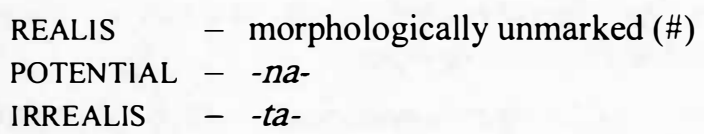

The three moods can be contrasted with a single motion verb. In order to make this clear, I here mark the absence of a mood morpheme with \# and gloss it RLS (realis) in 8(28)-8(30) (though not elsewhere in this book).

$\begin{array}{lllll}8(28) \text { a. } & \text { Meka i-\#-nae? } \\ & \text { where 3SG-RLS-go } & \text { b. } & \text { Ega i-ta-nae. } & \text { NEG 3SG-IRR-go } \\ & \text { Where has he gone? } & \text { He didn't go. } & \text { FUT 3SG-POT-go. } & \text { He will go. }\end{array}$

\subsubsection{REALIS MOOD}

In realis mood the event is characterised as actual, or real. The reported world and the actual world are identical - traditionally the indicative mood. The main function of the realis mood is the reporting of past events.
8(29) To-\#-gelu
po to-\#-ne-nei
ma dobu a-\#-ga-gale-hi.
IPL.EXC-RLS-embark and IPL.EXC-RLS-DUR-come and field 1SG-RLS-DUR-see-3PL We got on board (the plane) and coming along I saw the fields.
8(30) Bada i-\#-bahe-na gelete-u.
man 3SG-RLS-say-LIG appear-1SG
The bada nominated me.

\subsubsection{IRREALIS MoOD ta-}

Irrealis mood characterises an event as non-actual. The reported world has no correspondence to the actual world. The irrealis prefix is often used with the negative adverb; both simple (8(31)) and durative (8(32)) aspects occur with irrealis mood. 
8(31) Hai dewa ega i-ta-dumalu.

their custom NEG 3SG-IRR-straight

Their custom is not right.

8(32) Ma lawa ega hi-ta-tu-tou duma.

but person NEG 3PL-IRR-DUR-cry very

But the people did not weep much.

Without the negative adverb the construction becomes contrary-to-fact.

8(33) A-gei-ni po a-ta-peu.

1SG-climbed-3SG and 1SG-IRR-fall

I climbed it and almost fell.

8(34) Geka bagibagi-na uyahi-na a-ta-me-mae, apo nugote numa geka this work-DEF 'at'-3SG 1SG-IRR-DUR-stay FUT perhaps house this

uyahina a-ta-wo-bagibagi.

'at'-3SG ISG-IRR-DVP-work

If I had stayed with this work, I would possibly work in this building.

\subsubsection{Potential Mood na-}

With potential mood the event is characterised as one which may become real. The real world may come to correspond to the reported event.

Potential mood is used to express events in the future; the free-form future-tense marker apo is often used in conjunction with potential mood.

8(35) Ata ba-bada apo hi-na-guta-ya po hi-na-wele-ta. ourINC PL-man FUT 3PL-POT-share-3SG and 3PL-POT-give-1PL.INC Our big men will share it out and give it to us.

Potential mood readily occurs with durative aspect.

8(36) Ega i-ta-geno duma apo i-na-kada-kadau.

NEG 3SG-IRR-worry very FUT 3SG-POT-DUR-journey

He didn't worry much that he would be journeying.

Potential mood is used to express imperatives. With singular imperatives the subject prefix is usually omitted.

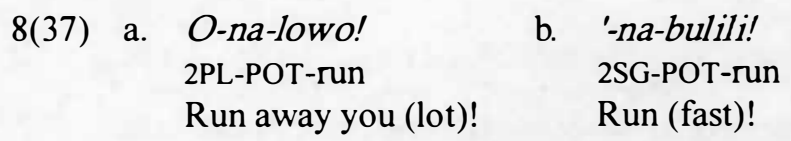

With most verb stems there is no separate marker of potential mood in the first person neutralisation with the realis has taken place. 
TABLE 5: POTENTIAL MOOD MARKING WITH -nae 'go'

\begin{tabular}{|l|l|}
\hline apo a nae & I will go \\
apo u na nae & you(SG) will go \\
apo i na nae & he will go \\
apo ta nae & we(INC) will go \\
apo to nae & we(EXC) will go \\
apo o na nae & you(PL) will go \\
apo hi na nae & they will go \\
\hline
\end{tabular}

8(38) I-na-lupali apo ta-hagu-ya. 3SG-POT-ask FUT 1PL.INC-help-3SG

If he asks (us) we will help him.

8(39) Apo hoimalatom ta-nae u animae uyahi-na.

FUT morning 1PL.INC-go my residence 'at'-3SG

In the morning we will go to my place.

Accordingly, the hortatory function remains unmarked.

\section{8(40) Ta-womahili. \\ I PL.INC-leave \\ Let's go.}

However, when potential mood is combined with the derivational prefix om- we get vowel elision n'om-, which remains constant for all persons, singular and plural. Example $8(41)$ illustrates this morpheme with the Labe equivalent of $8(40)$.

8(41) Ta-n'om-hoe.

IPL.INC-POT-leave

Let's go.

\subsection{COMBINING TENSE, ASPECT AND MOOD}

The forms and basic functions of tense, aspect and mood have been introduced. This section outlines various changes in form involved when these systems are combined, and gives examples of the various possible combinations.

In a recent grammatical study of an Austronesian language of Papua New Guinea, Bugenhagen (1990:26) questions the validity of treating tense, aspect and mood (TAM) together:

There is no evidence for such a grouping in Mangap-Mbula. Modal notions are encoded by a variety of fornal devices, including: 1) auxilliary verbs, 2) sentence final adverbs, 3) complementizers, and 4) intonation, while aspect is encoded by 1) reduplication, 2) various verb phrase internal adverbs, and 3 ) a number of verb serialization constructions. Temporal notions, on the other hand, are encoded by temporal adverbial constructions. To conflate such a menagerie of formal encoding together under a single heading, however hyphenated, would be a colossal mistake.

As the Tawala situation resembles this description the warning should not go unheeded, for analysis should always rest primarily on the forms of a language. However, to demonstrate the combinatory potential of the three systems gives insight into the inner 
functioning of the verb phrase and verbal clause. In addition TAM operate in Tawala with a degree of overlapping forms, necessitating, to a degree, a combined approached.

In the following sections I do not discuss the full range of items affecting TAM; discussion is limited to verbal morphology, adverbs and mood particles.

\subsubsection{TAMFORMS}

Table 6 lists the irregular forms which derivational prefixes take when marked for durative aspect. In addition both potential and realis moods are included to illustrate the neutralisation in first person forms. The durative aspect forms in the present tense illustrate the fusion of tense with the person and number subject prefixes. Vowel elision in simple aspect and potential mood of the stative derivational forms can also be seen.

The three verbs chosen to illustrate these aspects of Tawala TAM are the regular verb baha 'speak', the valence-increasing wi-gei- 'put s.th. up' and the valence-decreasing omboina 'meet together'.

TABLE 6: VERBAL MORPHOLOGY

\begin{tabular}{|c|c|c|c|}
\hline & SIMPLE ASPECT & $\begin{array}{l}\text { DURATIVE ASPECT } \\
\text { (PRESENT TENSE) }\end{array}$ & POTENTIAL MOOD \\
\hline $\begin{array}{l}\text { 1SG } \\
\text { 2SG } \\
\text { 3SG } \\
\text { 1PL.INC } \\
\text { 1PL.EXC } \\
\text { 2PL } \\
\text { 3PL }\end{array}$ & $\begin{array}{l}\text { a-baha } \\
\text { u-baha } \\
\text { i-baha } \\
\text { ta-baha } \\
\text { to-baha } \\
\text { o-baha } \\
\text { hi-baha }\end{array}$ & $\begin{array}{l}\text { a-baha-baha } \\
\text { e-baha-baha } \\
\text { e-baha-baha } \\
\text { ta-baha-baha } \\
\text { to-baha-baha } \\
\text { o-baha-baha } \\
\text { he-baha-baha }\end{array}$ & $\begin{array}{l}\text { a-baha } \\
\text { u-na-baha } \\
\text { i-na-baha } \\
\text { a-baha } \\
\text { to-baha } \\
\text { o-na-baha } \\
\text { hi-na-baha }\end{array}$ \\
\hline $\begin{array}{l}\text { 1SG } \\
\text { 2SG } \\
\text { 3SG } \\
\text { 1 PL.INC } \\
\text { 1PL.EXC } \\
\text { 2PL } \\
\text { 3PL }\end{array}$ & $\begin{array}{l}\text { a-wi-gei- } \\
\text { u-wi-gei- } \\
\text { i-wi-gei- } \\
\text { ta-wi-gei- } \\
\text { to-wi-gei- } \\
\text { o-wi-gei- } \\
\text { hi-wi-gei- }\end{array}$ & $\begin{array}{l}\text { a-i-gei- } \\
\text { e-i-gei- } \\
\text { e-i-gei- } \\
\text { ta-i-gei- } \\
\text { to-i-gei- } \\
\text { o-i-gei- } \\
\text { he-i-gei- }\end{array}$ & $\begin{array}{l}\text { a-wi-gei- } \\
\text { u-na-wi-gei- } \\
\text { i-na-wi-gei- } \\
\text { ta-wi-gei- } \\
\text { to-wi-gei- } \\
\text { o-na-wi-gei- } \\
\text { hi-na-wi-gei- }\end{array}$ \\
\hline $\begin{array}{l}\text { 1SG } \\
\text { 2SG } \\
\text { 3SG } \\
1 \text { PL.INC } \\
\text { 1PL.EXC } \\
\text { 2PL } \\
\text { 3PL }\end{array}$ & $\begin{array}{l}\text { a-'m-boina } \\
u \text {-'m-boina } \\
\text { i-'m-boina } \\
\text { ta-'m-boina } \\
\text { to-'m-boina } \\
o \text {-'m-boina } \\
\text { hi-'m-boina }\end{array}$ & $\begin{array}{l}\text { a-yam-boina } \\
\text { e-yam-boina } \\
\text { e-yam-boina } \\
\text { ta-yam-boina } \\
\text { to-yam-boina } \\
\text { o-yam-boina } \\
\text { he-yam-boina }\end{array}$ & $\begin{array}{l}\text { a-n'om-boina } \\
u \text {-n'om-boina } \\
i \text {-n'om-boina } \\
\text { ta-n'om-boina } \\
\text { to-n'om-boina } \\
o-n^{\prime} o m-b o i n a \\
\text { hi-n'om-boina }\end{array}$ \\
\hline
\end{tabular}

Note that, with the wi-prefix, vowel elision results in the loss of durative marking in the third person non-present tense and hence neutralisation with simple aspect.
/i-i-geil $>$ i-gei- $\quad$ he was putting s.th. up
/hi-i-geil $>$ hi-gei- $\quad$ they were putting s.th. up 


\subsubsection{TAM FUNCTIONS}

Potential combinations of TAM are explored in Table 7. Not all combinations are possible (-). Those combinations which are possible (+) are illustrated in examples 8(42)$8(67)$. Durative and simple aspect are compatible with any acceptable marked combination of tense and mood.

TABLE 7: COMBINATIONS OF TAM

\begin{tabular}{|l|c|c|c|}
\hline MOOD: & PAST & PRESENT & FUTURE \\
\hline REALIS & + & + & - \\
\hline IRREALIS & + & - & + \\
\hline POTENTIAL & + & + & + \\
\hline
\end{tabular}

In the following subsections I give priority to tense even though tense receives minimal morphological marking within the verb phrase.

\subsubsection{PAST FUnCTIONS}

(a) Past Realis

Past realis is used to express situations that actually happened.

8(42) (Pom) i-nae u pitapita.

yesterday 3SG-go LOC bush

Yesterday he went to the bush.

When two clauses are combined in a sentence, durative aspect in the first marks temporal overlap and simple aspect marks succession.

8(43) Houga-na i-ne-nae wagaloke i-gale-ya.

time-DEF 3SG-DUR-go possum 3SG-see-3SG

While he was going along he saw a possum.

Combined with the tense adverb amaka 'already', the construction indicates completed aspect.
8(44) a. Bada amaka i-nae. man already 3SG-go
The man has/had gone.
b. Amaka i-tugu-tugula...
already 3SG-DUR-sit
He was already sitting...

(b) Past Irrealis

The most common use of past irrealis is in clauses with negative polarity expressing situations that did not eventuate.
a. Ega wam i-ta-nei.
NEG boat 3SG-IRR-come
The boat didn't come.
b. Ega lawa i-ta-hagu-hi.
NEG person 3SG-IRR-help-3PL
He didn't help people.

The past irrealis is also used to express events that almost happened.

8(46) (Kikina ma) a-ta-peu.
little but ISG-IRR-fall.
I almost fell.


Contrary-to-fact constructions often use past irrealis with the mood particle itapa. The Tawala joke 8(47) uses an interplay of durative and simple aspects.

8(47) Itapa i-ta-ne-nae po palouma hi-ta-wiyaga-ya apo iyowaka
CTF 3SG-IRR-DUR-go and witch 3PL-IRR-chase-3SG FUT how
i-ta-lowo?
3SG-IRR-run.away
If he was going and witches chased him, how would he escape?

(c) Past Potential

In these constructions, potential mood is used in conjunction with the irrealis mood particle ipa.

8(48) Lolowa hai luhogala ipa hi-na-ma-mae.

before their desire IRR 3PL-POT-DUR-stay

Previously, it was their desire to stay.

8(49) Keduluma-na ipa i-na-uni-hi po e-ne-nae.

woman-DEF IRR 3SG-POT-kill-3PL and 3SG.PRES-DUR-go

The woman was going along intending to kill them.

\subsubsection{PRESENT FunCtions}

Present tense is never marked when mood is marked.

The irrealis mood with durative aspect indicates an ongoing situation (contrast $8(45 \mathrm{~b}$ ) with $8(50)$, both used with negative polarity).

8(50) Ega lawa i-ta-hagu-hagu-hi.

NEG person 3SG-IRR-DUR-help-3PL

He doesn't help people.

If used in a conditional clause, potential mood combined with durative aspect also applies to an ongoing situation.

8(51) Apo lawa ega i-na-woo-bagibagi...

FUT person NEG 3SG-POT-DUR-work

If a person won't work...

The functions of simple and durative aspects are rather divergent with the present realis, and are thus treated separately.

(a) Simple Present Realis

Simple present realis is marked by present-tense subject prefixes. The simple aspect is not used at all with irrealis or potential moods. It views an action as though currently taking place in its entirety, as a unit.

8(52) I-lupa po e-hopu po e-na'-po boga u sipoli-na. 3SG-jumpand 3SG.PRES-go.down and 3SG.PRES-go-and sea LOC middle-3SG He jumped and goes down and goes into the depths of the sea.

The most common usage of simple present realis is in the first clause of purpose constructions, where it is used in place of durative aspect. 


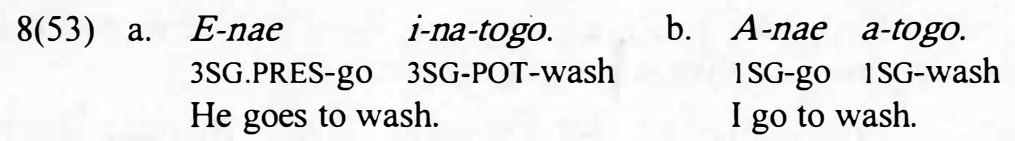

The present tense is only morphologically marked in the second and third person singular and third person plural. Compare 8(53a) with 8(53b), which demonstrates neutralisation of both present tense (a-nae) and potential mood (a-togo) in the first person singular.

Present tense is also used to express the customary aspect.

$$
\begin{aligned}
& \text { 8(54) Lawa hilahilage-na he-guluw'-i po i-kokoe. } \\
& \text { person finish-3SG 3PL.PRES-bury-3SG and 3SG-finish } \\
& \text { They bury the dead person and it is finished. }
\end{aligned}
$$

(b) Durative Present Realis

The present realis is normally used with the durative aspect to refer to actions that are still progressing (8(55)) and habitual actions (8(56)).
a. Wam e-ne-nei.
boat 3SG.PRES-DUR-come The boat is coming.
b. Mek' e-ne-nae?
where 2SG.PRES-DUR-go
Where are you going?
8(56) Houga magomagou-na e-ne-nae u Alotau. time many-3SG 3SG.PRES-DUR-go LOC Alotau He often goes to Alotau.

Combined with the tense adverb amaka 'already', the construction indicates that the action has already begun.

8(57) Ata lawa amaka he-ne-nae.

ourINC person already 3PL.PRES-DUR-go

Our friends are already going.

The present tense can be used in a story, in which case it indicates a lively historic present.

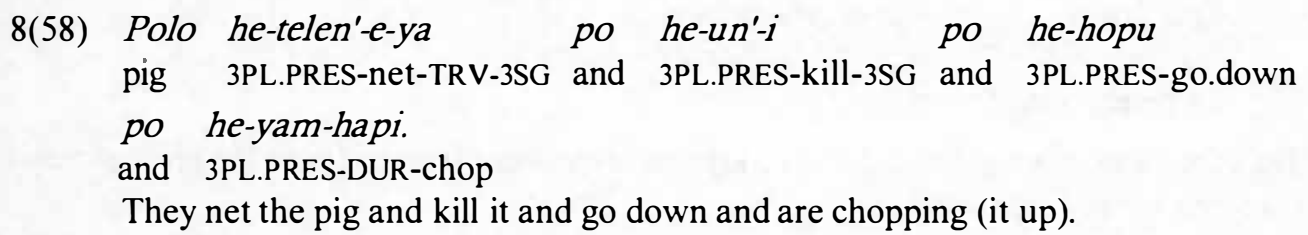

\subsubsection{FUTURE FUNCTIONS}

Future tense is usually marked by the tense adverb apo (apega with negative polarity).

There are no examples of future realis. When referring to the future a verb must be marked for either irrealis or potential moods.

(a) Future Irrealis

The future marker with irrealis mood is used to express contrary-to-expectation situations. 
8(59) Apo i-ta-nae...

FUT 3SG-IRR-go

Were he to go...

(b) Future Potential

The main use of the future is to express situations that are likely to happen or, with negative polarity, unlikely to happen.

$8(60)$
a. Apo hi-na-nei.
FUT 3PL-POT-come
b. Apega hi-na-nei.
FUT.NEG 3PL-POT-come
They will come. They won't come.

The future potential is readily used with durative aspect.

8(61) Apo hi-na-ne-nae.

FUT 3PL-POT-DUR-go

They will be going along.

It can also express waming.

8(62) Ap' u-na-peu.

FUT 2SG-POT-fall

You'll fall.

Commands employ only the potential marking on the verb and no tense adverb.

8(63) O-na-lowo.

2PL-POT-run

Run away (you lot)!

Negative commands use the negative future adverb apega.

8(64) Apega u-na-nae.

FUT.NEG 2SG-POT-go

You must not go.

Hypothetical constructions employ the particle inapa.

8(65) Inapa ega u-na-ne-nae apo hi-na-pani-m.

HYP NEG 2SG-POT-DUR-go FUT 3PL-POT-tie-2SG

If you don't go they will imprison you.

Negative durative potential constructions indicate lack of compulsion.
$8(66)$ a. Ega u-n'-an-ani-hi.
NEG 2SG-POT-DUR-eat-3PL
b. Ega u-na-ne-nae.
NEG 2SG-POT-DUR-go
You don't have to eat them.
You don't have to go.

8(67) Ega u-na-tu-tou.

NEG 2SG-POT-DUR-cry

You don't need to cry. 


\subsection{SERIAL VERBS}

Serial verbs are productive constructions, with the main verb and the modifying verb retaining a degree of independence as free forms. Thus -baha gae 'speak upwards (towards hills)' consists of a main verb -baha 'speak' and a modifying verb -gae 'go up'.

It is not possible to argue that these constructions are lexical compounds rather than serial verbs: 1) the constructions are highly productive and properly belong in the grammar rather than the lexicon; 2) some transitive forms have an inflectional morpheme marking ligature in the same way that modifiers do (cf. §8.12). In this section the serial verbs are in square brackets.

\section{8(68) [A-gale-na tuhaga-ya]... ISG-see-LIG find-3SG \\ I discovered...}

In that the distinguishing feature of the verb phrase is the presence of a subject prefix marked for person and number, the fact that the second verb in Tawala serial construction lacks this prefix indicates that the second verb no longer has its function as a main verb, but is rather a modifier of the main verb. A subject marker before the second verb in the chain would automatically signal two clauses, rather than a single serial verbs.

8(69) [A-nae a-togo $]$.

ISG-go ISG-bathe

I go (in order) to bathe.

However, with transitive constructions it is the modifying verb which determines transitivity and is therefore strictly not a modifier, hence the term 'serial verb'. Thus transitive constructions provide circumstantial evidence that intransitive constructions are also to be regarded as serial verbs. The dividing line between serial verbs and modifier constructions is the ability of the modifier to function independently as a verb.

Mood and aspect are also only marked on the head, never the modifying verb $(8(71)$, $8(72))$.

\subsubsection{INTRANSITIVE SERIAL VERBS}

Not all subclasses of verbs can modify a main verb in a serial verb construction. Motion verbs and stative verbs, in particular, are productive as modifying verbs, but other subclasses are also represented. As far as possible I illustrate serial verbs with the main verb -baha 'say'.

\subsubsection{MOTION VERBS}

\begin{tabular}{llll} 
MODIFIER ROOT & \multicolumn{2}{c}{ SERIAL CONSTRUCTION } \\
-gae & go up & -baha gae & speak towards hills \\
-ge-gae & DUR-go.up & -baha gegae & boast \\
-bulili & run & -baha bulili & talk quickly \\
-geleta & arrive & -lupa geleta & jump arrive (flee)
\end{tabular}


8(70) Kukuku [i-lupa geleta] didiyala u toya-na. pheasant 3SG-jump arrive pampas LOC overgrown-3SG The pheasant coucal escaped into the tall pampas grass.

\subsubsection{STATIVE VeRbS}

\begin{tabular}{lll} 
MODIFIER ROOT & $>$ & \multicolumn{2}{l}{ SERIAL CONSTRUCTION } \\
-tahaya be first & -baha tahaya & speak first \\
-kadidila be strong & -baha kadidila & speak firmly \\
-apapoe be wrong & -baha apapoe & speak abusively \\
-dumalu be straight & -baha dumalu & speak frankly \\
-uyogigae be angry & -baha uyogigae & speak angrily
\end{tabular}

8(71) Tula-m uyahi-na [u-na-lidumalu tahaya]... friend-2SG 'at'-3SG 2SG-POT-straighten first

Straighten (things) with your friend first...

8(72) [U-na-baha dumalu], tam palouma? 2SG-POT-speak straight youSG witch

Tell us frankly, are you a witch?

A number of other stative roots also function in the modifier slot; as yet no clear subclasses have emerged.

\subsubsection{OTHER VERBS}

\begin{tabular}{llll} 
MODIFIER ROOT & $>$ & \multicolumn{2}{l}{ SERIAL CONSTRUCTION } \\
-tu-tou & DUR-cry & -baha tutou & wail \\
-winama & joke & -baha winama & speak jokingly \\
-towolo & stand & -baha towolo & stand to speak \\
malitom & daybreak & -baha malitom & talk till day \\
momota & tighten & -towolo momota & stand firm
\end{tabular}

8(73) [Hi-eno malitom].

3PL-sleep daybreak

They slept till daytime.

\subsubsection{TRAnSiTIVE SERIAL VerbS}

Transitive serial verb constructions are numerous and only a small representation is given here. Transitivity within the serial verb is a function of the modifier verb. The 'intensifier' function of intransitive adverbial modifiers is parallelled by three serial verbs.

\subsubsection{MODIFIER VERBS}

With most verbal modifiers the root is used within its normal semantic range, as illustrated here combined with -houna 'put'. 


\begin{tabular}{llll} 
SERIAL VERB ROOT & \multicolumn{2}{l}{ SERIAL CONSTRUCTION } \\
-gowad'-i & hide s.th. & -houna gowad'-i & steal/conceal s.th. \\
-tahae-ya & lead s.th. & -houna tahae-ya & place s.th./s.o. first \\
-kaha-ya & separate s.th. & -houna kaha-ya & appoint s.th./s.o. \\
-damane-ya & cross s.th. over & -houna damane-ya & transfer s.th./s.o. \\
-hopune-ya & take s.th. down & -houna hopune-ya & humiliate s.o. \\
-gelete-ya & take s.th. up & -houna gelete-ya & initiate s.o.
\end{tabular}

The transitive suf fix attaches to the end of the verb phrase.

$\begin{array}{ll}\text { MAIN VERB ROOT } \\ \text {-himil'-i } & \text { send s.th. } \\ \text {-mamal'-i } & \text { greet s.o. } \\ \text {-houn'-i } & \text { put s.th. } \\ \text {-winagan'-i } & \text { choose s.th. }\end{array}$

\begin{tabular}{ll}
\multicolumn{2}{l}{ SERIAL CONSTRUCTION } \\
- himila tahae-ya & send s.o. first \\
-mamala tahae-ya & greet s.o. first \\
- houna tahae-ya & put s.o. first \\
-winagana tahae-ya & choose s.o. first
\end{tabular}

\subsubsection{TRANSITIVE INTENSIFIERS}

$\begin{array}{llll}\text {-lagona } & \text { go over s.th. } & \text { lagon'-i } & \text { surpassingly } \\ \text {-hale-ya } & \text { throw s.th. } & \text { hale-<ya> } & \text { completely }\end{array}$

8(74) Geka dobu-hi [hi-lowo hale-hi].

this village-DEF.PL 3PL-flee throw-3PL

They fled (from) these villages.

Serial constructions involving the modifier verbs -lagona 'surpass (s.th.), go over (s.th.)' are variable-focus verbs and are often transitive even when there is no morphological marking for object, as these typically function with predicate focus.

\subsubsection{COMPARATIVE FUNCTION}

Of the various verbal modifiers none is more important than lagona 'surpass', which is used in Tawala with a comparative function.

$\begin{array}{ll}\text { MAIN VERB ROOT } \\ \text {-lata } & \text { grow } \\ \text {-dewadewa } & \text { be good } \\ \text {-wakeke } & \text { be white } \\ \text {-wigapola } & \text { be rich } \\ \text {-apapoe } & \text { be bad } \\ \text {-yeuyeu } & \text { be clean }\end{array}$

$>$ SERIAL CONSTRUCTION

\begin{tabular}{|c|c|}
\hline $\begin{array}{l}\text {-lata lagona } \\
\text {-dewadewa lagona } \\
\text {-wakeke lagona } \\
\text {-wigapola lagona } \\
\text {-apapoe lagona } \\
\text {-yeuyeu lagona }\end{array}$ & $\begin{array}{l}\text { surpass s.th. } \\
\text { be better than s.th. } \\
\text { be whiter than s.th. } \\
\text { be richer than s.th. } \\
\text { be worse than s.th. } \\
\text { be cleaner than s.th }\end{array}$ \\
\hline
\end{tabular}

Thus we see that lagona 'surpass' is used in Tawala to express approximately what comparative constructions express in English by the morpheme '-er'.

8(75) Om umauma wai-muli-na [i-haki lagona]. yourSG drink CON-behind-3SG 3SG-good surpass

Your last drink is better (than the first).

A 'superlative' construction in Tawala adds the intensifier duma to lagona; in this case the construction is intransitive. 
8(76) Kaoha apo [i-na-lata lagona duma]. joy FUT 3SG-POT-grow surpass very That joy will be the greatest.

Object-focus constructions are also common in the data.

8(77) Am gawiya [u-na-kadidili lagoni-hr]. yourSG enemy 2SG-POT-strong surpass-3PL You must overcome your enemies.

\subsubsection{4 'COMPLETED' FUNCTION}

The hale-ya 'throw s.th.' constructions are important; the semantics of the modifier verb vary according to the head, but generally indicate that the action was completely carried out.

\begin{tabular}{|c|c|c|c|}
\hline MAIN VEF & ROOT & SERIAL CONSTRU & ION \\
\hline & cut & -tala hale-ya & cut it (tree) o \\
\hline -hamaga & wipe & - hamaga hale-ya & wipe s.th. off \\
\hline & burn & -apu hale-ya & burn s.th. up \\
\hline -lowo & flee & -lowo hale-ya & flee from s.th. \\
\hline$-h o e$ & open & -hoe hale-ya & destroy s.th. \\
\hline -lupen'-i & untie & -lupena hale-ya & release s.th. \\
\hline
\end{tabular}

The intensifier hale-ya 'throw s.th.' also occurs as a second-order modifier (just twice in 65 occurrences, both times with a serial verb of motion indicating the direction of departure).

8(78) Wam luwaga [hi-lupa hopu hale-h1]. boat two 3PL-jump down throw-3PL They jumped down and left the two boats.

\subsubsection{Grammar of Serial Verb CONSTRuctions}

Here we look at the inherent transitivity of the component verbs of serial verb constructions and the transitivity of the resultant serial verb construction itself. In addition to the valence of the construction as a whole, enquiry can be made as to the valence of the specific roots involved as head and modifier. There are four possible combinations, of which only three occur.

8.10.3.1 $\mathrm{V}^{\mathrm{ITR}}+\mathrm{V}^{\mathrm{ITR}}>\mathrm{V}^{\mathrm{ITR}}$

All the verbs listed and discussed in $\$ 8.10 .2$ belong to this class (further discussed in $\S 8.10 .5)$.

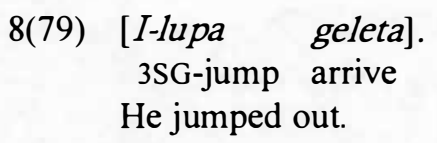

Common constituents of the head slot are verbs of motion and rest, with the modifier indicating direction of motion. 
-lupa hopu jump down

-dala hopu crawl down

-me hopu stay down (remain in humble position)

-bulili hopu run down

The three verbs -gae 'ascend', -mae 'stay' and -nae 'go' undergo vowel deletion when used in serial constructions, becoming -ge, -me and -ne respectively.

\section{SIMPLE}

-ne gogona go together

-me gowada stay hidden
DURATIVE

-nene gogona be going together

-meme gowada be staying hidden

In a rare construction, not only is the head motion verb reduplicated but the modifier is as well. This is the only case of grammatical reduplication of a modifier that I am aware of; it probably signifies repeated attempts. In $8(80)$ a reduplicated form is contrasted with a non-reduplicated one.

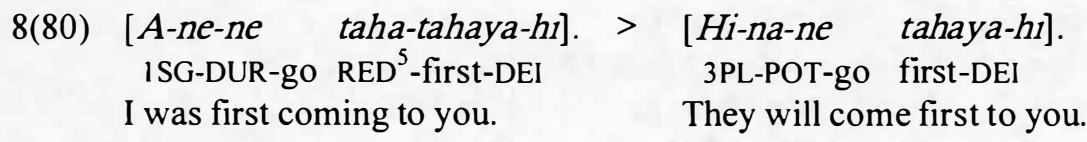

8.10.3.2 $\mathrm{V}^{\mathrm{ITR}}+\mathrm{V}^{\mathrm{TR}}>\mathrm{V}^{\mathrm{TR}}$

The transitive verb modifiers of intransitive verbs are limited to the two transitive intensifiers lagoni and hale-ya. In addition to intensifying the action these modifying verbs make the whole construction transitive.

(a) Active intransitive verbs are modified by hale-ya 'throw s.th.'.

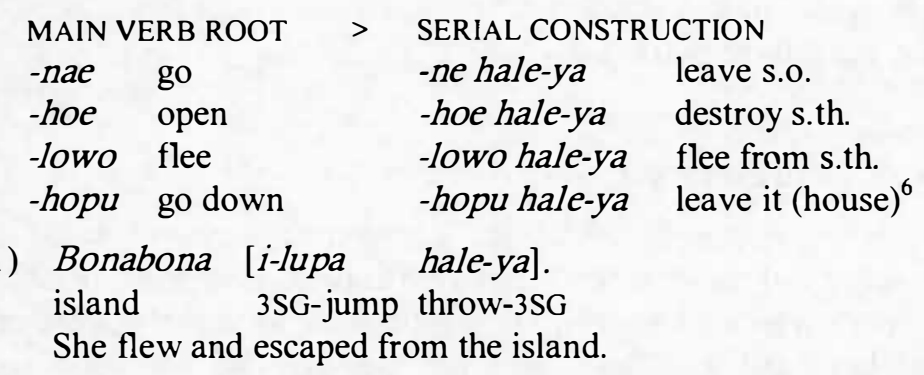

(b) Stative and process verbs are modified by lagon' $-i$ 'surpass s.th.'. In the following examples third person plural indexing is used for the object clitic.

\begin{tabular}{llll} 
MAIN VERB ROOT & \multicolumn{2}{l}{ SERIAL CONSTRUCTION } \\
-lata & grow & -lata lagoni-hi & surpass them \\
-haki & be good & -haki lagoni-hi & be better than them \\
-apapoe be bad & -apapoelagoni-hi & be worse than them \\
-kadidila be strong & -kadidila lagoni-hi & overpower them
\end{tabular}

\footnotetext{
5 This is glossed REDuplication because I am not sure of its meaning. It is not a normal durative form as durative is marked on the main verb.
}

6 A house is usually built above the ground. 
8(82) [O-na-dewadewa lagoni-h1].

2PL-POT-good surpass-3PL

$\mathrm{Be}$ better (in customs) than them!

8.10.3.3 $\mathrm{V}^{\mathrm{TR}}+\mathrm{V}^{\mathrm{TR}}>\mathrm{V}^{\mathrm{TR}}$

This is the most diverse group, with many classes of verbs filling the head slot. The list under §8.10.2.1 illustrates something of the range of the modifier slot. The verbs also function with the two transitive intensifiers lagon'-i and hale-ya.

8(83) [ $U$-na-boli hale-ya].

2SG-POT-chop throw-3SG

Chop it off.

When lagona 'surpass' is used following a transitive verb the transitivising suffix is used. The following forms should be contrasted with the last list above.

\begin{tabular}{llll}
\multicolumn{2}{c}{ MAIN VERB ROOT $>$} & \multicolumn{2}{l}{ SERIAL CONSTRUCTION } \\
-tuhaga-ya & find s.th. & -tuhaga lagon'-e-ya & find s.th. abundantly \\
-houn'-i & put s.th. & -houna lagon'-e-ya & pile s.th. on top \\
-nugotuhu-ya & think s.th. & -nugotuhu lagon'-e-ya & hope s.th. \\
-dewa-ya & do s.th. & -dewa lagon'-e-ya & do s.th. better
\end{tabular}

8(84) [Hi-tuhaga lagon'-e-ya].

3PL-find surpass-TRV-3SG

They raised more than enough (money).

8.10.3.4* $\mathrm{V}^{\mathrm{TR}}+\mathrm{V}^{\mathrm{ITR}}>\mathrm{V}^{\mathrm{ITR}}$

This construction is not found in the Tawala data $^{7}$. In order to use a serial verb in which the modifying verb is intransitive, an effective prefix must be used.

\subsubsection{EFFECTIVE MARKER}

With serial constructions an 'effective' marker ${ }^{8}$ indicates that the second verb expresses the result of the transitive action denoted by the first verb.

8(85) Bada-na ipa [i-na-houna i-dumalu me-ya]... man-DEF IRR 3SG-POT-put EFF-straight RFX-CPY

In order that the man might make himself right...

That the effective marker is not a third person singular subject marker is shown by the fact that it does not agree with the subject $(8(86))$; nor does it agree with the object of the verbal head (8(87)). 


\section{8(86) [Ta-gale-na i-dumalu-ya]. \\ IPL.INC-see-LIG EFF-straight-3SG \\ We regard him as a good bloke.}

There are three transitive verbal heads which are commonly used in serial constructions with stative verb modifiers, marked with an effective prefix. The heads are listed with the transitive form of the verb in each case.

$\begin{array}{llll}\text {-houn'-i } & \text { put s.th. } & \text {-houna... } & \text { put... } \\ \text {-bahe-ya } & \text { say s.th. } & \text {-bahena... } & \text { proclaim... } \\ \text {-gale-ya } & \text { see s.th. } & \text {-galena... } & \text { regard... }\end{array}$

The stative modifier often begins with the effective prefix $i$, also present with some derivational prefixes (e.g. wo- $j$ - 'cause by hand').

$\begin{array}{lll}\text {-dumalu be straight } & \text {-houna i-dumalu-ya } & \text { place s.th. correctly } \\ & \text {-bahena i-dumalu-ya } & \text { proclaim s.th. correct } \\ & \text {-galena i-dumalu-ya } & \text { regard s.o. as right } \\ \text {-gobu be dirty } & \text {-galena i-gobu-ya } & \text { regard s.o. unclean } \\ \text {-apapoe be bad } & \text {-galena i-apapoe-ya } & \text { despise s.o. }\end{array}$

The last example above (at least) is a variable-focus verb; $8(87)$ is an example with the predicate-focus form of the verb.

8(87) Lawa gehou-hi bi-hiyei ma [e-ga-gale-na
person other-3PL BEN-3PL and 2SG.PRES-DUR-see-LIG EFF-bad
You are passing judgement (about people).

\subsubsection{DiRECTIONAL Deictics}

A set of deictics that function with motion verbs is listed in $\$ 5.6 .2$ (Table 6). Motion deictics are marked for spatial location of the action in relation to the speaker and addressee.

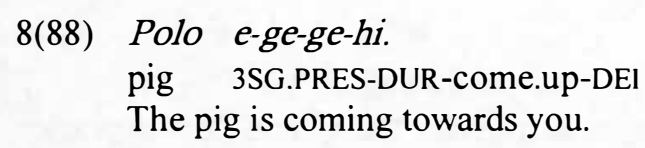

The function of the deictic marker on the verb in $8(88)$ is parallel to its function with the locative postposition (e-ge-gei uyahi-m 'he is coming to you').

These deictics commonly modify verbs and are therefore similar to serial verb constructions. Their function is to indicate the direction in which the situation of the main verb took place. The deictic nae 'away' is a verb in its own right: -nae 'go'. However, in the case of mai 'towards speaker' the form has now lost its verbal identity and only has a deictic function. ${ }^{9}$

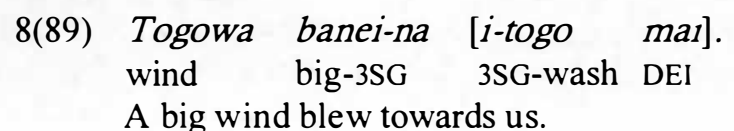


8(90) Gog'-iyai [i-tahaya ma1].

ancestor-IPL.EXC 3SG-first DEI

Our ancestor came first.

Deictic verbs are a second order of serial verbs following a serial construction in which the first modifying verb is a motion verb or a verb of speaking (or writing).

TABLE 8: DEIXIS WITH MODIFIERS

\begin{tabular}{|l|l|l|l|}
\hline DIRECTION: & TO SPEAKER & TO ADDRESSEE & AWAY \\
\hline come/go down & hopu mai & hopu $m a-h i$ & hopu nae \\
\hline come to stay & ne memai & ne mema-hi & ne memae \\
\hline speak come/go & baha mai & baha $m a-h i$ & baha nae \\
\hline call come/go & tou mai & tou ma-hi & tou nae \\
\hline
\end{tabular}
$8(91)$ a. [Hi-liya
hopu mal].
b. [Hi-liya
hopu nae].
3PL-go.together down DEI
They came down together.
They went down together.

8(92) [I-baha hopu maI].

3SG-say down DEI

He spoke down towards the speaker.

When a word ends in -na, that suffix is dropped and mai/mahi is replaced by -nail nahi, e.g. tago-na > tago-nail-nahi 'cross.over-DEl'.

8(93) Apo [a-ne yagiyagi-nar] uyahi-m.

FUT ISG-come quickly-DEI 'at'-2SG

I will come quickly to you.

Unlike verbal modifiers the deictic modifiers follow the object enclitic.

8(94) Hi-ne-nae ega [hi-ta-gunawile-hi ma1].

3PL-DUR-go NEG 3PL-IRR-return-CPY DEI

They kept going and did not come back.

8(95) [Hi-ne hale-hi mar] $u$ Labe.

3PL-go throw-3PL DEI LOC Labe

They left them and came to Labe.

\subsection{PARTICLE MODIFIERS}

Particle modifiers include all non-verbal modifiers. As with serial constructions transitivity plays an important role in these construction types. Two second-order modifiers and a post-object modifier are also discussed.

Modifiers seem to have arisen through the grammaticisation of serial verbs, a process that seems to be continuing today with the serial verb -lagona 'go over, surpass' (its verbal function has largely been replaced by -tagona 'go over') leaving the modifier verb to function as an adverb 'surpassingly'. In a count of its usage in texts it occurs 66 times in its modifier function and only twice in its verbal function, both times in the form i-lagona duma 'it really surpasses'. 
Numerals and one noun (see below) also function as verbal modifiers, so that grammaticisation involves more than serial verbs.

Grammaticisation has moved a further stage with the form -galenaitete 'care for', which is analysable into the serial verbs -gale-na 'look-LIG' and i-tete 'EFF-bridge'. However in present-day Tawala, tete 'bridge/steps/ladder' is a noun and does not function as a verb. In addition the form itete does not occur with any head other than -galena. Finally, classing itete as a modifier would introduce an extra level of modifiers in the VP.

8(96) Apo [hi-na-gale-na i-tete-na imahi-ye-na duma-ya].
FUT 3PL-POT-see-LIG EFF-steps-LIG properly-TRV-LIG very-3SG
They will care for him extremely well.

I conclude that -galenaitete is synchronically a lexical item. However, the verb stem -galena is so productive with modifier constructions that it is usually written separately, by Tawala speakers, even when it occurs with itete.

\subsubsection{FIRST-ORDER MODIFIERS}

Particle modifiers are posthead modifiers "that specify the mode of action of the verb" Crystal (1980:16). They contrast with prehead adverbs, which are clausal rather than phrasal in scope.

\subsubsection{INTRANSITIVITY WITH MODIFIERS}

Intransitive modifiers differ from their transitive counterparts in three ways: firstly, only transitive constructions take the object enclitic; secondly, the intransitive verb stem never takes ligature; and finally, the two sets of modifiers are distinct, though there is some overlap. Intransitive particle modifiers form a number of semantic classes.

(a) Intensifiers

$\begin{array}{ll}\text { pahi } & \text { entirely } \\ \text { imahi } & \text { completely, properly } \\ \text { gawata } & \text { incessantly, strongly } \\ \text { wahaga } & \text { unceasingly, exceedingly } \\ \text { labatana } & \text { strongly, forcefully }\end{array}$

8(97) I-ugo imahi.

3SG-bear.fruit completely.

It bore fruit prolifically.

8(98) To-kaoha labatana.

IPL.EXC-happy strongly

We were intensely happy.

(b) Limiters

$\begin{array}{ll}\text { awa } & \text { only } \\ \text { hota } & \text { only, just } \\ \text { kikina } & \text { a little } \\ \text { emosi/emota } & \text { together (as one) } \\ \text { luwaga } & \text { both }\end{array}$


The members of this class all have separate functions: awa and hota belong to the general modifier class; kiki-na 'small-3SG' is an adjective; and emosi 'one' and luwaga 'two' are numerals. Numerals function in a similar manner to limiters, to indicate the number of items involved in an action.

8(99) U-bolobolou hota. 2SG-decrepit just

You are just decrepit (for failing a task).

8(100) To-wiotonana kikina.

IPL.EXC-wait a.little

We waited briefly.

8(101) Amaka hi-ne emosi hi-lowo emosi.

already 3PL-come one 3PL-flee one

They came together they fled together.

8(102) Kedewa hi-hilage luwaga.

dog 3PL-finish two

Both the dogs died.

(c) Specifiers

$\begin{array}{ll}\text { gogona } & \text { together } \\ \text { yabayababa } & \text { emptily, vainly } \\ \text { yagiyagina } & \text { quickly } \\ \text { powa } & \text { mistakenly } \\ \text { woloe } & \text { completely, 'finish' }\end{array}$

8(103) I-woe-woe yagiyagina.

3SG-DUR-paddle quickly

She paddled rapidly.

8(104) Ega o-na-i-nugonugotuhu powa...

NEG 2PL-POT-DUR-think mistakenly

Don't mistakenly think that...

8(105) Amaka i-togo woloe po i-yeuyeu.

already 3SG-wash finish and 3SG-be.clean

He has already washed and is clean.

Tawala woloe is similar to the Melanesian Pidgin word pinis in constructions such as go pinis 'leave permanently'.

8(106) Hi-bagibagi woloe.

3PL-work finish

They finished the work. live'.

The following examples show a range of modifiers used with a single head -mae 'stay,
-me hota wait idly
-me imahi live well
-me gogona stay together (plural)
-me luwaga live together (two) 
-me wahaga stay for ever

-me gawata stay incessantly

\section{8(107) Baha-hi u nugonugo-mi hi-na-me wahaga. word-DEF LOC heart-2PL 3PL-POT-stay forever Those words will remain in your hearts forever.}

Particle modifiers contrast with the modifying verb of a serial constructions in that they never occur independently as verbs. Forms such as *hi-woloe '3PL-finish' are ungrammatical. To function as a verb, a particle modifier requires a derivational prefix, for example -li-woloe-ya (-DVP-completely-3SG) 'finish-it' or -wo-imahi-ye-ya (-DVPproperly-TR V-3SG) 'attend to s.th./prepare s.th.' .

\subsubsection{TRanSITIVITY WITH MODIFIERS}

In a number of ways transitivity markedly affects the operation of modifiers.

When a modifier follows a transitive head, the object marker attaches to the modifier that is, it cliticises to the final item of the verb phrase. Transitivity in these constructions is the result of the head verb being transitive. The transitivity applies to the whole construction and the transitive enclitic attaches to the construction as a whole. A number of modifiers require the transitive marker -ge to function transitively, e.g. imahi-ye-ya 'properly' and $a w^{\prime}-e-y a$ 'only, futilely'.

The range of modifiers occurring with transitive verbs is different from the intransitive set listed in the previous section. The adverbs are a much smaller set selected from the modifiers which function intransitively. They are here listed with both singular and plural enclitics and also with their intransitive counterparts.

(a) Intensifiers

$\begin{array}{lll}\text { imahi } & >\text { imahi-ye-ya/hi } & \text { properly } \\ \text { duma } & >\text { duma-ya/hi } & \text { very } \\ \text { yabayababa } & >\text { yababa-ya/hi } & \text { emptily, vainly } \\ \text { pahi } & >\text { pahi-<hi> } & \text { entirely } \\ \text { 8) Hi-winagana } & \text { yababa-ya. } & \\ \text { 3PL-choose } & \text { vainly-3SG } \\ \text { They chose him in vain (i.e. made a useless choice). }\end{array}$

With the intensifier pahi-, the verb functions as a condition verb in which the undergoer subject is the identical referent to the undergoer object.

8(109) Neula hi-hilage pahi-hi. coconut 3PL-finish entirely-CPY The coconuts had completely died.

8(110) Ta-hilage pahi-ta.

1PL.INC-finish entirely-CPY

We will be entirely wiped out (destroyed). 
(b) Limiters

$$
\begin{array}{lll}
\text { awa } & >a w^{\prime}-e-y a & \text { only/futilely } \\
\text { emota } & >\text { emot'-e-ya } & \text { together (one) }
\end{array}
$$

8(111) Hi-bih'-e-na aw'-e-ya.

3PL-search-TRV-LIG only-TRV-3SG

They sought him in vain.

8(112) I-wila-wila emot'-e-ya.

3SG-DUR-mix one-TRV-3SG

He mixed it (i.e. two types of blood).

Verbs with a final / $e$ / employ the ligature marker -na before modifiers.

-bih'-e-ya seek s.th. -bih'-e-na imahi-ye-ya seek s.th. carefully

-dewe-ya do it dewe-na me-ya do it again

\subsubsection{SECOND-ORDER MODIFIERS}

In my data, up to two modifiers occur in the Tawala verb phrase; there are, however, severe limitations on the second modifier, which is one of two morphemes: duma 'very' (superlative marker) and meme 'again'.

\subsubsection{SUPERLATIVES}

The modifier duma 'very' belongs to the class of general modifiers in that it modifies both nouns and verbs.
$8(113)$ a. bada natu duma-na man child very-3SG the man's real son

b. Bada u-me duma. man 2SG-stay very Bada, you stayed a long time.

However, duma is distinct from the other modifiers in that it also functions as a secondorder modifier, often intensifying the first-order modifier. This construction is rare with intransitive verbs, however.
8(114) I-gae
imahi
duma.
3SG-ascended completely very
It went up exceedingly high.

Note that duma frequently has a superlative function.
8(115) To-kaoha labatana duma.
IPL.EXC-happy strongly very
We are completely happy.

8(116) O-na-bagibagi kadidila duma.

2PL-POT-work be hard very

Work to your utmost.

8(117) I-wakeke lagona duma.

3SG-be.white surpass very

It was really white. 
In $8(117)$ the construction is intransitive; $8(118)$ is a condition construction and $8(119)$ has object focus.

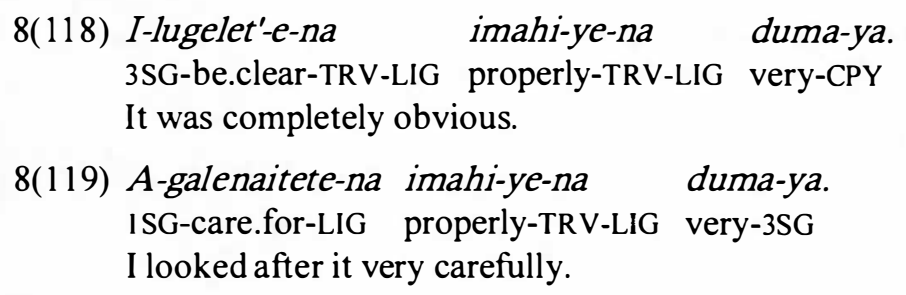

\subsubsection{REPEATED ACTION}

The second-order particle modifier meme 'again' is used to indicate repeated action.

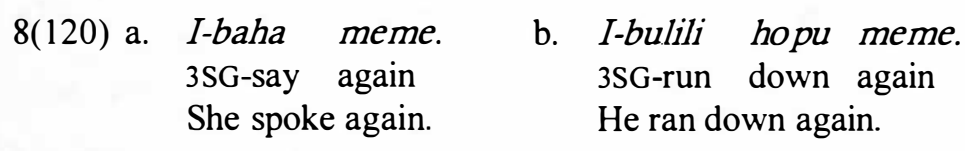

Both intransitive and transitive constructions are used. The intransitive specifier meme corresponds to the transitive form $m e-<y a>$ 'again-<3SG $>$ '.

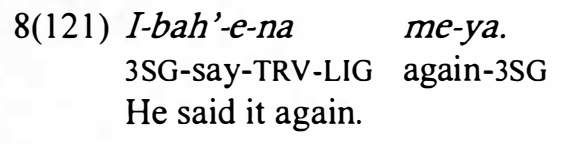

8(122) I-na-houna i-dumalu me-ya.

3SG-POT-put EFF-straight again-3SG

He will put it right again.

The transitive form me-<ya> commonly has a reflexive function, where the object enclitic has the same referent as the subject prefix. Unlike condition verbs, which have undergoer subjects, the subject of a verb with the modifier $m e$ - is an actor and the object is an undergoer. Hence when the referent of the subject and the actor are identical we have a truly reflexive construction.

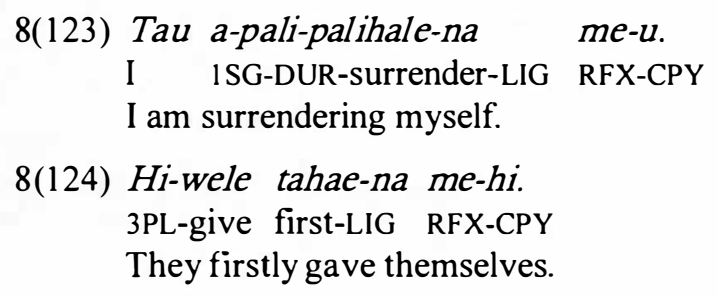

\subsubsection{POST-OBJEct MODIFIER}

In addition to directionals, one other modifier can fill the post-object modifier slot: the general modifier pite 'like, similarly'. As we have seen, this morpheme is a general modifier and is quite distinctive in its other functions as well.

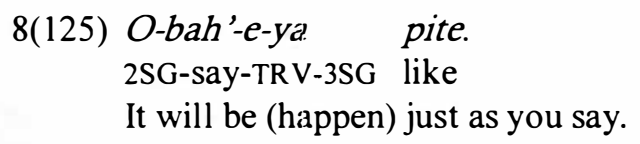




\subsection{LIGATURE}

The ligature marker -na is used on certain transitive verbs when followed by a modifier or serial verb.
8(126) a. I-bah'-e-na
me-ya.
3SG-Say-TR V-LIG again-3SG
b. I-hanapu-ge-na duma-ya.
3SG-know-TRV-LIG very-3SG
He said it again.
She knew it completely.

The ligature is suffixed to verb stems ending in / $e /$. Two situations are involved.

1) Ligature is used with verbs which employ the transitive marker -ge.

$\begin{array}{llll}\text {-baha } & \text { speak } & \text {-bah'-e-na } & \text { speak-TRV-LIG } \\ \text {-bowi } & \text { make a denial } & \text {-bowi-ye-na } & \text { deny-TRV-LIG } \\ \text {-gimala } & \text { trade } & \text {-gimal'-e-na } & \text { trade-TRV-LIG } \\ \text {-lowo } & \text { run away } & \text {-lowo-ge-na } & \text { fear-TRV-LIG } \\ \text {-luhogala } & \text { desire } & \text {-luhogal'-e-na } & \text { desire-TRV-LIG } \\ \text {-hopu(-na) } & \text { descend } & \text {-hopun'-e-na } & \text { take.down-TRV-LIG }\end{array}$

The last root, hopu, is irregular in that transitivisation is built on the form hopuna, which never occurs in isolation.

8(127) A-luhogal'-e-na duma-ya.

ISG-want-TR V-LIG very-3SG

I really want/love $\mathrm{him} / \mathrm{her} / \mathrm{it}$.

2) Ligature is used with some verbs that have stems ending in $/ e /$.

$$
\begin{array}{ll}
\text {-gale-ya } & \text {-see-3SG } \\
\text {-gale-na } & \text {-see-LIG } \\
\text {-tahae-ya } & \text {-precede-3SG } \\
\text {-tahae-na } & \text {-precede-LIG }
\end{array}
$$

8(128) A-gale-na tuhaga-ya...

ISG-see-LIG find-3SG

I discovered that...

8(129) Hi-wele tahae-na me-hi.

3PL-give first-LIG RFX-CPY

They first of all gave themselves.

The verb gale-is irregular in that it always takes the ligature even when the derived construction is intransitive.
8(130) Apo gasi ta-gale-na nae buka gehou-na ugoli-na. FUT also IPL.INC-see-LIG DEI book other-3SG 'at'-3SG Let us examine another book.

Other verbs ending in $/ e /$ do not take the ligature.

$\begin{array}{llll}\text {-hoe-ya } & \text { open-3SG } & \text {-hoe hale-ya } & \text { open throw-3SG } \\ \text {-wele-ya } & \text { give-3SG } & \text {-wele tahae-ya } & \text { give first-3SG } \\ \text {-wiapapoe-ya } & \text { destroy-3SG } & \text {-wiapapoe duma-ya } & \text { completely destroy-3SG }\end{array}$


8(131) Ginouli-hi a-wele daman'-e-hi.

things-DEF ISG-give over-TRV-3PL

I transferred those things over.

The ligature attaches to one or two modifiers, so that it is not unusual to have two consecutive words marked with ligature.

8(132) Hi-hanapu-ge-na imahi-ye-na duma-ya.

3PL-know-TR V-LIG properly-TRV-LIG very-3SG

They completely understand it. 


\section{NOUN PHRASES}

\subsection{CONSTITUENTS OF THE SIMPLE NOUN PHRASE}

Noun phrases (NPs) are typically constructions "made out of a head noun plus some modifiers" (Givón 1990:465). NPs combine with VPs to form verbal clauses, the basic building blocks of narrative discourse.

The constituents of the Tawala noun phrase are as follows:

(Deictic) (Head) (Modifier) (Number) (Limiter) (Topic)

All items are optional. Any item can stand alone as a clausal NP.

(a) DEICTIC - demonstrative - a small set of items with a deictic function. When a demonstrative occurs without a head noun it can be modified by a small set of items.

(b) HEAD - The noun phrase head can be simple - a noun, pronoun, demonstrative, name or indefinite; or the head can be complex - a possessive construction, a relative clause or a nominalised form.

(c) MODIFIER - a construction modifying the head, often marked by a pronominal enclitic for agreement with the head - an adjective, an adjective phrase or an indefinite modifier.

(d) NUMBER - a slot that can be filled by a numeral. As numerals are often clauses, the internal structure of the item filling the number slot can be exceedingly complex.

(e) LIMITER - a small number of items specifying a limit to the NP as a whole and also marked with a pronominal enclitic for agreement with the head.

(f) TOPIC - A second function of the demonstrative within the NP is topicalisation.

The set of pronominal enclitics (Table 1) attach to the final item of many NP constituents: 1) the demonstrative, as a definite marker; 2) the head noun, as a possession marker (marking the person and number of the possessor), as a definite marker and as a marker indexing the person and number of the free-form pronoun; 3 ) the adjective, marking person and number agreement with the head noun; and 4) the limiter, also marking person and number agreement with the head noun. 
TABLE 1: PRONOMINAL ENCLITICS

\begin{tabular}{|c|c|}
\hline PERSON/NUMBER & PRONOMINALENCLITICS \\
\hline 1SG & $-u /-w e^{1}$ \\
2SG & $-m$ \\
3SG & $-n a$ \\
1PL.INC & $-t a$ \\
1PL.EXC & $-(i) y^{2} I^{1}$ \\
2PL & $-m i$ \\
3PL & $-h i$ \\
\hline
\end{tabular}

An understanding of the Tawala NP is central to an understanding of the functioning of these enclitics.

In this chapter NPs within clauses are in square brackets, and the constituent being focussed on is underlined, where considered necessary.

\subsection{NOUN PHRASE HEAD}

In this subsection we examine only simple items filling the NP head: nouns, pronouns, demonstratives, names and indefinites.

\subsubsection{NouNS}

Both underived and derived nouns freely occur by themselves (9(1)), or with other elements of the NP (9(2) and numerous examples within this subsection).

9(1) [Wam $]$ to-beiha.

boat IPL.EXC-search

We searched for a boat (to charter).

9(2) [Polo natu-na oloto-na emosi hota] e-ma-mae.

pig child-3SG male-3SG one only 3SG.PRES-DUR-stay

There is just one small male piglet left.

In $9(2)$ the head is a complex structure - a possessive phrase.

\subsubsection{EmPhatic Pronouns}

The emphatic pronouns are a set of stressed independent pronouns whose relationship to other pronominal sets has already been discussed $(\S 6.1 .1)$.

The following rule applies to the first person singular form:

$u>-w e / u$

2 For deletion rules of initial /i/ or final vowel of root see $\S 4.3 .1$. 
TABLE 2: EMPHATIC PRONOUNS

\begin{tabular}{|c|c|}
\hline PERSON/NUMBER & EMPHATIC PRONOUNS \\
\hline 1SG & tau \\
2SG & tam \\
3SG & tauna \\
1PL.INC & tauta \\
1PL.EXC & tauyai \\
2PL & taumi \\
3PL & tauhi \\
\hline
\end{tabular}

Emphatic pronouns are distinguished from personal markers on nouns and verbs. An independent emphatic pronoun may occur in the head slot of the NP in addition to the obligatory pronominal indexing of subject and object on the verb (9(3)). The primary function of emphatic pronouns is the marking of prominence and change of subject, whereas the primary functions of pronominal affixes are the tracking of referents and the indexing of grammatical relations.

9(3) [Naka tauhi $]$ hi-nei.

that they 3PL-come

Those ones have come.

The emphatic pronouns are only used for human referents and anthropomorphisms. On the other hand, demonstratives are used for either human or non-human referents. The same set of personal pronouns is used as both subject NP (9(3)) and object (9(4)).

9(4) [Tauna] to-wotago-ya.

him 1PL.EXC-follow-3SG

(It is) him we follow.

Emphatic pronouns are never modified by adjectives, but they may be modified by quantifiers agreeing with the head in person and number.

9(5) a. tauta atapu-ta b. tau tunawa-u

weINC all-1PL.INC I alone-1SG

we/us all I alone

9(6) [ [Tauyai atapu-yar] to-beiha.

weEXC all-1PL.EXC 1PL.EXC-search

We all searched.

Emphatic pronouns are also modified by possessed numerals. This construction is the normal device for indexing dual and trial number etc. The construction can occur with or without the pronoun head (9(7) and $9(8)$ respectively).

9(7) [Taumi omi tonuga] hi-gale-mi.

youPL yourPL three 3PL-see-2PL

They saw you three.

9(8) [ [ Hai tonuga] i-weluwini-hi.

their three 3SG-take.away-3PL

He took those three. 


\subsubsection{DEMONSTRATIVES}

Demonstratives readily function as heads of NPS.

9(9) [Geka] amaka a-howa-tepa-ni.

this already ISG-spit-top-3SG

I have already worked magic on this (one).

In $9(10)$ the underlined demonstrative is used anaphorically.

9(10) [Naka bada-na] i-woe-woe, [naka] i-ne-po... that man-DEF 3SG-DUR-paddle that 3SG-come-and

The bada was paddling; he came and...

When a demonstrative functions as the head constituent of the NP it commonly is accompanied by one of two general modifiers:

hota/hosi only, just

pite/ pete similarly

Variant forms are dialectal and to a certain extent stylistic.

The general modifier hota/ hosi is found with all the major word classes. It is commonly used to modify demonstratives, prompting the local sense 'here' rather than 'this'.

9(11) [ $U$ ba-bada] [geka hota] hi-mae.

my PL-man this only 3PL-stay

My ancestors stayed here.

The general modifier pite/ pete only occurs with demonstratives and verbs; with demonstratives it is best translated as 'like', though it is not to be confused with manner constructions using mei 'like'.

9(12) [Habulu-na] e-me-mae; $\quad$ ee [naka] [geka pite] galena-na. small-3SG 3SG.PRES-DUR-stay yes that this like appearance-3SG A small (one) is there; yes that (one's) appearance is like this (one).

\subsubsection{NAMES}

A name normally occurs without modification. When it is expanded it is in terms of a complex phrase (e.g. possessive or appositional phrase) and not the constituents of the simple NP.

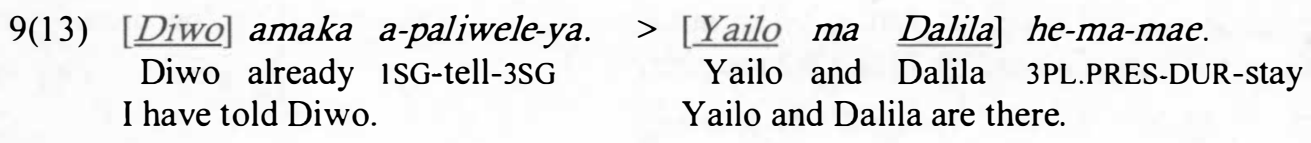

\subsubsection{INDEFINITES}

Basic interrogatives frequently fill the head of a noun phrase, functioning as indefinites.

9(14) Apo [iyai] [geka ginouli-hi] i-na-dewa-dewa-hi...

FUT who this thing-DEF 3SG-POT-DUR-do-3PL

Whoever does these things... 
9(15) Apo [awai] gasi a-nugo-nugotuhu-hi a-bah'-e-hi.

FUT what also ISG-DUR-think-3PL ISG-Say-TRV-3PL

I also said what I was thinking.

\subsection{DEFINITE MARKER}

The definite marker $-n a /-h i$ is used to mark an item whose identity the speaker assumes is known to the hearer; most often there is an anaphoric reference in the immediate context. However, unlike definite markers in many languages, these markers are optional and seem to be used when the item is both definite and in focus.

9(16) Hi-hopu po ega.yaka tewela-na, amalai hewali-na, naka hi-awala 3PL-go.down and so child-DEF today youth-DEF that 3PL-carry gelet'-e-ya.

appear-TRV-3SG

They went down and so the child [discourse topic], now (become) the youth, that (one) they bring up.

9(17) Itapa tau kapeu apo a-ta-pu-pou duma po pou-we-hi

CON I butterfly FUT 1SG-IRR-DUR-egg very and egg-1SG-DEF

hi-ta-luwowola po motamota.

3PL-IRR-hatch and worm

If I were a butterfly I would lay many eggs and my eggs would hatch and become worms.

Demonstratives also receive definite marking.

9(18) Dobu-na gowa-na Iwilabe ma gaima gowa-na Tilabe no-noka-hi... land-DEF name-3SG Iwilabe and rock name-3SG Tilabe RED-that-DEF The land called Iwilabe and the rock called Tilabe, those exact ones...

When a demonstrative modifier has a definite marker, the marker is reduplicated, forming a unique morpheme (-nana) having only this one function.

9(19) Inapa omi dewa [naka pite-nana/*pite-na]...

HYP yourPL custom that like-DEF

If your custom is like that...

9(20) [Naka hota-nana] a-ne hale-hi.

that only-DEF ISG-go throw-3PL

Like that (with all that work) I left them.

9(21) Ma a-dewa-dewa-hi, tam gasi u-na-dewa-hi [naka pite-nana].

and ISG-DUR-make-3PL youSG also 2SG-POT-make-3SG that like-DEF

As I am making them, you also make them like that.

With topicalisation the definite marking is on the head noun and not on the demonstrative.

9(22) Ma [dobu-na noka] dobu banei duma-na. and town-DEF thatTOP town big very-3SG

As for the town there it is a big town. 


\subsection{DEMONSTRATIVES}

The three demonstratives, geka proximal, naka neutral and noka distal, have a locative or spatial function ('here', 'there', 'far away' respectively); geka 'this' and naka 'that' also have a referential function. We noted above that the demonstrative can occur as the head of an NP; it also modifies head nouns.

9(23) Ma [geka u houga-na] ega emoemota-na [noka dewa-hi odubo-hr]... and this LOC time-DEF NEG ability-3SG there custom-DEF old-3PL But at this time it is not possible for those old customs...

\subsubsection{Marking Clausal Focus}

At the beginning of an NP the function of the demonstrative is to place the NP within clausal focus - the speaker makes it "the centre of his communicative interest; 'focus' in this sense is opposed to presupposition" (Crystal 1980:148). The presence or absence of demonstratives is determined by the pragmatics of the discourse.

9(24) [ Naka bada-na] i-woe-woe. that man-DEF 3SG-DUR-paddle

That man was paddling (his canoe).

9(25) [ Geka (tauhi hai tu-bagibagi) gehou-na] i-nei. this they their PER-work other-3SG 3SG-come This (fellow), one of their workers, came.

9(26) [Naka Ukarumpa ma Kainantu] a-gale-hi. that Ukarumpa and Kainantu 1SG-see-3PL I saw Ukarumpa and Kainantu.

9(27) [Naka lawa] [geka dobu-hr] hi-lowo hale-hi. that person this town-DEF 3PL-flee throw-3PL Those people fled from these towns.

\subsubsection{MARKING TOPICALISATION}

The demonstrative also occurs at the end of the NP, in which case it marks topicalisation - another pragmatic function. Topicalisation is very common within both verbal and nonverbal sentences. Again, distal and proximal forms are applicable.

9(28) Ma [odubo-na naka] a-lau-hilage duma.

and old-3SG thatTOP ISG-DUR-finish very

But as for the old times, I used to get very tired.

Topicalisation can occur with a demonstrative in the following phrase, so that two demonstratives are used consecutively.

9(29) Ma [meyagai geka] [naka meyagai dewadewa duma-na]. and village thisTOP that village good very-3SG As for this village that is a very good village. 


\subsection{MODIFIERS}

A modifier may be definite - an adjective (phrase) - or indefinite - an interrogative.

\subsubsection{ADJECTIVES}

Adjectives are mostly a derived class of words that function as posthead modifiers within the NP. An adjective takes a pronominal enclitic specifying the person and number of the head of the NP, as the number and person is often not explicit in the head itself.

$\begin{array}{rlrl}9(30) \text { a. } & \begin{array}{l}\text { numa dewadewa-na } \\ \text { house good-3SG }\end{array} & \text { b. } & \begin{array}{l}\text { numa dewadewa-hi } \\ \text { house good-3PL } \\ \text { good houses }\end{array} \\ & \text { a good house } & \text { d. } & \begin{array}{l}\text { lawa dewadewa-ta } \\ \text { person good-1PL.INC }\end{array} \\ \begin{array}{lll}\text { c. } & \text { lawa dewadewa-mi } \\ \text { person good-2PL } & & \text { us good people }\end{array} & \end{array}$

9(31) [Mamae odubo-na] yohola hi-na-dewa-dewa-ya. stay old-3SG later 3PL-POT-DUR-do-3SG They will continue following the old life-style.

9(32) [Bolu habulu-mi] ega o-na-mato-matouta. group small-2PL NEG 2PL-POT-DUR-be.afiraid You (members of the) small group don't be afraid.

An adjective readily occurs as the sole constituent of the NP, though usually by deletion of the head noun.

9(33) [(Ginouli) yoliyoli-na] $i$-na-yoli.

thing sinking-3SG 3SG-POT-sink

A thing that sinks will sink.

9(34) [(Logaloga) apapoe-mi] o-na-ma-mae.

children bad-2PL 2PL-POT-DUR-stay.

You bad children will stay (behind).

In 9(35) there are two NPs in apposition, the first being a pronoun.

9(35) [Taumi] [ol-oloto wou-mI] i-na-wiatatiye-mi.

youPL PL-male new-2PL 3SG-POT-show-2PL

You new (i.e. newly initiated) men, he will teach you.

It is possible to omit the pronominal enclitic from the adjective, in which case the construction is non-specific.

9(36) [Houga dewadewa] to-wialon'-i.

time good IPL.EXC-face-3SG

We struck a period of good weather.

9(37) Hoimalatom apo [houga dewadewa]...

tomorrow FUT time good

Tomorrow if it is good weather... 


\subsubsection{ADJECTIVE PHRASES}

Adjectives can be modified, though in my data this is more common with predicative use than with attributive. Only two general modifiers function within the adjective phrase: duma 'very' and hota/ hoti/hosi 'only, just'. The pronominal clitic attaches to the final item of the adjective phrase - the adjective or the modifier if one is present.

$9(38)$ a. gadiwewe banei duma-na rain big very-3SG a very big rain b. houga kuku hota-na time short only-3SG a very short time

9(39) [ Witai banei duma-na] hi-wialon'-i. heavy big very-3SG 3PL-face-3SG They faced a really big problem.

The ablative enclitic attaches to the phrase as a final enclitic.

9(40) ita dewa odubo-na-gei

ourINC custom old-3SG-ABL

from our old customs

\subsubsection{INDEFINITE MODIFIERS}

Interrogative indefinites function not only as heads of NPs, but also as modifiers of nouns, marking NPs as indefinite in the sense that their referents are unknown or not specified. The structure involves an embedded indefinite relative clause.

9(41) [Lawa iyai/awai] e-i-haguhagu] o-na-hagu-ya. person who/what 3SG.PRES-DUR-help 2PL-POT-help-3SG Help a person who helps.

9(42) [ $U$ bagibagi awai] a-dewa-dewa-hi... my work what ISG-DUR-do-3PL Whatever work I do...

A reduplicated form of the interrogative functions as a unit within the modifier slot, indicating that several separate items or individuals are involved.

9(43) [ $A$ baha awai awai] i-bahe-bah'-e-hi.

his word what what 3SG-DUR-say-TRV-3PL

He was speaking whatever (came to his mind).

9(44) [Lawa iyai iyai] $u$ baha i-no<o>noli-hi... person who who my word 3SG-hear<DUR $>-3 \mathrm{PL}$

Those people who were hearing (i.e. responding to) my words...

\subsection{NUMBER PHRASES}

Numerals are second-order posthead modifiers. In Tawala, numerals are never marked by pronominal enclitics. 
9(45) [Bolima luwaga] hi-kokoe. year two 3PL-finish

Two years went by.

9(46) [Natu-natu-na wohepali] hi-me-mae.

PL-child-3SG four 3PL-DUR-stay

He had four children.

Adjectives and numerals can occur within the same phrase.

9(47) [Kiu muhomuho-hi luwaga] hi-yato.

bird smallPL-3PL two 3PL-land

Two small birds landed.

9(48) [Alugo palopalouma-hi tonuga] hi-geleta.

spirit witchish-3PL three 3PL-appear

Three witch spirits appeared.

Numerals greater than five involve one or more embedded clauses.

9(49) [Wamahiya nima luwaga hi-tutu po emosi] i-me-mae.

moon hand two 3PL-hit and one 3SG-DUR-stay

He was staying eleven months.

Complex nominalised numeral constructions are a special form of possessive phrase.

Numerals can be modified by the general modifier hota 'only'.

9(50) [ Wam luwaga hota] hi-gota.

boat two only 3PL-arrive

Only two boats arrived.

\subsection{LIMITERS}

Quantifiers function as limiters within a third-level modifier slot; they all take pronominal enclitics marking person and number agreement with the head: tunawa-na (L. tuqawa-na) 'alone', atapu-na 'all', tupo-na 'part', tapu-na 'different' and gehou-na 'other'.

9(51) Ma wawine [tauna tunawa-na] i-hanapuge-ya.

and woman she alone-3SG 3SG-know-3SG

But the woman, she alone knew it.

9(52) [Ginouli atapu-na naka] i-yoli.

thing all-3SG thatTOP 3SG-sink

The whole thing had sunk.

The head noun can be deleted, leaving the quantifier as the only constituent of the NP; the enclitic pronoun indexes the person and number of the head.

9(53) [Atapu-yai] to-dewadewa.

all-IPL.INC IPL.INC-good

We are all well. 


\section{9(54) [Lawa luwaga naka] [gehou-na] Kukuku ma [gehou-na] Oima. person two thatTOP other-3SG pheasant and other-3SG ant As for those people, one was Lizard and the other Ant.}

The limiter is a third order of modifiers, following adjectives and numbers.

9(55) [Ginouli apapoe-na atapu-na]
thing bad-3SG $\frac{\text { all-3SG }}{\text { 3SG-finish }}$

All the bad things are finished.

9(56) [Dewa luwaga gehou-na] he-ma-mae. custom two other-3SG 3PL.PRES-DUR-stay

There are two more customs.

The order of the modifiers in 9(55) and 9(56) cannot be reversed. When an adjective and a limiter occur together, both can be marked for agreement with the head (9(55), 9(57)).

9(57) [Meyagai apapoe- $\underline{\text { i }}$ gehou- $\underline{\text { hi }}]$ to-gale-hi.

village bad-3PL other-3PL IPL.EXC-see-3PL

We saw the other bad villages.

If the pronominal enclitic is omitted from the adjective, the construction is non-specific (9(36), 9(37), 9(58)).

9(58) [Dewa apapoe gehou-na] e-me-mae.

custom bad other-3SG 3SG.PRES-DUR-stay

Another bad custom exists.

The items wawine-na 'female' and oloto-na 'male' form a special subclass of nouns that also function within the limiter slot. These two items should probably not be classed as adjectives, as they are marked for plural number.

SINGULAR PLURAL

oloto- ol-oloto- male(s)

wawine- wiwine- female(s)

9(59) [(Natu-we) emosi hota oloto-na] e-ma-mae.

child-ISG one only male-3SG 3SG.PRES-DUR-stay

I have just one son.

This situation is not without a degree of ambivalence, as the order of constituents in 9(59) can be reversed, as in 9(60), with the numeral following the noun in the adjectival position.

9(60) [Polo natu-na oloto-na emosi hota] e-ma-mae.

pig child-3SG male-3SG one only 3SG.PRES-DUR-stay

There is just one male piglet.

9(61) [(natu-natu-na ol-oloto-hi) luwaga]

PL-child-3SG PL-male-3PL two

his two male children

An alternative analysis would class the two items as a special subclass of adjectives, their special semantics being responsible for their unique plural forms. 


\subsection{MARKING NEW NPs}

The quantifier gehou<-na> 'other' marks new items which are introduced for the first time into a text $(9(54), 9(62))$. The item is indefinite in the sense that the speaker has not referred to the item previously and thus gehou<-na>contrasts with the definite marker.

9(62) Maliwa po ilimo po gasi [mayau gehou-h1] he-me-mae. maliwa and ilimo and also tree other-3PL 3PL.PRES-DUR-stay There are maliwa and ilimo and other types of tree.

If it is required to spell out that the new item is also indefinite in the sense that the item is unspecified or unknown, then the quantifier is prefixed with the unspecified marker $i$.

9(63) Naka hosi [bonabona i-gehou-na] i-gale-ya.

that only island UNSP-other-3SG 3SG-see-3SG

There he saw a certain island.

$\begin{array}{llll}\text { 9(64) Ega.yaka } & \text { [hewa-hewali } & \text { i-gehou-h1] } & \text { hi-wiwogatala. } \\ \text { so } & \text { PL-youth } & \text { UNSP-other-3PL } & \text { 3PL-plan }\end{array}$

And so certain youths made plans.

\subsection{THE MODIFIER gasi}

The modifier gasi 'also' is perhaps best regarded as an operator on the NP and possessive phrase (similar to adverbs which are clause operators), in that it has no fixed position, but is placed adjacent to the item it modifies.

9(65) Ma [gasi ginouli gehou-na] a-gale-ni.

and also thing other-3SG 1SG-see-3SG

I saw something else also.

9(66) [A logaloga ma gamogamo gasi] i-na-wi-am imahi.

his children and animal also 3SG-POT-DVP-eat properly

He will properly feed his children and animals also.

\subsection{POSSESSIVE PHRASES}

NP's with possessive meaning... have one and the same structure, cross-linguistically: the phrase is an endocentric NP with the possessed noun as head and the possessor as its modifier or dependent.

Nichols (1988:558)

The NP head is often filled by a single item, but can also be filled by complex structures including possessive phrases.

9(67) [Bada a gapola] o-na-galenaitete-hi.

man his possession 2SG-POT-care.for-3PL

Look after the man's things carefully.

The distinguishing features of Tawala possession are that possession is head marked and there is an alienability opposition. Nichols (1988:582) demonstrates that the presence of head-marked possession in a language "virtually guarantees that the language will have an alienability opposition". 
Tawala possessive phrases are typically Oceanic in both grammar and semantics. Tawala has two possessive constructions that have generally been referred to as 'alienable' and 'inalienable' possession (Codrington 1885, Ray 1926, Lynch 1973, Pawley 1973, etc.). ${ }^{3}$ Both structures consist of an optional possessor noun followed by the possessed noun. Both structures are head marked. They differ in the form of marking as well as in the semantics of the participating nouns. With alienable possession $(9(68))$ the possessive marker is an independent possessive pronoun that comes before the head; with inalienable possession (9(69)) the possessive marker is a pronominal enclitic on the head.

9(68) $[$ Peuka $\underline{a}$ wam] i-yoli.
Peuka his boat 3SG-sink
Peuka's canoe sank.
9(69) [ Yailo natu-na] i-nae.
Yailo child-3SG 3SG-go
Yailo's child has gone.

ALIENABLE: (POSSESSOR NP) $+<a>$ POSSESSED NOUN

INALIENABLE: (POSSESSOR NP) + POSSESSED NOUN<-na>

The person/number forms of the possessive pronouns and possessive (pronominal) enclitics are set out in Table 3. A relationship in form between the enclitics and the independent pronouns is obvious for most items.

TABLE 3: POSSESSIVE PARTICLES

\begin{tabular}{|l|l|l|}
\hline PERSON/ & POSSESSIVE & POSSESSIVE \\
NUMBER & PRONOUNS & ENCLITICS \\
\hline ISG & $u$ & $-u /-w e$ \\
2SG & om/am & $-m$ \\
3SG & $a$ & $-n a$ \\
IPL.INC & ata/ita & $-t a$ \\
IPL.EXC & $i$ & $-(i) y a i$ \\
2PL & omi & $-m i$ \\
3PL & hai & $-h i$ \\
\hline
\end{tabular}

With many nouns the Tawala speaker does not freely choose which type of possession to use; this is already determined by the lexicon. Certain noun subclasses involve bound nouns and must be morphologically marked with a pronominal enclitic. These are the inalienable class, a closed set of nouns which include kinship terms, body parts, relationship terms (both spatial and whole-part) and quantifiers. Other nouns belong to an open set called the alienable class. In this situation we are dealing with possessive classes and not gender. ${ }^{6}$

3 Oceanic languages are distinguished by a proliferation of possession classes (Lynch 1973). Papuan Tip languages have either two or three classes (Lithgow 1976b). Having only two classes - alienable and inalienable - Tawala does not reflect any Oceanic innovations, only the proto-Oceanic pattern. $a m$ is Labe dialect, $o m$ other dialects.

5 A good deal of free variation occurs between these forms, though the distinctions are dialectal - Labe prefers ata and Diwinai ita. The form eta is also occasionally encountered - possibly originally a Kehelala form. 
This is, however, only part of the picture. Some nouns do have a genuine choice between alienable and inalienable structures: a yam (woida) has a different relationship to its garden (tano) (woida tano-na 'the yam's garden') than a woman (keduluma) has who tends her garden (keduluma a tano 'the woman's garden').

When there is a choice in Tawala, alienable possession marks situations where the possessor has control over the relationship, and inalienable possession marks situations in which the possessor does not have control over the relationship. Many abstract nouns action nominalisations - can function as alienable or inalienable possession, illustrating the contrast between plus or minus control.

$\begin{array}{ll}\text { Inalienable Possession }-[- \text { CONTROL }] & \text { Alienable Possession - [+CONTROL] } \\ \text { 9(70) bada bagibagi-na }> & \text { bada a bagibagi } \\ \text { man work-3SG } & \text { man his work } \\ \text { the man's work } & \text { the man's work } \\ \text { (= work done for the man) } & \text { (= work done by the man) }\end{array}$

This option between the two structures is similar to the subjective genitive and objective genitive distinction of European languages. Thus a luhogala 'his love (for someone)' contrasts with luhogala-na 'his love (someone's love for him)'.

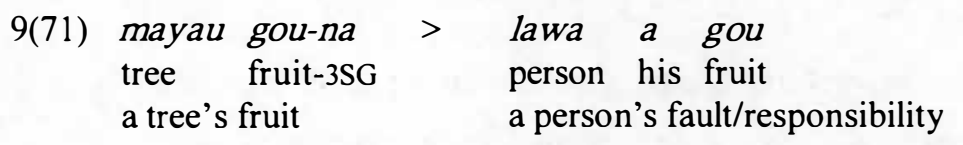

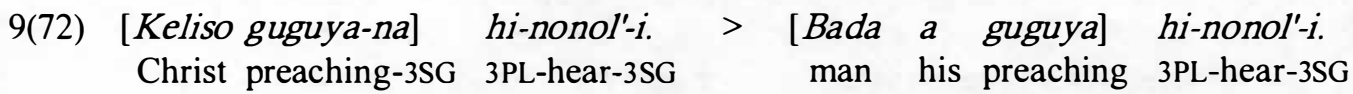

They heard the preaching about Christ. They heard the man's preaching.

\subsubsection{INALIENABLE Possession}

We noted above that the inalienable possessive construction consists of an optional possessor NP and a possessed NP marked for person and number agreement with the possessor NP.

$($ POSSESSOR NP) + POSSESSED NOUN $<-$ na>

\begin{tabular}{|c|c|c|c|c|c|c|}
\hline $9(73)$ & a. & $\begin{array}{l}\text { nou-we } \\
\text { sister-1SG } \\
\text { my sister }\end{array}$ & b. & $\begin{array}{l}\text { polo giu-na } \\
\text { pig tail-3SG } \\
\text { pig's tail }\end{array}$ & c. & $\begin{array}{l}\text { koiba-ta } \\
\text { stomach-1PL.INC } \\
\text { our stomachs }\end{array}$ \\
\hline & d. & $\begin{array}{l}\text { neula sipoli-na } \\
\text { coconut middle-3SG } \\
\text { coconut trunk }\end{array}$ & e. & $\begin{array}{l}\text { mayau lugulugu-na } \\
\text { tree leaves-SG } \\
\text { tree leaves }\end{array}$ & f. & $\begin{array}{l}\text { goila mata-na } \\
\text { river eye-3SG } \\
\text { source of river }\end{array}$ \\
\hline & g. & $\begin{array}{l}\text { numa hine-na } \\
\text { house inside-3SG } \\
\text { house's inside }\end{array}$ & h. & $\begin{array}{l}\text { Bohibohi mutu-na } \\
\text { Bohibohi point-3SG } \\
\text { Bohibohi Peninsular }\end{array}$ & i. & $\begin{array}{l}\text { kamkam pou-na } \\
\text { chicken egg-3SG } \\
\text { chicken's egg }\end{array}$ \\
\hline
\end{tabular}

Hopper and Thompson (1984:724) point out that the morphology of inalienable possession in many languages demonstrates 'reduced categorality'. Thus in Tawala inalienable possession is encoded by an attached suffix in contrast to alienable possession which is encoded by a free-form possessive pronoun. 
In 9(74) the possessor (in parenthesis) is expanded to a modified NP.

9(74) (polo habulu-hi) tala-hi

pig small-3PL blood-3PL

the blood of piglets

The possessed noun of both alienable $(9(75))$ and inalienable $(9(76))$ constructions can also be modified.

9(75) [Bada a wam wou-na] i-gota.

man his boat new-3SG 3SG-arrive

The man's new boat arrived.

9(76) [Pegapega ano-hi gou-h1] i-'mgomugomu.

corn core-3PL ripe-3PL 3SG-break

She is breaking off ripe corn heads.

The marker on the head indexes the dependent possessor, and the marking on the adjective agrees with the head, hence they do not have to agree.

9(77) [Natu-natu-we dewadewa-m1] taumi.

PL-child-1SG good-2PL youPL

You are my good children.

The inalienable-possessive construction can be marked with the ablative enclitic.

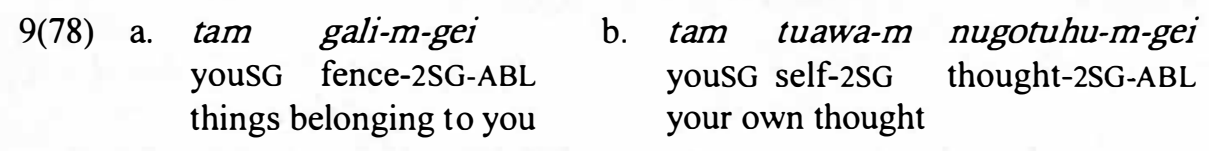

9(79) [Oya tepa-n'-e1] hi-hopu mai.

mountain top-3SG-ABL 3PL-come.down DEI

They came down from the top of the mountain.

\subsubsection{Alienable Possession}

We noted above that the alienable possessive construction consists of an optional possessor NP, a possessive pronoun marked for person and number specification of the possessor, and a possessed NP.

(POSSESSOR NP) $+<a>+$ POSSESSED NOUN

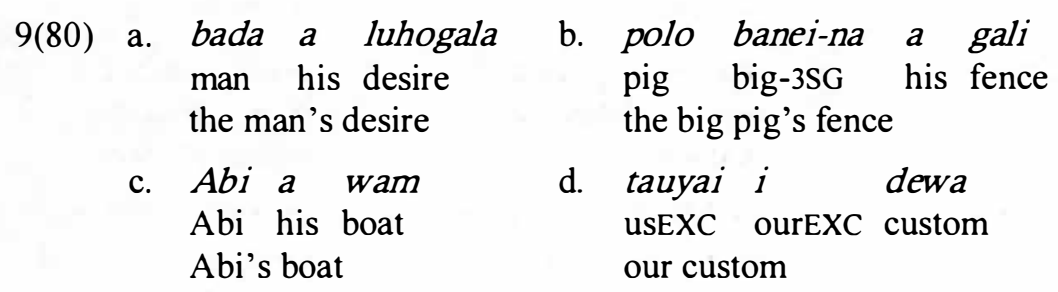


$\begin{array}{llll}\text { e. taniwaga a lugagayo f. } & u \text { tewela } \\ \text { ruler } & \text { hy child } \\ \text { the boss's rule } & & \text { my young sibling? }\end{array}$

In $9(81)$ the head noun (underlined) is a nominalised construction.

9(81) [Geka tauhi hai tu-bagibagi gehou-na] $i$-nei. this they their PER-work other-3SG 3SG-come One of their workers came.

The alienable-possessive construction can be marked with the ablative enclitic.

9(82) I-tu-tou [hina-na a tou-get].
3SG-DUR-cry mother-3SG her cry-ABL
He was calling with his mother's call.

When two possessive phrases are coordinated, identical nouns in the second conjunct are deleted. In 9(83) the possessor (bada) is deleted and in 9(84) both the possessor (bada) and possessed (natu-na) nouns are deleted. (This option is not available if the alienability of two items is different.)

9(83) [bada natu-na wawine-na] ma [a polo wawine-na] man child-3SG female-3SG and his pig female-3SG the man's female child and his female pig

9(84) [bada natu-na wawine-na] ma [oloto-na] man child-3SG female-3SG and male-3SG the man's female and male children

\subsubsection{Modified Possessive Construction}

Possessive suffixes may be omitted if a general modifier is present and the marking on the noun and the modifier is identical. This presents the speaker with two options.

9(85) bada natu duma-na
$\begin{aligned} & \text { man child real-3SG } \\ & \text { the man's real child }\end{aligned}$

When the possessor is a non-third person referent the issue becomes clearer.

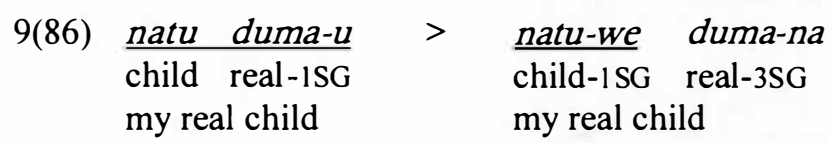

The different morphological marking indicates different structures; however, I am not aware of the meaning difference involved here. In order to clarify the situation I have underlined the heads in the phrases here. The head must end with a pronominal enclitic that indexes the possessor; a modifier preceding the pronominal enclitic is part of the head phrase and is morphologically unmarked. If a modifier occurs after this pronominal enclitic it is a posthead modifier (filling the modifier slot of the NP) and must agree with the head.

This kinship term does not belong to the bound class. Nichols (1988:568) notes that "for most languages there are other nouns of the same semantic types, whose possession is equally inherent, but which just happen not to belong to the bound set". 
The option does not exist with the alienable construction, as the possessive marker occurs bef ore the head.

9(87) $\frac{i \quad \text { meyagai }}{\text { ourINC village very-3SG }}$
our real village (burial place)

\subsubsection{ReCURSIVE Possessive Phrases}

One possessed construction is often embedded within another, with no restriction on the type of embedding - alienable within alienable or inalienable constructions and vice versa.

9(88) Wawine [go<o>ga-na (pona-hi)] i-nonoli-hi.

female ancestor $<$ PL $>$-3SG voice-3PL 3SG-hear-3PL

The woman heard the voices of her ancestors.

9(89) [Tu-bahapiko a (baha ano-na)] i-lugelete-ya.

PER-riddle his word core-3SG 3SG-appear-CPY

The bard's prediction has come about.

\subsection{ABLATIVE ENCLITIC}

The ablative marker is a final enclitic of the NP.

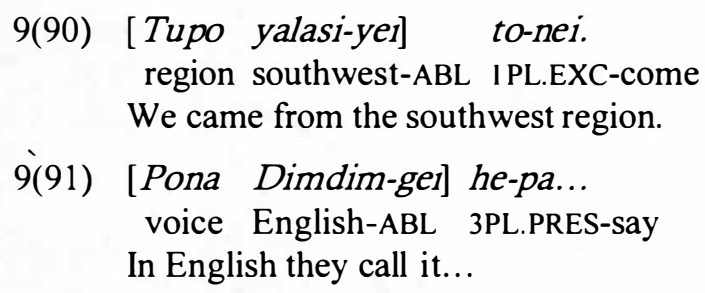

Recall that the ablative enclitic marks three basic relationships: instruments $(9(92))$, origin (9(93)) and path $(9(94))$.

9(92) Kedewa-na woe-gei i-lau-laun-i.

dog-DEF paddle-ABL 3SG-DUR-hit-3SG

She was hitting the dog with a paddle.

9(93) Beya-n'-ei tala hi-kolo-kololo.

ear-3SG-ABL blood 3PL-DUR-drip

Blood was dripping from his ears.

9(94) Mei iyeta luwaga bog'-ei i-teno-tenom nae.

like day two sea-ABL 3SG-DUR-float go

For about two days he drifted in the ocean.

With inalienably possessed phrases the ablative suffix fuses with the pronominal enclitic.
9(95) To-lupali [Yesu gowa-n'-e1].
1PL.EXC-pray Jesus name-3SG-ABL
We pray in Jesus' name.


9(96) [Lawa mata-h'-iyer] hi-gale-ya. person eye-3PL-ABL 3PL-see-3SG

The people saw it with their own eyes.

\subsection{COMPOUND PHRASES}

The distinguishing feature on compound phrases is the presence of two items juxtaposed or joined with a conjunction.

$$
\text { ITEM + (CONJUNCTION })+ \text { ITEM }
$$

There is a strong tendency for the two items to have identical structure. Hence, if one is a simple noun the second usually is also; if the first has a demonstrative then the second usually has also, etc. Basically, the heads of any simple NPs (interrogative, adjective, possessive phrase etc.) can be combined to form a compound phrase.

There are two types of compound phrase, depending on the nature of the juncture and also on verbal agreement.

TABLE 4: COMPOUND PHRASE TYPES

\begin{tabular}{|l|c|}
\hline PHRASE TYPE & JUNCTURE \\
\hline COORDINATE PHR ASE & $p o, m a$ \\
ALTERNATE PHRASE & $b o, o o$ \\
\hline
\end{tabular}

The conjunction $p o$ 'and' is used when the items are closely related in the mind of the speaker. The conjunction ma 'and, also' is used when the two items are different or thought to have separate identity in the mind of the speaker. Judgements differ from speaker to speaker in the same situation, and also a speaker's judgement differs in the same kind of situation at a different time.

\subsubsection{CoORdinate PhraSe with po}

Within coordinate phrases, $p o$ is more common than ma (which is more common at the clause level). The po construction is also used to join items that cannot be joined by maidentical items, numerals, certain modifiers, antonym pairs, etc.

\subsubsection{NoUNS}
a. goila po oya water and mountain
b. pitapita po niha-na bush and beach-DEF rivers and mountains the bush and the beach c. oloto po wawine male and female a male and a female

\subsubsection{Pronouns AND KinSHIP TeRmS}
a. tau po tam
b. ama-ta
po hina-ta
po ata
ba-bada
I and yousG I and you father-1PL.INC and mother-1PL.INC and ourINC PL-man
our fathers and mothers and our big men 


\subsubsection{MODIFIERS}

Quantifiers can be coordinated.

9(99) a. meyagai gehou-hi po gehou-hi

village other-3PL and other-3PL

various villages

b. gutaguta tapu-na po tapu-na

parts different-3SG and different-3SG

various parts

When adjectives are conjoined, an antonym pair is involved. Marking for number and person must be identical on each part.

ADJECTIVE + po+ ANTONYM

9(100) meyagai banei-hi po habulu-hi

village big-3PL and small-3PL

big and small villages

Only po is used when identical numerals or quantifiers are conjoined; the structure has a distributive meaning.

$\begin{array}{lll}\text { 9(101) a. emosi po emosi } & \text { b. yamoha po yamoha } & \text { c. ubona emosi po emosi } \\ \text { one and one } & \text { each and each } & \text { star one and one } \\ \text { each one } & \text { each one } & \text { each star }\end{array}$

Only $p o$ is used with interrogative indefinites.

$\begin{array}{llllll}9(102) \text { a. } \begin{array}{l}\text { meka po meka } \\ \text { where and where }\end{array} & \text { b. } \begin{array}{l}\text { awai po awai } \\ \text { what and what } \\ \text { wherever }\end{array} & \begin{array}{l}\text { c. iyai po iyai } \\ \text { whotever }\end{array} & \begin{array}{l}\text { who and who } \\ \text { whoer }\end{array}\end{array}$

\subsubsection{POSSESSIVE PHRASES}

9(103) [ata tano bagibagi-na] po [ata gamogamo galenaitete-hr] ourINC garden work-3SG and ourINC animal care.for-3PL our agriculture and our husbandry

\subsubsection{COORDINATE PHRASE WITH ma}

The range of items which can be joined by $m a$ is less extensive than the po constructions; numerically, they are also less frequent in texts. The ma construction is never used when the two items are identical (as with numerals and interrogatives); rather ma has an additive meaning.

$\begin{array}{ll}\text { 9(104) a. } & \text { tu-Wao ma tu-wisili } \\ & \text { PER-row and PER-fishing } \\ \text { an oarsman and fisherman [same person in context] } & \\ \text { b. a keduluma ma hina-na } & \text { c. polo ma aniani dimdim } \\ \text { his woman and mother-3SG } & \text { pig and food European } \\ \text { his wife and his mother } & \text { pork and trade food }\end{array}$



d. hina-hina-hi ma am-ama-hi
e. tau ma Mika
PL-mother-3PL and PL-father-3PL their mothers and fathers
I and Mika
Mika and I

Only non-identical numerals and quantifiers are joined with $m a$; the resultant meaning is additive rather than distributive.

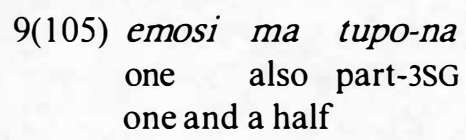

\subsubsection{Alternate PhRases}

Two conjunctions, bo 'or' and $o o$ 'or', are used for alternatives. The bo form has a broader function and greater frequency of use; the latter form is probably a borrowing from English, but is used widely in the two dialects I have had most contact with. It has not been possible to establish any meaning difference between the two conjunctions, however there is a broad functional distinction between them, as the following data reveal; simple NPs (9(106)) and possessive phrases $(9(107))$ are used with either form.

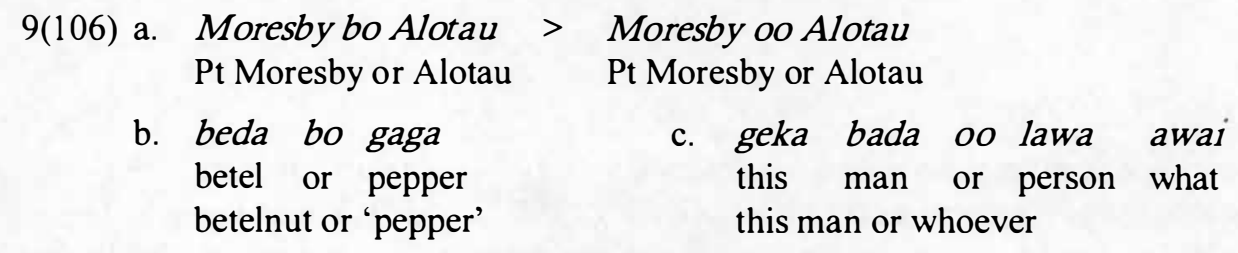

9(107) a. googa-ta hai dewa oo ita dewa ancestor-1PL.INC their custom or ourINC custom our ancestors' customs or our customs

b. hai rais bo hai ti habulu-na their rice or their tea small-3SG their (small) meal or cup of tea [food involved]

With numerals (9(108), 9(109)), pronouns (9(110)) and kinship terms (9(111), 9(112)) only the bo form is used.

9(108) a. bolima emosi bo wamahiya 10 year one or moon ten a year or 10 months b. iyeta luwaga bo wohepali day two or four two days or four

9(109) [Iyeta luwaga bo wohepali] e-togo-togo geleta. day two or four 3SG.PRES-DUR-blow arrive It blows for two to four days.

$\begin{array}{lllll}9(110) \text { a. } \begin{array}{lll}\text { tam bo tau } \\ \text { yousG or me }\end{array} & \text { b. } \begin{array}{l}\text { tam bo Tibe } \\ \text { yousG or Tibe } \\ \text { you or me }\end{array} & \begin{array}{l}\text { om lawa bo tunawa-m } \\ \text { you or Tibe }\end{array} & \begin{array}{l}\text { yoursG person or alone-2SG } \\ \text { your friend or you yourself }\end{array}\end{array}$

9(111) u hewa-hewali bo natu-natu-we

my PL-youth or PL-child-ISG

my followers or my children 
9(112) Geka Yailo natu-na bo au-na.

this Yailo child-3SG or uncle-3SG

This is Yailo's child or nephew/niece. [non-verbal hypothetical construction]

A third alternative NP can be added as an afterthought.
9(113) [Beda bo gaga] to-wele-ya [bo aniani]. betel or pepper 1PL.EXC-give-3SG or food We give him betelnut or 'pepper', or food.

Coordinate structures are often embedded within coordinate structures.

9(114) [(Moresby bo Alotau) oo (meka po meka)]
Moresby or Alotau or where and where
Moresby or Alotau or wherever

The alternative construction is used to give alternative lexical items, in this case dialectal alternatives.

9(115) Bisiya bo gina-ginahi ta-bol'-i.

sago or RED-sago 1PL.INC-cut-3SG

We cut sago fronds (for walling).

\subsection{CONJOINED NPs}

The associative conjunction mite $<-h>>$ 'together- $<3 \mathrm{PL}>$ ' is involved in conjoining NPs that function as core arguments of the clause. Givon (1984:127-130) defines the associative case role as a "co-agent...that is outside the focus of importance...i.e. one who performs the action together with the subject agent, though is in some sense in a less-focal, subservient role". This definition captures nicely the function of the associative phrase $(9(116))$ in Tawala, where it differs semantically from the comitative phrase $(9(117))$ precisely because it codes a co-actor, whereas the comitative phrase involves a subservient actor. Within the clause the verb is marked for agreement with both the actor and the co-actor, but does not include the subservient actor.

9(116) [Bada natu-na miteht] hi-nei.

man child-3SG together 3PL-came

The man came with his child.

9(117) Bada [a kedewa-na] i-nei.

man COM dog-3SG 3SG-come

The man came with his dog.

The two constructions differ also in respect to their function within the proposition. The comitative phrase is an oblique argument and is a true prepositional phrase. Associative phrases fill core arguments, and mitehi functions as a conjunction rather than a postposition.

Postpositions are marked for pronominal agreement with their object. As the postpositional phrase is an oblique argument, the pronominal agreement is not crossreferenced on the predicate. 
9(118) [Lawa ubei-mi] a-ne-nae. person BEN-2PL 1SG-DUR-go

I am going for you people.

In contrast the pronominal enclitic of associative phrases indexes additional items of the argument, and the predicate agreement includes both items.

9(119) [ Taumi mite-u] ta-kaoha.

youPL with-1SG 1PL.INC-happy

Let's be happy (together).

The postpositional conjunction mitehihas lost its inflection for person and number in its normal function with the simple associative phrase. However, with mite $<$-hi> inflection for person and number is retained within the pronominal associative phrase.

\subsubsection{Simple Associative Phrase}

The simple associative phrase differs from coordinate phrases in that the postpositional conjunction mitehi (some dialects miteka) comes after the conjoined items, not between them. With no inflection for person and number agreement, mitehi is accordingly glossed 'together'.

9(120) O tinani-hi [natu-natu-we hina-mi mitehi]. oh greeting-PL PL-child-1SG mother-2PL together Greetings, my children with your mother.

9(121) [ Tau ma Bryan a manago miteht] to-gelu. I and Bryan his family together 1PL.EXC-embark I, with Bryan and his family, got on board.

9(122) Ipa [logaloga hina-mi po goga-mi mitehr] o-na-ma-mae. CON children mother-2PL and grandmother-2PL together 2PL-POT-DUR-stay Children with your mother and grandmother, you all ought to stay.

The first conjunct can be omitted if its reference is recoverable. Hence the structure is:

(NP) NP mitehi

9(123) Wam hi-gelu-ya ega [bada miteht]. boat 3PL-board-3SG NEG man together They boarded the boat without the man.

\subsubsection{Pronominal Associative Phrases}

The pronominal associative phrase consists of an independent pronoun together with an associative conjunction (mite $<-h i>$ ) marked for person and number. Hence the structure is:

Pronoun mite $<$-hi>

On the surface, mitehi in 9(124) appears to be the same as in 9(123); however, the presence of a pronoun within the NP indicates an assocative conjunction in 9(124). 
9(124) Ega [tauna mite-hi] hi-ta-lui.

NEG he with-3PL 3PL-IRR-go.in

He did not go in with them.

The pronominal nature of associative conjunctions is clear in the following examples.

9(125) [ Tau mite-mI] ta-memae.

I with-2PL IPL.INC-stay

I and you are staying together.

9(126) [Taumi mite-u] ta-kaoha. youPL with-ISG IPL.INC-happy

Be happy (together) with me.

Note that in the last two and the next two examples the subject marking on the verb clearly cross-references both items of the pronominal associative phrase

9(127) [ Tam mite-iyal] ta-nae.

youSG with-1PL.INC IPL.INC-go

(Please) come with us.

9(128) Apo [tauhi mite-u] to-gelu.

FUT they with-1SG 1PL.EXC-embark

They will embark with me.

The pronoun is occasionally separated from the postposition; the conjunct is omitted from the pronominal associative phrase because it is elsewhere in the clause.

9(129) Apo tau (houga magomagou-na) mite-mi ta-memae.

FUT I time all-3SG with-2PL 1PL.INC-stay

I will stay with you always.

\subsection{PHRASES IN APPOSITION}

NPs can be placed in apposition, with no restriction on either NP; the second NP clarifies the first or makes it more specific.

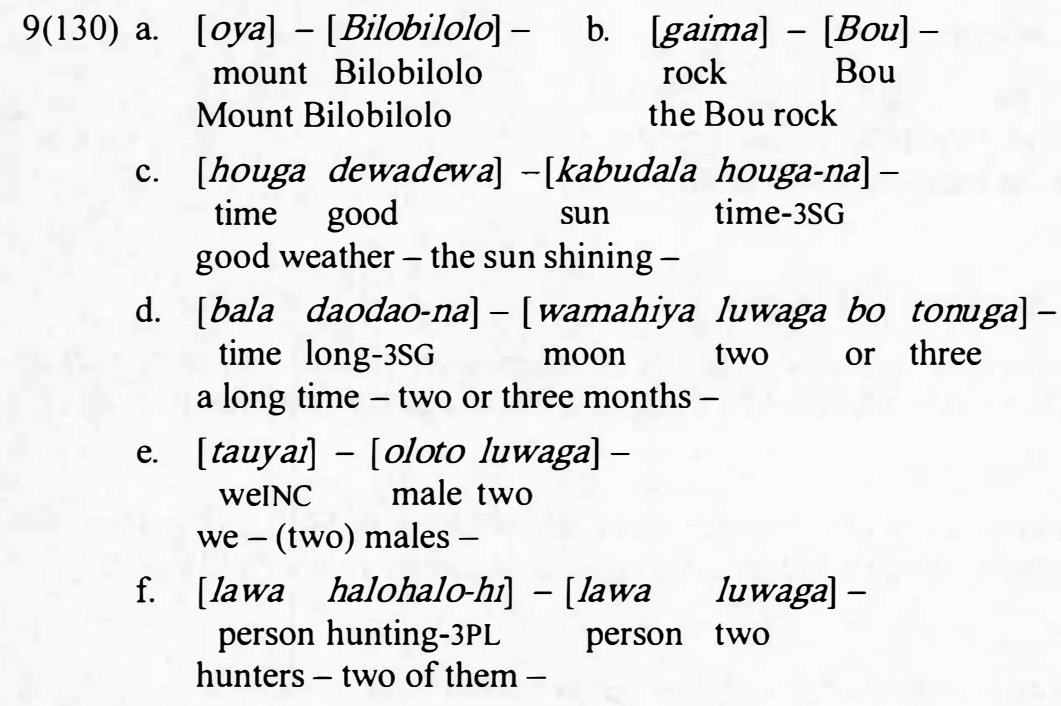




\section{ADPOSITIONAL PHRASES}

...something corresponding to the core/oblique distinction in English seems to exist in most such languages. One set of cases, commonly called 'syntactic' cases, code the core functions, another, commonly called 'semantic' cases, mark the oblique functions...the grammatical function of obliques...can for the most part be identified with their semantic role.

Andrews (1985:82)

\subsection{PREPOSITIONAL PHRASES}

There are five distinct prepositional phrase types (in square brackets in this section): two closely related locative phrases, a manner phrase, a comitative phrase and a human condition phrase. In each case the phrases are distinguished by the prepositions involved.

TABLE I: PREPOSITIONAL PHRASE TYPES

\begin{tabular}{|l|c|}
\hline PHRASE TYPE & PREPOSITION \\
\hline SPECIFIED LOCATIVE & $u$ \\
UNSPECIFIED LOCATIVE & hoi \\
MANNER & mei \\
COMITATIVE & $a$ \\
HUMAN CONDITION & anai \\
\hline
\end{tabular}

Three syntactic patterns are involved with these prepositional phrases.

1) With the specified and unspecified locative phrases the preposition takes a noun as its object, and the phrase is unrelated to any other nominal item in the clause.

2) With the manner and comitative phrases the preposition takes an NP as its object - a clear distinction from 1). The prepositional phrase is unrelated to any other nominal item, except with non-verbal constructions.

3) With the possessive locative phrase the prepositional phrase involves two nominals with the preposition sandwiched between them. The preposition attaches to the following head item; the preceding dependent is optional.

These relationships associated with prepositions (PREP) are summarised in the following list; the head $\left({ }^{\mathrm{HEAD}}\right)$ and dependent $\left({ }^{\mathrm{DEP}}\right)$ relationships are marked.

(1) PREP + NOUN

(2) $P R E P+N P$

(3) $\left(\mathrm{NP}^{\mathrm{DEP}}\right)+$ PREP + NOUN ${ }^{\text {HEAD }}$

As prepositions receive word level stress (syllable underlined) I regard them as words and not clitics.

\footnotetext{
10(1) A-nae [hoi tawali].

ISG-go LOC reef

I went to the reef.
} 
The single-syllable prepositions are lengthened, particularly when the following syllable is stressed.

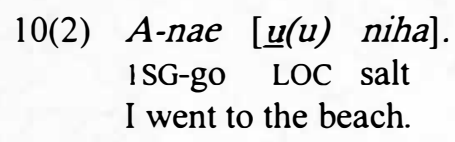

The issue is of special relevance when the specified locative preposition $u$ occurs within an alienably possessed phrase, as $u$ often gains a transitional consonant, underlined in $10(3)$. Both the possessive pronoun and the preposition are lengthened.

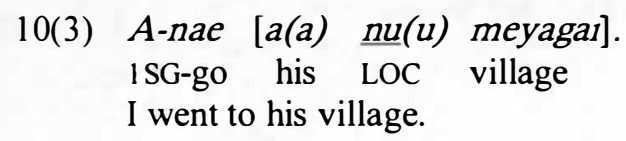

\subsubsection{Specified Locative Phrases}

The specified and unspecified locative phrases are distinguished by the separate prepositions: $u$ phrases refer to specified locations:
u numa in/to the house
u pitapita in/to a specified section of bush

whereas hoi phrases refer to unspecified or more general locations:

$$
\begin{array}{ll}
\text { hoi numa } & \text { in/to a house } \\
\text { hoi pitapita } & \text { in/to the bush }
\end{array}
$$

It is thus possible to say a-nae u yu numa 'I went to my house' but not *a-nae hoi $u$ numa 'I went to a house of mine' if one has only a single house. The two constructions are contrasted in the following examples.
10(4) Ataima wawine-na i-geleta [ $\underline{\underline{u}}$ meyagai $]$. today woman-DEF 3SG-appear LOC village That woman arrived at the village today.
10(5) Ta-tei-na hopun'-e-ya [hoi meyagar].
IPL.INC-pull-LIG down-TRV-3SG LOC village
We drag it (any log for making a canoe) down to a village.

Sentence 10(4) involves a specified village known to the speaker and the hearer. Sentence $10(5)$ is from a procedural discourse describing the stages of making a canoe. The sentence ref ers to any village to which a log might be dragged in order to be hollowed out. The log is brought in from the forest to an unspecified place near to human habitation.

The specified locative phrase consists of the preposition $u$ and a noun.

$$
u+\text { NOUN }
$$

Only place names, relationship terms and a limited number of locational nouns can form the head of this phrase. 


$\begin{array}{ll}\text { u Alotau } & \text { in/to Alotau } \\ \text { u Labe } & \text { in/at Rabe } \\ \text { u Kehelala } & \text { in/to East Cape }\end{array}$

10(6) Ega.yaka to-gunawile-iyai [u Alotau $]$. so 1PL.EXC-return-CPY LOC Alotau

So we returned to Alotau.

Geographical locations optionally use this construction when the context clearly indicates a specified location, or when the location is itself specified, as is bonabona 'island' by its encompassing coastline. At this point there is overlap with the unspecified locative phrase.

$$
\begin{aligned}
& \text { u pitapita in/to the bush } \\
& \text { u oya in/to the garden }{ }^{1} \\
& u \text { bonabona in/on the island }
\end{aligned}
$$

10(7) Lawa [u pitapita] hi-me-me nae.
person LOC bush 3PL-DUR-stay go
The people lived as nomads in the bush.

The construction cannot be used with nouns modified by an adjective, or with nouns with an animate or human referent; these situations require the use of the postposition uyahi- When a noun is modified by a relationship term, the locative preposition comes between the noun (with optional adjective 10(9)) and its modifier.

10(8) Ta-nae [mayau u baba-na].
1PL.INC-go tree LOC base-3SG
Let's go to the base of the tree.

10(9) [Neula bandolo-na u tepa-na] hi-duhu-duhuna. coconut bundle-3SG LOC top-3SG 3PL-DUR-sit They were sitting on top of the coconut bundle.

\subsubsection{UNSPECIFIEd Locative Phrase}

The unspecified locative phrase consists of the preposition hoiplus a noun:

$$
\text { hoi+ NOUN }
$$

The preposition hoi (L. hau) is used to refer to locations which have non-specified boundaries or general locations, or where the speaker has a sense of foreignness at the location. The term 'unspecified' is not meant to imply 'non-specific' though at times it does have that meaning (see 10(4)).

The following are typical unspecified indigenous locations.

hoi kokowaga among the dead hoi tawali on/at the reef

1 The use of oya for 'garden' is a Labe dialectal expression resulting from the fact that gardens are mostly built in the mountains. 
hau yayata in the light

hau pitapita to/in the bush

10(10) Am-iyai [hoi yada], natu-natu-m tauyai.

father-1PL.EXC LOC sky PL-child-2SG weEXC

Our father in the sky, we are your children.

The following phrases involve non-indigenous and hence foreign concepts.

$\begin{array}{ll}\text { hau Komiuniti } & \text { in the community } \\ \text { hau Yunaited Sios } & \text { in the United Church } \\ \text { hoi Hedkota Konsela } & \text { at council headquarters } \\ \text { hoi buka } & \text { in the book } \\ \text { hoi sataulo(Greek) } & \text { on the cross }\end{array}$

10(11) O-nae [hoi trening]. 2PL-go LOC training You went for training.

Boats take this preposition, presumably because their location is vague, depending on the direction and force of the wind at a given time.

10(12) Ta-hopu [hoi wam].
IPL.INC-go.down LOC boat
Let's go down to the boat.

\subsubsection{Possessive Locative Phrase}

The use of the specified locative prefix with possessive phrases is unique in that the preposition occurs between the optional possessor NP and the possessed noun.

$$
\left(\mathrm{NP}^{\mathrm{POSSESSOR}}\right)+u+\text { NOUN }{ }^{\text {POSSESSED }}
$$

With an inalienably possessed NP the change is minimal.

10(13) [Numa u gabouli-na] e-ma-mae. house LOC under-3SG 3SG.PRES-DUR-stay It is under the house.

10(14) [Boga u sipoli duma-na] i-hopu. liquid LOC middle real-3SG 3SG-go.down He went down right in the middle of the ocean.

In 10(15) the dependent NP is omitted, as is usually the case with non-third-person referents.

10(15) O-hanapu-ge-ya $[u \quad$ liyaliya-mI $]$ e-ma-mae.

2PL-know-TRV-3SG LOC near-2PL 3SG.PRES-DUR-stay

You know he stays near you.

In 10(16) and 10(17) the dependent NP (in curved brackets) is expanded. 
10(16) $\left[\left(\begin{array}{lllll}A & \text { neula bandolo-na }) \text { u tepa-na }] & i \text {-duhuna. }\end{array}\right.\right.$

his coconut bundle-3SG LOC top-3SG 3SG-sit

He sat on top of his coconut bundle.

10(17) [(Naka Kokoda) u gado-na] to-witago-ni.

that Kokoda LOC neck-3SG IPL.EXC-pass-3SG

We passed (=flew over) the Kokoda Pass.

With alienably possessed NPs the situation is complicated by the fact that both the possessive pronoun and the locative preposition intervene between the possessor NP and the possessed head noun.

$$
\left[\mathrm{NP}^{\text {POSSESSOR }}+<a>+u+\text { NOUN }^{\text {POSSESSED }}\right]
$$

Transitional consonants occur between the possessive pronoun and the locative preposition.

10(18) [ Tauyai $i$ yu ani mae] i-lui.

weEXC OurEXC LOC place stay 3SG-enter

It came into our residence.

10(19) Hi-nae [bada a nu meyagar].

3PL-go man hi LOC village

They went to the man's village.

In 10(20) the possessor NP is omitted.

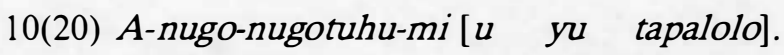

ISG-DUR-think-2PL my LOC worship

I will remember you in my prayers.

\subsubsection{MANNER PHRASE}

The preposition mei 'like' combines freely with NPs, making it one of the most productive morphemes in the language.

$$
\text { mei+ NP }
$$

The manner phrase always follows the verbal predicate and can indicate the manner in which the predication is performed.

10(21) Ega hi-ta-me-me gogona [mei geka houga-na].

NEG 3PL-IRR-DUR-stay together like this time-2SG

They didn't live in harmony like (we do at) this time.

10(22) Tauta tekis ta-hepa me-ya [mei lolowa]. weINC tax IPL.INC-lift again-3SG like before We will raise the tax (money) like (we did) before.

10(23) Kikina nugonugo-u i-witai [mei Mabel]. little mind-1SG 3SG-heavy like Mabel I am a little depressed like Mabel (is depressed).

On the other hand the manner phrase may expand on one of the arguments of the clause. 
10(24) Pona-na i-nonol'-i [mei togowa].

voice-3SG 3SG-hear-3SG like wind

He heard her voice (sounding) like the wind.

One common use of the preposition me $i$ is with time phrases, indicating the approximate time when an event took place (10(25)) or the approximate duration of an event (10(26)).

10(25) To-yato [mei tri kilokk].

1PL.EXC-land like three o'clock

We landed at about $3 \mathrm{pm}$.

10(26) To-mae [mei iyeta luwaga].

1PL.EXC-stay like day two

We stayed about two days.

Non-verbal manner clauses are common.

10(27) Anigalena-na [mei gamogamo natu-hr].

appearance-3SG like animal child-3PL

He looked like a baby animal.

\subsubsection{Comitative Phrase}

The comitative phrase includes the preposition $a$ and an inalienably possessed noun marked for person and number agreement.

$$
a+\mathrm{NP}<-n a>
$$

The pronominal enclitic agrees anaphorically with the subject.

10(28) Bada [a kedewa-na] i-nae.

man COM dog-3SG 3SG-go

The man went with his dog.

That two NPS are involved is seen by the fact that the verb agrees only with the subject $\mathrm{NP}$, not including the comitative phrase. In this, the construction differs from associative phrases.

The comitative preposition is to be distinguished from the third-person singular possessive pronoun.

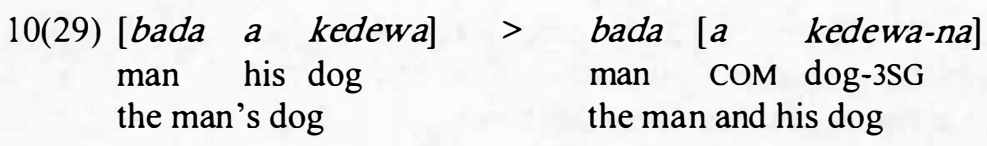

In the comitative construction the object of the preposition is obligatorily marked with a pronominal enclitic. Nouns which would normally be possessed alienably thus receive inalienable marking.

10(30) Taumi [a nima gapola-ml] o-nei. youpL COM hand things-2PL 2PL-come You have come with your hand luggage. 
10(31) Iyowai po [a gawiya gapola-mi] o-nei. how and COM war things-2PL 2PL-come How is it that you come with weapons?

Example 10(32) contains a coordinated comitative phrase.

10(32) Hi-nae [a nima gawiya gapola-hı] po [a nima heuta-h1]. 3PL-go COM hand war possession-3PL and COM hand torch-3PL They went with their hand weapons and (coconut frond) hand torches.

Nouns which are normally inalienably possessed are not used with this construction, e.g. kin terms, where the meaning 'the man with his son' would involve the use of an associative phrase: bada natu-na mitehi- not * bada a natu-na.

\subsubsection{HUMAN CONDITION PHRASE}

The human condition phrase is structurally identical to the comitative phrase, apart from the different preposition.

$$
a n a i+\text { NOUN<-na> }
$$

In contrast to the comitative phrase, which encodes accompaniment of an 'external item' (a concrete item often carried in the hand) of the head NP, the human condition phrase encodes an 'internal condition', often a psychological state. Hence the object of the preposition is often an abstract noun.

10(33) Tewela [anai wiyateyate-na] i-polou. child CON respect-3SG 3SG-bow The child bowed down in respect.

In 10(34) the subject is a pronoun; in 10(35) it is omitted.

10(34) Tau [anai habulu-we] a-nae Kehelala. I CON small-1SG 1SG-go Kehelala (When) I was young I went to Kehelala.

10(35) [Anai kaoha-u] a baha a-nonol'-i. CON joy-1SG his word ISG-hear-3SG I heard his word with joy.

The human condition phrase can function as a the predicate of non-verbal clause.

10(36) Tau [anai habulu-we] ma a-nae Ist Keip Mision Sikulu.
I CON small-1SG and 1SG-go East Cape Mission School
I was young and I went to the East Cape Mission School.

\subsection{POSTPOSITIONAL PHRASES}

Tawala postpositional phrases are grammaticised inalienable possession phrases, in which the postposition is the possessed (head) noun marked with an adnominal enclitic for person and number agreement with the dependent noun the object of the postposition. The 
postposition is thus distinguished as a head-marked item, indexed for person and number agreement with the object of the postposition.

There are four postpositions which are presented in simplified form in Table 2 and fully expanded later in the respective sections.

TABLE 2: POSTPOSITIONAL PHRASE TYPES

\begin{tabular}{|l|c|}
\hline PHRASE TYPE & POSTPOSITION \\
\hline LOCATIVE & uyahi-<na> \\
ABLATIVE & uyahi-<nei> \\
REASON & tepa-<nei>i \\
BENEFACTIVE & bi-<nei> \\
\hline
\end{tabular}

That Tawala postpositions are historically inalienably possessed nouns is evidenced by the different stages of grammaticisation that different postpositions represent.

(a) The postposition tepa-<ne> 'from the top' is still used in its nominal function:

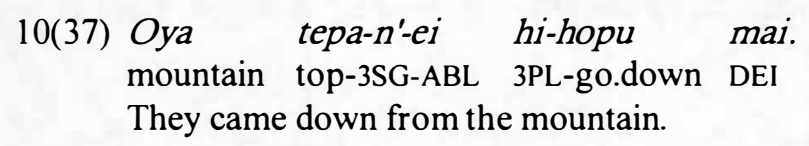

The postpositional form is unchanged (10(38)) though the meaning has changed. The postposition is a relator, with the object expressing reason.

10(38) Beda tepa-n'-ei a-nei.

betel RSN-3SG-ABL 1SG-come

I have come for betel nut.

(b) The two adpositions with the base form uyahi-, and the benefactive form $b i-<n e \dot{\text { s }}$, only occur in data as postpositions. Thus these items have lost any nominal functions, and have no independent meanings. ${ }^{2}$

The functions of the locative postposition and possessive locational phrase are different, though they do overlap.

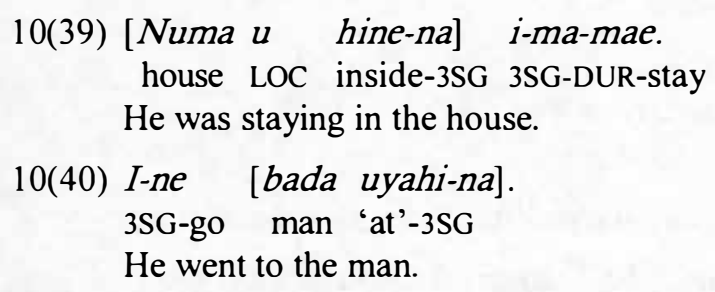

The ablative suffix used with the ablative, reason and benefactive postpositions follows the normal patterns established for Tawala grammar. 'there' as a possessive locational phrase. Synchronically, however, the form * yahi-na never occurs and the root * yahi has no meaning. 


\subsubsection{Locative PostPosition Phrase}

We noted two prepositional strategies for marking location. The prepositions are used only with non-human referents. If a human referent is involved then the locative postpositional phrase must be used, employing the postposition uyahi- $<$ na $>$ (L. ugoli$<$ na $>$ ) 'to/at/with $<$ it $>$ '. In addition, the prepositions are only used with unmodified nouns. If an NP is involved as the object of the adposition then a postpositional construction must be used.

The pronominal enclitic on the postposition indexes the person and number of the dependent NP.

TABLE 3: PERSON/NUMBER FORMS OF THE LOCATIVE POSTPOSITION

\begin{tabular}{|c|c|}
\hline PERSON/NUMBER & LOCATIVE FORMS \\
\hline ISG & uyahi-u \\
2SG & uyahi-m \\
3SG & uyahi-na \\
1PL.INC & uyahi-ta \\
IPL.EXC & uyahi-yai \\
2PL & uyahi-mi \\
3PL & uyahi-hi \\
\hline
\end{tabular}

The locative postposition combines with an NP to form the locative postposition phrase:

$$
\text { (NP) + uyahi-<na> }
$$

Locative postpositional phrases differ from locative prepositional phrases in that the latter only take an obligatory noun as their object. With the postpositional phrase a wide range of items can occur in the optional NP slot: a pronoun (10(41)), expanded NP (10(42)), possessed NP (10(43)), compound phrase (10(44)), nominalised clause (10(45)) and numeral (10(46)).

10(41) [ Tauhi uyahi-hl] ibig'ei to-hopu.

they 'at'-3PL evening-ABL IPL.EXC-go.down

In the evening we went down to them.

10(42) [Bonabona gehou-na uyahi-na] i-libe-ya.

island one-3SG 'at'-3SG 3SG-wash.up-CPY

He got washed up on an island.

10(43) [Bada a numa uyahi-na] to-geleta.

man his house 'at'-3SG 1PL.EXC-arrive

We arrived at the man's house.

10(44) $[$ Hina-u po ama-u uyahi-hl] a-me-mae. mother-1SG and father-1SG 'at'-3PL 1SG-DUR-stay

I stayed with my mother and father.

10(45) $[$ I houga gelu wam uyahi-na] naka a-winugoneina. ourEXC time embark plane 'at'-3SG that 1SG-ignorant

At the time we embarked our plane I was ignorant. 
10(46) [ Wiluwaga-na uyahi-na] naka Wagaloke i-'mhoe. second-3SG 'at'-3SG that possum 3SG-leave On Tuesday Possum left.

\subsubsection{ABlative Phrase}

The ablative postposition is formed by adding the ablative enclitic to the locative postposition uyahi-<na $>$ to form uyahi-<nel> (L. ugoli-<nei>) ('at'-3SG-ABL) 'from/by $<$ it>'.

TABLE 4: PERSON/NUMBER FORMS OF THE ABLATIVE POSTPOSITION

\begin{tabular}{|l|l|}
\hline PERSON/NUMBER & ABLATIVE FORMS \\
\hline ISG & uyahi-u-gei \\
2SG & uyahi-m-gei \\
3SG & uyahi-n'-ei \\
1PL.INC & uyahi-t'-iyei \\
1PL.EXC & uyah'-iyes \\
2PL & uyahi-m'-iyei \\
3PL & uyahi-h'-iyei \\
\hline
\end{tabular}

The ablative phrase consists simply of an optional NP and a postposition.

$$
\text { (NP) + uyahi-<n'-eis }
$$

$\begin{array}{ll}\text { aeu uyahin'ei } & \text { by my feet } \\ \text { tano uyahih'iyei } & \text { from the gardens } \\ \text { uyahiugei } & \text { from me }\end{array}$

Like the locative postposition, the ablative postposition occurs with a wide range of items in the NP slot, e.g. a pronoun (10(47)), noun (10(48)), compound phrase (10(49)), possessed NP (10(50)) and clause (10(51)).

10(47) [ Tau uyahi-u-geI] hi-nei.

I 'at'-1SG-ABL 3PL-come

They come from me.

10(48) Apo u-na-tuhaga-ya [tani-taniwaga uyahi-h'-iyeI].

FUT 2SG-POT-find-3SG PL-ruler 'at'-3PL-ABL

You will get it from those in charge.

10(49) [Aniani ma muhala ugoli-h'-iyel] to-hagu-hagu-hi. staples and meat 'at'-3PL-ABL 1PL.EXC-DUR-help-3PL

We help them by (means of) vegetables and meat.

10(50) [Oima ma Kukuku hai dewa uyahi-h'-iyel] hi-wotago-ya. ant and pheasant their custom 'at'-3PL-ABL 3PL-follow-3SG They follow' along Ant's and Pheasant's custom. 
10(51) [Popopo a dewa i-dewa-dewa-ya uyahi-n'-eI] ta-lau-labiya. lizard his custom 3SG-DUR-do-3SG 'at'-3SG-ABL 1PL.INC-DUR-sago We collect sago following the custom which Lizard does.

The postposition can be omitted and the ablative enclitic added directly to the noun.

$\begin{array}{ll}\text { ibig'ei } & \text { by evening } \\ \text { oyagei } & \text { from the mountain } \\ \text { tanigan'ei } & \text { with his ear }\end{array}$

The forms in the following examples demonstrate the contrast.

10(52) [Wagaloke taniga-n'-eI] i-mhiguhigu. possum ear-3SG-ABL 3SG-ladle

Possum ladled with his ear.

10(53) [ Taniga-na uyahi-n'-el] i-mhiguhigu. ear-3SG 'at'-3SG-ABL 3SG-ladle

He ladled with his ear.

\subsubsection{REASON PHRASE}

The postposition tepa- $<n^{\prime}-e l>$ (RSN-3SG-ABL) ' $<$ its $>$ reason' is structurally a simple ablative phrase with a specialised function (see discussion in $\S 10.2$ above).

$$
(\mathrm{NP})+t e p a-<n>-e i
$$

The following examples demonstrate a range of structural options for the reason phrase.

10(54) Amalai ata luwaga ta-duhu-duhuna [Yaubada tepa- $n^{\prime}-e$ ] . today ourINC two 1SG.INC-DUR-sit God RSN-3SG-ABL We two are sitting here today because of God (i.e. he brought us together).

10(55) I-taniwaga [lawa emosi tepa-n'-eI]. 3SG-rule person one RSN-3SG-ABL $\mathrm{He}$ is ruling because of one person.

10(56) [Hai luhogala powa tepa-h'-iyet] apo wiyuwa hi-na-wialon'-i. their desire mistaken RSN-3PL-ABL FUT pain 3PL-POT-face-3SG Because of their lusts they will experience suffering.

\subsubsection{BENEFACTIVE PHRASE}

Givón (1984:126) defines the benefactive case as "the conscious benefiter from an agentinitiated event". This may be the proto-typical situation, but the examples in the Tawala corpus are much broader and include purpose and reason as well as an unconscious benefiter and even extent of time etc. 
Two dialect forms of the benefactive preposition are currently in use as 'stylistic' variants by speakers of the Diwinai and Labe dialects. ${ }^{4}$ Thus the underlying structures of the two forms are as follows:

$$
\begin{array}{ll}
b i-n>-e i & u-b e i-<n a> \\
\text { BEN-3SG-ABL } & \text { LOC-BEN-3SG }
\end{array}
$$

However, as neither locative nor ablative morphemes are productive within the benefactive postposition, these two forms are glossed identically as 'BEN-<3SG>'.

TABLE 5: BENEFACTIVE POSTPOSITIONS

\begin{tabular}{|l|cl|}
\hline PERSON/ & \multicolumn{2}{|c|}{ BENEFACTIVE- } \\
NUMBER & \multicolumn{2}{|c|}{ ALTERNATE FORMS } \\
\hline ISG & $u b e-u$ & bi-u-gei \\
2SG & $u b e-m$ & bi-m-gei \\
3SG & $u b e i-n a$ & bi-n-ei \\
IPL.INC & $u b e i-t a$ & bi-t-iyei \\
IPL.EXC & $u b e i-y a i$ & bi-yai-yei \\
2PL & $u b e i-m i$ & bi-mi-yei \\
3PL & ubei-hi & bi-hi-yei \\
\hline
\end{tabular}

tau ubeu for me

lawa ubeihi for people

bitiyei for us

10(57) [Bi-mge ] a-kaoha.

BEN-2SG ISG-happy

I am happy for/about you.

10(58) [ Gatowa bi-ne1] ta-bagibagi.

roof BEN-3SG 1PL.INC-work

We are working for (=making) the roof.

Note that the preferred position of the demonstrative within a postpositional phrase $(10(58), 10(61))$ is following the noun.

10(59) Tauna amaka i-wononogo [houga geka bi-net].

he already 3SG-prepare time this BEN-3SG

He had made preparations for this time.

The benefactive often involves purpose or reason.

naka binei because of that

awai binei? for what purpose?

yaka binei for that reason

10(60) [ Awai bi-net] hi-nei?

what BEN-3SG 3PL-come

What is the reason for their coming?

4 Both forms have been constructed on a noun root * bei. In the case of the Kehelala dialect, benefactive forms were modelled on the prepositional possessive locative phrase ${ }^{*} u+b e i-<n a>$, and Labe forms on the ablative postposition phrase ${ }^{*}$ beit $<$ na $>+e i$. 
10(61) [Diploma bi-ne1] e-i-trening. diploma BEN-3SG 3SG.PRES-DUR-train She is doing a course to get a diploma.

First and second person forms usually occur without an accompanying noun (10(62)), though a free-form pronoun is common (10(63)).

10(62) I-nonogo i yam [ubei-yar].

3SG-prepare ourEXC food BEN-1PL.EXC

She had prepared food for us.

10(63) [Tauta bi-tiyel] i-baha-baha.

usINC BEN-1PL.INC 3SG-DUR-say

He was speaking on our behalf.

Extent of time is also indicated by this construction.

10(64) He-me-mae amalai bi-nei ma [hoimalatom ubei-na]. 3PL.PRES-DUR-stay today BEN-3SG and tomorrow BEN-3SG They are staying for today and for tomorrow. 


\section{NON-VERBAL CLAUSES}

Ideally, our discussion of the syntactic structure of the nuclei of kernel-sentences should be conducted within the framework of some generally accepted and universally applicable system of grammatical analysis. Unfortunately, no such system exists.

Lyons (1977:469)

\subsection{EQUATIVE CLAUSE}

A good starting place for an analysis of Tawala equative clauses is the definition offered by Mosel (1984:157): "Equative Clauses consist of two juxtaposed noun phrases NP ${ }^{1}$ and $\mathrm{NP}^{2}$ expressing that the NP ${ }^{1}$ referent is what NP ${ }^{2}$ refers to".
11(1) a. Tau Batutuli.
b. Tauhi ega mi
Tawala.
I (am) Batutuli.
they NEG people Tawala
They are not Tawala people.

The commonly drawn distinction between equative and ascriptive clauses (Lyons 1977:471-472) is significant for Tawala, where there is a three-way contrast between equative, possessive and descriptive clauses (the predicate is in square brackets to clarify the structure involved).

\section{EQUATIVE \\ 11(2) Tauna [Limi natu-na]. he Limi child-3SG \\ He is Limi's child.
EQUATIVE
11(3) Tauna [bada dewadewa-na]. he man good-3SG
$\mathrm{He}$ is a good man.

\author{
POSSESSIVE \\ Limi [natu-na]. \\ Limi child-3SG \\ Limi has a child.

DESCRIPTIVE
Bada [dewadewa-na].
man good-3SG
The man is good. \\ DESCRIPTIVE
}

Structurally, the Tawala equative clause consists of a subject NP and a predicate NP.

$$
N P^{S} N P^{P}
$$

This differs markedly from the traditional analysis of English equative clauses, where it is the copula that is regarded as the "verb with equative function" (Crystal 1980:133). Instead of having a pair of NPs with some sort of existential verb combining them, Tawala equative clauses "identify a referent and say of the referent...that it has a certain property or is a member of a certain class... The referent...we will call the subject. What is said about the referent is expressed by the predicate...". This definition, selected from a broader definition of Lyons (1977:470), captures the situation nicely. The predicate NP predicates something in a manner analogous to the verb of verbal clauses, which is the prototypical predicate. Nowhere is that predicate less like the prototype than it is with equative clauses, particularly those encoding a qualification relationship. 


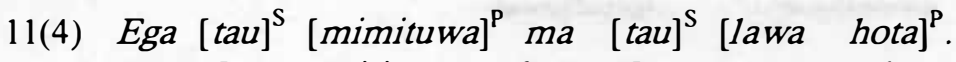 NEG I spirit but I person only \\ I am not a 'bush' spirit but a real person.}

\subsubsection{Minimal Equative Clauses}

By far the most common form of equative clause in Tawala has a deictic element filling the subject NP. Two options are available for the deictic subject: an emphatic pronoun marked for person and number, or a demonstrative. If an emphatic pronoun is used the referent is understood to be human or at least a being acting like a volitional human. ${ }^{1}$

Tam amaka, bada. You're okay (lit. enough), sir.

Tauna wawine.

Tauna meka?

She is a woman.

Tau geka.

Where is he?

I am here.

Note that the predicate NPS in the lists above and below contain non-nominal items. Just as demonstratives and interrogatives etc. can function as heads of NPs, so these items can function as NPS within the predicate of the equative clause.

If a demonstrative is the subject then the referent is non-human or of questionable status, though the demonstrative is commonly used with a pronominal predicate with a human referent (first example in the list below). The equative construction is somewhat complicated by the fact that demonstratives are not only used as subjects (list below) but also as predicates (last example in both lists). In addition the emphatic pronoun is used as the deictic subject (above) and as the existential predicate (in the first example below).

$\begin{array}{ll}\text { Geka tauna. } & \text { This is him. } \\ \text { Geka awai? } & \text { What is this? / Who is this? } \\ \text { Geka malatomtom. } & \text { This is moming (now). } \\ \text { Naka togowa. } & \text { That is wind. } \\ \text { Naka lawa. } & \text { It's a person. } \\ \text { Naka moina. } & \text { That is true (lit. truth). } \\ \text { Naka noka pite. } & \text { It is like that (distal). }\end{array}$

The contrast between pronominal and demonstrative constructions is illustrated in the next two pairs.
Tauna iyai?
Who is he/she?
Naka awai?
What is that?
Naka amaka.
That's enough.
Tauna amaka.
He/she's okay.

In a corpus of 66 examples of the third person singular free-form pronoun (tauna) there are 4 examples of its use for non-human referents. As both speakers have spent most of their lives outside the Tawala area, their irregular usage is suspect. 


\subsubsection{EXPANDED SUBJECTS}

When the subject contains new information or is given special prominence, the deictic item is replaced by a noun (11(5)) or a possessive phrase (11(6)-11(8)) (the subject is in square brackets in these examples).

11(5) [Wiwine] alinawa.

women widow

The women are widows.

11(6) [Holopu ama-na] Yailo.

Holopu father-3SG Yailo

Holopu's father is Yailo.

11(7) a. [Galena-hl] awai? appearance-3PL what

What are they like?

b. [Natu-na] iyai?

child-3SG who

Who is his child?

11(8) [(Lawa) hai luhinigigal] ega ano-na. person their rejection NEG core-3SG

The people's rejection is without basis. (i.e. The people have no reason to be angry.)

\subsubsection{EXPANDED NP PREDICATES}

Any NP can fill the predicate slot of an equative clause, making it a highly versatile construction. Examples below include a simple NP (11(9)), a coordinate NP (11(10)), interrogative NPs (11(11)), possessive phrases (11(12)-11(14)) and embedded nominalised clauses (11(15), 11(16)). In the following examples the predicate is in square brackets; curved brackets indicate that the item could be omitted given the right pragmatics.

11(9) Naka [dobu banei duma-na].

that village big very-3SG

That is a very big village.

11(10) Naka [a luwa oo a baha ano-na]. that his rule or his word core-3SG That was his ruling or the crux of his speech.

$\begin{array}{llll}11(11) \text { a. Tauna [(lawa) iyar]. } & \text { b. Naka [(ginouli) awal]. } \\ \text { he person who } & \text { that thing what } \\ \text { Who is that? } & \text { What is that? }\end{array}$

11(12) Tauyai [(Keudi) natu-natu-na]. weEXC Keudi PL-child-3SG We are Keudi's children.

Sentences 11(12) and 11(13) demonstrate clearly a feature that is true for all equative clauses - there is no pronominal agreement between the subject and predicate. In this they differ from head-marked clauses.

11(13) Tau [hai president]. I their leader I am their leader. 
11(14) Naka [(bada) a nugotuhu]. that man his thought That is the (big) man's opinion.

11(15) Lani-na geka [lawa tu-hilage]. man-DEF this person PER-dead As for this man, he was a dead person.

11(16) Naka [lawa hai ani-kaoha]. that person their thing-happy That is the thing that makes people happy.

\subsection{ADPOSITIONAL CLAUSES}

Mosel (1984:162) states: "In Locational Clauses the predicate denotes the position, the goal or the source of the subject referent". This is a reasonable definition for Tawala adpositional clauses generally, though the manner adpositional clause requires a broader definition.

Adpositional non-verbal clauses have predicates filled by adpositional phrases, making them a subset of equative clauses.

$$
\mathrm{NP}^{\mathrm{S}} \mathrm{PP}^{\mathrm{P}}
$$

As Tawala has both prepositions and postpositions, there are two subtypes of adpositional clauses. These structures differ in the order of constituents within the predicate.

Prepositional clauses have a simple preposition (underlined) before the NP of the predicate.

11(17) Tauna [mei lawa $]^{\mathrm{P}}$.

he like person

$\mathrm{He}$ is like a person (i.e. is a human being).

Postpositional clauses have a head-marked postposition (underlined) following the NP of the predicate.

11(18) Tauna [wam uyahi-na $]^{\mathrm{P}}$.
he

$\mathrm{He}$ is at the boat.

\subsubsection{Prepositional Clauses}

With these constructions the preposition and the locative noun are both obligatory.

$$
\left.\left(\mathrm{NP}^{\mathrm{s}}\right) \text { [preposition }+\mathrm{NP}\right]^{\mathrm{p}}
$$

There are only two varieties of prepositional clauses, corresponding to the manner phrase and the specified locative phrase. The grammar of these two structures is so distinctive that they must be outlined separately. 


\subsubsection{Prepositional ManNer Clause}

Structurally, a prepositional manner clause consists of subject NP and an adpositional phrase marked with the preposition mei 'like'.

$$
\mathrm{NP}^{\mathrm{S}}[\text { mei NP}]^{\mathrm{P}}
$$

Semantically, the manner clause requires an expansion of Mosel's definition given above; here the subject NP is said to resemble the predicate NP.

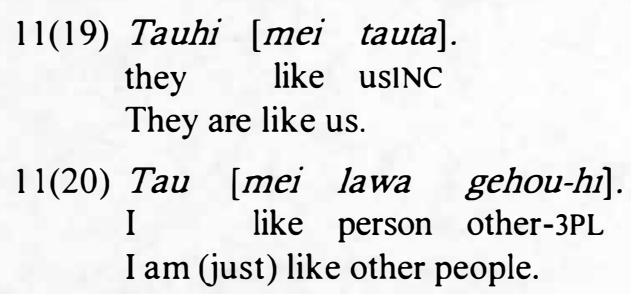

The grounds of comparison are sometimes spelled out by an expanded subject (square brackets) as in the following examples, which have embedded nominalised clauses.
11(21) [ Tau tu-bagibag1] mei tam.
I PER-work like youSG
I am a worker like you are.
11(22) [Naka ani-galena-na] mei tauta. that thing-appearance-3SG like usINC
That bird looked like us (people).

Idiomatic questions using the mei construction without a subject NP are also in common use.

Mei awai? Such as what?

Mei iyai? Such as who?

Tense-aspect and negative clitics (both underlined) come before the predicate (in square brackets).

11(23) I mae ega [mei lolowa].

ourEXC stay NEG like before

Our life was not like previously.

11(24) Apo [mei tauni gehou-na].

FUT like town other-3SG

It will be like other towns.

\subsubsection{Locational Clause}

Structurally, this clause differs significantly from the prepositional manner clause. The locational clause is an adpositional clause with a possessed NP in the prepositional phrase.

$$
\left(N P^{S}\right)\left[\left(N P^{\text {dependent }}\right) u \text { noun } n^{\text {head }}<-n a>\right]^{P}
$$

Both the subject NP and the dependent noun of the predicate (possessor NP) are optional, making it difficult to disambiguate some structures, though I have no examples in my 
corpus with both nouns omitted. The head noun of the predicate phrase is marked for agreement with the dependent noun.

The following examples include a fully expanded prepositional phrase (11(25)), a prepositional phrase with no dependent noun expressed (11(26)) and a locational clause with no subject NP (11(27)) (the predicate is in square brackets).

11(25) Tauhi [numa u gabouli-na]. they house LOC underneath-3SG

They are under the house.

11(26) Tam $[u$ liyaliya- $u$. youSG LOC near-1SG

You are near to me.

11(27) [Mayau u baba-na]. tree LOC base-3SG

It is at the base of the tree.

The head noun can be a body part, as in the following idiomatic expressions.
11(28) a. [Tam u nima-m]. youSG LOC hand-2s It is in your hands.
b. [Yaubada u mata-na]. God LOC eyes-3SG
It is before God's eyes (i.e. known to him)

\subsubsection{Postpositional Clause}

This construction is closely related to the locational clause of the previous section in that it is head marked. However, the head marking is not on the head noun but on the postposition itself. A minimal clause predicate consists of:

$$
\left(\mathrm{NP}^{\mathrm{S}}\right)\left[(\mathrm{NP})+\text { postposition }^{\mathrm{P}}\right.
$$

In having a postposition with an optional object it differs from the prepositional clauses, which require an object with the preposition.

Examples include an expanded postpositional clause (11(29)), a postpositional clause with no object with the postposition (11(30)) and an interrogative construction (11(31)).

$$
\begin{aligned}
& \text { 11(29) Tau [iwa-u uyahi-na]. } \\
& \text { I bro.in.law-1SG 'at'-3SG } \\
& \text { I was with my brother-in-law. }
\end{aligned}
$$

$\begin{array}{lll}\text { 11(30) a. Tau ega [uyahi-hr]. } & \text { b. } & \text { I-gehou-hi [ugoli-u]. } \\ & \text { UNSP-other-3PL 'at'-1SG } \\ \text { I NEG 'at'-3PL } & & \text { I have others. }\end{array}$

11(31) $A$ bihaga [ugoli-m]?

its number 'at'-2SG

How many do you have?

Example 11(32) has an expanded subject NP. 
11(32) [Ginouli emosi hota] ega uyahi-m... thing one only NEG 'at'-2SG There is just one thing you do not have...

An ablative postpositional clause is distinguished by the presence of an ablative postposition in the predicate. The following examples include an expanded construction (11(33), 11(34)) and a deleted subject NP (11(35)).

\section{1(33) Lawa-na ega [Yaubada uyahi-n'-e1]. person-DEF NEG God 'at'-3SG-ABL That man is not from God.}

11(34) Naka [lawa atapu-hi ugoli-hi-yer].

That person all-3PL 'at'-3PL-ABL

That was from all the people.

11(35) [Tau uyahi-u-ge1].

I 'at'-1SG-ABL

(It is) from me.

\subsection{EXISTENTIAL CLAUSE}

Tawala existential clauses are common in everyday conversation and in quoted speech, though they only occasionally occur within extended discourse. The existential clause consists simply of a nominal predicate (cf.§12.2.3 for further discussion).

$$
\begin{gathered}
\mathrm{NP}^{\mathrm{P}} \\
\text { 11(36) }[\text { Gadiwewe }]^{\mathrm{P}} \text {. } \\
\text { rain } \\
\text { (It/there is) rain. }
\end{gathered}
$$

As with all types of non-verbal clauses, various clausal adverbs are optionally employed, but as these are not definitive of clause types they are not included in the definitions.

\section{1(37) Apega gadiwewe. \\ FUT.NEG rain \\ (It) will not rain.}

Mosel (1984:156) states "Existential clauses consist of only one noun phrase stating the existence of what is referred to by that noun phrase". This definition is acceptable for the Tawala data also.

A wide variety of word classes occur as predicates of existential clauses; the following list commences with four nouns, followed by two proper nouns (a person's name and a place name), a demonstrative (functioning as a locative), two free-form pronouns and, finally, a negative predicate. Some of these items are difficult to translate as existentials and the English only approximates the Tawala and also applies to a single pragmatic context, whereas these sentences occur in a variety of contexts.

Gadiwewe. (There is) rain.

Bolibolima. The south-easterly (is blowing).

Gamogamo. (They are) animals.

Moina. (It is) true (lit. truth). 
Yoela. (There is) Yoela.

Kainantu. (It is) Kainantu.

Geka. (It is) here. / This (is the place).

Tau. (It's) me.

Tauna. (It's) him/her/it.

Eega. (It is) not/not (so).

11(38) Gahu i-lata ma gadiwewe.

mist 3SG-grow and rain

There was thick mist and it was raining.

The predicate form of the negative eega differs from the negative particle ega, which has a single vowel. (In the Labe dialect a glottal stop separates the contiguous vowels of the predicate form: eqega.)

\subsubsection{LiMiTING MODIFIERS}

The predicates of existential clauses take one of a set of general modifiers: hota/hosi/ hoti 'only, just', pite 'like', duma 'very'.

Noka hota. (It is) over there

Geka hosi. (It is) just here.

Naka pite. (It is) like that.

Eega duma. (It is) definitely not.

Only the hota form is used with nouns.

Lawa hota. (It is) just a person.

\subsubsection{Negating Existential Clauses}

Negative existential clauses are common (existential predicates are in square brackets).

11(39) Ega [wipoya] po ega [wayau].

NEG hot and NEG cold

(It is) not hot and (it is) not cold.

11(40) Iyeta tunawa-na ma ega [uguwa].

day only-3SG but NEG dark

(It was) always daytime and never dark.

11(41) Ega [naka pite].

NEG that like

(Do) not (do it) like that.

There is a clear asymmetry between positive and negative clauses. Most existential clauses can be negated, but many negative existential clauses, especially when a verbal root is employed, cannot be made into positive clauses by deleting the negative particle; a verbal stative clause would be required.
11(42) $\underset{\text { Ega }}{\text { EgG hot }}$ [wipoya]. $\quad>\quad \begin{aligned} & \text { I-wipoya/* wipoya. } \\ & \text { 3SG-hot }\end{aligned}$
(It is) not hot.
(It is) hot. 
None of the negative clauses in 11(43) could function as positive clauses.
$11(43)$... ega [kikina matouta] po ega [widagudagu], ega [lowo] ma i-tugu-tugula. NEG little fear and NEG struggle NEG run but 3SG-DUR-sit ... (he is) not a little bit afraid, and (he has) not struggled, (he has) not run away but he keeps sitting (here).

We see another common item found only in negative constructions involving the modifier kikina '(a) little'. This construction is further distinguished in that it has the modifier preceding the head instead of following it.

11(44) Ega [kikina ponapona] bo [gololo gehou-na].

NEG little talking or noise other-3SG

(There was) no talking or other noise.

When the existential clause has internal structure, that structure cannot be interrupted by a negative.

\section{1(45) Ega [lawa hota]. / * Lawa ega hota. \\ NEG person only \\ (It is) not a real person.}

Examples (11(44)-11(46)) show expanded NPs function ing as predicates of existential clauses.

\section{1(46) Ega [dobu gehou-na]. \\ NEG village other-3SG \\ (There is) no other village.}

The negative sentences in 11(47) have no positive counterparts. The third-person singular suffix has no referent; its function is to show that the verb root is nominalised.
11(47) a. Ega geno-na!
NEG worry-3SG
Not to worry!
b. Ega dao-na.
NEG long-3SG
It wasn't long.

\subsubsection{Adverbs With Existential Clauses}

The following sentences illustrate the use of existential clauses with past tense (examples 11(24), 11(37) above show future tense).
11(48) a. Amaka [aipom].
already evening
b. Amaka [gadiwewe].
(It is) already evening.
already rain
(It has) already rained.

Existential clauses occur with nugote 'perhaps', as in the following constructed example.
11(49) Nugote [tau].
perhaps me
Could it be me? 


\subsection{HEAD-MARKED NON-VERBAL CLAUSES}

As verbal clauses are also head-marked it is necessary to give this section a title which unambiguously separates the non-verbal and verbal head-marking types. However, within this section I refer to head-marked non-verbal clauses simply as head-marked clauses.

There is nothing remarkable about the Tawala equative clauses; they are parallel to equative clauses in many languages. Even the absence of a copula is a common feature, in some contexts at least: "In many languages the verb 'be' is not necessary in less-marked tense-aspects" (Givón 1984:91). However, a number of features have combined in Tawala to bring about the metamorphosis of a set of head-marked clauses which are quite distinct from equative clauses. The best way to get the overall picture of the relationships involved is to compare a set of head-marked clauses with their equative counterparts (the predicate is in square brackets).

$\begin{array}{ll}\text { 11(50) } \begin{array}{l}\text { DobS [banei-na]. } \\ \text { village big-3SG }\end{array} & \begin{array}{l}\text { EQUATIVE CLAUSE } \\ \text { The village is big. }\end{array} \\ \begin{array}{l}\text { that village banei-na] } \\ \text { POSSESSIVE CLAUSE }\end{array} & \text { That is a big village. } \\ \text { 11(51) Limi ega [natu-na]. } & \text { Tauna ega [Limi natu-na]. } \\ \text { Limi NEG child-3SG } & \text { he NEG Limi child-3SG } \\ \text { Limi has no child. } & \text { He is not Limi's child. }\end{array}$

In fact the surface string of the possessive sentence in 11(52) could also be an equative clause, with the dependent noun of the predicate omitted, Limi is not his child.

The structure of the above clauses is contrasted in the following trees, from which I omit the negatives in the interests of simplicity (however, the importance of the negative is discussed below).

DESCRIPTIVE

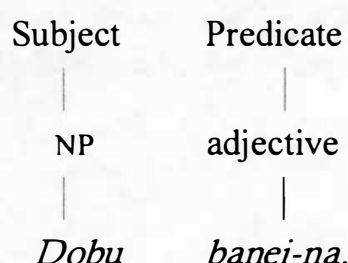

POSSESSIVE

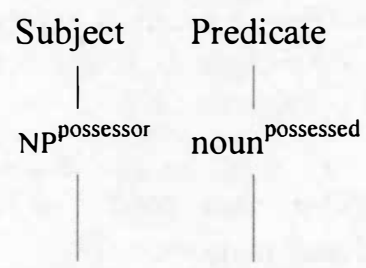

Limi

natu-na
EQUATIVE

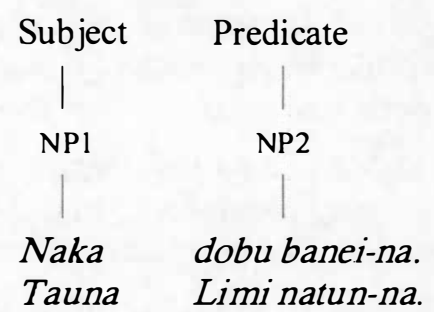

The two head-marked clauses have parallel though different structures. The predicate of the descriptive clause is an adjective phrase, and the predicate of the possessive clause is a possessed noun. The expansion of either predicate is rare. Givón's description of copular sentences (1984:91) accounts for the Tawala head-marked clauses: "These are sentences with a subject and predicate... The predicate may be either a noun (nominal predicate) or [an] adjective (adjectival predicate)".

The two equative sentences above have identical structure, which is, however, quite distinct from the head-marked clauses. With the equative clause the predicate is commonly 
an expanded NP, and in addition the subject is typically a deictic item, an option not available to head-marked clauses. Semantically, equative and head-marked clauses also have quite distinct meanings, though at times English lacks the distinction, making a literal translation impossible.

The situation is, however, more complex, in that the subject NP can be omitted from the equative clause. We thus find constructional homonymy, with a complete overlap in the surface manifestation of morphemes between head-marked and equative clauses, though there is subtle intonational difference. ${ }^{2}$

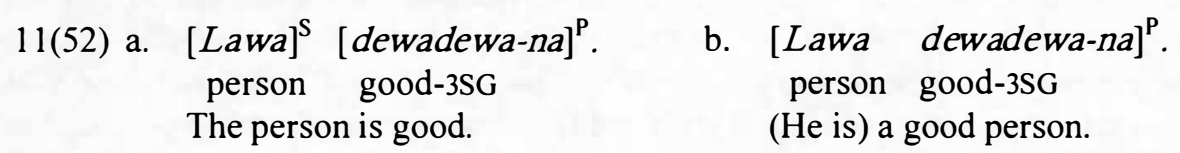

The ambiguity involved is resolved by pragmatic context and not by morphology.

The head-marked clauses seem to have taken, or be in the process of taking, a further step, in which the pronominal enclitic <-na> is a kind of subject agreement marker within the predicate, analogous to subject agreement marking on the verb.

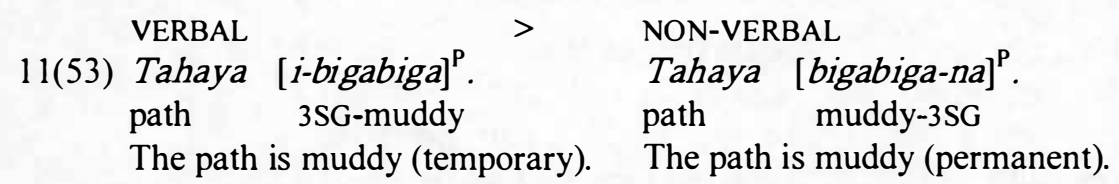

There is almost the feeling that we have here two classes of verbal predicate, the one with prefixed subject agreement and the other with suffixed subject agreement. This point surfaces again later in the chapter, of fering a possible explanation for some intractable data.

It is the use of the pronominal enclitic on the predicate, agreeing with the subject, which led me to call these constructions 'head-marked'. This agreement (absent in equative clauses, where any 'agreement' is phrase internal) is one clear distinction between headmarked and equative clauses.

A test that can be applied to distinguish between equative and head-marked clauses is the use of the negative. The negative takes a position before the predicate and never comes within an NP. Hence, if a negative particle is found between a possessor noun and its possessed noun it is clear that it is a possessive clause.

11(54) $\begin{array}{c}\text { Lawa-na }^{\mathrm{S}} \text { ega } \\ \text { person-DEF }\end{array}$ NEG father-3SG and $]^{\mathrm{p}}$ po ega
NEG motha-na $]^{\mathrm{P}}$.
The man had no father and had no mother.

In contrast to $11(54)$, an equative clause (11(55)) places the negative before the predicate NP and never within it.
11(55) [Tauna] ${ }^{\mathrm{S}}$ ega [Yoela goga-na she NEG Yoela grandmother
She is not Yoela's real grandmother. meanings involved, as in (11(56)), native speaker intuition is probably needed to adequately perform the task as it is difficult to know which structure a speaker has in mind when uttered as minimal pairs. 
This test results in the possibility of constructing the following sentence, consisting of an equative clause followed by a possessive clause. This sentence caused the informant to laugh, ${ }^{3}$ though he agreed that the construction is fully grammatical and has the meaning I attach to it.

\section{1(56) Ega [Limi natu-na] babana Limi ega [natu-na]. \\ NEG Limi child-3SG because Limi NEG child-3SG \\ (That) is not Limi's child because Limi has no child.}

\subsubsection{Descriptive Clause}

...the special form of a 'predicative adjective' as it is often called, tends to be limited to southeastern Papua.

Capell (1969:39)

The descriptive clause consists of an NP functioning as the subject and an adjective functioning as the predicate.

$$
\mathrm{NP}^{\mathrm{S}} \text { adjective }<-n a>^{\mathrm{P}}
$$

\section{1(57) Dedede tahatahaya-na. \\ story first-3SG \\ The story is the first.}

Lichtenberk (1983:328) notes that "Manam adjectives occur not only in attributive position but also as predicators". The traditional distinction between the attributive and predicative use of adjectives highlights the unmistakable resemblance which the simple NP shares with the descriptive clause.

NOUN PHRASE

11(58) [Tewela habulu-na ${ }^{\mathrm{NP}}$ i-peu. child small-3SG 3SG-fell The small child fell.

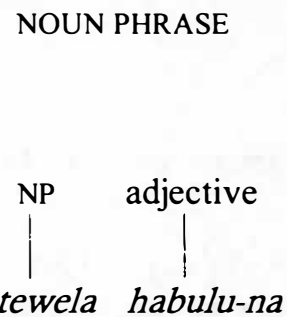

\section{CLAUSE}

Tewela habulu-na.

child small-3SG

The child is small.
DESCRIPTIVE CLAUSE

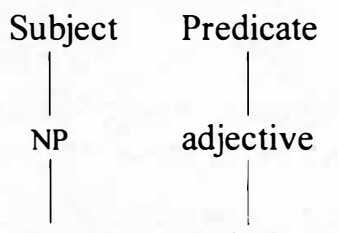

Tewela habulu-na.

The structure of these two constructions is distinct, as is their intonation; the clause has sentence-final intonation, not found on the phrase. As noted in Chapter 3, the adjective is the dependent in the noun phrase but the head within the descriptive clause.

Presumably at the juxtaposition of almost identical structures. The Tawala people do not play with words or pun as we do in English. 
As with other non-verbal clauses there is a clear asymmetry in polarity. In the case of descriptive clauses, the negative is seldom used with descriptive predicates, though it is regularly used with corresponding equative clauses. In the few examples where the adjective predicate of a head-marked clause is negated, the construction indicates that the negative condition is permanent.

11(59) Baha ega sigasiga-na.

word NEG end-3SG

The talk has no end.

11(60) Gamogamo ega lupalupa-na.

animal NEG flying-3SG

The animal does not fly.

11(61) Dobu ega gehou-na.

village NEG other-3SG

The village has no other (place or thing).

The descriptive clause contrasts with the alienable possessive construction.

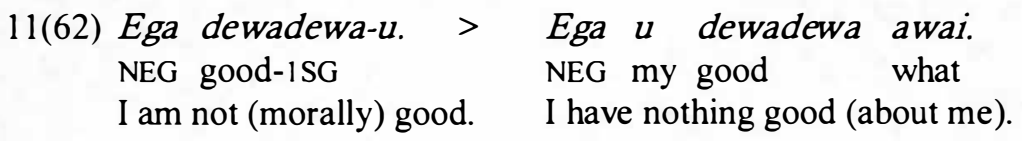

\subsubsection{Possessive Clauses}

Justification is offered above for treating the possessive clause as a clause type separate from the equative clause. Some corroboration of this analysis is found in Mosel (1984:163164), who proposes two categories for the Tolai possessive clauses which are somewhat parallel to the Tawala equative and possessive clauses (details are given at several points below).

The grammatical relations involved in a possessive clause are similar to those that pertain to the descriptive clause, except that the predicate is a noun instead of an adjective phrase.

$\mathrm{NP}^{\mathrm{S}} \mathrm{NOUN}<-n a>^{\mathrm{P}}$

Semantically, these clauses always involve the possessor noun functioning as the subject, and the possessed noun as the predicate. ${ }^{4}$
11(63) a. [Limi] $]^{S}$ ega [natu-na $]^{\mathrm{P}}$.
Limi NEG child-3SG
Limi has no child.
b. $[\text { Polo }]^{\mathrm{S}}$ ega [hai yam $]^{\mathrm{P}}$. pig NEG their food The pigs have no food.

Lyons (1977:473f.) cautions against taking the idea of 'possession' too literally: "Generally speaking ... a phrase like ' $X$ 's $Y$ ' means no more than 'the $Y$ that is associated with $X$ '." In Tawala the possession clause is often most closely represented in English by the formula ' $\mathrm{X}$ has Y', as in 11(63). At other times the relationship is not easily expressed in English at all.

4 In contrast to Tawala, the clause in Tolai has the grammatical relations reversed, so that "the possessed NP functions as the subject, whereas the predicate is formed by a possessor" (Mosel 1984:163). 
It is evident from the data in 11(63) that the possessive clause fits clearly within the category of head-marked clauses, in that there is subject agreement on the predicate. Note, however, that the subject agreement in the first case is marked by a pronominal enclitic and in the second by a possessive pronoun. This is, of course, precisely the situation that is described for the possessive phrases. There are two clause types corresponding to the inalienable possessive NP and alienable possessive NP. Contrast the sentences in 11(63) with $11(64)$ and $11(65){ }^{5}$

\section{1(64) [Kiu natu-hl $]^{\mathrm{NP}}$ lawa atapu-na i-luhogal'-e-ya. bird child-3PL person all-3SG 3SG-love-TRV-3SG ${ }^{6}$ \\ The birds' child loved all the people.}

11(65) [Polo hai neula $]^{\mathrm{NP}}$ i-ani.

pig their coconut 3SG-eat

$\mathrm{He}$ ate the pigs' coconut.

As the tree below suggests, there is no structural distinction between inalienable and alienable possessive clauses, apart from the position of the pronominal possessive marker (the pronominal enclitic with the former and the possessive pronoun with the latter) the pronominal forms are identical to those used with possessive noun phrases.

POSSESSIVE PHRASE

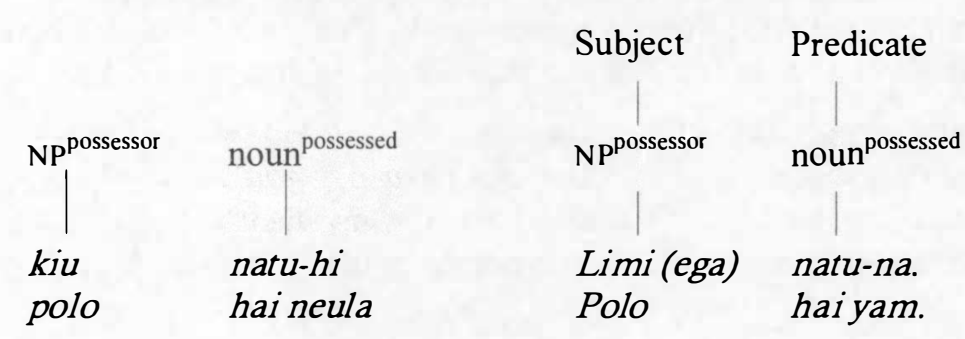

Even though these two clause types are essentially the same, a description of their syntax is simplified by keeping the two types separate.

ALIENABLE: [NP $\left.{ }^{\text {possessor }}\right]^{S}\left[<a>N^{\text {possessed }}\right]^{\mathrm{P}}$

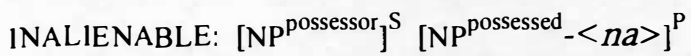

While alienability is largely determined by the noun class, with verbal nouns there is a genuine choice. Inalienable possessive clauses basically reflect [-control] situations, as opposed to alienable possessive clauses which indicate a greater degree of control. Noun classes reflect this same distinction. The following data demonstrate the contrast; both constructions are in common use.
11(66) Hai luhogala beda.
$>$ Beda nugonugo-hi.
their desire betel
betel mind-3PL
They want betel nut. [+control]
They need betel nut. [-control]

5 Tolai has a different order of possessed and possessor nouns for the NP and clause, thus avoiding
constructional homonymy. 


\subsubsection{Alienable Possessive Clause}

A convincing translation of the head-marked clause often requires a reversal of the function of NPs - the Tawala predicate becomes the subject of the English translation. ${ }^{7}$

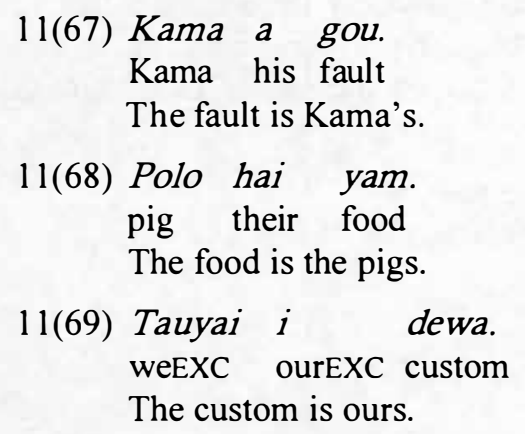

In 11(67)-11(69) the possessed item is definite. An indefinite construction would involve the use of the 'existential' verb mae 'stay'.

11(70) Polo hai yam e-ma-mae.

pig their food 3SG.PRES-DUR-stay

The pigs have food.

The use of a negative with these constructions not only distinguishes between headmarked and equative clauses but facilitates a more direct English translation.

$\begin{array}{ll}\text { ALIENABLE POSSESSIVE } & \text { EQUATIVE } \\ \text { 11(71) Tau ega } u \text { gou. } & \text { Naka ega tau } u \text { gou. } \\ \text { I Nat NEG I my fault } \\ \text { The fault is not mine. } & \text { That is not my fault. } \\ \text { 11(72) Polo ega hai yam. } & \begin{array}{l}\text { Ega polo hai yam. } \\ \text { pig NEG their food }\end{array} \\ \text { The pigs have no food. } & \text { (It is) not the pig's food. }\end{array}$

Note that in the second sentence in 11(72) the negative is structurally the counterpart of the definite construction in 11(68) but is itself indefinite. Sentence 11(73) is the counterpart of $11(67)$.

\section{1(73) Geka lawa-na ega a powa awai. this person-DEF NEG his mistake what This person has done nothing wrong.}

11(74) Moina, hai wigou ega ano-na.

truly their accusation NEG core-3SG

Truly, their accusation had no substance.

The following negative construction is a declaration of need.

Mosel (1984:163) states "the possessed NP functions as the subject, whereas the predicate is formed by a possessor". This distinction is actually made in Tolai syntax (by word order) not just in the translation. 


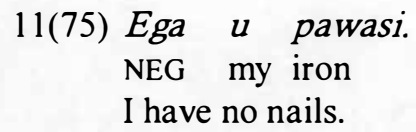

Example 11(76) has an expanded subject NP.

11(76) [Bada natu-natu-na mitehi $]^{\mathrm{S}}$ hai numa.
man

The bad $a$ and his children have a house.

\subsubsection{Inalienable Possessive Clauses}

In the general discussion of head-marking clauses the distinction is drawn in Tawala between an equative clause (with a possessive phrase in the predicate) and a head-marked possessive clause (with the possessor NP as subject and the possessed NP as predicate). In this section, only head-marked clauses are discussed. ${ }^{8}$

These clausal constructions have a decidedly unusual sound to English ears, and the following translations are, accordingly, neither very literal nor very meaningful.

\section{1(77) Ginahi bagibagi-na.}

sago work-3SG

Sago (has) its work. (i.e. (It is) work (for making) sago.)

11(78) Gapola luhogala-hi.

thing desire-3SG

Things (have) their love. (i.e. Their love (is for) possessions.)

11(79) Baha ano-na.

word core-3SG

The speech (has) substance/meaning.

In the following examples the subject NP is expanded.

Mosel (1984:164) states that Tolai does not have this clause type: "The relationships denoted by inalienable possessive phrases differ from those of the alienable possessive phrases in that they cannot be expressed on sentence level by predicating either the possessed noun phrase ('I have a father'), or the possessor noun phrase ('the father belongs to me', 'the father is mine'), which is quite natural, since inherent relationships cannot be predicated". Mosel's own data seems to argue against her position, as seen in the second sentence of her example (186) on page 165 of the Tolai Syntax, which she translates '.. they had neither uncle, nor brother, nor sister, they had nobody at all'. (A more literal translation, showing the presence of the four clauses and the sentence-break marked in the text, would read: '.. they had no uncle, no brother, no sister, nobody at all'.) These clauses seem identical in structure to those described for Tawala here. The crucial test would be to discover whether or not a possessor noun phrase can be expressed, which seems likely. In the Tolai example, the subject possessor is expressed in the previous sentence and presumably omitted from the non-verbal sentence because it is given, just as it would be in Tawala. Mosel's (p.165) interpretation is that the possessive clauses are existential "a clause that consists of only one noun phrase and denotes that what is referred to by the noun phrase exists". Or in the clauses in question, "to express that somebody does not have this certain kind of relative". I discovered in my analysis of Tawala existential clauses that it is crucial to limit data to a single referent; by admitting a possessor particle we have two referents and hence potentially two NPs. It is only in admitting inalienable possessive nouns that Mosel's analysis of Tolai existential clauses (pp.156-157) differs from that offered for Tawala. I conclude, therefore, that the Tawala and Tolai structures may well be identical in these two clause types. 
11(80) [Meyagai gehou-na] ${ }^{\mathrm{S}}$ bagibagi-na.

village other-3SG work-3SG

Another village (has) its work. (i.e. (It is) work (for) another village.)

11(81) [(Lawa) hai luhinigigal ${ }^{\mathrm{S}}$ ega ano-na.

person their refusal NEG core-3SG

The people's refusal (has) no foundation. (i.e. The people had no right to refuse (it).)

Example 11(81) also illustrates a negative modifier with the predicate. The predicate can be expanded in other ways too, as in $11(82)$.
11(82) I-gehou-ta
ega [wai hina-hina-ta
po am-ama-ta] $]^{\mathrm{P}}$.
UNSP-other-IPL.INC NEG CON PL-mother-1PL.INC and PL-father-1PL.INC
Some of us (have) the condition (of having) no mothers and fathers.

In Tawala, inalienable possessive clauses are readily negated.
11(83) a. Peuka ega natu-na.
Peuka NEG child-3SG
b. Bada-na ega pona-na.
man-DEF NEG voice-3SG
Peuka has no child.
The man had no voice.

11(84) Lawa-na ega ama-na po ega hina-na.

man-DEF NEG father-3SG and NEG mother-3SG

The man had no father and had no mother.

\subsection{COMPLEMENT CLAUSES}

Possessive clauses fall into two classes: 1) those that take only a subject, and 2) those taking a subject and a complement $\left({ }^{\mathrm{C}}\right)$. Both alienable and inalienable clauses include a subclass of 'bivalent' predicates.

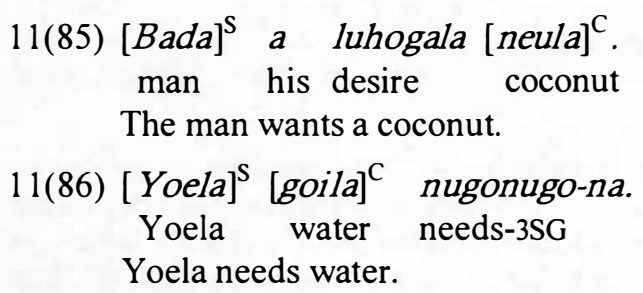

The situation is analogous to the valence distinction that exists between intransitive and transitive. The parallel nature of the structure is particularly striking in examples like 11(86), where the non-verbal order SCP matches the SOP word order of verbal clauses.

Complementation is described in Chapter 15. However, some aspects need to be introduced at this point in order to give a complete picture of non-verbal clauses.

The concept of 'complement' itself is vague - "a major constituent of sentence or clause structure, traditionally associated with 'completing' the action specified by the verb" (Crystal 1980:74). Complementation in Tawala is a broader functional domain than that found in English, as evidenced by the following data where complements 'complete' nonverbal predicates. 
11(87) Ega [a tekis $]^{\mathrm{C}}$ emoemota-na.

NEG her tax ability-3SG

She is not able (to pay) her tax.

11(88) $A$ luhogala [beda po gaga $]^{\mathrm{C}}$.

his desire betel and pepper

His desire is (for) betel nut and 'pepper'.

$11(89)$ Ama-m [awal $]^{\mathrm{C}}$ nugonugo-na?

father-2SG what need-3SG

What does your father want?

The complement is simply a second grammatical function occurring optionally with some predicates in addition to clausal subject - the primary function. The predicate is indexed for subject agreement; the complement is not cross-referenced on the predicate.

11(90) [Bagibag1] ${ }^{\mathrm{C}}$ emoemota-ta.

work ability-1PL.INC

We can do the work.

The inalienably possessed noun gowana also functions as a two-place predicate.

$\begin{array}{cll}\text { 11(91) Tauna ega gowa-na bada. } & \\ \text { he } & \text { NEG name-3SG man }\end{array}$

$\mathrm{He}$ is not called 'sir'. OR He has not the name bada.

Semantically the grammatical predicate functions like a verb in that it predicates a relationship between the subject and the complement. The possessive construction (11(91)) contrasts with the equative (11(92)).

11(92) Tauna gowa-na ega bada.

he name-3SG NEG man

His name is not 'sir'.

Tense-aspect particles precede the predicate. Again the distinction between the possessive (11(93)) and the equative (11(94)) clause is evident.

11(93) Apo gowa-na Yoni.

FUT name-3SG Yoni

He will be called Yoni.

11(94) Gowa-na apo Yoni.

name-3SG FUT Yoni

His name will be Yoni.

The preferred position for the negative is immediately preceding the predicate.

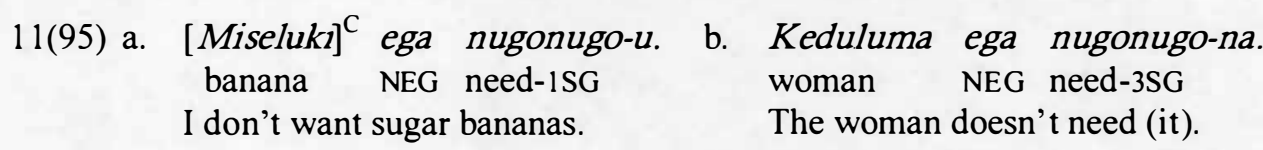

However a negative can come before the NP complement (also 11(87)). 
11(96) Tauhi ega [tu-mulamula $]^{\mathrm{C}}$ nugonugo-hi.

they NEG PER-medicine mind-3PL

They don't want a medicine man. 


\title{
A UNIFIED CLAUSE MODEL
}

\begin{abstract}
One of the most fundamental problems in the analysis of clause structure is the characterization of predicates and the semantic relations which obtain between them and their arguments.
\end{abstract}

Foley and Van Valin (1984:27)

\subsection{VERBAL VERSUS NON-VERBAL CLAUSES}

That there are verbless sentences in several of the world's languages invalidates the assumption that the verb is an indispensable element of the sentence in all natural languages.

Lyons (1977:437)

As we have seen, Tawala abounds in non-verbal clauses. Sometimes a non-verbal clause (12(2)) is constructed on the same lexical root as a verbal clause (12(1)).
12(1)
A-luhogal-e-ya
(polo u-na-lup-e-na
hale-ya).
1SG-desire-TRV-3SG pig 2SG-POT-fly-TRV-LIG throw-3SG
I desire (you to release the pig).
12(2) U luhogala (numa dalabu uyahi-na hi-na-tawine). my desire house rest 'at'-3SG 3PL-POT-marry
My desire is (that they marry in the church).

The constructions in 12(1) and 12(2) are parallel in that each consists of a sentence with an embedded complement clause (in brackets); they differ, however, in that the main clause of the first sentence is verbal and that of the second is non-verbal. The same contrast is reflected in interrogative constructions.

12(3) a. Awai u-luhogal-e-ya? b. Om luhogala awai?
$\begin{gathered}\text { what 2SG-desire-TRV-3SG } \\ \text { What is it you want? }\end{gathered}$

In Chapter 11 we saw that non-verbal constructions are much more complex than these examples would indicate, and in many cases there are no parallel verbal constructions. However, the above examples do show the need to take non-verbal constructions seriously in any description of Tawala clauses.

We noted that in many cases non-verbal constructions involve the same surface string as NPs. For example, a string such as toleha banei-na may have two separate analyses. ${ }^{1}$ In $12(4)$ it is an NP - in this case the object NP.

Givón (1984:77) states, "Adjectives may appear in sentences either as predicates or as noun modifiers". 
12(4) [Toleha banei-na $]^{\mathrm{O}} \quad[\text { i-dewa-ya }]^{\mathrm{P}}$.

feast big-3SG 3SG-make-3SG

He made a big feast.

In 12(5) the same surface string functions as a non-verbal clause in which the noun is the subject and the adjective the predicate.

12(5) $\left[\text { Toleha }^{\mathrm{S}} \quad \text { [banei-na }\right]^{\mathrm{P}}$.
feast big-3SG
The feast is big.

Given that there are a variety of non-verbal clauses, these need to be accounted for in any universal approach to the clause. This chapter builds on the theory presented in Chapter 7 (the layered structure of the clause) which unites all Tawala clauses within a single framework by proposing a functional definition of the clause.

\subsection{A THEORETICAL APPROACH TO NON-VERBAL CLAUSES}

Theoreticians have given considerable attention to the analysis of the verbal clause, and the descriptivist has a rich variety of concepts and terminology to choose from. The situation is vastly different with non-verbal clauses, which often receive not much more than a passing mention. This theoretical bias is reflected in the grammatical descriptions of the Austronesian languages of Papua New Guinea that sometimes make no mention of nonverbal clauses which are clearly endemic to the area. Presumably many grammars reflect the state of the art rather than adequate descriptions of non-verbal clauses. After all, few grammars claim to be exhaustive, and concentration of effort is inevitably given to areas one feels comfortable with.

One notable exception is Mosel's (1984) Tolai syntax and its historical development, ${ }^{2}$ which presents the most comprehensive analysis of non-verbal constructions to date - and became seminal to my own approach.

\subsubsection{Defining The Non-verbal Clause}

Clauses are, broadly speaking, predicational strings, although both predicational and strings must be qualified somewhat. Thus many languages contain non-verbal or nominal clauses. Nominal clauses differ in internal relationship from language to language...That clauses tend to be strings is true provided we admit that some nesting - noticeably use of nominalized or relativized clauses as exponents of subject and object - occurs as well. Longacre (1976:273)

Clauses are the building blocks of discourse. In the above quotation Longacre explicitly states that it does not matter whether the building blocks contain a verb or not; they are still to be regarded as predicational strings. This, of course, differs from the traditional approach to grammar, where the verb was seen as the defining characteristic of the clause. Obviously a broad definition of the clause is needed, one that incorporates non-verbal structures. 


\subsubsection{Predicates of Non-Verbal Clauses}

we include forms from other languages which may not seem like predicates to the speaker of English. In many languages the combination of words translated by good he (or he good) is functionally equivalent to English clauses which include the verb to be, such as he is good.

Elson and Pickett (1964:64-65)

For the purposes of clause analysis I adopt the Tagmemic approach of using the term 'predicate' to refer to the grammatical function played by the verb phrase within a clause, which distinguishes it from not only the subject NP but also the object NP. Hence a transitive clause consists of:

\section{SUBJECT + OBJECT + PREDICATE ${ }^{3}$}

Using the term 'predicate' rather than 'verb' has a number of advantages. In the first place, SOP avoids the confusion implicit in the SOV usage which mixes two levels of analysis: grammatical functions (S and O) with word class (V). As Crystal (1980:280) points out, if "a Subject may have a noun as its exponent" then the undesirable consequence is that "a Verb may have a verb as its exponent". ${ }^{4}$ It is clear that a separate term is required if we are to adequately describe grammatical functions at the clause level, and predicate has been used in more than one tradition for that very purpose. ${ }^{5}$

More importantly, the use of 'predicate' enables us to describe the unity of function that exists between verbal and non-verbal clauses. In 12(6) the two bracketed items differ in a number of respects: they belong to different word classes - a verb and a noun; one is prefixed, the other suffixed, by person/number marking, ${ }^{6}$ and they are of course different lexical items, though their meanings are basically the same. In spite of these differences the bracketed items clearly have a unity of grammatical function. That unity is captured in the functional label of 'predicate' $\left({ }^{P}\right)$ appended to the bracket.

$\begin{array}{lll}\text { 12(6) a. Beda [a-luhogale-ya] }{ }^{\mathrm{P}} . & \text { b. } \begin{array}{l}\text { Beda } \\ \text { betel 1SG-desire-3SG }\end{array} & \text { betel mind/need-1SG } \\ & \text { I desire betel nut. } & \text { I want betel nut. }\end{array}$

In verbal clauses the exponent of the predicate is a verb. In non-verbal clauses the exponent can be an adjective (12(7)), an NP (12(8)), a possessed noun (12(9)) etc.

\section{2(7) Dedede [tahatahaya-na]. story first-3SG \\ (This) story is first.}

\footnotetext{
3 Crystal (1980:280) mentions that 'predicator has also been suggested by some theorists to refer to the verbal element in Subject-Verb-Object constructions, viz Subject-Predicator-Object'; Lyons (1977:434) makes this same suggestion. I follow the standard usage in discussing language typology (see $\S 3.1$ etc.). Hence I refer to Tawala as an SOV language for typological purposes.

5 The term 'predicate' is also used by linguists in referring to the semantic structure of propositions or predications as consisting of a predicate and its arguments; I endeavour to make the context clarify whether I am talking of a semantic predication with its accompanying arguments, or a grammatical predicate with its grammatical relations. 'predicate', for the purposes of a unified model of verbal and non-verbal clauses.
} 
12(8) Tauna [Limi natu-na].

he Limi child-3SG

$\mathrm{He}$ is Limi's child (son).

12(9) Limi [natu-na].

Limi child-3SG

Limi has a child.

Givón (1984) summarises what he calls copular sentences in which "the predicate may be either a noun (nominal predicate) or [an] adjective (adjectival predicate)" (p.91). Some languages require a copular verb 'be' "as the surface/syntactic main verb of the construction". Givón considers the function of this "semantically-empty copula" to be "primarily a tense-aspect carrier". Hence the predicate is a grammatical function corresponding to the semantic predicate. "Verbs....are most commonly the predicate of a sentence" (p.73), but a non-verbal item (with or without a surface copula) can also be the grammatical predicate: an "adjectival predicate" or a "nominal predicate" (p.190).

\subsubsection{SUBJeCtLESS Clauses}

Any adequate definition of the clause must take into account its fundamental role as the basic unit of communication. It is important to keep this factor in mind as we approach nonverbal clauses, which clearly have a major communicative role in Tawala. It is not adequate to see these structures as 'incomplete sentences' or to develop models involving underlying verbal structure. Under the definition proposed in this chapter, even minimal non-verbal constructions such as existential clauses are complete clauses as they stand.

\section{2(10) Gadiwewe.}

rain

It is raining./Rain is coming. etc.

One major piece of evidence witnessing to the clausal nature of non-verbal constructions such as $12(10)$ is their isolability.

The minimal unit functioning as a clause, in Tawala, is the predicate. In this, Tawala offers counter-evidence to claims that a clause must always contain a subject and a predicate, such as Lyons' (1968:334):

It is a fundamental principle of traditional grammar, and also of much modern syntactic theory, that every simple, declarative sentence consists of two obligatory constituents, a subject and a predicate.

In that Tawala existential clauses have no subject, ${ }^{7}$ the conclusion seems inescapable that subject NPs are not obligatory items of all clauses.

\subsubsection{Grammatical Relations Of Non-verbal Clauses}

...the properties of core NPs suggest that they should be viewed as bearing 'abstract grammatical relations': structural relationships which are not necessarily directly reflected by

In English, meteorological clauses use a dummy subject, "It is raining". Presumably many languages, like Tawala, have just a predicate and no dummy subject. 
coding features, and do not necessarily correlate precisely with semantic roles, pragmatic functions, or other aspects of meaning.

Andrews (1985:82)

I claim in the previous section that not all Tawala clauses have a subject constituent; however, a word needs to be said about those that do. There appears to be no reason to regard the subject of a non-verbal clause as significantly different from the prototypical subject of the verbal clause. Hence in addition to a predicate I find a subject in most Tawala non-verbal clauses, in line with Givón (1984:91), who defines copular sentences as those "with a subject and predicate". 8

In addition to a subject NP I have found it necessary to introduce a complement NP (underlined in 12(11)) for some non-verbal predicates, corresponding to the object NP of a verbal predicate. In other words, some nominal predicates are two-place predications. A complement may be an NP (12(11)) or a clause (12(2)).

\section{2(11) Tau u luhogala beda. I my desire betel I want betel nut.}

Finally, it needs to be stressed that there is a predicate in every clause, whether that predicate be a verbal, adverbial, adjectival or nominal element - and that this predicate must be clearly distinguished from the subject NP and any other NPs which the clause may contain. I am thus proposing a structural unity for all Tawala clauses, whether verbal or non-verbal: (subject) + predicate. In order to avoid circular reasoning, however, it now becomes vital to define non-verbal clause boundaries by some independent means - that is, not by the presence of an item regarded as a predicate - and it is to this problem we now turn.

\subsection{ISOLATING NON-VERBAL CLAUSES}

Just as narrative discourse is the domain of the verbal clause so, in Tawala, descriptive discourse is the domain of the non-verbal clause and the main source of data. Everyday conversation is also a fruitful source of data. This section explores how these non-verbal clauses are to be distinguished from identical strings used as NPs. The presence of singleword existential clauses presents an even greater problem. For example, how do we distinguish a demonstrative functioning as the predicate of a clause from a demonstrative modifying a head noun? In 12(12), is the demonstrative functioning as the sole member of a separate clause, or is it a constituent of the verbal clause?

12(12) Geka ma polo a-matute-ya.

this and pig 1SG-frighten-3SG

Which of the following translations is correct?

1) Here I frightened the pig.

2) It was here that I frightened the pig.

The principles enunciated below propose a solution to this question. We find that coordinating conjunctions, particularly ma, are used to combine constructions of equal 
status. In addition, demonstratives frequently occur in isolation as non-verbal predicates and sole members of clauses, and so their clausal status is independently established. It thus becomes clear that, in 12(12), translation 2) is correct and not 1).

A number of features combine to give a clear picture of the borders of non-verbal clauses within descriptive discourse. We now examine each of these features in turn.

\subsubsection{INTONATION}

Intonation contours help in the recognition of the borders of a clause. Thus, given a spoken text, sentences - including verbless sentences - can often be identified by intonation.

\subsubsection{Clause Operators}

We saw in Chapter 11 that many non-verbal items operate with tense and negative adverbsthus giving the item clausal status.

\begin{tabular}{|c|c|c|}
\hline 12(13) a. & $\begin{array}{l}\text { Ega hina-na. } \\
\text { NEG mother-3SG } \\
\text { He had no mother. }\end{array}$ & $\begin{array}{l}\text { b. Apo gadiwewe. } \\
\text { FUT rain } \\
\text { It will rain. }\end{array}$ \\
\hline
\end{tabular}

\subsubsection{PARENTHESIS}

Often within a text a sentence will be isolated by pauses and clausal intonation; semantically, the text is not dependent on the parenthetical sentence. Such a sentence is analysed as a separate predication even though it has no verb contained in it. In context, $12(14)$ is found between sentences with totally different, though not unrelated, topics. It gives cultural background to me, an outsider, as to why vegetables and meat are being focused on in the text.

12(14) I ani-wimeiha naka aniani ma muhala.
ourEXC thing-payment that vegetables and game

(Our currency is vegetables and meat.)

\subsubsection{Parallel Structures}

On many occasions we find a string of clauses which are clearly parallel in function and even somewhat in syntax, some of which are verbal and some non-verbal - and yet all are clearly coordinated clauses. Example 12(15) contains two non-verbal clauses (in square brackets) between two verbal clauses.

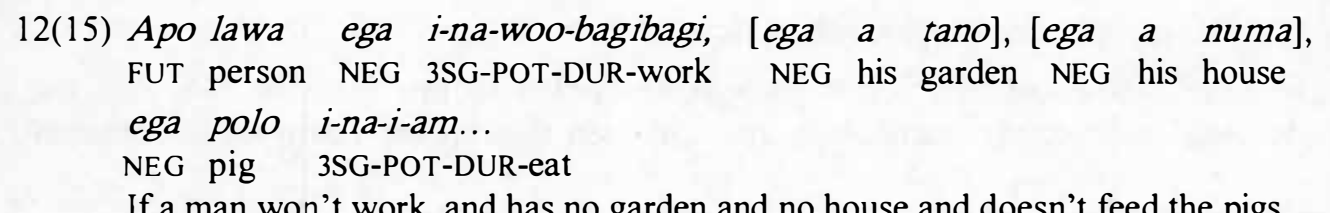

Here we see that non-verbal clauses are not marked for mood, a point we return to below. 
Often an isolated non-verbal utterance has clear internal structure of a parallel nature, either with or without a conjunction. Such constructions are interpreted as two further nonverbal examples of coordinated clauses.

12(16) [Ega beda uyahi-u], ma [gaga ega uyahi-u]. NEG betel 'at'-1SG and pepper NEG 'at'-1SG

I have no betel nut and I have no 'pepper'.

12(17) [ Tau bani-u], [tam u tewela].

I big-1SG yousG my younger.sibling

I am older, so you are my younger brother.

\subsubsection{CONJUNCTIONS}

The two coordinating conjunctions combine items of equal rank, whether word, phrase, clause or sentence. There are no clear exceptions to this rule. In 12(18) there are two conjunctions (underlined). The question is whether the item in square brackets is to be considered a temporal NP or a non-verbal clause embedded in the adverbial time slot. The rule being proposed in this section settles the point; the second ma is not joining phrases, for the following element is a clause. The bracketed string must also be a clause - a nonverbal descriptive clause.

12(18) ...i-ma-mae ma [hauga gehou-na] ma tu-wisili hi-ne... 3SG-DUR-stay and time other-3SG and PER-fishing 3PL-come ...he was there and it was another time and fishermen came...

A similar line of reasoning applies to the following examples, which demonstrate a variety of non-verbal clause types and a number of different conjunctions. Note that in 12(19) winugototogo is a stative verb, not a non-verbal clause.

12(19) Pona-m i-winugototogo ma [om yatu dagugu-hr] $\underline{\underline{m a}}$ voice-2SG 3SG-melancholic and yoursG adze sound-3PL and e-lai-didiga... 3SG.PRES-DUR-beautiful

Your voice is melancholic and your adze has sounds and it is beautiful...

12(20) Hi-mamae ma [magou-hi 150 Olokaiwa], ma hi-nei... 3PL-stay and number-3PL150 Orokaiva and 3PL-came They were there and the number of Orokaivans was 150 and they came...

12(21) [ $U$ houga tahatahaya-na] apoma plein a-gelu-ya. my time first-3SG then plane 1SG-embark-3SG It was my first time and then I embarked the plane.

12(22) [Naka noka pite] ee i-na-po... that there like and.so 3SG-go-and It was like that and so he went and...

The situation is transparent in 12(23). Conjunctions often separate sentences; certainly the clauses are distinct. 
12(23) [Amaka] ma ega.yaka logaloga-hi hi-paliwele-ya... already and so children-DEF 3PL-tell-3SG

It was enough and so the children told her...

\subsubsection{ISOLATION}

Hundreds of isolated sayings are in daily use as predications, particularly in questionand-answer dialogue. Constant usage in isolation distinguishes these from elliptical constructions which usually require a spoken context. (Many other examples are given in Chapter 13, in various sections, to illustrate non-verbal clause types.)

12(24) [Om luhogala
yoursG desire
What do you want?
12(25) [Ega nugonugo-u.]
NEG mind-1SG
I don't want (it).

\subsection{UNITING VERBAL AND NON-VERBAL CLAUSES}

Lyons (1977:469) lists the following clause types as identifiable "in very many unrelated languages".

\section{TABLE 1: CLAUSE TYPES ACCORDING TO LYONS}

\begin{tabular}{|ll|l|}
\hline (a) & $\mathrm{NP}+\mathrm{V}$ & intransitive \\
(b) & $\mathrm{NP}+\mathrm{V}+\mathrm{NP}$ & transitive \\
(c) & $\mathrm{NP}(+\mathrm{Cop})+\mathrm{NP}$ & equative \\
(d) & $\mathrm{NP}(+\mathrm{Cop})+\mathrm{N} / \mathrm{A}$ & ascriptive \\
(e) & $\mathrm{NP}(+\mathrm{Cop})+$ Loc & locative \\
(f) & $\mathrm{NP}(+\mathrm{Cop})+$ Poss & possessive \\
\hline
\end{tabular}

This classification proved useful to my understanding of the nature of Tawala clauses, though a number of alterations needed to be made to Lyons' classification in order to account for the Tawala data. In particular we need to label the grammatical functions of the constituents.

We note above that an item such as an adjective or noun functions as the predicate of a non-verbal clause just as a verb functions as the predicate of a verbal clause. Lyons does not display the grammatical functions of his clause-level items but instead depends on word order to convey these grammatical relations, which, of course, means that his scheme is applicable only to English and other strictly Svo languages. To avoid confusion it is essential to indicate which item in a particular clause type is the predicate and correspondingly which is the subject etc., irrespective of whether the grammatical roles are marked by word order or morphology.

Also, because of a mismatch between the grammatical relations marked on the verb (in square brackets in Table 2 and the potential NPs within the clause, it is necessary to indicate both. 
TABLE 2: TAWALA CLAUSE TYPES

\begin{tabular}{|c|c|c|c|c|c|}
\hline $\begin{array}{l}\text { (a) } \\
\text { (b) } \\
\text { (c) } \\
\text { (d) } \\
\text { (e) } \\
\text { (f) } \\
\text { (g) } \\
\text { (h) } \\
(\text { i) } \\
\text { (j) }\end{array}$ & $\begin{array}{l}\left(\mathrm{NP}^{S}\right) \\
\left(\mathrm{NP}^{\mathrm{S}}+\mathrm{NP}\right) \\
\left(\mathrm{NP}^{\mathrm{O}}+\mathrm{NP}^{\mathrm{O}}\right) \\
\left(\mathrm{NP}^{\mathrm{S}}\right) \\
\mathrm{NP}^{\mathrm{S}} \\
\mathrm{NP}^{S} \\
\mathrm{NP}^{S} \\
\mathrm{NP}^{S} \\
\mathrm{NP}^{S}\end{array}$ & $+\mathrm{NP}^{\mathrm{O} 2}$ & $\begin{array}{l}+V P^{P} \\
+\mathrm{VP}^{\mathrm{P}} \\
+\mathrm{VP}^{\mathrm{P}} \\
+\mathrm{VP}^{\mathrm{P}} \\
+\mathrm{NP}^{\mathrm{P}} \\
+\mathrm{NP}^{\mathrm{P}} \\
+\mathrm{NP} \\
+\mathrm{ADJ}^{\mathrm{P}} \\
+\mathrm{PP}^{\mathrm{P}} \\
+\mathrm{NP}^{\mathrm{P}} \\
\end{array}$ & $\begin{array}{l}{[\mathrm{S}]} \\
{[\mathrm{S}+\mathrm{O}]} \\
{[\mathrm{S}+\mathrm{O}]} \\
{[\mathrm{S}+\mathrm{O}]}\end{array}$ & $\begin{array}{l}\text { intransitive } \\
\text { transitive } \\
\text { ditransitive } \\
\text { condition } \\
\text { equative } \\
\text { complement } \\
\text { possessive } \\
\text { descriptive } \\
\text { adpositional } \\
\text { existential } \\
\end{array}$ \\
\hline
\end{tabular}

Tawala has ten basic clause types. A single example of each type follows.

(a) Intransitive

12(26) [Gadiwewe ma gahu] ${ }^{\mathrm{S}}$ [i-lata duma] ${ }^{\mathrm{P}}$. rain and mist 3SG.S-big very

There was impenetrable rain and mist.

(b) Transitive

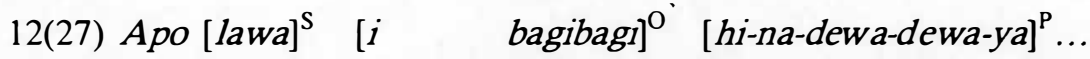
FUT person ourEXC work 3PL.S-POT-DUR-do-3SG.O If people do our work...

(c) Ditransitive

12(28) Ega [aniani po muhala $\left.]^{02}{ }^{0 \text { lawa }}\right]^{\mathrm{O}}\left[{ }^{\text {ta-wele- } h 1}\right]^{\mathrm{P}}$. NEG food and meat person IPL.INC.S-give-3PL.O We do not give those people staples and meat.

(d) Condition

12(29) $[\text { Koiba-u }]^{\mathrm{S}=\mathrm{O}} \quad[\text { i-hogo-ya }]^{\mathrm{P}}$. stomach-1SG 3SG.S-full-CPY My stomach is full.

(e) Equative - Minimal

12(30) $[\text { Naka }]^{\mathrm{S}} \quad$ [amaka $^{\mathrm{P}}$. that enough That is enough.

Equative - Nominalised NP

12(31) [Tauna $]^{\mathrm{S}}$ [aniani tu-mpahi-na] ${ }^{\mathrm{P}}$. he food PER-finisher-3SG.S

$\mathrm{He}$ is the one who finishes the leftover food.

(f) Complement

12(32) $[\text { Tau }]^{\mathrm{S}}\left[\begin{array}{ll}u & \text { luhogala }\end{array}{ }^{\mathrm{P}} \quad\left[\right.\right.$ beda $^{\mathrm{C}}$. I 1SG.S desire betel I want betel nut. 
(g) Possessive

$$
\begin{gathered}
\text { 12(33) }\left[\text { Liml }^{\mathrm{S}} \quad{\text { [natu-na }]^{\mathrm{P}}}^{\text {Limi }}\right. \text { child-3SG.S } \\
\text { Limi has a child. }
\end{gathered}
$$

(h) Descriptive

$$
\begin{gathered}
\text { 12(34) }\left[_{\text {Dedede }}^{\mathrm{S}} \quad{\text { [tahatahaya-na }]^{\mathrm{P}} \text {. }}_{\text {story }}\right. \text { first-3SG.S } \\
\text { This is the first story. }
\end{gathered}
$$

(i) Adpositional

$$
\begin{aligned}
& \text { 12(35) } \left.\left[\text { Tauh }^{\mathrm{S}}\right]^{\mathrm{m}} \text { mei tauta }\right]^{\mathrm{P}} \text {. } \\
& \text { they like usINC } \\
& \text { They are like us. }
\end{aligned}
$$

(j) Existential

$$
\begin{aligned}
& \text { 12(36) } \text { [Gadiwewe }^{\mathrm{P}} \text {. } \\
& \text { rain }
\end{aligned}
$$

It is raining.

\subsubsection{Functional Relationship Between Clause Types}

The verbal clause is the prototypical clause of narrative discourse and the non-verbal clause is the prototypical clause of descriptive discourse. Of course, both clause types are found interacting with each other at many points in the language. While verbal clauses function in most situations, several functions of non-verbal clauses have been isolated; these include introductory remarks, background, parenthesis and concluding comments; sentence complements; lists; and indirect quotes.

\subsubsection{Layered Structure Of Non-verbal Clauses}

A layered structure similar to that found in verbal clauses is discernible in non-verbal clauses, but inevitably there are qualifications. While these qualifications are often of a trivial nature, there are also significant differences. Nevertheless, it is insightful to view the non-verbal clauses from the perspective of a layered structure.

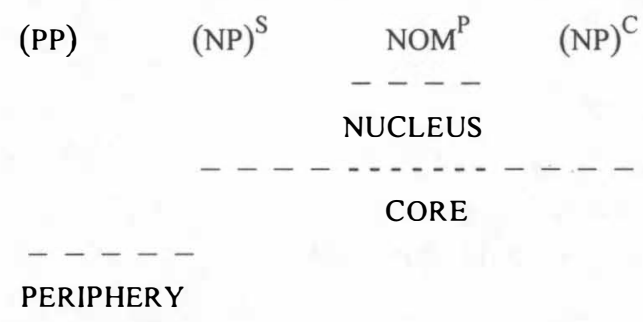

FIGURE 1: THE LAYERED STRUCTURE OF NON-VERBAL CLAUSES

We can readily identify a NUCLEUS which we again call the predicate (see §7.2). The non-verbal predicate: is often an NP but it can be a noun, adjective, adverb or adpositional 
phrase. The diagnostic feature of verbal clauses is the person/number indexing of the subject as a verbal prefix. Some non-verbal clauses are also head-marked; there is person/number indexing of subject, but in this case it is normally a pronominal enclitic placed on the predicate.

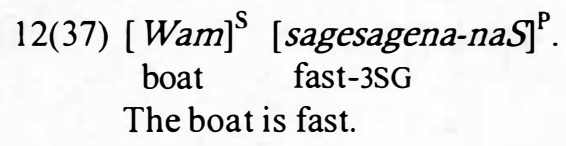

Non-verbal clauses have a recognisable CORE item - the SUBJECT of the clause. These core items do not possess the same degree of optionality found in the verbal core; with the non-verbal clause they are often obligatory. Not only are the items obligatory but they are also often restricted - a demonstrative or a simple noun, in contradistinction to an NP. The structure of core items differs according to clause type. In addition to a subject, one nonverbal clause type has an additional core item - a COMPLEMENT - as a core item. The complement corresponds to the object of the verbal clause. It is used with two-place nonverbal predicates.

Many of the prepositional phrases associated with the PERIPHERY of verbal clauses do not occur with non-verbal clauses.

\subsection{CLAUSE OPERATORS WITH NON-VERBAL CLAUSES}

Tense, aspect and mood of verbal clauses are described elsewhere. None of the prefixes found with the verb operate with non-verbal clauses. On the other hand 'adverbs' function as clause operators with both verbal and non-verbal clauses. Two of these operators are very common with non-verbal clauses: tense and negation.

\subsubsection{TENSE-ASPECT MARKERS}

Non-verbal clauses occur with all three tenses (underlined).

12(38) Apo gadiwewe? > Apega gadiwewe.

FUT rain FUT.NEG rain

Will it rain? It will not rain.

12(39) Amaka gadiwewe. > Ega gadiwewe.

already rain NEG rain

It has already rained. It did not rain.

12(40) Naka tewela-na amalai keyalu u moya-na.

that child-DEF today casuarina LOC top-3SG

That child is now in the top of the casuarina.

The future tense particle apo is often used with hypothetical conditions.

12(41) Apo lawa Kehelala-gei ma i-nae...

FUT person Kehelala-ABL and 3SG-go

Suppose there is a person from East Cape and he goes...

It can also apply to a whole sentence, not just the immediate clause. 
12(42) Apo gowa-u-gei ma am po ani-eno dewadewa-hi i-na-tuhaga-hi. FUT name-1SG-ABL and food and place-sleep good-3PL 3SG-POT-find-3PL It will be because of me that he (my son) will be given good food and a place to sleep.

\subsubsection{ASPECT AND MOOD}

Aspect and mood are marked as prefixes on verbs. They never occur with non-verbal clauses. Example 12(43) is illuminating in that two non-verbal clauses are sandwiched between verbal clauses. Both verbal clauses are marked for potential mood and durative aspect but the non-verbal clauses are not, even though semantically they are indeed potential mood (non-verbal predicates are in square brackets.)

12(43) Apo lawa ega i-na-woo-bagibagi, ega [a tano], ega [a numa], FUT person NEG 3SG-POT-DUR-work NEG his garden NEG his house

ega polo i-na-i-am...

NEG pig 3SG-POT-DUR-eat

If a man won't work, and has no garden and no house and doesn't feed the pigs...

The negative adverb is not placed within the predicate bracket, because with verbal clauses it is a clause operator, operating in any position prior to the verbal phrase. It thus seems reasonable to treat the non-verbal negator also as a clausal rather than a phrasal item.

\subsubsection{NEGATING NoN-VERBal Clauses}

Many non-verbal clauses can be negated, but there is clear asymmetry in the polarity of non-verbal clauses. Not all non-verbal clauses can be negated and not all negative nonverbal clauses can have the negative particle removed. Often there is a structural difference between negative and positive clauses. (This factor surfaced at a number of points in Chapter 11.)

Three important rules apply to the negative particle (underlined). These rules play an important role in further distinguishing descriptive non-verbal clauses from equative clauses (predicates are in square brackets).

1) The negative particle comes before the predicate. This observation is true for all clauses whether verbal or non-verbal.

12(44) $A$ dewa ega [dewadewa-na].

his custom NEG good-3SG

His custom/habit is not good.

However, it does not necessarily come immediately before the predicate.

12(45) Ega beda [uyahi-u].

NEG betel 'at'-1SG

I have no betel nut.

2) The unmarked position for the negative particle is immediately before the predicate. With non-verbal constructions this is usually the only option. 
12(46) a. Ega [awai gehou-na]. b. Egą $[a$ tano po puwaka]. NEG what other-3SG

There is nothing. NEG his garden and pig He has no garden or pigs.

12(47) Tau ega [ $u$ dewadewa awar]. I NEG my good what I have nothing (morally) good about me.

12(48) Ma i mae ega [mei lolowa]. But ourEXC stay NEG like before But our life is not like it was before.

3) The negative can never occur within a noun phrase. The presence of a negative within any 'NP' clearly indicates that the structure is functioning as a clause.

12(49) a. Naka ega [gadiwewe]. that NEG rain That is not rain.

12(50) a. Limi ega [natu-na]. Limi NEG child-3SG Limi has no child. b. Tauta ega [ita ani-goda]. IPL.INC NEG ourINC thing-stir We have nothing to stir with.

In 12(51) the negative particle follows an expanded subject NP.

12(51) Naka bada-na ega [emoemota-na]. that man-DEF NEG ability-3SG That man is not able to do it. 


\title{
RELATIVE CLAUSES
}

\begin{abstract}
...the study of relative clauses has been biased, until quite recently, by concentration on data from English and the construction of abstract analyses to account for these characteristics. We shall not be criticizing these analyses qua analyses of English, but... will demonstrate some of the limitations of trying to build a universal syntactic theory solely on the basis of English data and abstract analyses thereof.

Comrie (1981:131)
\end{abstract}

\subsection{INTRODUCTION}

Studies of universals suggest three basic construction types involving "embedded clauses" (Thompson and Longacre 1985:172, Noonan 1985:43 and Schachter 1985:50-51): 1) relativisation, where the embedded clause modifies a noun filling an argument slot of the main clause; 2) complementation, where the embedded clause functions as the subject or object of a complement-taking predicate; and 3) adverbialisation, where the embedded clause modifies the core of the main clause. Nominalisations, often akin to relative clauses, are clearly embedded within the clause.

\subsection{DEFINITE RELATIVE CLAUSE}

Tawala does not formally distinguish restrictive from non-restrictive relative clauses; instead there are a number of other formal distinctions: definite and indefinite relative clauses, and verbal and non-verbal relative clauses.

\subsubsection{Basic Structure of Relative Clauses}

Structurally, the relative construction consists of:

$$
\text { [domain noun + restrictive clause] + main predicate }
$$

(a) The domain noun is "the common noun in a relative clause which expresses the domain of relativisation' (Keenan 1985:142). The domain 'noun' is occasionally expanded to an NP (e.g. 13(4), 13(25)). The preferred position of the domain noun is the first constituent of the relative clause (13(1)), regardless of its grammatical role.

(b) The restrictive clause "identifies a subset of the domain" (Keenan 1985:142). The restrictive clause includes the domain noun, as Tawala has internal-headed relative clauses: the restrictive clause following the domain noun is in fact normal word order; predicates normally follow the core NPs within the clause.

The domain noun is capitalised and the restrictive clause is in square brackets in this chapter. The main predicate follows the restrictive clause and is orthographically unmarked. 


\section{3(1) [Kwasikwasi pom u-gima-gimal'-e-ya] i-tutuma. \\ machete yesterday 2SG-DUR-buy-TRV-3SG 3SG-blunt \\ The bush-knife that you bought yesterday is blunt.}

The domain noun is optionally marked as pragmatically definite - an item already referred to.

\section{3(2) [Kwasikwasi-na u-gima-gimal'-e-ya] i-tutuma. machete-DEF 2SG-DUR-buy-TRV-3SG 3SG-blunt \\ The bush-knife that you bought is blunt.}

Keenan (1985:143) distinguishes between external- and internal-headed relative clauses, the latter involving domain nouns which occur within the restrictive clause. Three pieces of evidence indicate that Tawala has internal-headed relative clauses: 1) it is never possible to separate the domain noun from the restrictive clause. Note that the temporal item in 13(1) does not apply to the main clause, only to the restrictive clause; 2) Tawala has no relative pronoun, a situation typical of intermal-headed relative clauses; and 3) peripheral arguments are marked with a cataphoric definite marker $(13(17))$ when they are modified by restrictive clauses.

Tawala restrictive clauses are often identical in form to independent clauses; the embedded clause in 13(1) (Kwasikwasi pom ugimagimaleya) may also function as an independent clause with the meaning 'You were buying the machete yesterday'. This independent function applies only to clauses embedded in core NPS and not to those embedded in peripheral PPs (13(17)-13(19)).

The distinguishing feature of relative clause $s$ in Tawala is that the restrictive clause is marked for durative aspect; there is, however, no subordinating particle or dependence marker. The relative clause does not need to be semantically durative, but can refer to a single point in time - a very distinctive use of an aspect which otherwise signals durative, repetitive or progressive action. This special use of the durative is seen in 13(1), where the action in the restrictive clause is clearly punctiliar.

Stative verbs, which have no reduplicated form, are an exception to the general rule that the durative marks the restrictive clause.
13(3) [MI
DIMDIM hi-maga duma] he-ma-mae.
people horizon 3PL-many very 3PL.PRES-DUR-stay
Numerous Europeans are staying there.

When the relative clause is a complex construction, only the second verb - the ongoing/resulting situation - needs to be marked for durative aspect.

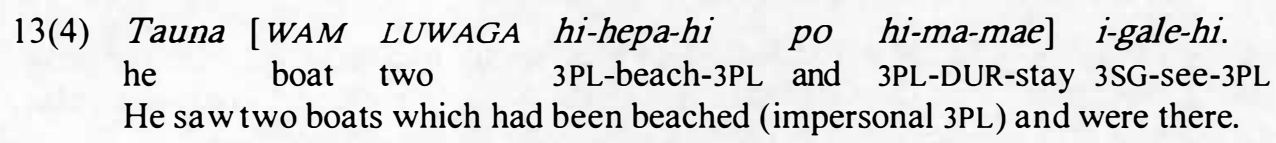

In 13(4) the subject of the main clause (tauna) precedes the relative clause, demonstrating relative clause embedding. . The main clause consists of the whole sentence: the subject, the embedded relative clause in the object slot and the main predicate.

Usually the predicates of both the relative clause and the main clause 'cross reference' to the domain noun. Clauses differ as to the grammatical relation of the domain noun to the 
main clause and the restrictive clause; it can be the subject or object of the main clause. In $13(1), 13(3), 13(5), 13(6)$ it is the subject of the main clause which is relativised.

\section{3(5) [NEULA hi-yau-yautu] hi-hilage pahi-hi. coconut 3PL-DUR-breathe 3PL-die entirely-CPY The coconuts that were alive completely died.}

\section{3(6) [LAWA TAUMI wam-na o-na-gelu-gelu-ya] geka hosi o-na-nei. person youPL boat-DEF 2PL-POT-DUR-embark-3SG this place 2PL-POT-come Come here you people who are to board the boat.}

In 13(5) and 13(6) the domain noun is the subject of the main clause and also of the restrictive clause; in 13(7) the domain noun is the subject of the main clause and the object of the restrictive clause.

13(7) $[$ MAYAU
tree-kika-kikalo-ya $]$ apo $i$ - $n^{\prime}$-alata.
The wood he is rubbing will burst into flame.
clause.

In 13(8) the domain noun is the object of the restrictive clause as well as of the main

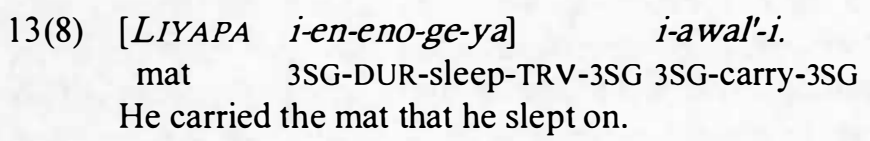

In 13(9) the subject of the main clause differs from that of the relative clause. The domain noun is the object of both clauses.

\section{3(9) [NUMA-NA to-wogo-wogo-ya] amaka hi-apu-ya. house-DEF 1PL.EXC-DUR-build-3SG already 3PL-burn-3SG They have burned the house that we built.}

A secondary object is never cross-referenced to its goverming verb. When a domain noun is a secondary object it follows the normal pattern and is not cross-referenced on the main verb. In 13(10) the domain noun is the secondary object of both the restrictive clause and the main clause.

\section{3(10) [WOIDA a-wele-wele-m] apo u-na-wele-hi. yam ISG-DUR-give-2SG FUT 2SG-POT-give-3PL The yams that I gave you, you give to them.}

\subsubsection{Topicalisation of Relative Clause}

A common strategy is to topicalise the relative clause by means of the demonstrative naka 'that' (underlined). The demonstrative marks the NP as topicalised, confirming that the relative clause is to be interpreted as nominal in spite of its clausal structure.

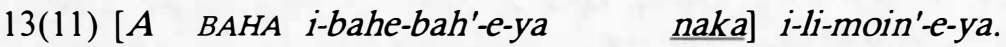

$$
\begin{aligned}
& \text { his word 3SG-DUR-say-TRV-3SG TOP 3SG-DP-true-TRV-CPY } \\
& \text { As for his word he was proclaiming it came true. }
\end{aligned}
$$


13(12) [MEYAGAI noka a-ga-gale-hi naka] meyagai dewadewa duma-na. village there ISG-DUR-see-3PL TOP village good very-3SG As for the villages which I saw there are very big villages.

13(13) [PONA WABIHAGA he-me-mae naka] tauhi he-wo-bagibagi-ye-hi. voice how.many 3PL.PRES-DUR-stay TOP they 3PL-keep-work-TRV-3PL As for the many languages that exist they (the linguists) keep working on them.

The topicalised relative clause receives normal marking for durative aspect. I originally recorded 13(14) with simple aspect (in a text), but my data was edited by Yailo to the form it now has.

13(14) [NUMA hi-wogo-wogo-hi naka] hi-lata duma. house 3PL-DUR-build-3PL TOP 3PL-grow very As for the houses which have been built [impersonal 3PL] they are very big.

With the topicalised relative clause the domain noun is often repeated, particularly when the head is a locative or temporal noun.

13(15) Ma [HOUGA-NA to-ne-nae naka] houga i-apapoe duma. and time-DEF IPL.EXC-DUR-go TOP time 3SG-bad very As for the time when we were going along, the time (weather) was really bad.

13(16) [MEYAGAI NOKA a-gele-geleta naka] meyagai dewadewa duma-na. village there ISG-DUR-arrive TOP village good very-3SG As for the village that I arrived at, the village is a very good.

Peripheral arguments - in my data only temporal arguments - may also be modified by a restrictive clause.

13(17) [HoUGA-NA dobu uyahi-hi o-na-lui-lui] o-na-wimaamala. time-DEF village 'at'-3PL 2PL-POT-DUR-enter 2PL-POT-greet

The time when you enter the villages greet (the people).

The distinguishing feature of peripheral relative clauses is the domain noun, which is marked with a definite suffix. This morpheme is a cataphoric subordinating marker referencing the time indicated in the adverbial clause.

13(18) [HoUGA-NA hi-lau-geleta] lawa luwaga hi-tuwaga-hi. time-DEF 3PL-DUR-appear person two 3PL-find-3PL

When they arrived they found two people.

Although there is much in common between peripheral and core relative clauses - both include a domain noun within a modifying clause which precedes a main clause - they differ formally in three ways:

1) The domain noun of a peripheral clause has a cataphoric definite marker, referring to the embedded predicate. The peripheral relative clause is thus formally a dependent clause, whereas the core relative clause is always formally an independent structure. The dependent nature of the peripheral relative clause is illustrated in the following examples. The dependent clause in 13(19) cannot stand as an independent structure (13(20)). 
13(19) [HoUGA-NA hi-gele-geleta] pona-pona hi-nonol'-i. time-DEF 3PL-DUR-arrive PL-voice 3PL-hear-3SG

The time when they arrived they heard voices.

13(20) *Houga-na hi-gele-geleta... time-DEF 3PL-DUR-arrive

The time they were arriving...

For 13(20) to function as an independent clause a demonstrative would need to be added (13(21)); the definite marker is now anaphoric.

13(21) Naka houga-na hi-gele-geleta.

that time-DEF 3PL-DUR-arrive

They were arriving at that time.

2) The domain noun of the core relative clause can stand alone with the main clause the embedded predicate can be omitted - this is not true of the peripheral clause. In 13(22) (cf. 13(19)) the domain noun (hougana) cannot stand without the modifying clause; the sentence is simply not grammatical. Sentences such as 13(19) are strong evidence for the internal-headed nature of the Tawala relative clause.

13(22) * ${ }^{*}$ Houga-na...] pona-pona hi-nonol'-i.

time-DEF PL-voice 3PL-hear-3SG

At that time they heard voices.

Example 13(22) would be grammatical as a relative clause meaning 'the time when they were hearing voices...'; however, it requires a main clause to follow it.

3) The similarity between core and peripheral relative clauses is particularly striking when the latter is marked for durative aspect $(13(18), 13(19))$. However, the peripheral relative clause differs from the core relative clause in that it does not have to be marked for durative aspect (13(23), 13(24)).

13(23) [KABUDALA-NA i-geleta hoi wam] naka amaka hi-gelu. sun-DEF 3SG-arrive LOC boat that already 3PL-embark

When he arrived at the boat they had already embarked.

13(24) [HoUGA-NA a-gae Hailan], Ukarumpa a-me-mae. time-DEF ISG-go.up Highland Ukarumpa 1SG-DUR-stay

When I went up to the (Eastern) Highlands, I stayed at Ukarumpa.

Relative clauses may also be embedded within postpositional constructions (cf. $\S 16.2 .1)$.

13(25) [POPOPO A DEWA i-dewa-dewa-ya] uyahi-n'-ei ta-lau-labiya. lizard his custom 3SG-DUR-do-3SG 'at'-3SG-ABL IPL.INC-DUR-sago We collect sago following the custom which Lizard does.

In Tawala, verbal relative clauses are also found embedded within the subject of nonverbal main clauses. The domain noun is most naturally the object of the restrictive clause.

13(26) [PONA-NA i-no<o>nol'-1] mei togowa.

voice-3SG 3SG-hear $<$ DUR $>-3$ SG like wind

Her voice which he heard was like the wind. 


\section{3(27) [BAHA-HI a-bahe-bah'-e-h1] ega tau $u$ nugotuhu-gei. word-DEF ISG-DUR-say-TRV-3PL NEG I my thought-ABL \\ The message that I have spoken is not my (own) thoughts.}

Attempts to elicit a domain noun as the subject of a non-verbal clause and also the subject of a restrictive clause result in a switch to a verbal main clause.

\subsection{INDEFINITE RELATIVE CLAUSE}

Indefinite relative clauses are distinguished by the presence of an interrogative as the domain noun. These relative clauses are mostly embedded within verbal clauses but an occasional non-verbal main clause is found. Indefinite relative clauses are marked for durative aspect only when the semantics of the situation require it. The domain noun stands in the same core grammatical relations as those given for definite relative clauses: subject of the main clause (13(28)) and object of the main clause (13(29), 13(30)).

13(28) [IYAWOI hi-na-gelu Yesu a wam] apega yautu-hi hi-na-hale-hi. whoPL 3PL-POT-embark Jesus his boat FUT.NEG breath-3PL 3PL-POT-throw-3PL Those who embark on Jesus' boat will not die.

13(29) Apo [IYAI geka ginouli-hi i-na-dewa-dewa-hi] lawa hi-na-gale-ni... FUT whosG this thing-DEF 3SG-POT-DUR-do-3PL person 3PL-POT-see-3SG People will see anyone who does these things, that...

In 13(29) the domain interrogative is both the subject of the restrictive clause and the object of the main clause; in 13(30) it is the object of both the restrictive and main clauses.

13(30) [AWAI hi-'mtele-ya] hai u numa he-hu-houn'-i.

what 3PL-leave-3SG their LOC house 3PL.PRES-DUR-put-3SG

They would put what they left in their house.

The domain noun of the peripheral relative clause can also be replaced by an interrogative.

13(31) [MEKA TOKA i-tugu-tugula] apo o-na-wi-tugula-me-ya.

where just 3SG-DUR-sit FUT 2PL-POT-DP-sit-again-3SG

You cause him to sit again just where he was sitting.

13(32) [MEYANAI operation hi-wele-ya] ita Guyau ta-witumagan'-e-ya.

when operation 3PL-give-3SG ourINC chief IPL.INC-believe-TRV-3SG

Whenever they operate on him we trust our Lord (to help him).

\subsection{NON-VERBAL RELATIVE CLAUSES}

The non-verbal relative clause is rather rare; a more usual strategy is the use of a nonverbal construction as the functional equivalent of the relative clause. If we accept Comrie's functional definition of a relative clause as "a head and a restricting clause", the way seems open to interpret non-verbal clauses as true relative clauses.

These clauses are structurally parallel to verbal relative clauses - a domain noun included in a non-verbal relative clause which typically precedes the rest of the main clause. The restrictive clause may modify either the subject or the object of the main clause; 
13(33)-13(35) demonstrate a range of nominalised restrictive clauses which are subjects of main clauses.

13(33) [ TAUTA Poleni a lawa] ta-nei... weINC Poleni his friend IPL.INC-come We who are Poleni's friends have come...

13(34) [TAUHI ega hai wekiwekilala] apega hi-na-i-gimagimala. they NEG their sign FUT.NEG 3PL-POT-DUR-trade They who have no pass will not (be able to) trade.

13(35) [LAWA GEHOU-NA guyau tu-wiponawogo-na] i-ma-mae. person another-3SG chief PER-obey-3SG 3SG-DUR-stay There remained another person who was a supporter of the chief.

Example 13(36) illustrates non-verbal relativisation of the object NP of the main clause and 13(37) a secondary object.

13(36) [GATOWA DIIDINA-NA ani-mpanipant] ta-kekeh'-i. thatch sewing-3SG thing-bind IPL.INC-peel-3SG

We peel thatch-twine which is for binding.

13(37) Lawa [hai luhogala AWAI] apo u-na-wele-wele-hi. person their desire what FUT 2SG-POT-DUR-give-3SG Give (those) people what they desire.

The position of the interrogative in 13(37) is a function of the non-verbal predicate luhogala; the restrictive clause may function independently: Hai luhogala awai? 'What do they want?'.

One common embedded nominalisation is a clause giving the name of a person or thing.

13(38) [LANI-HI gowa-hi Wagaloke ma Popopo] hi-me-mae. men-DEF name-3PL possum and Lizard 3PL-DUR-stay Those men who are called Possum and Lizard were staying (there).

13(39) [GAMOGAMO gowa-hi bulumakau] hi-nei. animal name-3PL cattle 3PL-came Animals that are called cattle came. 


\section{NOMINALISED CLAUSES}

\subsection{INTRODUCTION}

A common form of embedding in Tawala is nominalisation, where a proposition is expressed as a non-verbal predication embedded within the noun phrase. There are three classes: agentive, instrument/location and action nominalisations. The first two classes share a degree of structural unity: the respective nominaliser followed by a verb stem.

$$
\text { tu-/ani-+ verb stem }
$$

The prefixes $t u$ - (agentive) and ani-(instrument/location) attach to a verb stem and receive the secondary stress associated with the onset of words. With some verb stems this results in vowel elision.

$$
\begin{array}{ll}
\text { tu-'mginoula } & \text { one who builds } \\
\text { ani-'mbenena } & \text { thing that is given }
\end{array}
$$

Verb stems themselves are not truly independent forms but occur in a limited number of contexts, most of them bound. The first two have verbal functions, the rest have nominal functions. These contexts are illustrated here with the verb stem bagibagi 'work'.

1) with a subject prefix - hi-bagibagi 'they worked' - verb.

2) with any of a number of derivational affixes - e.g. hi-wi-bagibag'-i 'they borrow s.th.' - derived verb.

3) with an inalienable pronominal enclitic - bagibagi- $h i$ 'their work (done for them)' verbal noun.

4) with an alienable possessive pronoun - hai bagibagi 'their work (done by them)' verbal noun.

5) with the agentive nominaliser - tu-bagibagi 'the one who worked' - derived noun.

6) with the instrument/location nominaliser - ani-bagibagi 'a thing/place for working' derived noun.

The whole nominalised clause may include two further items:

7) in the case of agentive nominalisation, an object (an unmodified noun) - tano tubagibagi 'one who works a garden'.

8) in the case of action nominalisation, an alienable NP (and possessive pronoun) indicates the subject of the nominalised action - logaloga hai bagibagi 'the work which the children did'.

Tawala nominalised forms lose most verbal characteristics: they are not indexed for subject and object; they are not marked for tense, aspect or mood. However, they do take dependent NPS. 
They have a number of clearly nominal characteristics: they receive singular $(14(4 \mathrm{~b})$, 14(6a)) and plural $(14(4 a), 14(5), 14(6 b))$ definite marking; the object nouns may take an alienable possessor NP (14(6b)-14(8)); they may occur as objects of a postposition (14(11), 14(15), 14(25), 14(26)); and they can be modified by a limiter (14(1)).

\section{4(1) [SIL hai tu-bagibagi gehou-na] hi-himili-yai. \\ SIL their PER-work other-3SG 3PL-send-DEI \\ S.I.L. sent us one of their workers.}

\subsection{AGENTIVE NOMINALISATION $t u-$}

Tawala has a productive process whereby verbs are expressed as nouns meaning 'one who "verb"s'. I follow the traditional label for these constructions - agentive nominalisation - "even though, strictly speaking, the noun need not be in an 'agent' relationship with the verb from which it is derived" (Comrie and Thompson 1985).

Tawala has two kinds of agentive nominalisation, corresponding to intransitive and transitive clauses.

\subsubsection{INTRANSITIVE NOMINALISATION}

The intransitive nominalisation consists of an intransitive verb stem with the nominalising prefix $t u$-.

$$
t u-V E R B^{\text {intrans }}
$$

$\begin{array}{lllll}\text { apapoe } & \text { be bad } & > & \text { tu-apapoe } & \text { one who sins (social misfit) } \\ \text { memae } & \text { inhabit } & > & \text { tu-memae } & \text { one who stays (inhabitant) } \\ \text { towolo } & \text { be standing } & > & \text { tu-towolo } & \text { one who stands (officer) } \\ \text { koiba } & \text { be pregnant } & > & \text { tu-koiba } & \text { one who is pregnant } \\ \text { hilage } & \text { be dead } & > & \text { tu-hilage } & \text { one who is dead }\end{array}$

The referent of the nominalised verb corresponds to the subject of the verb. Thus the $t u$ (PER) in tu-hilage 'a dead person' corresponds to $i$ - (3SG) in $i$-hilage 'he/she/it is dead'. The construction can be apposed to a noun specifying the nature of the person involved in the predication, in which case the construction is referential because of the first noun.

$\begin{array}{rlr}\text { 14(2) a. } & \begin{array}{l}\text { lawa tu-hilage } \\ \text { person PER-be.dead }\end{array} & \text { b. tauhi } \\ \text { the person who is dead } & & \text { the on } \\ \text { the } & \\ \text { c. } & \begin{array}{l}\text { anai tapu-yai } \\ \text { with different-1PL.EXC }\end{array} & \text { tu-apapoe } \\ & \text { Ps people who sin }\end{array}$

It is probably best to consider these as phrases in apposition, rather than to regard the nominalised form as a modifier of the head noun, although this latter alternative would be in line with the general nominal characteristics of these forms. 


\subsubsection{TRANSITIVE NOMINALISATION}

The transitive nominalisation consists of a noun phrase, the nominalising prefix $t u$-and a transitive verb.

$$
\text { NP } t u \text { VERB }{ }^{\text {trans }}
$$

14(3) tano tubagibagi

garden PER-work

one who works a garden (a garden worker)

In 14(3) the noun tano corresponds to the object of the transitive clause tano i-bagibagi 'he/she/it worked a garden'. There is a rich and distinctive vocabulary involved in these constructions.

$\begin{array}{ll}\text { kopala tubagibagi } & \text { one who works copra } \\ \text { numa tu-wogo } & \text { one who builds houses } \\ \text { wam tu-'mginoula } & \text { one who builds (things) boats } \\ \text { kewokewou tu-'mtahi } & \text { one who carves canoes } \\ \text { hiyamoni tu-tala } & \text { one who cuts grass } \\ \text { labiya tu-'mhapi } & \text { one who pounds (chops) sago }\end{array}$

In 14(4) the nominalised verbs are indefinite. Each constructions is made definite by the addition of a definite marker (a pronominal enclitic) on the head, marking it as pragmatically definite.
a. numa tu-wogo-hi house PER-build-DEF.PL
b. aniani tu-pahi-na the ones who built the house food PER-complete-DEF.SG the one who finished the food

Intransitive constructions can be made definite in the same manner.

\section{4(5) tu-apapoe-hi \\ PER-bad-DEF.PL \\ the ones who sin}

When a transitive verb stem requires a transitivising suffix as part of its stem, this is also present in the corresponding nominalised construction, because the verbal noun is derived from a verb stem.
14(6) a. tano banei-na tu-bagibagi-ye-na
garden big-3SG PER-work-TRV-DEF.SG
the one who works the big garden
b. Yaubada a nugotuhu tu-bagibagi-ye-hi
God his thought PER-work-TRV-DEF.PL
the ones who obey God's thoughts

The following sentence examples contain agentive nominalisations (in square brackets) functioning as the object $(14(7))$, the subject $(14(8))$, and the object of a postposition (14(9)).
14(7) [Yaubada a tu-bagibag1] he-lilig'-e-hi.
God his PER-work 3PL.PRES-oppose-TRV-DEF.PL
They oppose the ones working for God. 
14(8) [Yaubada a nugotuhu tu-bagibagi-ye-hr] he-me-mae.

God his thought PER-work-TRV-DEF.PL 3PL.PRES-DUR-stay

People live (there) who work God's thoughts.

14(9) [Lugagayo tu-lagona-na] bi-nei paliguba ta-wialon'-i. law PER-pass-DEF.SG BEN-3SG curse IPL.INC-face-3SG

We face a curse because of the one who has broken (lit. passed over) the law.

\subsection{INSTRUMENT/LOCATION NOMINALISATION ani-}

Tawala also has a productive process whereby an action verb can form a noun meaning an instrument for 'verbing' (Comrie and Thompson 1985:353) or a place where 'verb' happens (p.355). At times the same Tawala form has both meanings:

$\begin{array}{lllll}\text { togo } & \text { wash (self) } & > & \text { ani-togo } & \text { thing/place for washing } \\ \text { eno } & \text { sleep } & > & \text { ani-eno } & \text { thing/place for sleeping } \\ \text { ulona } & \text { cook } & > & \text { ani-ulona } & \text { thing/place for cooking } \\ \text { duhuna } & \text { sit } & > & \text { ani-duhuna } & \text { thing/place for sitting }\end{array}$

The two meanings are distinguished in discourse in that things are commonly found in ablative constructions and places in locative constructions.

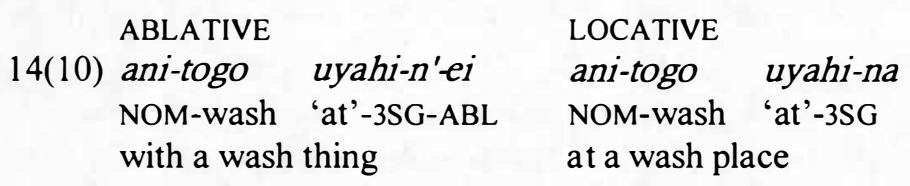

In most cases, however, the construction has a single meaning.

$\begin{array}{lllll}\text { libolu } & \text { chat } & > & \text { ani-libolu } & \text { place for chatting } \\ \text { gimala } & \text { trade } & > & \text { ani-gimala } & \text { place for trading } \\ \text { mae } & \text { stay } & > & \text { ani-mae } & \text { place for staying } \\ \text { goda } & \text { stir } & > & \text { ani-goda } & \text { thing for stirring } \\ \text { kaoha } & \text { be happy } & > & \text { ani-kaoha } & \text { thing (reason) for rejoicing }\end{array}$

14(11) Ani-gimala uyahi-na i-ma-mae. NOM-trade 'at'-3SG 3SG-DUR-stay $\mathrm{He}$ is at the (market).

14(12) Heliam, meka ata ani-goda? friend where ourINC NOM-stir Friend, where is our ladle?

Examples 14(13) and 14(14) contain location nominalisations (in square brackets) in which the subject is expressed by a possessive pronoun.
14(13) $[I$
ani-gae]
gadiwewe i-waya.
ourEXC NOM-ascend rain
3SG-take.it

Our ascent was blocked by rain.
14(14) $[\mathrm{Om}$ ani-taniwaga] hi-na-galena tuhaga-ya. yourSG NOM-rule 3PL-POT-see find-3SG
They will discover your kingdom.


Throughout this chapter only, the nominaliser ani-is glossed by its grammatical function (NOM); however, elsewhere in the grammar it is glossed by its semantic function as 'place' or 'thing'.

\subsection{ACTION NOMINALISATION}

A final productive nominalisation is the process whereby verbal events are expressed as nominal clauses meaning one's 'verbing'. This structure involves the same surface string as a possessive construction, with a verb filling the head slot.

$$
\left(N P^{\text {possessor }}\right)<a>V E R B^{\text {possessed }}
$$

In this construction the verb stem functions as a verbal noun. The subject of the nominalised clause is expressed as a possessor marked for number, usually an alienable construction.

$\begin{array}{ll}\text { lawa haibagibagi } & \text { people's working } \\ \text { lawa hai nae } & \text { people's going } \\ \text { lawa haikadau } & \text { people's journeying } \\ \text { lawa hai tawine } & \text { people's marrying } \\ \text { lawa hailuhogala } & \text { people's desiring }\end{array}$

14(15) Lawa [hai kadau] uyahi-hi i-hagu-hi. person their journey 'at'-3PL 3SG-help-3PL He helps people in their joumeying.

The possessor (lawa) is the object of the main verb in 14(15); non-third-person examples function in a similar manner. In 14(16) and 14(17) the nominalised clause is topicalised.

14(16) [Taumi omi nae] naka ega i-ta-dewadewa. youPL yourPL go TOP NEG 3SG-IRR-good That you are going is not good.

14(17) [Om mae] po [om nae] naka ipa u-na-galenaitete-hi. yourSG stay and yourSG go TOP IRR 2SG-POT-look.after-3PL Be careful about your staying and your going.

Transitive verbs do not participate in this construction: * lawa hai numa bagibagi-ye-hi 'the people's building the house'. In order to express this concept the object NP becomes an oblique argument: lawa hai bagibagi numa binei 'the people's working for the house'.

The possessed NP is also expressed with inalienable constructions.

$$
\begin{aligned}
& \text { 14(18) Meyagai bagibagi-na i-lata duma. } \\
& \text { village work-3SG 3SG-grow very } \\
& \text { The village's work (= Work done for the village) is very extensive. }
\end{aligned}
$$

In $§ 9.10$ we noted the distinction between inalienably possessed and alienably possessed nominalisations as being parallel to the objective and subjective genitives of European languages. Inalienably possessed clauses (14(19)) are not commonly found as subordinate clauses. On the other hand, subordinated alienably possessed clauses (14(20)) are common. 
14(19) [Neula hopu-na] i-wipilipili.

coconut down-3SG 3SG-difficult

It is difficult to get down from a coconut palm.

14(20) [Kalado a hopu] i-dewadewa.

Kalado his down 3SG-good

It is good that Kalado went down.

One common form of inalienably possessed nominalised clause is common, however. The structure of this clause is unique. We noted in $\S 9.6$ one strategy for referring to the number of a referent. When more complex numerals are involved a special inalienable nominalised structure is used.

$($ POSSESSOR NP) + magou $<-n a>+$ NUMERAL

The nominal magou-<na $>$ 'number-3SG' is related to the adjective magomagou-<na $>$ 'many/numerous'.

14(21) [Pou magou-hi tonuga] i-tami-hi.

egg number-3PL three 3SG-takePL-3PL

He took three eggs.

Given that numerals are frequently embedded number clauses that begin with nouns (nima...'hand (five)', oloto...'male (twenty)' etc.), the function of number nominalisation is to signal clearly that the domain of the numeral is a number ('five' or 'twenty') and not a 'hand' or 'male'.

14(22) [Poha magou-na' nim'itutu po tonuga] hi-lihogo-hi. basket number-3SG five and three 3PL-fill-3PL

They filled eight baskets.

14(23) [Bolima magou-na nima luwaga hi-tutu po luwaga] hi-kokoe... year number-3SG hand two 3PL-hit and two 3PL-finish When twelve years had gone by...

Embedded nominalisations (14(21)-14(24)) differ in their grammatical relations: the object of the main verb (14(21), 14(22)); the subject of the main verb (which is itself an embedded adverbial clause) (14(23)); and a peripheral item (14(24)).

14(24) A-me-mae [bolima magou-na nim'itutu].
ISG-DUR-stay year number-3SG five
I stayed for five years.

\subsection{FURTHER FUNCTIONS OF NOMINALISED CLAUSES}

As we have seen above, nominalised clauses have a broader function than non-verbal relative clauses (14(7)-14(9)); they also function as objects of postpositions $(14(25), 14(26))$ and complement clauses (14(19), 14(20)).

14(25) Apega lawa hi-na-maga [om bagibagl] uyahi-na. FUT.NEG person 3PL-POT-many yourSG work 'at'-3SG There will not be many people at your work. 
14(26) Apo [i kadau] uyahi-hi ega to-ta-genogeno.

FUT ourEXC journey 'at'-3PL NEG 1PL.EXC-IRR-worry

When we are joumeying (lit. in/at our journeys) we are not anxious.

In addition, they function generally as predicates of equative clauses, as one of the main clause types of descriptive discourse.

14(27) Tauna [tano tu-bagibag1].

he garden PER-work

$\mathrm{He}$ is a garden worker.

14(28) Tauhi [tu-wisili hai ani-mae].

they PER-fish their NOM-stay

It is the place where those fish live.

14(29) Lanina geka [lawa tu-hilage].

person this person PER-die

This person was a dead person. 


\section{COMPLEMENT CLAUSES}

\subsection{NOTIONS OF COMPLEMENTATION}

Complement clauses have aspects in common with embedded coordinate clauses. What is surprising is the fact that some Tawala complements are formally coordinated to the main clause. Other complement clauses are best interpreted as juxtaposed to the main clause, making them structurally similar to purpose clauses.

In most languages, cognition-utterance verbs take a surface sentence as their complement, with its subject not necessarily co-referential to the subject of the main verb...In terms of meaning, verbs in this group most often code mental attitude such as knowledge, belief or hope...they may also be verbs of utterance.

Givón (1984:119)

Predicates fall into two classes: those that take complements and those that do not. In the following description of Tawala complementation I draw a distinction between main clauses and complement clauses. The main clause includes a complement-taking predicate (CTP) that takes a clause as its complement - the complement clause. The complement clause itself is from an open set of clauses that fill the complement slot of the main clause.

Two classes of CTPs are evident in Tawala: modality predicates, and predicates of utterance and cognition. Information verbs take a sentential complement and do not properly belong to the CTP class, although they overlap with it. Before we can proceed to an examination of these classes a number of other issues need to be addressed.

Crystal (1980:74) notes that "the domain of complementation remains an unclear area in linguistic analysis, and there are several unsolved issues". In my description of Tawala complement clauses I have faced four crucial issues:

1) the relationship of complement clauses to core arguments;

2) coordination of complement clauses;

3) the range and meaning of complementisers;

4) that some CTPs are non-verbal.

\subsubsection{COMPLEMENTS AND CORE ARGUMENTS}

Complements are usually considered arguments of predicates. Thus Noonan (1985:42) states:

By complementation we mean the syntactic situation that arises when a notional sentence or predication is an argument of a predicate. For our purposes, a predication can be viewed as an argument of a predicate if it functions as the subject or object of that predicate. 
In Tawala most complements are object complements and normally follow the predicate, 'they are thus syntactically distinct from core arguments, which precede the predicate.

There are two exceptions to this rule. Firstly, when subject complements occur, they come before the verb (complement clauses are in square brackets).

15(1) $[$-gu<u>guya lawa uyahi-h1] naka ega i-ta-dewadewa.
2SG-preach<DUR person 'at'-3PL TOP NEG 3SG-IRR-good
As to your preaching to people it is not good.

Note the function of the demonstrative in 15(1) and 15(2); it appears to be a topicalisation marker rather than a complementiser.
15(2) [Meka ta-nae po ta-wiheliheliyam] naka i-dewadewa duma. where IPL.INC-go and IPL.INC-make.friend TOP 3SG-good very
Wherever we go we have friendship that is very good.

Secondly, nominalised object complements may occur in the normal core NP slot.

15(3) [I $\quad$ nae Ukarumpa uyahi-na $]$ apo a-dede-ya.
ourEXC go Ukarumpa 'at'-3SG FUT 1SG-tell-3SG
I will tell about our going to Ukarumpa.

15(4) [Plein hai ani-yato] a-gale-hi. plane their place-land 1SG-see-3PL

I saw where the planes landed.

Syntactically, there is nothing to distinguish these nominalised NPs (15(3), 15(4)) from regular core arguments (15(5)). (In the remaining examples in this section, core arguments are in curved brackets.)
15(5) Ma (ginouli atapu-hi) i-palihale-hi goga-na wawine-na uyahi-na.
And thing all-3PL 3SG-permit-3PL grandchild-3SG female-3SG 'at'-3SG
He handed over control of all his things to his granddaughter.

In $15(5)$ there is an object NP which precedes the verb, whereas the object verbal complement (15(6)) always follows the verb.

\section{5(6) O-na-palihale-hi [po hi-na-galenaitete-ya]. \\ 2PL-POT-permit-3PL and 3PL-POT-care.for-3SG \\ Permit them to care for him.}

In Tawala, with some predicates one finds an object NP and a complement in the same clause, a situation not discussed by either Noonan (1985) or Dixon (1987:2), who assumes "a 'complement clause' which functions in object or subject slot in place of an NP".

Thus with verbs of utterance there are three slots: speaker/subject, addressee/object and message/complement. Sentence 15(7) contains both an addressee/object and a message/complement.

In following the verb Tawala complements reflect the Proto Oceanic SVO word order, whereas the core arguments have the innovative SOV word order. 
15(7) (Hai lawa) u meyagai hi-paliwele-hi [naka lawa i-gehou-na

their friend LOC village 3PL-tell-3PL that person UNSP-other-3SG

i-ne'-po e-dane-danene].

3SG-come-and 3SG.PRES-DUR-steal

They told their friends at the village that someone else came and were stealing.

Similarly, with the attention and cognition verbs in 15(8) and 15(9) the sentences contain both an object NP and a complement (a message about that object).

15(8) (Plein) a-ga-gale-hi [naka hi-maga duma].

plane 1SG-DUR-see-3PL that 3PL-many very

I saw planes that they were numerous.

15(9) (Guyau) a-witumagan'-e-ya [naka tauna u liyaliya-u].

chief 1SG-trust-TRV-3SG that he LOC near-1SG

I believe the chief (God) that he is near me.

Finally, intransitive verbs (verbs requiring derivational affixes to occur with an object $\mathrm{NP})$ are also found with complements (15(10), 15(11)), even though they do not take an object NP with this form of the verb.

15(10) Hi-i-wogatala [naka apo iyowai hi-na-bagibagi].

3PL-DUR-plan that FUT how 3PL-POT-work

They were planning how they would (do their) work.

Most languages have a contrast between a sentence-like complement type, "one that without its complementizers has roughly the same syntactic form as a main clause" (Noonan 1985:49), and a non-sentence-like complement, where the complement clause has a syntactic form that is clearly subordinated and could never be used as a main clause. All Tawala complements are sentence-like and can stand on their own as independent clauses, though there is a distinction between nominalised NPs (15(3), 15(4)) which can occur before or after the CTP and verbal clauses which occur only after the CTP.

\subsubsection{COORDINATION OF COMPLEMENT Clauses}

The issue at stake here is a mismatch between form and function in that some Tawala complement clauses are coordinated rather than subordinated to the main clause. In this the Tawala data contrast with current theory. Complement clauses are generally regarded as embedded within the main clause; that is, they "fill a functional slot in the structure of the main clause" (Dixon 1988:268). Example 15(11) illustrates the problem to which we seek to give an answer in this section.

15(11) Nugote Yaubada i-baha [po u-nei uyahi-u].
perhaps God 3SG-say and 2SG-come 'at'-1SG
Perhaps God commanded you to come to me.

The construction in $15(11)$ is the normal way to report command complement clauses in Tawala. 
We have cause in Chapter 16 to note the "mismatch between form and function": adverbial clauses which functionally modify the 'main' clause are often conjoined to the main clause with coordinating conjunctions, making them formally independent.

15(12) Houga-na wam hi-gale-ya ma hi-kaoha labatana. time-DEF boat 3PL-see-3SG and 3PL-happy strongly When they saw the boat they were extremely happy.

Similarly, with relative clauses there is apparently little change of meaning between the relative construction - bracketed item omitted in 15(13) - and two coordinated clauses, joined with a conjunction, the preferred form.

\section{5(13) Maliboi u tahaya i-en-eno (ma) i-tuhaga-ya. flying.fox LOC path 3SG-DUR-sleep and 3SG-find-3SG He found a flying-fox sleeping by the path.}

Admittedly, there is a sharp distinction between the two coordinating conjunctions po and $m a$. The former indicates a close connection, and the latter indicates contrast between the coordinated clauses. Thus $p o$ is not an entirely inappropriate marker of functional embedding.

\section{5(14) Lawa awai nugonugo-na [po i-na-nae]... person what need-3SG and 3SG-POT-go Whoever needs/wants to go...}

Examples 15(15)-15(18) illustrate the range of subordinate-coordinate structures available with the CTP - paliwele- (these data were elicited).

15(15) Natu-we a-paliwele-ya [ipa i-na-wele-u].

child-1SG 1SG-tell-3SG IRR 3SG-POT-give-1SG

I told (commanded) my son to give me (it).

The bracketed clause in $15(15)$ is a complement clause that is juxtaposed to the main clause. By way of contrast, the bracketed clause in $15(16)$ is coordinated with the main clause, however the conjunction ma marks the second clause as being counter to expectations; here the bracketed clause is not a complement, but is independent structurally and functionally.

\section{5(16) Natu-we a-paliwele-ya ma [i-na-wele-u]. \\ child-1SG 1SG-tell-3SG and 3SG-POT-give-1SG \\ I told my son but he will give me it (anyway).}

Between the extremes of $15(15)$ and 15(16) lie two more options. Although the bracketed clause in 15(17) is formally coordinated, functionally it is dependent and is the normal way to express realis complements of verbs of command in Tawala. In 15(15) the result of the command is unknown; in 15(17) the command was carried out.

15(17) Natu-we a-paliwele-ya [po i-wele-u].

child-1SG 1SG-tell-3SG and 3SG-give-1SG

I told (commanded) my son and he gave it to me.

In $15(18)$ the bracketed clause is an indirect quote complement. This option is akin to $15(15)$ and is functionally and structurally subordinated. 
15(18) Natu-we a-paliwele-ya [naka i-wele-u].

child-1SG ISG-tell-3SG that 3SG-give-1SG

I told my son that he (not my son) gave me (it).

\subsubsection{COMPLEMENTISERS}

Complementizers typically derive from pronouns, conjunctions, adpositions or case markers, and, rarely, verbs, and so may resemble words currently used in these capacities.

Noonan (1985:47)

Tawala has three candidates for complementisers, which seem to be derived in typical fashion as outlined in Noonan: the irrealis particle ipa; the neutral demonstrative naka 'that': and the close-link conjunction $p o$ 'and'.

15(19) Hina-na i-lupali-ye-ya [ipa i-na-waya]. mother-3SG 3SG-ask-TRV-3SG IRR 3SG-POT-take.it

He asked his mother if she would take it.

15(20) A-ga-gale-hi [naka hi-buli-bulili].

1SG-DUR-see-3PL that 3PL-DUR-run

I saw that they were running.

15(21) O-na-palihale-hi [po hi-na-galenaitete-ya].

2SG-POT-permit-3PL and 3PL-POT-care.for-3PL

Let them look after him.

In addition, juxtaposition of clauses can also mark a complement clause; as Noonan (1985:45) comments, "some complement types have no complementizer associated with them at all".

15(22) Hi-i-wogatala [hi-na-bagibagi].

3PL-DUR-plan 3PL-POT-work

They are planning to work.

With many constructions the subject of the complement agrees in person and number with the object of the CTP.

15(23) Natu-we a-paliwele-ya [ipa i-na-wele-u].

child-1SG ISG-tell-3SG IRR 3SG-POT-give-1SG

I told (commanded) my son to give me (it).

15(24) Apo u-na-lupali-ye-u [po goila a-wele-m].

FUT 2SG-POT-ask-TRV-ISG and water ISG-give-2SG

Ask me to give you water.

\subsubsection{COMPLEMENTISER FUNCTIONS}

The functions of complementisers ipa, po and naka, and of juxtaposition, are all related to the functions these forms have in other structures; there is little evidence of grammaticisation having taken place with any of them. 
(a) The irrealis marker ipa functions as a complementiser within the complement clause; it is particularly common with verbs of desire, where there is a high degree of uncertainty about the realisation of the desire.

15(25) Nugonugo-u [ipa a-nae].

need-1SG IRR ISG-go

I want to go (but there is strong doubt I'll be able to).

15(26) Kailaki a luhogala [ipa ago-na i-na-hale-ya].

Kailaki his desire IRR spouse-3SG 3SG-POT-throw-3SG

Kailaki would like to divorce his wife.

The irrealis marker can be used in addition to the complementiser, making it clear that it is not functioning as a complementiser in 15(27). The naka here seems to introduce an indirect quote (cf. 15(31)).

\section{5(27) Tauyai $i$ luhogala [naka ega ipa to-na-i-otonana]. weEXC ourEXC desire that NEG IRR IPL.EXC-POT-DUR-wait We desire to not keep waiting.}

(b) The conjunction po also functions within complement clauses in a manner that is not inconsistent with its broader function. In contradistinction to ma, which marks contrast between clauses, po always marks a limit on one of the clauses. In the case of complements, po often involves a limitation of both the CTP and the complement; for instance, there must be person/number agreement between the clauses when the construction involves the non-verbal CTP emoemota $<-$ na $>$ ' $<$ his $>$ ability'.

15(28) Emoemota-u [po a-bagibag1].

ability-1SG and ISG-work

I have the ability to (= I can) work.

(c) The demonstrative naka 'that' has a number of functions, and some of these involve subordinating one clause to another - in this case a complementiser.

15(29) Numa a-gale-hi [naka hi-lata duma].

house 1SG-see-3PL that 3PL-grow very

I saw that the houses are very big.

This use in 15(29) is analogous to topicalisation (15(30)).

15(30) Numa hi-wogo-wogo-hi naka hi-lata duma.

house 3PL-DUR-build-3PL TOP 3PL-grow very

As for the houses which they have built, they are very big.

The prototypical function of the naka complement is seen with verbs of utterance or cognition, where it introduces an indirect quote complement (15(7), 15(31)); with verbs of attention (15(8), 15(20)) it is a 'message' complement.

15(31) Ago-na i-paliwele-ya [naka aniani i-na-wele-ya].

spouse-3SG 3SG-tell-3SG that vegetables 3SG-POT-give-3SG

He told his wife to give him food. 
(d) Complements juxtaposed to the main clause (marked below by $\#$ ) are usually best translated by an infinitive construction.

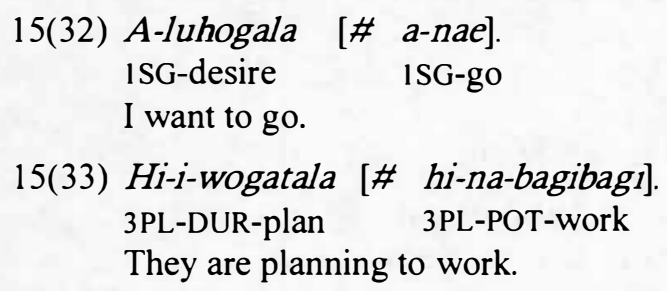

In the remainder of this section the complementiser functions are contrasted in identical environments. Each group of examples starts with natural text followed by contrasting elicited examples demonstrating shades of meaning in line with the functions suggested above. In each case there is only a three-way distinction, with one of the complementisers not available. (The explanations given in brackets were offered by the Tawala speaker.)

15(34) O-na-wileta [*\#/po tula-ta-na o-na-hagu-ya]. 2PL-POT-try /and friend-1PL.INC-DEF 2PL-POT-help-3SG

Try and help our friend (overcome the difficulties).

15(35) O-na-wileta [ipa tula-ta-na o-na-hagu-ya].

2PL-POT-try that friend-1PL.INC-DEF 2PL-POT-help-3SG

Try to help our friend (it may be impossible).
15(36) O-na-wileta [naka tula-ta-na o-na-hagu-ya].
2PL-POT-try that friend-IPL.INC-DEF 2PL-POT-help-3SG
The thing to try for is to help our friend.

The following examples all have non-verbal CTPs.

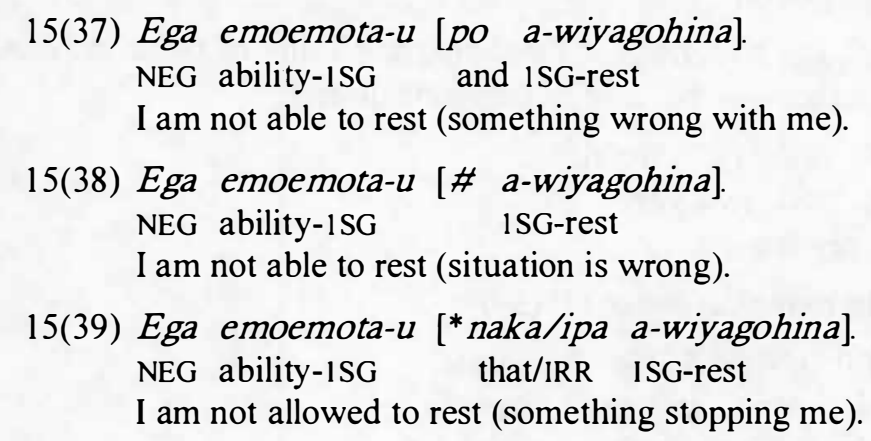

\subsubsection{REALIS VERSUS IRREALIS COMPLEMENTS}

In general ipa marks an irrealis complement as opposed to the three realis complements naka $a^{2}$ po/ \#. Dixon (1987:2) sees this distinction as fundamental and to be found in most of the languages of the world. Noonan (1985:51) notes: 
...there are rarely more than two sentence-like mood distinctions available in complement systems, though a number of languages have more than two mood distinctions available for use outside the complement system.

It is necessary to distinguish complements marked by ipa from those marked with potential mood, where the following rule applies:

If a CTP is marked for potential mood, the complement clause will also be so marked (15(34)-15(36)), though neutralisation sometimes obscures this (15(24)). The reverse is not true: if a complement is marked for potential mood the CTP does not also have to be $(15(19), 15(23), 15(40), 15(41)$. The realis-irrealis distinction is contrasted nicely in 15(40) and 15(41), though both complements have potential mood.

15(40) Hi-wiwogatala [naka apo hi-na-bagibag].

3PL-plan that FUT 3PL-POT-work

They made plans that they would work.

15(41) Hi-wiwogatala [ipa apo hi-na-bagibagl].

3PL-plan IRR FUT 3PL-POT-work

They discussed whether they could do the work.

Examples 15(42), 15(43) and 15(44), 15(45) demonstrate that there is no distinction between verbal and non-verbal complement clauses in terms of the realis-irrealis distinction. Note that a realis complement can be marked for the uncertainties of the future by both potential mood and future tense (15(40), 15(44)). The irrealis complementiser does not so much mark uncertainties as express the extreme difficulties, and even the unlikelihood, of accomplishing the event expressed in the complement. Examples 15(42) and 15(43) imply 'Oh that I might/could divorce my wife!'.

Many verbal CTPs have corresponding nominalised constructions.

15(42) A-luhogal-e-ya [ipa ago-u a-hale-ya].

ISG-desire-TRV-3SG IRR wife-1SG ISG-throw-3SG

I want to divorce my wife.

15(43) U luhogala [ipa ago-u a-hale-ya].

My desire IRR wife-1SG ISG-throw-3SG

My desire is to divorce my wife.

15(44) Hi-i-wogatala [naka apo iyowai hi-na-bagibagi].

3PL-DUR-plan that FUT how 3PL-POT-work

They were planning how they would (do their) work.

15(45) Hai wi-wogatala [naka iyowai hi-na-bagibagi].

their DVP-plan that how 3PL-POT-work

Their plan was how they would (do their) work.

Two nominal main clauses have no verbal counterparts. These are formed using the complement-taking nominals emoemota-na 'ability-3SG' and nugonugo-na 'need-3SG' (see $\S 11.5$ for an introduction to these constructions). The syntax of each is distinctive and is presented separately below, but illustrated here: 
15(46) Ega emoemota-na [ipa meka i-na-wiyagohina].

NEG ability-3SG IRR where 3SG-POT-rest

It (the bird) was not able to find a place to rest.

15(47) Tu-wigawiya nugonugo-hi [ipa hi-na-womomo-hi].

PER-fight need-3PL IRR 3PL-POT-hold-3SG

The warriors wanted (attempted) to seize them.

Other examples throughout this present chapter also illustrate these points.

\subsection{CLASSES OF COMPLEMENTATION}

Apart from the subject complements, there are two major classes of CTPs in Tawala: the modality predicates, and other CTPS - predicates of attention, utterance and cognition.

\subsubsection{MODALITY CTPS}

Modality predicates consist of a number of different structures depending on the nature of the CTP:

1) the non-verbal CTPs - (a) emoemota <-na > '<his> ability' and (b) nugonugo $<$-na $>$ ' $<$ his $>$ need/want';

2) the verbal/nominal CTPs - (c) luhogala 'desire/like/love', (d) wileta 'try' and (e) wiwogatala 'plan';

3) the transitive CTP - (f) dewa- 'make'.

The non-verbal CTPS are indexed for subject with pronominal enclitics, whereas the nominal form of the verbal/nominal CTP is indexed with preposed possessive pronouns, and the remaining CTPs index subject with a verbal prefix.

With the two non-verbal structures the verbal complement follows the predicate, whereas the non-verbal complement precedes the predicate. In this feature they are like verbs which have a separate slot for object and complement.

(a) emoemota- 'ability'

The subject and the complement of the CTP are often coreferential (15(28), 15(37)15(39), 15(48), 15(49)).

15(48) Emoemota-m [apo u-na-dewa-hl]? ability-2SG FUT 2SG-POT-do-3PL

Are you able to make them?

15(49) Ega emoemota-na [ $p o$ a tano i-na-tala-ya].

NEG ability-3SG and her garden 3SG-POT-cut-3SG

She will not be able to cut the garden (clearing).

Altermatively, the CTP may be marked for an impersonal subject (15(50)). 


\section{5(50) Ega emoemota-na [ipa ta-nei Yaubada ugoli-na]. NEG ability-3SG IRR IPL.INC-come God 'at'-3SG \\ It is not possible for us to come to God.}

The irrealis/realis distinction between 15(49) and 15(50) indicates the degree to which the complement predication is seen as a possibility.

(b) nugonugo 'need/want'

With this class the subject of the CTP does not have the impersonal option of the previous class - the clauses are coreferential (15(47), 15(51), 15(52)).

15(51) Nugonugo-u [ipa a-nae].

need-ISG IRR 1SG-go

I want/need to go.

15(52) Ega nugonugo-iyai [ipa to-lautanigana].

NEG need-IPL.EXC IRR IPL.EXC-listen

We don't want to listen.

Examples 15(53)-15(55) illustrate this CTP with a full range of complementisers. (As with the previous sets these were elicited.)

15(53) Nugonugo-u [ipa apega a-nae].

desire-1SG IRR FUT.NEG 1SG-go

I wish I wasn't going.

15(54) Nugonugo-u [naka apega a-nae].

desire-ISG that FUT.NEG 1SG-go

My desire is that I not go.

15(55) Nugonugo-u [*po/\# apega a-nae].

desire *and FUT.NEG 1SG-go

My desire is to not go.

The positive counterpart of 15(55), using the conjunction po, is acceptable (15(14)).

(c) luhogala 'desire/like/love'

In contrast to the inalienably possessed nugonugo, which expresses [-control], the alienably possessed luhogala expresses [+control], though the two structures are often interchangeable - compare 15(56) with 15(51).

15(56) $U$ luhogala [ipa a-nae].

my desire IRR ISG-go

I desire/want to go.

15(57) Tauyai $i \quad$ luhogala [naka ega ipa to-na-i-otonana].

uSEXC OurEXC desire that NEG IRR 1PL.EXC-POT-DUR-wait

We want that we not have to wait. 
Luhogala functions not only as a non-verbal predicate $(15(57))$ but also occasionally as a verbal predicate $(15(58))$.

15(58) Ma ega i-ta-luhogal'-e-ya [ipa omi baha i-na-nonol'-1]. and NEG 3SG-IRR-desire-TRV-3SG IRR yourPL word 3SG-POT-hear-3SG He doesn't want to obey you (your instruction).

(d) wileta 'try'

This is a variable-focus CTP taking a complement with the predicate-focus $(15(59))$ or object-focus $(15(60))$ forms of the verb.

15(59) Puwaka hi-wileta [ipa hi-na-lu1] ma ega emoemota-hi. pig 3PL-try IRR 3PL-POT-enter but NEG ability-3PL

Pigs tried to get in but were not able.

15(60) A-wileta-hi [ipa hai witumagana hi-na-bowi-ye-hi]. 1SG-try-3PL IRR their belief 3PL-POT-deny-TRV-3PL

I tried to make them deny their beliefs.

In 15(60) the object of the CTP is a human referent who is a subject of the complement clause.

Wileta also functions as a nominal predicate.

15(61) Yohola $i \quad$ wileta banei-na [ipa tauna to-lai-kaoha-ya].
Later ourEXC attempt big-3SG IRR him IPL.EXC-DUR-happy-3SG
We were still trying hard to make him happy.

(e) wiwogatala 'plan'

This is an intransitive CTP.

15(62) Hi-wiwogatala meme [naka apo iyowaka ma hi-n'-omgenalili-ye-ya]. 3PL-plan again that FUT how and 3PL-POT-make.jealous-TRV-3SG They planned again how to make him jealous.

15(63) Amaka hi-wiwogatala [ipa Poleni hau tahaya hi-na-uni]. already 3PL-plan IRR Poleni on road 3PL-POT-catch They had planned to kill Poleni on the road.

The nominalised form of this CTP is also common. In my data the subject of the complement clause is always coreferential with the subject of both verbal $(15(62), 15(63))$ and non-verbal (15(64)) CTPS.

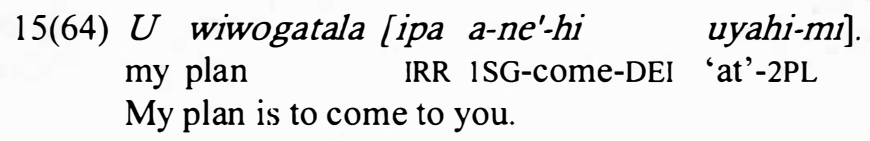


(f) dewa 'make'

Tawala has an range of derivational prefixes, expressing a variety of causative relationships. As an alternative, some younger speakers with extensive schooling in English use a periphrastic construction involving the transitive verb dewa- 'to do/make' as a CTP parallel to the English modal verb 'make'.

15(65) I-dewa-ya [po hi-tupeu].

3SG-did-3SG and 3PL-fall

He made them fall.

This construction is rejected by older speakers as being ungrammatical, especially as the pronominal enclitic of the CTP should agree with the complement subject (in 15(65) the third person plural object $-h t$ ) to be a regular complement-taking verb.

\subsubsection{OTHER CTPS}

There are three classes of non-modal CTPs. Classification is based on semantics but there is some syntactic evidence for the three classes.

\subsubsection{VERBS OF ATTENTION}

Two CTPs are involved here: gale 'see' and nonola 'hear'. Both verbs are transitive and both take only complements with the complementiser naka, which as we have seen is the 'message' complementiser. The complement clause gives details of the object; in my data the subject of the complement clause is always coreferential with the object of the CTP.

15(66) A-gale-hi [naka hi-buli-bulili].

ISG-see-3PL that 3PL-DUR-run

I saw that they were running.

In the durative aspect gale means 'observe' (15(8), 15(66)).

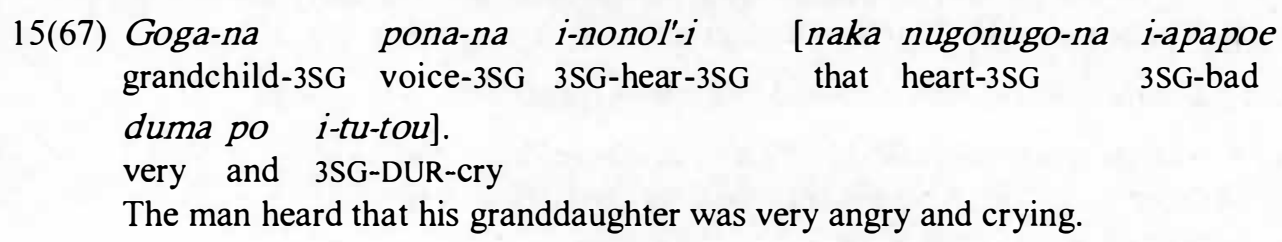

\subsubsection{VERBS OF COGNITION}

Three verbs are involved in this class: hanapu 'know, understand', nugotuhu 'think' and witumagana 'believe'. These form a diverse group of CTPs and need a major study in order to define their respective parameters. I simply offer an example of each type at this point, in addition to $15(9)$ above.

15(68) Ega ta-ta-hanapu-ge-ya [meka ta-ne-nae].
NEG IPL.INC-IRR-know-TRV-3SG where 1 PL.INC-DUR-go
We don't know where we are going.


15(69) $U$ nugonugo-u amaka a-nugotuhu-ya [naka u yaga].

LOC heart-1SG already 1SG-think-3SG that my debt

In my heart I already knew it was my debt.

15(70) Hi-i-tumagana [ipa tu-wigapola i-na-hagu-hi].

3PL-DUR-believe IRR PER-riches 3SG-POT-help-3PL

They believed that the rich man might help them.

\subsubsection{VERBS OF UTTERANCE}

Four common CTPs are involved here: baha 'say, speak, command', paliwele 'tell, command', lupali 'ask, beg, request', palihale 'permit'.

We already noted that with verbs of utterance there are three slots: speaker/subject, addressee/object and message/complement. Message complements are introduced with the demonstrative naka.

15(71) A lawa uyahi-hi i-baha [naka hi-awal'-1].

his friend 'at'-3PL 3SG-say that 3PL-carry-3SG

He told his friends it had been carried (impersonal 3PL).

15(72) Hai lawa u meyagai hi-paliwele-hi [naka lawa i-gehou-na their friend LOC village 3PL-tell-3PL that person UNSP-other-3SG i-ne'-po e-dane-danene].

3SG-come-and 3SP.PRES-DUR-steal

They told their friends at the village that someone else came and kept stealing.

In Tawala there is no lexical item meaning 'to command'; other verbs of utterance express this meaning when accompanied by a complement clause introduced with the complementiser $p o$.

15(73) Yaka i-baha [po goga-na wawine-na i-gae hoi tano]. so 3SG-say and grandchild-3SG female-3SG 3SG-go LOC garden So he commanded his granddaughter to go up to the garden.

With palihale 'permit' the command becomes permission.

15(74) Logaloga o-na-palihale-hi [po hi-na-nei uyahi-u]. children 2SG-POT-permit-3PL and 3PL-POT-come 'at'-1SG Let the children come to me.

With the verb lupali 'ask, beg' the irrealis complementiser is commonly used, reflecting the uncertainty of the response.

15(75) A-lupali-ye-m [ipa u tano u-na-gale-ya].

ISG-ask-TRV-2SG IRR my garden 2SG-POT-see-3SG

I ask you to look at my garden. 


\subsection{QUOTATION SENTENCE}

An indirect quote is signalled by the demonstrative complementiser naka used with a complement clause.

15(76) Natu-we a-paliwele-ya [naka i-wele-u].

child-1SG ISG-tell-3SG that 3SG-give-1SG

I told my son that he (not my son) gave me (it).

Tawala quotation sentences are best regarded as independent sentences cosubordinated to a special quotation formula. The quotation formula involves an optional utterance verb followed by the direct quote verb - pa 'say/saying'. The two verbs receive identical subject indexing and identical mood marking.

15(77) A-baha, a-pa 'Geka tauhi...'.

ISG-say ISG-say this they

I spoke saying, 'These are the people...'.

15(78) O-na-paliwele-hi o-na-pa, 'Omi wasawasa o-na-gale-ya'.

2PL-POT-tell-3PL 2PL-POT-say yourPL rich.man 2PL-POT-see-3SG

You tell them saying, 'Look at your rich man'.

15(79) I-pa, 'Ta-nae ta-wisili'.

3SG-say IPL.INC-go 1PL.INC-fish

She replied, 'Let's go fishing'.

In 15(80) the utterance verb is separated from the quote verb by peripheral items (first sentence). The second quote is introduced by $i$-pa, which signals the response of a second speaker.

15(80) Wagaloke i-baha Popopo uyahi-na i-pa, 'Heliyam, apo u-na-nei possum 3SG-say lizard 'at'-3SG 3SG-say friend FUT 2SG-POT-come po ginahi ta-hapi'. I-pa, 'Oo i-dewadewa duma'. and sago 1PL.INC-chop 3SG-say oh 3SG-good very

Possum spoke to Lizard saying, 'Friend, come and we will chop sago'. He (his friend) replied, 'Oh, that is very good'.

The utterance 'verb' can be a construction which does not necessarily involve a verb of speaking.

15(81) Nugotuhu i-nei i-pa, 'Tauta Yaubada a bagibagi ubei-na thought 3SG-come 3SG-say weINC God his work BEN-3SG ta-nei'. IPL.INC-come

The thought came (to me), saying, 'We all have come to do God's work'. 


\section{COMBINATION OF CLAUSES}

\subsection{INTRODUCTION}

In many languages, and possibly all ... what are traditionally called phrases and clauses may be juxtaposed or embedded one within another within the same sentence.

Lyons (1977:388)

It appears that all languages have a set of two-clause constructions in which one clause can be said to modify the other in a way similar to the way in which an adverb modifies a proposition.

Thompson and Longacre (1985:171)

Clauses which may be said to be subordinated can be contrasted with coordinated clauses, not in terms of a strict dichotomy but rather as a continuum.

We have seen in the description of complement clauses that a major problem with the description of Tawala sentence structure is the mismatch between form and function. The problem becomes more acute in this present chapter. Thus, for example, in 16(1) the bracketed clause is structurally identical to a relative clause, apart from the fact that it is conjoined to the main clause with a coordinating conjunction. The clause in brackets functions here as an adverbial clause, yet it is not subordinated as adverbial clauses are normally regarded as being.

\section{6(1) [Houga-na wam hi-gale-ya] ma hi-kaoha labatana. time-DEF boat 3PL-see-3SG and 3PL-happy strongly \\ When they saw the boat they were exceedingly happy.}

That an adverbial clause can modify not just a verb but a series of clauses is clear from 16(2).

16(2) [Houga-na lawa i-na-hilage] apo au-na bo goga-na tauna apo time-DEF person 3SG-POT-die FUT uncle-3SG or grandparent-3SG him FUT lawa-na hilahilage-na i-na-woimahi-ye-ni po hi-na-tu-tou. person-DEF dead-3SG 3SG-POT-put.properly-TRV-3SG and 3PL-POT-DUR-weep If/when a person dies, his uncle or grandfather will place the dead person properly and they will weep.

Broadly speaking I have given priority to structure within this chapter and tried to keep semantic categories in perspective by the labels used. Some introductory remarks are in order. The following 'adverbial clauses', not all involving subordinated clauses, are distinguished in Tawala. I mostly follow the semantic categories of Thompson and Longacre (1985:177):

$\begin{array}{lll}\text { temporal } & \text { result } & \text { consequence } \\ \text { locational } & \text { purpose } & \text { avoidance } \\ \text { manner } & \text { condition } & \text { cause (reason) }\end{array}$

The suggested universal distinction made by Thompson and Longacre (1985:177) between "clauses substitutable for by a single word" (the first three of the above list) and 
"clauses not substitutable for by a single word" (the remainder of the above list) breaks down with Tawala, as some of the latter clauses are also substitutable for by a single item, for example the result clause in 16(3) (a head-marked postposition with the dependent omitted).

\section{6(3) [Ugoli-n'-eI] amaka wiatatiana atapu-na amaka o-nonol'-i. 'at'-3SG-ABL already teaching all-3SG already 2SG-hear-3SG \\ From (as a result of) this you have already heard all the teaching.}

The final three items of the above listing are structurally coordinated in Tawala. The remaining 'subordinate' structures represent four construction types in Tawala. One may question the wisdom of lumping all these semantic categories together under some universal adverbial-subordinate-clause complex. The implication of such an approach is that these items may be expected to have some sort of structural unity in the languages of the world. We return to this point shortly.

Attempts to apply the classic coordinate-subordinate dichotomy to exotic languages have increasingly met with resistance in recent years. Various solutions have been proposed. Foley and Van Valin (1984:243) suggest that we should "employ three kinds of nexus rather than two: coordination, subordination, and cosubordination". However, I have not found the cosubordination category particularly useful in solving the problems encountered in the Tawala data.

Kuno (1973:209) suggests that the dichotomy should be replaced with a continuum - a concept which provides a useful way of viewing some Tawala conjunctions which do not readily divide into discrete coordinate-subordinate categories. In the following description I assume that the Tawala data are best described in terms of a continuum. I point out some facts in favour of this approach, but have not attempted to spell out the nature of the nexus in individual cases; in the more problematic cases I point out the conflicting facts and/or I avoid delineating the precise nature of Tawala clause juncture - that must wait for a more comprehensive treatment in the future.

The future direction of studies is suggested in two seminal works that appeared in the 1980s. Haiman and Thompson (1984:511) demonstrate that the intuitive notion 'subordination' is a composite of a number of properties: "we would like...to propose that there are at least seven formal properties that are often associated with clause combinations designated as "main-subordinate"".

Lehmann (1988) argues that there are six functional parameters relevant to clause linkage, each of them a continuum that extends from a pole of maximal elaboration to a pole of maximal compression. The two poles are complementary forces which are involved in clause linkage: 1) "the elaboration of a phrase into a more fully developed construction which contains its own predication" (p.216) and 2) "the compression of a full-fledged clause to a nominal or adverbial constituent of a matrix clause" (p.217).

The clauses described in this chapter fall into five classes, depending on the nature of the linkage between the clauses involved. Structures range from prototypical subordinate clauses (embedded within adpositional phrases) to prototypical coordinate clauses (contrast, adversative, alternation and succession). 
TABLE 1: CLAUSE COMBINATION STRATEGIES

\begin{tabular}{|c|c|c|}
\hline $\begin{array}{l}\text { Embedding in } \\
\text { PoSTPOSITIONAL PHRASES: } \\
\text { PREPOSITIONAL PHRASES: }\end{array}$ & $\begin{array}{l}\text { locational } \\
\text { result } \\
\text { manner }\end{array}$ & $\begin{array}{l}\text { uyahi-na } \\
\text { uyahi-nei } \\
\text { mei }\end{array}$ \\
\hline $\begin{array}{l}\text { POSTPOSED SUBORDINATE } \\
\text { ClAUSES: }\end{array}$ & $\begin{array}{l}\text { 'end-point' } \\
\text { 'until' } \\
\text { purpose }\end{array}$ & \\
\hline PREPOSED ClaUSES: & $\begin{array}{l}\text { succession } \\
\text { conditionals } \\
\end{array}$ & -kokoe ma \\
\hline COORDINATED ClAUSES: & $\begin{array}{l}\text { avoidance } \\
\text { cause } \\
\text { consequence } \\
\text { coupling } \\
\text { contrast } \\
\text { adversative } \\
\text { alternation } \\
\text { succession }\end{array}$ & $\begin{array}{l}\text { meka po } \\
\text { babana } \\
\text { (ega) yaka } \\
\text { po } \\
\text { ma } \\
\text { tamogi } \\
\text { bo } \\
\text { apom(a) }\end{array}$ \\
\hline
\end{tabular}

The semantic labels of the coordinated clauses mostly follow Longacre's (1985:241ff.) classification; however definitions offered in the appropriate sections below are based not on universals but on the Tawala data.

\subsection{CLAUSES EMBEDDED IN POSTPOSITIONAL PHRASES}

With these structures, the main clause includes an embedded postposition clause. As pointed out in the respective sections, these structures are identical to the phrase level constituents, except that they contain an embedded clause as the object of the adposition. (In $\S 16.2$ and $\S 16.3$, adpositions are underlined and embedded clauses (the objects of the adpositions) are in square brackets.)

\subsubsection{Locational Clause - uyahina}

This construction involves an embedded clause within a locative postposition phrase. The embedded structure could be analysed as a relative clause, however I have chosen to include the construction here because of the similarity of structure with other adpositional structures - the presence of an adposition. Also these constructions differ from relative clauses in that the embedded clause may follow the main verb (16(8), 16(9)).

The postposition is marked for agreement with the object of the postposition, in this case the embedded clause. The function of the postposed locational clause is to specify the point at which the action in the main clause took place.

16(4) [Bod gehou-na hi-gilum'-1] uyahi-na to-geleta. board other-3SG 3PL-write-3SG 'at'-3SG IPL.EXC-arrive

We arrive at a board on which something was written (impersonal 3PL). 
16(5) [Hai meyagai hi-dewa-dewa-ya] ugoli-na hi-gi-ye-ya.

their village 3PL-DUR-make-3SG 'at'-3SG 3PL-take-TRV-3SG

They took him to where they were making their village.

In 16(6) a complex name phrase is embedded within the embedded clause.

16(6) [Epot gehou-na e-memae (gowa-na Gusap)] uyyahi-na to-yato. airport other-3SG 3SG.PRES-stay name-3SG Gusap 'at'-3SG 1PL.EXC-land

We landed at an airport which is there, called Gusap.

This adpositional locational clause also occurs with the indefinite interrogative.

\section{6(7) [Meka mayou-na ita luhogala] uyahi-na apo ta-tala-ya. \\ where tree-DEF ourINC desire 'at'-3SG FUT 1PL.INC-cut-3SG}

At the place where there is a tree we desire (for a canoe), we will cut it down.

The following postpositional locational clauses are postverbal clauses. As with other postverbal clauses (16(9)) it would seem that these embedded clauses are not part of the spatio-temporal setting but rather they limit the extent of the action expressed in the main verb.
16(8) I-baha nae [lawa-hi i-ot-otu-ge-ht] ugoli-na... 3SG-say go person-DEF 3SG-DUR-call-TRV-3SG 'at'-3SG He spoke to the people that he called to...

Verbless relative clauses are also found subordinated in the postverbal position.

16(9) To-damana [bonabona gowa-na Kilitent] ugoli-na. 1PL.EXC-cross island name-3SG Kiliteni 'at'-3SG

We crossed over to an island which is called Kiliton.

\subsubsection{Result Clause - uyahinei}

The result clause has the same structure as the ablative phrase, though with an embedded clause as the object of the postposition. The postposition is marked for agreement with the object of the postposition - in this case the embedded clause.

The subordinating conjunction uyahi<n>ei (L. ugoli<n>el) '(and) because of this, from this' specifies that the main clause is a result of the embedded clause.

16(10) [Kabudala i-kokoe] ugoli-n'-ei am-a-hilage.

sun 3SG-finish 'at'-3SG-ABL food-1SG-hunger

Because the sun has set I am hungry.

16(11) [Apo aniani po ani-eno] uyahi-n'-ei apo hi-na-hagu-ya a FUT food and place-sleep 'at'-3SG-ABLFUT 3PL-POT-help-3SG his

kadau uyahi-na.

joumey 'at'-3SG

Because (he needs) food and a place to sleep they will help him in his journey.

16(12) [Naka tahaya i-wibigabiga] ugoli-n'-ei tahaya tapu-na to-wotago-ya. that path 3SG-muddy 'at'-3SG-ABL path different-3SG 1PL.EXC-follow-it Because that path was muddy we followed a different path. 
16(13) [Popopo a dewa i-dewa-dewa-ya] uyyahi-n'-ei ta-lau-labiya. lizard his custom 3SG-DUR-do-3SG 'at'-3SG-ABL IPL.INC-DVP.DUR-sago Because Lizard was following (lit. doing) his custom (making holes in sago) we process sago.

\subsection{CLAUSES EMBEDDED IN PREPOSITIONAL PHRASES}

This construction involves an embedded clause within a manner phrase. Recall that the manner phrase is signalled by the preposition mei 'like'.
16(14) Ani-galena-na mei [amaka i-hilage].
thing-appearance-3SG like already 3SG-die
It looked as if it had died.
16(15) Ata lawa ta-luhogal'-e-hi mei [ipa ta-luhogal'-e-na
ourINC friend IPL.INC-desire-TRV-3PL like IRR IPL.INC-desire-TRV-LIG me-ta].
again-1PL.INC

Let us love our friends as we ought to love ourselves.

In $16(16)$ the manner adverbial clause functions as a reason clause, though this is presumably only an etic view of things.
16(16) Nugonugo-u i-kaoha duma mei [amaka nonogo o-dewa-ya]. heart-1SG 3SG-happy very like already preparation 2PL-make-3SG I was very happy like (because) you had made preparation.

\subsection{POSTPOSED SUBORDINATE CLAUSES}

The postposed and the preposed subordinate clauses are temporal clauses. Postposed subordinate clauses are generally aspectual, in contrast to the preposed subordinate clauses, which are part of the spatio-temporal setting.

\subsection{1 'END-POINT' Clause}

The end-point temporal clause is a serial construction (though not to be confused with serial verbs), composed of a main clause followed by a serial clause. The serial clause is a subordinate clause that follows the main clause and functions as an aspectual marker, indicating the consummation of the action in the main verb.

\section{6(17) I-ga-gale-ya [po i-kokoe]. 3SG-DUR-see-3SG and 3SG-finish He completely examined it.}

This serial clause is formally coordinated to the main clause with the close-link coordinating conjunction $p o$. In this construction the stative verb -kokoe 'be finished' is restricted in tense-aspect and participants. The subject of -kokoe is always third person, and always agrees in number with the object of the main verb, if one is present (16(17)-16(20)), otherwise it is singular $(16(21))$. 
16(18) Ginahi i-tala-ya [po i-kokoe].

sago 3SG-cut-3SG and 3SG-finish

He finished cutting the sago.

The serial clause also takes the same mood as the main clause; in 16(19) potential mood is neutralised with realis in the first person.

16(19) Mayau ta-tala-hi [po hi-na-kokoe].

tree IPL.INC-cut-3PL and 3PL-POT-finish

We will finish cutting down the trees.

16(20) I-na-alahi [po i-na-kokoe].

3SG-POT-burm and 3SG-POT-finish

It will bum it right up.

This construction does not invariably have an aspectual function; thus 16(21) does not seem to be aspectual.

16(21) Ma hi-kao-kaoha [po i-kokoe].

and 3PL-DUR-happy and 3SG-finish

Then they were happy and it was finished.

Example 16(21) does not mean *'they were completely happy'. Rather it seems to be a good example of an 'adverbial' clause used as a discourse marker 'they were happy ever after', as Thompson and Longacre (1985:206) note:

Adverbial clauses may be used to provide cohesion for an entire discourse by assisting to maintain the discourse perspective and by helping to articulate the sections of the discourse.

In the context, 16(21) marks the end of a paragraph, thus warming the hearer that there is to be a change in the discourse perspective. The new paragraph commences Ma amalai...'But now...'

\subsection{2 'UNTIL' ClAUSE}

The end-point subordinate clause uses a nominalised possessive construction with the noun siga 'end', together with a complement, to indicate the end point of the action expressed in the main clause. These clauses function primarily as temporal adverbial clauses but sometimes involve locational overtones. Like end-point temporal clauses, they follow the verb and are thus aspectual, indicating the extent of the action.

16(22) Niha-gei to-bulili [a siga Lae to-geleta]. salt-ABL 1PL.EXC-run its end Lae IPL.EXC-arrive We sped (in a plane) along the edge of the sea until we got to Lae.

16(23) Apega i-na-nae [a siga-na bada i-na-gale-ya]. FUT.NEG 3SG-POT-go its end-DEF man 3SG-POT-see-3SG He would not leave until he had seen the man.

16(24) Apega polo po kamkam hi-n'-ani-hi [a siga bolima emosi]. FUT.NEG pig and chicken 3PL-POT-eat-3PL its end year one They will not eat pork or fowl until a year is finished. 
With negative polarity, siga 'end' and its related adjective sigasiga-na 'final-3SG' are both used without a complement.

$$
\begin{aligned}
& \text { 16(25) I-nae [ega a siga]. } \\
& \text { 3SG-go NEG its end } \\
& \text { It went on without end. }
\end{aligned}
$$

$$
\begin{aligned}
& \text { 16(26) E-ge-gae [ega sigasiga-na]. } \\
& \text { 3SG.PRES-DUR-go.up NEG final-3SG } \\
& \text { It keeps going up without ending. }
\end{aligned}
$$

\subsubsection{INDEFINITE LOCATION CLAUSE}

There is a scarcity of locational adverbial clauses in Tawala, which may find its explanation in the tendency to coordinate rather than embed adverbial clauses.

\section{6(27) Meka ta-nae po ta-wiheliheliyam. \\ where IPL.INC-go and 1PL.INC-make.friend \\ Wherever we go we have friendship.}

These clauses are structurally the same as indefinite relative clauses, except that they commonly follow the main clause, particularly with motion and posture verbs.

\section{6(28) I-nae [meka amalai a lawa naka hi-tukoyama].} 3SG-go where today his friend that 3PL-pretend He went where his friends just now pretended to go.

16(29) I-tugu-tugula [meka nao-na hi-hu-houn'-1].

3SG-DUR-sit where face-3SG 3PL-DUR-put-3SG

He kept sitting wherever they faced him.

\subsection{PURPOSE CLAUSE}

Purpose sentences consist of a motion clause followed by a juxtaposed purpose clause.

16(30) I-nae i-na-togo.

3SG-go 3SG-POT-wash

He was going to bathe.

While the purpose clause is independent in form, its subject must be coreferential with the subject of the motion clause and cannot be expanded by an NP. These restrictions make it clear that the second clause is subordinated.

It is the clauses that are juxtaposed and not the predicates. The motion verb can be followed by a location.

\section{6(31) To-nae goila u mata-na to-witogotogo. 1PL.EXC-go river LOC eye-3SG IPL.EXC-play.wash We are going to the river source to swim.}

An object NP (in brackets) can also be added to the purpose clause. 
16(32) To-nae u pitapita [katawe gou-hl] to-beiha.

IPL.EXC-go LOC bush mango ripe-3PL 1PL.EXC-seek

We are going to the bush to look for ripe mangoes.

\subsection{PREPOSED SUBORDINATE CLAUSES}

The preposed subordinate clause marks temporal succession but is distinguished from temporal succession clauses by the presence of a subordinate clause indicating the completion of a time specified in the NP contained in the subordinate clause:

$$
\mathrm{NP}^{\mathrm{TEMP}}<j>\text {-kokoe ma, }
$$

The construction '(TIME) <it>-finish and,' indicates that the main clause, which follows the subordinate clause, begins after the time indicated by the 'subordinate' clause. The conjunction $\mathrm{ma}$ is another example of mismatch between form and function. As the construction necessarily involves a change of person-number indexing on the predicate, the contrast conjunction ma marks change of subject. However the ma is followed by a pause, contrasting with the more usual pattern of a pause before the conjunction.

16(33) [Bolimatonuga hi-kokoe ma], a-nae Huhu LGC uyahi-hi a-bagibagi. year three 3SG-finish and 1SG-go Huhu LGC 'at'-3PL 1SG-work After three years I went to work for the Huhu Local Government Council.

16(34) [Iyeta emosi i-kokoe ma], wi-luwaga-na uyahi-na... day one 3SG-finishand ORD-two-3SG 'at'-3SG

After one day (was finished), on the second (day)...

16(35) [Mei kabudala gaogao-na tonuga hi-kokoe ma], ago-na i-geleta-i. like sun gap-3SG three 3SG-finish and spouse-3SG 3G-arrive-DEI After about three hours were finished, his wife arrived.

\subsection{CONDITIONAL CONSTRUCTIONS}

These are referred to as conditional constructions rather than conditional clauses, since two clauses are required. The basic structure is a condition clause followed by a main clause. The form of the condition clause is an independent clause unmarked by any subordinator, and the form of the main clause is a second independent clause optionally introduced by naka 'that' or yaka 'so'. These connectors are best regarded as anaphorics cross-referencing the whole subordinate clause. Thus Tawala marks the relationship between the two clauses in the main clause, if it is marked at all.

Subsumed under conditional constructions are:

conditional clauses

hypothetical clauses

contrary-to-fact clauses

These three conditional types reflect the semantics of the subordinate clause - the degree of reality assumed for the condition - and are formally distinguished by the mood of the clauses (not by the presence or absence of naka/ yaka). Hypothetical clauses are marked with $(h)$ inapa and contrary-to-fact clauses are marked with (h)itapa. (Within the following subsections the condition clause is in square brackets.) 


\subsubsection{REAL CONDITION}

Conditional clauses are independent clauses juxtaposed to the main clause without any subordinating particle, though the main clause may be introduced by naka 'that' (16(37)).

16(36) [Ega u-ta-uma $]$ apo ta-nae.
NEG 2SG-IRR-drink FUT 1PL.INC-go

If you don't drink [alcohol] we will go.

16(37) [I-na-dumol'-1] naka a-nae.

3SG-POT-calm-3SG that 1SG-go

If it is calm I'll go.

16(38) [Kalado apo i-na-net] apo ugoli-na u-na-baha...

Kalado FUT 3SG-POT-come FUT 'at'-3SG 2SG-POT-say

If Kalado comes tell him...

The condition clause does not invariably come first; in 16(39) the order is reversed.

16(39) Ega i-ta-geno duma [apo i-na-kada-kadau].
NEG 3SG-IRR-worry very FUT 3SG-POT-DUR-journey
He won't worry much if he is journeying.

\subsubsection{HYPOTHETICAL - inapa/ hinapa}

Hypothetical clauses differ from real condition clauses in two respects: firstly, the condition clause is marked for hypothetical mood by inapa/hinapa; and secondly, the main clause is optionally marked by either naka 'that' or yaka 'so'.

The meaning distinction between the two mood particles is not connected to similar forms marking singular and plural third person on verbs; rather it indicates the truth condition of the condition clause, which is either uncertain (inapa 'if, suppose') or more likely (hinapa 'if, when'). For example, in 16(40) there had been a long period of constant rain making the condition very uncertain. In 16(41) the situation is from an outline of a feature of Tawala culture - 'what happens if...'. Example 16(42) presents an inevitable occurrence if/when the kerosene is not replenished.

16(40) [Inapa haumalatom kabudala i-na-lalana] naka apo ta-toleha. HYP tomorrow sun 3SG-POT-shine that FUT IPL.INC-feast If the sun shines tomorrow then we will hold the feast.

16(41) [Inapa tauyai to-nae] apo natu-natu-iyai hi-na-hagu-hi. HYP ourEXC 1PL.EXC-go FUT PL-child-IPL.EXC 3PL-POT-help-3PL If (suppose) we go our children will help them.

16(42) [ Hinapa i-na-kokoe] yaka u-na-boho-ya. HYP 3SG-POT-finish so 2SG-POT-extinguish-it If it [kerosene] runs out then extinguish it [lamp].

16(43) [Hinapa to-hanapu-ge-ya] apo tauyai gasi to-houna. HYP IPL.EXC-know-TRV-3SG FUT weEXC also IPL.EXC-put If we learn about it we will also contribute. 


\subsubsection{CONTRARY TO FACT - itapa/ hitapa}

Like the hypothetical sentence the main clause of the contrary-to-fact construction is optionally marked by naka 'that' or yaka 'so'.

Again the meaning distinction between the two forms indicates the truth condition of the condition clause - impossible (itapa) or possible (hitapa).

16(44) [Itapa tau kedewa] apo taniwaga-u a yu numa a-ta-eno. CON I dog FUT master-ISG his LOC house ISG-IRR-sleep If I were a dog I would sleep in my master's house.

16(45) [Itapa a-ta-hanapu-ge-ya] apega geka pite a-ta-baha. CON ISG-IRR-know-TRV-3SG FUT.NEG this like 1SG-IRR-say

If I had known it I would not have spoken like this.

16(46) [ Hitapa gadiwewe pom] yaka apega bulumakau hi-ta-uni. CON rain yesterday so FUT.NEG cow 3PL-IRR-kill

If it had rained yesterday they would not have killed the cow.

16(47) [Hitapa hai nugoapapoe ugoli-u] yaka hi-ta-nei.

CON their anger 'at'-ISG so 3PL-IRR-come

If they were angry with me they would have come.

\subsection{COORDINATED CLAUSES}

The division of Tawala text material into sentences is sometimes difficult, as there is often no distinction in principle between a sequence of clauses constituting a sentence and a sequence of sentences constituting a paragraph. This is particularly true of structures which employ coordinate conjunctions, which are distinguished by their ability to join either clauses or sentences. ${ }^{1}$ As Longacre (1985:239) notes, "the decision to opt for one sentence or two when and and but are involved is sometimes delicate, if not arbitrary". In Tawala the same problem exists with each of the coordinating conjunctions (except meka po).

There are, however, a number of features which combine to delineate sentence borders in most cases.

1) Phonologically, sentences begin with a higher onset and end with a lower coda than clauses. There is greater potential for pauses between sentences and that is usually where the speaker takes a breath.

2) Semantically, a sentence forms a cohesive unit with a specific topic and within specified spatio-temporal parameters. New sentences are signalled by the introduction of a new topic - overt subject or object NPs - or a new spatio-temporal setting.

3) Syntactically, there are numerous clues to sentence borders, of which only a small sampling is offered here. The conjunction po 'and', for example, rarely introduces a new sentence, as it marks two clauses as a cohesive unit. On the other hand ma 'and, but' combines both clauses and sentences, as it signals a change of subject or other new item. When combined with other conjunctions it typically marks a sentence 
break, for example ma tamogi 'but'. Without ma, tamogi typically joins clauses rather than sentences.

The conjunction ega yaka 'so' frequently marks the beginning of a new sentence, whereas yaka 'so' rarely does.

Within narrative discourse, many sentences end with an 'end-point' clause which marks the end of a sequence of actions.

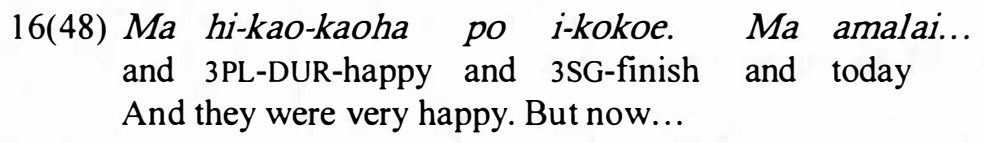

Sentence divisions within narrative discourse are often unambiguously marked with tailhead linkage.

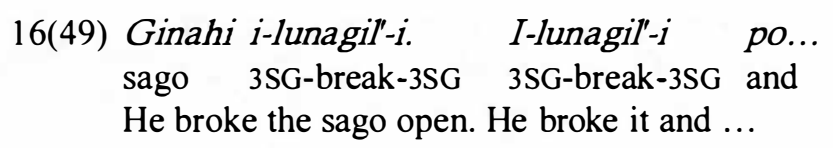
16(50) ...po hina-hi hi-tuhaga-ya. Hina-hi hi-tuhaga-ya po... and mother-3PL 3PL-find-3SG mother-3PL 3PL-find-3SG and .... and they found their mother. They found their mother and...

Definite markers (both definite (16(51)) and indefinite (16(52)) - underlined) usually mark the commencement of a new sentence (though it is not necessarily the first item that is marked). They typically (re)introduce a topic, thus marking a new sentence or even a paragraph.
16(51) Yailo wam-na hi-dewa-dewa-ya i-gale-hi.
Yailo boat-DEF 3PL-DUR-make-3SG 3SG-see-3PL
Yailo saw them making that boat.

16(52) Ma niha wedu-na gehou-na i-waya.

and salt cup-3SG other-3SG 3SG-take.it

Then she took another salt-water ladle.

\subsection{TYPES OF CLAUSE COORDINATION}

A coordinating conjunction joins clauses which are structurally independent. The conjunction itself is loosely attached to the second clause. It is with coordinate constructions that the greatest degree of functional independence between clauses is exhibited. However, this group also manifests features of a Kuno-type continuum. Thus the coupling conjunction po 'and', always indicates a degree of dependence between the two clauses. Similarly, the conjunctions meka po, babana and (ega) yaka also indicate a degree of semantic dependence (avoidance, cause and consequence respectively); thus with these clauses it is possible to identify 'main' clauses.

The distinction between $p o$ and $m a$ is of the utmost importance, as these are by far the most common conjunctions in the language. At the phrase level $p o$ is more common than $m a$; however, the reverse is true at the clause level and above, where po indicates 'close' and $m a$ 'loose' coordination. In these functions they almost intersect with the semantic notions of coupling and contrast. 


\subsubsection{AVOIDANCE - meka po}

The conjunction meka po 'lest' (lit. 'where and'), marks an avoidance clause.

16(53) Ta-ni-niye-ya [ [meka.po mimituwa ma apo togowa ta-wialon'-1]. IPL.INC-DUR-take-3SG lest spirit and FUT wind IPL.INC-face-3SG We are taking (= returning) him lest (he is) a spirit and we encounter wind $(=\mathrm{a}$ storm). ${ }^{2}$

16(54) Apega u-na-gelu [ [meka.po apo duba banei-na u-na-wialo-nl]. FUT.NEG 2SG-POT-embark lest FUT storm big-3SG 2SG-POT-face-3SG Don't embark lest you encounter a big storm.

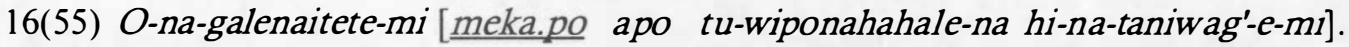
2PL-POT-watch-CPY lest FUT PER-disobedient-3SG 3PL-POT-rule-TRV-2PL Watch yourselves lest the disobedient people influence you.

16(56) Ega wale-walehi-m u-na-otu-ge-hi [meka.po apo

NEG PL-brother-2SG 2SG-POT-call-TRV-3PL lest FUT

hi-na-otu-ge-m gasi].

3PL-POT-call-TRV-2SG also

Don't call your brothers lest they call you also.

\subsubsection{CAUSE - babana}

The causal clause follows the 'main' clause. Semantically the result is compared to baba 'a base on which the result (the main clause) stands'.

Here the subordinating conjunction has two forms, both marked for person and number of the main predication:
1)
baba-na
2) mata-baba-na
base-3SG
eye-base-3SG

The second form is more intensive, mata stressing the point of focus. ${ }^{3}$ Although the conjunction clusters phonologically with the 'adverbial' clause, the pronominal index is an anaphoric reference to the 'main' clause, meaning 'its base' and hence the gloss (reason3SG).
16(57) Hina-u a-luhogale-ya, [baba-na e-lugahan'-e-u].
mother-1SG 1SG-desire-3SG reason-3SG 3SG.PRES-hold-TRV-1SG
I love my mother because she holds me (on her lap).

16(58) I-hopu mai, [matababa-na i-luhogal'-e-m].

3SG-descend DEI reason-3SG 3SG-desire-TRV-2SG

She came down because she loves you. 
16(59) Ginouli geka hi-gele-geleta, [matababa-hi ipa guyau a bahapiko thing this 3PL-DUR-appear reason-3PL IRR chief his prophecy i-na-lugelete-ya]. 3SG-POT-reveal-CPY

These things happened in order to fulfil God's prophecy.

Many sentences suggest that the causal construction can belong to a separate sentence altogether.

16(60) Apega toleha-na a-ta-dewa-ya po meilolowa. [ FUT.NEG feast-DEF 1SG-IRR-make-3SG and like before reason-3SG custom odubo-hi amaka hi-kokoe.] old-3PL already 3PL-finish

I won't make a feast like before. The reason (is that) the old customs are finished.

\subsubsection{CONSEQUENCE - (ega) yaka}

The conjunction yaka expresses strong consequence; when combined with the negative marker ega (ega yaka) it expresses loose consequence.

\subsubsection{STRONG CONSEQUENCE - yaka}

The conjunction yaka 'so, consequently' expresses that the following clause is the consequence of the previous clause.

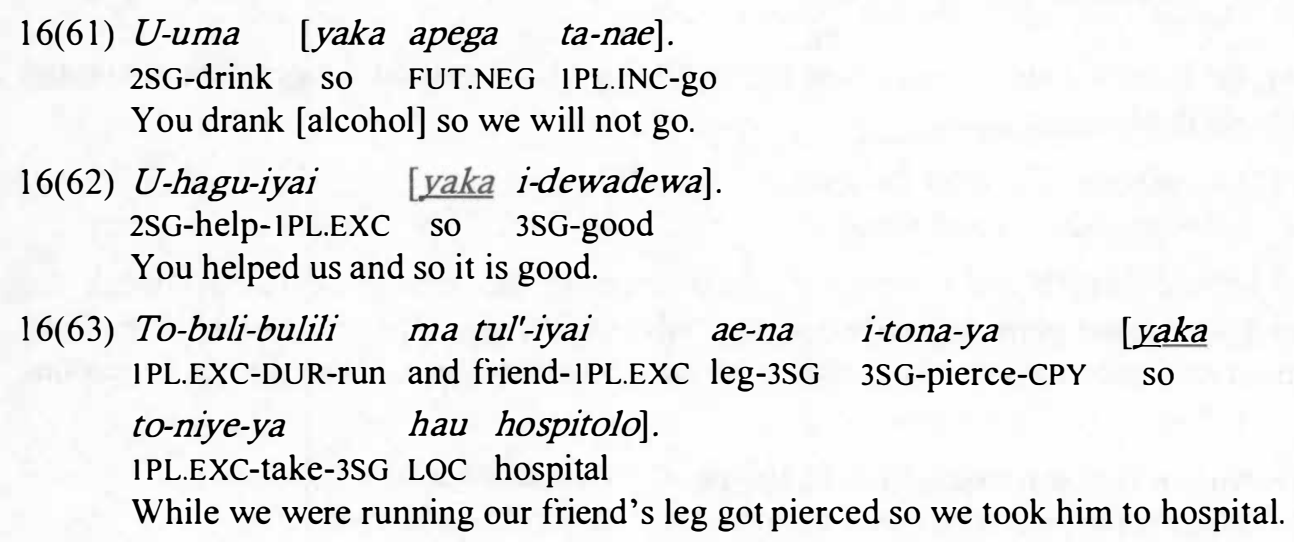

While we were running our friend's leg got pierced so we took him to hospital.

\subsubsection{LOOSE CONSEQUENCE - ega yaka}

The conjunction ega yaka 'so' (lit. 'not consequently'), indicates that the semantic relationship between the clauses is not a truly consequential relationship but rather a loose consequence - at times little more than a sequence and hence a prototypical coordinating conjunction and then - though at other times the meanings of yaka and ega yaka seem to overlap, with the latter also meaning 'consequently'. 
16(64) Hina-na pona-na i-nonol'-i. [Ega.yaka hina-na i-lupa uyahi-na]. mother-3SG voice-3SG 3SG-hear-3SG so mother-3SG 3SG-fly 'at'-3SG His mother heard his voice. And so his mother flew to him.

16(65) Gaeba-na i-li-hogo-ya po tewela i-wele-ya. [Ega.yaka tewela-na bowl-DEF 3SG-DVP-fill-3SG and child 3SG-give-3SG so child-DEF i-houn'-i ...] 3SG-put-3SG

He filled the bowl and gave it to the boy. And so the boy put it ...

Frequently ega yaka occurs following po, in which case it is always nestled between clauses; following $m a$ it is more ambivalent, usually between clauses but occasionally between sentences.

\section{6(66) I-nugonugotuhu po [ega.yaka i-pa ...] 3SG-think and so 3SG-say}

He was thinking and so he said ...

$\begin{array}{lll}\text { 16(67) I-tu-tou ma [ega.yaka hina-na } & \text { i-ne'-po ...] } \\ \text { 3SG-DUR-cry and so mother-3SG } & \text { 3SG-come-and } \\ \text { He was crying and so his mother came and ... }\end{array}$

\subsubsection{COUPLING - po}

The conjunction $p o$ 'and' indicates a close connection between two clauses - sometimes repetition of the predicate, sometimes identity of the subject, always agreement in polarity etc. Longacre (1985:241) defines coupling as "a non-temporal underlying and relation". Tawala, however, uses po for both temporal and non-temporal relations. Both verbal (16(68)) and non-verbal clauses (16(69)) are commonly joined by $p o$.

\section{6(68) Apo a-ne-nae po a-ne-nae po $u$ meyagai... FUT ISG-DUR-go and ISG-DUR-go and LOC village I went and went and (came) to the village ...}

16(69) Ega kikina matouta po ega widagudagu.

NEG little fear and NEG struggle

He had no fear and did not struggle.

This conjunction can be used with a change of subject if the second clause is an outcome of the first; in 16(70) the subject of clause 1 becomes the object of clause 2 .

\section{6(70) To-nae po hi-gohili-yai. \\ 1 PL.EXC-go and 3PL-surprise-1PL.EXC \\ We went and they surprised us.}

Various functionally embedded clauses use this coupling device. Firstly, we noted in Chapter 15 that $p o$ functions as a complementiser, particularly in marking the complement of 'utterance' complement-taking predicates as commands (16(71)), though it is also found with other predicates, including modality complement-taking predicates $(16(72))$.

16(71) I-baha po goga-na i-gae hoi tano. 3SG-say and grandchild-3SG 3SG-go.up LOC garden He commanded his grandchild to go to the garden. 
16(72) Ega emoemota-na po a tano i-na-tala-ya.

NEG ability-3SG and her garden 3SG-POT-cut-3SG

She will not be able to cut her garden (clearing).

Spatio-temporal clauses are commonly joined to the main clause with po. In 16(73) and $16(74)$ the clause preceding the conjunction would be a standard relative clause if no conjunction was present. The conjunction gives a degree of independence to the dependent clause, yet in the case of 16(73) the internal-headed definite enclitic marks the preconjunction clause as dependent.

16(73) Houga-na to-gele-geleta po a-ga-gale-ya.

time-DEF 1PL.EXC-DUR-arrive and 1SG-DUR-see-3SG

The time when we arrived I saw it.

16(74) Meka ta-nae po ta-wiheliheliyam.

where IPL.INC-go and IPL.INC-make.friend

Wherever we go we have friendship.

Peripheral arguments may also be joined to the main clause with $p o$.

16(75) Guyau tepa-n'-ei po u nugotuhu u-na-wotago-ya.

chief top-3SG-ABL and my thought 2SG-POT-follow-3SG

For God's sake follow my suggestion.

A number of idiomatic interrogative constructions also employ po within their structure.

16(76) Iyowaka po i-peu?

how and 3SG-fall

How is it that he fell?

16(77) Awai bi-nei po i-nae?

what BEN-3SG and 3SG-go

For what reason did he go?

The following elicited sentences demonstrate the distinction between the conjunctions $m a$ and po. In each case po indicates that the following clause is functionally a complement, whereas ma signals a contrastive clause.

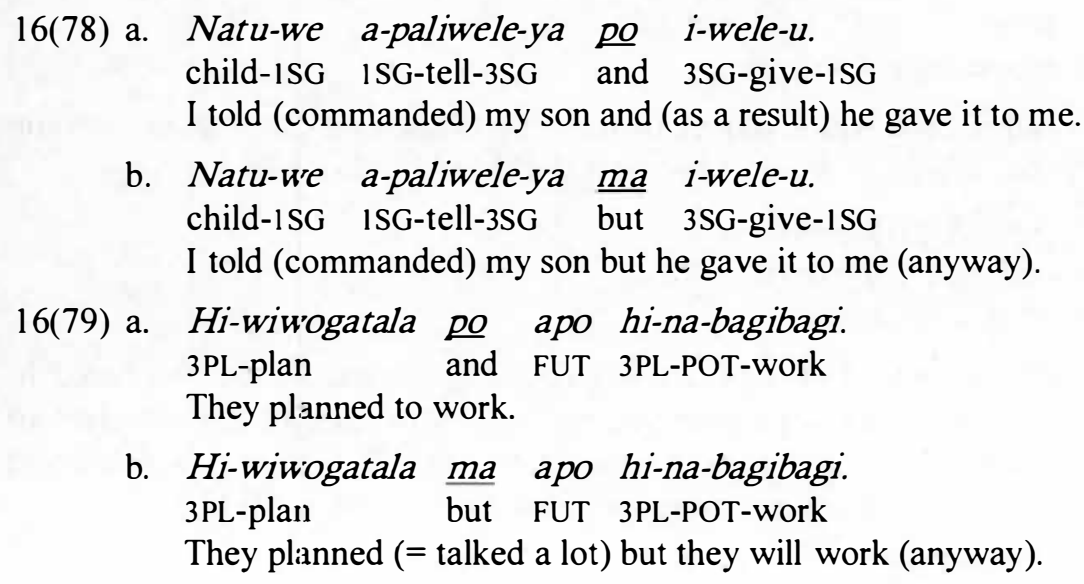




\subsubsection{CONTRAST - ma}

The contrastive conjunction ma has a very different set of functions from the coupling conjunction po, even though they can both be glossed 'and'. The conjunction ma marks a clause as being in contrast to the previous clause - a change of subject, mood or spatiotemporal setting.

16(80) Dimdim hai bolima hi-habulu ma hai lata hi-bulili.

European their year 3PL-small but their grow 3PL-run

Europeans are only young but their growth is rapid.

16(81) Pona a-nonol'-i ma gamo-u i-witai.

language 1SG-hear-3SG but mouth-1SG 3SG-heavy

I can hear the language but can't speak it.

16(82) Upom-gei am lawa hi-nei ma iyowaka po tam ega u-ta-nei? night-ABL yourSG friend 3PL-come but how and youSG NEG 2SG-IRR-come Your friends came last night but how is it you didn't come?

Change of polarity is also marked with ma.

16(83) Ega i-ta-tawine ma e-ma-mae.

NEG 3SG-IRR-marry but 3SG.PRES-DUR-stay

He has not married but is just staying.

16(84) ... galena-na ega lawa hota ma galena-na naka mei appearance-3SG NEG person only but appearance-3SG that like mimituwa ... spirit

... his appearance is not that of a real person but like a spirit ...

In 16(85) two contrasting alternate conditional clauses are joined by ma.

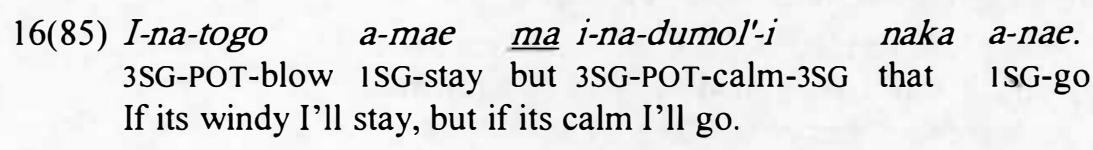

In 16(86) ma join two NPs within an equative clause.

16(86) Geka ega u bagibagi ma lawa hai bagibagi.
this NEG my work but person their work
This is not my work but the people's work.

Longacre (1985:232) defines contrast as "underlying but relations". However, English conjunctions do not have the same areas of meanings as the Tawala. Often there are situations where ma must be translated 'and' and the English 'but' corresponds to the Tawala adversative tamogi.

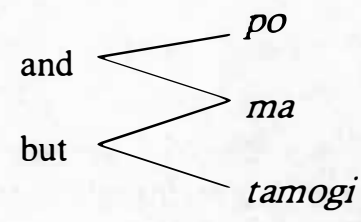


16(87) Hi-ma-mae ma ama-hi i-gota.

3PL-DUR-stay but father-3PL 3SG-arrive

They were staying then (= when) their father arrived.
16(88) O-na-ma-mae ma a-nae ita yam a-beiha.
2SG-POT-DUR-stay but 1SG-go ourINC food 1SG-seek
You stay and (= while) I will go to seek our food.

In $16(87)$ and $16(88)$ the initial clause is marked for durative aspect, which has the function of temporal overlap. Adverbial clauses are normally separated from the main clause by ma. Thus adverbial clauses are formally coordinated, though functionally subordinated.
16(89) I-tugu-tugala ma hi-woe.
3SG-DUR-sit and 3PL-paddle
While he was sitting they paddled.
16(90) To-buli-bulili $\underline{\text { ma }}$ tul'-iyai ae-na i-tona-ya.
IPL.EXC-DUR-run and friend-1PL.EXC leg-3SG 3SG-pierce-CPY
While we were running our friend's foot got pierced.

Peripheral phrases or words are also sometimes separated from the remainder of the clause by the contrastive conjunction. These are interpreted as non-verbal clauses (16(91)), except when they involve a subordinating postposition (16(92)-16(94)), in which case they are formally marked as both coordinated and dependent.

16(91) Geka ma polo a-matut'-e-ya.

this and pig 1SG-fear-TRV-3SG

It was here I was frightened by the pig.

16(92) Geka baha-na bi-nei ma lawa hi-kaoha.

this word-DEF BEN-3SG and person 3PL-happy.

Because of this word the people were happy.
16(93) Ma $i$ am uyahi-na ma tau a-wihinimaya.
but ourEXC meal 'at'-3SG and I 1SG-embarrass
But during our meal I felt embarrassed.

16(94) Yaka a koyama uyahi-n'-ei ma a luyagohana i-wime-ya.

so his lying 'at'-3SG-ABL and his life 3SG-take-3SG

So by his trickery he saved his life.

Comparison is often expressed by spelling out the contrasting features separated by the contrast conjunction.

$\begin{array}{lllll}\text { 16(95) Gahi-na } & \text { i-dao } & \underline{m a} & \text { gahi-u } & \text { i-kuku. } \\ \text { stature-3SG } & \text { 3SG-long } & \text { but } & \text { stature-1SG } & \text { 3SG-short } \\ \text { He is taller than I am. OR His height is more than mine. }\end{array}$

\subsubsection{ADVERSATIVE - tamogi}

The adversative conjunction tamogi 'but' indicates that the second clause is an exception or contrary to expectation and can be translated 'but on the other hand'. 
16(96) Tauna kiu natu-na tamogi lawa atapu-na i-luhogal'-e-ya. he bird child-3SG but person all-3SG 3SG-desire-TRV-3SG He was a bird's child but he loved all the people.
16(97) Ega u mone tamogi a-'m-am ma a-ma-mae. NEG my money but 1SG-DUR-eat and 1SG-DUR-stay I have no money but I am eating and living.

The adversative is often made stronger by combination with the contrastive conjunction ma.

16(98) Am kwasikwasi ega i-ta-kam ma tamogi e-tala-tala. yourSG machete NEG 3SG-IRR-sharp and but 3SG.PRES-DUR-cut Your machete is not sharp but it is cutting.

16(99) Tuwega ma tamogi apo geka hoti a-n'-omgiluma woloe. news and but FUT here only 1SG-POT-write finish There is (more) news but I will finish writing only here.

Use of ma tamogi often indicates the start of a new sentence.

\subsubsection{ALTERNATION - bo}

Although there are two conjunctions signalling alternation ( $b o$ and $o o$ ), only the former is used to conjoin clauses.

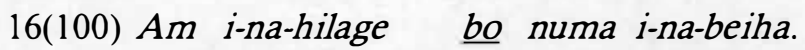

food 3SG-POT-finish or house 3SG-POT-seek.

He will hunger for food or seek housing.

16(101) Ta-apu-ya $\underline{\text { bo }}$ i-na-alahi.

1PL.INC-burn-3SG or 3SG-POT-burnTR

We burn it or it burns itself.

This construction is used with 'yes-no' questions; the second clause simply contains the non-verbal negative predication.

16(102) He-ne-nei imahi bo eega?

3PL.PRES-DUR-come properly or NEG(existential)

Are they coming properly or not?

\subsubsection{SUCCESSION - apom(a)}

The two forms of this conjunction also have a discernible meaning distinction.

\subsubsection{1 apoma ${ }^{4}$}

Succession involves actions performed in succession - "an underlying and then relation" (Longacre 1985:244). have meant 'then, next, later' which would account for the present-day usage of each of these items. 
16(103) Moina duma-na hi-bahe-bah'-e-ni apoma a-gale-ni. truth very-3SG 3PL-DUR-say-TRV-3SG then ISG-see-3SG In very truth they had spoken about it then I saw it.

16(104) U-na-nugotuhu tahae-ni apoma u-na-lumodale. 2SG-POT-think first-3SG then 2SG-POT-collect.timber Calculate it [the size] first and then cut [house] timbers.

\section{6(105) Hi-ul-ulona ma aipom apoma hi-'mam.} 3PL-DUR-cook and evening then 3PL-eat They cooked (it) and evening came then they ate (it).

To speak about doing something for the first time involves a non-verbal clause and apoma.

16(106) $U$ houga tahatahaya-na apoma plein a-gelu-ya.
my time first-3SG then plane ISG-embark-3SG
It was my first time to board a plane.

\subsubsection{2 apom}

Closely related to apoma is the morpheme apom 'then', which is used to express a looser relationship between the two clauses - the succession is less direct. The structure in $16(107)$ is parallel to that using the contrastive conjunction (16(93)). Typically, it appears at the commencement of a new sentence (16(108)), frequently with the contrastive conjunction (16(109)).

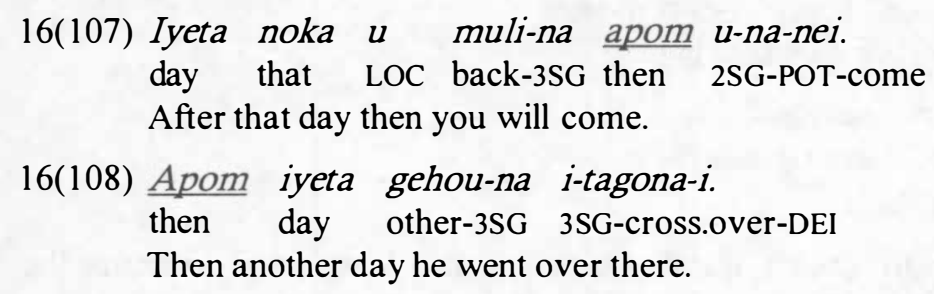

16(109) O-n'-omboina ma apom mitin gehou-na o-na-nei po... 2PL-POT-meet and then meeting other-3SG 2PL-POT-come and You meet and then come to another meeting and ...

\subsection{TEMPORAL RELATIONS}

Temporal relations are...important to natural languages...The distinguishing of temporal overlap from succession is a linguistic universal... Longacre (1976:113)

In Tawala temporal adverbial clause structure is sensitive to the semantic relationship between the action in the two predicates. Distinctions are coded by both the order of the clauses and the aspectual marking of the subordinate clause.

Spatio-temporal relations are distinguished according to the order of the clauses. A clause with an adverbial function (irrespective of whether it is subordinated or coordinated) has a different function depending on whether it precedes or follows the main clause. Those 
that precede the main clause are part of the spatio-temporal setting and those that follow the main clause are aspectual.

16(110) [Houga-na hi-lau-geleta] lawa luwaga hi-tuwaga-hi. time-DEF 3PL-DUR-arrive person two 3PL-find-3PL When they arrived they found two people.

16(111) Tauna i-to<o>togo [iyeta magou-na nimitutu]. she 3 SG- $<$ DUR $>$ sick day number-3SG five She was sick for five days.

16(112) A-me-mae [bolima magou-na 12 hi-kokoe] ma ... ISG-DUR-stay year number-3SG 12 3PL-finish and I stayed for 12 years and then ...

Longacre (1976:114-117) distinguishes four semantic varieties of temporal overlap, each of which is found in Tawala. Types are distinguished as to whether the activity in the adverbial and main clauses is continuous or punctiliar.

TABLE 2: VARIETIES OF TEMPORAL OVERLAP

\begin{tabular}{|c|c|}
\hline ADVERBIAL CLAUSE & MAIN CLAUSE \\
\hline continuous & continuous \\
\hline continuous & punctiliar \\
\hline punctiliar & continuous \\
\hline punctiliar & punctiliar \\
\hline
\end{tabular}

These four varieties are illustrated respectively in the four following examples. In Tawala continuous activity is marked by durative aspect; punctiliar activity is simple aspect and hence unmarked. Durative aspect is used in the subordinate clause when there is temporal overlap (16(113)-16(114)); simple aspect is used in the subordinate clause when there is temporal succession (16(115)-16(116)).

16(113) [Hauga-na ta-me-mae u Diwinar] ma a-i-nugonugotuhu... time-DEF 1PL.INC-DUR-stay LOC Diwinai and 1SG-DVP.DUR-think When we were staying at Diwinai I was thinking ...

16(114) [Iyeta gehou-na a-me-mae] ma i-nei u numa uyahi-na. day other-3SG 1SG-DUR-stay and 3SG-came LOC house 'at'-3SG While I was staying, he came to my house.

16(115) [Houga-naa-gae] Ukarumpa a-me-mae. time-DEF 1SG-go Ukarumpa 1SG-DUR-stay

When I went up I stayed at Ukarumpa

16(116) [Kabudala-na i-geleta hoi wam] naka amaka hi-gelu. sun-DEF 3SG-arrive LOC boat that already 3PL-embark When he arrived at the boat they had already embarked.

These relationships function irrespective of whether they are coordinated (16(113)16(114), 16(117)-16(118)) or juxtaposed (16(115)-16(116)). Contrast 16(117) with 16(116) and $16(118)$. 
16(117) [Houga-na wam hi-gale-ya] ma hi-kaoha labatana. time-DEF boat 3PL-see-3SG and 3PL-happy strongly

When they saw the boat they were exceedingly happy.

\section{6(118) [Hauga-na ta-me-mae] u Diwinai ma a-i-nugonugotuhu... time-DEF 1PL.INC-DUR-stay LOC Diwinai and ISG-DVP.DUR-think When we were staying at Diwinai I was thinking...}

The temporal interrogative used in the subordinate clause also indicates temporal overlap.

16(119) [Meyanai hi-gelu-ya] ega hi-ta-matouta.
when
3PL-embark-3SG NEG 3 PL-IRR-fear
Whenever they got on board it they were not afraid.

\subsection{BEYOND THE SENTENCE}

There has always been something dubious...about a research strategy which submits clause combinations to the most searching analysis when there is no pause or intonation break between them, and officially ignores virtually synonymous combinations which are separated by such a break. Unquestionably, the pause is a universal icon of disassociation...But the implicit claim that utterances separated by such a pause are mutually independent is an untenable one.

Haiman and Thompson (1988:ix)

I recognise that this grammar is only a partial description of Tawala grammar. In particular, such areas as cohesion (Ezard 1978b), prominence and reference have received only a passing mention, as has the whole realm of discourse pragmatics (not to mention the wider issues of pragmatics). I offer a quote from Givón (1984:10) which points in the direction that future studies of Tawala grammar need to take.

While the study of sentences in isolation is a necessary preliminary step in identifying the inventory of coding devices which make morpho-syntactic structure, the goal of the investigation is to elucidate how those devices are used in coding and communicating human knowledge. 


\section{DERIVATIONAL PROCESSES}

\subsection{DERIVATIONAL VERSUS INFLECTIONAL MORPHOLOGY}

The main motivation for separating the chapters on word derivation (17 and 18) and word classes ( 5 and 6 ) has been the advantage of a more simple presentation. The decision has not been without a certain cost, however. While there is a sharp distinction between derivational and inflectional morphology in Tawala, the two classes do overlap at a number of points (e.g. the morpheme wai- has both inflectional and derivational functions).

Some may well query the detailed treatment given to derivational processes within this grammar purporting to be a reference grammar. After all:

...classical transformational grammar shares the Bloomfieldian view that the lexicon is the
repository of idiosyncrasies and irregularities - as it were, the waste products of syntax and
phonology rather than material fit for investigation in its own right.

Harlow and Vincent (1988:5)

Increasingly, however, I have come to recognise the important role played by derivational processes in Tawala, some of which are crucial to an understanding of Tawala syntax.

Derivational morphology cannot be simply assigned to the lexicon, as there are certain generalisations that are lost in a mere listing of words. Numerous such features are noted later in the chapter, but at this point it should be noted that derivational, like inflectional, processes are all agglutinative in nature, ${ }^{1}$ involving "simple juxtaposition of formatives" (Anderson 1985:11) and hence usually have transparent meaning (to Tawala minds).

Table 1 summarises the differences between derivational and inflectional morphology for Tawala. While the persuasive power of individual distinguishing features varies tremendously, taken together they present powerful motivation for the derivationalinflectional distinction. Various levels of analysis are involved - phonological, morphological, syntactic, semantic and lexical. Some features are complementary, involving overlap with different levels of analysis. Some features are secondary, resulting from the model I have adopted; for example, the distinction between lexicon and grammar is theorydependent.

1 follow Anderson (1985:24) in his premise "that it is the individual word formation processes, not languages" that are described by the traditional typological types. 
TABLE 1: FEATURES DISTINGUISHING AFFIXES

\begin{tabular}{|c|c|c|}
\hline & DERIVATIONAL AFFIXES & INFLECTIONAL AFFIXES \\
\hline $\begin{array}{l}\mathrm{PHO} \\
\text { (a) } \\
\text { (b) }\end{array}$ & $\begin{array}{l}\text { NOLOGICAL } \\
\text { Often two syllable } \\
\text { Never single vowels }\end{array}$ & $\begin{array}{l}\text { Single syllable } \\
\text { Often single vowels }\end{array}$ \\
\hline $\begin{array}{l}\text { MOF } \\
\text { (c) } \\
\text { (d) }\end{array}$ & $\begin{array}{l}\text { PHOLOGICAL } \\
\text { Mostly prefixes } \\
\text { Involve core of words - operate on the } \\
\text { roots }\end{array}$ & $\begin{array}{l}\text { Prefixes and suffixes } \\
\text { Periphery of words - operate on } \\
\text { the stems }\end{array}$ \\
\hline $\begin{array}{l}\text { SYN } \\
\text { (e) } \\
\text { (f) } \\
\text { (g) }\end{array}$ & $\begin{array}{l}\text { Change subclass and valence of verbs } \\
\text { Operate within the word } \\
\text { Operate on restricted subclasses }\end{array}$ & $\begin{array}{l}\text { Do not change word classes } \\
\text { Index exterior items } \\
\text { Operate on all items }\end{array}$ \\
\hline $\begin{array}{l}\text { SEM } \\
\text { (h) } \\
\text { (i) }\end{array}$ & $\begin{array}{l}\text { Have multiple meanings } \\
\text { Change root meanings }\end{array}$ & $\begin{array}{l}\text { Have constant function } \\
\text { Do not change root meanings }\end{array}$ \\
\hline
\end{tabular}

\subsubsection{Phonological Features}

(a) Inflectional affixes are almost entirely single syllables. This is also true for strict derivational prefixes; most other types of derivation (e.g. the classificatory prefix underlined in 17(1)) involve two syllables.

17(1) I-na-pali-wele-u. 3SG-POT-CLP-give-1SG

She will inform me.

(b) A number of inflectional affixes employ a single vowel - all Tawala vowels are so employed. ${ }^{2}$ No derivational prefix involves a single vowel except the durative aspect form of wi- (causative prefix) which is $i$.

17(2) A-i-bagibag'-i.

1SG-DUR-work-3SG

I am using it.

\subsubsection{Morphological Features}

(c) With a single exception, derivational affixes are prefixes, whereas inflectional affixes include numerous clitics as well as prefixes.

(d) Derivational affixes operate within the core of the word, combining with the root to form a stem. Inflectional affixes combine with the stem (or root) to form words. Two levels below word level are distinguished (following Nida 1949, Matthews 1974 etc.). pronoun $u$ in $u$.rae 'my going' with the second person singular subject prefix $u$-( $u$-nae 'you went'). 
ROOT the part of the word carrying basic meaning.

STEM 1) compound stem - a root combined with a second root, e.g. hopu.mai 'come down', giu.dao 'scorpion' (lit. tail.long).

2) derived stem - a root combined with a derivational affix, e.g. Iu-mayau 'collect firewood' (lit. go-fire/firewood).

Stems often have a basic meaning difference from the root and must be listed separately in the lexicon, e.g. haba 'red pigment' >-lu-haba 'chew betelnut' (cause-red).

The following (verbs) show some typical combinations of roots with derivational prefixes (DVP) and inflectional affixes.

17(3) a. a-wi-nugo.kaoha-ya 1SG-DVP-heart.joy-3SG I make her happy
b. a-li-peu-ya ISG-DVP-fall-3SG I dropped it

a-hopu mai
ISG-go DEI
I came down

\subsubsection{Syntactic FEATURES}

(e) Derivational affixes often involve a change in word class. Adjectives are formed from verbs and nouns. Verbs can be formed from nouns (17(4a)) and also from some closed word classes $(17(4 b))$.
a. i-wi-bada
3SG-DVP-man

he became a man b. i-lu-tonug'-e-hi

3SG-DVP-three-TRV-3PL

he got (= speared) three

Verbs derived from other verbs usually involve a valence change (Chapter 18).
17(5) i-towolo $>$ hi-wi-towol'-i
3SG-stand 3PL-DVP-stand-3SG
it was standing theystood it up

On the other hand, inflectional affixes only change word class in a functional sense: verb stems can function as nouns taking the corresponding inflectional affixes or possessive pronoun.

\section{7(6) hi-bagibagi > hai bagibagi \\ 3PL-work their work \\ they work their working}

(f) The domain of the derivational affix is limited to the word, with a change in the fundamental meaning of the core itself, and often involving change in the valence of the core. Inflectional affixes normally have the clause as their domain: person/number 'agreement' with the dependent NPs; tense/aspect/mood related to the contextual situation etc. Pluralisation of nouns is an inherent relationship and hence overlaps with derivational processes. Interestingly, it has the same morphology (reduplication) as some derived forms.

(g) Derivational affixes operate on a limited number of verb subclasses. Subject prefixes operate on all verbs. Obviously the object suffixes operate only with transitive verbs and are therefore limited. However, this limitation is not nearly as specific and restrictive as 
the derivational prefixes, e.g. the $l i$ - causative prefix is never used with basic motion verbs.

\subsubsection{Semantic Features}

(h) Inflectional affixes have a constant meaning with all classes of stem, whereas derivational prefixes tend to have a variety of meanings dependent on the subclass of word involved. Thus the causative prefix $l u$ - used with cultural items means 'to collect the item' $(17(7 a))$. Used with body parts it means to hit the item $(17(7 b))$.
a. a-lu-mayau
1SG-DVP-firewood
b. a-lu-giu-ni
ISG-DVP-tail-3SG
I collected firewood
I hit its tail

(i) Derivational prefixes involve a basic change in the meaning of the core of the word: polo 'pig' can become wo-polo 'to steal (a) pig' or lu-polo 'to go pig-hunting'. Inflectional prefixes never function in this manner.

\subsubsection{LeXiCAL Features}

(j) The meaning of derived stems is often unpredictable or idiomatic. The semantics involves more than a simple combination of the parts and must be individually listed in the lexicon. On the other hand, inflected forms are quite predictable to the person who knows the component meanings of all the morphemes involved.

Anderson (1985:4) calls the lexicon "the repository of what is idiosyncratic and unpredictable about linguistic forms". Even though derivational prefixes show regularities within severely confined contexts, the fact that there are so many of these contexts requires each derived form to be placed in the lexicon. Failure to do so would result in too great a reliance on a highly distinguished grammar. At the same time the fact that regularities are observed within subclasses and across word classes needs to be recorded in the grammar itself. Thus derived forms are a grey area between the grammar and the lexicon and need to be included in both. Inflectional prefixes on the other hand are clearly part of the grammar and are included in the lexicon only to point the novice to the appropriate grammatical section.

\subsection{LEXICAL COMPOSITION}

Our focus is less on the arbitrariness of lexical information than on the possibility of finding some systematic internal structure to the list of forms...

Anderson (1985:4)

While it is recognised that the lexicon contains much that is idiosyncratic and unpredictable, the rnajority of lexical items "involve isolable parts combined in principled ways" (Anderson 1985:5). In Tawala, four morphological processes are involved in forming new words:

1) compounding - root plus root:

$\begin{array}{lll}\text { natu.oloto } & \text { son } & \text { (child.male) } \\ \text { niu.domo } & \text { nostril } & \text { (nose.hole) }\end{array}$


2) derivational prefix plus root:
lu-bogahu smoke cigarette (make-smoke)
wi-awali load someone up (cause-carry)

3) classificatory prefix plus root:

pali-hale permit ('proclaim'-throw)

4) reduplication:

hale-halewa pineapple (halewa pandanus palm)

The processes involved in the derivation of the three major word classes differ fundamentally from each other. Table 2 contrasts selected common elements involved in compounds (a-c), derived forms (d) and productive reduplication (e).

TABLE 2: CONTRASTING TYPES OF WORD COMPOSITION

\begin{tabular}{|l|l|c|c|c|}
\hline \multicolumn{2}{|c|}{ TYPE OF DERIVATION } & \multicolumn{3}{c|}{ RESULTANT WORD CLASSES } \\
\cline { 3 - 5 } \multicolumn{2}{|c|}{} & NOUNS & VERBS & ADJECTIVES \\
\hline (a) & noun + noun & + & - & - \\
\hline (b) & noun + verb & - & + & - \\
\hline (c) & verb + verb & - & + & - \\
\hline (d) & wi-/lu-/li- + root & - & + & - \\
\hline (e) & reduplication & - & - & + \\
\hline
\end{tabular}

NOTE: reference to nouns and verbs in the left column of the table is to roots only.

Anderson (1985:22) surveys "a variety of dimensions on which word formation processes can be classified". Some of those dimensions for Tawala, along with comments on where each process is described, are:

1) Formal nature of derivations - surveyed above in this section as well as under the respective word classes below.

2) Semantic nature of inputs and outputs - Ezard (1992) gives detailed treatment; a summary is given below in the respective sections.

3) Syntactic relations - verbalising processes are summarised in this chapter; valence changes are outlined in Chapter 18.

4) Degree of productivity - outlined in the remaining paragraphs of this section.

'Productivity' is used in three senses, and we look at each of these in turn. In the first place, productivity "refers to the absolute number of forms included in the scope of a word formation process" (Anderson 1985:16). In this grammar I largely restrict comment to those forms which are highly productive. An examination of the lexicon reveals items with compositional elements not discussed.

Secondly, productivity refers to "the extent to which a morphological process applies to the forms that constitute its input range" (Anderson 1985:16-17). Obviously, derivational processes differ a good deal in their productivity in this sense. Tawala derivational prefixes are more productive than classificatory prefixes; $w i$ is more productive than $l i$ - etc. Nevertheless, all the processes described in this chapter are highly productive, typically applying to dozens of items. 
Finally, productivity is used in the sense of "the extent to which a process is semantically "compositional" (Anderson 1985:22). The general tendency is for Tawala derivation to be semantically transparent. The least transparent items are those which employ derivational prefixes, but even these show a high degree of homogeneity when the subclass of the root is accounted for.

Tawala derivational processes are highly productive in every sense of the word, and an understanding of the processes involved is vital to an appreciation of the grammar. However, the subject is so vast that only a summary can be presented in a volume of restricted size attempting to handle the complete grammar.

\subsection{DERIVATION OF NOUNS}

A number of derivational processes are observed with nouns. They have a varying degree of productivity, ranging from fossilised items to fully productive derivation.

\subsubsection{INHERENT REDUPLICATION}

Many Tawala nouns have an inherently reduplicated form - in fact with many roots only the reduplicated form exists; if there is a non-reduplicated root its meaning is often unrelated and is listed as a separate lexical item. Even though the reduplicated forms are no longer productive they follow the same productive reduplication processes outlined in $\S 4.4$.

Ezard (1980:150-153) lists the semantic domains of nouns with inherently reduplicated form. The following is a summary of the data in that paper, presented in a revised format.

\subsubsection{CONDITION NOUNS}

A number of separate categories should be distinguished here.

(a) Problem conditions, e.g. badebade 'deaf-and-dumb person', dayadayabu 'poor person', apapula 'boil, abscess'.

(b) Multiple parts, e.g. apape- 'wing', nudanuda 'rubbish', tolotolo 'ribs'.

(c) Repetitive conditions, e.g. bolibolima 'south-east trade winds'; bagibagi 'work', guhuguhu 'earthquake', lepolepo 'wake of boat', gaogao 'week' (gao 'gap').

(d) Repetitive use, e.g. kewokewou 'outrigger canoe', kwasikwasi 'machete', nakanaka 'shelf', wekiwekilala 'sign (of ownership)', yabiyabi 'rudder'.

\subsubsection{NATURAL. KINDS}

Many natural species have names with reduplicated forms. This is by far the largest class of reduplicated nouns and it is possible to further subdivide them and give a tentative rationale for their form. It should be stressed that no productive processes are posited in the following data, even though related forms of an unreduplicated nature are included for comparison.

Again, a number of semantic classes are evident. 
(a) Diminution, ${ }^{3}$ e.g. halehalewa 'pineapple' (halewa 'pandanus'), kapekapeu '(small) moth' (kapeu 'butterfly, large moth'), motamota 'worm' (cf. mota 'snake').

(b) Onomatopoeia, e.g. mukumuku 'pigeon', kukou 'dog' (Kehelala dialect), kukuku 'pheasant coucal'.

(c) Continuous state, e.g. gumaguma 'hermit crab' (guma 'empty'), yuwayuwa 'poisonous cone shell' ( wiyuwa 'to pain'), buhubuhu 'borer beetle' (buhu 'to bore').

(d) Multiple parts, e.g. habohabo 'sea urchin' (many spikes), botoboto 'spotted cuscus' (many spots), goigoi 'mango' (much fruit).

(e) Multiple items, e.g. diwidiwi 'ants', yakoyako 'shells', gidagida 'kunai grass'.

\subsubsection{Semiproductive Reduplication}

Reduplication is employed to mark plural in some subclasses of noun, such as nouns of human reference, relationship terms, body parts. Even though the process involves inflectional morphology, productive reduplication of relationship terms and body parts belongs to the lexicon for a number of reasons. Firstly, reduplication does not apply to the whole subclass. Secondly, many of the reduplicated forms are irregular and must be listed separately. Thirdly, one often hears the plural form used for the singular (leduledu 'coconut cup', hiwahiwape 'widow' etc.). With this class it is the unreduplicated form that is marked for singular reference; the reduplicated form is unmarked and is either singular or plural. This process presumably accounts for the reduplicated form of many inherently reduplicated lexical items; they have simply lost the marked form.

As is true of a number of areas of Tawala grammar, pluralisation is sensitive to the animacy hierarchy, with human referent and relationship terms being pluralised. In addition, many body-part members can also be pluralised. Other nouns make no distinction for number, relying on number marking on possessives, pronouns and pronominal enclitics, adjectives, number phrases, postpositions and nominals, and person markers on verbs. Plural is also marked by reduplication in the following noun classes.

\subsubsection{HUMAN REFERENCE}

$\begin{array}{llll}\text { keduluma } & \text { woman } & \text { kedukeduluma } & \text { women } \\ \text { hewali } & \text { youth } & \text { hewahewali } & \text { youths } \\ \text { hiwape } & \text { widow } & \text { hiwahiwape } & \text { widow(s) } \\ \text { oloto } & \text { male } & \text { ololoto } & \text { males }\end{array}$

The following forms have irregular reduplication patterns, including partial reduplication, no reduplicated form and suppletion.

$\begin{array}{llll}\text { wawine } & \text { female } & \text { wiwine } & \text { females } \\ \text { bada } & \text { man } & \text { babada } & \text { men } \\ \text { guguhini } & \text { maiden } & \text { guguhini } & \text { maidens } \\ \text { tewela } & \text { child } & \text { logaloga } & \text { children }\end{array}$

This category is also found in Island Melanesia and elsewhere in Austronesian languages (Codrington 1885:147). 


\subsubsection{BODY PARTS}

Some animal and human body parts are reduplicated to mark plural. They occur with a pronominal enclitic marking the 'possessor' of the part in question. Not all body parts are pluralised, even when they occur in twos, hence mata-na means 'his eye' or 'his eyes' (possibly because, unlike limbs, they do not operate independently).

$\begin{array}{llll}\text { nima-na } & \text { his hand } & \text { nimanima-na } & \text { his hands } \\ \text { ae-na } & \text { its leg } & \text { aeae-na } & \text { its legs }\end{array}$

Some body parts have inherently reduplicated forms: ahahe-na 'his jaw'; ununu-na 'his head'; apape-na 'wing'; deledele-na 'his shin'; tolotolo-na 'his ribs/side', etc.

A wide range of the parts of living things can be marked for plural. With body parts of animals and humans the pronominal enclitic is bound, however with inanimate items it is optional; forms are presented here without 'possessive' marking. In each case the reduplicated form may be used for singular referents.

$\begin{array}{llll}\text { lugu } & \text { leaf } & \text { lugulugu } & \text { leaf/leaves } \\ \text { laga } & \text { branch } & \text { lagalaga } & \text { branch(es) } \\ \text { hilili } & \text { coral finger } & \text { hilihilili } & \text { coral finger(s) }\end{array}$

A small number of unconnected parts (not seen in relationship to a specific entity) are also pluralised. These cannot take the pronominal enclitic; that is, they cannot be inalienably possessed.

$\begin{array}{llll}\text { galu } & \text { new shoot } & \text { galugalu } & \text { new shoot(s) } \\ \text { heya } & \text { piece of coral } & \text { heyaheya } & \text { piece(s) of coral } \\ \text { ledu } & \text { coconut cup } & \text { leduledu } & \text { coconut cup(s) }\end{array}$

The word guta 'share, portion' is unique in that it belongs to both the above categories and operates with a reduplicated and non-reduplicated form in each, corresponding to alienably and inalienably possessed items. In both cases it is the plural which is the marked form.

$\begin{array}{llll}\text { guta } & \text { share of food } & \text { gutaguta } & \text { shares of food } \\ \text { guta-na } & \text { its (body) part } & \text { gutaguta-na } & \text { its parts }\end{array}$

\subsubsection{Fully Productive Reduplication}

With the noun subclass of relationship terms we have a fully productive inflectional process (reduplicated form marks plural); this is the 'kinship terms' subclass. Strictly, this belongs in Chapter 5 because it is an inflectional rather than a derivational process. It is included at this point to keep all nominal reduplication together.

As relationship terms are bound forms (with pronominal enclitics marking the person and number of the 'possessor'), the data are presented here in the inclusive form -ta, the most natural form for a group of people discussing kinship terms. As relationship terms mostly follow regular reduplication patterns, only a representative sampling is presented here. 


$\begin{array}{llll}\text { natu-ta } & \text { our child } & \text { natunatu-ta } & \text { our children } \\ \text { ama-ta } & \text { our father } & \text { amama-ta } & \text { our fathers } \\ \text { oi-ta } & \text { our cousin } & \text { oioi-ta } & \text { our cousins } \\ \text { nou-ta } & \text { our 'sister' } & \text { nounou-ta } & \text { our 'sisters' }\end{array}$

The following form is irregular.

goga-ta our ancestor googa-ta our ancestors

\subsubsection{COMPOIND NOINS}

Mithun (1984:848) notes: "Compounding is done for a reason. Some entity, quality or activity is recognized sufficiently often to be considered name-worthy in its own right...". In Tawala, compounding combines uninflected stems, thus naming items by identifying qualities they have in relationship to other more common items. They follow the normal typology of the language by placing the descriptive stem following the head - both verb modifiers and adjectives follow the head they 'modify'.

A small number of Tawala nouns (about $10 \%)^{5}$ are made up of noun+noun compounds. Some of these defy explanation. Even though meanings can often be assigned to the root nouns which form the compound, these are no longer productive because the resultant meanings are not compositional and many of the component root nouns are no longer used as nominal stems: guguwepo 'frigate bird' (gugu 'breast', (w)epo '?'), dedewaga 'box' (dede 'tell a story', ${ }^{*}$ waga 'boat ${ }^{6}$ ).

On the other hand, many compounds are productive in the sense that they are compositionally transparent and new items can presumably be readily constructed:

\begin{tabular}{|c|c|c|}
\hline NOUN & NOUN.NOUN & \\
\hline statue & tala.oloto & (blood/cut.male) \\
\hline son & natu.oloto & (child.male) \\
\hline twins & natu.lagalaga & (child.branches) \\
\hline snail & yako.nelunelu & (shell.mucous) \\
\hline brain & ununu.pou & (head.egg) \\
\hline eyebrow & mata.tutu & (eye.joint) \\
\hline eyelid & mata.keyaka & (eye.cup) \\
\hline eyelash & mata.ipi & (eye.lip) \\
\hline nostril & niu.domo & (nose.hole) \\
\hline
\end{tabular}

There are a few compound nouns in which the second root of the compound is verbal rather than nominal.

4 nou- is actually a sibling of the opposite sex.

This figure is based on a basic 1,300-word vocabulary, and is lower than a count based on the complete lexicon. For example most food varieties (yams, taro, bananas etc.) are compounds.

6 The POC *waga 'canoe' has the reflex wam 'boat (generic)' in Tawala. The root is also found in fossilised form in compounds such as the noun koko-waga 'grave' (testicle-boat). 


$\begin{array}{lll}\text { NOUN } & \text { NOUN.VERB } & \\ \text { scorpion } & \text { giu.dao } & \text { (tail.long) } \\ \text { headband } & \text { tepa.pani } & \text { (forehead.bind) } \\ \text { healthy } & \text { kamna.dewadewa } & \text { (disposition.good) }\end{array}$

\subsubsection{Productive Derivation of Nouns}

Four fully productive processes are involved in deriving nouns. The first two do not involve a change in class membership - nouns are derived from nouns; in the third and fourth types, nouns are derived from underlying verbs. In each case a pre-stem nominaliser is involved.

\subsubsection{NOUNS DERIVED FROM NOUNS}

(a) Inhabitants - mi-

The nominalising proclitic $\mathrm{mi}^{7}$ is used with the noun subclass of place names to refer to the inhabitants of the place named.

$\begin{array}{ll}\text { mi-Tubetube } & \text { people from Tubetube } \\ \text { mi-Papua } & \text { Papuans } \\ \text { mi-Diwinai } & \text { people from Divinai } \\ \text { mi-Tawala } & \text { Tawala-speaking people } \\ \text { mi-dimdim } & \text { Europeans }\end{array}$

A singular referent employs the ablative enclitic: dimdim-gei 'a European'.

(b) Region/Quadrant - tupo-

The noun tupo 'region' is related to the body-part noun tupo 'part-'. (It is also used in alienable possessive phrases, e.g. gavman a tupo 'governmental authority'). In its nominalising function it occurs as a proclitic without possessive marking.

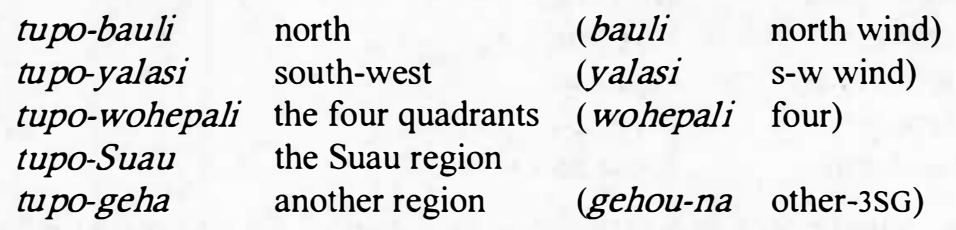

\subsubsection{NOUNS DERIVED FROM VERBS}

For a grammatical analysis of nominalisation see Chapter 14.

Dimdim is a word commonly used in Milne Bay languages. Originally it seems to have meant people from the ocean - cf. dumdum 'deep sea'. 
(a) Things and Places - ani-

The proclitic ani-is used with a verb stem to indicate the place at which an action takes place, or the thing which is used for the action. This combined meaning is often referred to by separate lexical items in English.

$\begin{array}{llll}\text { ani-ulona } & \text { kitchen } & \text { (ulona } & \text { cook) } \\ \text { ani-tugula } & \text { chair } & \text { (tugula } & \text { sit) } \\ \text { ani-goda } & \text { ladle } & \text { (goda } & \text { stir) } \\ \text { ani-gimala } & \text { shop } & \text { (gimala } & \text { exchange) }\end{array}$

Often the stem is a derived form itself.

$\begin{array}{llll}\text { ani-lu-wayawayau } & \text { fan } & \text { (wayau } & \text { cold) } \\ \text { ani-'m-giluma } & \text { pen/pencil } & \text { (om-giluma } & \text { DVP-carving) } \\ \text { ani-me-gowada } & \text { fortress } & \text { (me-gowada } & \text { stay-hide) } \\ \text { ani-uma-buuwa } & \text { beer } & \text { (uma-buuwa } & \text { drink-crazy) }\end{array}$

(b) Persons - tu-

The proclitic $t u-{ }^{9}$ is used with a verb to indicate the person who does the action indicated by the verb, or who is in the condition indicated by the verb.

$\begin{array}{llll}\text { tu-hilage } & \text { dead person } & \text { (hilage } & \text { die) } \\ \text { tu-meuputa } & \text { foreigner } & \text { (me-uputa } & \text { stay-outside) } \\ \text { tu-danene } & \text { thief } & (\text { danene } & \text { steal) } \\ \text { tu-wi-baabani } & \text { speaker } & (\text { baha } & \left.\text { word }^{10}\right)\end{array}$

Some nouns are derived from verbs that have been derived from nouns by the use of a derivational prefix.

$\begin{array}{llll}\text { tu-wi-tuwega } & \text { news spreader } & \text { (tuwega } & \text { news) } \\ \text { tu-wi-gawiya } & \text { soldier/enemy } & \text { (gawiya } & \text { fight) } \\ \text { tu-wi-pakulo } & \text { poet } & \text { (pakulo } & \text { riddle) } \\ t u-l u-m u l a m u l a & \text { doctor } & \text { (mulamula } & \text { medicine) }\end{array}$

Some nouns are derived from other nouns.

$\begin{array}{llll}\text { tu-balau } & \text { sorcerer } & \text { (balau } & \text { sorcery) } \\ \text { tu-wasawasa } & \text { rich person } & \text { (wasawasa } & \text { riches) } \\ \text { tu-panipani } & \text { prisoner } & \text { (panipani } & \text { bond) } \\ \text { tu-taniwagena } & \text { the ruler } & \text { (taniwaga } & \text { rule) }\end{array}$

\subsection{DERIVATION OF ADJECTIVES}

Almost all adjectives have a reduplicated form, most derived (synchronically or diachronically) from underlying verbs. The process is fully productive and at least one

\footnotetext{
$9 \quad$ A reflex of $\mathrm{POC}^{*}$ tau 'person'.

10 It is likely that wi-baabani is historically derived from baha, however there is no longer any active relationship.

11 The form taniwage-na includes the definite marker, which is not part of the derived stem.
} 
introduced word has been adjectivised, i.e. patipati- 'patched' (pati 'to apply putty'). Adjectives fall into a number of groups with respect to derivation.

\subsubsection{By REDUPLICATION OF VERB ROOT}

By far the most common form of derivation is where adjectives are derived by reduplication of a wide range of verb roots, of which the following list is representative.

\begin{tabular}{|c|c|c|c|}
\hline $\begin{array}{l}\text { gwae-gwae- } \\
\text { gobu-gobu- } \\
\text { wite-witei- } \\
\text { hopu-hopu- } \\
\text { ge-ge- } \\
\text { towo-towolo- } \\
\text { eno-eno- } \\
\text { pi-peu- } \\
\text { dala-dala- } \\
\text { baha-baha- } \\
\text { bowi-bowi- } \\
\text { hogo-hogo- } \\
\text { ti-teina- }\end{array}$ & $\begin{array}{l}\text { murky } \\
\text { dirty } \\
\text { heavy } \\
\text { humble } \\
\text { elated } \\
\text { standing } \\
\text { lying } \\
\text { fallen } \\
\text { crawling } \\
\text { spoken } \\
\text { denied } \\
\text { full } \\
\text { pulled }\end{array}$ & $\begin{array}{l}\text { (-gwae } \\
\text { (-gobu } \\
\text { (-witai } \\
\text { (-hopu } \\
\text { (-gae } \\
\text { (-towolo } \\
\text { (-eno } \\
\text {-peu } \\
\text { (-dala } \\
\text { (-baha } \\
\text { (-bowi } \\
\text { (-hogo-ya } \\
\text { (-tein'-i }\end{array}$ & $\begin{array}{l}\text { be made murky) } \\
\text { be dirty) } \\
\text { be heavy) } \\
\text { go down) } \\
\text { go up) } \\
\text { stand) } \\
\text { lie down) } \\
\text { fall) } \\
\text { crawl) } \\
\text { speak) } \\
\text { make a denial) } \\
\text { be full) } \\
\text { pull s.th.) }\end{array}$ \\
\hline
\end{tabular}

17(8) gulawa titeina-na twine pulled-3SG a tight rope

\subsubsection{By Reduplication of Noun Root}

Adjectives derived by reduplication of a noun root - a relatively rare occurrence.

$\begin{array}{llll}\text { palo-palouma- } & \text { witch-ish } & \text { (palouma } & \text { witch) } \\ \text { siga-siga- } & \text { final } & \text { (siga } & \text { end) } \\ \text { gi-geima- } & \text { stony } & \text { (gaima } & \text { stone) } \\ \text { guyo-guyou- } & \text { princely } & \text { (guyau } & \text { chief) } \\ \text { tani-taniwaga- } & \text { ruling } & \text { (taniwaga } & \text { rule) }\end{array}$

\subsubsection{BY USE OF wai-}

(a) Some adjectives are derived by the use of the proclitic wai- without any reduplication of the root. Various underlying roots are observed.

$\begin{array}{llll}\text { wai-muli- } & \text { last } & \text { (wi-muli- } & \text { be last) } \\ \text { wai-poya- } & \text { hot } & \text { (wipoya- } & \text { be hot) } \\ \text { wai-goila- } & \text { watery } & \text { (goila } & \text { water) } \\ \text { wai-hagu- } & \text { helpful } & \text { (hagu- } & \text { help s.o.) }\end{array}$

A subclass uses body parts to form adjectives describing classes of animal.

$\begin{array}{llll}\text { wai-hopu- } & \text { marsupial } & \text { (hopu- } & \text { pouch) } \\ \text { wai-pape- } & \text { winged } & \text { (pape- } & \text { wing) }\end{array}$


$\begin{array}{llll}\text { wai-apala- } & \text { hairy } & (\text { apala- } & \text { hair }) \\ \text { wai-ae- } & \text { legged } & (\text { ae- } & \text { leg })\end{array}$

(b) Some adjectives employ both reduplication and the proclitic wai-. These adjectives are derived from noun roots.

$\begin{array}{llll}\text { wai-wawi-wawine- } & \text { effeminate } & \text { (wawine } & \text { female) } \\ \text { wai-dona-dona- } & \text { horny } & \text { (dona- } & \text { tusk) } \\ \text { wai-dubu-dubu- } & \text { sandy } & \text { (dubudubu } & \text { dust) } \\ \text { wai-goi-goila- } & \text { watery } & \text { (goila } & \text { water) } \\ \text { wai-pelo-pelo- } & \text { decorated } & \text { (pelopelo } & \text { streamers) }\end{array}$

Most colour terms also employ the proclitic wai- along with reduplication of various roots.

$\begin{array}{llll}\text { wai-didibale- } & \text { black } & \text { (didibala } & \text { dark/night) } \\ \text { wai-ida-idaga- } & \text { green/blue } & \text { (idaga } & \text { raw/uncooked) } \\ \text { wai-gomi-gomida- } & \text { green } & \text { (gomida } & \text { unripe) } \\ \text { wai-kani-kaniyoga- } & \text { yellow } & \text { (kaniyoga } & \text { turmeric) } \\ \text { wai-kuli-kuli- } & \text { mottled } & \text { (kulikuli } & \text { mottle) }\end{array}$

\subsubsection{UNPRODUCTIVE DERIVATION}

Some adjectives no longer demonstrate a productive derivational process. These all have regular reduplicated forms except for the first item.

$\begin{array}{llll}\text { banei- } & \text { big } & \left({ }^{*} \text { bane }\right) & \\ \text { apapoe- } & \text { bad } & \left({ }^{*} \text { apoe }\right) & \\ \text { bigabiga- } & \text { muddy } & \left({ }^{*} \text { biga }\right) & \\ \text { gugou- } & \text { sweet } & \left({ }^{*} \text { gou- }\right. & \text { fruit }) \\ \text { dewadewa- } & \text { good } & (- \text { dewa-ya } & \text { do/make-it })^{13}\end{array}$

\subsubsection{STATIVE VERB RELATIONSHIP}

A few 'adjectives' do not have reduplicated forms though they are related to stative verbs.

$\begin{array}{llll}\begin{array}{l}\text { ADJECTIVE } \\ \text { odubo- }\end{array} & \text { VERB } & & \\ \text { old } & \text { (-odubo } & \text { be old) } \\ \text { wou- } & \text { new } & \text { (wou } & \text { renew) } \\ \text { habulu- } & \text { small } & \text { (-habulu } & \text { be small) }\end{array}$

\subsubsection{ORDINAL NUMERALS FROM CARDINAL NUMERALS}

Ordinal numerals are derived from the simple cardinal numerals:

12 Made from strips of pandanus.

13 The root dewa is also a noun 'custom'; the three word classes are possibly related: it is Tawala 'custom' (noun) 'to do/make' (verb) 'good' (adjective) things. 


$\begin{array}{llll}\text { wi-emosi-na- } & \text { first } & \text { (emosi } & \text { one) } \\ \text { wi-luwaga-na- } & \text { second } & \text { (luwaga } & \text { two) } \\ \text { wi-tonuga-na- } & \text { third } & \text { (tonuga } & \text { three) } \\ \text { wi-wohepali-na- } & \text { fourth } & \text { (wohepali } & \text { four) } \\ \text { wi-nim'itutu-na- } & \text { fifth } & \text { (nim'itutu } & \text { five) }\end{array}$

\subsection{DERIVATION OF VERBS}

As the head of the VP, a verb takes a person/number prefix, indexing clause subject, as well as a number of optional affixes.

The data base for this and the next chapter consists of a corpus of just over 250 underived verb roots. In this sample $52 \%$ are intransitive, $48 \%$ are transitive $(22 \%$ being variable-focus verbs). Verbs not involved in the actual statistics include 60 serial verbs and hundreds of derived verbs. Many intransitive and transitive stems change valence by the application of derivational affixes (Chapter 18).

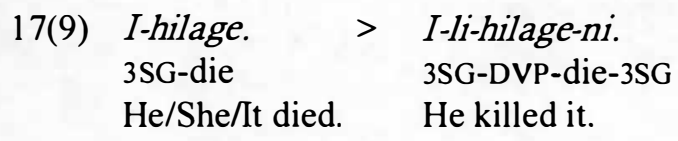

Within texts, at least $50 \%$ of Tawala verbs have derived stems. By far the most productive manner of forming new verb stems is with derivational prefixes. They are employed both in deriving verbs from other word classes and in the formation of verb stems from verb roots. Contrasting with derivational prefixes is a set of less productive classificatory prefixes.
17(10) I-hedal'-i. > I-tupa-hedal'-i.
3SG-break-3SG 3SG-CLP-break-3SG
He-broke-it. He broke it (by knocking it).

Since tupa- is no longer a free form, -tupa-hedali is not regarded as a serial verb. Serial verb constructions are not considered compounds but part of the verb phrase.
17(11) I-lupa hale-ya.
3SG-jump throw-3SG
She flew and escaped it (the island).

Compound verbs are a special class of human-propensity verbs, consisting of a body-part root plus a verb. These are so prolific, with grammar so distinctive, that they are a major subclass of verbs in their own right.

17(12) I-taniga-pota.

3SG-ear-block

He is disobedient.

\subsubsection{Classificatory PREFIXES}

Classificatory prefixes are distinguished from derivational prefixes in a number of ways (Ezard 1978a). Firstly, the derivational prefixes have one syllable and the classificatory prefixes have two. Secondly, the derivational prefixes are highly productive, functioning with a large number of subclasses, whereas the classificatory prefixes by comparison 
function within a limited framework, with just a few roots (some possibly en route to fossilisation). Thirdly, the derivational prefixes have a special form for durative aspect, whereas the classificatory prefixes follow normal reduplication patterns. Finally, the derivational prefixes often have a causative sense, whereas the classificatory prefixes simply indicate the manner in which the action is done (as first noted by Capell 1943:236253); a special effective marker is required for the construction to express causation.

The effective marker (EFF) is a morpheme used following classificatory and derivational prefixes (and the main verb in a serial verb constructions), indicating that the verb which follows the marker is the result of the classificatory prefix which precedes it.

$\begin{array}{ll}\text { 17(13) Hi-kawa-moina. } & \text { Hi-kawa-i-moin'-e-ya. } \\ \text { 3PL-CLP-true } & \text { 3PL-CLP-EFF-true-TRV-3SG } \\ \text { They declared (it) true. } & \text { They established it as true. }\end{array}$

None of the classificatory prefixes is an independent verb root; in this they differ from serial verb constructions. While it is plausible that classificatory prefixes may be the result of grammaticisation of serial verbs, I have found little evidence in support of this. The forms only occur as the prefixes outlined in this section. The equivalent free forms show no relationship to these prefixes. Thus tape- 'to do by hand' bears no resemblance to nima 'hand', and kawa- ${ }^{14}$ 'to proclaim' and pali- ${ }^{15}$ 'to speak' are not related to baha 'to speak'.

As the classificatory prefixes indicate the manner in which an action is done it is helpful to group the prefixes together according to functional types. (For a slightly different classification and also more detail see Ezard 1978a.)

\subsubsection{INSTRUMENTAL PREFIXES}

These involve doing an action by means of a body part or particular action.
hana-hedali
break s.th. with teeth
tape-hedali
break s.th. with hands
tupa-hedali
break s.th. by knocking

These classificatory prefixes frequently occur with the effective marker.

17(14) Hi-tape-i-lowo-ya.

3PL-CLP-EFF-run-3SG

They scared it off.

\subsubsection{DeClaration Prefixes}

The verbs of speaking are often causative, not just 'declaring something...' but 'making it...' Two prefixes are involved: kawa- 'to proclaim' and pali- 'to speak'.

$\begin{array}{llll}\text { kawa-moina } & \text { proclaim true } & \text { (moina } & \text { be true) } \\ \text { kawa-i-apapoe }^{16} & \text { proclaim bad } & \text { (apapoe } & \text { be bad) }\end{array}$

cf. POC * gama 'mouth, opening' (Ross pers. comm.); the Tawala reflex is gamo- 'mouth'.

15 The Tawala word pali 'sing, chant magic formula' is, synchronically, a different root from the classificatory prefix.

This form does not occur without the effective prefix. 


\begin{tabular}{|c|c|c|}
\hline $\begin{array}{l}\text { pali-wele } \\
\text { pali-lougo }\end{array}$ & $\begin{array}{l}\text { inform } \\
\text { heal by magic }\end{array}$ & $\begin{array}{l}\text { (wele- } \\
\text { (lougo }\end{array}$ \\
\hline $\begin{array}{l}\text { Amaka } \\
\text { already }\end{array}$ & $\begin{array}{l}\text { ale-ya. } \\
\text {-throw-ya }\end{array}$ & \\
\hline
\end{tabular}

\subsubsection{Modal. Classificatory Prefixes}

These verbs stress various modes of action - change in state by the sudden appearance or disappearance of an item, multiple or ordered action. Three prefixes are involved: welu'(dis)appear', hulu- 'to happen together' and yei- 'do first'.

$\begin{array}{llll}\text { welu-lui } & \text { disappear inside } & \text { (lui } & \text { enter) } \\ \text { welu-waya } & \text { bring forth } & \text { (waya } & \text { take it) } \\ \text { hulu-geleta } & \text { spill over, flood canoe } & \text { (geleta } & \text { arrive) } \\ \text { hulu-niyeya } & \text { cast lots } & \text { (niyeya } & \text { take it) } \\ \text { yei-lupa } & \text { jump ahead } & \text { (lupa } & \text { jump) } \\ \text { yei-togo } & \text { washed earlier } & \text { (togo } & \text { wash) }\end{array}$

17(16) Hi-ne-nei $u$ tahaya hi-welu-powa.

3PL-DUR-come LOC path 3PL-CLP-mistake

While coming along the path they disappeared (got lost).

17(17) Ma houga gehou-na naka o-na-yei-lubayada.

but time other-3SG that 2PL-POT-CLP-ask

Next time ask first.

\subsubsection{Derivational Prefixes}

Derivational prefixes ( $w i-, l u-, l i$ - and $w a$ ) attach to roots to form a wide range of verbs. Words of almost any class can fill the root slot, and an elaborate system of word subclasses is required to account for the intricacies of grammar and the nuances of meaning involved. Without doubt this is the most difficult and highly productive area of Tawala grammar.

Each of the Tawala derivational prefixes has more than one form. Durative aspect is marked by change of form rather than reduplication as found elsewhere in the language.

TABLE 3: DURATIVE FORMS OF DERIVATIONAL PREFIXES

\begin{tabular}{|l|c|c|}
\hline & SIMPLE FORM & DURATIVE FORM \\
\hline Valence-increasing & $w i-$ & $i-$ \\
& $1 u-$ & lau- \\
& $w O-$ & wOo- \\
& $1 i-$ & lai- \\
\hline Valence-decreasing & $o m-$ & yam- \\
\hline
\end{tabular}


The prefixes $w i$ - and $l i$ - are primarily valence-increasing derivational prefixes and wo and $l u$ - are primarily employed in the derivation of new lexical items, though there is considerable overlap between the two functions.

\subsubsection{Semantic Classes and Verbal Derivation}

Although Tawala derivational prefixes are exceedingly complicated, a large degree of order was discovered when the usages of the prefixes were examined from the semantic perspective of word classes and subclasses. In this I followed the approach advocated by Dixon (1982:8):

We work from the assumption that the syntactic properties of a lexical item can largely be predicted from its semantic description. Semantics is thus held to be prior to syntax.

An extensive study of several hundred verbs revealed a general principle: Insofar as two words share significant semantic components so their syntax overlaps.

The data presented in the remaining part of this chapter, and in the next, are sensitive to the semantics of the root. Accordingly the word class of the root from which the form is derived is mentioned in each case. The semantic aspects of these prefixes are treated extensively in Ezard (1992).

\subsubsection{Verbs DeRIVED FROM NOUNS}

Five noun subclasses are a fruitful source of verbs when combined with the derivational prefixes $w i-, l u-, l i$ - and $w O$. Each subclass is unique both in semantics and grammatical relations. The semantics involved are summarised in Table 4 and the grammatical relations are set out in the discussion following the table.

TABLE 4: DERIVATIONAL PREFIXES WITH NOUNS

\begin{tabular}{|c|c|c|c|c|}
\hline & $w i-$ & lu- & li- & $W O-$ \\
\hline $\begin{array}{l}\text { MEANINGS } \\
\text { ROOTS }\end{array}$ & become like... & 'go' and do... & become new... & hold... \\
\hline $\begin{array}{l}\text { Body part } \\
\text { hand, head }\end{array}$ & $\begin{array}{l}\text { cover, protect or aid } \\
\text { noun }\end{array}$ & hit noun & - & hold noun \\
\hline $\begin{array}{l}\text { Kinship } \\
\text { child, father }\end{array}$ & $\begin{array}{l}\text { enter or adopt new } \\
\text { relationship }\end{array}$ & - & (multiply well) & - \\
\hline $\begin{array}{l}\text { Human reference } \\
\text { youth, man }\end{array}$ & $\begin{array}{l}\text { become/behave like } \\
\text { noun-socially }\end{array}$ & $\begin{array}{l}\text { act like noun } \\
\text { - physically }\end{array}$ & $\begin{array}{l}\text { change s.o. into } \\
\text { noun }\end{array}$ & - \\
\hline $\begin{array}{l}\text { Cultural item } \\
\text { stone, wood, pig }\end{array}$ & $\begin{array}{l}\text { a. area covered by n. } \\
\text { b. spread area with } \\
\text { noun }\end{array}$ & collect/catch noun & $\begin{array}{l}\text { be transformed } \\
\text { into noun }\end{array}$ & $\begin{array}{l}\text { a. hold } \mathrm{n} \text {. } \\
\text { b. steal } \mathrm{n} \text {. } \\
\text { c. carry } \mathrm{n} \text {. }\end{array}$ \\
\hline $\begin{array}{l}\text { Relationship } \\
\text { in, after }\end{array}$ & relative motion & pile in location & - & $\begin{array}{c}\text { put hand in } \\
\text { location }\end{array}$ \\
\hline
\end{tabular}

Where a derived verb form has not been encountered this is marked with a dash (-).

Item in brackets is not productive with all roots. 
Derived verb stems are formed by prefixing one of the derivational prefixes to a noun subclass. The following data present examples of each of the derived forms. An indication of the grammatical class of the derived verb is to be found in the code(s) following the root:

$\mathrm{O} \quad-\quad$ object enclitic - transitive verb

CPY - object enclitic - condition verb

TRV $\quad-$ transitiviser $^{18}$

\subsubsection{BODY PARTS}

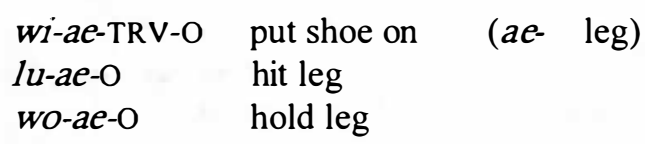

17(18) Am kwasikwasi-gei u-na-lu-giu-ni. yourSG machete-ABL 2SG-POT-DVP-tail-3SG Hit its tail with your machete.

\subsubsection{KINSHIP TERMS}

wi-natu-na ${ }^{19}$ have/adopt a child (natu- child) li-natu-TRV-O have many children

17(19) Ega nou-we, ma a-wi-nou-na. NEG sister-1SG but ISG-DVP-sister-3SG

She is not my sister, but I adopted her as a sister.

\subsubsection{Human REFERENCE}

wi-bada $\quad$ become a man
$\begin{aligned} & \text { lu-ba-bada act like men } \\ & \text { li-bada-CPY turn into a man }\end{aligned}$
Bada e-lau-hewa-hewali.
man 3SG.PRES-DVP-PL-youth
The man is acting like a teenager.

17.5.4.4 CULTURAL ITEMs ${ }^{20}$

$\begin{array}{llll}\text { wi-gai-gaima } & \text { be stony } & \text { (gaima } & \text { stone) } \\ \text { lu-gaima } & \text { collect stones } & & \\ \text { li-gaima-CPY } & \text { turn into stone } & & \\ \text { wo-gaima } & \text { hold stone to throw } & & \end{array}$

\footnotetext{
18 The main function of the suffix $-g e$ is transitiviser, which normally involves valence increase 18.4.1).

19 The plural form is wi-natu-natu-na 'adopt children'.

20 Stones are a cultural item because they form the artificial ground cover around villages. Villages are often associated with a particular stone.
} 
wo-mayau steal firewood (mayau tree/wood)

wo-polo-CPY be loaded with pork (polo pig)

17(21) Ta-nae ta-lu-mayau.

1PL.INC-go 1PL.INC-DVP-tree

Let's go and collect firewood.

\subsubsection{RELATIONSHIP TERMS}

wi-muli- follows.th. (muli- behind)

lu-hine- pile s.th. inside (hine- inside)

wo-hine put hand inside

17(22) Yaniyani hi-lu-tepan'-e-ya.

staples 3PL-DVP-top-TRV-3SG

They piled food up on top.

\subsubsection{Verbs DeRIVED FROM Closed WORD Classes}

\subsubsection{NUMERALS}

Although the processes involved in deriving verbs from numerals are strictly derivational, they are fully productive. This demonstrates the fact that grammar operates on a semantic basis - if the semantics are constant then the grammatical operations will be identical. The problem lies in the fact that two roots are seldom identical in meaning; however, with numerals semantics are identical apart from the number specified. The following processes involving the derivational prefixes are productive for the cardinal numbers.

$\begin{array}{llll}\text { wi-emot'-TRV-O } & \text { unite s.th. } & \text { (emota } & \text { one) } \\ \text { lu-emot'-na } & \text { grow in bunch } & & \\ \text { wo-emot'-TRV-O } & \text { gather together } & & \\ \text { lu-luwag'TRV-O } & \text { spear two } & \text { (luwaga } & \text { two) } \\ \text { lu-tonug'-TRV-O } & \text { spear three } & & \\ \text { lu-wohepali-TRV-O } & \text { spear four } & & \end{array}$

17(23) Iyana i-lu-tonug'-e-hi.

fish 3SG-DVP-three-TRV-3PL

He speared three fish (with one throw).

Numerous other productive derivational morphemes operate with the cardinal numbers and with the adverb gogona 'together': om- 'number caught on hook'; ona- 'number caught in net'; hage- 'number going alone'; tu- 'step on a number'; ne-RED- 'number going along together'.
hi-'m-tonuga
three were caught together on a hook
hi-ona-tonuga three were caught together in a net
hi-hage-tonuga three went alone
hi-ne-tonu-tonuga
three were going together

In addition, numerals are productive with some classificatory prefixes: tape- 'break(number)' (see Ezard 1992 for further details). 


\subsubsection{RESPONSES}

The response $e e$ 'yes' is verbalised with the derivational prefix lu-: lu-ee-na(-TRV-O) 'to make an affirmation (affirm s.th.)'. The negative response eega 'no' is never verbalised (that is handled by the verb bowi(-TRV-O) 'to make a denial, deny s.th.').

\subsubsection{ADVERBS}

Two adverbs combine with derivational prefixes to give a number of verb stems: imahi 'properly' > wo-imahi(-TRV-O) 'look after (s.th.)'; and yagiyagina 'quickly' > wiyagiyagina-TRV-O 'bring s.th. quickly', lu-yagiyagina 'act quickly'; wo-yagiyagina-TRV-O 'carry s.th. quickly'.

\subsubsection{COLOUR TERMS}

Colour terms are involved in two types of verbal derivation: 1) stative verbs derived with wi- plus a colour term, e.g. wi-idaidaga 'be green' (from idaga 'raw'); and 2) the concept of wearing uniform colours, e.g. lu-wakewakeke 'be dressed in white' (from wakewakeke 'white'). In addition there are a number of idiomatic uses, e.g. lu-idaidage-o 'make s.th. green' and wo-kayakaya 'hold fire-brand' (kayakaya- 'red').

17(24) Tu-wipanipani hi-lu-kayakaya.

PER-bound 3PL-DVP-red

Prisoners are dressed in red.

\subsubsection{VERBS DERIVED FROM VERBS}

Verbs derived from other verbs fall into two classes: those that involve a valence change and those that do not. Only the latter are presented in this section; those involving valence change are presented in Chapter 18.

\subsubsection{INTENSIFIED ACTION}

Verb roots with the derivational prefix $l u$ - are lexicalised forms resulting from the lexicalisation of serial motion verbs. ${ }^{21}$ The meaning 'to go (along)...' captures the meaning in many if not most of the derived forms. I set out the following lists on the basis of the semantic classes of the roots, as in each case this gives insight into the resultant meaning.

(a) Intransitive Forms

1) Motion verbs form an important subclass of this derivational process. The meaning of the derived form is unpredictable and often context-specific, however it again usually involves a permanent condition.

21 Nowhere is the original meaning of the POC * rao ' $g o$ ' serial-verb constructions retained more clearly than in the use of $l u$ - to derive the intensified forms listed in this section. 


$\begin{array}{llll}\text { lu-dala } & \text { creep forward } & \text { (dala } & \text { crawl) } \\ \text { lu-hala } & \text { scratch (of chicken) } & \text { (hala } & \text { dance/skip) } \\ \text { lu-tutu } & \text { be promiscuous } & \text { (tutu } & \text { pound/hit) }\end{array}$

Motion verbs are used with the derivational prefix $l u$ - in the context of shooting, often to indicate the direction in which the shot went wrong.

$\begin{array}{llll}\text { lu-nae } & \text { shoot } & \text { (nae } & \text { go) } \\ \text { lu-gae } & \text { shoot high } & \text { (gae } & \text { go up) } \\ \text { lu-hopu } & \text { shoot low } & \text { (hopu } & \text { go down) }\end{array}$

There are some related metaphorical uses with the root gae, where two separate derived forms are based on different aspects of the verb: simple and durative.

$\begin{array}{llll}\text { lu-gae } & \text { be ambitious } & \text { (gae } & \text { go up) } \\ \text { lu-gegae } & \text { be proud } & \text { (gegae } & \text { be going up) }\end{array}$

2) Several verbs of speaking are also derived.

$\begin{array}{llll}\text { lu-baha } & \text { boast } & \text { (baha } & \text { talk) } \\ \text { lu-lupali } & \text { beg } & \text { (lupali } & \text { ask, request) } \\ \text { lu-hiyawa } & \text { wail/recount }{ }^{22} & \text { (hiyawa } & \text { count/read) }\end{array}$

3) Verbs of posture are also intensified using this construction, though the original meaning of ' $\mathrm{go}$ ' is lost.

$\begin{array}{llll}\text { lu-towolo } & \text { stand poised with spear } & \text { (towolo } & \text { stand) } \\ \text { lu-tugula } & \text { sit fishing } & \text { (tugula } & \text { sit) } \\ \text { lu-eno } & \text { rest head on hand } & \text { (eno } & \text { lie down) }\end{array}$

4) The derivational prefix $l u$ - intensifies some further intransitive verbs, indicating a permanent or long-lasting condition. Note that the first word in the following list relies on a different meaning for eno from that of the previous list.

$\begin{array}{llll}\text { lu-eno } & \text { be lazy } & \text { (eno be sleeping) } \\ \text { lu-hilage } & \text { be exhausted } & \text { (hilage be finished) } \\ \text { lu-gobu } & \text { be unkempt } & \text { (gobu be dirty) } \\ \text { lu-gudu } & \text { be blocked } & \text { (gudu be shut) }\end{array}$

5) An intensified form of human-propensity verbs is derived by the use of the prefix $l u$ together with a reduplicated verb root, except where it is already reduplicated.
lu-upudoodola
be intractable
lu-nugodewadewa
be kind
lu-nugohegoya
be peace-loving ${ }^{23}$
(upudodola
be idle)
(nugodewadewa be untroubled)
(nugohegoya be placid)

b) Transitive Forms

The derivational prefix $l u$ - intensifies object focus verbs, usually indicating an irreversible action. These verbs are all transitive.

23 To be lunugohegoya is to be incapable of retaliation - a highly admired quality in one's friends. 


$\begin{array}{llll}\text { lu-momohi } & \text { bind s.th. tight } & \text { (momohi } & \text { pull s.th. tight) } \\ \text { lu-popoya } & \text { join s.th. } & \text { (popoya } & \text { knot s.th.) } \\ \text { lu-lawi } & \text { snap s.th. off } & \text { (lawi } & \text { hit/jerk s.th.) } \\ \text { lu-gomuya } & \text { snap s.th. off } & \text { (gomuya } & \text { snap s.th. shut) } \\ \text { lu-guduya } & \text { block s.th. } & \text { (guduya } & \text { shut s.th.) }\end{array}$

17(25) Bada a polo i-lu-momohi.

man his pig 3SG-DVP-bindTR

The man secured his pig.

\subsubsection{REPEATED ACTION}

Tawala uses the prefix wo-to derive words which are distinguished from the underived root by a meaning of repeated action. Again it is useful to distinguish the semantic and grammatical classes of the root.

(a) Intransitive Verbs

1) With consumption and motion verbs, the prefix wo- indicates that the action is carried out in stages. With verbs of motion, the implication is that the activity is done by hand. Two additional prefixes function with these roots: $t u$ - 'persistent action done by foot' and $h u$ - 'persistent forceful action'.

$\begin{array}{llll}\text { wo-am } & \text { 'nibble' food } & (\text { am } & \text { eat }) \\ \text { wo-uma } & \text { 'sip' drink } & (\text { uma } & \text { drink }) \\ \text { wo-eno } & \text { sleep in catnaps } & (\text { eno } & \text { sleep }) \\ \text { wo-nae } & \text { move a little } & \text { (nae } & \text { go }) \\ \text { wo-hopu } & \text { move down a little } & \text { (hopu } & \text { go down) }\end{array}$

17(26) Hi-wo-uma po hi-buuwa. 3PL-DVP-drink and 3PL-crazy

They kept drinking and they are drunk.

17(27) Hanali uyahi-na yaniyani u-n'-upum'-i ma u-na-wo-am. foodhouse 'at'-3SG staples 2SG-POT-pile-3SG and 2SG-POT-DVP-eat Pile food in your foodhouse and steadily eat (it over the following months).

2) The wo- prefix with stative verbs indicates a permanent result of an action.

$\begin{array}{llll}\text { wo-dewadewa } & \text { be fixed } & \text { (dewadewa } & \text { be good) } \\ \text { wo-apapoe } & \text { be worn out } & \text { (apapoe } & \text { be bad) }\end{array}$

3) Verbs of speaking involve not only the prefix wo but also a reduplication of the stem. Intense action is involved here.
wo-otuotu
have an outcry
(otu
call out)
wo-bahabaha
continually complain (baha
speak)

4) Verbs of posture indicate the taking of a position.
wo-tugula
assume sitting position
(tugula
sit)
wo-towolo
assume standing position
(towolo stand) 
5) With a number of intransitive verbs the prefix wo- is used to indicate persistent action. These appear to be isolated examples.

$\begin{array}{llll}\text { wo-lupa } & \text { keep going up } & \text { (lupa } & \text { jump/fly) } \\ \text { wo-bagibagi } & \text { keep working } & \text { (bagibagi } & \text { work) } \\ \text { wo-houna } & \text { keep blowing (of wind) } & \text { (houna } & \text { put) } \\ \text { wo-gawiya } & \text { keep fighting } & \text { (gawiya } & \text { fight) } \\ \text { wo-maamae } & \text { stay longer } & \text { (mamae } & \text { stay) }\end{array}$

(b) Transitive Verbs

1) With object-focus verbs the prefix wo is used in its basic meaning of repeated action. The subclasses included in my data are verbs of carrying, cutting, breaking and manipulating; one example of each is given.

$\begin{array}{llll}\text { wo-awali } & \text { keep carrying things } & \text { (awali } & \text { carry s.th.) } \\ \text { wo-hapi } & \text { keep chopping s.th. } & \text { (hapi } & \text { chop s.th.) } \\ \text { wo-gomuya } & \text { keep breaking things } & \text { (gomuya } & \text { snap s.th.) } \\ \text { wo-kahaya } & \text { keep dividing things } & \text { (kahaya } & \text { divide s.th.) }\end{array}$

2) With the following roots the meaning is a permanent result of an action.

$\begin{array}{llll}\text { wo-buiya } & \text { change s.th. } & \text { (buiya } & \text { turn s.th. over) } \\ \text { wo-haleya } & \text { let s.th. go } & \text { (haleya } & \text { throw s.th.) }\end{array}$

\subsubsection{HAND AND FOOT ACTION}

The prefixes wo- 'by hand', tu- 'by foot' and $h u$ - 'by force' operate with verbs of transfer to indicate action done by the appropriate means. I illustrate their range of meaning with examples of the first prefix only.

$\begin{array}{llll}\text { wo-niyen'i } & \text { push s.th. by hand } & \text { (niyena } & \text { take s.th.) } \\ \text { wo-neiyai } & \text { pull s.th. by hand } & \text { (neiyai } & \text { bring s.th.) } \\ \text { wo-daman'i } & \text { hand s.th. over } & \text { (daman'i } & \text { cross bay/river) } \\ \text { wo-tagon'i } & \text { follow s.o. } & \text { (tagon'i } & \text { cross mountain) }\end{array}$

The prefix wo- derives verbs which indicate feeling the unseen with the hands.

$\begin{array}{llll}\text { wo-dalanae } & \text { grope forward } & \text { (dala.nae } & \text { crawl.go) } \\ \text { wo-beiha } & \text { search in the dark } & \text { (beiha } & \text { search) } \\ \text { wo-dadan'i } & \text { try by feeling } & \text { (ludadan'i } & \text { try s.th.) }\end{array}$

\subsubsection{ITERATIVE ACTION}

The distinctive feature of this derivational type is the use of the prefix wi- along with a reduplicated verb stem (durative aspect). (The last member of the following list may not 
belong here as the verb stem is intrinsically reduplicated, however the semantic relations are suggestive. $)^{24}$

$\begin{array}{llll}\text { wi-ne-nae } & \text { try to go } & \text { (nae } & \text { go) } \\ \text { wi-ge-gae } & \text { argue (try to go up) } & \text { (gae } & \text { go up) } \\ \text { wi-hola-hola } & \text { sexual intercourse } & \text { (hol'i } & \text { pull s.th. in) } \\ \text { wi-kaha-kaha } & \text { fight/be separated } & \text { (kaha } & \text { divide) } \\ \text { wi-tala-tala } & \text { cut grass } & \text { (tala } & \text { cut) } \\ \text { wi-bagibagi } & \text { use a tool } & \text { (bagibagi } & \text { work) }\end{array}$

17(28) Kasi-gei i-wi-talatala.

knife-ABL 3SG-DVP-cut

He was cutting (the grass) with a grass-knife.

\subsubsection{HUMAN-PROPENSITY VERBS}

A highly productive area of Tawala lexical items involves the use of human-propensity verbs. Emotions, attitudes and psychological states can hardly be talked about without the use of these verbs. They match closely the 'human propensity' adjectival class of Dixon (1982:19), but in Tawala they are clearly verbal, with a distinctive syntax of their own note the two grammatical forms in 17(29) and 17(30).

Human-propensity verb stems consist of two roots: a body-part and a verb root. Whereas serial verbs have verbal roots as both elements in the compound (verb+verb), human propensity compounds have a noun as the initial item of the compound (noun+verb). These nouns are a restricted list, of body parts: nugo 'heart/mind', mata- 'eye', taniga- 'ear' and hini- 'skin' etc. The second element of the compound is normally a stative verb root, e.g. -apapoe 'to be bad', -kadidili 'to be hard', -maga 'to be many' -dumoli 'to be calm'. But it can be an active verb, e.g. -guluwi 'to bury s.th.'. Some compounds are fossilised with no meaning able to be supplied for the second element, e.g. nugo.neina 'to be ignorant', nugo.tuhu 'to think'.

$\begin{array}{lll}\text { mata.maga } & \text { be promiscuous } & \text { (eyes.many) } \\ \text { nugo.gohola } & \text { be surprised } & \text { (heart.jump) } \\ \text { upu.dodola } & \text { be lazy } & \text { (back.unbending) } \\ \text { gamo.bagibagi } & \text { be talkative } & \text { (mouth.work) } \\ \text { kamna.apapoe } & \text { be poorly } & \text { (disposition.bad) } \\ \text { taniga.pupu } & \text { be disobedient } & \text { (ear.block) }\end{array}$

17(29) nugo-na i-gohola > i-nugo.gohola heart-3SG 3SG-jump 3SG-heart.jump his heart jumped he was surprised

17(30) nugonugo-na i-apapoe > i-nugo.apapoe heart-3SG 3SG-bad 3SG-heart.bad he was angry [-control] he was angry

24 A possible member of this class is gawiya 'fight', wi-gawiya 'be fighting, be at war'. I have omitted this example from the list as the derived verb lacks reduplication. 
Semantically, the class as a whole probably represents a metaphorical extension of physical condition clauses, some of which still bear an active derivational relationship.

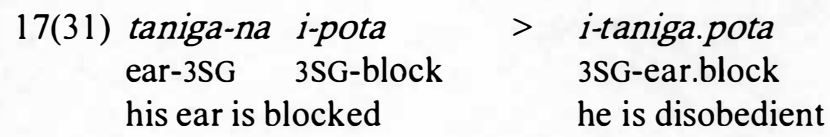

Of course once the semantic domain of human-propensity compound verbs became a viable category in languages of the area, the way was open for the creative use of new metaphors which have no resemblance to physical conditions. While typical examples are given within this section, exhaustive listing is restricted to the lexicon because of the idiomatic nature of the compounds, e.g. nugo.kadidili 'to be resolute' (heart.hard); hini.maya 'to be ashamed' (skin.feeling); mata.maga 'to be promiscuous' (eye.many).

Idiomatic compounds combine with derivational prefixes to give a range of causative meanings.

TABLE 5: DERIVATIONAL PREFIXES WITH HUMAN PROPENSITY STEMS

\begin{tabular}{|l|l|c|c|}
\hline \multicolumn{1}{|c|}{ wi- } & \multicolumn{1}{c|}{$l u-$} & \multicolumn{1}{c|}{$l i-$} & WO- \\
\hline $\begin{array}{l}\text { demonstrate state } \\
\text {-by words }\end{array}$ & $\begin{array}{l}\text { cause state } \\
\text {-physically }\end{array}$ & $\begin{array}{c}\text { 1) cause state } \\
\text {-empathy } \\
\text { 2) (idiomatic) }\end{array}$ & $\begin{array}{c}\text { persistently demon- } \\
\text { strate state }\end{array}$ \\
\hline
\end{tabular}

An example of each of these is given in the following list.

$\begin{array}{lll}\text { wi-nugo.dubu } & \text { speak of sorrow } & \text { (mind.dust) } \\ \text { lu-nugo.tootogo } & \text { show mercy } & \text { (mind.sick) } \\ \text { li-nugo.guluwa-O } & \text { cause to forget, be forgotten } & \text { (mind.bury) } \\ \text { li-nugo.emota-O } & \text { unite } & \text { (mind.one) } \\ \text { wo-nugo.dubu } & \text { keep mouming } & \text { (mind.dust) }\end{array}$




\section{VERBAL VALENCE}

\subsection{GRAMMATICAL RELATIONS AND VALENCE CHANGE}

...there are in most languages, and probably in all, grammatically productive mechanisms for decreasing or augmenting what might be referred to as the intrinsic valency of a verb.

Lyons (1977:487)

Chapter 17 discussed changes within the verb stem that involve semantic changes of the verb itself. However, processes of verbal derivation can also involve changes in verbal valence - the number of arguments associated with a predicate. In Tawala, changes in verbal valence involve not only the use of derivational prefixes but also a transitivising suffix and a detransitivising prefix. The presence of one of these affixes may signal important syntactic processes, including transitivisation, detransitivisation and causativisation. Tawala has no passive construction - a valence-decreasing strategy - but it does have numerous valence-increasing strategies.

It is the usual practice of grammars to give detailed treatment of grammatical relations and syntactic roles as part of the explication of the clause. This is undoubtedly the right course of action for a dependent-marking grammar, where the clausal NPs are marked for such relationships. However, in Tawala, subject and object are primarily marked on the head item of the clause - the verbal predicate. The VP (which is typically just the verb itself with its affixes) is the clause in miniature. Accordingly, it is difficult to separate the analysis of verbal clauses from the verb phrase or even from the discussion of verbal valence as contained in this chapter.

Dixon (1979:61) posits "three core semantico-syntactic relations" - three universal grammatical relations: ${ }^{1}$

$\begin{array}{lll}\text { Intransitive } & \text { subject: } & \text { s function } \\ \text { Transitive } & \text { subject: } & \text { A function } \\ \text { Transitive } & \text { object: } & \text { O function }\end{array}$

Although Tawala morphology and syntax make only a two-way distinction in grammatical relations - subject and object (that is, no formal distinction is made between transitive and intransitive subject) - the three universal grammatical relations are needed to account for the relationships that exist between transitive and intransitive verbs. Accordingly I use the convention of underlining to signify the universal grammatical relations $\underline{\mathbf{S}}, \underline{\mathrm{A}}$ and $\underline{\mathrm{O}}$. I reserve the symbols $\mathrm{S}$ and $\mathrm{O}$ for the marked grammatical relations of subject and object; thus $\mathrm{S}=\underline{\mathrm{S}}$ and $\underline{\mathrm{A}}, \mathrm{O}=\underline{\mathrm{O}}$.

When verbal derivation involves change of valence, it is essential to keep track of the underlying grammatical relations. It is also essential to distinguish valence increase from

Comrie (1981) uses S. A and P for the same relations. 
valence decrease. For verbs involving valence increase two patterns emerge: for some verbs $\underline{\mathrm{S}}$ of the derived verb coincides with $\underline{\mathrm{O}}$ of the basic verb; for others it coincides with $\underline{\mathrm{A}}$.

(a) $\underline{\mathrm{S}}$ Coincides with $\underline{\mathrm{O}}$

Valence increase $1>2$

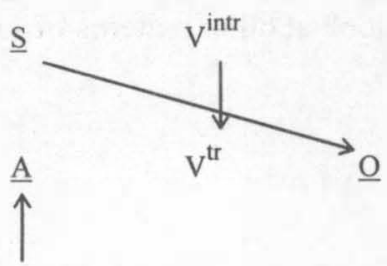

$\begin{array}{llll}\text { 18(1) } \begin{array}{l}\text { I-kam. } \\ \text { 3SG-sharp }\end{array} & > & \text { A-li-kam- } & \text { ya. } \\ \text { S } & & \text { ISG-DVP-sharp-3SG } \\ \underline{\text { It }} & \underline{\mathrm{A}}\end{array}$

18(2) A-luyawata. > A-luyawahi-hi. ISG-heal ISG-healTR- PL

$\underline{\mathrm{S}} \underline{\mathrm{A}} \underline{\mathrm{O}}$

I was healed. I healed him.

In 18(1) and 18(2) the $\underline{S}$ of the intransitive verb coincides with the $\underline{\mathrm{O}}$ of the transitive verb with an $\underline{\mathbf{A}}$ introduced. The change in valence is marked by the derivational prefix $l i$ in 18(1), but by a transitive form of the verb root in 18(2).

(b) $\underline{\mathrm{S}}$ Coincides with $\underline{\mathrm{A}}$

Valence increase $1>2$

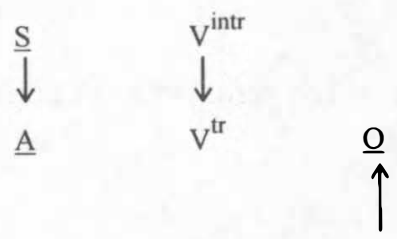

18(3) A-matouta. > A-matout'-e- ya.

ISG-fear ISG-fear-TRV-3SG

$\underline{\text { S }} \underline{\text { A }} \quad \underline{\mathrm{O}}$

I am afraid. I fear it.

18(4) I-lowo. > I-lowo-ge- ya.

3SG-flee $\quad$ 3SG-flee-TRV- 3SG

$\underline{\mathrm{S}} \quad \underline{\mathrm{A}} \quad \underline{\mathrm{O}}$

She fled. $\quad$ She ran from it.

In 18(3) and 18(4) the $\underline{S}$ of the intransitive sentence is identical with the $\underline{A}$ of the transitive sentence with an $\underline{\mathrm{O}}$ introduced. The valence increase is marked by the transitivising suffix $-<g>e$. 
Thus we have a two-fold distinction between verbs with $\underline{\mathbf{s}}>\underline{0}$ relationship contrasting with other verbs with $\underline{\mathbf{S}}>\underline{\mathrm{A}}$ relationship. Pawley (1973) shows that this distinction is widespread in Oceanic languages. Dixon (1988:204) refers to these as $\underline{0}$-type and $\underline{A}$-type verbs respectively and notes that Fijian has an almost even split between the two.

As we have seen, Tawala has both A-type and O-type verbs, but the situation is not just a two-way split; a number of valence-changing verb classes emerge with different types of transitivity and focus. Firstly, however, we need to look at other patterns of valence change.

(c) $\underline{\text { A }}$ Coincides with $\underline{\mathrm{S}}$

Valence decrease $2>1$

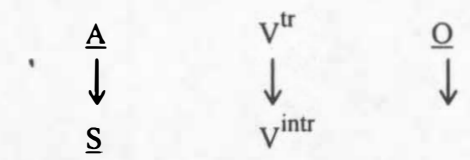

$\begin{array}{lll}\text { 18(5) } & A \text {-apu- ya. }> & A \text {-'m-apu. } \\ \text { ISG-bake-3SG } & \text { ISG-DVP-bake } \\ \underline{\text { A } ~} \underline{\mathrm{O}} & \underline{\mathrm{S}} \\ \text { I baked it. } & \text { I was baking. }\end{array}$

In $18(5)$ the $\underline{A}$ of the transitive sentence is identical with the $\underline{S}$ of the intransitive sentence with an $\underline{0}$ deleted. The valence decrease is marked by the derivational prefix om- This type is the mirror image of the previous class (b).

$$
\begin{aligned}
& \underline{\mathrm{AOV}}+o m->\underline{\mathrm{S} V} \\
& \underline{\mathrm{S} V}+-g e>\underline{\mathrm{AOV}}
\end{aligned}
$$

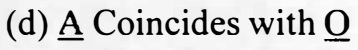

Valence increase $2>3$

O-type causative (CS) verbs are derived from transitive verbs with the derivational prefix wi-.

\begin{tabular}{|c|c|c|c|c|c|c|c|}
\hline $18(6)$ & $\begin{array}{l}\text { Iyana } \\
\text { fish }\end{array}$ & $\begin{array}{l}\text { bi-ani- } \\
\text { 3PL-eat- }\end{array}$ & $\begin{array}{l}\text { hi. } \\
\text { 3PL }\end{array}$ & $>$ & $\begin{array}{l}\text { Iyana } \\
\text { fish }\end{array}$ & $\begin{array}{l}a- \\
1 S G-\end{array}$ & $\begin{array}{l}\text { wi-ani- hi. } \\
\text { DVP-eat-3PL }\end{array}$ \\
\hline & They & $\underline{\mathrm{A}}$ & $\underline{\mathrm{O}}$ & & $\begin{array}{l}\mathrm{O} 2 \\
\text { I fed th }\end{array}$ & $\underline{\mathrm{A}}$ & CS \\
\hline
\end{tabular}

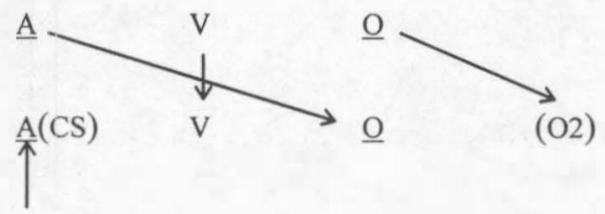

In $18(6)$ the $\underline{A}$ of the underived verb coincides with the $\underline{O}$ of the derived verb. The $\underline{O}$ of the underived verb is made a secondary object (not marked on the verb) with the derived verb. The $\underline{A}$ of the derived verb is introduced. 
Valence increase is marked by derivational prefixes $w i-, l i-, l u$ - and $w o$ and the transitivising suffix -ge. Derivational prefixes result in O-type verbs and the transitiviser in A-type verbs. Valence decrease is marked by the prefix -om.

\subsubsection{The TRansitive Marker $-g e^{2}$}

This morpheme is mostly a transitivising suffix in present-day Tawala (glossed TRV); however some verbs do have two contrasting transitive forms, e.g. -daman'-i 'cross LOC' > daman'-e-ya 'take s.th. across'.

Such contrast is rare in Tawala, where transitive verbs normally fall into two classes: those that simiply append the object enclitic to the verb stem, and those that add the transitive marker -ge before appending the object enclitic. Objects marked with the transitive marker are higher on the transitivity scale (Hopper and Thompson 1980) than morphologically unmarked objects; in particular, the object is more affected when the transitivising suffix is used, as illustrated in the following data.

$\begin{array}{llll}- \text { daman'-i } & \text { cross LOC } & - \text { daman'-e- } & \text { take s.th. across } \\ \text {-gei-ni } & \text { climb LOC } & -g i-y e- & \text { take s.th. up }\end{array}$

18(7) Neula i-gei-ni.

coconut 3SG-ascend-3SG

He climbed the coconut palm.

In 18(7) the object is not affected by the action; however, in $18(8)$ the object is totally affected in that it is moved to a new location.

18(8) Oya ugoli-na i-gi-ye-ya.

mountain 'at'-3SG 3SG-take.up-TRV-3SG

He took it up to the mountain.

When a locative argument occurs in a clause in which a transitive marker occurs it is an oblique argument (18(8)).

The transitive marker can operate in conjunction with derivational prefixes. The following list illustrates the complete set of options available combining derivational prefixes with the verb -damana 'to cross a bay/river'. In these examples, the transitive marker does not increase the valence but again indicates that the object is more affected.

$\begin{array}{llll}\text {-daman'-i } & \text { cross bay } & \text {-daman'-e- } & \text { take s.th./s.o. across } \\ \text {-widaman'-i } & \text { bridge gap } & \text {-widaman'-e- } & \text { take s.th./s.o. across } \\ \text {-ludaman'-i } & \text { cross bridge } & \text {-ludaman'-e- } & \text { pour s.th./s.o. across } \\ \text {-wodaman'-i } & \text { carry across } & \text {-wodaman'-e- } & \text { hand s.th./s.o. across } \\ \text {-tudaman'-i } & \text { step across } & \text {-tudaman'-e- } & \text { push s.th./s.o. across } \\ \text {-hudaman'-i } & \text { jump across } & \text {-hudaman'-e- } & \text { swing s.th./ s.o. across }\end{array}$

18(9) Goila a-widaman'-i. > Kewokewou a-widaman'-e-ya. river 1SG-cross-3SG canoe ISG-cross-TRV-3SG

I crossed the river. I took the canoe across.

2 The transitive marker -ge is a reflex of the POC * ${ }^{*} a k$, a 'remote' object marker (see below). 
In the following pairs the two forms are synonyms sensitive only to fine distinctions of context.

$$
\begin{array}{llll}
\text {-tona-ya } & \text { spear-3SG } & - \text { ton'-e-ya } & \text { pierce-TRV-3SG } \\
\text {-dewa-ya } & \text { do-3SG } & - \text {-dew'-e-ya } & \text { do-TR.V-3SG }
\end{array}
$$

The difference between a-tona-ya 'I speared it' and a-ton'-e-ya 'I pierced it again' seems to be the degree to which the object is affected. However, in this case the object is less affected when the transitive marker is used. In 18(10) the objects are totally affected (in each case they died).

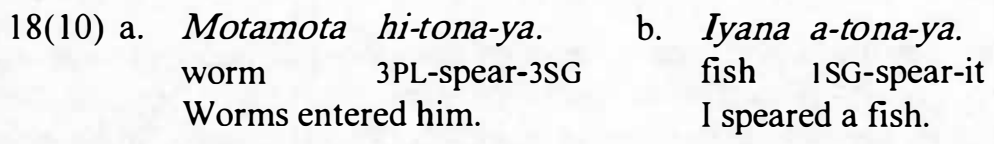

In $18(11)$ the object is only partially affected; it was injured but not destroyed.

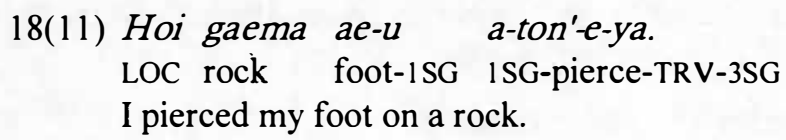

Similarly with -dewa-ya; the object in 18(12) is effected by the verb - it did not exist before. With the transitive marker $(18(13))$ the object is only partially affected - a custom is merely followed.
18(12) Toleha banei-na i-dewa-dewa-ya.
feast big-3SG 3SG-DUR-do/make-3SG
He was making a big feast.

18(13) Popopo a dewa i-dewe-dew'-e-ya.

goanna his custom 3SG-DUR-do/make-TRV-3SG

The goanna was doing his custom (making s.th. according to custom).

\subsubsection{The Detransitivising PrefiX om-}

The prefix $o m$ - attached to a transitive verb marks a reduction in valence. ${ }^{3}$

$\begin{array}{llll}\begin{array}{l}\text {-bulum-ya } \\ \text {-gei-ni }\end{array} & \text { sweep s.th. } & \text {-om-bulum s.th. } & \text {-om-geina be sweeping } \\ \text {-hiyaw'-i } & \text { count s.th. } & \text {-om-hiyawa } & \text { be reading } \\ \text {-popo-ya } & \text { join s.th. } & \text {-om-popo be joined }\end{array}$

That the process is at least partially productive is seen by the presence of a borrowed item (bulum 'broom') and an introduced concept (-omhiyawa 'reading') in the above list (see $\S 18.4 .1$ for a longer listing).

18(14) Buka he-yam-hiyawa.

book 3PL.PRES-DVP.DUR-read

They are reading books. 
We noted above that these are A-type constructions in that the derived $\underline{\mathrm{S}}$ corresponds to $\underline{\mathrm{A}}$ in the underived verb. However, 18(14) has an object NP and, as we see below, the derived verb is not a true intransitive.

The semantic shift involved in the following items probably means that there is no longer any active relationship between these two forms.

$\begin{array}{llll}\text {-gomu-ya } & \text { snap s.th. } & \text {-om-gomu } & \text { to miscarry } \\ \text {-hoe-ya } & \text { open s.th. } & \text {-om-hoe } & \text { to depart } \\ \text {-boin- } i & \text { bundle s.th. } & \text {-om-boina } & \text { to meet together }\end{array}$
18(15) Wagaloke i-m-hoe po i-nae tula-na uyahi-na.
possum 3SG-DVP-depart and 3SG-go friend-3SG 'at'-3SG
Possum left and went to his friend.

The following examples seem to be idioms; any derivational relationship which may have existed is now lost.

$\begin{array}{llll}\text {-boho be extinguished } & \text {-om-boho } & \text { be greedy } \\ \text {-poipoi } & \text { be dried up } & \text {-om-poipoi } & \text { be processed }\end{array}$

The following data represent a special subclass involving the 'detransitive' marker. In that the prefixes are used with intransitive verbs, there is no change in valence involved. Instead there is a change in macrorole of subject: the subject of the derived verb seems to be an undergoer in that the derived verbs refer to the automatic actions of animals.

$\begin{array}{llll}\text {-hopu } & \text { go down } & \text {-om-hopu } & \text { move down } \\ \text {-gae } & \text { go up } & \text {-om-gae } & \text { move up } \\ \text {-lupa } & \text { jump } & \text {-om-lupalupa } & \text { jerk }\end{array}$

18(16) Iyana he-yam-gae.

fish 3PL.PRES-DVP.DUR-go.up

The (school of) fish have gone up.

18(17) Polo i-'m-lupalupa.

pig 3SG-DVP-jumpDUR

The pig jerked (back on tasting the poison).

\subsection{CLASSES OF VALENCE CHANGE}

Combining various derivational patterns we find that in Tawala there are five basic classes of valence variation.

\section{1) A-Type Derived Transitives}

\section{$1>2$ valence}

In this type, various classes of intransitive verbs employ the valence-increasing transitivising suffix -ge to derive transitive verbs in which the $\underline{A}$ of the derived verb coincides with the intransitive $\underline{\underline{S}}$ of the underived verb. 
INTRANSITIVE TRANSITIVE

-geleta arrive -gelet'-e- take s.th. up

-kaoha be happy -kaoh'-e- welcome s.o.

With this construction only object-focus verbs are derived.

2) A-Type Derived Intransitives

$2>1$ valence

In this class, transitive verbs employ the valence-decreasing prefix om- to derive predicate-focus verbs. The intransitive $\underline{S}$ of the derived verb coincides with $\underline{A}$ of the transitive verb.

TRANSITIVE INTRANSITIVE

-apu- bake s.th. -om-apu be baking

-kaha- separate s.th. -om-kaha be separated

3) O-Type Derived Transitives

$1>2$ valence

In this class, transitive verbs are derived from intransitive verbs employing the derivational prefixes $w i-, l i-, l u$ - and $w o$. The $\underline{\mathbf{S}}$ of the underived intransitive verb is identified with $\underline{O}$ of the derived transitive verb, with an $\underline{A}$ introduced.

$\begin{array}{llll}\text { INTRANSITIVE } & \text { TRANSITIVE } & \\ \text {-hopu go down } & \text {-wi-hopu- } & \text { put s.th. down } \\ \text {-towolo } & \text { be standing } & \text {-wi-towolo- } & \text { stand s.th./s.o. }\end{array}$

4) O-Type Derived Causatives

$2>3$ valence

O-type causative verbs are derived from transitive verbs with the derivational prefix wi-. The $\underline{\mathrm{A}}$ of the underived verb coincides with $\underline{\mathrm{O}}$ of the derived verb. The $\underline{\mathrm{O}}$ of the underived verb is made a secondary object (not marked on the verb).

\begin{tabular}{|c|c|}
\hline TRANSITIVE & CAUSATIVE \\
\hline $\begin{array}{ll}- \text {-lui-ya } & \text { put on s.th. } \\
- \text {-awal'-i } & \text { carry s.th. }\end{array}$ & $\begin{array}{l}\text {-wi-lui-ya } \\
\text {-wi-awal'-i }\end{array}$ \\
\hline
\end{tabular}

5) O-Type Unmarked Valence Change

$1>2$ valence

Tawala has a small sample of O-type verbs which have no marker to indicate valence change, in which intransitive $\underline{S}$ is identified with transitive $\underline{0}$. This type accounts for less than half a dozen examples, of which only three have transparent relationships. 


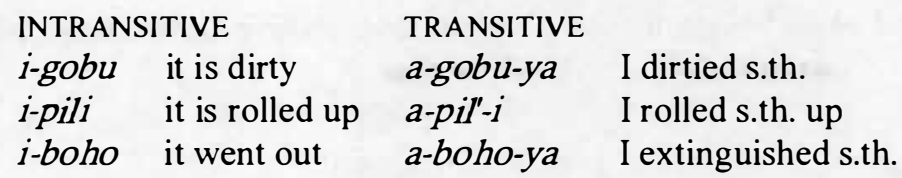

This is scarcely a large enough corpus to build any adequate theory on. However, the scarcity of examples points away from any clear A-type/O-type distinction in underived Tawala verbs; the data may be fossils from a historical distinction of the kind found in present-day Fijian. Tawala verb roots normally require a derivational affix to effect a comparable change of verbal valence. As we have seen, derivational prefixes normally result in O-type verb derivations and the transitivising suffix normally results in A-type verb derivation.

\subsection{VALENCE INCREASE}

\subsubsection{The SEMANTICS of VALENCE INCREASE}

Valence-changing affixes operate within certain defined word classes. There is little overlap between A-type and O-type verb classes. The transitivising suffix operates only with intransitive verbs: verbs of speaking, relationship verbs, psychological verbs and motion verbs. Derivational prefixes derive transitive verbs from intransitive verbs: motion and manner-of-motion verbs, posture verbs and stative verbs. In addition the derivational prefix derives causative verbs (ditransitives) from transitive verbs: consumption verbs and transportation verbs.

The semantic classes operating with the derivational prefixes and transitivising suffix are summarised in Table 1.

TABLE I: DERIVATIONAL PREFIXES WITH INTRANSITIVE VERBS

\begin{tabular}{|l|c|c|c|c|c|}
\hline SEMANTIC CLASS & $-g e$ & wi- & li- & Iu- & WO- \\
\hline speaking & + & - & - & - & - \\
relationship & + & - & - & - & - \\
psychological & + & - & - & - & - \\
motion & + & + & - & - & - \\
manner of motion & - & - & + & + & - \\
posture & - & + & + & + & + \\
stative & - & + & + & + & - \\
\hline
\end{tabular}

Overlap between the transitivising suffix and derivational prefixes is found only within derivations involving motion verbs. The two classes involve clear morphological and semantic distinctions:

Verbs derived with the transitivising suffix involve transportation - a change of location of both subject and object (18(18a)). Verbs derived with derivational prefixes, on the other hand, involve manipulation only - a change in the position of the object $(18(18 \mathrm{~b}))$.
18(18) a. Mayau hi-gi-ye-ya.
b. Mayau hi-wi-gei-ni.
wood 3PL-go.up-TRV-3SG
wood 3PL-DVP-go.up-3SG
They took the wood up.
They stood the wood up. 
The majority of derived verbs belong to one of the major transitive classes established in Chapter 5:

condition verbs
object-focus verbs

That there are no derived variable-focus verbs is not surprising, since they already function as the equivalent of either intransitive or transitive verbs - recall that variable-focus can function as either predicate focus or object focus. Significantly, however, a new class of predicate-focus verbs derived from object-focus verbs is introduced. Table 2 lists the various classes of derived verb giving the class from which each is derived and the derivational affix involved in each case.

TABLE 2: DERIV ATION OF TRANSITIVE VERB SUBCLASSES

\begin{tabular}{|l|c|l|}
\hline UNDERIVED VERB CLASS & & DERIVED VERB CLASS \\
\hline speaking & -ge & object focus \\
relationship & & \\
psychological & & \\
motion & $w i-$ & \\
\hline motion & $l i-$ & object focus \\
manner-of-motion & $l u-$ & \\
posture & $w O-$ & \\
stative & $l u-$ & condition \\
\hline stance & -guna & condition \\
\hline object focus & -om & predicate focus \\
\hline object focus & & \\
\hline
\end{tabular}

\subsubsection{A-TYPE VALENCE INCREASE}

Verbs in this section involve transitive verbs derived from intransitives, in which the $\underline{A}$ of the transitive verb is identical to the $\underline{S}$ of the intransitive. Valence increase is marked by the transitive marker. The derived transitive verbs belong to the object-focus verb subclass. Verbs of speaking are well represented in this group, but other subclasses are also involved.

(a) Verbs of Speaking

$\begin{array}{llll}\text {-lupali } & \text { make request } & \text {-lupali-ye- } & \text { beg for s.th./s.o. } \\ \text {-bowi } & \text { make a denial } & \text {-bowi-ye- } & \text { deny s.th./s.o. } \\ \text {-baha } & \text { speak } & \text {-bah'-e- } & \text { say s.th. to s.o. } \\ \text {-gagayo make a vow } & \text {-gagayo-ge- } & \text { vow s.th./vow to s.o. }\end{array}$

The underived intransitive verb in $18(19 a)$ corresponds to the derived transitive in $18(19 b)$.

18(19) a. Lawa magomagou-hi u mata-hi ma i-bowi. person many-3PL LOC eye-3PL and 3SG-deny It was before many people and (= that) he made a denial. 
b. Pita Yesu i-bowi-ye-ya.

Pita Yesu 3SG-deny-TRV-3SG

Peter denied Jesus.

With -lupali-ye- the addressee is the primary object, marked by the object enclitic on the verb; the secondary object is a core NP (18(20)). (With the intransitive form of the verb the thing requested is a peripheral NP, e.g. tapake binei i-lupali 'he asked for tobacco'.)

18(20) Tapake a-lupali-ye-hi.

tobacco 1SG-ask-TRV-3PL

I asked them for tobacco.

However, with $-b a h^{\prime}-e$ - the addressee is a peripheral NP. The message is the secondary object.

$\begin{array}{llll}\text { 18(21) Lugagayo } & \text { atapu-hi bada } & \text { i-bah'-e-hi } & \text { lawa uyahi-hi. } \\ \text { law } & \text { all-3PL man } & \text { 3SG-Say-TRV-3PL } & \text { person 'at'-3PL } \\ \text { OBJECT---.---.- SUBJECT } & & \text { OBLIQUE-.---.-- }\end{array}$

The official recited all the laws to the people.

(b) Relationship Verbs

$\begin{array}{llll}\text {-taniwaga } & \text { rule } & \text {-taniwag'-e- } & \text { rule s.th./s.o. } \\ \text {-gimala } & \text { trade } & \text {-gimal'-e- } & \text { trade (s.th.) with s.o. } \\ \text {-beiha } & \text { seek } & - \text { bih'-e- } & \text { seek s.th./s.o. } \\ \text {-luhogala } & \text { desire } & \text {-luhogal'-e- } & \text { desire s.th./s.o. }\end{array}$

18(22) Guyau i-taniwaga. > Lawa atapu-hi i-na-taniwag'-e-hi. chief 3SG-rule The chief ruled. person all-3PL 3SG-POT-rule-TRV-3PL He will rule everyone.

18(23) Hai lawa hi-gimala. > Hipuli a-gimal'-e-ya. their person IPL-trade land ISG-trade-TRV-3SG Their friends traded. I purchased a property.

(c) Psychological Verbs

$\begin{array}{llll}\text {-matouta } & \text { fear } & \text {-matout'-e- } & \text { fear s.th./s.o. } \\ \text {-lowo } & \text { flee } & \text {-lowo-ge- } & \text { flee s.th./s.o. } \\ \text {-hanapu } & \text { understand } & \text {-hanapu-ge- } & \text { know about s.th./s.o. } \\ \text {-kaoha } & \text { be happy } & \text {-kaoh'-e- } & \text { welcome s.o. }\end{array}$
18(24) A-matouta duma. > Polo a-matut'-e-ya. ${ }^{5}$ 1SG-fear very pig ISG-fear-TRV-3SG I was very afraid. I was afraid of the pig.

18(25) Apo to-kaoha. > Ega o-ta-kaoh'-e-u.

FUT IPL.EXC-happy NEG 2PL-IRR-happy-TRV-1SG

We will be happy. You did not welcome me. 
(d) Transportation Verbs

Verbs of transportation are derived from motion and motion-goal verbs using the transitive marker -ge, however there is a degree of morphological irregularity with each of the forms derived from motion verbs.

$\begin{array}{llll}\text {-nae } & \text { go } & \text {-ni-ye- } & \text { take s.th. on } \\ \text {-gae } & \text { go up } & \text {-gi-ye- } & \text { take s.th. up } \\ \text {-hopu } & \text { go down } & \text {-hopu-ne- } & \text { take s.th. down }\end{array}$

18(26) Beda i-ni-ye-hi.

betel 3SG-take-TRV-3PL

She took the betel nut.

18(27) Bandolo ta-ni-ni-ye-ya.

bundle IFL.INC-DUR-take-TRV-3SG

Let us bring bundles (of coconuts).

Two further trarısportation verbs are derived from motion-goal verbs.

-geleta appear/arrive -gelet'-e- take s.th./s.o. up

-damana cross over -daman'-e- take s.th./s.o. across

18(28) LeI ${ }^{6}$ to-geleta. $>$ Tewela-na hi-gelet'-e-ya u numa.

Lae 1PL.EXC-arrive child-DEF 3PL-arrive-TRV-3SG LOC house

We arrived at Lae. They took the child to the house.

More commonly verbs of transfer such as -daman'-e-ya and -gelet'-e-ya appear in serial verb constructions with -houna 'put', -bahena 'speak' or -awala 'carry', e.g. -houna geleteya 'place s.th. in view', -bahena geleteya 'reveal s.th.', -awala geleteya 'carry into view'.

\subsubsection{O-TYPE VALENCE INCREASE}

Verbs in this section involve transitive verbs derived from intransitives in which the $\underline{O}$ of the transitive verb coincides with the $\underline{S}$ of the intransitive. Valence increase is marked by a derivational prefix.

\subsubsection{Derived OBject Focus}

Object-focus verbs are derived with each of the derivational prefixes: $w i-, l i-, l u$ - and wo-

\subsection{THE PREFIX wi-}

(a) Motion Verbs

The prefix wi- is a productive morpheme with motion verbs and involves the movement of an item in the direction indicated by the verb; that is, the object is caused to take a 
new position. These are derived verbs of manipulation - a change in the position of the object.

$\begin{array}{llll}\text {-gei } & \text { come up } & \text {-wi-gei- } & \text { put s.th. up } \\ \text {-hopu } & \text { go down } & \text {-wi-hopu- } & \text { put s.th. down } \\ \text {-damana } & \text { go across } & \text {-wi-daman'- } & \text { put s.th. across } \\ \text {-peu } & \text { fall } & \text {-wi-peu- } & \text { drop s.th. }\end{array}$

18(29) Numa ta-wi-gei-ni.

house IPL.INC-DVP-come.up-3SG

Let us put the thatch on.

The verb -peu 'fall' differs from the others in the class in that it has an undergoer, rather than an actor, as subject. Data such as these make it clear that Tawala derivational processes are not sensitive to macroroles.

(b) Posture Verbs

With posture verbs the wi- prefix again derives verbs of manipulation - the object is caused to take a position.

$\begin{array}{llll}\text {-towolo } & \text { be standing } & \text {-wi-towol'- } & \text { stand s.th./s.o. } \\ \text {-tugula } & \text { be sitting } & \text {-wi-tugul'- } & \text { seat s.th./s.o. } \\ \text {-eno } & \text { be lying down } & \text {-wi-eno- } & \text { lie s.th./s.o. } \\ \text {-tagela } & \text { swivel } & \text {-wi-tagel'- } & \text { turn s.th./s.o. }\end{array}$

18(30) Hewali-na hi-wi-eno-ya. youth-DEF 3PL-DVP-lie-3SG

They lay the (sick) youth down.

These verbs are often used metaphorically.

18(31) Tewela hi-wi-towol'-i po tauna tu-wisili.
child
They-DVP-stand-3SG and he PER-fishing
They eled the child to be a fisherman.

(c) Manner-of-Motion Verbs

With these derived verbs the object is potentially an animate agent.

$\begin{array}{llll}\text {-lupa } & \text { jump/fly } & \text {-wi-lupa- } & \text { let s.o. go } \\ \text {-dala } & \text { crawl } & \text {-wi-dala- } & \text { get s.o. to crawl }\end{array}$

With manner-of-motion verbs the prefix wi-is used to indicate the causing of an item to act. It is important to note that the object is an animate actor, in contrast to $\mathrm{li}$ constructions (in which the object is an undergoer).

18(32) Kapeu hi-wi-lupa-ya.

butterfly 3PL-DVP-fly-3SG

They let the butterfly go.

7 Note that this derived verb is not a verb of manipulation. 
(d) Stative Verbs

Stative verbs are a productive source of transitive verbs with wi-. The $\underline{A}$ causes the state to come about. These verbs are often used in reference to metaphorical states, whereas those derived with $l i$ - are more often physical.

$\begin{array}{llll}\text {-dao } & \text { be long } & \text {-wi-dao- } & \text { lengthen s.th. } \\ \text {-kapala } & \text { be hard } & \text {-wi-kapala- } & \text { harden s.th. } \\ \text {-apapoe } & \text { be bad } & \text {-wi-apapoe- } & \text { destroy s.th. }\end{array}$

18(33) $A$ baha i-wi-dao-ya.

his word 3SG-DVP-long-3SG

He spoke at length.

18(34) Nugonugo-na i-wi-kapala-ya.

heart-3SG 3SG-DVP-hard-3SG

He remained resolute.

\subsection{THE PREFIX 1i-}

(a) Stative Verbs

The prefix $l i$ - is fully productive with stative verbs - the $\underline{A}$ of the derived transitive verb is a causer - effective in bringing a physical state about.

$\begin{array}{llll}\text {-kam } & \text { be sharp } & \text {-li-kam- } & \text { make s.th. sharp } \\ \text {-dumalu } & \text { be straight } & \text {-li-dumalu- } & \text { make s.th. straight } \\ \text {-kapala } & \text { be hard } & \text {-li-kapala- } & \text { make s.th. hard } \\ \text {-yeuyeu } & \text { be clean } & \text {-li-yeuyeu- } & \text { make s.th. clean } \\ \text {-dewadewa } & \text { be good } & \text {-li-dewadewa- } & \text { make s.th. good }\end{array}$

18(35) Fael-gei a-li-kam-ya.

file-ABL ISG-DVP-sharpen-3SG

I sharpened it with a file.

This prefix can also be used metaphorically.

18(36) Om yaga uyahi-u u-na-li-dumalu-ya.

yourSG debt 'at'-1SG 2SG-POT-DVP-staight-3SG

Pay off the debt you owe to me.

The root -gobu 'be dirty' with the derivational prefix $1 i$ - is reduplicated (-1i-gobugobu'make s.th. dirty'), suggesting derivation from the adjective (gobugobu-na 'dirty-3SG') rather than from the stative verb (-gobu).

(b) Posture Verbs

With posture verbs the prefix $l i$ - is used to indicate that an item is caused to take a position (forcefilly).

-towolo be standing -li-towol'- force s.th. up

-tugula be sitting -li-tugul'- force s.th. down

-eno be lying down -li-eno- force s.th. down 
$\begin{array}{llll}\text {-tagela } & \text { swivel } & \text {-li-tagel'- } & \text { knock s.th. over } \\ \text {-peu } & \text { fall } & \text {-li-peu- } & \text { topple s.th. }\end{array}$

18(37) Kiwou-gei a-li-towol'-i.

stick-ABL ISG-DVP-stand-3SG

I stood it up with a stick.

18(38) Kedewa mayou-gei a-li-eno-ya.

dog tree-ABL ISG-DVP-lie-3SG

I knocked the dog down with the firewood.

18(39) Premiya hi-li-peu-ya.

Premier 3PL-DVP-fall-3SG

The Premier has been toppled (from office).

(c) Manner-of-Motion Verbs

-lupa jump/fly -li-lupa- spring s.th.

-dala crawl -li-dala- knock to crawling position

These verbs contrast with wi-constructions, where the object of the derived verb is animate. We have here a clear contrast between a derived inanimate-object verb (li-) and a derived animate-object verb ( $w i$ ).
18(40) a. Walo a-li-lupa-ya. trap 1SG-DVP-jump-3SG
I sprung the trap.
b. Kiu a-wi-lupa-ya.
bird 1SG-DVP-jump-3SG
I let the bird go.

\subsection{THE PREFIX lu-}

Linguistic categories are rarely discrete. While the $l u$ - prefix is primarily a non-valencechanging derivational prefix indicating intensified action, examples to the contrary do exist. At times $l u$-is a valence-changing prefix, though some examples should be regarded as idioms rather than productive derivations. The derivational prefix $l u$-is usually employed in conjunction with the transitive marker - ge.

(a) Stative Verbs

-bigabiga be muddy -lu-bigabiga- make s.th. muddy -odubo be old -lu-odubo-ge- follow s.th. (traditional)

(b) Manner-of-Motion Verbs

-dala crawl -lu-dala-ge- drop one's hand

-bulili run -lu-bulili-ye- hit s.th. fast

(c) Motion-Goal Verbs

The motion-goal verbs also require the transitive marker in addition to the lu-prefix. 
geleta arrive lu-gelet'-e- comprehend s.th.

damana cross over lu-daman'-e- inherit s.th.

18(41) $A$ wipoya u-lu-daman'-e-ya.

his heat 2SG-DVP-cross-TRV-3SG

You inherited his power.

These $1 u$ - constructions have subjects with [-control]. They contrast with woconstructions which have subjects with [+control].

18(42) a. Amaka to-lu-gelet'-e-ya.

already 1PL.EXC-DVP-arrive-TRV-3SG

We already comprehend it.

b. Yaubada i-wo-gelet'-e-ya uyahi-ta.

God 3SG-DVP-arrive-TRV-3SG 'at'-1PL.INC

God revealed it to us.

\subsection{THE PREFIX wo-}

In the previous chapter we noted that the prefix wo with posture verbs derives forms with the meaning 'taking a position'. These verbs undergo a valence change when used with the effective marker $i$ -

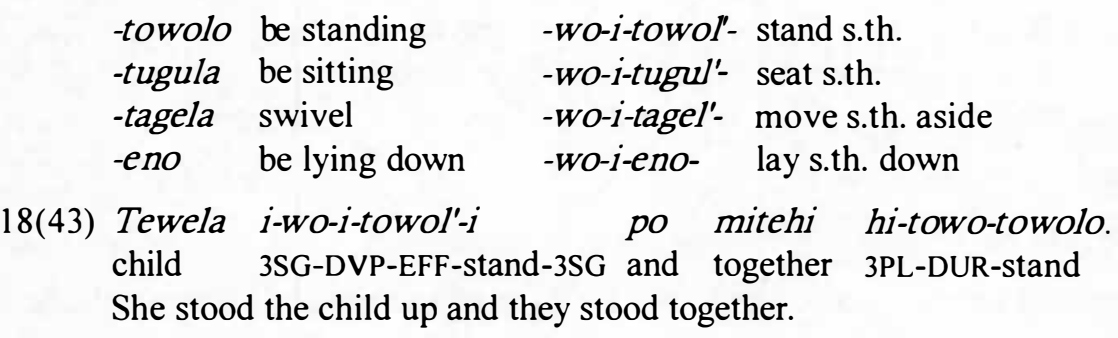

\subsubsection{DERIVED CONDITION lu-}

Here the derived verbs are condition verbs with the usual reflexive morphology. Again the derivational prefix $l u$ - is used in combination with the transitive marker -ge.

-towolo be standing -lu-towolo-ge-CPY jerk upwards

-tugula be sitting -lu-tugul'-e-CPY jerk downwards

-tagela swivel -lu-tagel'-e-CPY jerk sidewards

-eno be sleeping -lu-eno-ge-CPY jerk from sleeping

18(44) Gaima a-lu-tugul'-e-u.

stone ISG-DVP-sit-TRV-CPY

I ducked the stone.

\subsubsection{Derived Causative wi-}

In contrast to the other types listed above, this class of derivation involves the derivation of ditransitive from transitive verbs. The $\underline{A}$ of the underived verb becomes the $\underline{O}$ of the 
derived verb; the $\underline{0}$ of the underived verb becomes a secondary object in the clause in which the derived verb operates; the $\underline{A}$ of the derived verb is an introduced causer. Causative verbs are derived from variable-focus verbs.

(a) Consumption Verbs

$$
\begin{array}{llll}
\text {-ani } & \text { eat (s.th.) } & \text {-wi-ani- } & \text { feed s.o. } \\
\text {-uma(-ya) } & \text { drink (s.th.) } & \text {-wi-uma- } & \text { cause s.o. to drink } \\
- \text { lui-ya } & \text { put on s.th. } & \text {-wi-lui- } & \text { put clothes on s.o. }
\end{array}
$$

18(45) Logaloga laisi a-wi-ani-hi.

children rice 1SG-DVP-eat-3PL

I fed the children rice.

The verb lui 'enter' is an A-type motion verb with a transitive meaning, e.g. meyagai alui-ya 'I entered the village'. It also has the meaning 'entering clothes', which functions similarly to verbs of bodily consumption and suggests a verb subclass of 'bodily needs'.
18(46) Am pilipou u-na-lui-ya. > Guyau hi-wi-lui-ya. yourSG trousers 2SG-POT-enter-3SG chief 3PL-DVP-put.on-3SG Put your trousers on. They dressed the chief.

(b) Verbs of Carrying

Both the underived and the derived verbs are variable-focus verbs within this subclass.

$\begin{array}{llll}\text {-awali } & \text { carry on shoulder } & \text {-wi-awali } & \text { load (s.o.) on shoulder } \\ \text {-naba } & \text { carry on head } & \text {-wi-naba } & \text { load (s.o.) on head } \\ \text {-gedu } & \text { carry on back } & \text {-wi-gedu } & \text { load (s.o.) on back }\end{array}$

With verbs of carrying, the $\underline{\mathrm{A}}$ of the underived verb becomes the $\underline{\mathrm{O}}$, as a new actor, the causer, loads him/her up.

18(47) Kopala u-na-wi-awali-u.

copra 2SG-POT-DVP-carry-ISG

Put the copra (bag) on my shoulder.

\subsection{VALENCE DECREASE}

A number of distinct features of Tawala grammar are involved in valence decrease.

\subsubsection{DeRIVEd Predicate-Focus om-}

This class involves a reduction of transitivity and A-type verbs.

$\begin{array}{llll}\text { OBJECT-FOCUS } & \text { ACTIVITY } & \\ \text {-apu-ya } & \text { bake s.th. } & \text {-om-apu } & \text { be baking } \\ \text {-dewa-ya } & \text { do s.th. } & \text {-om-dewa } & \text { be working } \\ \text {-gei-ni } & \text { climb s.th. } & \text {-om-geina } & \text { be climbing } \\ \text {-hap-i } & \text { chop s.th. } & \text {-om-hapi } & \text { be chopping } \\ \text {-hepa-ya } & \text { beach canoe } & \text {-om-hepa } & \text { be beached/grounded } \\ \text {-himil'-i } & \text { send s.th. } & \text {-om-himila } & \text { be sent(?) }\end{array}$


-hiyaw'-i count s.th. -om-hiyawa be reading

-hune-ya praise s.o. -om-huna be praising

-kaha-ya separate s.th. -om-kaha be separated

-popo-ya join s.th. -om-popo be joined

-tein'-i pull s.th. -om-teina be persuading

18(48) Amaka hi-'m-hapi woloe.

already 3PL-DVP-chop finish

They have already finished chopping (sago).

18(49) Lolowa Yunaited Sios ma Kwato hi-'m-kaha.

before United Church and Kwato 3PL-DVP-separate

Earlier the United Church and Kwato became separate.

However, the derived verb is not intransitive but rather a predicate-focus transitive with two core NPs, only one of which can be indexed on the verb. An object NP can occur within the clause, however it is a generic object - the semantic equivalent of object incorporation.

18(50) Gulawa i-yam-dewa.

rope 3SG-DVP.DUR-do

He is making rope.

18(51) Wam hi-'m-hepa.

boat 3PL-DVP-beach

They had beached canoes.

\subsubsection{DERIVED INTRANSITIVES $\boldsymbol{w i -}$}

We noted above that the wi- prefix derives transitive and causative verbs. There are a few reduced-valence derivations also involving this same prefix. Both A-type and O-type verbs are involved.

(a) O-Type Verbs

TRANSITIVE INTRANSITIVE

-poya-ya heat s.th. -wi-poya be hot

-gwae-ya muddy s.th. -wi-gwae be murky

-wila-ya mix s.th. -wi-wila be going round

18(52) Polo goila i-gwae-ya. > Goila i-wi-gwae.

pig water 3SG-muddy-3SG river 3SG-DVP-murky

The pig muddied the water. The river is murky.

(b) A-Type Verbs

$\begin{array}{llll}\text { TRANSITIVE } & & \text { INTRANSITIVE } & \\ \text {-gun'-i } & \text { give birth to s.o. } & \text {-wi-gunaguna } & \text { nurse } \\ \text {-tona-ya } & \text { pierce s.th. } & \text {-wi-tona } & \text { fight }\end{array}$


-heda-ya wean s.th./s.o. -wi-heda adopt

-kaha-ya divide s.th. -wi-kaha decide ${ }^{8}$

These verbs are a minor 'class' contrasting with the main classes. They should probably be regarded as irregular lexical patterns, rather than actual derivational classes.

18(53) Iyana a-tona-ya. > Polo he-i-tona.

fish 1SG-spear-3SG pig 3PL.PRES-DVP.DUR-spear

I speared a fish. The pigs are fighting.

\subsubsection{DeRIVED Condition guna-}

Verbs derived by the spontaneous prefix guna-belong to the class of condition verbs, in which the referent of the object enclitic is the same as the subject prefix. Thus, in terms of morphological marking on the predicate, these verbs do not change their valence, but syntactically the clause is reduced from two potential core NPs to one.

$\begin{array}{llll}\text {-hedal'-i } & \text { break s.th. } & \text {-guna-hedal'-CPY } & \text { break by itself } \\ \text {-lolo-ya } & \text { tear s.th. } & \text {-guna-lolo-CPY } & \text { tear by itself } \\ \text {-gudu-ya } & \text { close s.th. } & \text {-guna-gudu-CPY } & \text { close by itself } \\ \text {-lupen'-i } & \text { open s.th. } & \text {-guna-lupen'-CPY } & \text { open by itself } \\ \text {-hoe-ya } & \text { untie s.th. } & \text {-guna-hoe-CPY } & \text { open by itself }\end{array}$

18(54) Amaka gudu i-guna-hoe-ya...

already door 3SG-SPON-untie-CPY

The door was already open...

The common verb gunawile- 'return' belongs to this class.

18(55) Kikina ma apo a-guna-wile-u.

little and FUT 1SG-SPON-round-CPY

I will retum soon.

Wi-kaha also has a transitive forn wi-kaha-ya 'decide it'.

It is difficult to assess whether the subject of this verb is truly an undergoer rather than an actor; certainly there is a parallel construction in which the subject is unambiguously an actor: Apo a-nememe. (FUT 1SG-come-again) 'I will come again'. 


\section{TAWALA TEXTS}

\section{A. YAILO'S LIFE STORY}

Part of a larger text recorded on magnetic tape by Yailo Robert at Ukarumpa in November 1974. Yailo transcribed and lightly edited the text, removing constructions he considered ungrammatical.

A.1 Yailo u meyagai Bou uyahi-na hi-guni-u ${ }^{1}$ bolima 1935.

Yailo my village Bou 'at'-3SG 3PL-bear-1SG year 1935

I, Yailo, was born at my village Bou in the year 1935.

A.2 Ma hina-u po ama-u uyahi-hi a-me-mae bolima magou-na and mother-1SG and father-1SG 'at'-3PL 1SG-DUR-stay year number-3SG

12 hi-kokoe ma a-nae Ist Keip Mision Skul.

12 3PL-finish and 1SG-go East Cape Mission School

And I stayed with my mother and father for twelve years, then I went to East Cape Mission School.

A.3 Skul uyahi-na a-me-mae bolima magou-na nimitutu hi-kokoe ma, school 'at'-3SG 1SG-DUR-stay year number-3SG five 3PL-finish and a-gunawil'-e-u po a-nae hina-u ma ama-u uyahi-hi po ISG-return-TRV-CPY and 1SG-go mother-1SG and father 'at'-3PL and a-me-mae bolima luwaga.

ISG-DUR-stay year two

I stayed at school for five years, then returned and went and stayed with my mother and father for two years.

A.4 Bolima luwaga hi-kokoe ma, a-nae u Kuyalo agriculture treining year two 3PL-finish and 1SG-go LOC Kuyalo agriculture training bolima tonuga.

year three

After two years I went to the Kuyalo agricultural college for three years.

A.5 Bolima tonuga hi-kokoe ma, a-nae Huhu Lokal Gavman Kaunsel year three 3PL-finish and 1SG-go Huhu Local Government Council uyahi-hi a-bagibagi bolima wohepali. 'at'-3PL 1SG-work year four

After three years I went to the Huhu Local Government Council and worked for four years.

The third person plural reference is probably an "impersonal passive" - see sentence 10 . 
A.6 Ma bolima wohepali hi-kokoe ma, otu ${ }^{i-n e i}$ uyahi-u ipa a-nae and year four 3PL-finish and call 3SG-come 'at'-1SG IRR ISG-go u Bwaruada Distrik Baibel Skul.

LOC Bwaruada District Bible School

After four years I received a call to go to Bwaruada District Bible School.

A.7 Ega.yaka 1963 Methodist Sios hai Sinod uyahi-na Ist Keip minister so 1963 Methodist Church their Synod 'at'-3SG East Cape minister i-bah'-e-na gelet'-e-u po Oktoba 1963 a-nae Baibel Skul. 3SG-speak-TRV-LIG appear-TRV-1SG and October 1963 1SG-goBible School. And so at the 1963 Methodist Church Synod the East Cape minister nominated me and in October 1963 I went to Bible School.

A.8 Po bolima emosi i-kokoe ma, a-lui pastrol training po bolima and year one 3SG-finish and 1SG-enter pastoral training and year tonuga a-bagibagi-ye-ya.

three 1SG-work-TRV-3SG

And after one year I entered pastoral training and worked at it for three years.

A.9 Houga-na pastrol training uyahi-na a-me-mae ma nugotuhu a-waya time-3SG pastoral training 'at'-3SG ISG-DUR-stay and thought 1SG-get a-pa, "Hilaki pona Tawala uyahi-na Buka hi-ta-dewa-ya". ISG-say oh.that language Tawala 'at'-3SG book 3PL-IRR-make-3SG While I was doing pastoral training the thought came to me, "I wish the Book (Bible) was translated into the Tawala language".

A.10 Nugotuhu geka a-wi-waya naka 13 January 1966 ma u buka habulu-na thought this ISG-DVP-get that 13 January 1966 and my book small-3SG uyahi-na a-gilum'-i po i-me-mae naka amaka nugo-u i-guluw'i. 'at'-3SG 1SG-write-3SG and 3SG-DUR-stay that already mind-1SG 3SG-bury-3SG I got this thought on the 13th of January 1966 and wrote it in my note-book and I had forgotten that it was there. ${ }^{4}$

A.11 Ma 1967 a-gunawil'-e-u po a-nei Ist Keip po pastrol and 1967 1SG-return-TRV-CPY and 1SG-come East Cape and pastoral bagibagi-na a-dewa-ya bolima magou-na wohepali. work-3SG 1SG-do-3SG year number-3SG four

Then in 1967 I returned and came to East Cape and did pastoral work for four years.

A.12 Ma pastrol bagibagina a-hopu hale-ya naka 1971 po u meyagai and pastoral work-3SG 1SG-go.down throw-3SG that 1971 and my village a-me-mae bolima luwaga. ISG-DUR-stay year two I resigned from pastoral work, that was 1971 and I remained in my village for two years.

This is a Methodist expression meaning that God chooses a person for a specific task. Thus otu inei uyahiu really means 'God called me'. 
A.12 Ma pastrol bagibagina a-hopu hale-ya naka 1971 po u meyagai and pastoral work-3SG 1SG-go.down throw-3SG that 1971 and my village a-me-mae bolima luwaga. ISG-DUR-stay year two

I resigned from pastoral work, that was 1971 and I remained in my village for two years.

A.13 Ma 1974 uyahina S.I.L. hai tu-bagibagi gehou-na hi-himili-yai u and 1974 'at'-3SG S.I.L. their PER-work other-3SG 3PL-send-DEl LOC Diwinai pona Tawala tu-giluma-na po gasi Buka tu-bui-na Diwinai language Tawala PER-write-3SG and also Book PER-turn.over-3SG gowa-na $B$ Ezard. name-3SG B Ezard

Then in 1974 S.I.L. ${ }^{5}$ sent us one of their workers to Diwinai - a writer of the Tawala language and also a translator of the Book - his name is B. Ezard.

A.14 Iyeta gehou-na a-me-mae ma natu-na mitehi hi-nei $u$ numa day other-3SG 1SG-DUR-stay and child-3SG together 3PL-come my house uyahi-na po i-lubayad'-e-u i-pa, "Tula-u, iyowai om luhogala 'at'-3SG and 3SG-ask-TRV-1SG 3SG friend-1SG how yourSG desire apo u-ta-hagu-we".

FUT 2SG-IRR-help-1SG

Another day I was at home and he came with his child to my house and asked me, "My friend, how about it, do you want to help me?"

A.15 Ega.yaka a-pa, "Tula-u, om nugotuhu apo a-wi-ponawogo-ge-ya so ISG-say friend-1SG yourSG thought FUT 1SG-DVP-obey-TRV-3SG baba-na ega tam om nugotuhu ma nugote Yaubadai-baha po because-3SG NEG youSG yourSG thought and perhaps God 3SG-say and u-nei uyahi-u yaka apo a-hagu-m". 2SG-come 'at'-1SG so FUT 1SG-help-2SG

And so I said, "My friend, I will obey your thought because it is not your thought but surely God spoke and you came ${ }^{6}$ to me, consequently I will help you".

A.16 Ma Oktoba 27 uyahi-na u buka habulu-na a-laga-laga-hi po January and October 27 'at'-3SG my book small-3SG 1SG-DUR-leaf-3 and January 131966 nugotuhu-na a-tuhaga-ya ipa pona Tawala buka-na naka 131966 thought-3SG ISG-find-3SG IRR language Tawala book-3SG that John Wycliffe a bagibagi a-nugotuhu-ya.

John Wycliffe his work 1SG-think-3SG

Then on October the 27 th I was leafing through my notebook and I found the thought of January 13th 1966 about the (possible) Tawala Book (and) I thought about John Wycliffe's work. 
A.17 Ma a-baha a-pa, "Geka tauhi hai tu-bagibagi gehou-na i-nei". And 1SG-speak 1SG-say this them their PER-work other-3SG 3SG-come Then I said, "This, one of their" workers has come".

A.18 Apoma u nugotuhu-na odubo-na i-nei $u$ nugonugo-u po mei then my thought-DEF old-3SG 3SG-come LOC heart-1SG and like nugotuhu wou-na uyahi-u ma Yaubada a-wotalagi-ye-ya. thought new-3SG 'at'-ISG and God ISG-praise-TRV-3SG Then that old thought came into my mind and was like a new thought to me and I praised God.

A.19 Tauna amaka i-wononogo houga geka bi-nei. he already 3SG-prepare time this BEN-3SG He had already prepared for this time.

\section{B. THE ORIGIN OF SAGO MAKING}

This is a traditional origin story recorded by Yailo Robert at Diwinai in October 1974. Yailo transcribed and lightly edited the text, removing constructions he considered ungrammatical. Only the first section of the story is given here.

B.1 Tawala dedede-na.

Tawala story-3SG

This is a Tawala story.

B.2 Dedede tahatahaya-na naka lawa luwaga hai bagibagi, ginahi story first-3SG that person two their work sago

bagibagi-na ubei-na.

work-3SG BEN-3SG

The first story is (about) the work of two people, it is about the work of sago.

B.3 Lani-hi gowa-hi Wagaloke ma Popopo hi-me-mae po person-DEF.PL name-3PL Possum and Lizard 3PL-DUR-stay and hi-wi-wogatala.

3PL-DVP-plan

There were people whose names were Possum and Lizard and they made a plan.

B.4 Wagaloke i-baha Popopo uyahi-na i-pa, "Heliyam apo Possum 3SG-speak Lizard 'at'-3SG 3SG-say friend FUT u-na-nei po ginahi ta-hapi".

2SG-POT-come and sago 1PL.INC-chop

Possum said to Lizard, "Friend, come let's chop sago".

B.5 "Oo, i-dewadewa duma."

Oh 3SG-good truly

"That is a very good (idea)." 
B.6 Apom iyeta geha-na i-tagona- ${ }^{\beta}$ naka Wagaloke a-nu then day other-3SG 3SG-cross.over-DEl that Possum his-LOC ani-mae tauna i-me-mae gaima Bou. NOM-stay he 3SG-DUR-stay stone Bou Then another day he came across to Possum's place; he was staying at the Bou stone.

B.7 Apoma i-ne-i po i-pa, "Heliyam, ta-gae ginahi then 3SG-come-DEl and 3SG-say friend IPL.INC-go sago ta-tala-ya".

1PL.INC-cut-3SG

Then he came and said, "Friend, let's go and cut the sago".

B.8 Hi-gae naka Wagaloke ginahi i-nagil'-i. 3PL-go.up that Possum sago 3SG-open-3SG They went up and Possum opened the sago.

B.9 I-lunagil'-i po i-kolo-kololo po i-kokoe. 3SG-open-3SG and 3SG-DUR-drip and 3SG-finish He opened it and it was dripping (until) it finished.

B.10 Ma hi-gag'-i po hi-hopu hi-lupeto. And 3PL-undo-3SG and 3PL-go.down 3PL-stir They undid it and went down and stirred ${ }^{9}$ (it).

B.11 Tula-na io i-pa, "Heliam, meka ata ani-goda?" friend-3SG 3SG-say friend where ourINC NOM-stir His friend said, "Friend, where is our stirring paddle?".

B.12 I-pa, "Ani-'m-goda he-me-mae". 3SG-say NOM-DVP-stir 3PL.PRES-DUR-stay He replied, "Our stirring paddles are here (lit. staying)".

B.13 Wagaloke i-towolo naka giu-n'-ei i-m-goda. Possum 3SG-stand that tail-3SG-ABL 3SG-DVP-stir Possum stood and stirred with his tail.

B.14 I-'m-goda po i-kokoe ma, hi-awala hopu-ne-ya. 3SG-DVP-stir and 3SG-finish and 3PL-carry down-TRV-3SG He stirred and it was finished and they carried it down.

B.15 "Heliyam, ega ita keyaka." friend NEG ourINC cup

"Friend, we have no cup."

B.16 "Oo, keyaka he-me-mae."

$\mathrm{Oh}$ cup 3PL.PRES-DUR-stay

"Oh there are cups." 
B.17 Wagaloke taniga-n'-ei i-'m-higuhigu.

Possum ear-3SG-ABL 3SG-DVP-ladle

Possum ladled with his ear.

B.18 Hi-am po i-kokoe ma, hi-wi-wogatala meme i-pa, "Hoimalatom 3PL-ate and 3SG-finish and 3PL-DVP-plan again 3SG-say tomorrow ap'-eega" ma iyeta noka $u$ muli-na apom u-na-nei". FUT-NEG and day that LOC behind-3SG then 2SG-POT-come They ate and it was finished and they made new plans saying, "Not tomorrow but the day after that, then you come".

B.19 I-pa, "Oo, i-dewadewa". 3SG-say oh 3SG-good He said, "It is good".

B.20 Uyahi-n'-ei wagaloke ta-gale-ya geka houga-na naka giu-na 'at'-3SG-ABL possum weINC-see-3SG this time-3SG that tail-3SG i-lupeto-ge-ya yaka giu-na-na i-wakeke. 3SG-ladle-TRV-3SG so tail-3SG-DEF 3SG-white And so we see the possum today has a white tail as a result of using it to stir sago.

B.21 Ma taniga-na uyahi-n'-ei i-'m-higuhigu yaka taniga-na-na i-wakeke. And ear-3SG 'at'-3SG-ABL 3SG-DVP-ladle so ear-3SG-DEF 3SG-white And it has white ears from ladling. 


\section{REFERENCES}

Anderson, Stephen R., 1985, Typological distinctions in word formation. In Shopen, ed. 1985, 3:3-56.

Andrews, Avery, 1985, The major functions of the noun phrase. In Shopen, ed. 1985, 1:62-154.

Armstrong, W.E., 1923, Report on anthropology of South-Eastern Division (excluding Woodlark Is.), Engineer Group, Bohilai, East Cape, Normanby Is. (South Coast), Fergusson Island (Morima). Papua Annual Report for the Year 1921-22, 26-39.

Baldwin, Fr, c. 1950, Tawala grammar. MS. - personal copy.

Berlin, B. and P. Kay, 1969, Basic color terms: their universality and evolution. Berkeley and Los Angeles: University of California Press.

Bugenhagen, Robert D., 1990, A grammar of Mangap-Mbula: an Austronesian language of Papua New Guinea. Doctoral dissertation, Australian National University, Canberra.

Callow, Kathleen, 1974, Discourse considerations in translating the word of God. Grand Rapids: Zondervan.

Capell, Arthur, 1943, The linguistic position of South-Eastern Papua. Sydney: Australasian Medical Publishing Co.

1969, A survey of New Guinea languages. Sydney: Sydney University Press.

Chung, Sandra and Alan Timberlake, 1985, Tense, aspect and mood. In Shopen, ed. 1985, 3:202-258.

Codrington, Robert H., 1885, The Melanesian languages. Oxford: Oxf ord University Press.

Com rie, Bernard, 1976, Aspect: an introduction to the study of verbal aspect and related problems. Cambridge: Cambridge University Press.

1981, Language universals and linguistic typology: syntax and morphology. Oxf ord: Basil Blackwell.

Comrie, Bernard and Sandra A. Thompson, 1985, Lexical nominalization. In Shopen, ed. 1985, 3:349398.

Crowley, Terry, 1982, The Paamese language of Vanuatu. PL, B-87.

Crystal, David, 1980, $A$ first dictionary of linguistics and phonetics. London: Andre Deutsch.

Dik, Simon C., 1978, Functional grammar. Amsterdam: North Holland Publishing Co.

Dixon, R.M.W., 1979, Ergativity. Language 55/1:59-138.

1982, Where have all the adjectives gone? Berlin: Walter de Gruyter.

1984, The semantic basis of syntactic properties. Berkeley Linguistic Society 10:583-595.

1987, Complementation in English, Fijian and Dyirbal. Paper presented to the Wenner-Gren Foundation for Anthropological Research on 'The role of theory in language description', Jamaica.

1988, A grammar of Boumaa Fijian. Chicago: The University of Chicago Press.

Elson, Benjamin F. and Velma B. Pickett, 1964, An introduction to morphology and syntax. Santa Ana: SIL.

Ezard, Bryan, 1977, A basic word list for Papua New Guinea. Work Papers in New Guinea Languages $21: 45-74$.

1978a, Classificatory prefixes of the Massim cluster. In S.A. Wurm and Lois Carrington, eds Second international conference on Austronesian linguistics: proceedings, 1159-1 180. PL, C-6 I.

1978b, Insights on cohesion from Tawala. Oceanic Linguistics 17/2:107-132.

1980, Reduplication in Tawala: including a comparison with Motu. KIVUNG 12/2:145-160.

1981, The Tawala dialects: an initial enquiry. MS.

1984, The functional domains of passives. Notes on linguistics 29:5-15. Dallas: SIL.

1992. Tawala derivational prefixes: a semantic perspective. In M.D. Ross, ed. Papers in Austronesian linguistics No.2, 147-250. PL, A-82.

1995, Tawala. In D.T Tryon, ed. Comparative Austronesian dictionary. Intercontinental Dictionary Series, vol.1: Berlin: Mouton de Gruyter.

Ezard, Janet, 1970, Yamalele phonology. MS. Ukarumpa: SIL.

Ezard, Janet and Bryan Ezard, 1974, Tawala phonology. MS. Ukarumpa: SIL.

Foley, William A., 1986, The Papuan languages of New Guinea. Cambridge language surveys. Cambridge: Cambridge University Press. 
Foley, William A. and Robert D. Van Valin, Jr, 1984, Functional syntax and universal grammar. Cambridge: Cambridge University Press.

Givón, T., 1984, Syntax: a functional-typological introduction, vol.I. Amsterdam: John Benjamins.

1990, Syntax: a functional-typological introduction, vol.II. Amsterdam: John Benjamins.

Grimes, Joseph, 1975, The thread of discourse. The Hague: Mouton.

Gross, Maurice, 1979, On the failure of generative grammar. Language 55/4:859-885.

Gudschinksy, Sarah C., 1964, The ABC's of lexicostatistics. In Dell Hymes, ed. Language in culture and society: a reader in linguistics and anthropology, 612-623. New York: Harper and Row.

Haiman, John and Sandra Thompson, 1984, "Subordination" in universal grammar. Proceedings of the Tenth Annual Meeting of the Berkeley Linguistics Society, 510-523. Berkeley: Berkeley Linguistics Sociedty.

1988, Introduction. In John Haiman and Sandra Thompson eds Clause combining in grammar and discourse. Typological studies in language No.18. Amsterdam: John Benjamins.

Harlow, Steve and Nigel Vincent, 1988, Generative linguistics: an overview. In Frederick J. Newmeyer, ed. Linguistic theory: foundations. Linguistics: the Cambridge Survey vol. I, 1-17. Cambridge: Cambridge University Press.

Hockett, C.F., 1958, A course in modern linguistics. New York: Macmillan.

Hopper, Paul J. and Sandra A. Thompson, 1980, Transitivity in grammar and discourse. Language 56:251299.

1982, Introduction. In Paul J. Hopper and Sandra A. Thompson, eds Studies in transitivity. Syntax and semantics, vol.5. New York: Academic Press.

1984, The discourse basis for lexical categories in universal grammar. Language 60:703-752.

Hyman, Larry M., 1975, Phonology: theory and analysis. New York: Holt, Rinehart and Winston.

Jelinek, Eloise, 1984, Empty categories, case, and configurationality. Natural language and linguistic theory 2:39-76.

Keenan, Edward L., 1985, Relative clauses. In Shopen, ed. 1985, 2:141-170.

King, Copland, 1901, A grammar and dictionary of the Wedau language. Sydney: W.A. Pepperday.

Kuno, Susumu, 1973, The structure of the Japanese language. Cambridge, Mass.: Harvard University Press.

Lehmann, Christian, 1988, Towards a typology of clause linkage. In John Haiman and Sandra Thompson, eds Clause combining in grammar and discourse. Typological studies in language No.18, 181-225. Amsterdam: John Benjamins.

Licktenberk, Frantisek, 1983, Oceanic Linguistics special publication 18: A grammar of Manam. Honolulu: University of Hawaii Press.

Lithgow, David R., 1976, History of research in Austronesian languages: Milne Bay Province. In S.A. Wurm, ed. New Guinea area languages and language study, vol.2: Austronesian Languages, 157-170. PL, C39.

Longacre, Robert E., 1976, An anatomy of speech notions. Lisse: Peter de Ridder.

1985, Sentences as combinations of clauses. In Shopen, ed. 1985, 2:235-286.

Lynch, John, 1973, Verbal aspects of possession in Melanesian languages. Oceanic Linguistics 12:69-102.

Lyons, J., 1968, Introduction to theoretical linguistics. London and New York: Cambridge University Press.

1977, Semantics. London: Cambridge University Press.

McElhanon, K.A., 1971, Classifying New Guinea languages. Anthropos 66:120-144.

MacGregor, W.M., 1890, Aboriginal vocabulary of Awaiama: table showing certain principal words, etc., used by aboriginals of Awaiama, Taupota, and Garua, British New Guinea. Annual Report of British New Guinea 1890.

Matthews, P.H., 1974, Morphology: an introduction to the theory of word-structure. Cambridge: Cambridge University Press.

Mithun, Marianne, 1984, The evolution of noun incorporation. Language 60/4:847-894.

Mosel, Ulrike, 1984, Tolai syntax and its historical development. PL, B-92.

Myhill, John, 1988, Nominal agent incorporation in Indonesian. Journal of Linguistics 24:111-136.

Nichols, Johanna, 1986, Head-marking and dependent-marking grammar. Language 62:56-119.

1988. On alienable and inalienable possession. In William Shipley, ed. In honor of Mary Haas, 557-609. Berlin: Mouton and Gruyter.

Nida, Eugene A., 1949, Morphology. Ann Arbor: University of Michigan Press.

Noonan, Michael, 1985, Complementation. In Shopen, ed. 1985, 2:42-140.

Pawley, Andrew K., 1973, Some problems in Proto-Oceanic grammar. Oceanic Linguistics 12:103-188. 
Pawley, Andrew K. and Roger C. Green, 1984, The Proto-Oceanic language community. In Robert Kirk and Emoke Szathrnary, eds Out of Asia: peopling the Americas and the Pacific, 161-184. Canberra: The Journal of Pacific History.

Pike, Kenneth L., 1967, Language in relation to a unified theory of the structure of human behaviour. The Hague: Mouton.

Ray, Sidney H., 1907, Linguistics. Reports of the Cambridge anthropological expedition to Torres Straits, vol.3. Cambridge: Cambridge University Press.

1926, A comparative study of the Melanesian Island languages. Cambridge: Cambridge University Press.

1938. The languages of the eastern and south-eastern divisions of Papua. Journal of the Royal Anthropological Institute 68:153-208.

Ross, Malcolm D., 1979, The Austronesian languages of Papua: towards a family tree. Mimeo, University of Papua New Guinea.

1983, The genetic relationships of the Austronesian languages of Papua. Paper presented at the Fifteenth Pacific Science Congress, Dunedin.

1988, Proto Oceanic and the Austronesian languages of western Melanesia. PL, C-98.

1989, Early Austronesian settlement in the Pacific: linguistic evidence. MS.

1990, Early Oceanic linguistic prehistory: a reassessment. The Journal of Pacific History 25:135-149.

Schachter, Paul, 1976, The subject in Philippine languages: topic, actor, actor-topic, or none of the above? In C.N. Li, ed. Subject and topic, 491-561. New York: Academic Press.

1985, Parts of speech systems. In Shopen, ed. 1985, 1:3-61.

Shopen, Timothy, ed., 1985, Language typology and syntactic description. vol.1: Clause structure. vol.2: Complex constructions. vol.3: Grammatical categories and the lexicon. Cambridge: Cambridge University Press.

Simons, Gary, 1977, The role of purpose and perspective in planning a language survey. Work Papers in New Guinea Languages 21:9-19.

Summer Institute of Linguistics, 1973, Languages of the East Papua region. Ukarumpa: SIL.

Swadesh, Morris, 1954, Perspectives and problems of Amerindian comparative linguistics. Word 10/23:306-332.

Thompson, Sandra A. and Robert E. Longacre, 1985, Adverbial clauses. In Shopen, ed. 1985, 2:171-234.

Van Valin, Robert D., Jr and William A. Foley, 1980, Role in reference grammar. In Edith Moravesik and Jessica Wirth, eds Current approaches to syntax. Syntax and semantics vol.13, 329-352. New York: Academic Press.

Williams, H.T., c.1962, Kehelala dictionary. MS. 


\section{INDEX}

$a$ (preposition), 166

ablative, 106, 216

ablative enclitic. See enclitics: ablative

ablative phrase, 167, 238

ablative postposition, 169-170, 179

ablative suffix, 38, 54, 105, 168

absence: obligatory, 88

abstract noun, 52, 150, 167

accompaniment, 87, 167

accomplishment verb, 58, 64, 100

action nominalisation, 150, 213, 217

actions

automatic, 285

by foot, 276-277

by force, 277

by hand, $276-277$

consummation of, 239

durative, 20

end of sequence, 245

end point of, 240

extent of, 237,240

first time, 254

forceful, 276

in succession, 253

intense, 276

intensified, 274

irreversible, 275

iterative, 277

manner of, 269

modes of, 269

multiple, 269

ordered, 269

persistent, 276

person who does, 265

point of, 237

progressive, 20

repeated, $20,275,277$

result of, 276-277

taking position, 276

thing used for, 264

active clause. See clauses: active

active verb. See verbs: active

actor, 59, 61, 87, 95, 97-98, 102, 137, 158, 292-

293, 298

definition, 99

actual event, 116

addressee, 62, 131, 222, 233, 289

adjectival classes, 101 adjectival predicate. See predicates: adjectival adjective phrase, 139, 145

adjectives, 20, 24, 28, 50-51, 54, 56-57, 74, 77, 79, $133,139,147,151,155,163,185,194-196$,

203, 257, 259, 261, 263, 294 attributive, 26, 145, 185 derived, 50, 265-267 predicative, 26, 145, 185

adjectivisation, 265

adnominal enclitic. See enclitics: adnominal adpositional clauses, 177-178, 237

adpositional phrases, 92, 95, 103, 107, 161, 177, 203

adpositions, 87, 104-105, 168, 236

adverbial clause, 210, 218, 223, 234, 240-241, 251, 254-255

adverbialisation, 206

adverbs, 78, 107, 132, 135, 203, 273

clausal, 180

future, 78

sentential, 113

tense, 107

adversative, 81, 236, 251-252

adversative conjunction, 252

afterthought, 157

agent, 91, 158, 293

agentive nominalisation, 213-215

agreement, 73, 79, 89, 139, 141, 147, 153, 158,

$167,176,178,184,186,190,225,237-239,257$ adjectival, 74

in polarity, 248

alienability opposition, 149

alienable. See possession: alienable

alienable class, 150

alienable construction, 217

alienably possessed NP, 165

alternate phrase, 154, 156

alternation, 253

alternative, 81

alternative construction, 157

amaka, 78, 204

amalai, 78, 204

anai, 167

anaphora, 74, 88, 96, 142, 210, 242, 246

ani $-213,216,219$

animacy, 61, 71-72, 100,103, 112

animacy hierarchy, 103, 112, 261

anthropomorphism, 141 
anti-passive, 95

antonym pair, 155

apega, 78, 203

apo, 78, 204

apposition, 145, 160, 214

appositional phrase, 142

arguments, 87, 89, 104, 107, 220

ascriptive clause, 174

aspect, 107, 113-114, 125, 203-204, 207, 213, 239-

240,254

durative, 255

punctiliar, 255

simple, 255

assessment, 80

associative conjunction, 158-159

associative phrase, 158-160

ataima, 78

attitudes, 101, 278

attributive adjective, 26

A-type derived intransitive, 286

A-type derived transitive, 286

A-type verb, 282-283, 287, 297-299

automatic response, 64

'automatic-action' verb. 61

automatic-reflex condition verb, 64

auxiliary verb, 27

avoidance, 81, 246

awa, 77

babana, 245

background, 92, 202

basic numerals, 79

benefactive, 106, 167, 171

beneficiary, 87

benefiter: unconscious, 171

bi-<nei $>, 167-168,171$

bivalent predicate. See predicates; bivalent

bivalent verb. See verbs: bivalent

bo, 81, 154, 156-157, 253

bodily needs, 297

body parts, $52,150,179,258,261-262,266,268$ -

$269,271,278$

body-part metaphors, 101

borrowings, 17-18, 285

bound forms, 262

bound noun. See nouns: bound

bound object. See objects: bound

bound pronoun. See pronouns: bound

cardinal numerals, 79, 267, 273

case: associative, 158

case frames, 106

cataphora, 207, 210

causal construction, 247

causation, 81, 246, 268-269, 293

causative prefixes, 257

causative verb. $282,287-288,297$

causatives, 63, 231, 279 causativisation, 280

causer, 294, 297-298

change in state, 269

change of subject, 140, 242, 249-250

changes: suffix-derived, 38

classes of complementation, 228

classification, 75 clauses, 200, 236

classification of CTPs, 232

classificatory prefixes, $51,115,256,258-259,268$ 269,273

clausal focus, 144

clausal subject, 74

clause coordination, 245

clause in miniature, 280

clause juncture, 235

clause linkage, 236

clause operators, $78,198,203$

clause structure, 93

clause-initial position, 78

clauses, 2,4

active, 97-98

adpositional, 177-178, 202

adversative, 236

alternation, 236

ascriptive, 174, 200

avoidance, 236, 246

cause, 236

complement, 189, 202

condition, 89, 102, 201

conditional, 242

consequence, 236

contrary-to-fact, 242, 244

contrast, 236

coordinate, 220, 234, 244

core, 86,89

coupling, 236

definition, 194

descriptive, 174, 183, 185, 202

ditransitive, 89, 103, 201

embedded, 79, 176, 178, 193, 206-208, 238

end-point, 236, 240

equative, 174-177, 182-185, 188, 200, 202

existential, 81, 180-182, 196, 202

fundamental types, 89

human-propensity, 101

hypothetical, $242-243$

in miniature, 86,89

indefinite location, 241

independent, 28, 207, 222, 241-242

intransitive, 87, 89, 101-102, 200-201, 214

layered structure, 86

locational, 178-179, 241

locative, 200

manner, 177-178, 236

motion, 241 
negative, 181, 204

non-verbal, 21, 74-75, 180, 182, 185, 190,

193-205, 227, 248, 252-254

non-verbal: layered structure, 202

non-verbal, marked, 28

non-verbal, unmarked, 27

nucleus, $86,87,89$

periphery, 86

possessive, 174, 183-184, 186-189, 200,

202

postposition, 236

preposed subordinate, 241

prepositional, 179

purpose, 220, 236, 241

relative, 206

result, 236

spatio-temporal, 249

stative, 97

structural unity, 197

subjectless, 196

subordinate, 234, 242

succession, 236

temporal, 240

temporal succession, 241

transitive, 89, 99, 101, 200-201, 214

'until', 236

verbal, $27,86,193,195,197,202-204,227$,

248

verbal stative, 181

clitics, 73, 109

final, 74

negative, 178

possessive, $72-73$

pronominal, 73,145

close connection, 82,248

closed word classes, 257

close-link conjunction, 224, 239

co-actor, 158

cognition verb, 222

cohesion, 2, 73, 245, 256

colour, 57, 267, 273

comitative phrase, 158, 161, 166-167

commands, 123, 233, 249

negative, 124

comment, 91

communicational function, 2

comparative function, 127

comparison, 252

complement clause, 189, 218, 220-225, 227, 230234

complementation, 190, 206

complementisers, 77, 82, 220-221, 224-227, 229,

232-233, 249. See also ipa; naka; po

complements, 2, 189-191, 197, 203, 220-222, 225-

$228,232-233,240,250$

indirect quote, 226 irrealis, 227

message, 226

realis, 227

verbal, 228

complement-taking predicate. See CTPs

completed action, 114

completed function, 127

complex structures, 142, 149

compound phrase, 154

compound words, 256, 258, 263, 268, 278

compounding, 51

compounds, 109

concluding comments, 202

concrete item, 167

condition, 58, 136

condition clause, 89, 102, 244

condition marker, 57

condition noun, 260

condition verb, 63-64, 103, 135, 137, 271, 288-

289, 296, 299

conditional clause, 121, 242

alternate, 251

conditional construction, 242

conditional particle, 83

conditional sentence, 83

conditionals, 236

confirmation, 81

conjoined NPs, 158

conjoining clauses, 253

conjunctions, 76, 78, 81, 154, 158, 200, 235, 249, 251

adversative (tamogi), 252. See also tamogi alternation (bo and oo), 253. See also bo and $o o$

associative (miteht), 158-159

avoidance (meka po), 245-246

close-link, 224

consequence ((ega) yaka), 245, 247-248

contrast (ma), 242, 250. See also ma

coordinating, 197, 199, 244-245

coupling (po), 248. See also po

sequences, 81

subordinating, 238, 246

succession (apoma and apom), 253-254

conjuncts, 82

consequence, $81,246-247$

consequential relationship, 248

consonants, 29

transitional, 40, 162, 165

sequences, 30

constituents, 91

order of, 86

peripheral, 87

constructional homonymy, 183

consumption verb, 64, 276, 288, 297

context, 82,88 
continuous aspect, 255

contrary-to-expectation, 123, 252

contrary-to-fact, 83, 116, 121, 242, 244

contrast, 81, 250

contrastive clause, 250

contrastive conjunction, 242, 252, 254

control, 102, 150, 230, 296

degree of, 101

potential, 61

coordinating conjunction, 223, 234, 244-245, 248

coordination, $82,152,155,220,234-236,239$,

$241,251-252,254-255$

clause, 220, 222-223, 244

NP, 176

phrase, 154, 156, 158

copula, 174, 182

copular sentence, 196-197

copular verb, 196

copy, 102

core, 86, 99, 103-105, 203, 206, 210, 220

core arguments, 158

core NP, 87, 96, 98, 101, 207, 221, 290

core of word, 257-258

coreferential, 229, 241

cosubordination, 233, 235

coupling, 81, 245

CPY, 63

cross-referencing, 89, 208

CTPs, 220, 222-223, 225, 227-232, 249

intransitive, 231

nominal, 228

non-modal, 232

non-verbal, 220, 225-226, 228

transitive, 228

verbal, 228

cultural items, $64,257,271-272$

customary aspect, 122

declaration prefix, 269

declarative utterance, 81

definite construction, 188

definite marker, 139, 142, 148, 210, 213, 215, 245

definite modifier, 144

definite object, 74

definite relative clause, 206, 212

degree of independence, 249

deixis, 62, 107, 131, 139, 175, 183

directional, 76

spatial, 76

deletion, 145, 147

demonstrative pronoun. See pronouns:

demonstrative

demonstratives, 43, 52, 74, 76-77, 139-140, 143,

172. 175, 180, 197, 209-210, 221, 224, 226, 233

function, 141, 197

naka. See naka

neutral, 76 dependence: degree of, 245

dependent adjective, 26

dependent clause, 210, 249, 252

dependent marking, 23, 25, 75, 90

dependent noun, 167, 178

dependent NP, 164, 168, 213

dependent-marking grammar, 280

dependents, 24, 51, 73, 161, 235

derivation, $75,138,255,259,262,265,267,273-$

274, 277

adjectives, 51

prefixes, 51

verbs, 69

words, 259

derivational affixes, 98, 213, 222, 256-257, 267, 287-288

derivational prefixes, $20,52-53,63-64,66,80$,

$115,118,130,231,256-260,265,268,270-271$,

273-275, 279-280, 284, 287-288, 292. See also

li-; Iu-; om-; wi-; wo-

derivational processes, 20, 260, 292

derived causative, 297

derived noun, 140

derived stem, 68,256

derived verbs, $267,283,286,288,292,294,296-$ 299

descriptive clause, 174, 183, 185

descriptive discourse. See discourse: descriptive

detransitive marker. See om-

detransitivisation, 280

detransitivising prefix, 285. See also om-

dialects, 6, 10, 31, 39, 69, 75, 171, 181

dialogue, 200

diminution, 261

direct object. See objects: direct

direction, 62, 274

direction of motion, 128

directional deictics, 130

discourse, 2, 76-77, 82, 86, 144, 180, 194, 216, 240,256

descriptive, 197-198, 202, 218

narrative, 197, 202, 245

discourse marker, 88, 240

discourse pragmatics, 90, 93

distal, 76, 143

distinction: $p o$ - $m a, 246$

disyllabic, 68

ditransitive clause. See clauses: ditransitive

ditransitive verb. See verbs: ditransitive

domain noun, 206-212

dual number, 72,141

duma, 77

dummy subject, 88

duration, 165

durative action, 20 
durative aspect, $43,59,61,99,107,113-114,116$, 118-119, 121-123, 204, 207, 209, 211, 232, 251, 255-256, 268, 270, 274, 277

effective marker, 130, 268-269, 296

ega, 78

embateka, 79

embedding, 153, 157, 176, 178, 199, 211, 213,

$218,220,223,234,236-238,241,249$ clauses, 79, 146, 193, 206-208

emotional response, 81

emotions, 101, 278

emphasis, 76

emphatic function, 74

emphatic pronouns. See pronouns: emphatic

enclitics

ablative, 38, 55, 145, 151-152, 154, 169-

170, 264

adjectival, 75

adnominal, 74, 111,167

object, $65-66,68-70,72,87-88,96,98,101-$ $103,107-111,132,137,271,283,299$

plural, 68

pronominal, 24, 28, 51, 53, 56-57, 68-69, $72-73,75,80,99,139,144-147,149-150$,

$153-154,158,166,168,184,186-187,203$,

$213,228,261-262$

transitive, 134

verbal, 96

end-point of action, 240

end-point subordinate clause, 240

end-point temporal clause, 239

equative clause, 174-177, 182-185, 188, 218, 251

event, 165

exception, 252

exclamation, 81

exclusive, 72

existential clause, 81, 180-182, 196

exophora, 74, 96

exophoric reference, 88

expanded prepositional phrase, 178

experiencer, 67

extent of action, 237, 240

extent of time, 171-172

external-headed relative clause, 207

farewell, 81

focus, $64,90-91,93,127,142$

foreign concepts, 164

form, 4

form and function, 222-223, 234, 241

formalism, 4

forms

$$
\text { composite, } 81
$$

demonstrative, 76

free noun. See nouns: free

free-form adverb, 78

free-form pronoun. See pronouns: free-form functional domains, 72, 78, 190

functional equivalents, 95, 212

functional parameters, 236

functional relationships: clauses, 202

functionalist grammarians, 4

functions, 132, 134, 234, 237, 255-258, 264, 269-

270, 276, 280, 297

adjective, 185, 201

adnominal enclitic, 74

adverbial, 254

anaphoric, 74

aspect, 239

comparison, 127

complementiser, 226

completion, 127

condition verb, 63

conjunction, 246

copula, 196

core, 161

deictic, 131

demonstrative, 76, 139, 175, 180, 197, 221, 226

derivational prefix, 268

durative aspect, 251

embedded clause, 206

emphatic pronoun, 140

enclitic, 140

end-point subordinate clause, 240

exophoric, 74

expanded NP, 182

grammatical, 91, 161, 190

grammatical predicate, 190

head of NP, 77

human condition phrase, 167

inalienably possessed noun, 190

independent clause, 210

inflection, 53

interrogative, 175

ipa, 82, 225

irrealis marker, 225

locative postposition, 168

ma, 250

manner adverbial clause, 239

modifier, 125, 133

naka, 225-226

nominalised clause, 218

non-emphatic, 74

non-verbal clause, 202

non-verbal predicate, 213

noun, 52, 148, 186, 201

$\mathrm{NP}, 185,187$

number nominalisation, 218

numeral, 79, 133

oblique, 161

passive, 72

phrase, 2 
po, 225, 249-250

predicative, 76

pronoun, 73

referential, 74

serial clause, 239

serial construction, 127

surf ace string, 194

syntactic, 54

third person singular suffix, 182

transitivity, 103

unity, 195

variable-focus verb, 288

verb, 97

verb phrase, 195

verb stem, 217

verbal clause, 202

word, 2

future adverb, 78

future tense, 78, 113, 117, 123, 182, 204, 227

gasi, 77

-ge, 282-283, 286, 289, 291, 295-296

geka, 76

gender, 72,150

general modifiers, 133, 141, 145, 147, 153

generic marking, 96

geographical location, 163

glottal stop, 181

goal, 177

grammar, 2, 258, 260-261, 270

grammatical functions, 190, 195-196, 200, 216

grammatical hierarchy, 2

grammatical incorporation, 65

grammatical predicate, 196

grammatical reduplication, 128

grammatical relations, $27,86,89,93,102,141$,

208, 212, 218, 280 non-verbal clauses, 197

grammatical roles, 206

grammaticisation, 132, 269

greeting, 81

habitual action, 122

hau, 163

head, $24,51,73,77,79,88,107-109,125,128$ -

$130,134,139-140,147,161-162,165,209,217$, $263,267,280$

head marking, $23,75,90,149,151,167,176-177$,

179. 182-183, 185-188, 203, 235

head noun, 24, 74, 143, 145, 147, 178-179, 214

head NP, 167

head phrase, 153

hearer, 76

heki, 79

hilaki, 79

hinapa, 83, 243

hitapa, 83, 244

hoi, 163-164 homonymy: constructional, 183

hortatory function, 117

hosi, 77

hota, 77

human, 71,112

human condition phrase, 161, 167

human object, 103

human propensity, 109, 279

human reference, 52, 74, 102, 141, 230, 271-272

human-propensity, 101, 268, 275, 278

hypothetical, 83, 124, 242-244

identity of subject, 248

idiomatic question, 178

idioms, 179, 249, 258, 279, 285, 295

imperative, 110, 117

impersonal subject, 229

impersonalisation, 72

inalienable. See possession: inalienable

inalienable class, 150

inalienable construction, 217

inanimate, $71,100,112$

inapa, 83, 242-243

inclusive, 72, 262

indefinite construction, 188

indefinite item, 148

indefinite marker, 245

indefinite modifier, 139, 144, 146

indefinite clauses, 206, 211, 241

indefinites, 83, 139-140, 142, 215, 237

independent clause, 28, 207, 222-223, 242

independent pronouns. See pronouns: independent independent structure, 210

indexing, 51, 74, 86-87, 93, 99, 103-104, 107, 110 , $112,139,141,147,153,167-168,190,203$,

$228,233,242,267,298$

object, 24

primary, 88,90

indicative, 116

indirect object. See objects: indirect

indirect quote. See quotes: indirect

infinitive construction, 226

inflection, 255-258, 261-262

inflectional function, 53

influence verb, 67

information verb, 220

inhabitants, 264

instrument, 55, 87, 154, 269

instrument nominalisation, 213, 216

intensified action, 274

intensifier function, 126

intensifiers, 78, 127, 129, 133, 135

interaction marker, 79

interjection, 80

internal-headed relative clause, 206-207, 210

interrogative construction, 179, 193, 249

interrogative indefinite, 146, 155 
interrogative NP, 176

interrogatives, 81, 83, 142, 144, 175, 211, 213, 237 locational, 76 temporal, 256

intonation, 198

intransitive clause. See clauses: intransitive intransitive construction, 127,138

intransitive form, 66

intransitive modifier, 132

intransitive predicate. See predicates: intransitive

intransitive $\underline{\mathrm{S}}, 286$

intransitive specifier, 136

intransitive verb. See verbs: intransitive

intransitive verb phrase. See verb phrases:

intransitive

introductory remarks, 202

ipa, 224-225, 227, 229-230, 233

irrealis marker, 225

irrealis mood, 78, 82, 107, 113, 115-116, 120-121, $123,224,227,229,233$

isolated sayings, 200

isolating non-verbal clauses, 197

itapa, 83, 242, 244

iterative action, 277

juncture, 154, 235

juxtaposition, 220, 223-224, 226, 234, 241-242,

255

kidahi, 79

kinship terms, 52, 150, 157, 262, 271-272

language change, 17, 231

layered structure: non-verbal clause, 202

length, 45, 109

lexical compounds, 124

lexical verbs, 87

lexicon, 150, 255-256, 258-259, 261

$1 i-, 259,270-271,279,281,283,286,289,292-294$

ligature, 23, 26, 108-109, 111, 124, 132, 135, 137138

limiters, 73, 78, 133, 135, 139, 147, 213

lists, 202

local demonstrative, 142

location, 55, 76, 241

clause, 178-179, 237

general, 162-163

interrogative, 76

nominalisation, 213, 216

noun, 52, 162, 177, 209

preposition, 54

specified, 162-163

unspecified, 162

locative construction, 216

locative function, 143

locative phrase, 105-106, 161, 167

specified, 177

locative postposition, 168-170

locative postpositional phrase, 168, 237 locative preposition, $162-163,165,169$

lolowa, 78

long-lasting condition, 275

loose connection, 82

loose consequence, 247

loose relationship, 254

lu-, 259, 270-271, 273-275, 279, 283, 286, 289, 292, 295-296

ma, 81, 154, 156, 197, 199, 223, 225, 241, 245-

$246,248,250-252,254$

function, 250

macroroles, 59, 87, 97, 285, 292

main clause, 206-208, 210-213, 220, 222-223, 226,

$228,234,236-244,246,249,251,254,0255$

main verb, 217-218, 237

manner clauses, 177-178, 239

manner construction, 142

manner of motion, 63

manner phrase, 161, 165, 238

manner-of-motion verb, 288, 293, 295

marking, 261

adpositional, 103

definite, 245

dependent. See dependent marking

head, 90

modifier, 153

morphological, 90

new NP, 148

noun, 153

syntactic, 90

meaning, 2

additive, 156

distributive, 155-156

predictable, 258

unpredictable, 258

mei, 165, 177-178, 238

message, 222, 233

message complement, 226

metaphors, 101, 279, 293-294

$m i-, 264$

minimal clause predicate, 179

mismatch: degree of, 89

modal classificatory prefixes, 269

modality, 79, 249

modality predicate, 220

modality verbs

ability (emoemota-), 228

desire/like/love (luhogala), 230

make (dewa), 231

need/want (nugonugo-), 229

plan (wiwogatala), 231

try (wileta), 230

modifier noun phrase, 25

modifier verb, 126-127

modifier verb phrase, 26 
modifiers, $26,73,75,107-108,125,128-130,132$, $134-135,137-139,144,146-148,153,155,181$, 214

demonstrative, 76

general, 77,136

limiting, 181

numeral, 79

particle, 78, 132

posthead, 52, 109

postnominal, 58

modifying clause, 210

moina, 79

monovalent, 63

mood, 82, 107, 113, 115, 119, 121, 125, 199, 203-

$204,213,233,239,242-243$

change, 250

hypothetical, 243

irrealis, 78

potential, 78,82

morphemes, 2

boundaries, 37

morphological marking, 65

morphology, 53, 255

verbs, 72

morphosyntax, 53

motion clause, 241

motion deictic, 131

motion verb, 61-62, 99, 108, 125, 128, 241, 274,

276, 288, 291-292, 297

motion-goal verb, $65,291,296$

multiple items, 261

multiple parts, $260-261$

naka, 76, 209-210, 217, 221, 224-227, 229, 231-

$233,242,244$

names, 139-140, 142

narrative discourse. See discourse: narrative

natural kinds, 260

nawa, 77

negation, 181, 203. See also ega non-verbal clauses, 204

negative (polarity), 78, 120-121, 123, 180-182,

184-185, 188-189, 191, 240, 253

particle, 181, 205

predicate form, 181

negative adverb, 116, 124, 198, 204

negative clitic, 178

negative command, 124

negative durative potential, 124

neutral, 76

neutral demonstrative, 143

neutralisation: tense and mood, 122

new inf ormation, 175

new items, 148

new participant, 88

new sentence, 245,254

nexus, 235 noka, 76

nominal predicate. See predicates: nominal nominal reduplication, 262

nominalisation, 206, 213-215, 217-218, 227, 240, 264

intransitive, 214

transitive, 214

nominalised form, 139, 231

nominalised NP, 221-222

nominalised restrictive clause, 212

nominaliser, 213, 216

nominals, 261

non-actual event, 116

non-derived verb root, 68

non-human, 74, 141

non-restrictive relative clause, 206

non-specific construction, 145, 147

non-specific object, 96

non-verbal clause. See clauses: non-verbal

non-verbal construction, 97

non-verbal predicate. See predicates: non-verbal

noun classes, 53

noun compound, 263

noun function, 148

noun phrases. See NPs

noun root, 266

nouns, $18,20,49-50,52,77,139-140,175,194$,

196, 203, 206, 257, 259

abstract, 52, 150, 167

animate, 163

body part, 52,261

bound, $55,72-73$

common, 52

continuous state, 261

cultural items, 52, 64

dependent, 167

derived, 213, 263-265

diminutive, 261

free, 55

head, 74

human reference, 52, 163, 261

kinship terms, 52

locational, 52, 54, 162, 177

multiple item, 261

multiple part, 260-261

onomatopoeic, 261

other, 52

personal, 52

place names, 52,54

possessed, $24,75,186,195$

possessor, 186

problem condition, 260

quantifiers, 52

relationship, 52, 54, 261

repetitive condition, 260

repetitive use, 260 
temporal, 113

verbal, $213,215,217$

NPs, 2, 28, 52, 73, 77, 86, 110,195

complement, 197

complex, 139

coordinate, 176

dependent, 164, 168

grammatical, 88

head, 140

interrogative, 176

juxtaposed, 174

modifier, 25

new, 148

object, 197

optional, 93

possessed, 164-165, 188

possessive, 24, 186-187

possessor, 73, 188

simple, 139, 176

subject, 87, 197

temporal, 199

$n u, 165$

nucleus, 97-99, 103, 203

nugote, 79

number, 51, 72, 101, 217, 261. See also person and number

number nominalisation, 218

number phrase, 146, 261

numerals, 73, 79, 132-133, 139, 146-147, 155-157, 218,272

basic, 79

cardinal, 79

distributive, 80

identical, 155

ordinal, 80

possessed, 141

object complement, 221

object focus, 230

object incorporation, 65,298

object indexing, 24,89

object marking, $59,64,74,94$

object NP, 65, 87, 96, 101, 197, 213, 217, 221-222, $241,285,298$

object of adposition, 236

object of CTP, 230, 232

object of postposition, 167, 215, 237-238

object suffixes, 109, 257

object-focus, 127, 136. See also verbs: object-focus objective genitive, 150, 217

objects, 2, 27, 63, 86, 90-91, 93, 102-104, 112 ,

$141,203,206,208,212-213,215,217-218,222$,

$225,233,239,249,280,288,292-293$

affected, 283

animate, 101

bound, 66

definite, 74 direct, 112

generic, 65

grammatical, 99

highly affected, 66

human, 101

inanimate, 100-101

indexing of, 111

indirect, 103, 112

non-referential, 95

non-specific, 96

partially affected, 284

person and number, 99

primary, 289

referential, 95

secondary, 103-104, 112, 208, 213, 283,

287, 289, 297

specific, 96

totally affected, 100, 283-284

oblique argument, 103, 158

om-, 282, 285-286, 298

onomatopoeia, 261

oo, 81, 154, 156-157, 253

optional items, 89

optional noun, 72

ordinal numerals, 80,267

origin, 154

orthography, 29

O-type derived causative, 287

O-type derived transitive, 286

O-type verb, 282-283, 287, 299

out of sight, 76

outcome, 249

paragraph marker, 240

paragraphs, 2, 240, 245

parenthesis, 198, 202

participants, 92, 239

new, 88

secondary, 87, 105

particle modifier, 132

particles, 124

conditional, 83

irrealis, 82

mood, 82

TAM, 190

parts of speech, 77

passive, 280

passivisation, 72, 94-95

past tense, $113,116,120,182$

path, 154

peripheral clause, 210

peripheral NP, 290

peripheral PP, 207

periphery, 87, 97, 99, 104-105, 107, 203, 207, 209, $218,234,249,251$

permanent condition/state, 97, 274-275

permission, 233 
person and number, $51,74-75,88,107,110,112$, $124,139,141,144,147,149,166-169,175$, 195, 203, 225, 246, 257, 262, 267 indexing, 242

person marking, 59, 72, 86, 88, 261

personal name, 52

personal pronoun, 73,141

persons, 72, 101, 265

pete, 77

phonemes, 2, 29

phonological shape, 68

phonological word, 108

phonology, 244, 255

phrases, 2

adpositional, 103, 107, 177

alienably possessed, 162

alternate, 156

associative, 158-159

benefactive, 171

comitative, $158,161,167$

compound, 154

coordinate, 156, 158

human condition, 161, 167

in apposition, 160

locative, 161-163, 177

manner, 161

noun, 73. See also NPs

possessive, 156, 164, 175-176, 186, 188

postpositional, 25, 167

prepositional, 178

reason, 171

verb, 86,107 . See also verb phrases

physical condition/state, 278, 294

pite, 77

place name, 162

place noun, 52

places, 264

plural, 20, 50, 54, 56, 72, 213, 257, 261-262

plural enclitic. See enclitics: plural

plural form, 148

pluralisation, 88, 261

po, 81, 83, 154-155, 223-225, 227, 230, 233, 239,

$245,248-249,251$

function, $249-250$

point of action, 237

polarity, 204, 240

change, 250

negative, 78

polysyllabic, 68

position: clause-initial, 78

position: marking, 104

possessed noun, 24. See also nouns: possessed

possessed NP, 217

possession, 26, 74, 139, 141, 149, 186, 261

alienable, 149-151, 153, 186-187, 213, 217, 262 inalienable, $24,73,149-151,153,186,188$ $189,217,262$

modified construction, 153

recursive phrase, 153

possessive classes, 150

possessive clause, 174, 183-184, 186-189

possessive clitic. See clitics: possessive

possessive construction, 139, 217, 240

possessive NP, 24, 187

possessive particle, 150

possessive phrase, 140,142, 147-149, 152, 156,

175-176, 186, 188

possessive pronoun, 149, 162, 165-166. See also

pronouns: possessive

possessive sentence, 183

possessor, 139, 217, 262

possessor noun, 24, 186

possessor NP, 74, 165

posthead modifier, 144, 146

postnominal modifier, 58

postobject modifier, 137

postposed subordinate clause, 239

postpositional clauses, 177, 237

postpositional phrase, 25,236

postpositional relator, 75

postpositions, 24, 26, 72, 105, 158, 163, 167-172,

$177,179,211,213,218,235,261$

ablative, 170

benefactive, 171

locative, 170

posture verb, $61,288,292,294,296$

potential control, 61

potential mood, $78,82,107,113,115,117-119$,

$121,123,204,227,239$

pragmatic functions, 64, 87, 94

pragmatic roles, 91,93

pragmatics, 82, 86, 91, 99, 105, 110, 144, 176,

$180,184,207,215,256$

predicate-focus, $97,127,130,230$

predicates, $28,65,86-87,91,107,174,178,180$,

193-197, 201, 205, 220-221, 228, 241, 249

adjectival, 185, 196

bivalent, 189

cognition, 220

complement-taking, 206

equative, 175

existential, 175

expanded NP, 176

intransitive, 110

modality, 220, 228

nominal, 78, 196-197, 230

non-verbal, $28,74,77,190,197-198,203-$

204, 213, 230

non-verbal clause, 195

pronominal, 175

transitive, 110 
utterance, 220

verbal, 74, 78, 197, 230

predicational strings, 194

predicative adjective, 26

prefixes, 51

$$
\begin{aligned}
& \text { classificatory, } 51 \\
& \text { derivational, } 51-53 \\
& \text { inflectional, } 46 \\
& \text { subject, } 46 \\
& \text { verbalising, } 51
\end{aligned}
$$

preposed subordinate clause, 241

prepositional clause, 177, 179

prepositional phrase, 158, 161, 169, 178, 203, 238

prepositions, 105, 161-168, 177, 179

locative, 54, 162-163, 165, 169. See also

mei

locative $u, 164$

present realis, 121-122

present tense, 107, 112-113, 118-119, 121-123

problem condition noun, 260

process verb, 61

proclitics: nominalising, 75

productivity, 259

progressive, 114

progressive action, 20

prominence, $24,76,140,175,256$

pronominal affixes, 141

pronominal clitic. See clitics: pronominal

pronominal construction, 175

pronominal enclitic. See enclitics: pronominal

pronominal indexing, 140, 246

pronominal prefixes, 90, 93, 99

pronouns, $2,52,72,90,139-140,145,157,261$

bound, 107

demonstrative, 76

emphatic, 72, 74, 88, 101, 105, 110, 140, 175

forms, 72

free-form, 139, 172

function, 73,140

independent, 72, 74, 140, 149

personal, 141

possessive, 72, 74-75, 149, 151, 186-187, 213, 228

proper, 72

relative, 207

unstressed, 74

prototypical clause, 202

prototypical subject, 197

proximal, 76, 143

psychological state, 167, 278

psychological verb, 61, 288, 290

punctiliar action, 207

punctiliar aspect, 255

purpose, 171-172, 220, 241

quadrant, 264 qualification relationship, 174

quantifiers, $24,52,57,74,141,147-148,150,155-$

156

question words, 77

questions: idiomatic, 178

quotation formula, 233

quotation sentence, 233

quote complement: indirect, 224, 226

quote: indirect, 202, 225, 233

quote verb: direct, 233

real condition, 242

real event, 116

real world, 78, 117

realis complement, 224

realis mood, 107, 113, 115, 118, 120, 227, 229,

239

realis-irrealis distinction, 227

reality: degree of, 242

real-world entity, 88

reason, $167,171-172,239$

recipient, 67

reduplication, $20,34,41,43,50,58-60,79,114$ -

$115,128,143,146,257,259-263,265-268,270$,

275-277, 294, 301

complete, 41

partial, 76

symmetry, 38

reference, 256

referent, 174, 177

referential function, 143

reflexive, 63, 102, 137, 296

region, 264

relations: non-temporal and temporal, 248

relationship noun, 52

relationship terms, 54, 150, 162-163, 261 , 271-272

relationship verb, 288,290

relative clause, 139, 206-212, 223, 234, 237-238, 249

definite, 206

indefinite, 146, 206, 211, 241

internal-headed, 206

non-restrictive, 206

non-verbal, 206, 211-212, 218

restrictive, 114, 206

topicalised, 209

verbal, 206, 211-212

relative pronoun. See pronouns: relative

relative time, 78

relativisation, 206

relators: postpositional, 39,73

repeated action, 20, 136

repetition, 114

repetition of predicate, 248

repetitive condition noun, 260

repetitive use noun, 260

response, 80, 273 
restrictive clauses, 206-209, 211-213

result, 238, 246

role and reference grammar, 4

roots, $68,256,259,263,266,268,271$

secondary object. See objects: secondary

secondary participant, 87, 105

secondary stress. See stress: secondary

semantic categories, 234

semantic classes, 260,270

semantic domains, 260, 279

semantic function, 216

semantic predicate, 196

semantic relationship, 248

semantic scope, 70

semantics, 244, 256-257

basis for syntax, 270, 272

sentence complement, 202

sentence introducer, 79

sentences, 2

conditional, 83

contrary-to-fact, 83

hypothetical, 83, 244

possessive, 183

verbless, 21,198

sentential adverb, 113

sentential complement, 220

sequence, 81

sequence of actions, 245

serial constructions, 127, 132, 239

serial motion verb, 274

serial verbs, 107, 109, 124, 128, 131-132, 137,

239, 267-269, 278, 291

grammar of, 128

intransitive, 125

transitive, 126

setting: spatio-temporal, 254

siga, 240

simple aspect, $61,107,114,116,118-119,121$,

$209,255,270,274$

simple NP, 176

simple present realis, 121

singular, 72, 213, 261-262, 264, 301

source, 177

space, 97

spatial deictic, 76

spatial function, 143

spatial location, 131

spatio-temporal clause, 249

spatio-temporal relations, 254

spatio-temporal setting, 87, 105, 107, 237, 239, 250

speaker, 62, 76, 131, 222, 233

speaking verb, 67

species: natural, 260

specific, 160

specific object, 96 specified locative, 161, 177

specifiers, 78, 133

spoken text, 198

spontaneous prefix (guna-), 299

states, 97

psychological, 101

stative clause, 89 . See also clauses: stative

stative modifier, 130

stative verb. See verbs: stative

stems, 68, 256, 267-268

classes of, 257

stress, 44, 108, 161-162

secondary, 44,213

strong consequence, 247

structures, 2,4

coordinate, 157

underlying, 89

subject complement, 221,228

subject indexing, 89

subject marking, $59,74,91,110$

subject NP, 88, 92, 178, 197

subject prefixes, $46,72,87-88,107,110,117-118$,

$124,213,257,299$

subject/tense prefixes, 112

subjective genitive, 150, 217

subjectless clause, 196

subjects, 2, 27-28, 63, 86-87, 90-91, 93, 97-99,

$102-103,107,112,141,158,174,194,197$,

203, 206, 208, 212-213, 215, 217-218, 222, 225,

$228,230-231,233,241,249,267,280,285$,

$288,292,296$

clausal, 74

deictic, 175

expanded, 175

grammatical, 99

indexing, 86, 110

person marker, 51

subordinate clause, $242,255-256$

subordinate-coordinate structure, 223

subordinating postposition, 252

subordination, $210,217,222,226,234-235,238$ -

$239,241-242,251,254$

subservient actor, 158

succession, 253-254

suffix-derived change, 38

superlative, 127, 135

suppletive form, 67

surface manifestation, 183

surf ace string, 75, 94

syllables, 33, 68, 256

syntactic relations, 259

syntactic roles, 87

syntax, 52, 187, 245, 256, 270

functions, 54

tagmemics, 2, 195

tail-head linkage, 245 
TAM. See tense aspect and mood tamogi, 245, 251-253

temporal argument, 209

temporal clause, 239-240, 254

temporal construction, 107

temporal interrogative, 256

temporal noun, 209

temporal NP, 199

temporal overlap, 251, 254-256

temporal succession, 241, 255

temporary state, 97

tense. 107, 112-113, 119, 198, 203, 213

future, 78,182

past, 182

present, 107

tense adverbs, 113, 122-123

tense aspect and mood, 118, 203, 257 functions, 119

tense-aspect, 178, 190, 196, 203, 239

tepa-<nei>, 167-168, 171

text, 198

things (instruments), 264

third person referent, 100

time, 55, 76, 97, 210

absolute, 52

completion of, 241

extent of, 171-172

relative, 52,78

word, 52

topic, 2, 76, 90-91, 93, 95-96, 104, 139, 245

clausal: primary and secondary, 94

primary, 93

secondary, 93

topicalisation, 76, 95, 139, 143-144, 209, 217, 221 , 226

tracking of referents, 141

transfer verbs, 62

transitional consonant, 162. See consonants:

transitional

transitional verb, 61

transitional vowel. See vowels: transitional

transitive clause. See clauses: transitive

transitive enclitic. See enclitics: transitive

transitive focus, 69

transitive intensifier, 126

transitive marking, 38, 68-69, 137. See also

transitivising suffix

transitive modifier, 132

transitive predicate. See predicates: transitive

transitive suffixes, 126

transitive verb. See verbs: transitive

transitive verb phrase. See verb phrases: transitive

transitivisation, 98, 134, 137, 280

transitivisers, 38, 71, 10 1, 103, 271, 283

transitivising clitic, 111 transitivising suffix $(-<g>e), 64,67,70,129,215$,

280, 283, 284, 287-289, 296. See also-ge

transitivity, 65, 298

degrees of, 65-66

transitivity scale, 66,283

transportation verb, 288, 291

trial number, 72, 141

trivalent, 103

truth condition, 83, 243-244

truth-value operator, 79

tu-, 213-215, 218

$u, 164$

u-bei-<na>, 171

ugoli $<n>e i, 238$

ugoli-<na $>, 168$

ugoli-<nei>, 169

uncertainty, 225, 233

unconscious benefiter, 171

undergoer, 59, 63, 87, 95, 97, 99, 102, 112, 135,

$137,285,292-293$

as subject, 61

definition, 100

underived verb, 298

underlying grammatical relations, 280

uniting verbal and non-verbal clauses, 200

units, 2

unity of function, 195

univalent nucleus, 102

universal theory, 4

unknown item, 148

unmarked, 261

unreduplicated, 261

unspecified locative, 161

unspecified marker, 148

uyahi<n>ei, 238

uyahi-<na>, 167-169

uyahi-<nei>, 167, 169-170

valence, $59,86-87,89,97,110,128,189,257$, 267,285

valence change, $259,274,280,286-287,295-296$

valence decrease, $66,118,270,280,282-283$, 285286, 298-299

valence increase, 118, 270, 280-283, 286, 288-289, 292

variable-focus, 230. See also verbs: variable-focus verb modifier, 263

verb phrases, $78,87,118,126,267$

constituents, 107

definition, 107

head, 109

modifier, 26

verb roots, $265,278,287$

verb subclasses, 257

verbal adjuncts, 107

verbal agreement, 154

verbal clause, 118, 197. See also clauses: verbal 
verbal complement. See complements: verbal verbal modifier, 108-109, 126-127, 132

verbal noun. See nouns: verbal

verbal predicate. See predicates: verbal

verbal prefixes, 108

verbal stem, 107

verbal valence, 87, 280, 287

verbalisers: prefix, 51

verbalising processes, 259

verbless sentence, 198

verbs, 18, 20, 49-50, 52, 58, 77, 195, 213, 217 ,

256-257, 259

'automatic-action', 61

accomplishment, 58, 64, 100

active, 58-59, 61, 87, 129, 278

attention, 226, 228, 232

automatic-reflex condition, 64

auxiliary, 27

basic motion, 257

bivalent, 63,99

breaking, 277

carrying, 277, 297

cognition, 222, 226, 228, 232

condition, 63-64, 87

consumption, 64

copular, 196

cutting, 277

derivation, 20

derived, 213, 267

desire, 225

ditransitive, 59, 67, 87, 103-104, 112, 288,

297

doubly marked, 102

feeling, 277

human-propensity, 101, 275

indexing, 87

influence, 67

intransitive, 58-59, 64-65, 68, 87, 96, 98-99,

$129,189,214,2.22,267.274-276,280-281$,

285-286, 288-289

main, 124

manipulation, 277, 292

manner-of-motion, 289

modality. See modality verbs

modifying, 124

morphology, 72, 119

motion, 61-62, 108, 128, 241, 289

motion-goal, 65

object-focus, $58,60,64,66-68,87,89,99$ -

$100,103,277,286,288-289,292$

posture, $61,241,275-276,289$

predicate-focus, $64,66,68,286,288$

process, 61,12 ? psychological, $61,289-290$

quote, 234

relationship, 289

rest, 128

serial, 107

speaking, 67, 269, 274, 276, 288-289

stance, 289

stative, $51,58-60,87,97,114,125,129$,

$199,207,267,273,276,278,288-289,293-$

295

transfer, 62, 277, 291

transitional, 61

transitive, 58-59, 63, 66, 68-69, 87, 99, 102-

$103,111,129,189,214,217,232,257$,

$267,271,275,277,280-283,285-286,287$,

288, 293, 297

transportation, 291

utterance, 222, 226, 228, 233-234, 249

variable-focus, $58,60,64-65,69,87,89$,

96-97, 99-100, 127, 130, 267, 288, 297

viewpoint, 82

vowels, 32,256

alternation, 37

deletion, 128

dissimilation, 37

elision, 35, 118-119, 213

final, 18,68

lengthened, 43

sequences, 32

transitional, 18

VP. See verb phrases

wi-, 259, 270-271, 273, 277, 279, 282-283, 286, 289, 292-293, 295, 297, 299

wo-, 270-271, 276-277, 279, 283, 286, 289, 292, 296

word breaks, 108

word classes, 20, 77, 180, 255-259, 268, 270, 301

closed, 72,257

open, 46,49

word derivation, 255, 259

word level, 256

word order: clause, 190

words, 2, 256

boundaries, 46

grammatical, 45

phonological, 45, 108

time, 52

yaka, 242-245, 247

yes-no questions, 253

yohola, 78

yu, 165

zero morphological marking, 107 

